

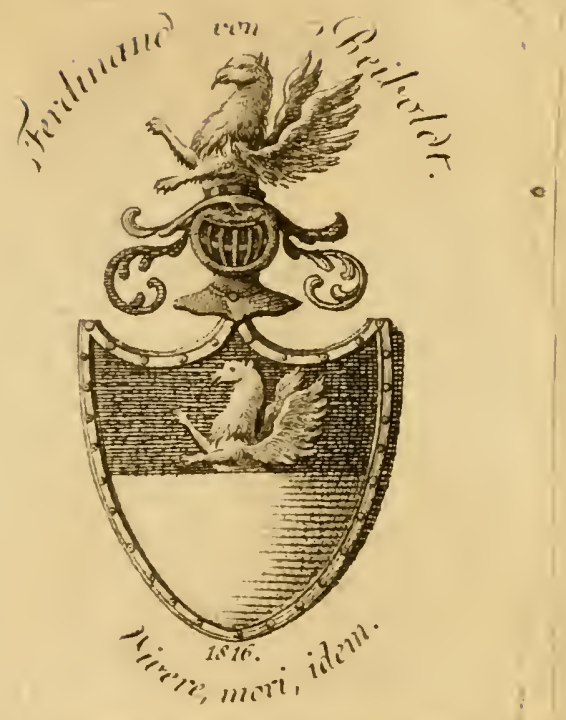

$+5111 \mathrm{Az}$ 




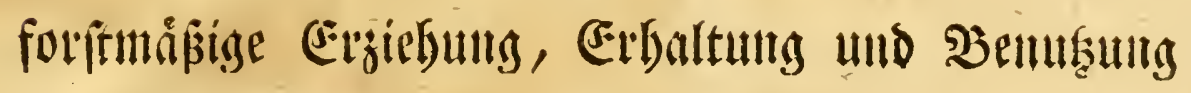
ber vorgaglidften

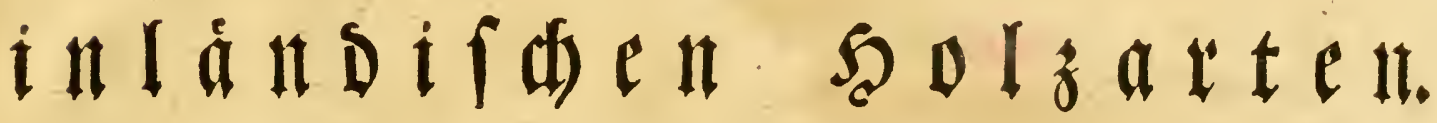
$\mathfrak{N} \in \mathfrak{b} \mathfrak{F}$

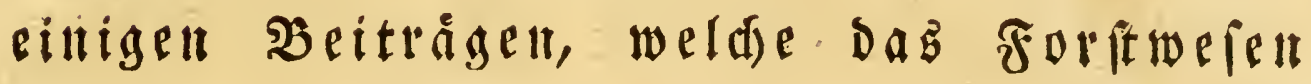
ágergaupt betreffer.

Bon

๔. \$. บon હiertorpff,

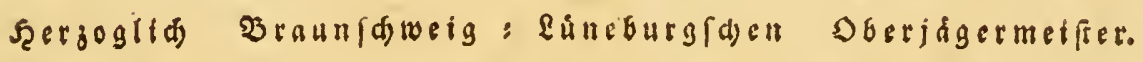

\section{Eriter $\mathfrak{i} \mathfrak{i} \mathfrak{e}$ ill,}

weldfer bie Forft = Botanie, bie शaturfunde ser Baiume ůberbaupt,

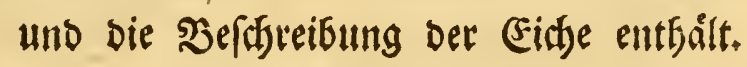

Mit illumintett Supfert.

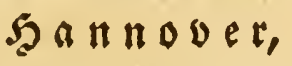

bei ben Bebribern Jath.

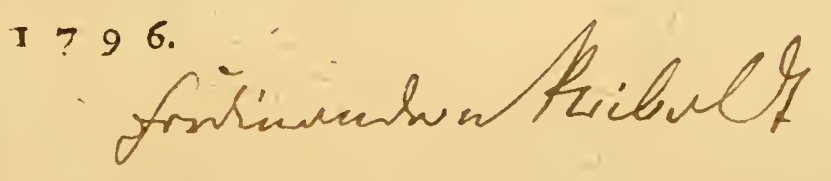





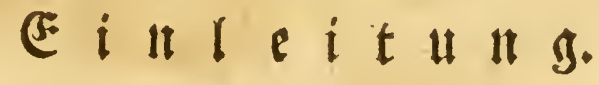

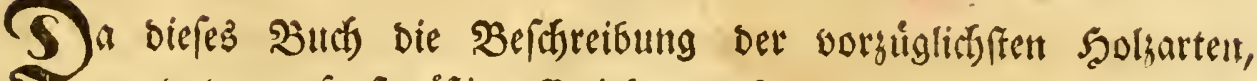

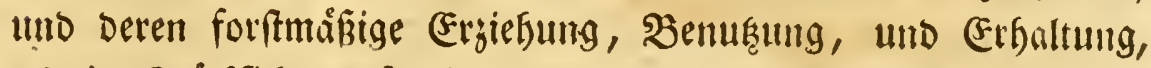

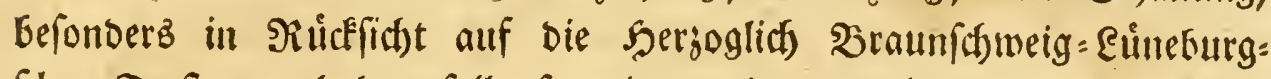
fiden gorften enthalten foll: fo wirb Darim nur Det Theil Der Gorfts

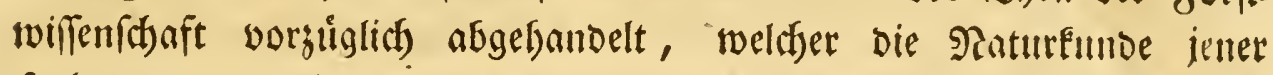
Soljarten und bie bei) Der (Ergiefung und Bennşzung Derfelben ges madten Erfabrumgen enthålt. Die uibrigen Theile Der Forfturffent:

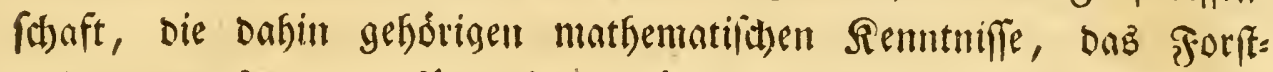

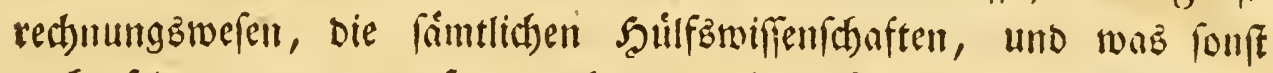

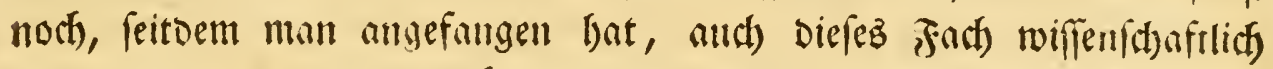
zu bearfeiten, Daju gerectuet wiro, merben barin nur in fo weit

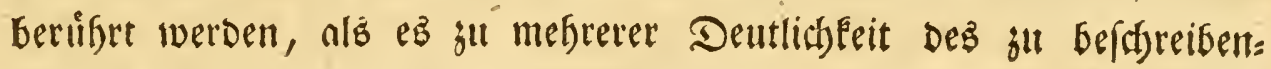
Den Giegenftandez nóthig fernn wird.

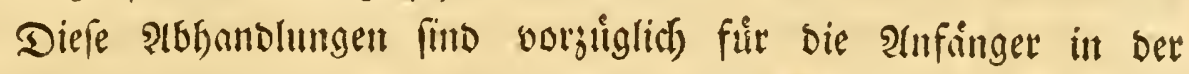
Forftwiffenfdhaft beftimmt, und Der Sanupt;wect Derfelben iff, fie bes

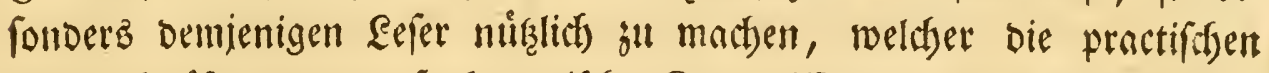

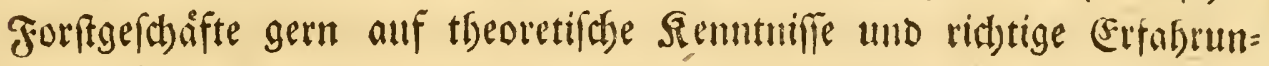

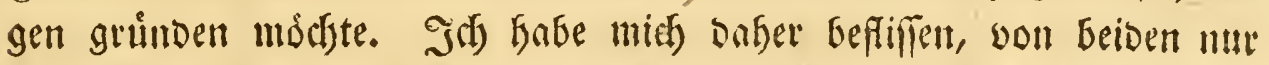

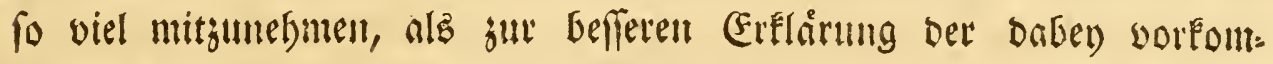

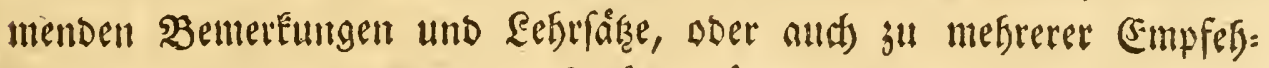

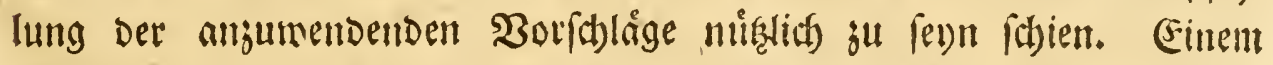

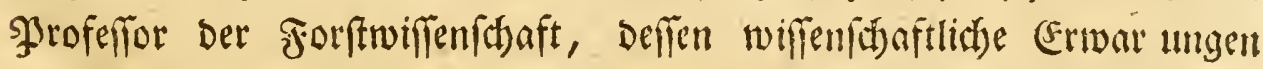
Gier nidft befriebigt werben, dirfte ez Daber wobl nidjt fajwer fallew, mir manche gelefrete Itnterlafiungs: Suinbe, vielleidgt auth bin unb 


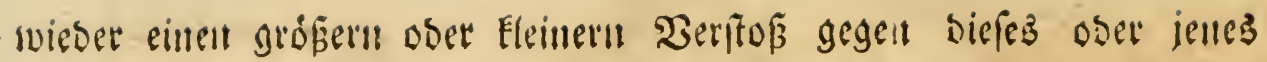

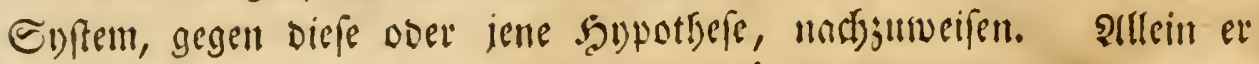
wit'b, boffe id, gencigt fern, mir biefe Simbent $j ! t$ erlafien, wenn er in

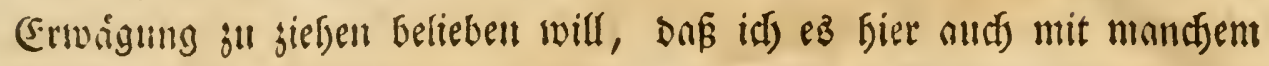

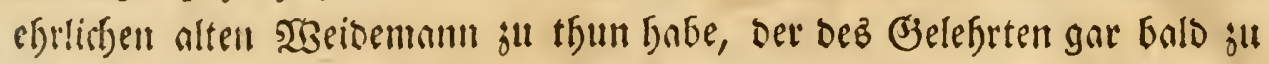

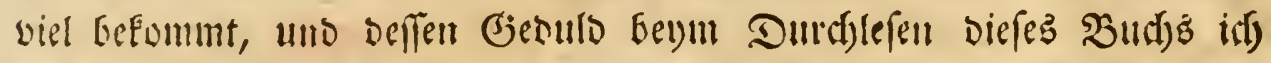

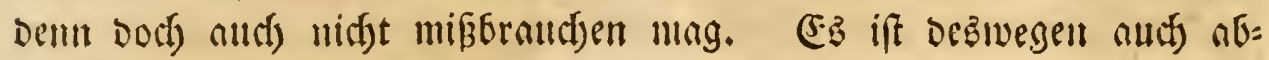

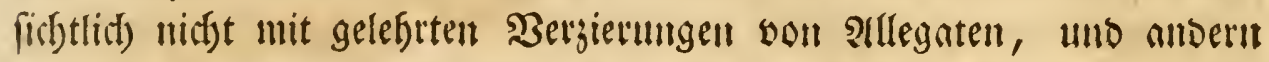

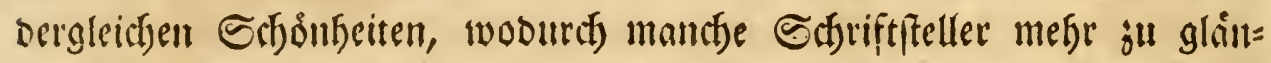

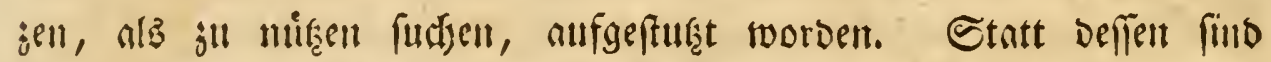
practif(t) Bemerfungen nantentlid) ju Berweifen angefuifrt,

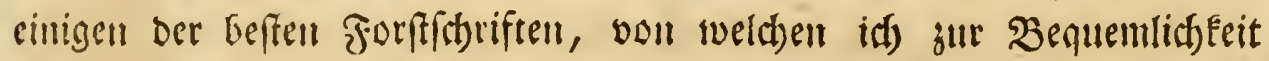

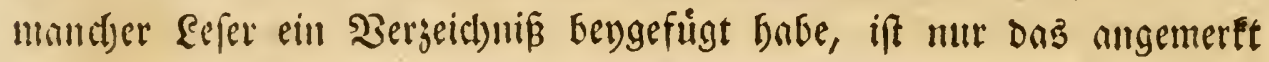
worder, waz jur Eeitung Dez angebenden Forftmames bey ber jut

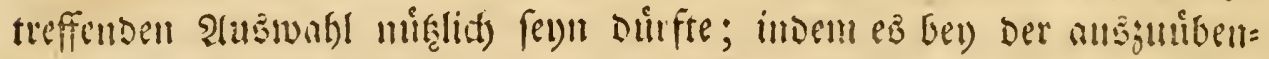

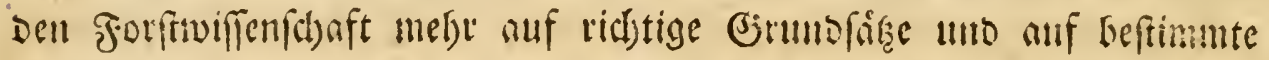

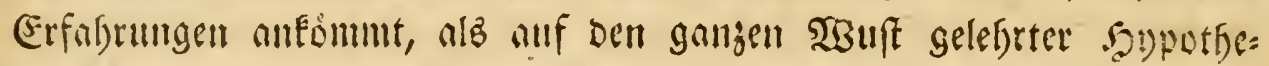

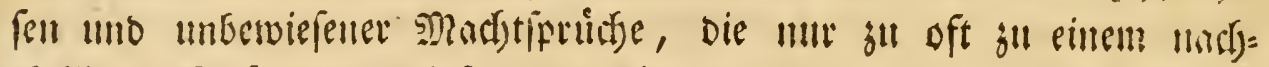

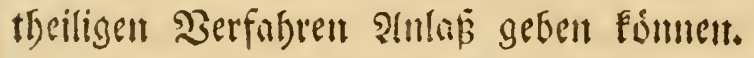

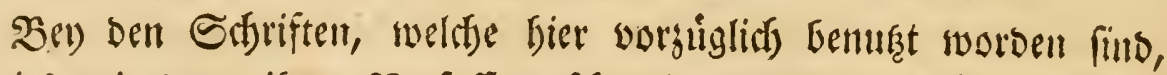

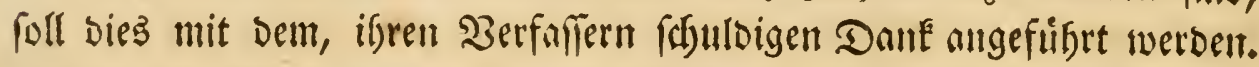
Diefez ben jebell Satze, Den id) mit jenen ßerfaffern gemein baben mag, inşbefondere ju wieberfolen, whirbe eine eben to unnuse, als

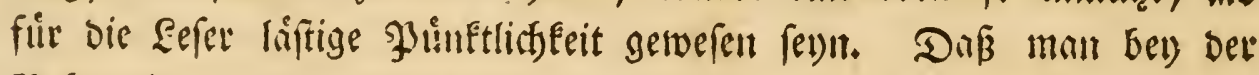

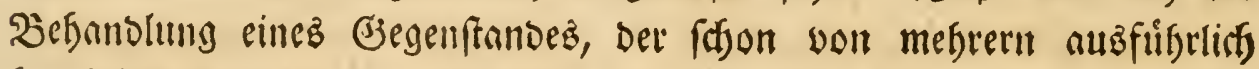
bentbeitet worben iff, nicft übernll meu fevn fonne, fonbern mandje B̧emerfung mit anbern gemein baben muiffe, verftebet fidf gang von

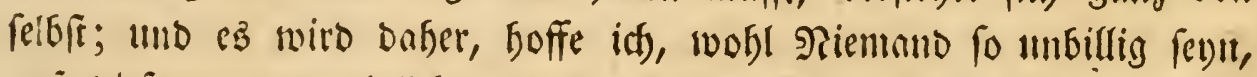
auf Diefen unvermeidlichen llmftand Den Borwurf eines gelefrten Dieffafla grimben jul wollen. 


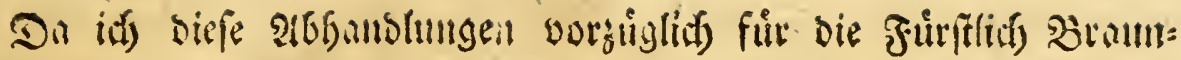

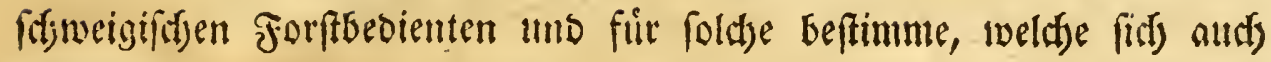
mitteibar mit bent Forftwefen befigaffrigen: fo werbe ifs es mir befonders angelegen fenn laffen, ben jedem vorlommenten Falle, wo Die Beweife aแz Bemerfungen gefuifrt werben follen, und in wel:

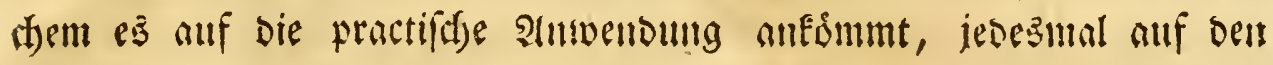
Ort und die Stelle jut werweifen, wo Der Eefer foldse Senfpiele vor:

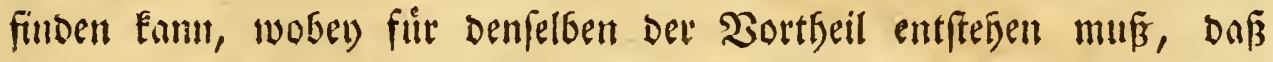

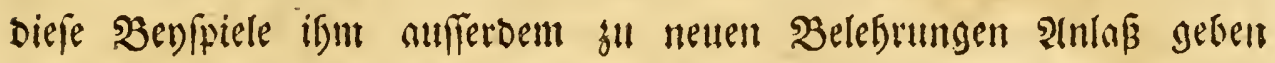
werben, wenn er bie Gelegenfeit baben folle, fie Einftig an Drt

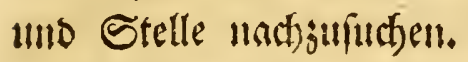

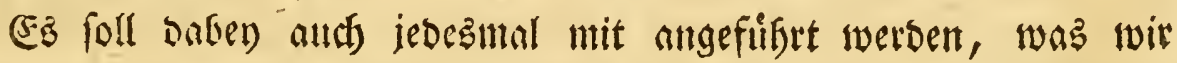
Dabel) Der Satur allein, uno waz wir Gingegen ifr unto Der gutent

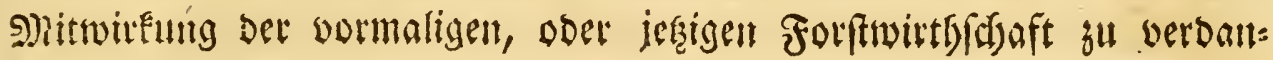
Fen gaben.

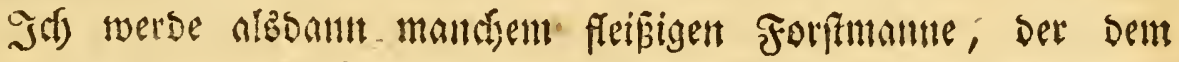
Etaate, befonderz fuir bie Zukunft, fo fefre widjtige Dienfte leifet,

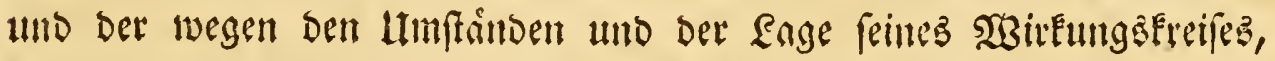

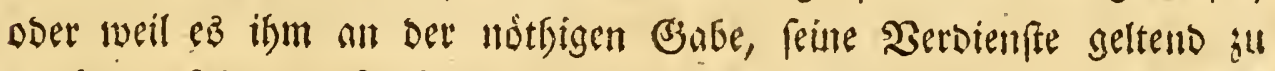
machen, feglte, oft fogar, Dem gleifjositigen Şublifum unbekant blieb, ocrbientes eob wiederfaften zu laffen, Gjelegenbeit baben; fo wie in anoern Fällen cin billiger Tabel nadjtbeiliger Forftefebandlun-

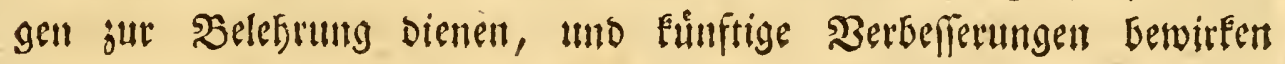
fant.

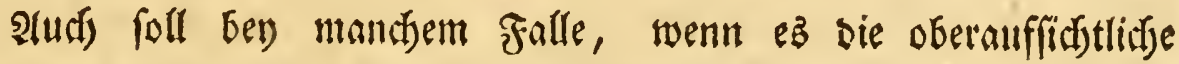

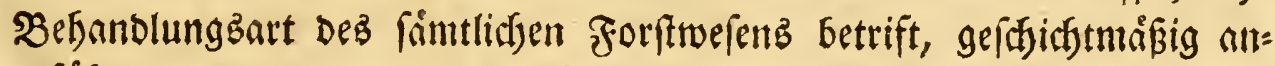
gefüftt werben, was barit feit Den lejten Guntert Jafreen in ben

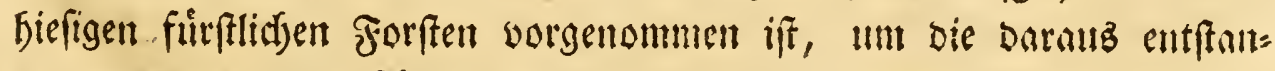

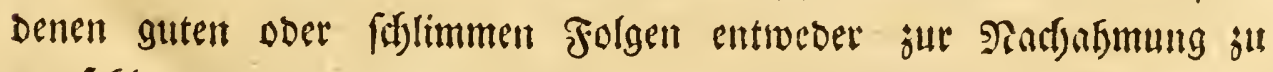
empfeblen, ober jur Şarnung aufjuftellen, wobey id forwofl ben 
aแşwártigen, alz cinfeimilifen Lefer ju befriebigen mich befonders bemifent werbe.

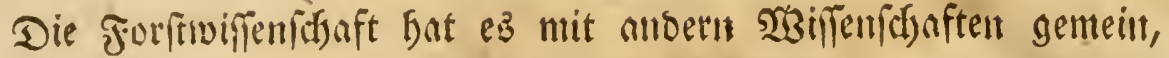

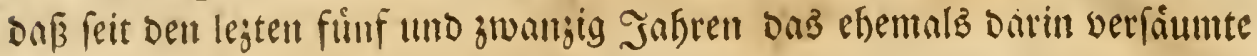

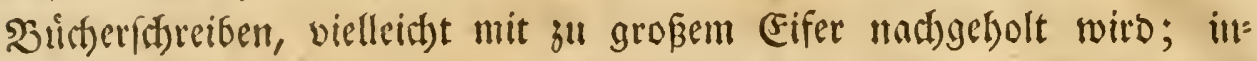
Dem wir reit jener Beit mit Forffithriften aller 2 rt von allen Seiten ber liberftronnt werden. Diez muß Denn auch freylid) fuir jeben, Der

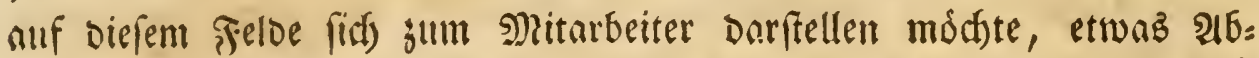

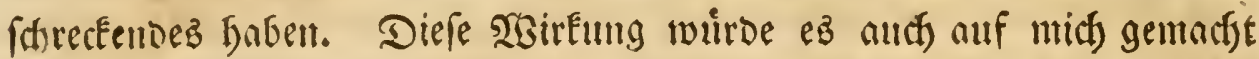

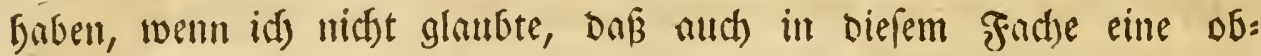

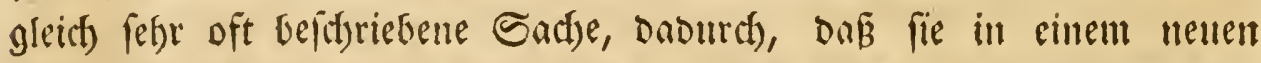
Eid)te Dargeftellt, ober Durdh wieberfyolte kemer Fungen beftatigt wirb,

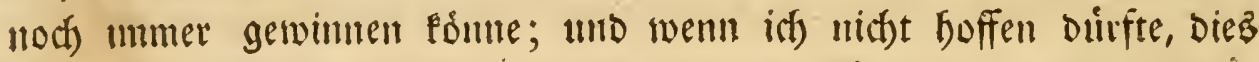
voirflich leiften zul Fonnien, Da id) mid) vorghiglich anf die fiefigent Furrftichen Forften einfdränfe, bev Deren oftern Befichtigungen idf bie befte belegcnbeit hatte, 'Bemertungen ju fanmlen und Durd) wieberfolte Beobadjtungell ju beridftigen.

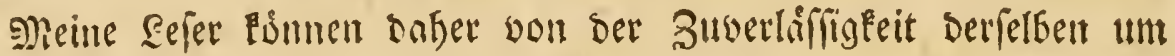
fo gewiffer feun, da ith gemug in Stande gewejen bin, mict) zut liberjengen, Dnß bie blos auf theoretifde Betmuthungen gegrindeten Eefrfärze bey Der 2nnventung oft eben fo unfither finto, als im ent= gegengefeften Fille, der in silteren Seiten faft unt alleu liblid ge=

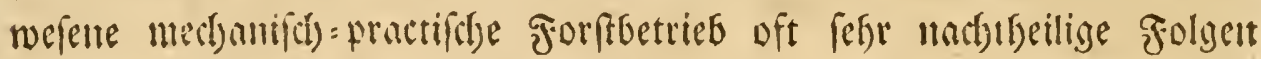
gatte. Go wie mun die geborige 2erbindung Der theoretifithen Semtmiffe mit Den fractifa)en (Erfafrungen unr allein die rid)tige und juverhiffige 2anweifung jut unern llnternefmungen in Diefem

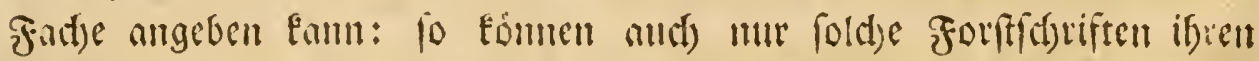

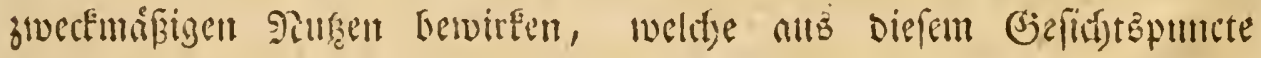

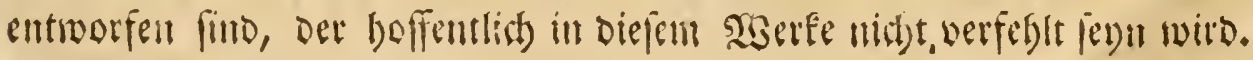




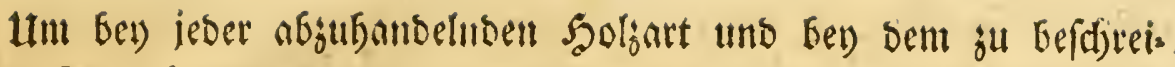

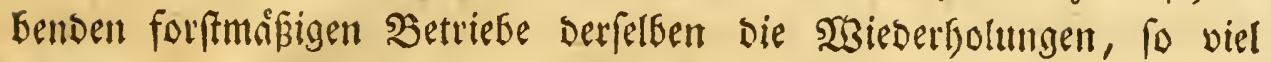

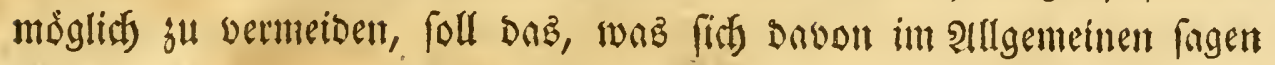

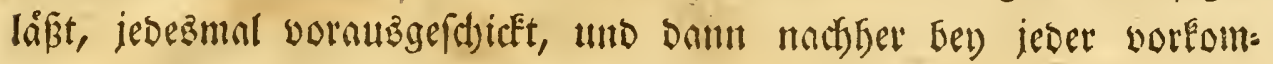

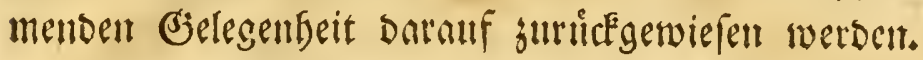

In Diefer श(bfid)t und in Der Bermutfung, dof es manthem meiner Eefer, Gefonderz Denen, welden ez an Den dozul nótrigen

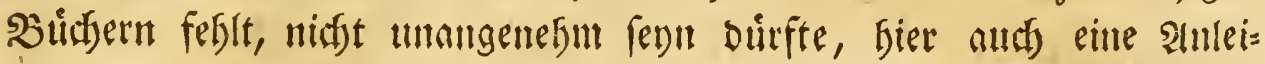

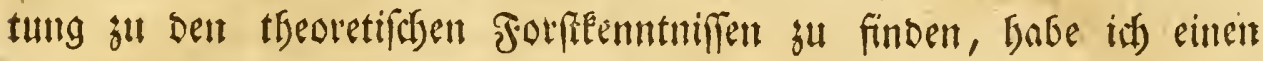

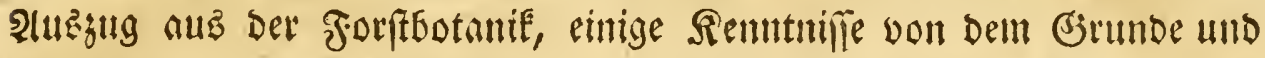
Boben, und bell tibrigen beym Forftbetriebe mitwirtenton Dingen, fo wie auth einige auf bie Ergiefung allet Şoljarten allgemein paf:

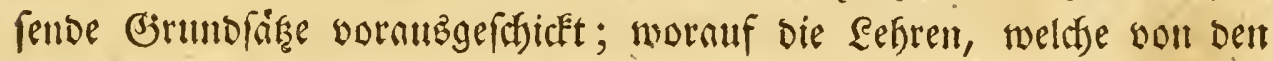
eingelnen Bammarten auf ben fontlidfen Forftbetrieb anwenbbar find, Diefen Pblyandungen folgen werben, Die ber Sefer unter ben lleberffyriften:

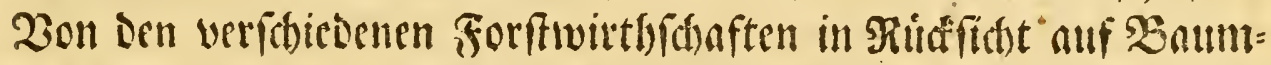

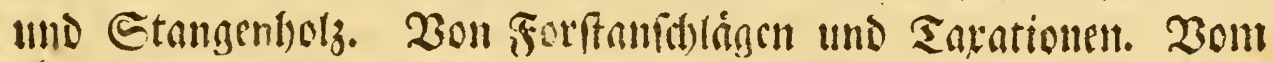
Fioblenwefen. Zom Solzhantel, und Solzhifen. Wun cinigen

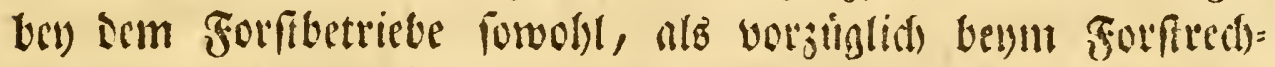

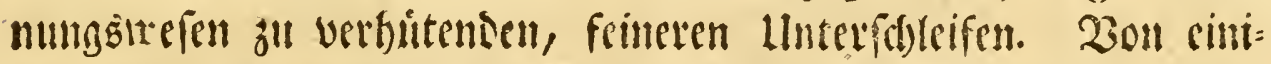
gen, bevur forftwefen nod) nidbt nuggerotteten fónoliden, Zot:

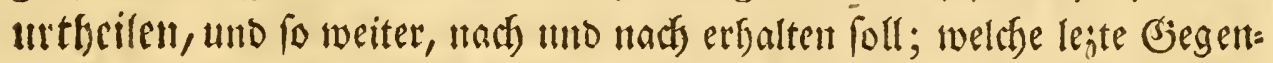
ftánde biz jeftrt ofnediez nod) am wenigften litterarifá) bearbeitet find. พBenn tibrigens in Den Sergoglidy Braunfhweigifhen Eantoern

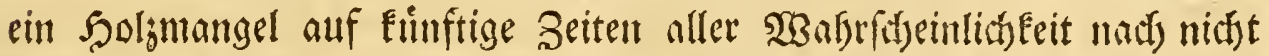
ju befirchten ift: fo baben bie Bemofner Derfelben biefes nicht allge= meine GJlidF Dem guten Forftbetriebe, ber Darin fhon feit einer Inn= gen Sieife bon Jafren eingefingt ift, unb ber noth immer verbeffert

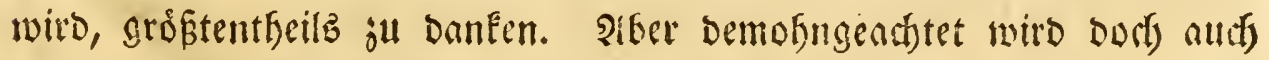
jeber $\mathfrak{B e r f u c h , ~ D u r d f ~ D e n ~ D e r ~ b i e f i g e ~ F o r f t b e t r i e b ~ n o d ) ~ f e r n e r ~ g e w i n t = ~}$ nen fann, uin to viel widftiger, ba borgliglich in ben Stribten ber 


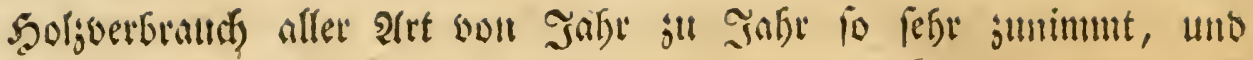

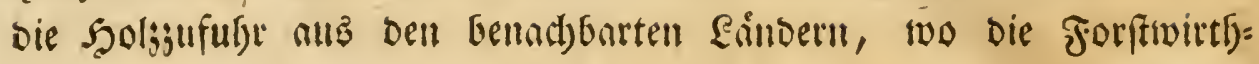

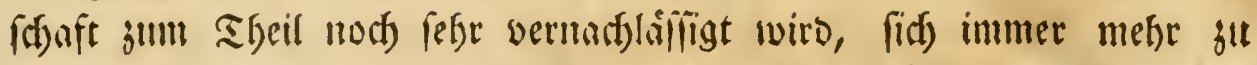

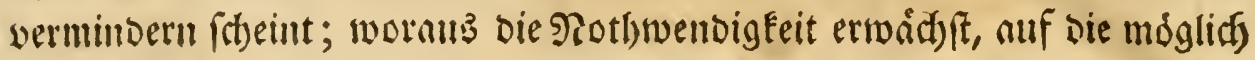

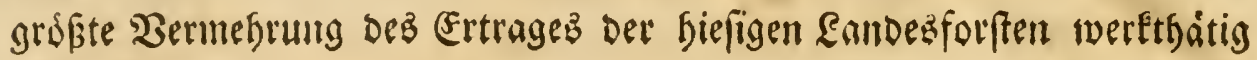
billjuarbeiten.

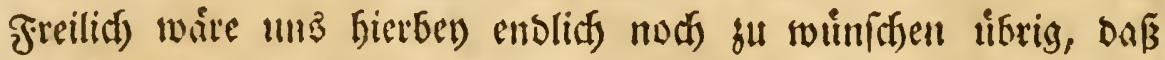

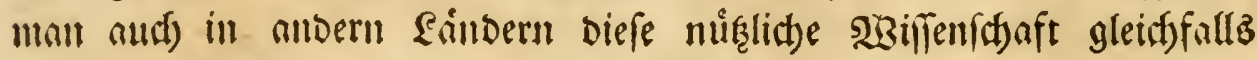
mit grofferm (Fifer z" betreiben fid) mód)te angelegen fegn laffen, und

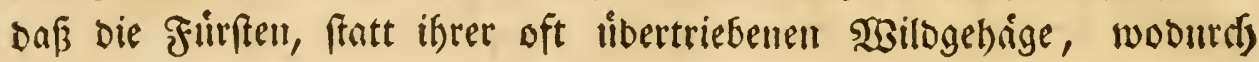
fie bie Şoljungen verwiften und ifre llntertbanen oft biz jur $2 \mathfrak{r}=$

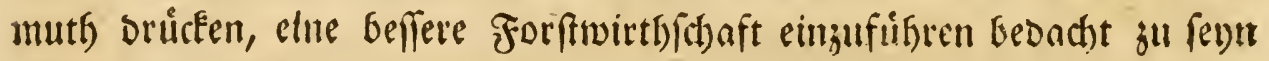
gerubeten. Möd)ten fie Dod) aud) bierin onsె $\mathfrak{B} e n$ fpiel unjeres ebeln Firrften befolgen wollen, ber gleich beyn 2mfange feimer multerfaften Regierung allen Jagomizbranch abfhaffe und die Jagb biz jum

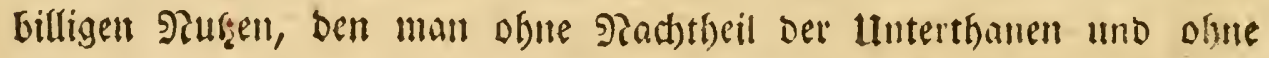
merflichen Sdanden fü bie Forften erfalten fnun, nus eigenem sriebe eimforanEte, um feine. Unterthanen aud) Dadurch glidflicter zu mathent.

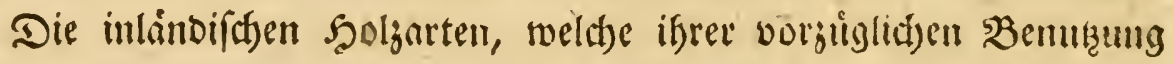
wegen in biefen 2byandungen bejdrieben werden follen, fino bie (Eid)e, die Buche, die Birke, die Erle, die Rlifter, die (Elit)e, der

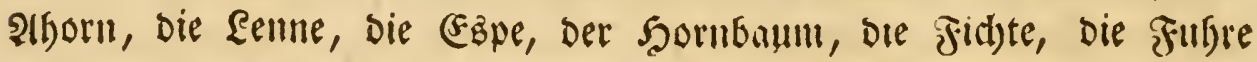

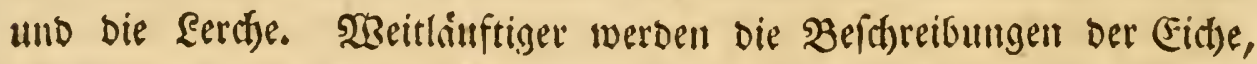

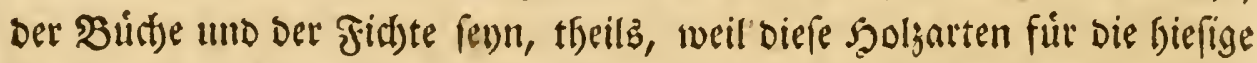

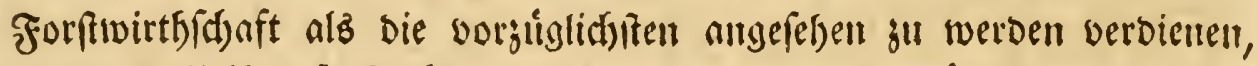

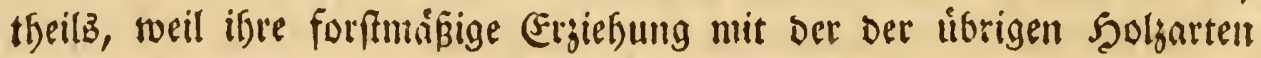

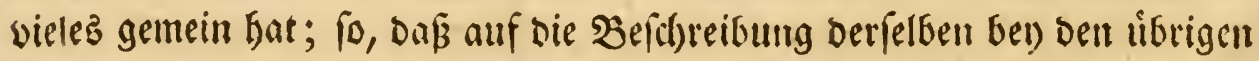

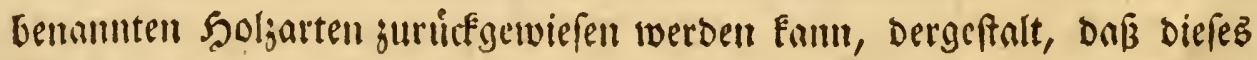

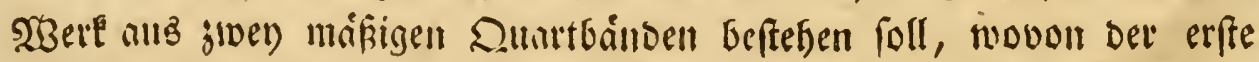

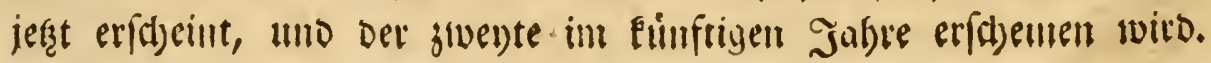




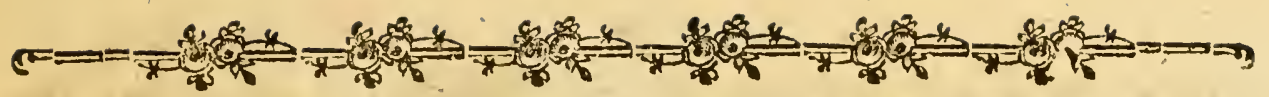

\section{EEviter $\mathfrak{A} \mathfrak{b}$ 价nit.}

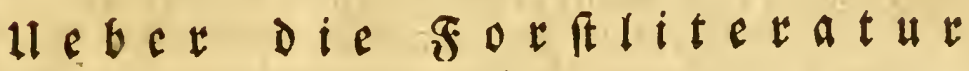

u $\mathrm{no}$

Bergeidunip einiger ber vorğiglidffen Sdriften, welde in biefem TaBerfe zum Theil benufgt worden finb.

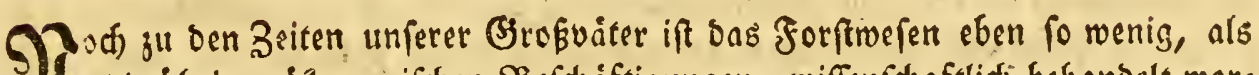

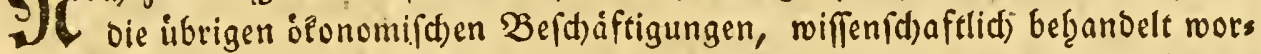

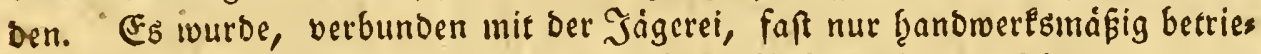
ben, unt an vielen Srten fogat als eine blofe Nebenfactse angefer̨en, bie man

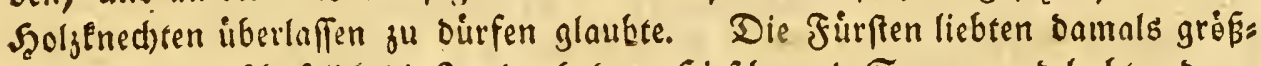

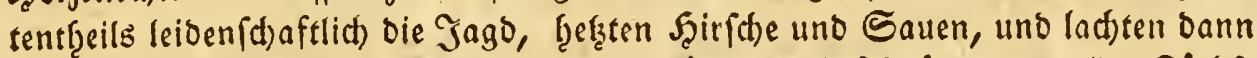

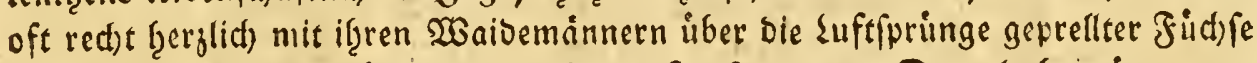
in-2llongeperifen uno iber bie mastirten Şaafen. - Damals begnigte man

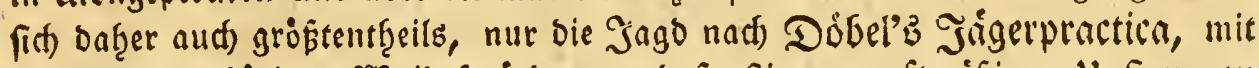

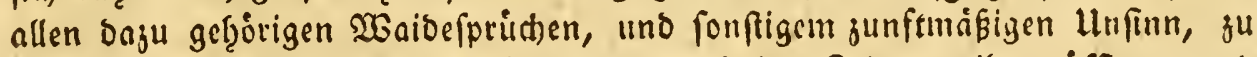
lernen, wie fold)es in mand)en linbern fum ţothen Beitbertreibe miffiger, uno

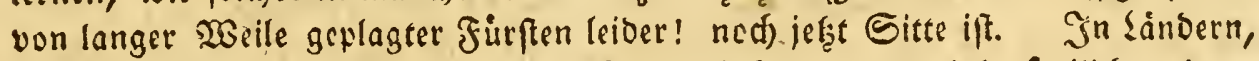
bie fid) einer weifern Regierung ju erfretten ḩaben, ift es jef̧t freilich anders. Seier wirb bas Jorftwefen mit Pled)t, als einer ber widftigften Şautpttbeile ber

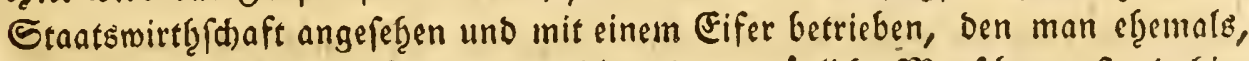

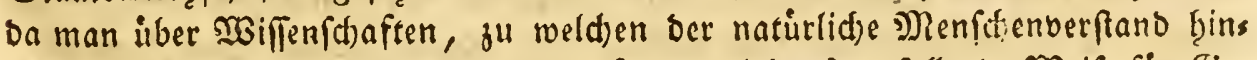

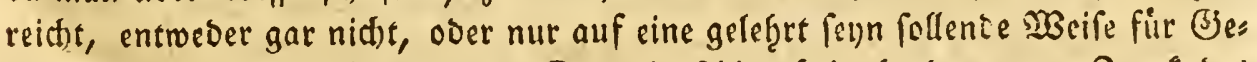
lef̧rte (d)rieb, gar nidht eannte. Pamals fdjien bcinahe ber ganje Zwedf ocs Ed)rifteteller: uno Büdjerwefens fein anderer, als ber ju foin: Epeculative (Errfer Therl) 
und unbegreiftide Dinge nur nod unbegreiflicher gu maden. Die naturlichen Dinge uno oeren Erforfdung rerben beinabe gang verfäumt. So verarbsites ten bie ₹feologen unfere armen Seclen und bie Juriften unfer Eigentfum in

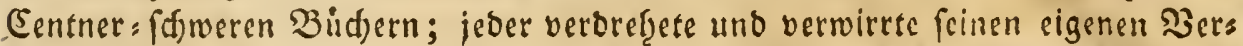

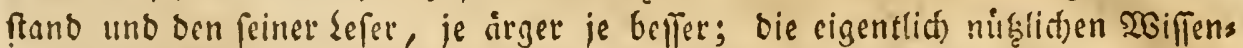

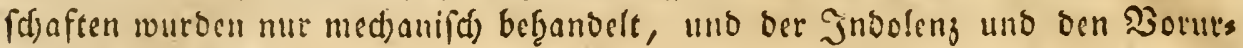
theilen ser unbenfenden Elaffe ber Menfden iberlaffen. War benr aud uns

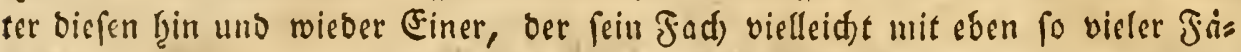

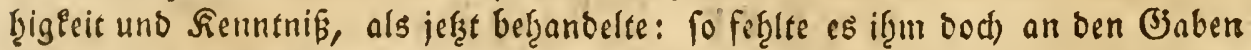
oder an ber fertigleit, es ju Papier ju bringen und befannt zu macten. Denn man glaubte bamals nid)t anders, als bedjtrabend ober auf Stelgen geţeno, (d) reiben ju birfen; und wer nidt traben ober anf Steljen getcen Eonnte, bet

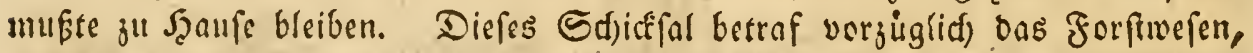
und baher haben wit aus jenen Zeiten faft gat Eeine Forffef riften, welthe noch jekt von einigem গluken feyn Ënnten. In neuern Seiten fingegen murbe bies

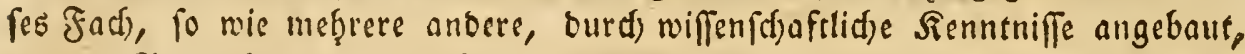
unb ber Bemerfungsgsift madjte autb fier, wie in andern Fid bern, auf. Seits bem fino einige vortrefflide Sefriften barin erfdienen; uno nadjoem nun auds an vielen Drten fich Drofefforen uno (Jelef̧rte Damit befdifitigen, uno man Forftafaosmien, und Forftphilantropine angelegt bat: fo fdeeint jefgt faft bie

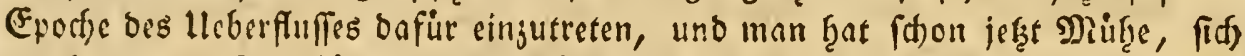

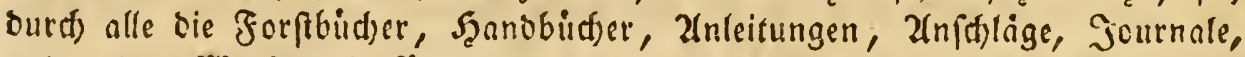
uno andere Werle, sie fir biefes Fad) arfdjeinen, burdjuarbeiten. Selbft foldse, beren $\mathfrak{Z}$ eruf es cigentlid) nidte ift, fich mit bem Forfwefen abjugeben, baben einige fetre nüflid)e Sd)riften baruber geliefert. So baben mir nuक als Forfinninner, mand)es für unfer Fad paffendes, einigen vortreffidsen $\mathfrak{B}$ its

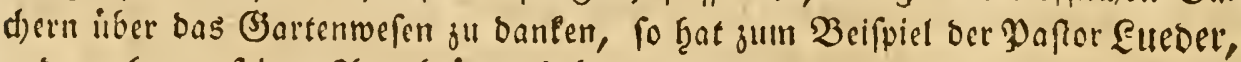

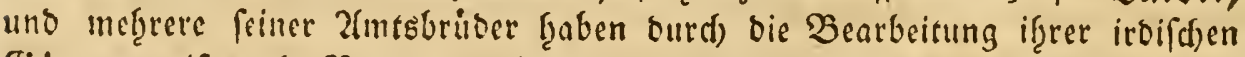

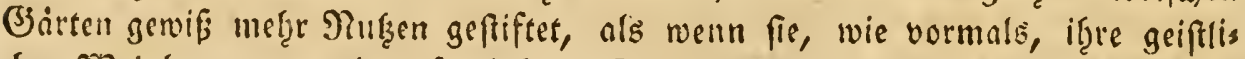
chen 2 Bumberge nur mit unfruchtbarer Dogmatil uno mit bem leibigen Dorns geroadjs ber \$olemil bepflanjt b̨itten.

Man Pann bie Sdriften über sas Forftwefen, bie freilid bei if̨rer grofen

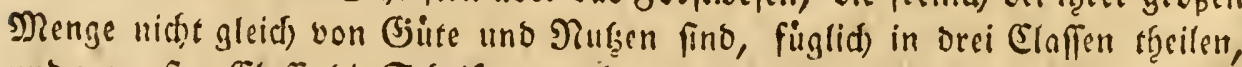

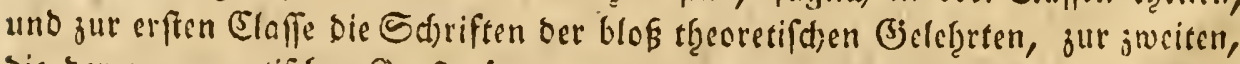
bie ber nur practifften forftmanner, unb zut oritten sie $\widetilde{S}$ thriften berer nef̧s men, weld)e Zfgeorie mit practifd)et Erfab̧rung verbanben. Nact) dicfer Elaffis 


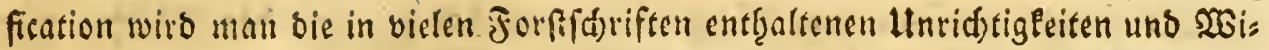

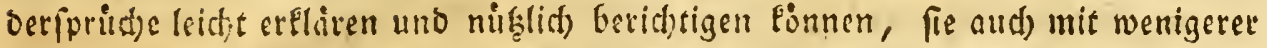

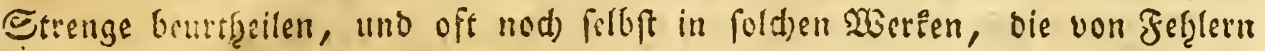
wimmeln, mandses (Sute finden. Wert fann es benn aud) zum Beifpiel einem

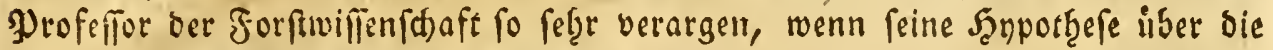
2Birtung bes froftes in oen forften nidt anwenobar gefunden miro, ba er fie binter bem warmen Dfen gefdrieben und ben Eisantzang im. bofen Raubreif in

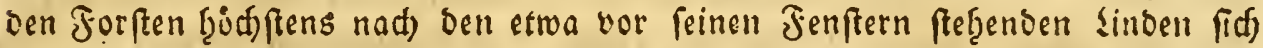
vorgeftellt hat; ooer menn er gegen die ßlösen in ben Jorften eifert, ba er bie Szimberniffe, fie zu befäen, nach feinem (Barten beurtbeilt, worin er jum Beften

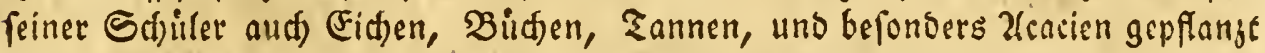
bat? Sanben wir if̧m bei bein allen bod) mandje wid)tige Bemerkung, bie auf

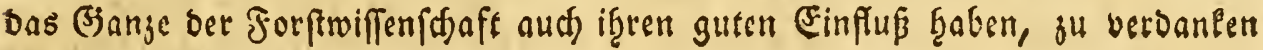
fdulloig fint.

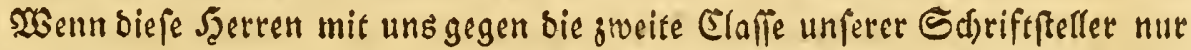
auf) ein menig oulbfamer wäen, uno, wegen einer etroa bemerlien Sunde ges gen biefes ober jenes Syftem, bas batin fonft enthaltene braudbare nidje gleidf mit verbaminen, ober blops beswegen verfdrwád)en wollten, weil es barin oft in

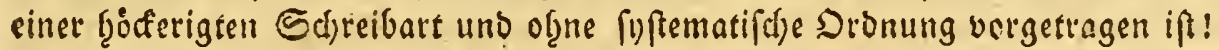

Den Shriftfellern ber britten Elaffe bqaben wir die beften Forfffhriften zu

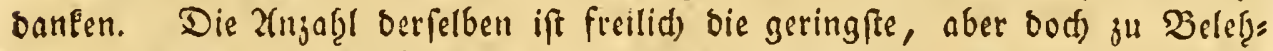
rungen, bie man aus ßithern ju etlangen fudd, in ben meiften fillen finteis

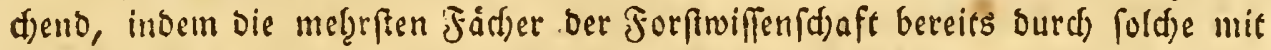
Bilid bearbeitet find, von benen ich einige ber beften, uno verginglid) bie, wels

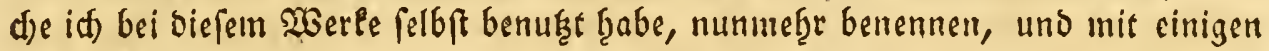

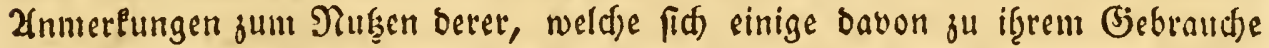
verfdaffen wollen, begleiten will. Ia) werbe bies mit bet reinften Hinpartfeis

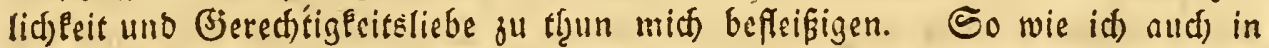

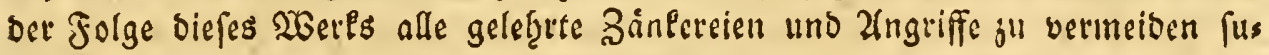
den werde.

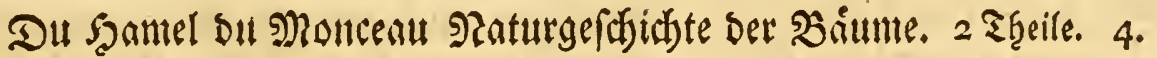
Deffelben $265 a n b l u n g$ von Båument, Stauben tno Etråudjen, weldje in FranEreidy in freier Euft gejogent werben. 2 Tleile. 4.

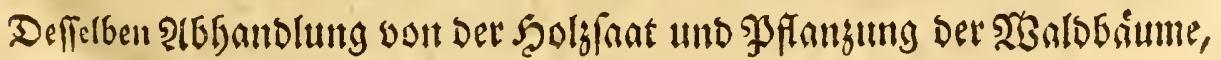

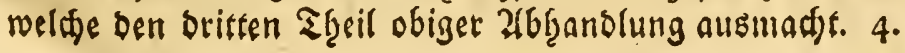




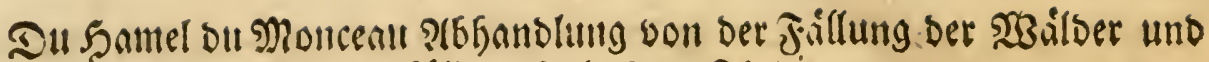

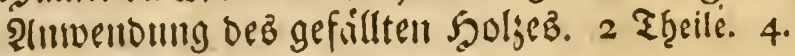

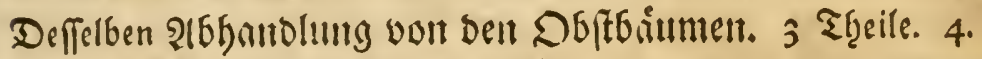

Diefe uno nod) einige Eleine Sd)riften, weld)e man in ben Zaten ber fós niglichen 2(eabemie ber WBiffenfd)aften zu Paris von bu Şamel bu Monceau findet, fino als bie beften Werfe anzufef̧en, weld)e bis ief̧e über bie Forftrifs fenfdjaft crfdjienen find. Sie verbienen baher mit Pied)t allen ubbrigen vorges pefżt fu werben; wäre es audy nur beswegen, weil fie mandsen fpateren Sdjrifts fieller jum Eeitfaden gedient ந̧aben.

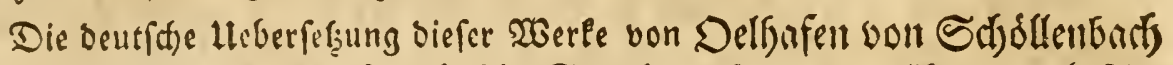

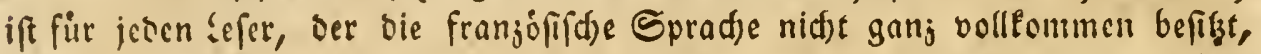
ber meit fdjonern Driginalauszabe vorzuzief̨en, weil if̧n biefe ber vielen ted)nis fden zlusbricfe megen, bie felbft ber Lleberfegzer zu meţrerer Deutlid) eeit ges

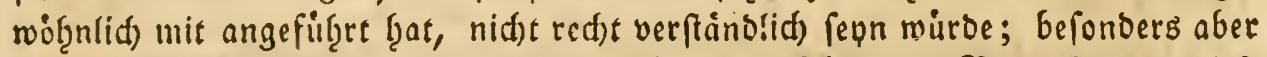
aud) beswegen, weil ber lleberfefger burd) einige fef̧r gute bemerfungen biefe

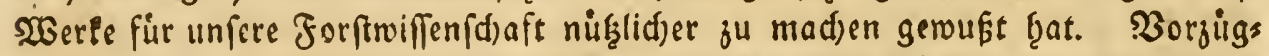

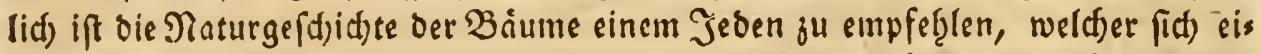
nige thecoretifd)e Renntniffe in ber Forftrwiffenfd)aft erwerben mill; aber gerabe

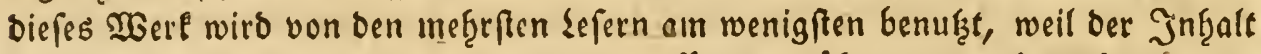
Deffelben im 2unfange etwas trocten uno für ungcubte unberftanolid) ju feun

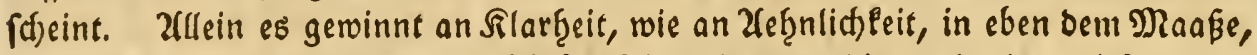
in weld)em man mit berjenigen 2(d)tfamleit, bie es verbient, barin ju lefen, uno Das Bele fene nod) einmal zu le fen fortfäbzrt.

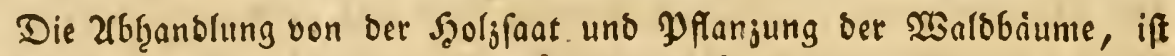
gleidffalls eine ber beften Sdriften, weldse man über biefen Begenftand ந̧at; und bie von ber Fällung ber Biume wairbe für uns nod) braudjbarer fenn, wenn

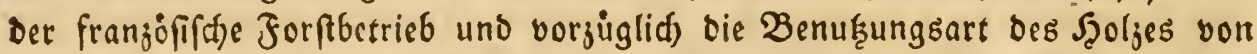
ben unfrigen nicht to fegre verfdfieden wären. Die fämtlidgen Sd)riften bes ou Szamel ou Monceau gef̧iren ju ber oben bemerlten britten Elaffe ber Forfts fdriften, uno fino beswegen um fo juverfid)tlid)er zu benufzen.

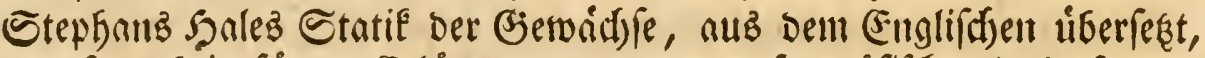
famt beigefuigten Erlåuterungen von Der framjoflifion ueberferzutg

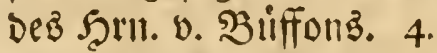

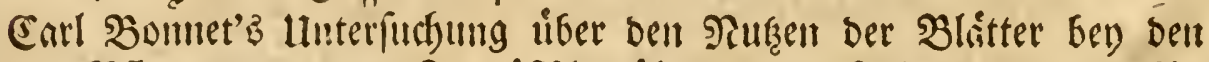

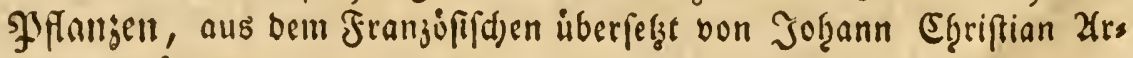
nolb. gróp 4 . 


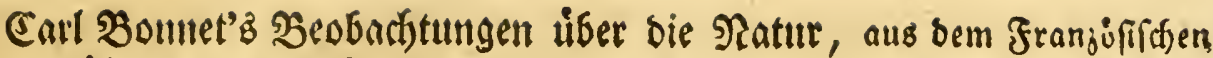
überfeģt von J. D. Titius. gr. 4. 2 Theile, neuefte vermef̨rte Zuflage.

Sowoţl' Sależ, als Sonnet's Schriften verbienen als Meifterwerle ans gefeţen zu werben, und eben aus biefen f̧at bu א̧amel bu Ronceau viele vor:

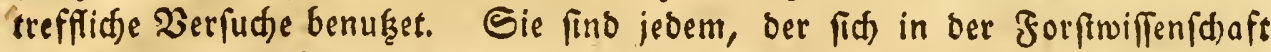
nid)t mit ber gemóthnlidjen unjulänglicten Thecorie begnügen will, nid)t genug zu empfeḩlen. Zubem enţ̧alten fie fïr bie Raturlunde to viele widtige Beis

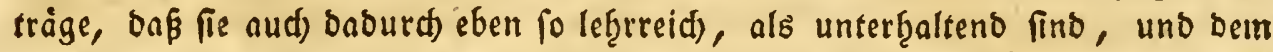
benenden Forftumann mandse fonft langmeilige 2lbendftunde nitglid) und anges ñef̧im madjen eionnen.

Expériences fur les végétaux, par Jean Ingen-Houfz. 8.

Expériences fur l'action de la lumière folaire dans la végétation, par Jean Senebier. 8.

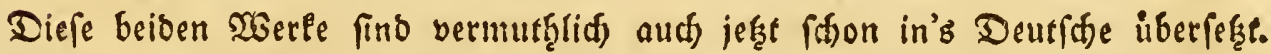
Der Sntzalt berfelben betrift ben theoretifaen Theil ber Forftwiffenfdaft nue

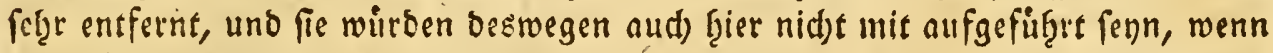

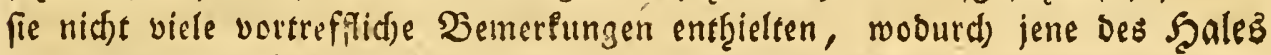
uno Bonnet's für ben Sefer nod) intereffanter merben fönnen.

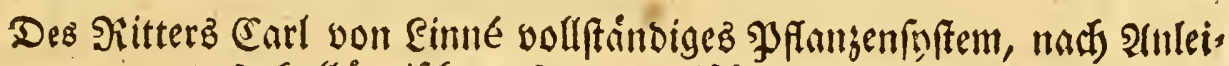

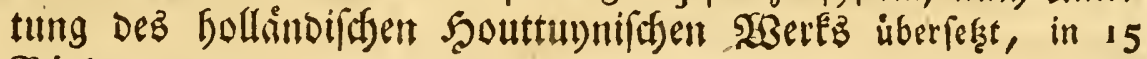
Bänoen. gr. 8.

Die 3erbienfte biefes groken Mannes find fo feg̨r betannt, und beffen vors

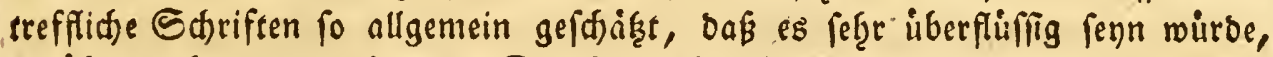
Daruber nod) etmas zu fagen. Da aber biefes $\mathfrak{W}_{\text {Ber }}$ bie ganze $\mathfrak{B}$ otanil begreift, bie fich bei ber Forftriffenfdaft nur auf bie Szoljarten uno einige menige Sirius

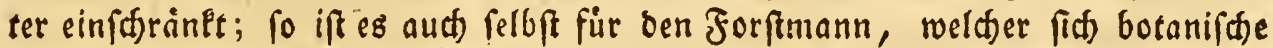
Renntniffe vorjuglid) ju erwerben gebenet, bod immer ein ju weitlauftiges WerE, und éann man fïb baher mit folgendem begnigen:

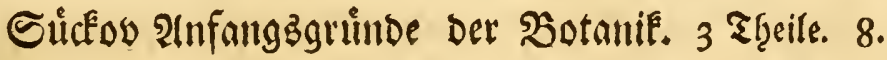

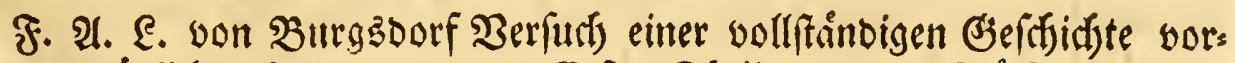
zuiglidyer Solgarten. 4. Erfter Theil, von-Der Budbe. Erfter Band Deż zweiten Theils, von ber (Fid)e.

Deffelben ßeitrige zur Erweiterung Der Forftriffenfaraft. 8. 


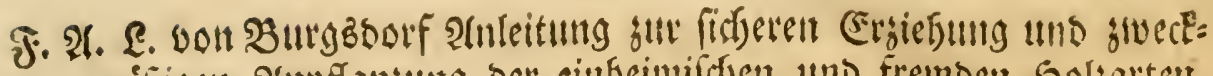

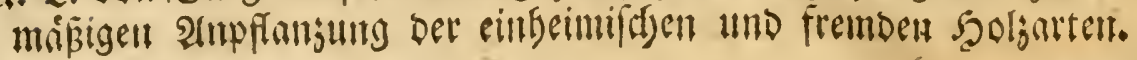
2 Theile. 8.

Deffen Trorfthanobud). 8.

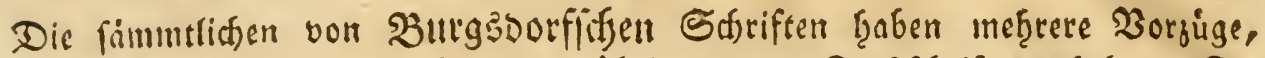

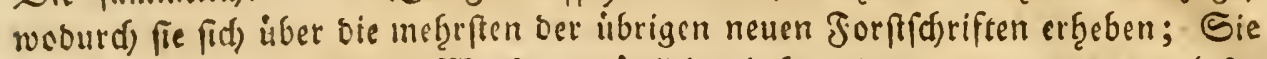

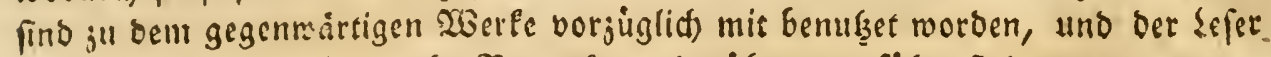
wiro beierin aud) nod) manthe Bemerfung dariber angefüţrt finoen.

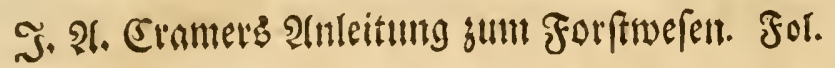

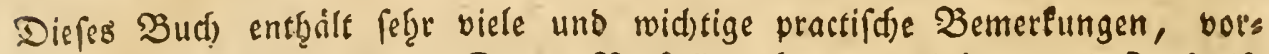
zinglid) voin Solflentwefen. Da ber 2 erfaffer aber eigentlid) nur bie Forftwifs

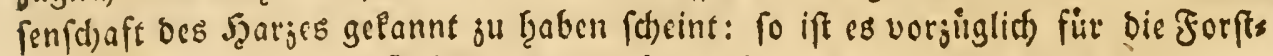
minner in ben ţöberen (Bebirggegenden braut)bar.

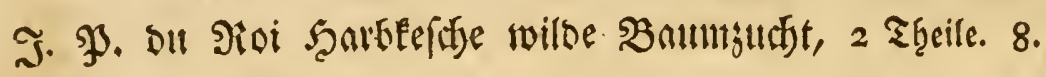

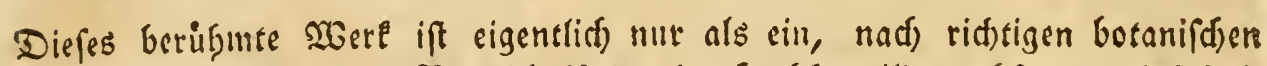

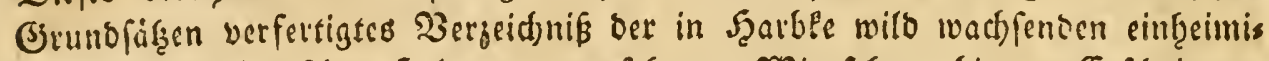

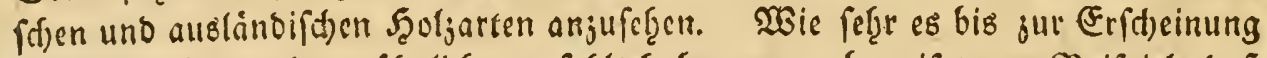

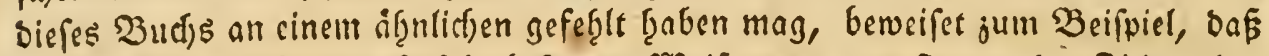
man nad) bempelfen bie fo febre befannte Weiß̈tanne, unn fie von ber Fid)te oder Diotf̧tanne beftintmt ju unterfdeiber, Abies du Roi nenut. 30 biefent

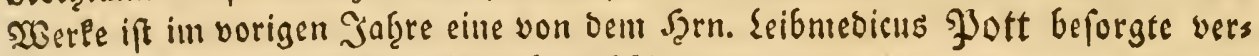
befferte und feģe vermeţrte 2lusgabe erfffienen.

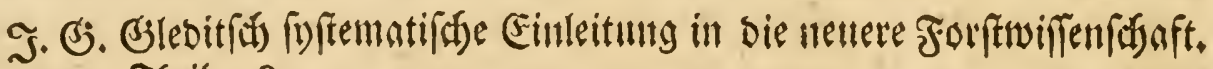
2 Ţeile. 8.

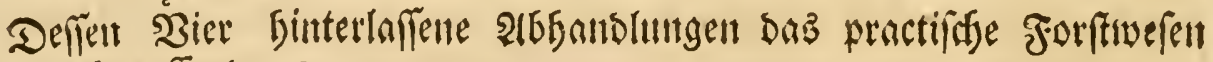
betreffento. 8.

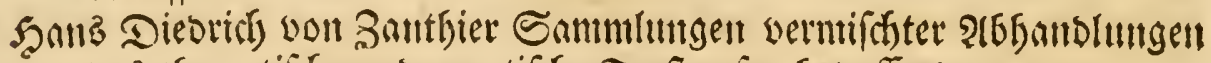
Das theoretifate und practifhe Jorftwejen betreffend, 8.

Beibe Sdyifffeller geţoren unter bie, weldgen wir bie braudbbarften Forfind)riften zu banken fabern.

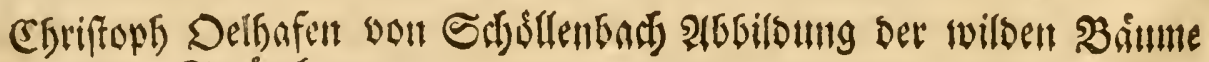
IIIID Strånd)er. 4.

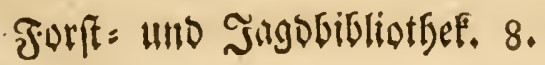

รัดนเน 


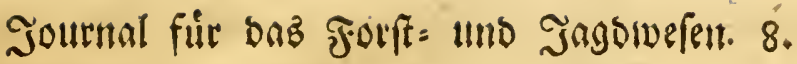

Trorftarchio won $2 \mathfrak{3}$. O3. vont Mofer.

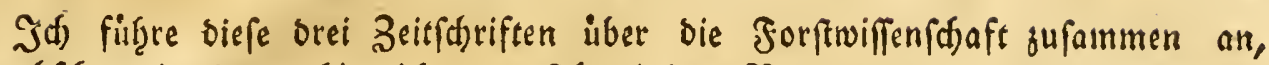

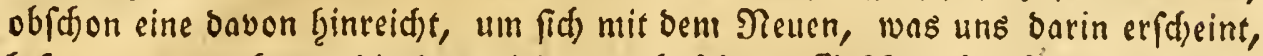
belannt zu macten; bie benn jeber nact, feinem befdomant fid felber qusfis den mag.

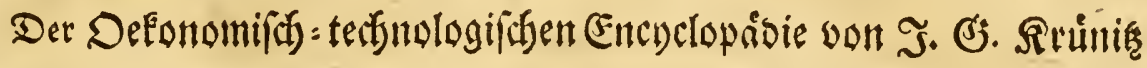

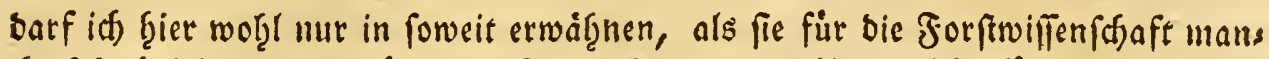

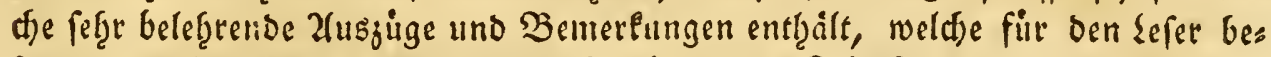
fonoers wid)tig fino, weil er bie onbei benuţten Sdjriften als bie Suellen ju metgrerer Belef̧rung angefüţre findst.

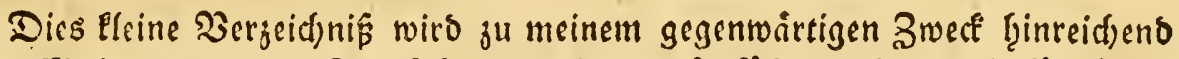

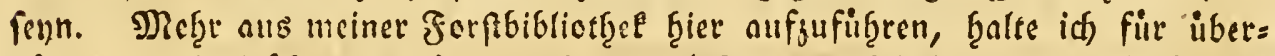

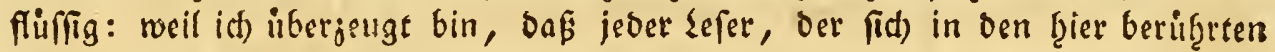

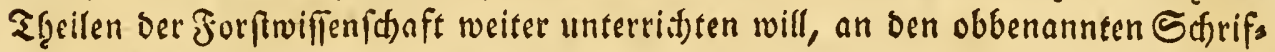
ten bollfommen genug f̧aben werbe, und bas er in ben ubrigen zaf̨lesidfen Sojriften nur wicberf̧olungen antreffen wirbe.

Schriften über einjelne Bjegenflande des Forftwefens aber, follen an ben getgerigen Stellen angefüg̨rt weroen. Lunter biefe geḩiren befonders bie peit

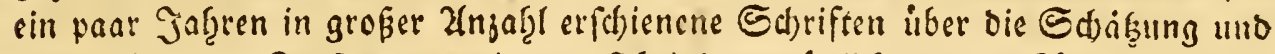

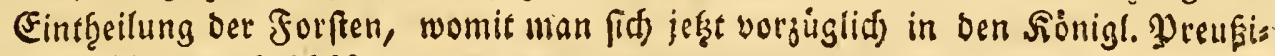
fóen కånoern befdåftigt. 


\section{3weiter $\mathfrak{A b}$ fidnit. \\ 2 onder For tibotani}

\section{§. I.}

Die Forftbotanif ift berjenige Sheil ber Forftwiffenfdaft, meldjer bie Sennts

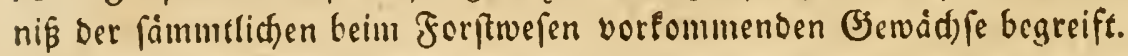

So mie bie Botanil einen Theil ber ganjen Naturfunde ausmad)t; fo ift bie Forftbotanif infondert̨eit cin Flgeil ber erfteren; fie fafe nur bie Sienntniffe Der Şoljarten und einiger wenigen $\mathfrak{P}$ flanjen in fids, bie auf bie Erjielzung Ders felben, ober auf irgend einen andern Forftnufgen $\mathfrak{B}$ şię̧ung ţaben, mitḩin nur einen Fef̧r geringen Theil ber gefamten Pflanjentunde.

Die Forfibotonil entrailt

a) bie Syftemfunde, und

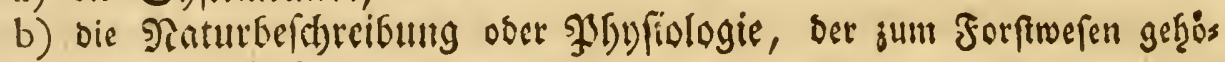
rigen (jew íd)je.

$$
\text { Die Ş. } 2 .
$$

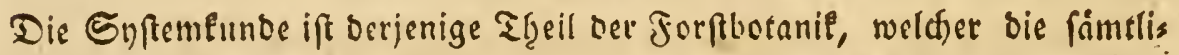

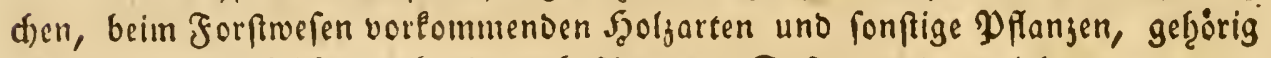
benennen, uno fold)e nad) einem beftimunten Eyfrem oronen lef̧rt.

Da das Forftwe fen es nur mit einem geringen Theile ber Poflanjen ju thun

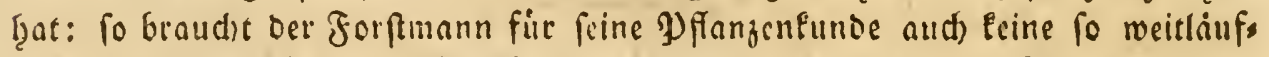
tige uno getebrte foftematifd) afbtheilungen, wie ber eigentlid)e $\mathfrak{B}$ otaniler, ber

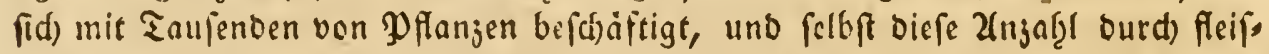
figes $\mathfrak{T a d}$ futsen und burd) bie (Entoecfungen in entfernten Sandern noch immer

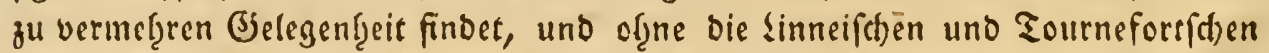

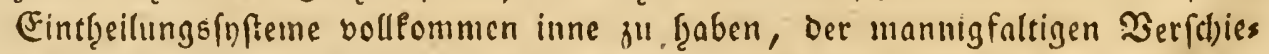
Denf̧eiten weger, nur zu oft jweifeln mitroe, in meld)es Fad) cr diefe ober jene

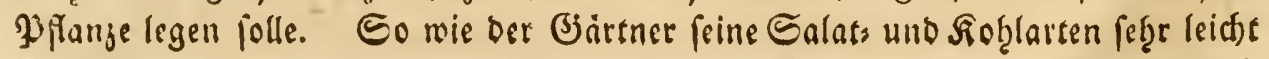


bulgarifd Genennen Eann; fo ift es aud ben Forftuannne leidf, bie ofrnebies

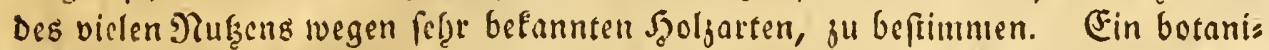
fdes Eintheilungsfuftem berfelben gebort alfo mef̨r jur theoretiffen Bicrbe ber Forftwiffenfd)aft, als jur Nothourft bei oer plattifden 2(usubung berfelben.

Die benannten Simmeifden und Tournefortfden Eintfeilungsfyfteme fino baf̧er firr ben J Jorftmann eben fo entbef̧rlid), als fie bem Sotanifer notfewerioig fino. Jener finbet aud an ben wenigen (Jemaid) fen, bie er ju unterfud)en hat, fo viele auffallende Linterfhiedsjeid)en und befondere (Figenfd)aften, baf er foldhe nid)t, wie sicfer, erft an ben Blumen, Blätern uno an ben Staubfíben bers felben aufjufuden gejroungen ift. Diefe Eintbeilungsfyfteme wirben bie $2 \mathfrak{b}$ : fid)t, weld)e man bamit ju erreid)en fudjen mogre, alfo mef̧r erfidweren, als erleichtern. Fir ben Forftmann ift besivegen bie in ban beften Forftichriften angenommene Fintbeilung ber Solzarten weit vorgujiefcen, obfichon fie an fid felbft hiod)ft fef̧lerb̧aft, uno bei Beftimmung ber Birenjen einer art von ber ans

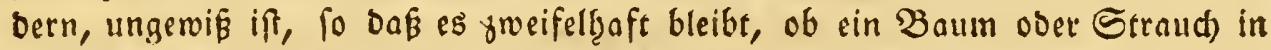
biefe ober iene Elaffe gefiort. Diefe gemeine (Fintbeilung aber, fo fefgr fie auth Den Theoretifer balcisigen fann, ift jur practifken Xusubung beym Jorftbetriebe vollevummen binlinglid); um fich bannit beutlid) uno verftánolich ausjubrúcten, uno jebes (Jemaids, was auf bas forftwejen irgeno eine Bejief̧ung bat, be= ftimmt anjugeben. Llebrigens babe id) midh bemübt, bei siefer bier angenoms menen Eintfeilung fo wenig Elaffen uno fo viele Ḃeftimmungen feftzufergen, als es inir móglid war.

$$
\text { §. } 3 .
$$

Die Bewaidfe, weldie auf bas Forftrefen eine Bejief̧ung haben, uno alfo jur Forftbotanil gef̧oren, weroen abgetţeilt:

a) In die $\mathfrak{S o l j a r t e n t}$ uno

b) In bie Sirftbolgartent ober Rråuter.

Die Şoljarten find Y̧flangen, welde fid butd) einen feften, metgrere Jabre beftandigen Stamm uno burd) fefte Wurjeln von ben ubrigen Planjen unters (d)eidert.

Die פichtholgartent find biejenige Siciter, weldhe auf bas Jorftrefen nut cine Rebenbejiebiung baben, beren Stiel weid uno locfer ift, uno nictit mefgrete Jubgre beftinoig bleibt. 


\section{§. 4 .}

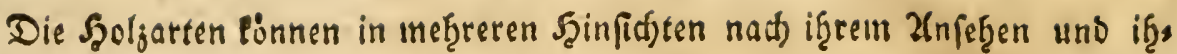
ren Szaupteigenfd)aften eingetţeilt werben;

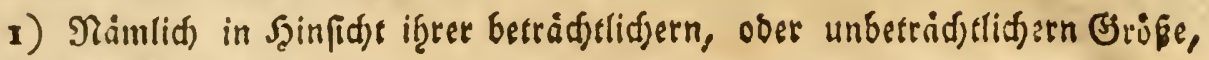
uno ba erid)cinen fie:
a) als Baiume
b) als Straiudjer uno
c) als Eroţols.

2) Jgree grösert ooer geringeren Şärte,

a) als b̧arte Şolzartern.

b) als reicfe Şoljarten.

3) Ş̧rer Şätter,
a) als laut: ober
b) als Tadelfgoljarten, ober
c) als nur im Sommer grin, uns
d) aud) im 2 Sinter ober immer grinende Szof gatten.

4) Des (jrundes uno Bobens, ben fie vorjuglids lieben,

a) als Eumpf; und Noorb̧oljarten, uno

b) als fold)e, weldfe einen trodenen, fanbigten, bergigten Stuno lieben.

5) Şrer Frudjt,
a) als Frud)tbiume in reiterem 2 erftande, weldfe bann wieber in ef= bare, und in nidft efbare, aud) in Sernobftarten, uno Steinobpts arten abgetheilt werben tönnen.
b) als Maftragende Baume,
c) als Briume mit geflugeltem Saamen,
d) als Bàume mit nictst: geftigeltem Saamen, uno fo reiter.

6) Jf̧ree vorjiglichen Denufzung,
a) als Baubzolj,
b) als Siobtlicoly,
c) als Brennfyoly,
d) als $S_{2} 0 l_{3}$ für Stellmader, Sdyreiner, Molbenţauer, Sajindelns madjer, uno fo meiter.

7) Des ben Biumen eigenem Silima, ober bes Sanbet, wo fie will wadj $[e n$,

a) als einfrcimifthe uno

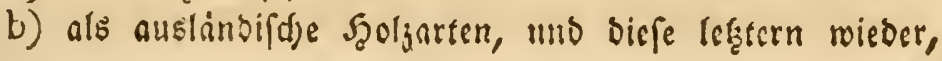




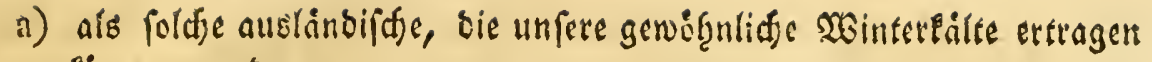
foinnen, uno

b) als foldbe, bic siefe nidjt ertragen founner.

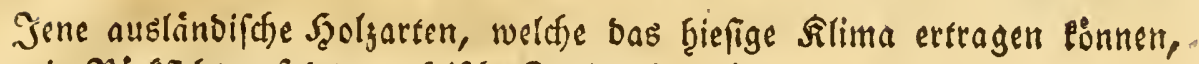
roctben in Rucffidst auf bos praetifd)e Forftroefen abermals getfeeilt,

a) in Foldje, weldfe mit গturgen in ben biefigen Forften forftmäfig. ges bogen werben ponner, und in foldes

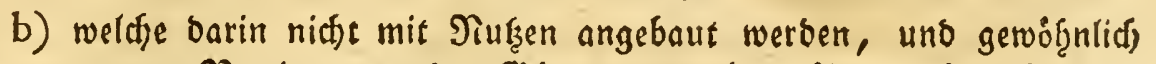

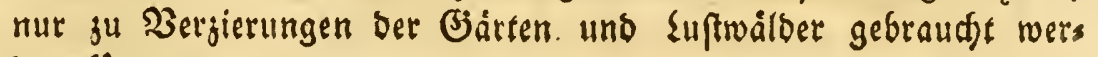
Den Ënner.

\section{§. 5 .}

Dergleidfen 2(btheilungen fann man fich bei bem fo vielfađjen Tutuen bes Şoljes und bei bem verfdiebenen Betriebe bes Jorftwefens fef̧r viele gebenęen. Eine jebe befonore 2 bfid)t veranlafit nidit nur eine andere jwectmásige Eins theilung, fondern verfthiesene Itmftande fönnen einen Biruns abgeben, die att

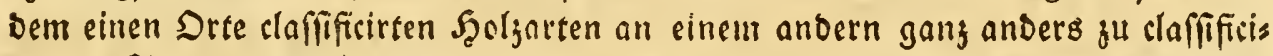
ren. So thailt ber Zimmermann, ber Sdjiffbauer, ber Stnbfroljidläger, ber

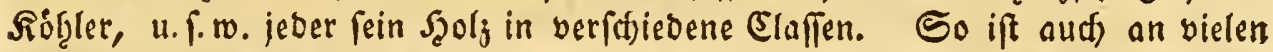

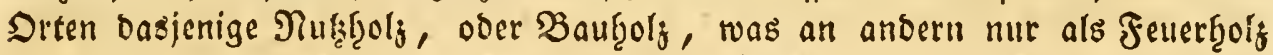

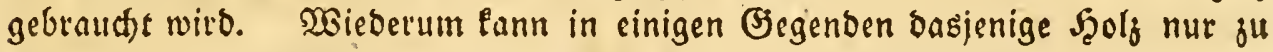
æ3aafen und Sicipgol; gezogen werben, woraus anderswo Băume ber erfen Brópe wathfen, und po weiter.

\section{§. 6.}

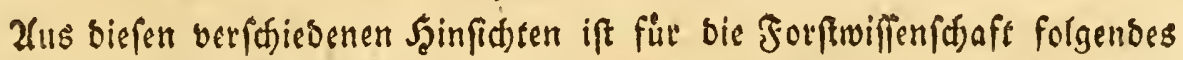
2lbtheilungsfrftem enefranden, uno in ben beften Jerffebriften, auf einige wes nige Unteridjebe nach, als bas $\mathfrak{B}$ raudjorife angenommen:

Die Szoljarten werden getteeilt

1) in Eaubfols uno

2) in Nabel = oder Tangelfols.

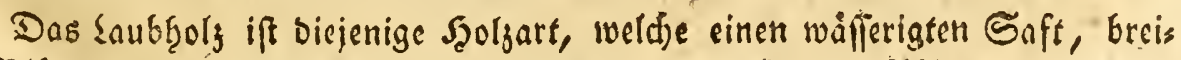

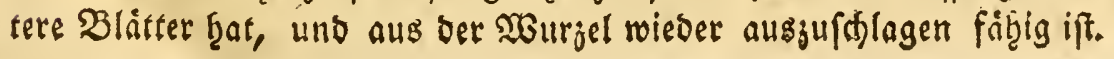




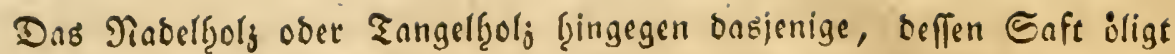
und trargig ift, bas aus bem abgefrauenen Stamm nid)t mieber ausfdylägt, unb oeffen Bläster, ooer Tangeln, wie man fie an einigen Drten ju nennen pflegt, nadelformig uno fdmal fino.

$$
\text { §. } 7 \text {. }
$$

Das \{aubf̨ol\} wirb weiter eingetf̧eilt

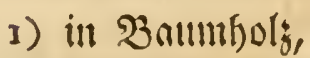

2) in Strnudb) [jols,

3) in Erofols unis ranfende Struiude.

Zum Baumbelz werben biejenigen Stoljarten gereed)net, welde gewifgntids nur einen geraben anfergntiden Stamm, uno eine Sirone treiben. Es roiro feiner (3róbe nach eingetbeilt:

a) In B̉numfiols Der erften Giroßß̨e, was gewif̨nlid) einen Stamm ober Sdaft von oreisig bis f̧unbert und meţrere Jus நृod) treitt.

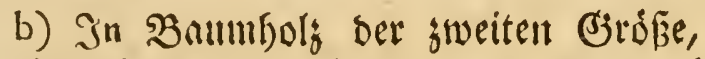

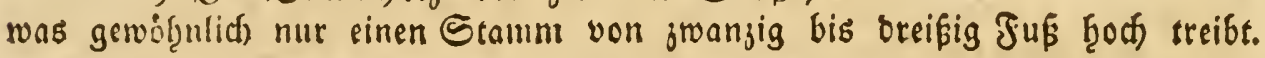

c) In Şaumbol ber britten Giro̊ße, was nut einen Stamm von zeధุn bis zroanjig Jup g̨od) ju treiben pflegt.

$$
\text { §. } 8 .
$$

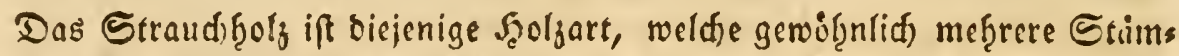
me von geringer Szobge und Stärle ful treiben pflegt: Daffelbe wiro ebenfalls singetḩeilt:

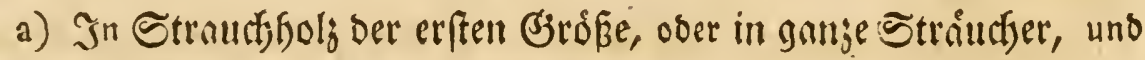

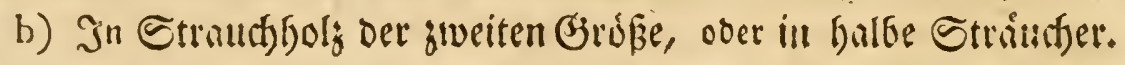

Jenes if basjenige, was eine Şobze von fects bis fed)jef̧n Juß ju erreiden

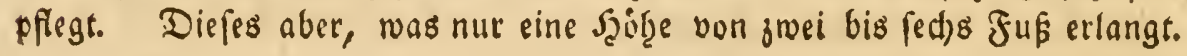

\section{§. 9.}

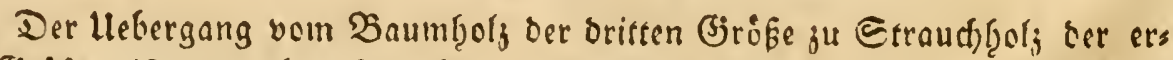

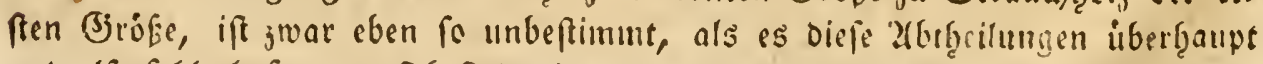

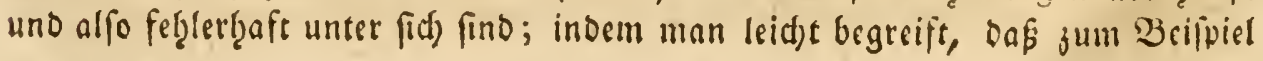




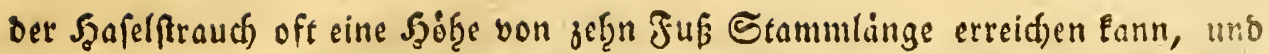
Dagegen felbft bie Eidje fid oft unter bas Strauchleolg verfried)t. allein ties wiro ben Forftoerftandigen bod) nid)t irre leiten, weil er bei genauerer unter= fucfung uno Beurtfeilung ber Sgoljarten in if̧rem gewól̨nlichen, natirtid)en, ungejwungenen Suftanbe leidt finden wirb, in weldhe Elnffe fie eigentlit) gef̧oren.

\section{§. 10. \\ 3) Die (5ibloolgftráutue}

erreichen nur eine fef̨r geringe Şob̨e, die bei einigen wenige Zolle beträgt; fie pflegen if̧ren $\mathfrak{M a d}$ stflum mit bem frudtbringen ju endigen.

\section{Die rantenden Striudbe}

fonnen fid) of̧ne Llnterftutzung nidhe beben, uno fricd)en, wenn fie an Eeinen

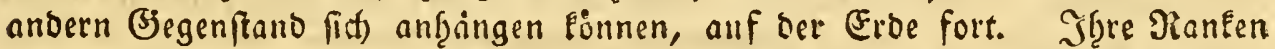
fino begljartig uno dauern, fo wie bie Stámmahen ober vielmef̧r Stiele ber Fros

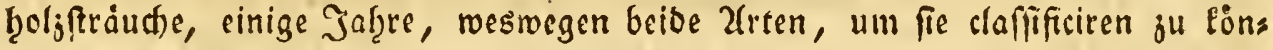
nen, ju ben Sgeljarten gerednet rerben. Lebrigens ift if̧r Forftgebraud) faft

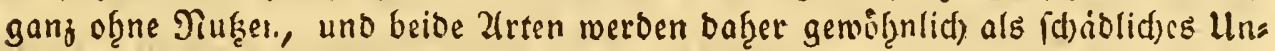
Fraut angefeten, uno nur bann benubt, wenn fie als fold)es in feltenen fällen,

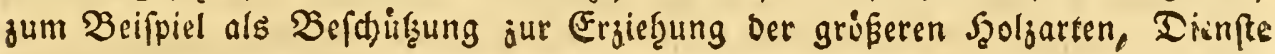
leiften Fonnen.

\section{§. I I.}

Das Pabel = und Tangelf̨olj wirb nur eingetbeilt:

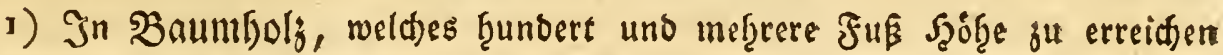
fähig ift, uno

2) In Straudbfols, welties nur ju einer geringen Söb̨e ju wad)fen pflegt.

$$
\text { S. } 12 .
$$

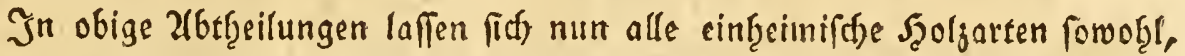
als bie, meld)e turs von auslandifhen bis jefet treannt fino, wenigftens mit fo

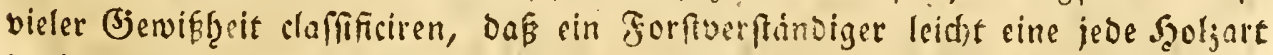
barin finben, une fid) Baturh bicjenigen 30 rtheile verfhaffen Eann, Die Inan bon bergleiden Eintheilungen ju erwarten ţat. 


\section{ङ. 13.}

Şenennung Der Saoljartent.

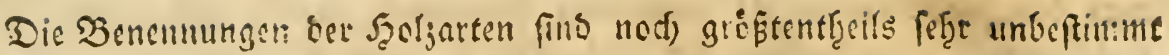
unb ungevis; felbft sic Tamen einigel der anjetenlid)ften unb belanntefters Bitume fint fo veridjicoen, baf man fiú) off bamit in siner Entfernung von wes

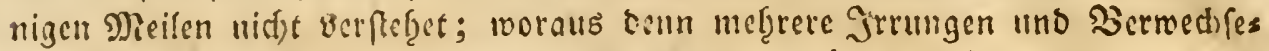
lungen ber einen Sadjart mit ber andern entfetzen miffen. So wird jum beis

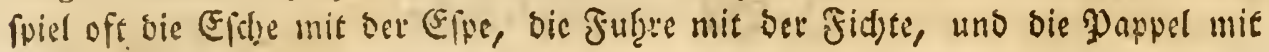
einigen Weibearten verwedfjett.

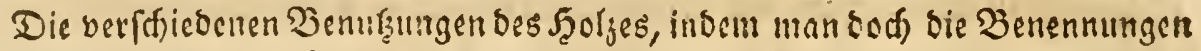

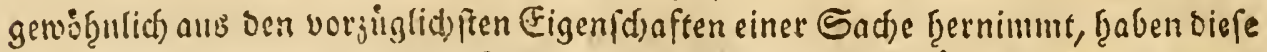

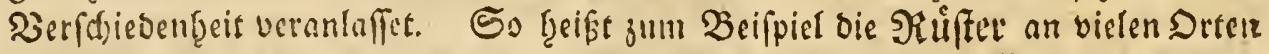
bie Sanftulme, weil man bort bavon bas Baft nufzat; Der Scoflumber an vielen

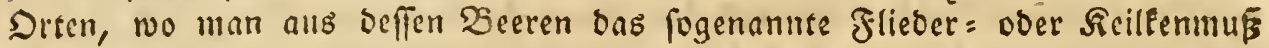
madte, Fflieber = ober Reilfentulff. Sei ber geniffen Benennung bes

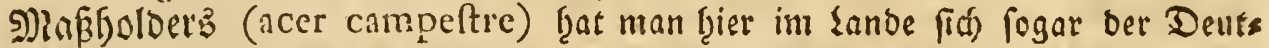
licheit wegen vorzujetenen, und if er in einigen Bsegenden nut als Epern, in anderen als Sppelooren, und nod) in andern als \$Beißepern belannt. Llntee Den Stralláfgóljern ift die Plomenclatur unenoliá, und wito man oft, ofene ber Straud) vorjuseigen, init ber Beteutung felbft unter ben forftuerftänbigen nicfet fertig. Die lltrad)e bavon liegt barin, baß Das Jorftrefen bis jef̧t jut wenig

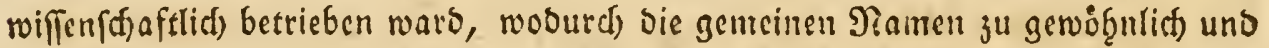
von 3cit ju Beit nod) vermetret worden find. WGer aud f̧ierin witb burd) forts

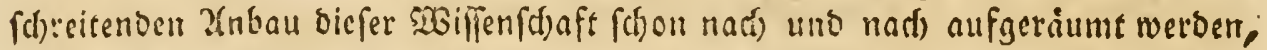
und bie genauern und beffern Benennungen werben bie fabledfern verorängen.

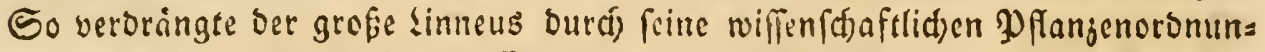
gen, bie fifjon jefgt butú) ganj Europa gelten, Eanfente foldfer gemeiner Nas men; und es iff bab̧ar autb bei ben $S_{2}$ oljarten fídon jiemlid) allgemein angenoms

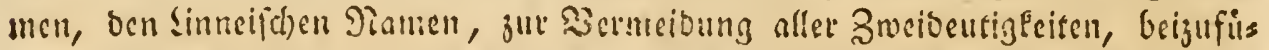

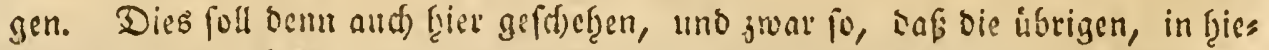

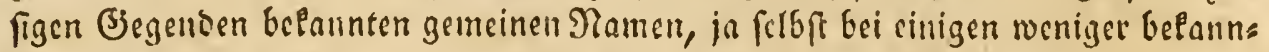

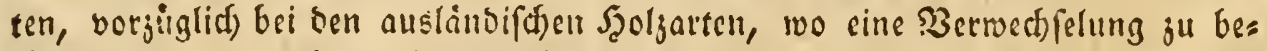
fürditen ftef̧et, auch autslindifdie Tamen bamit verbunben wetoen follen; bies

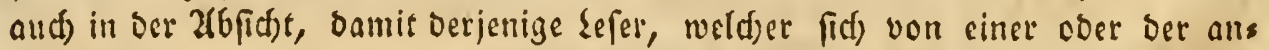

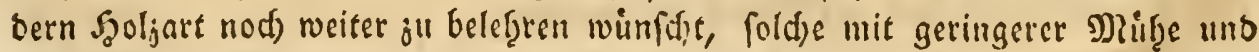

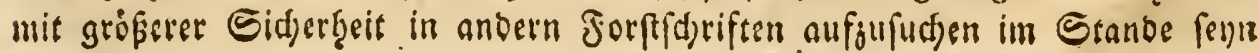
moge. 


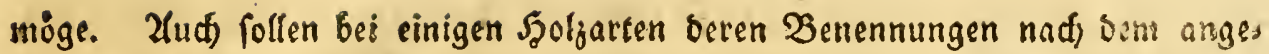

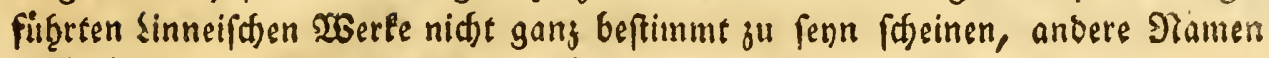
nach belannten Pfangenfigfemen beigefeg̨t werden.

$$
\text { §. } 14 .
$$

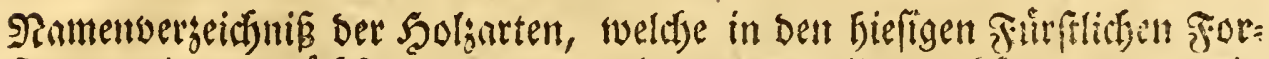

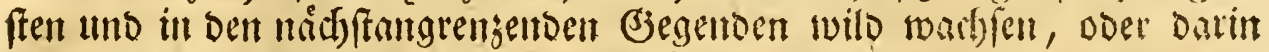

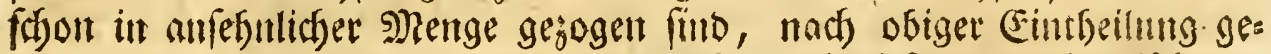
ordnet; wobei ber gemeine शame zlterft, nath biefem Der Eimneifde, und Denn Dic übrigen bier nod) befannten ßrovingial unamen angefilgtt werben.

$$
\begin{aligned}
& \text { §. } 15 . \\
& \text { (5) ife elaffe. }
\end{aligned}
$$

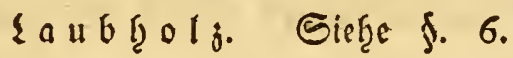

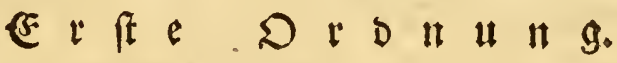

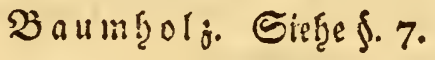

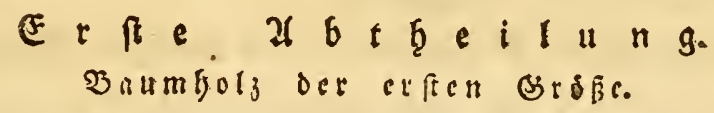

3. Die SBintereide, (Quercus robur) Trauberside, Sdjwarjeide,

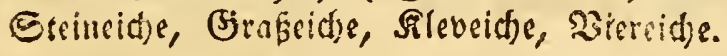

2. Die Sommereide, (Quercus fomina) (Miller) Etielciofe, Motfeis d)e, grof́e siafteidje.

3. Die Buiffe, (Fagus fylvatica) Mstb̧udfe, Maftüthe.

4. Die (5fife, (Fraxinus excelfior.)

5. Die Gommerimbe, (Tilia Europea) bie breitbläterigte Sinde, 2 seips

- linde, feollandiffie sinbe.

6. Die Thinterlube, (Tilia cordata). (Miller) bie fpite Sinde, Steins linde, Elcinbláttcrigte sinbe.

7. Der Rfforn, (Accr preudoplatanus) sie Dẹ́re, Ehre, Drrnbaun.

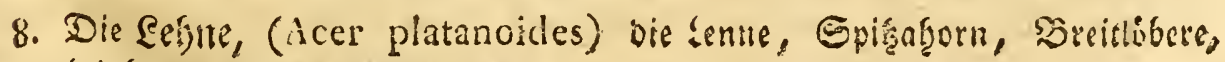
scinbauin. 
9. Die Stliftel, (Ulmus fativa) (Miller) bie lllme, bie rauţe Riufter, raubze Lllme, SIme, Safrilme, Jlisgenbaum, Effern, Leinbaum.

10. Die glatte Siliper, (Ulmus campeftris) glatte Lllme.

1. Die Rirfe, (Betula alba) Manbaum, Mave, Berle.

12. Die Eller, (Betula Alnus) bie Elfe, Errel, Erle.

13. Die weifie norbifite (Eller, (Betula Alnus incana.)

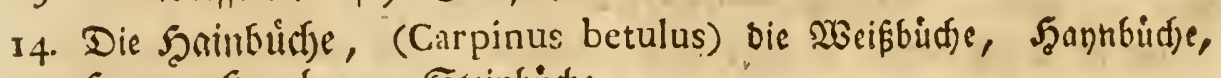
Syanne, Szornbaum, Steinbuid)e.

15. Der Twiffelbeerbaum, (prunus avium) SOlberpirfabbaum, Şolgs Pirfabbaum, Eaffebeerbaum. *)

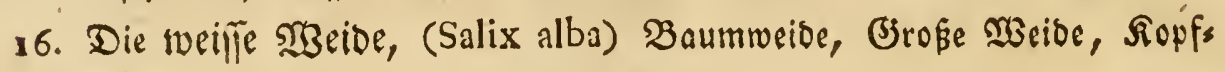
weibe.

17. Die Efpe, (Populus tremula) Bitterpappel.

18. Die Y̧appel, (Populus nigra) Pippel, Pappelweibe.

19. Die Sillerpappel, (Populus alba) bie 2reifepapper.

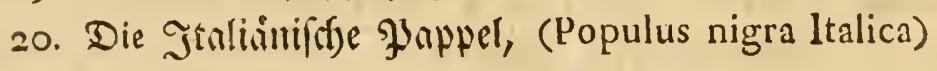

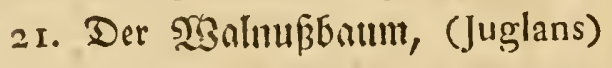

22. Die 2tacia, (Robinia preudoacacia) unådter Sdjottenborn.

Diefe brei lefzten 2(rten fino zrwar nid)t einfeimifd); oa fie aber bin uno ricber in ben forften angepflanzet find: fo follen fie hier billig als naturalifirt aufges nommen werben.

$$
\begin{aligned}
& \text { §. } 16 . \\
& \text { 3 weite abtheirung. } \\
& \text { Saumarten oex breiten ordfae. }
\end{aligned}
$$

I. Der Eljberbaum, (Crataegus torminalis) Dormbeere, 2(frectere,

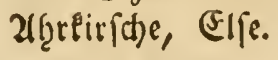

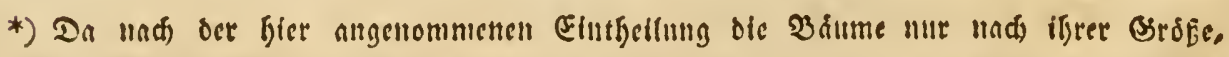

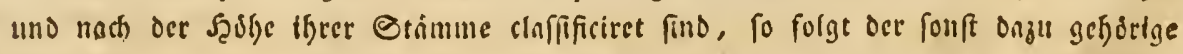

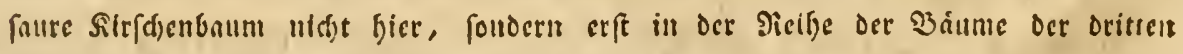

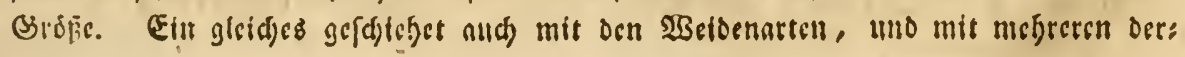
gictider. 
2. Der Soljbitnbaum, (Pyrus communis fylveftris) wilber Birnbaum.

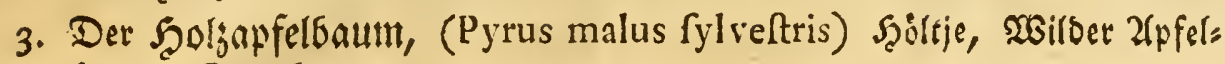
baum, Splitt)en.

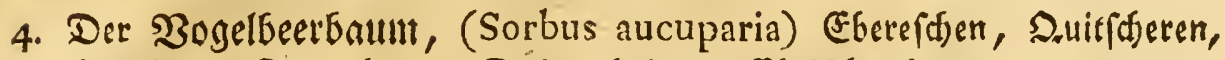
Suitfhen, Sippenbaum, Dof̧nenbef̧ren, Ebifd)beerbaum.

5. Per Spierlingbaum;, (Sorbus domeftica) Epieråpfelbaum, Ejd̨es rifen, oie appelefobe, Epeerbaum.

6. Der Mabílolder, (Acer campefte) ber Eleine 2f̧orn, Mabeller,

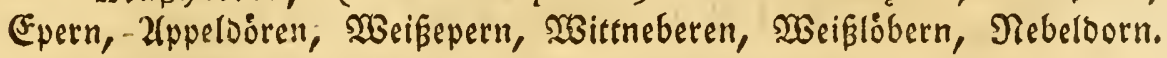

7. Die großje Maffertueide, (Salix amygdalina) Mandelrocibe.

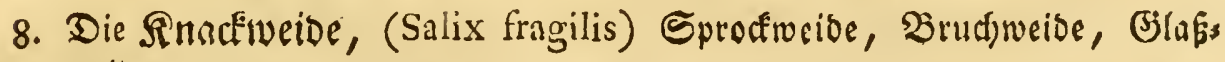
weibe.

9. Die gelbe Banoweibe, (Salix vittellina) Sjolomeibe.

10. Der wilde Pflammenbaum, (Prunus infititia) Sriedens ober Siteis Eenb.aum.

11. Der Sarıb, (Taxus baccata) Eibe, Eibenbaum, Farbaum. *)

$$
\begin{aligned}
& \text { §. } 17 .
\end{aligned}
$$

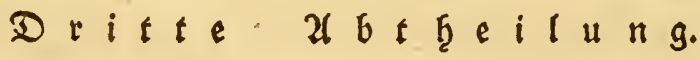

$$
\begin{aligned}
& \text { saumbolz ocr oritten Eirfác. }
\end{aligned}
$$

1. Der Traubenfirfd)baum, (prunus padus) Şoh̨lfirfide, falfater Fauls baum, Epin, Elpotr.

2. Der frure Rinfdosum, (Prunus cerafus)

3. Terlenbaumt, (Cornus mafcula) Cornefliridge.

4. Die Saalmeibe, (Salix caprea) Sob̨lweioe, Söhle, Malntentreioe.

5. Die Rorbeerweide, (Salix pentandra) glatte Saalweide, Bittermeibe.

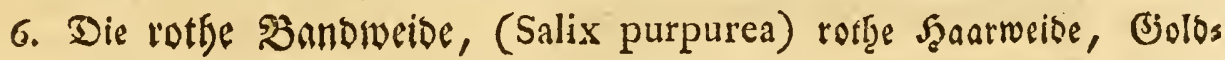
roeioe.

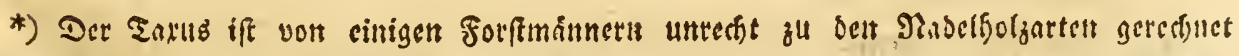

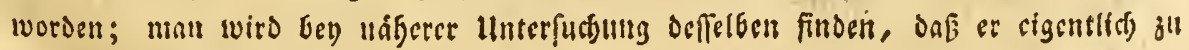
Den Eaubjolzarten gebort.

(Erfter Fyeil) 
7. Der Miffelbaum, (Mefpilus germanica)

8. Die Şülle, (llex aquifolium) Etedjpalme, WGalobieftel.

$$
\begin{aligned}
& \text { §. } 18 .
\end{aligned}
$$

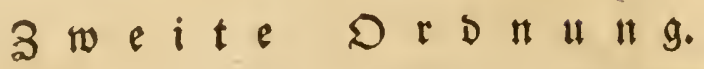

$$
\begin{aligned}
& \text { Straudholj. - Sief̧e \$.7. } \\
& \text { Ex f } e x b+h e i l u n g .
\end{aligned}
$$

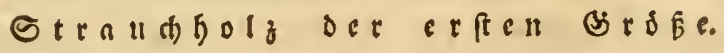

1. Der Şafelftraudf), (Corilus a vellana) Şafelnußs.

2. Der f(t)warge Şollunber, (Sambucus nigra) Flieder, Şolder, Sieils Penbuif), (jartenteolder.

3. Der rothe Syollumber, (Sambucus racemofa) Pleine Sholber.

4. Der Fielijorn, (Rhamnus catharticus) Sireujbeeren, Farbebeeren. Szunosberen.

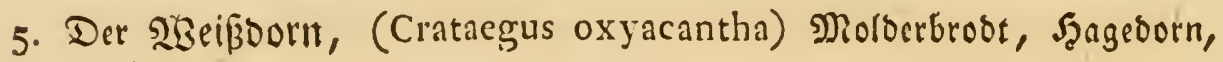
Szecfentorn.

6. Der Sdjlefllbort, (Prunus fpinof,) Sdrwarjoorn, Şecfentorn.

7. Dor Eiguffer, (liguftrum vulgare) Diţeinweiben, Spanifdes 2lfţorn, grincr Faullaum, Beinţolz, Mundf̧oly.

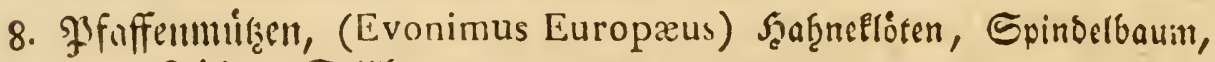
Eleme Ditfrer, Spillbaum.

9. Shetfentirfhenftraud), (Lonicera xylofteum) Etrif̧eren, Şunds: firfaen, Wolpermay, Walpurgismay, Sprüzern.

10. Der Şartriegel, (Cornus fanguinea) Şätteren.

11. Betberifzen, (Berberis vulgaris)

12. Quittenftrauch), (Pyrus cidonea filveftris)

13. Der Edfwalfenbeerftraud), (Viburnum opulus) Wilber, Sannes ball, Sdimalen.

14. Der Faulbaum, (Rhamnus frangula) Sdbiefbeeren, Steinbaum.

15. Die $\mathfrak{3 e r f t w e i d e , ~ ( S a l i x ~ a c u m i n a t a ) ~ e l e i n e ~ f p i r z i g e ~ S a b ̨ l w e i d e . ~}$ 
16. Die Rorbiveibe, (Salix viminalis) Wafferweibe, Srunorocibe, Erbs weide, Sirebsweide, $\mathfrak{B}$ anoweide.

17. Die gelbe Şact)rueibe, (Salix helix)

18. Die Mok̂nmarienweide, (Salix Rosmarini folia) eleine Silberweibe.

19. Die TBeimofe, (Rofa eglanteria)

20. Sagebuttenrofe, (Rofa villofa) Ritteloorn, Şagesorn.

$$
\text { §. } 16 .
$$

- Sweite 26theilung.

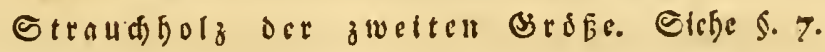

I. Der Sinfter, (Spartium Scoparium) Befenpfrieme, Gielfer, Senis fte, Dfriemen, Xiebchende, Brame.

2. Die blafie fieldrofe, (Rofa canina).

3. Die weiffe frelorofe, (Rofa alba)

4. Die gelbe frelorofe, (Rofa lutea)

(Miller)

5. Der Corintfenftrund), (Ribes alpinum) Poffelberen, Sraufenberen.

6. Der (jid)tbeerffralld), (Ribes nigrum) fdwarje Johannisberen.

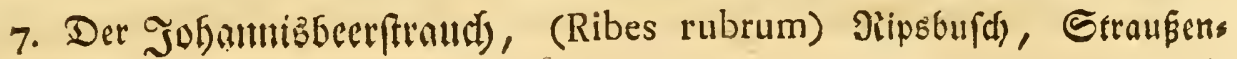
beere.

8. Der Stadjelgeerfinuth), (Ribes Uva crifpa) Stidberen.

9. Der forrbeginfter, (Genifta tinctoria) Sielbraut.

10. Die Salbey blútterige $2 B e i b e, "(S a l i x$ aurita)

Ir. Die fleine Sanbweibe, (Salix arenaria)

12. Der Rúbnpoft, (I edum paluftre) Poft, wilber Jiosmarien.

13. Der Gellerbalb, (Daphne mezereum) Seibelbaft, Subbaft.

14. Der Simbeerftranth), (Rubus idaus)

15. Der gropie B̈rombeerftrand, (Rubus fruticofus) Sirajbere.

16. Die Brofentive, (Betula nana) Moorbirke, Moofbirfe.

17. Der Miffel, (Vifcum album) melder eigentlid) aber fier nidst aufges fübre fern follte, weil er nid)t auf ber Erbe, fonbern auf andern Boumen als Sd)maroferpflanje wädjt. 
\$. 20.

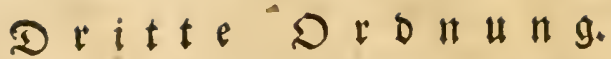

Erof̧oly uno ranlende Striudte. Siche \$. 10.

Erite abtheilung.

(5) 05018 .

1. Die Torfunirtfe, (Myrica Gale) Bärbermirtfe.

2. Die Şaulfect)el, (Ononis Spinofa) Stndjelfraut, Şacteln.

3. Die fleine Erdrofe, (Rofa fpinofifima) -Seenderofe.

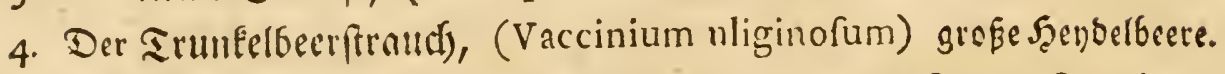

5 Die Şevbelbeere, (Vaccinium myrtillus) đdwarje Beere, Slanbeete.

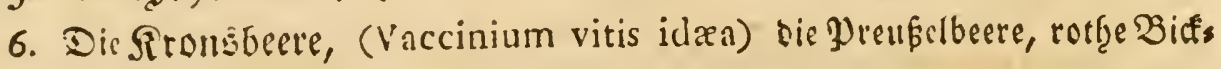
becre, Siranbecren.

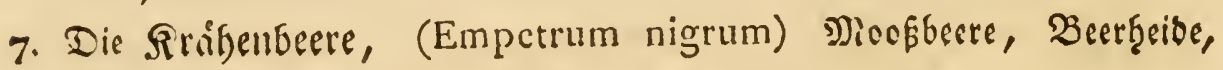
Nau\{djberen.

8. Die Bårenbecte, (arbutus uva urfi) Mef̧lbeere, Sanobecre.

9. Die Sacibe, (Erica vulgaris) Şeibefraut.

10. Dic Sumpffeibe', (Erica tetralix) rog̨e Saeibe, Befenteeibe, roins terḩeioe.

II. Der Torfrosmariu, (Andromeda polifolia)

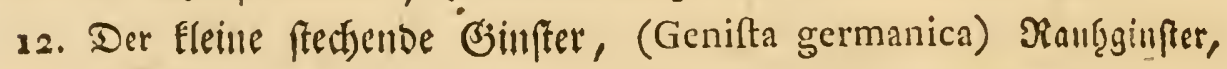
Stadtelpfriemen.

33. Der friedjende Gimfter, (Genifta pilofa) Şanriger s Binfter.

$$
\text { §. } 21 \text {. }
$$

Zueite 2tbtheilung.

Jinneflle Etráude.

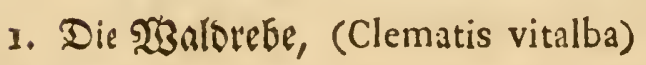

2. Das Beisblatt, (Lonicera periclymenum) wildes Caprifolium

3. Der Epfenl, (Hedera helix) Jren, Jrenblatt, Wintergrü, Effen, Eppid. 
4. Die Alpranfe, (Solanum dulcamara) Jclingericlieber.

5. Die शterthrombere, (Rubus cæfius) Brombeerranle.

6. Die Mópbeere, (Vaccinium occycoccos) Torfberte.

\author{
§. 22. \\ Siveite ciaffe. \\ Nabel = oder Tangelfiold. Sietze \&. 6 .

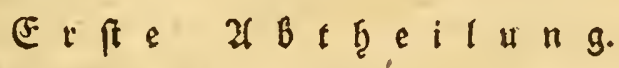

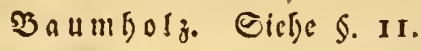

1. Die Siotftanne, (Pinus picea) (bu Roi) Sidjte, Şarjtanne.

2. Die Riefer, (Pinus Sylveftris) Jutgre, Jogrte, Sief̨en, Sief̨nbaum.

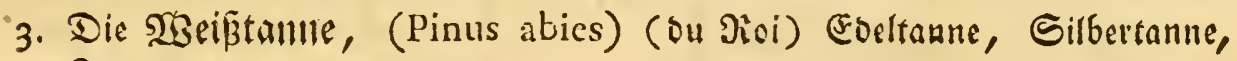
Tartanne.

4. Der Eerdfenbaum, (Pinus larix) sie Scrde, Serdfentanne mit feinen verfdiebrnen atbarten, als bie gemeine, bie rotbe uno fdjwarje serd)e.

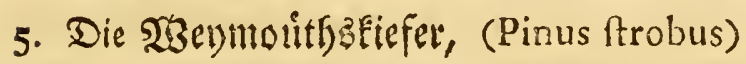

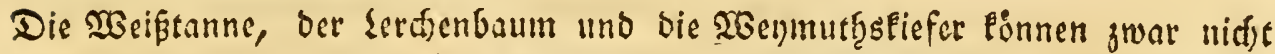
eigentlid) als cinfzeimifde Rabelfgoljarten angefergen werben, ba aber foldje, uno vorginglid ber gemeine Sert)enbaum, feit ben legten Beiten in ben ficfigen Fors

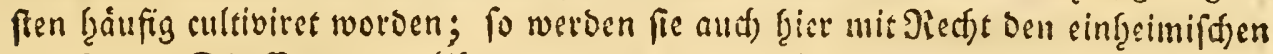
zugefefzt. Die Eeder von sibanon uno bie rothe Eeder aber, welthe alld) in eis

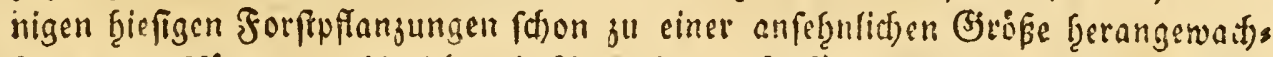
fen waren, Ëonnen wof̧l nid)t mit Redte ţier aufgefítget werden, weil fie in bem

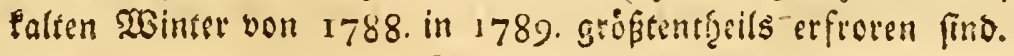

$$
\begin{aligned}
& \text { \$. } 23 . \\
& \text { 3 weite at btheitung. } \\
& \text { Straudforb. Elches.ir. }
\end{aligned}
$$

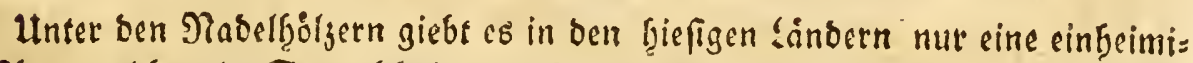

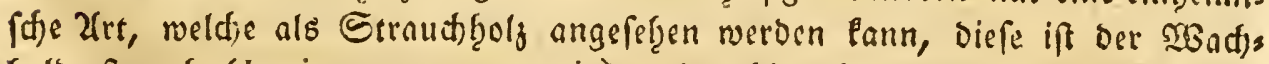
holderftraud) (Juniperus communis), wiewohl aud beffen Elafifficitung unter bie Natelfielzer nid)t ganj paffent zu fern fdeinet; ood) geţort er baju mit mefgs rerem Sied)te, als Der vorb̨in aud) Daju geredjnete ₹apus. 


\section{§. 24 .}

Da nun nad) Dem $\$$. 4. Diefe Syoljarten in Thidffidft auf bie Deftändigleit if̨rer Blätter getteeilet werben tönnen

1) in alljeit grime, uno

2) in nut im Sommer grime Soljarten; fo getgiren zu ben alljeit grinen

Die Fidjte oder Mothtanne.

Die $\mathfrak{B}$ eíktanne.

Die Riefer.

Die MBspmoutgrgtiefer.

Der Tarus.

Die Şille.

Der SEadifelberftraut.

Der אilitinpeft.

Der grofe Bromberftrauds

Der Siftel.
Die Şeibe.

Die Sumpfreioe.

Die Barenbeere.

Der Sorfrosmarien.

Der Pried)ende Binfter.

Die Sirą̧enbere.

Die Sironsbeere.

Der Ephru.

Die 2aferbrombere.

Die Noob́bere.

Diefe Şoljarten fint in bẹn befen Forftidrifen unter bie allgeit grínen Şolgs arten aufgenommen, bod (d) cinen mir einige berfelben, j. B. Die Brombeerars ten, fid) oaju nidit red)t ju qualificiren, weil bie Sllitter, weld)e fie ben winter

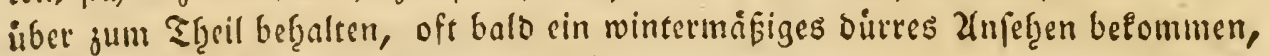
uno bor bem 2lusbrud) oer neuen Blätter abfallen.

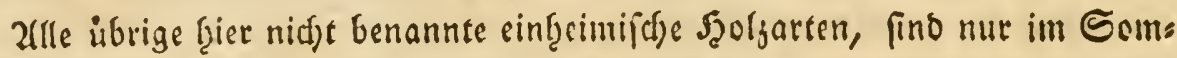
mer grine Şaljarten.

$$
\text { §. } 25 .
$$

Bon ber eintbeilung ber jolgaten in weide und barte Solgarten.

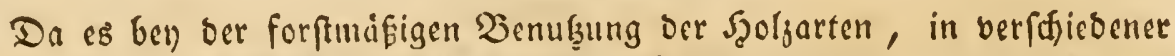

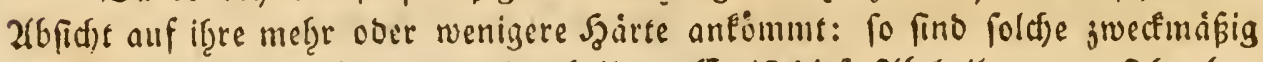
in Garte uno weidfe Szolzarten abjutfeilen: (Es ift biefe abtheilung an fid) eben fo unbeftimmt, wie es metgrere bergleid)en in biefem sad)e fino, indem bie

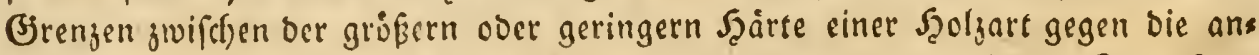
bere oft ourd) Rebenumfando verţâltnifinasifig angenommen wirb. So red)net

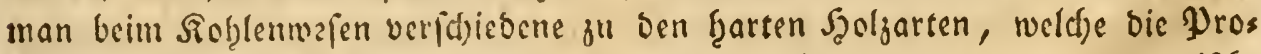

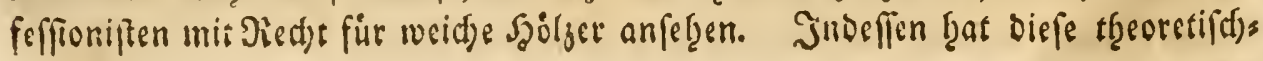




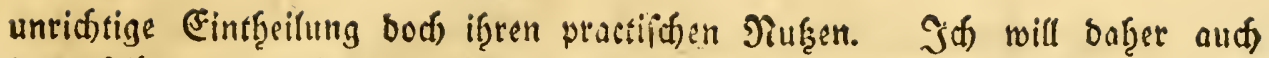
in Derfelben nut biejenigen $\mathcal{H}_{0}$ lzarten auffib̨ren, bei benen biefe Fintbeilung bes mef̧reren গukzens wegen ant wid)tigften ift, uno wie bie Sgolzarten bier bulgas rifd, entweber als weid)e ober als f̧arte forftmápig angenommen werden.

Man red)net unter bie barten Sgoljarten:

Die Eidfenarten,

die $\mathfrak{B}$ inde,

die (Fid)e,

ben Zbeorn,

bie Sebre,

sie Rifferarten,

sic Dirle,

Die Ellerarten,

Die Saainbidfe,

Den Iwiffelbeerbaum,

ben Malnubbaum,

die 2ucacia,

Den Elgebcerbaum,

ben Soljbiintoum,

oen Şolgopfelbaum, ben ఇogelbeerbaum,

Den Maf̧rolder,

Den Taxus,

Den Traubenfirfofbaum,

ben fouren Sirfdbaum,

ben Terlenbaum,

Den Mifpelbaum,

die Şille,

Den Şafelftrautf),

Den Sirenijorn,

ben Wriboort,

Den $\mathfrak{P}$ faffenmitzenftrauch,

ben Sectenfirfdenftraud),

Den Sartriegel,

Den Duittenfraud, uno fo weiter.

Unter bie weid)en Saubf̧oljarten werben gercénet:

Die Sinoenarten,

die fämuntliden Weibenarten,

bie Efpe,

bie Dappel,

sie Silberpappet,
Die italininiftre Pappel, aud) woḩ oet Foulbaum,

ber weid)ern Foblen zum Sdisfpulver wegen.

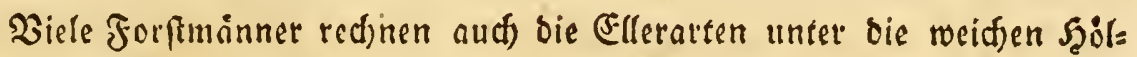

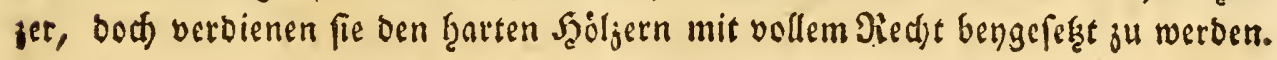

§. 26.

Dbfach in einigen ber beften Forffffriften biefe 26theilung ber Garten

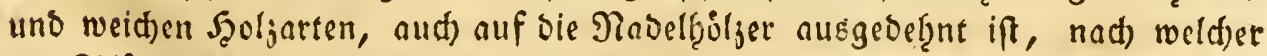

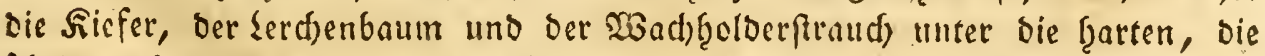
ubrigen aber unter bie meidjen Sgoljer gejählt werben, fo lömmt mir Dod ben 


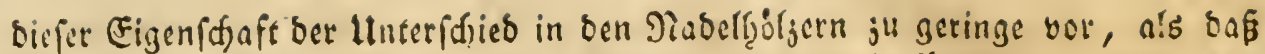
id) es roagen modfte, biefe Eintheilang berfelben aufjufüteren; nad) fiefriger

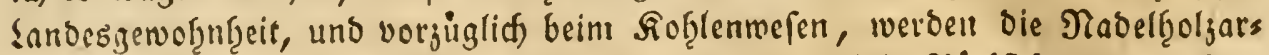

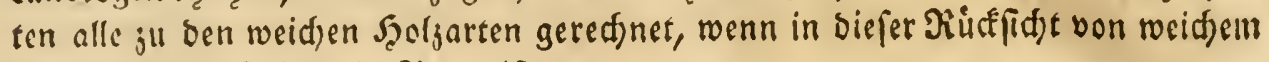
ober Gartem Solge Dic Jiebe ift.

\section{§. 27.}

Der פichtholzarten ober Sirciuter, weld)e bey bem forftwefen nut cine

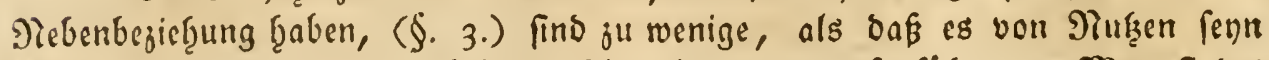

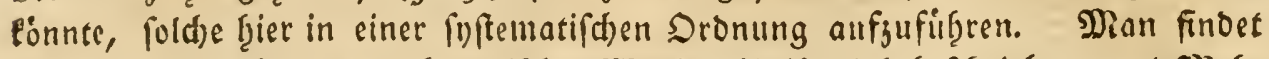

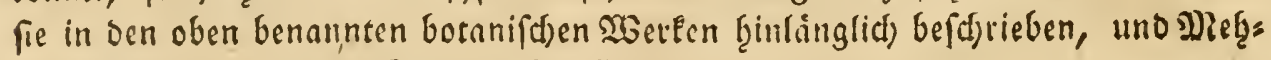
reres wiro babon in Der Jolge biefes 2 Serfs vorfommen.

\section{Dritter abfillt.}

\section{3on Der Siaturbeftercibung Der Báume und Der úbrigen beim Gouftive ven vorfommenden झצflantion.}

\section{§. 28 .}

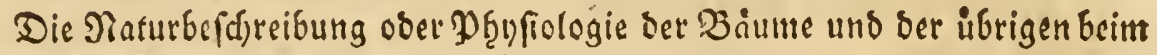

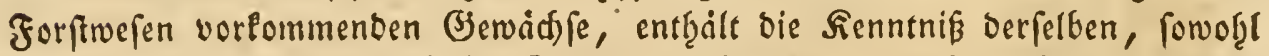
in Banjen, als ifgrer einfacten Theile, weld)e ben organifden Bau berfelben autmact)en, uno wie diefe auf das Leben berfelben roirlen; nebft allen bem, was

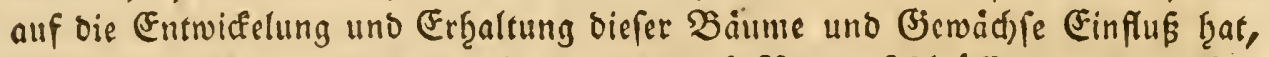
fo biel uns befannt ift, ober wir baraus nad)-23ernunfefdluffen of vermuthen Hifad) baben.

\section{§. 29.}

Fin jeber Baum ḩat einen Stamm, Wurjeln, Zweige, Blätter, Blus

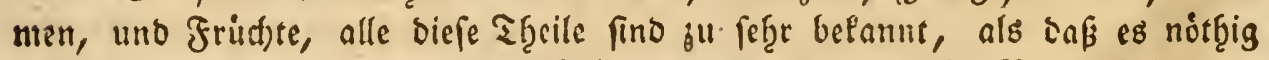
feyn folle, fie zu befiniten. afle Baiume finto von ber weifen Mafur beftimmt, sainit 


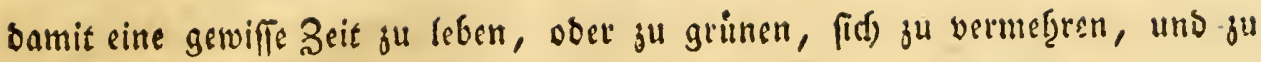
fterben, ober troden ju werben.

Ein jeder Baum lann fo fein vegetabilifaces Leben fortleben, und auf bie

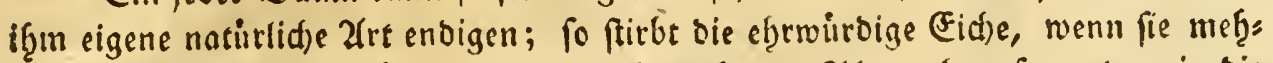

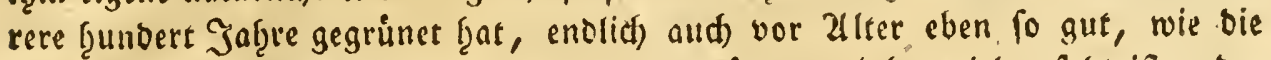

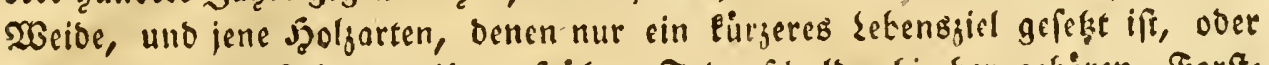

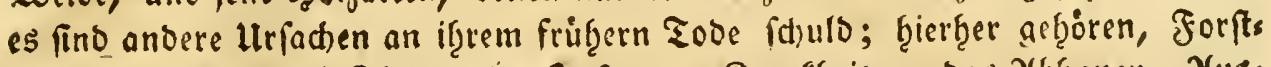
befchioigungen ourd Thiere ober Infecten, Siranflgeiten, Das 2lbfgauen, 24uss rooen, uno bergleiden aufälle meţrere.

$$
\text { §. } 30 \text {. }
$$

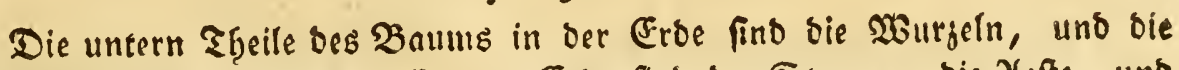
oheren Fbeile bes Baums auffer oer Erbe find ber Stamin, bie 2lefte, unb

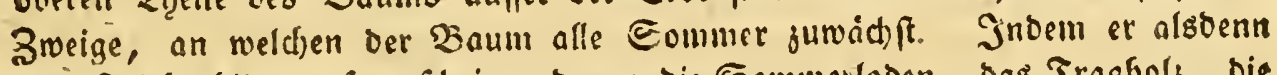
neue Triebe bilbet; fo erfteinen baran bie Sommerloden, bas Tragḩoly, bie

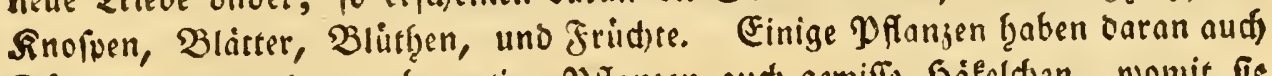
Dorner, uno anbere rebenartige YHFanjen auld) gewiffe Száfeld)en, nomit fie

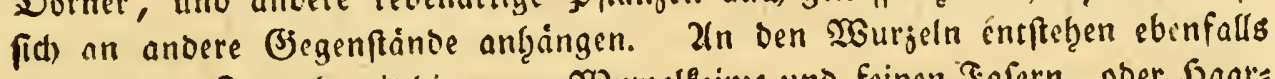
wabrend ber Suwad)szcit bie neuen $\mathfrak{S}$ Surgelleime und feinen Safern, ober Şaat: wurzeln.

\section{§. $3 \mathrm{r}$. \\ Bom Stamm.}

Der Stanm ift ber Theil bes Baums, welder fid oben in Bweige, uns in ber Erbe in 20 urjeln theilet. Der Stamm eines jeben Baums befteftet aus bem feften Şolje, Dem Eplint, Dem Mark uno der Borke, uno biefe felfft aus einem wundervollen Rib̨rens uno Drifengewebe. Der Gramm von den vars

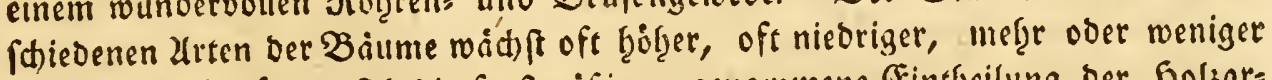

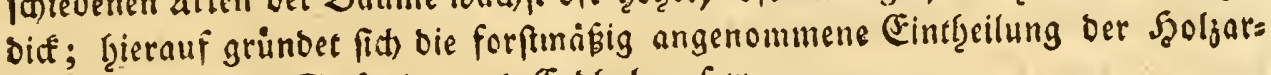
ten, in Baume, Eträucher uno Erob̧ols u. F. w.

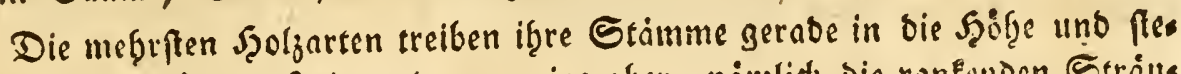
hen of̧ne Unterftif̧ung frei, andere wenige aber, nämlid) bie rankenocn Stráls d)e, wirben, wenn fie fich nidht mit if̧ren Briffeln uno Szaaten, ober bie, weld)e

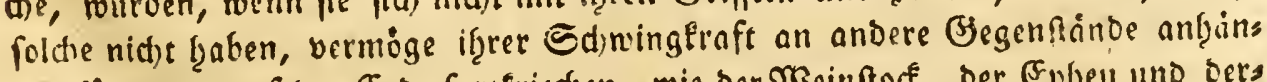
gen fönten, ouf Der Erbe fortfriedjen, wie ber Beinftof, Der Eptecu uno bers gleid)en mefrr.

(Evefter Theil) 
Die Stämme ber Bàume find walzenförmig, und erfd)einen bie 2(bjd)nitte berfelben in Birkelflactien. Dod ift beibes nidte im genaueften Berftanbe ju neţumen, weil man wob̨l menige Baume antreffen wirbe, beren Stämme volls fommen runo find. Bei einigen Syolzarten fino bie 2afdfuitte ber jungen

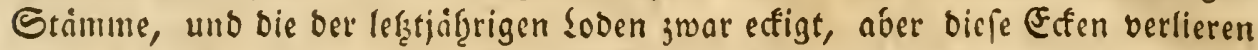

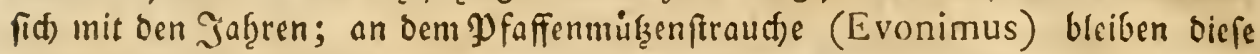
Ecten einige Jaf̧re fidttbar, an andern Eam man fie nur noct in ben jüngern Saf̧ren an ber Sorke bemereen, wie an bem Maffeloer (acer campeftre).

\section{§. 32. \\ on bett 3weigent.}

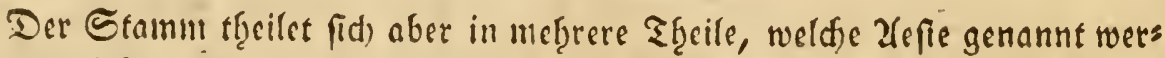
bett, uno biefe misocrum in noch meţrere Tlecile; sie gröseren, sicferen, beţals

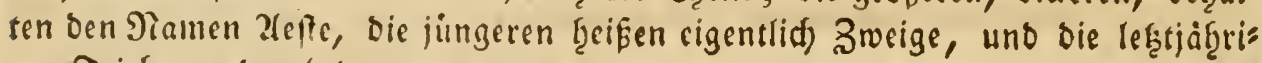
gen Eriebe merden Sooen genannt.

Es befteţen foldye aus eben ben Theilen, wie ber Staınu, uno fie traben

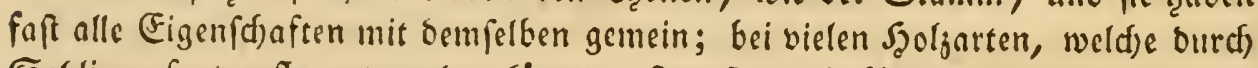

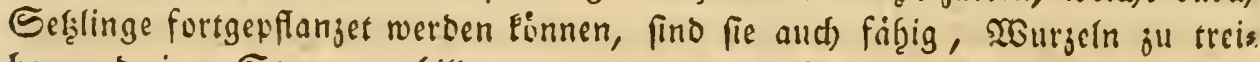
ben und einen Stamm ju bildem, wovon unten melgreres vorksmmen wiro.

\section{§. 33.}

Der gewöbnliffen Dronung gemåá, entfecten bie Zweige aus ben Bläts terfnofwen, bie bie meţrite Triebfraft haben, oft aber audl) aus den unfid)tbaren Finopen oder Sieimen im Şolje, weld)e in wahte Snofpen ausjutreiben fähig fino. Erfteres bemerlt man bei jungen nod) mit Blatt?nofpen beferisten Srieben

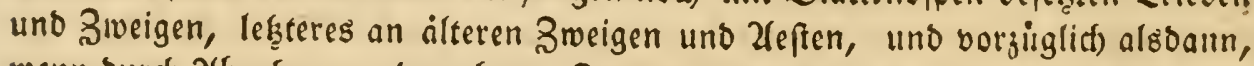
wenn burd) 2(bnefgmung ber oberen Zweige, ober fonft ourd) einen Zufall, bie Triebsifraft oerfelben geţemmet wiro, in weld)em Jalle ber Stamm uno oie un= teran 2efte bie Erjeugungstraft ber eingelnen Tgeile, weldte ben Theilen bes Bnums iberḩaupt eigen ift, ausiben.

\section{§. 34.}

In ben 3lweigen, welde gewooţnfid) aus ben Snofwen ber jüngern Triebe

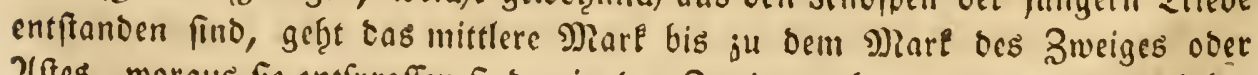
2lftes, woraus fie entfproffen find; in ben Broeigen aber, alts einer unfidstbas 


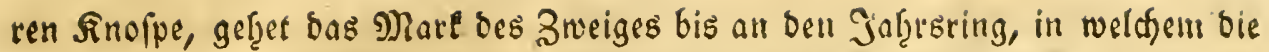
unfid)tbare Snofpe if̧re Entftef̧ung und Bilbungsifraft erf̧alten hat.

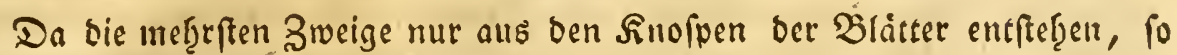

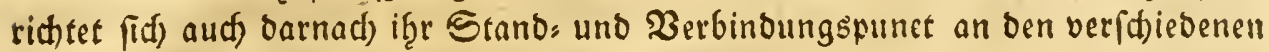
Saumatten: Eg figen bafer an fold en Biumen, an beren jungen sooen bie Bläter abwed) felno fteben, aud bie Zweige eben fo an ben jungen Zefter, wie 8. B. an ber Buid)e, (Eid)e. 2(n anbern, ben Blätern nach, gegeneinander iberfteteno, wie an oer Efate, Sirujootn u. f. w.

\section{§. 35 .}

Bei vielen Scoljarten find bie Zweige meb̧e an ben gerabin Feauptfalnm gelę̧net, uno mit diefen in eineın fpifzigen Winlel verbunden, wie vorjüglich

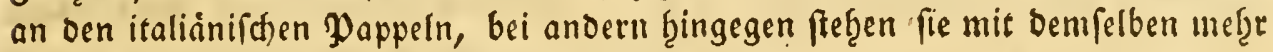
in gerabem Winlel, als bei ben গabelf̧oljarten.

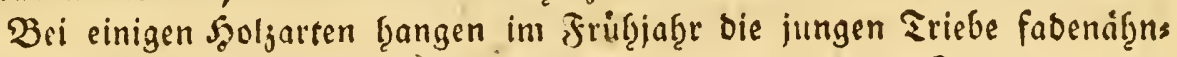
lid ḩerab, erḩalten aber, bei mę̧rerer Reife, bie if̨nen cigene Steflung; man fann oiefes j. B. an ber $\mathfrak{B}$ uche uno vorjuglid) an oer Trauerweibe (Salix Babylonica) beineren.

So mie mats sie Snofipen in Syofjenofpen und Frudtenofpen eintfeilet, fo finbet aud, oiefe Eintb̨rilung bei ben Zeften uno Zweigen Statt, incem es auls

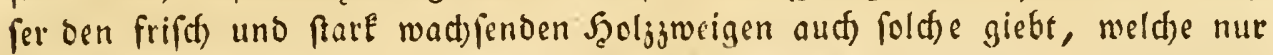
Frudtenofpen anfegzen, uno baber Fruct)tjweige genannt werden; if̧r Wad) thum ift oft auferft geringe, uno if̨r Szolj ift eigentlich furobe uno beftefget faft aus lauter Sellengewebe. So findet man an alten $\mathfrak{B}$ iud an oft laum orei $\mathfrak{F} \Perp \mathfrak{B}$

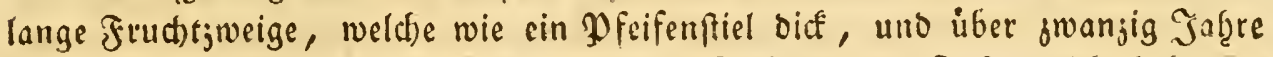

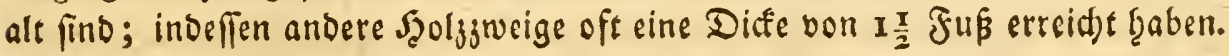

\section{§. 36 . \\ 20n Den THulgeli.}

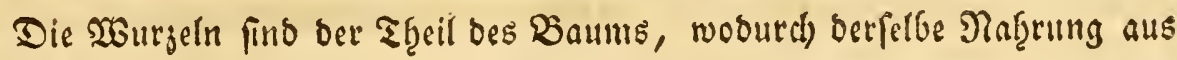
feinem Stanopuncte zieft.

Bei ben mef̧rften $\mathfrak{P}$ fanjen ift diefer Stanbpunct bie Erbe, bei einigen Wafferpflanjen bas Waffer, morin fie wadjen, bei andern, sie man Sdjmas roferpflanjen nennet, find es die Forper, an bie fie fich gefeft haben.

Die Şurgeln find baju beftimmt, um ben Baume feinen feften Stano

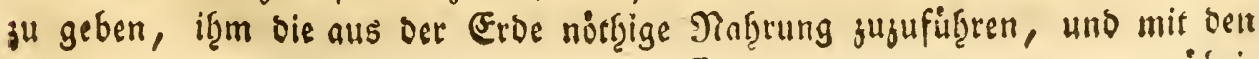




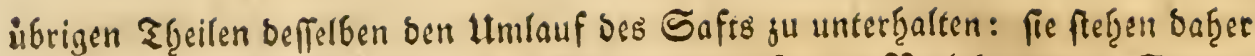
mit jenen in engèr 3 erbinbung. So idjabet oft eine 引erlef̧ung ant Stamm

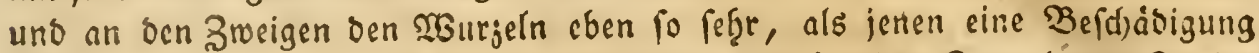

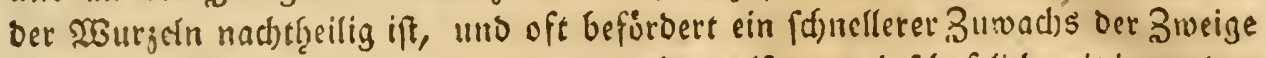
Das Wad) 2egetationggefdjaft firt bie Eriftent bes ganjen Baumes.

\section{\$. 37.}

Da bie Pflanzen nut auf einem feften Stanopuncte feţen bleiben, und

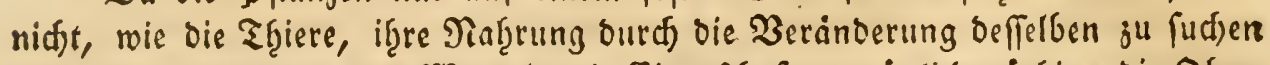

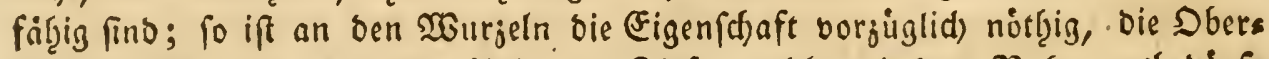
fläche bes Erobobens in ber Weite uno Tiefe, reld)e mit ben Thąrungsbedirfs

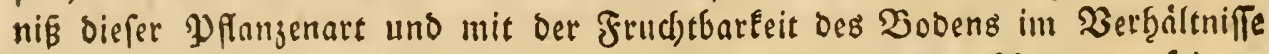

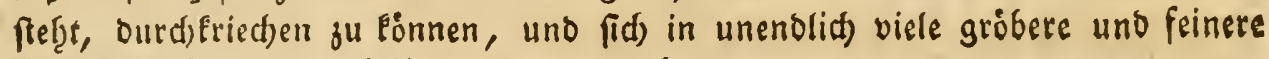
zrme uno Fafern ju t⿹̨eilen uno aแsjubeḩnen.

\section{§. 38.}

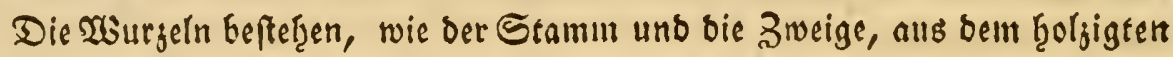
Siorper, Der mit Rindenlagen überzogen ift, und diefe forvofl, wie jene, cbens falls aus einem feinen Röbzrengewebe, und verfdoiebenen Befäßen.

\section{§. 39.}

So wic ber erfte Seim cines Saamentorns nur ein Stengel ift, fo ift es

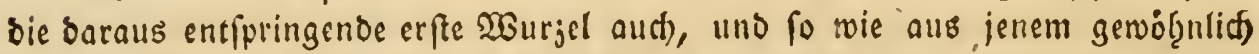

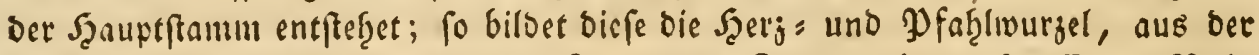

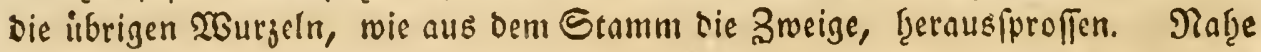

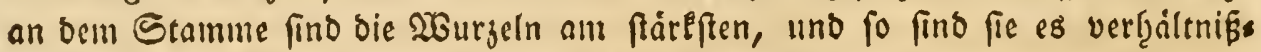
mäßig, if̧rer Entfernung von bemfelben, if̧rem Zalter, ober fonfrigem şad)ss

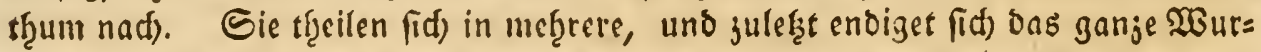

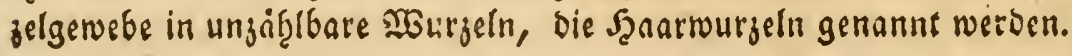

\section{§. 40.}

Die 2Eurgeln ḩaben aud bas mit ben ZCeften und Zweigen geinein, baß Fie nut an if̧re!n älferften Ende fid) verlingern, woldes babei bie Stclle ber an

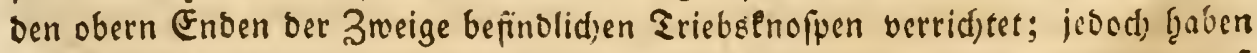

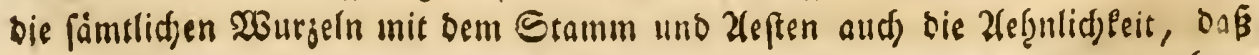


cbenfalls imitten aus ifnen, wiebet šutugeln, fo wie bort Sweige, austreiben

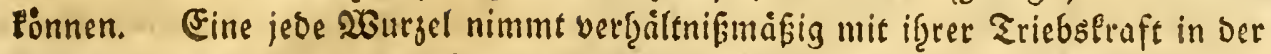
Dide zu, uno bilbet barnath einen färfern ober fdwåd)eren Jaf̧rsting. Sos

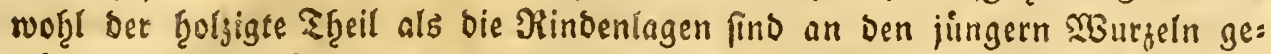
wóghnlid weniger feft und fdrwammigter, wie am Stamm uno an ben Zweigen, wovon bie Urfadje barin liegen mag, baßj fie nicht fo, wie biefe, ben abbarten.

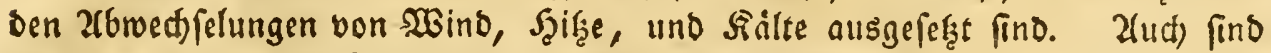

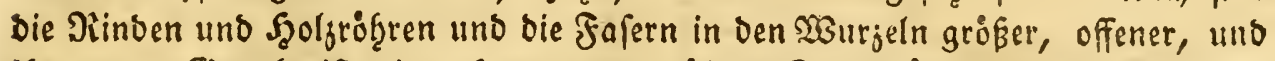
if̧r ganjes Serwebe ift mit mef̧rern uno gröpern Saugorufen verfeben, weil fie

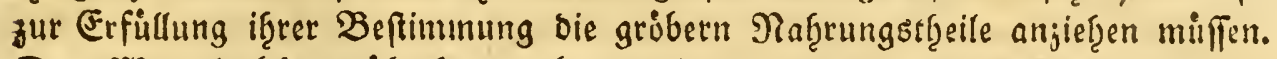

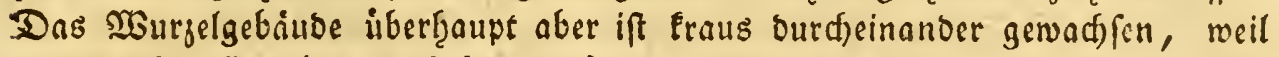

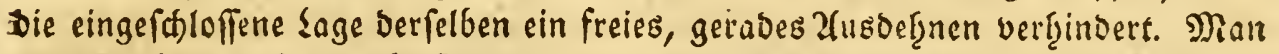
finoet baf̧er, baß biefelbe $\mathfrak{B}$ aumart in einem feften $\mathfrak{B}$ oben ein weit trauferes 2 urgelgeroebe, als in einem locteren Sanoboben bilbet.

\section{§. 4 .}

Die Wurgeln faugen ben, bem Baume jugufübrenben, Saft nidjt allein mit iţren iuberften Enben, fonoern aud mit ben Gaugungsgefáfen cin, wo=

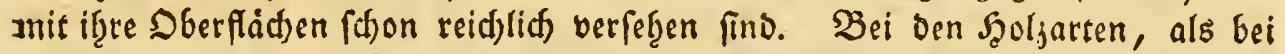

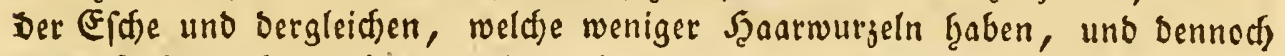

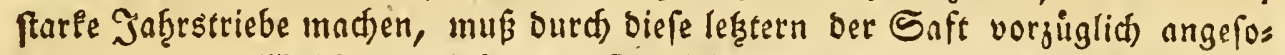

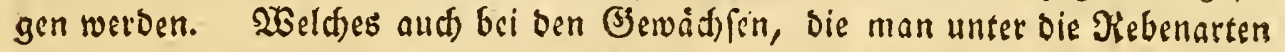

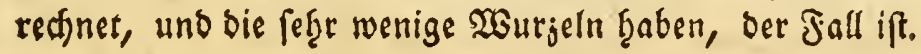

\section{§. 42.}

So wie vorguglid bei einigen $\mathcal{H}_{0}$ lgarten, bie in bie Erbe geftecten Zwrige 2Hurgeln treibell, uno mit Erfef̧ung Diefes Sheils wieber einen vollemmenen Baum ober Straud) bilden, eben fo fdjlagen bei ben mefrften $\mathfrak{F}_{\text {ol, arten alls }}$ ben $\mathfrak{W}$ urzeln wieber Soden aus, uno erfefzen bamit ben 216 gang oes Stammes.

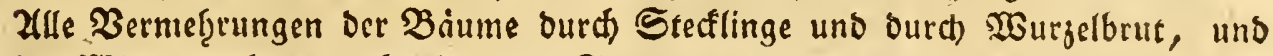

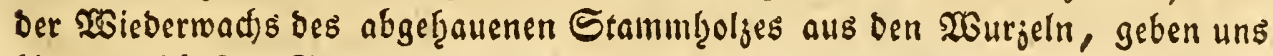
hiervon ḩåufige Beifpiele.

\section{§. 43.}

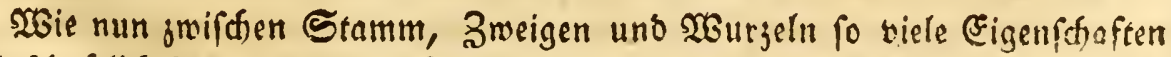
gemeinfdaftlid) fino, aud bein Stamm of̧ne Wurjeln, uno Eeine Wourjel of̣ne 
Stanm und Zweige eine lange Zeit unb fdfwerlid) ìber ein Jaf̧e lang fid gut erfialten und vegetiren fann, ${ }^{*}$ ) To bemerlt man bavon bod) bie auffallenditen Dinge von geringer Sarmonie jwifden benfelben, als zum Beifpiel ber nach) fo

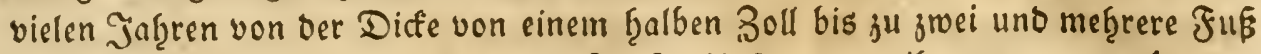
im Durdjmeffer fierangewadjpene gepfropfte Hrftamm treibt ganj unverånderte ŞBurjelbrut.

\section{§. 44.}

So wie Şif̧e, Froft und fonftige Beffidoigungen bem Stamm und ben

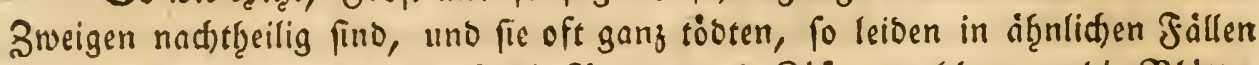
bie $\mathfrak{W} u r_{j}$ eln aud); es finto alfo bie Raupen uno $\mathfrak{K} a$ ajer, weld)e nur bie Blatter

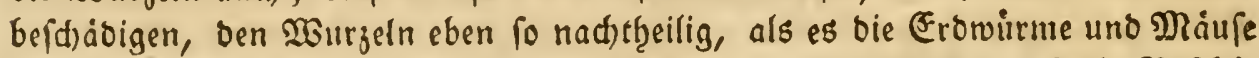

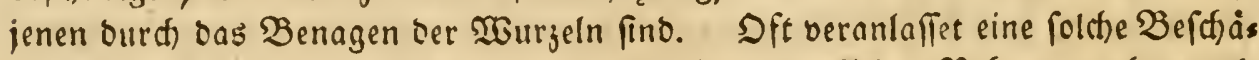

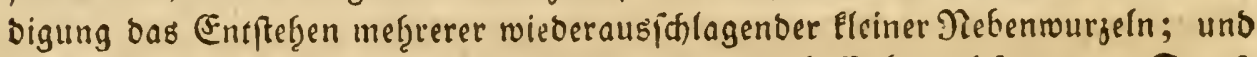

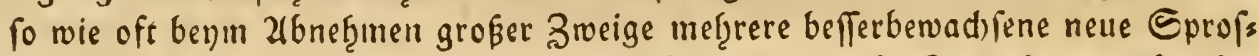

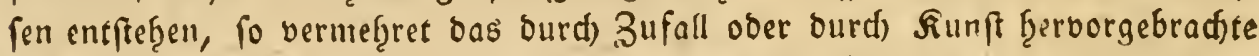

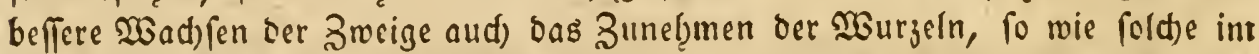
Begentf̧eil von siejen auf jene wirlt. EFin vorbem, jum Beifpiel, unterorudt geftandener Baum, wiro von ber Zeit an, oa er mef̧r suft erf̧alten haat, fos

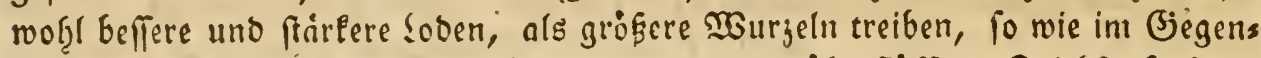
theil and) Der. Bsártner jene Baiume, Die megen uberfluffiger Srieblraft feine

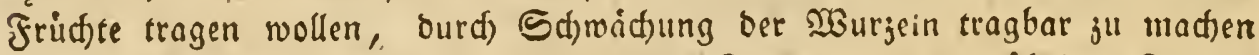
pflegt. 2(ud) feerben bie $20 u r j e l n$ mit ben Breigen uno ben übrigen Sheilen

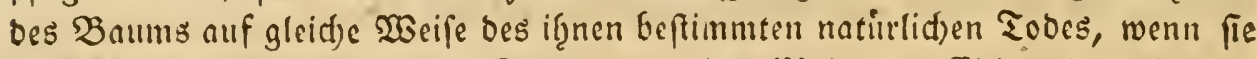

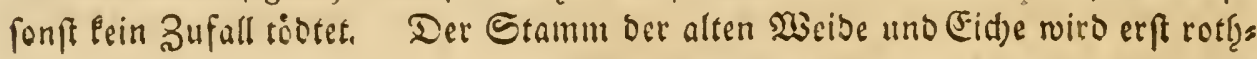

mos

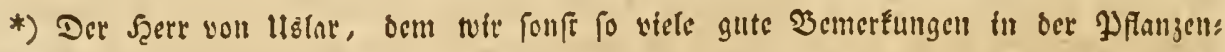

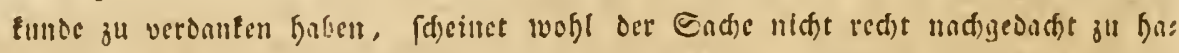

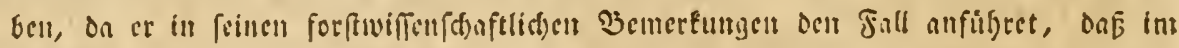

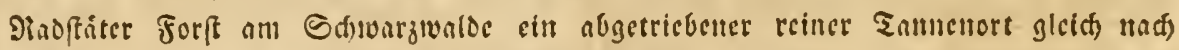

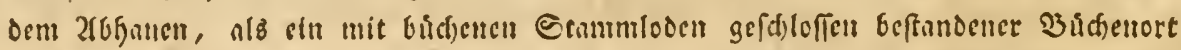

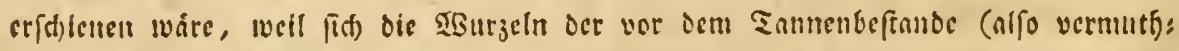

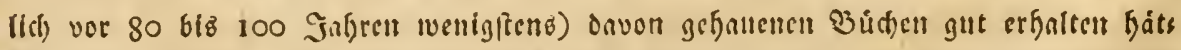

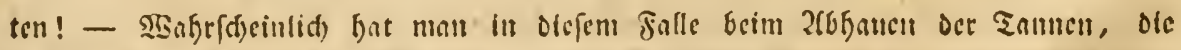

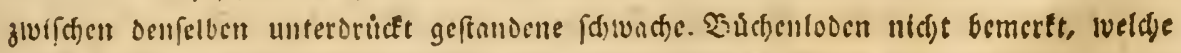

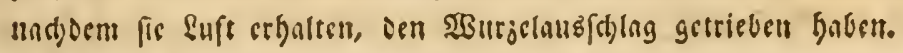




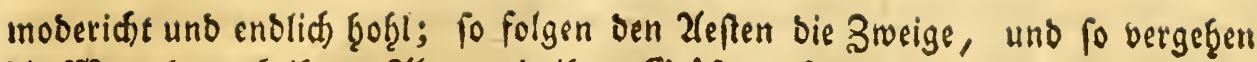

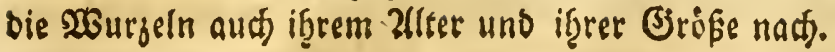

\section{§. 45 .}

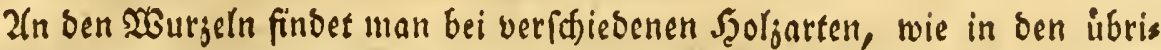

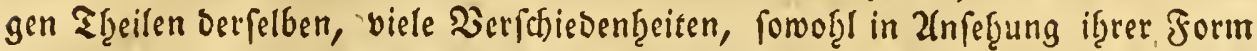
und ibzrer Farbe, als if̧rer fonftigen Eigenfafaften; fo find jum Beifpiel bie Wurzeln ber Efd)e viél bicfer und bas Benebe berfelben ift weit gróber, als an

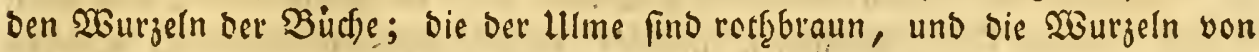

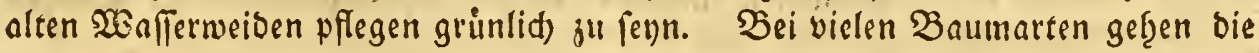
SBurgeln nur flnd) unter ber Dberflid)e ber (Eroe roeg, bei viclen aber geben fie meb̧r in bie ₹iefe. Erfteres ift jum Zeifpiel borguglid) bei ber Eller uno lef̧tes

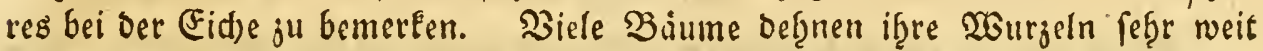
aus, wie bie (E) d)e uno Illme, biele begnigen fid) Damit, einen engern Daum

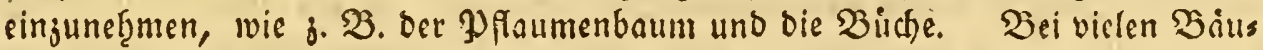

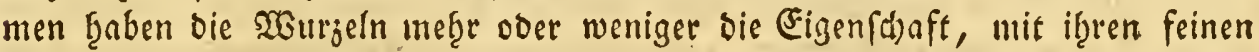

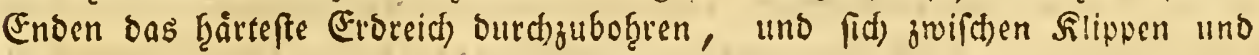

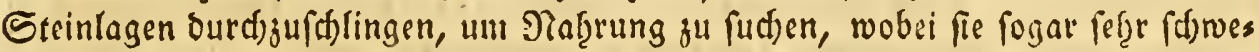
re Steine gu feben, uno Mauern ju fprengen fäbig fino. So fief̨et inan bie

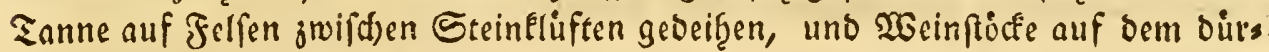
reften Steinboben faftige Trauben Sringen, bahingegen bie mefreften Laubbolys artelt einen tiefen frudtbaren Eroboden verlangen, wie bie Eidhe, die nur hiers

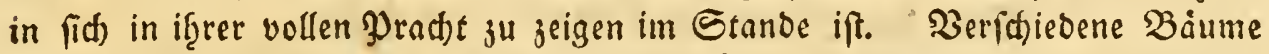
rreiben viele 2 urjelnbrut, als bas (Rusglabrum) ber Effigbaum, bie Erle uno die Sinde, andere gar Esine, roic Die Tannen und Jidjten.

\section{§. 46.}

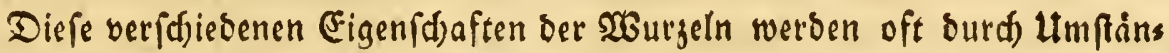
be und Bufall verindert. Daber fdight bie im Sumpf ftetende Eller vor jenee

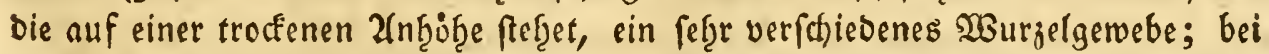

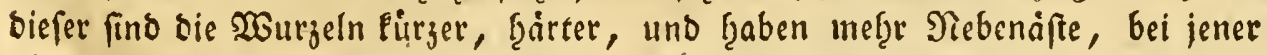
aber find fie, fo wie bie 2 urzeln aller $\mathfrak{B a}$ aume, wenn fie einen noffen $\mathfrak{B}$ oben.

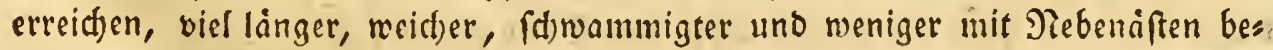
fefrt. Ein Baum ber auf oer einen Seite einen locferen uno fetten Boben er: reid)t, wito aud) Darin mefrere $\mathfrak{B}$ urjeln treiben, als auf ber anderen Seite in feftem und weniger frudtoarem Birunde; 10, wie man foldes aud in ben of 
abrectifelnden guten und fdledten Erolagen äbereinander bemerken fann, wo bie $20 u r z e l n$ beffelben Baums ebenfalls abred felno ibereinander fare uno (d) wad) find.

\section{\$. $47^{\circ}$}

So wie an ben Xeften und Zneigen, bie if̧nen unnöţigen ₹f̧eile von Zeit oll Zeit vertrocfinen uno abgeworfen werben, fo bertrocfnet uno vergetget aud

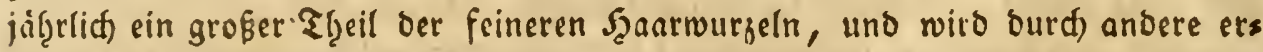

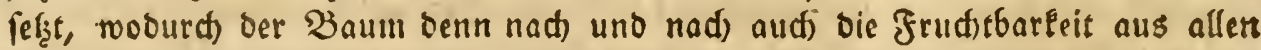

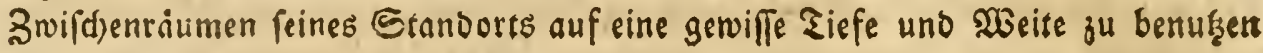
uno anjuzief̨en fäbzig ift.

\section{§. 48.}

(Bleid)wie oft ein weit jüngerer aft burd einen jufällig veranlaften ftars

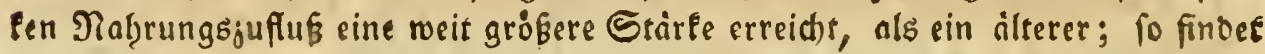
man biefes aud) an ben 2 Surjeln, uno befonders an folden, weldhe ourch etwas

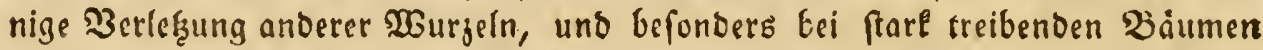
entitanden fino. Diefe fraben alsbenn wenigere und biafere Saarmurzeln und ftätere, mej̧r idbroammigte Jabrstinge; Dahingegen andere ältere Wourgetr weit magerer fino, und fefreres Şols haben.

\section{\$. 49.}

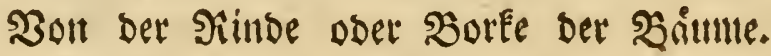

Der Stamm, bic Zroeige uno $\mathfrak{x}$ urjeln fino mit ber Dinde ober Borte bebect, und alle übrige Theile bes Baimm, als bie Blätter, Blitţen un Fridtete, find mit einer feinen Rindenţaut überjogen.

Die Pinbe ober Borte beftefte a) aus ber Dberţaut berfelben, ber man alls $\mathfrak{3}$ ergleidjung mit ben animalifden Förpern ben Tiamen Epidermis gegeben

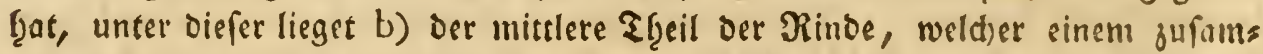
mengewad) fenen (d) wammigten Zellengewebe gleid)t, uno baber Den Tamen ers halten bुat, uno unter biefen liegen c) Die unteren \$indenlagen uno eigentlis

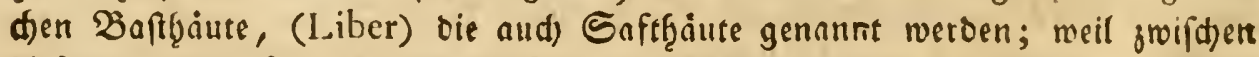

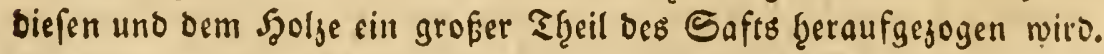

Die Epidermis ober Dberf̧aut fdeinet bei einigen Szoljarten nur aus eis

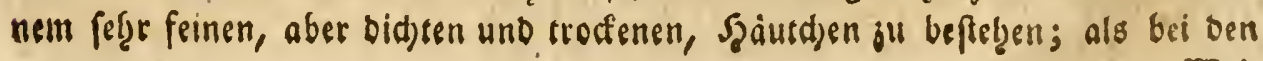


Weibenarten, bei ben Doftbäumen uno mef̧reren. Bei andern aber beftę̧t

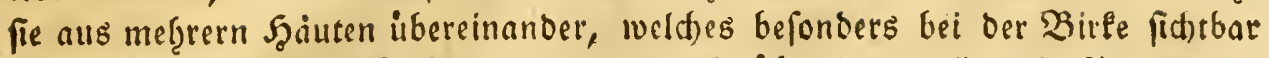
ift, bei ber man in ber Saftzeit fed)s und metrr vibereinanderliegende Dergaments Fiaute ablofen fann. Bei Sirfden uno Birlen ift fie ber Dueere bes Bauns

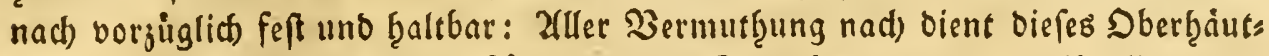

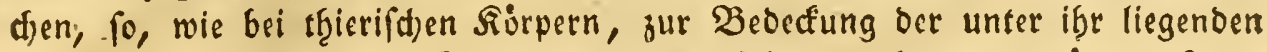

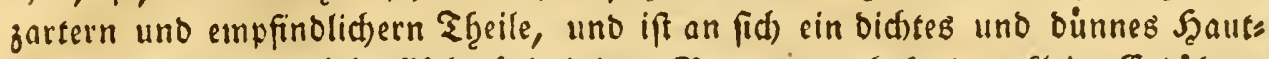

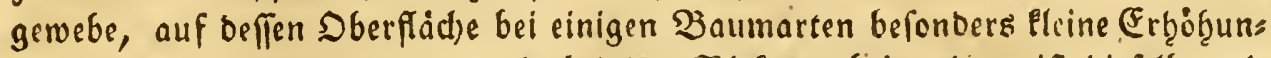
gen wä̧rgenommen merden, wie bei ben $\mathfrak{B} i r k e n ;$ bei andern ift biefelbe mit

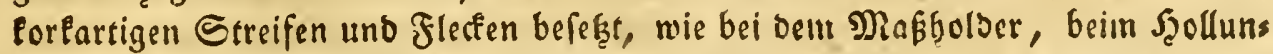

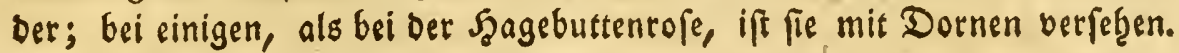

\section{§. 50.}

Die Epibermis erftrceft fid) fowobl ủber ben Stamm, als ùber alle Wours zeln, 3weige, Blattter, Sinofpen, Blitţen und Fruddte: Sie ift an einigen Şdjarten bef̧nbarer, mie an andern, weld)es man aus bem Zufreiffen berfelben

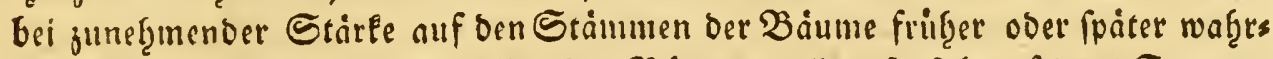
nimumt. Bei junefrmenoem alter ber Bảume berliert fie fid) auf bem Stamme uno hernad) allf ben alten fiarlen Zeften ganj; fie fd)sinet alsbann iberfluffig zu feyn, inbem bie, als ben anderen Fgeilen ber Binoe entftandene, gleidfain verb̨olste, Decfe if̨re Etelle vertritt.

\section{§. $5^{\mathrm{t}}$.}

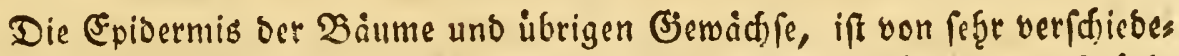
ner Farbe, of weí, grin, gelblid), grau, uno auf Den $\mathfrak{B l i t t h e n}$ und Fritc)s ten hat fie oft bie fdienften Jarben, aud) versindert fie auf veridjiebenen $\mathfrak{B}$ åus

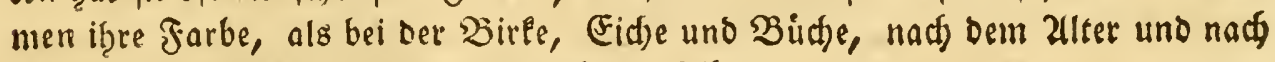

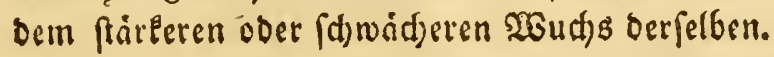

\section{§. 52.}

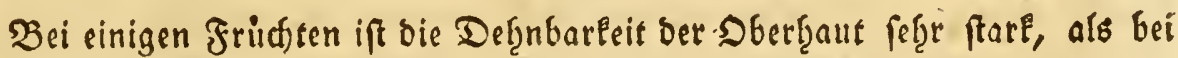
bicfen 2lepfeln, Birn und Pfirfden, bei andern aber, als bei YY faumen und

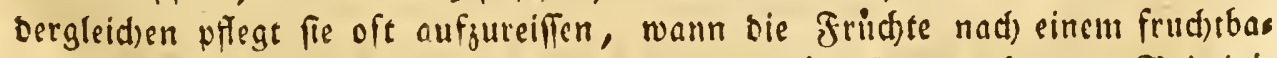

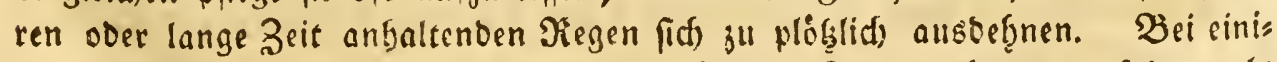
gen Baumarten wiro biefe Epidermis von Beit ju Zeit burd) neue erfeget, als bei bem Ylatanus, beim Weinftoc, bei ber $\mathfrak{u l m e}$ und bei gewiffen Strand)holgs (Erfter Tfect.) 


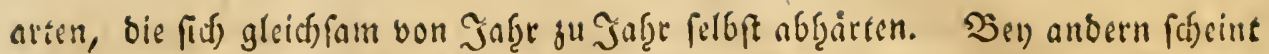

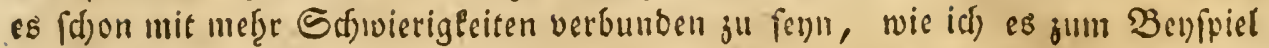
an ben Eidjen uno an einigen Doftarten bemerft f̧abe, beren Epibermis mit eis nem Theil ber ibrigen Rinoenlage flectenweife ourd) oen froft in Sntge 1788 . zerfitirt war, bey weld)en foldse nut ferbe unvolleommen in bem folgenden Soms

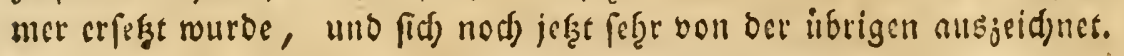

\section{§. 53.}

Das unter ber Epibermis liegende Zellengewebe madt ben mittelfen

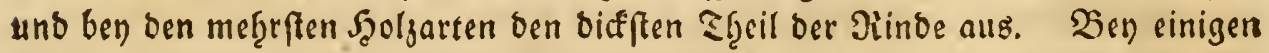
Baumen find bie jajern befferben beutlid ju effen, als bey ben Eidjen, ber Sinbe, ben Weiben, und mef̧rern Scoljarten, wo benn bie Zwilidentảume mit einem markigten 20 efen angefillt z"l fenn (d)einen; bel) andern aber ift bas nid)t, uno idfeinet biefelbe ganj aus verhinteten marligten Fiornern zu beftes. ben, wie bell der Buidje uno Birle.

2(ud) biefes Bellengewebe ift bey einigen Bäumen bef̧nbarer, wie bey ans bern, weld)es man ebenfalls aus bem fribern ober fpätern 2(ufreiffen bey juneţs

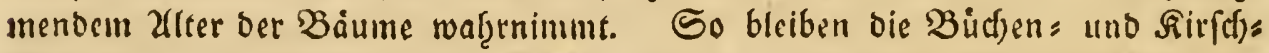
ftamme langere Beit glatt, als Birlen, EFpen und Eidjen, beren Botken balb uno part aufreínen.

\section{§. 54.}

Die untern Rindenlagen ober bie Safțäufe erffeinen jwar im erffen 2(ns blife als eine bid)te fefte $\mathfrak{B}$ aum

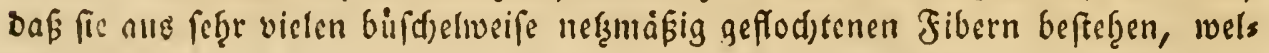

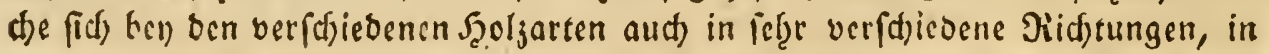
Den metreften aber in St)langenlinien beriferen, uno ocr sange bes Stammes

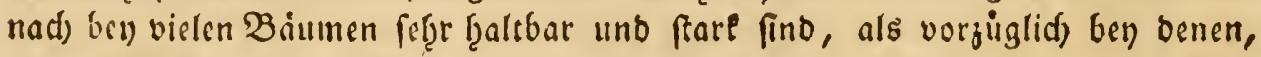
movon bie Piinbe fum Bafit gebraudet wirt, als ben sincen und lltinen. Bey

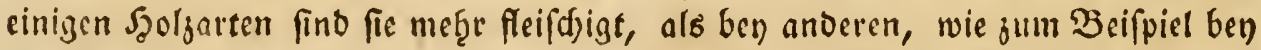
Der Enalweibe. Bey einigen liegen fie in mef̧rern Szauten über einander, als ben anderen; fo rabe idf bon ber sinde oft geţn und melgrere von einander abfons Dern fommen, bie aufeinanderliegend, nur sin (J)mebe ausjumadjen fdjienen.

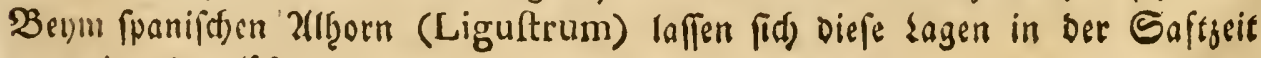
voll cinander löfen.

§. 55 . 


\section{§. 55.}

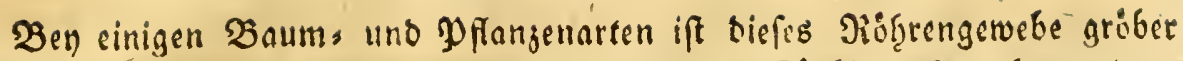

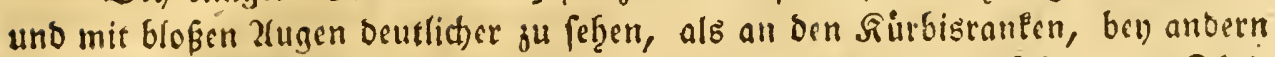

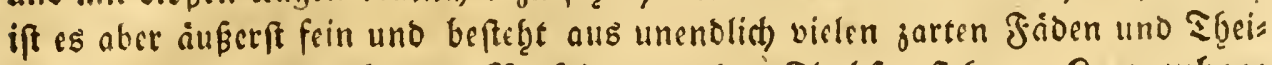

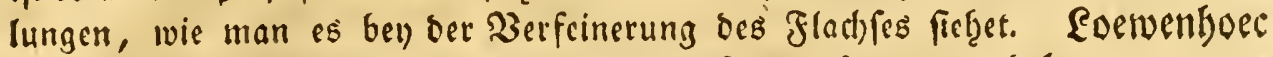

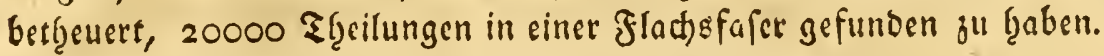

Zwifden bem Zellengerwebe und biefer Saftgant find nod) einige grö́fere,

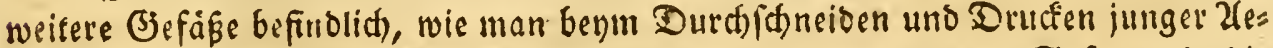
fite in ber Saftzeit bemerlen Eann, weldje einen ganj anbern Saft, wie bie

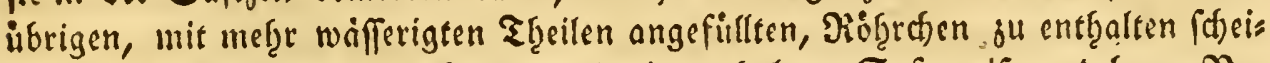
nen; benm Jeigenbaum erffjeint ber barin enthaltene Saft weís, uno benm $\mathfrak{R} a$

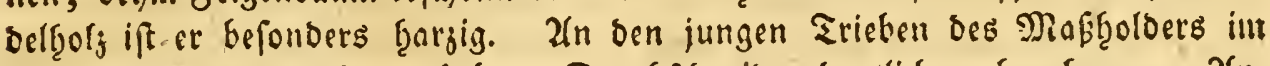

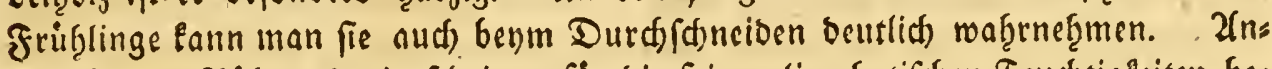
bere feinere Biob̨ren oarin fdeinen fitr bie feinen limptratifden feudtigleiten bes fiumint ju finn.

Diefe Tlgeile ber Pinde, ob fie gleid) ber sange bes Stammes nad) meţe

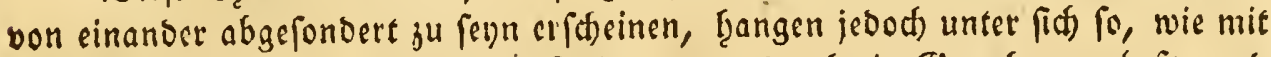

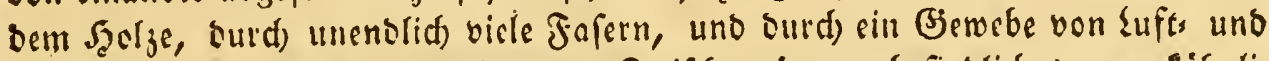

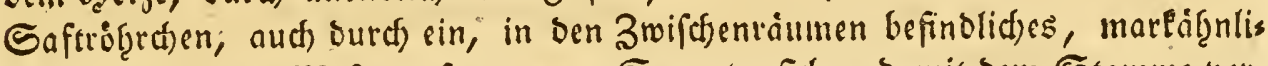
des, jellenartiges 2 efen jufanmen. So unter fid) und mit bein Stamme bers

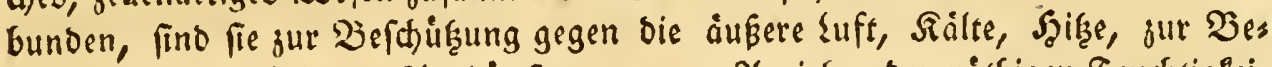
föroerung ber netthigen 2lusbinftung, jum. Injię̧en ber notthigen feud)tigleis ten aus ber Suft uno bes Saftes, jur Berefeinerung uno Bubereitung beffelben,

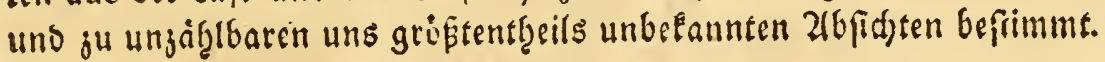

\section{\$. 56.}

Obige Theile unter fiff) verbunden, bilben nun bie Borte cber bie Sinbe

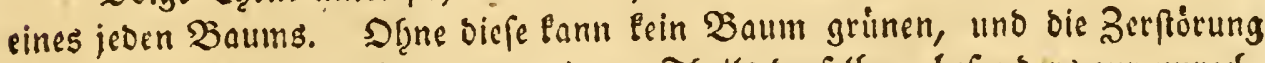

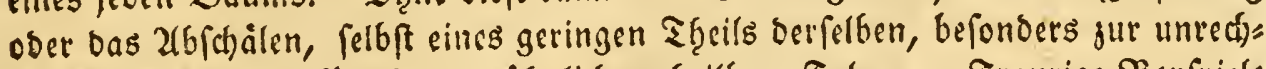

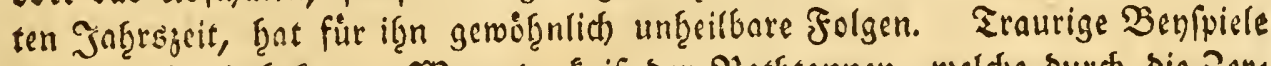

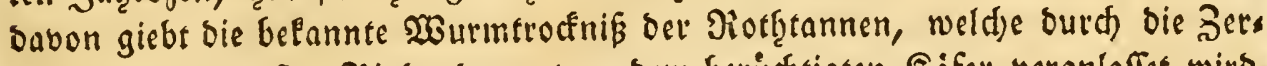

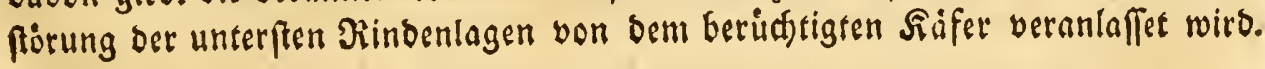

\section{§. 57.}

Jindeffen ift bey einigen $\mathfrak{B}$ ăumen bie Szeilung einer Pinbens ober Borfers befdribigung leidjer, als bey andern; bey ber (Fidje, bey ben weibenarten, F-2 


\section{4}

an ben Birnbaumen, an ben Lllmen, pflegt oft eine jiemlidy farle Entblöbung von ber Borle, fid) jum Trgeil anis ben Pändern ber unbefdábigten Rinbe, theils aud) aus bem $S_{\text {golje }}$ elbft ju eriefzen, wenn bie Befdábigung nur in ber Saftgeit gefdesten, uno gegen suft uno Şif̧e etruas beocfft gewefen ift. Ben andern aber ift bicfes auferft fdwer, als bey den Nabelgofjarten, Gen ben PPlaus

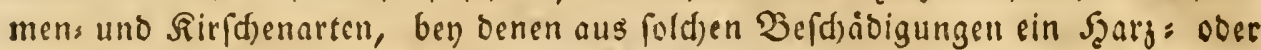

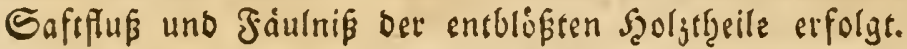

$$
\text { §. } 58 .
$$

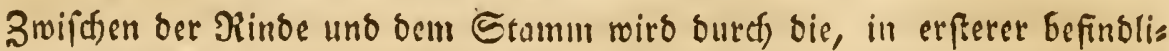
d)en vielen Saftrubgren ein Theil des Safts aufgejogen; bafelbft gefdieft das

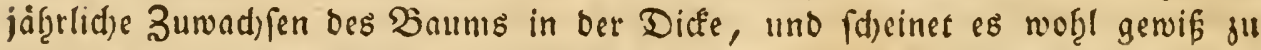

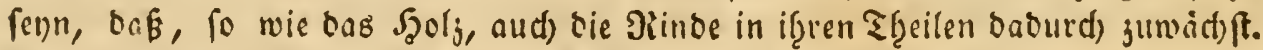
Die Minderlagen einer mef̧ere f̨unbert Jab̨re alten (Eid)e, fühtren oavon f̧uns bertjäbrrige Beneife; inoent man barin bie vielen ùbereinander liegenden, nach und nad bertroffneten Ringe bcutliff fetęen eann.

\section{§. 59.}

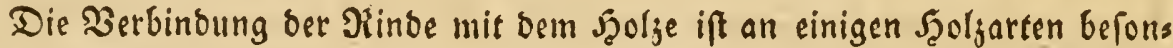
bers auf veriftiedenen Stellen fefter uno fid)tbarer, bie man bie Spiegeiffecfe bu nennen pflegt, wobon unten bey Der Befdreibung ber Şoljfibern ein meţreres borlommen wirb.

\section{§. 60. \\ Bon Dell $\mathfrak{\text { Blattern. }}$}

Die $\mathfrak{B l a ̈ t t e r ~ f i n d ~ b i e ~ T h e i l e ~ d e r ~ B a i u m e , ~ d i e ~ g e m i f ̧ n t i d ) ~ a n ~ b e n ~ j u n g e n ~}$

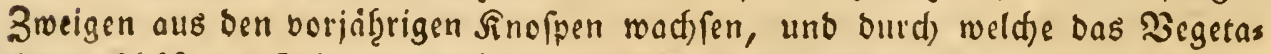
tionsgefd aft ber Baume vorgiglid berwirlt nirb. Sie wad)fen auds an bem Stamme uno an ben iltern 2leften nus oen, in bemicilben befindidfen ober ents

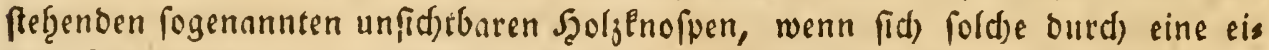
gene Beranlaffung zu waḩren Şolgenofpen zuvor ausgebildet ந̨aben, um Blätter fu tretben.

Nur in ben Eriebsinonaten wadjen an ben Baumen neue Blatter, uns

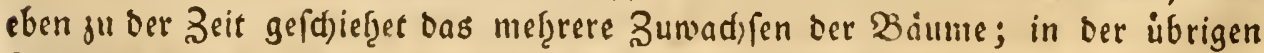
Jaf̧rgjeit werben bie an oemfelben neu bugewadjpenen Fleeile, verfeinert, vers

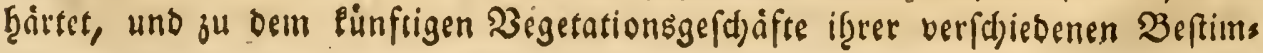




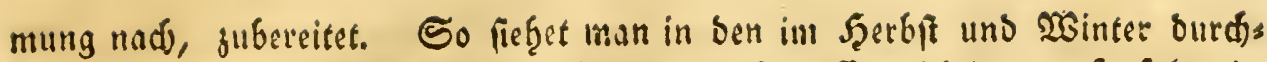
geft)nittenen Sinopfen fdon bie Blatter fur reifern Entwidelung aufs folgende Jab̨r liegen, weldbe in ben erften warmen Frib̨lingstagen bie Finopfe ausbeb̨nen, offinen, fid) in lurger Beit baraus entfalten, uno fu ber ifnen eignen (Jiópe wadffen. Der Baum erfdeint barauf bald in feiner Shjonţsit, woju bie Blátter bie bauerbृaftefte Bierbe fino, inbem biefe meiftens bis jum Saerbft, jene feinere Bierbe ber Blitţe aber oft nur einige Tage wảbrt.

\section{§. $6 \mathrm{I}$.}

Die $\mathfrak{B l a t t e r ~ w e r b e n ~ i f e r e r ~ ( j e f t a l t ~ n a d ) ~ e i n g e t h e i l t ~ i n ~ b i e ~ e i g e n t l i d ) ~ l o g e s ~}$ nannten $\mathfrak{B l a t t e r}$ bes \{aubfrolges, uno in bie nabelformigen $\mathfrak{S l a ̈ t t e r}$ bes Nabels நृolges. Beybe Blatterarten dawern entweber nur eine Triebgjeit, uno fallen im Şerbft ab, als bie Slatter ber Eiche, Budde, Serde uno ber ibrigen nut im Sommer grinen Baume, oder fie Dauetn mef̧rere Jaf̨re, als bie Ziláter ber Şülfen, Sannen, Fichten, Fuf̧ren, uno mef̧rerer aud in SBinter grumer Bàume. Die eigentlicben Slátter bes Laubf̧oljes fonnen weiter getteilt wers ben in einfade 2 latter, wie bie Wlatter ber Eidje, bes 2thorns, uno in gu: fammengeferste Blatter, beren meţrere auf einem gemeinfduftlidsen Stidle

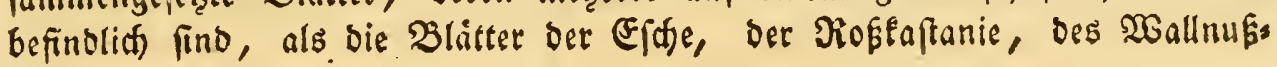
baums น. f. r.

\section{§. 62 .}

Die Blatter ber verffiebenen bammarten unterfasioen fid unter

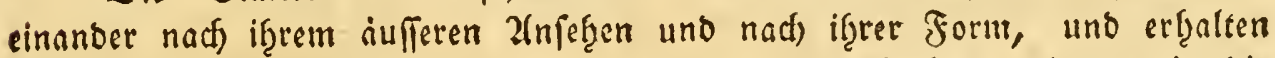
barnact mefrére B̉enennungen. So fino cinige $\mathfrak{B l a t t e r}$ glatt, wie bie Blatter bes Rirfdjlorbeers, ber Şulle; anbere find raub anjufithlen, wie bie Blätter bes Feigen: und Maulbeerbaums uno ber rauhen Lllme. Einige baben biefen Unterfitied nur auf einer Seite, wie bie Weioenblatter. Die $\mathfrak{B}$ làtter einiger $\mathfrak{B}$ äume fino bicf uno fettartig, als bie bes $\mathfrak{B}$ udsbaums, oer Eidje, ber Şullen; anoere fino feiner, pergamentartig, als bie ber sefrne. Einige baben ein blaffes Brun, wie bie Eld enblatter, andere ein bunfeles Sirin, als bie Ellernblitter. Einige find unten weis, wie verfilbert, als bie Blätter ber Silberpappel uno ciniger Weibenarten. Finige fino idsedfigt, wie

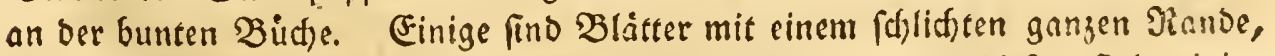
wie bie bes Buthshaums uno des Duittenftraud), uns-von biefen find einige

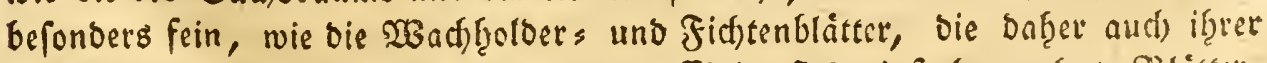

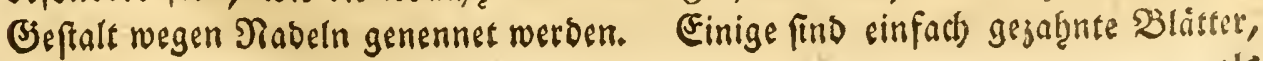


als an ber Binde, andere boppelt gezatinte, mie an ber Milfter. Einige fint eingefdnittene ober eingelerbte: Blätter, wie aum Mapbedber, andere eingefdnittene gegaf̧nte, als ant 2tḩorn. 2(noere gewellte, wie bie Eidfens blätter, bie man bent wieber in einmal, jwenmal, brenmal, u. f. w. eins geidnittene ober gewellte Blätter eintfreilen Eann. Einige haben Stad)eln, wie bie Szillfen. Finige find lange, wie bie SEeidenblätter, anbere tunbe, obale, Geerjförmige Blätter. Einige find langftielidte, andere Purjs fticlidte Blätter. Einige fizzen an ben Bweigen nur cinjeln, einige Ȩinges gen biildselweife, wic an ben Lerd)en. Einige ḩaben an ben Stielen eleine

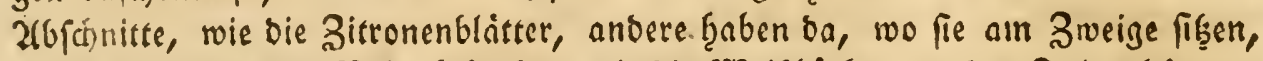

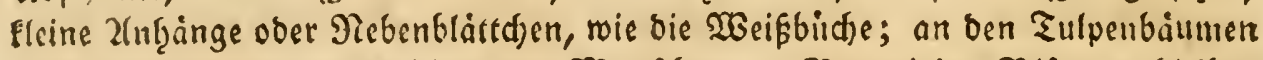

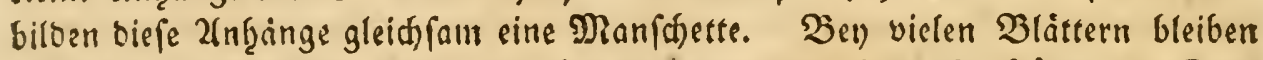
biefe 2nnfiange bis jum atbfätlen, ben anbern vertrocfnen fie fritger. Demt Botaniler find biefe und nod) weit meţrere $2(b t h e i l$ ngen und Benennungen ju

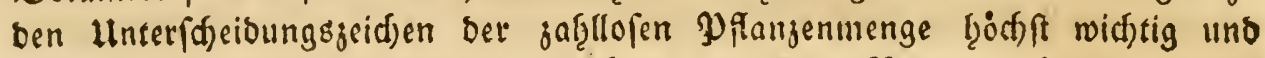
netşig, Dem Forftmann fino fie an fid von wenigem Pluffen: aber fie bienen bod), feine 2lufmerffamét auf anfd)einende Nebenfaden rege zu maden, was

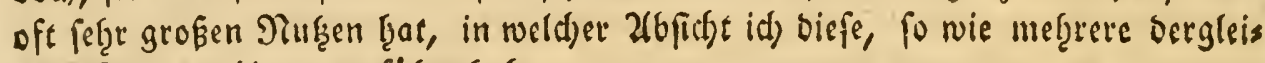
den Dinge, ḩier angefüf̧rt ţabs.

\section{\$. 63.}

Da bie Bläter an ben jungen Zreeigen bes kaubrolyes alls ben vorigiäţrigen Sinofpen entfeţen; To wie biefe unter ben 2(d)feln oer vorigs

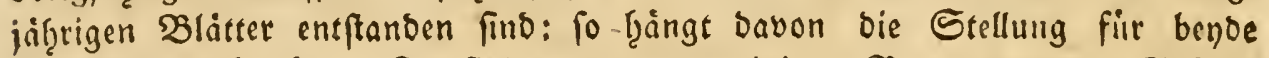
gemeinfduftlid) ab. So findet man an einigen Baumarten bie Blatter umb Sinofpen paarweife gegen eimander uber frefend, wie nn ber EFfde, und bey einigen wedffelsweife gegen einander über, als an ber Eidse, bey einigen fteţen bie Slitter in einter Schraubenlinie um ben 3roig, mie all Yoflaus

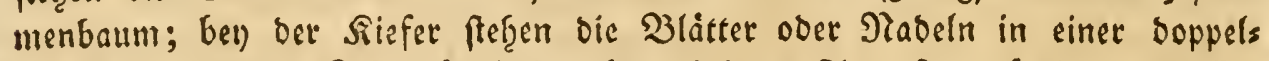
ten Epirals ober Sdraubentinie; bey einigen firzen fie auf einer gerwiffer

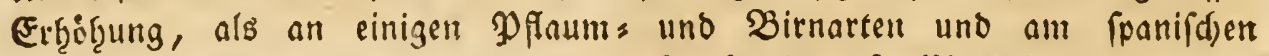
Jyollunter. $\mathfrak{B e y}$ cinisen, beren junge Triebe ftumpfe sBintel bilben, fif̧en

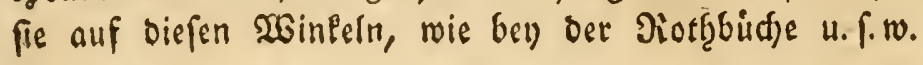

\section{§. 64 .}

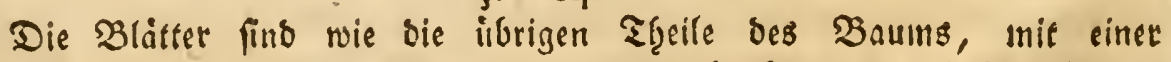
Dberţaut (Epidermis) bedect, und beftefien ebenfalls aus Sufts Sagfers und Saftgefäßen uno einem zellenförmigen Berwebe. Durd cinige biefer 


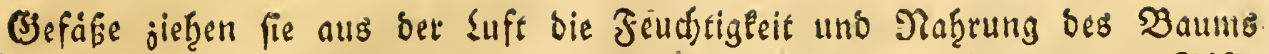

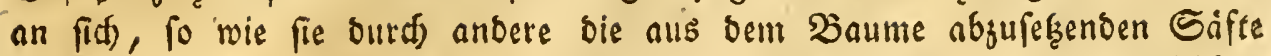
wieber abgeben, uno baher gleidfam wie bie kungen in ben animafijthen

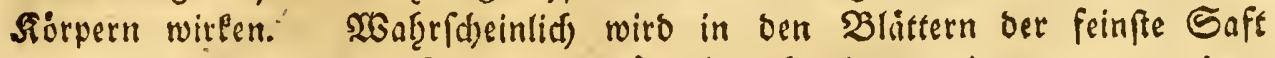
unto bie Tiaf̧rung bes Baums vorgh hlich zubereitet, wie man aus bem Berudfe uno Beffitmacte bes in ben SBlattern enffaltenen Safts uno olligs

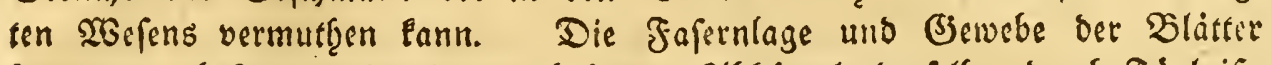

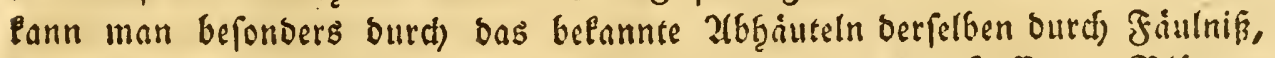
und aud bey ben ourdi eine gewiffe 2frt Bioupen angefreffenen Blätcern wah̨rnef̧umen.

Die Stiele ber Slatter firto aud) nad) ben Szoljarten unterfáfeoen; an einigen fino fie linger, an andern filtger; bey bielen biffer und fleis fefigt, bey andern feiner; bey vielen f̧albrund, platt, ḩof̧(runt u.f. w. Der untere Theil eines Blattftiels mit bem er an ben jungen Trieben figt, ift

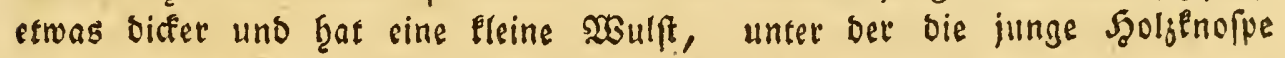
fich ausbilteet.

Die Etiele find an ben Blittern gleiffaum surds bas in beiben befindlide Rób̨rengewebe verbunden, uno fief̧t man in ben Slattern die

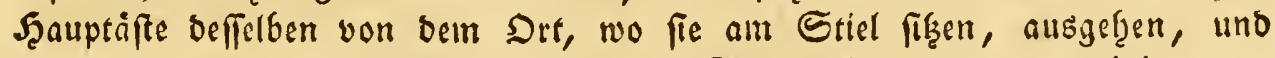

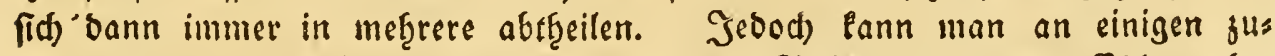

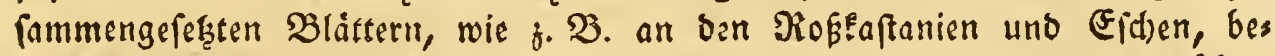

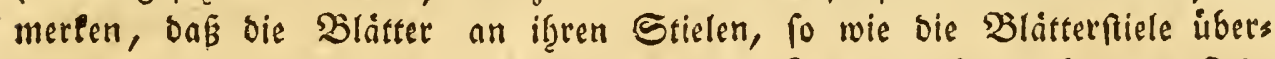
baupt on ben jungen 2leften, nur mit einem Zellengewebe verbunden fins,

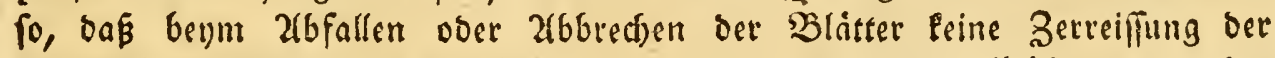

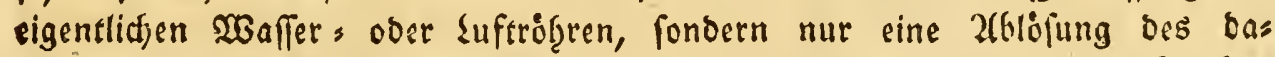
grifhen befindlidjen Zellengewebes vorgetgt. Die an ben jungen Trieben

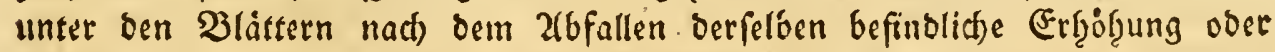
Der eigentlidfe Slattanfás (d)einet aud) vorjuglid) aus fold)en Beilengewebe

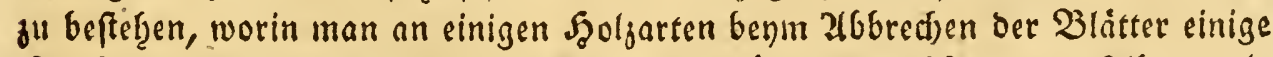
$\mathfrak{S g l}_{3}$ faden findet, bie baran nad) Dem naturlidien 2 (bfallen berfelben, als Puncte erfaceinen, wie an ber Moplaftanie.

\section{§. 65.}

Wie das 2(bfallen ber Blatter eigentlisf) jugetren mag, Eunnen wir uns

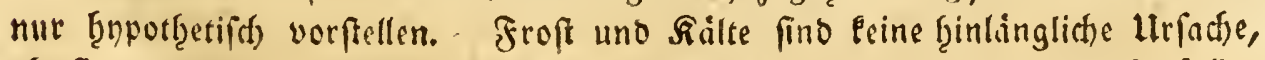
ob fie jwar bas zbfallen plogellid bemirten, benn aud) of̧ne diefe fallen von fommergrunen Baiumen Die Blätter ab; uno mintergrune SBäume 


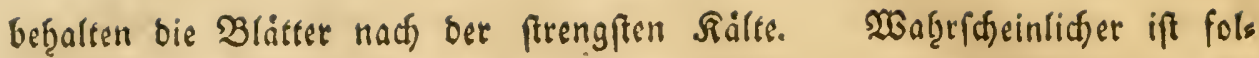
genoe $\mathfrak{H} r$ jach :

Die Blätter, ourch welde bie itbrige Fendfigfeit verounftet, werben aus Miangel ves im Şerbft nadjlaffenten Saftjufluffes, ober vielmef̧r nads

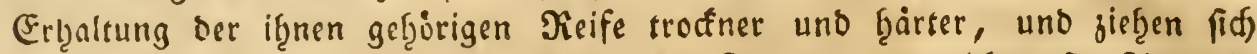
mit ifgen Stielen zufammen, indeffen bie Zreeige, an welden fie firzen, in ber Diffe juzunefimen fortfageren, woburd) benn eine ablöfung oes zrois fden benfelben befinoliden aellengemebes nad) und nad) verurfadset wiro; woju ein alsbann eintretender jufammenzief̧ender froft vieles beitrảge, bes fonters wenn ber barauf folgende Sonnenfdein bie Zweige wiever alls:

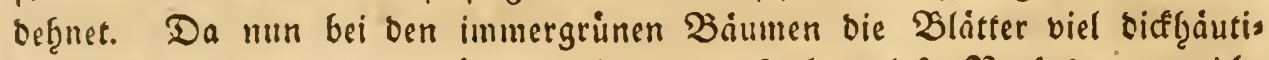
ger fino uno weniger ausbinften, fo leiben fold)e biefe Beranderung nid)t uno fallen von immergrủnen Sảumen mur von ben àltern Zweigen bie Blätter ab, nactboem diefe bie if̧nen eigene Pieife erf̧alten bुaben uno abferben, uno jene in ber Dicfe zunef̧men. Fin im Sommer abgef̧auener Baum berliert

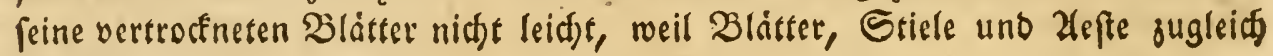
trocf́nen.

\section{§. 66.}

Die Blätter bienen vorgiglid)

a) Suft und Nab̨rung aus oer Suft eingurangen,

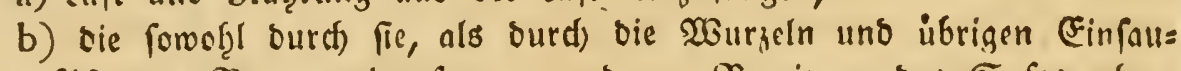
gungsgefáie oes $\mathfrak{B}$ aums eingefogene, und zur Bereisung bes Eafts abges nutgete Fendtigkeit wieber ju verbunften, unb

c) aus oer eingefogenen Taferung Den verfdicosmen Saft zujubereis

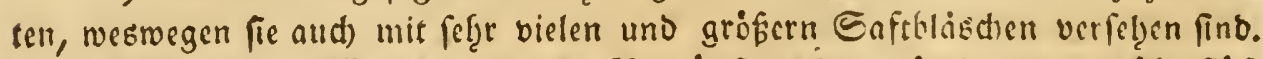
Da nun das Einfaugen uno 3erbinften oer nöthigen uno ùberflirs

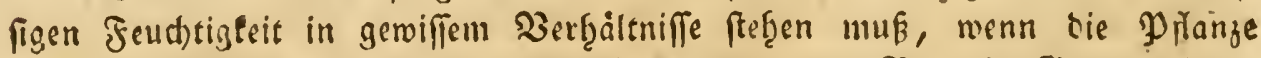

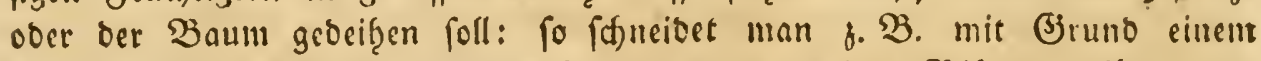
verfeģten 3 aum einige Zweige ab, Damit er weniger Blätter treite, uno alfo nidft ill viel bei eintretenden warmen trodfenen Sagen ausbinfte, inbem

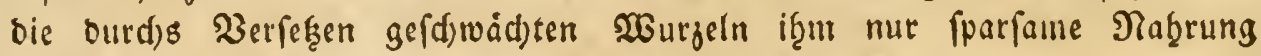
zujufübren im Etande find.

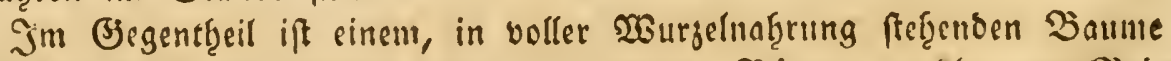

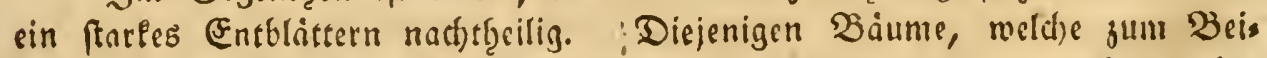
fpicl ron ben Maylafern uno Diaupen fef̧r gelitten haben, treiben baţer Das Jaf̧r nur geringe Triebe, und an Jruchtbäumen bleiben bie Jrid)te unvolls 
unvolleommen, wenn fie in Sommer viele Blatter berlieren, fo mie fie

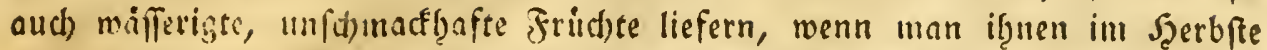

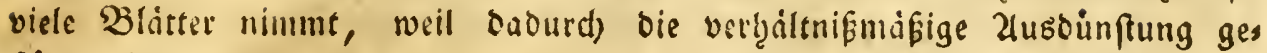
fort miro.

Diafe frifdjigte Bläter binften weniger aus, und fino foldhe bem 2nid)eine nad) mit meb̨rern $2 n_{j}$ ief̧ungsorganen berfeben, als birre feine Blatter. Jene Planjen, bie aus oer 2 turzel wenig Nabrung ju jisfen (J) legentzeit baben, funo alfo mit bicfen Blättern verfeben, wie ber Miftel, ber Epleu: fo wad)fen unter ben 2 flangen die 2lloes uno bie Serpens: arten in tem bitreften Staube; das belannte Sgauslaud auf ben trostnen uno i:n Sommer oft beiffen Dadjern; und eine andern P̧flanjen Eaum bilnlänglidje Jeuchtigleit ift iţnen oft mathţ̨eilig.

$$
\text { 8. } 67 .
$$

Die Blatter ber Baiume und fonftigen SFewåd) fins, fo wie in igret (Beftult, aud) in ifgen ubrigen (Figenfdafen fefre verid)ieben, uno fino bie

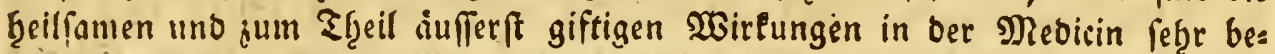

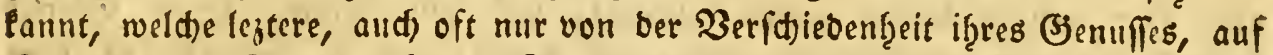

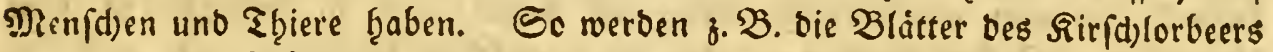
(Laurus cerafus) wenigftens in geringer Menge unfthäolid) in Mild) gelocdt, um berfelben einen manbelartigen angenef̧men Befdmad fu geben. Dab̨ins

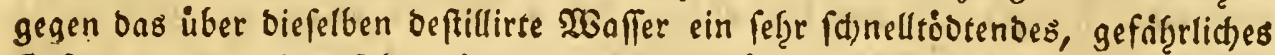
(Bift ift, bergleid)en fid) no(h) neuerlid) ber berudtigte (Jolomacher in Englano, Doctor Price, ju reiner Selbftergiftung jubereitet batte. Die Blätter bes

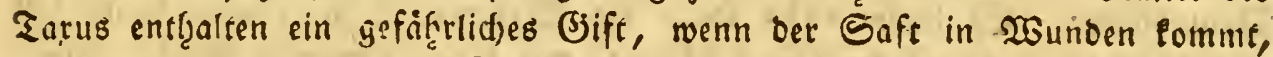

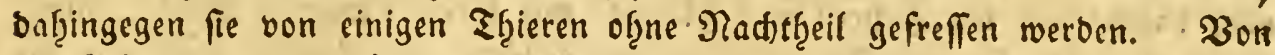

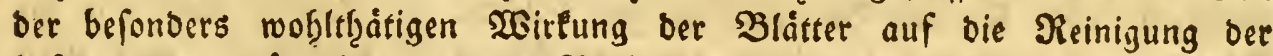
suft, uno vorginglid) von ber Berbefferung biefer burd jene, wenn fie

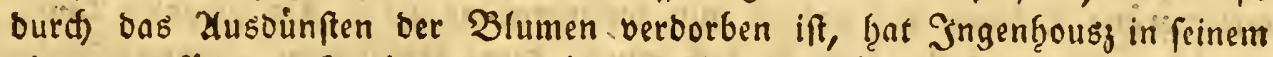
oben angefübrten $\mathfrak{B}$ ube: Experiences fur les V'égétaux einige merfrouts bige Elfab̨rungen uno Berfuche befannt gemadjt.

\section{§. 68 .}

Da bie Bläter iberḩaupt bas Begetationsgefdåft ber Bäume vors zuglid) beforbern, fo ḩat aud bie Natut folde Theile bes Bauns reid)er

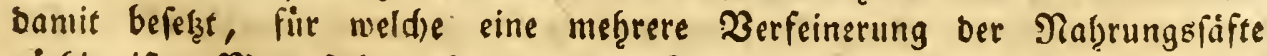

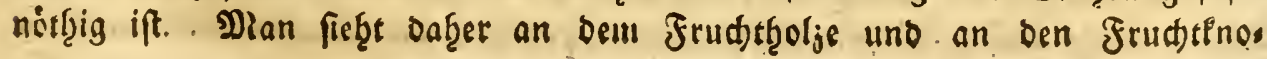


ten eine Fȩ̂r reidje Beblätterung, unt fingegen bie Blitter an ben foges

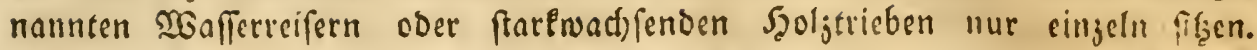

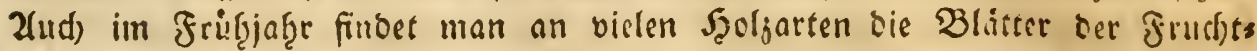
enopfe bereits ausgebiloct, wetn fid bie blätter aus ben sogljenipfen mแ eift zu entfalten anfangen, weil bie blumen und jungen friddse fdon

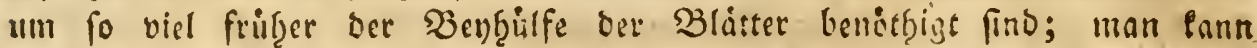
biefes vorjuglid) bey einiger. Frud)tbäumen waf̧rnef̧men.

\section{§. 69.}

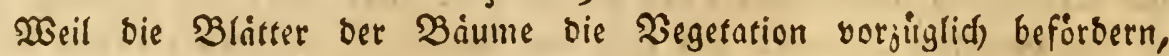
ullo aud) offne biefe Pein Baum lange Beit leben fann: fo miro aud surd fie ber Saft in ben Bäumen lingere Beit in Berwegung erf̧alten,

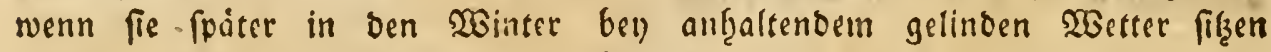
bleiben. EE war baţer ber fo frub̧e, den 12ten Rou. 1788. einfallende, ftarle Froft allen Dbfibaiumen, uno rogar ben Eid)en uno Biid)en gefäters lid) und tobtens, weil ref̧e viele nod) beblättert waren, uno ploblich ourds bie Rälte iberfallen wurben. Man finbet oaf̧er in ben Palten Begenden aud) fefrer wenige immer grine Baiume, uno nur foldje, beren Blätter aurferft fein uno nabelformigt find uno bafzer un fo weniger fu beum Iunlauf bes Saftes bentragen, ber in berglcidjen DSaumen aljo auds bes

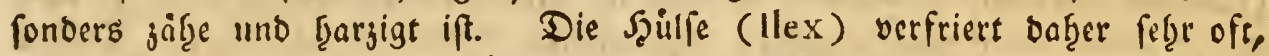

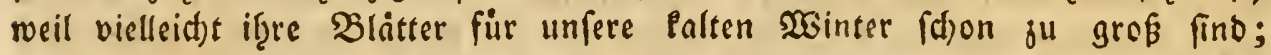
uno bie, aud) in Wointer laubbeţaltende, SBrombeere erbaălt fid in ftarlen sesinter nur unter ber Befdirfung bes Sdjnees uno ber abgefallenen Baumblätter. Es litten 1788 rogar die Weiftannen in plotten sanbe faft alle, baf̧ingegen bie Futren und fid)ten, mit if̧ren bünneren $\mathfrak{N a b e l n , ~ n i d ) t . ~}$ Ulebrigens aber (d)einen bie mintergrunen $\mathfrak{B l a ̈ t t e r ~ i m ~ W i n t e r ~ b o d ) ~ n u r ~ b i e ~}$ Berregung bes Saftes in einem geringen Grabe fll beforbern, weil man winnrgrine Båme auf andere nur fommergrine ifree 2lrt pfropfen eann, wie id) fold)es, bod) frenlid) nur unter bem gemäigigten Szimmelsftridfe in Englano, mit ben wintergrunen Eiden, bie auf andere gepfropft waren, seref̧en ḩabe.

\section{§. 70.}

Drgne biefe fint nod) verfabiebene Bemerfungen au ben Blattern auffals Jeno uno fonbetbar. So f. B. Eann man in Bitattern mit vorguglid grefén

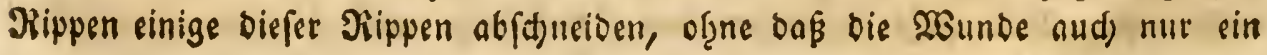


geringes Bertroffnen ber näbern Tgeile verurfad)en follte. So freffen auds)

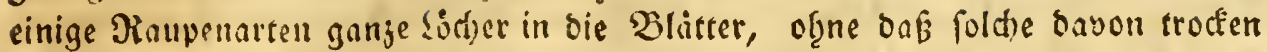
werben. Sicle arten von (S)allenfliegen (Cynipes) legen in bie Dberf̧aut ber untern Sippen ber Blatter ifgre Eier ab, rotaus oft grofe fogenannte Ballen

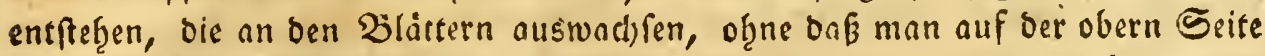
ocrfelben faum einen Flecken wafinimint. Das Wundervollefte aber ift bie

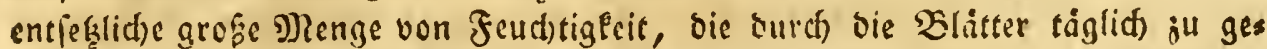
wiffen Zciten cingefogen, uno ju anbern ausgeounftet witb; woruber bie legres

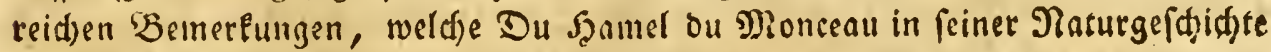
ber $\mathfrak{B a}$ ăme gefammelt ḩat, nad)gelefen ju werben verbienen.

\section{§. $7 \mathrm{r}$.}

Its cine befondere Erfdeinung, wie fef̧r bie Blätter ben Bäumen fadibs

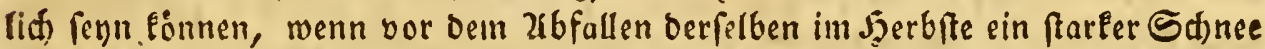
fält, verbient ber ben 22ften September 1793. in ber Tlad)t, bey voller WBino= ftille, gefallene Sd)nee angefübrt ju werben, bey belm man ben folgenden Mors gen in ben Bjarten bie gróseften saiume zerriffen und gefpalten fah. In ben Forfien lagen unter ben grofen (Fid)en Juber abgeriffener frarter Zefte; Fein Baum war veriftiont geblieben. Die jungen Stangentzoljortel waren am

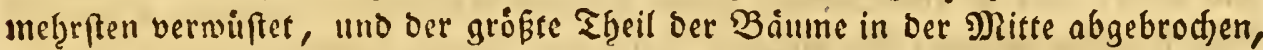
bie 2 Eege in ben Forften waren wie mit $\mathfrak{B e r h a c f e n ~ g e f p e r r e t , ~ f u r j ~ b e r ~ S d a b e n ~}$ war aufferft betrichtlid). Daben Ģatte ber Sd)nee auf ben Blattern faum einen $\mathfrak{3 i c r t e i}$ Zoll biff gilegen, uno mur bie Mienge ber Blatter verurfact)te bie

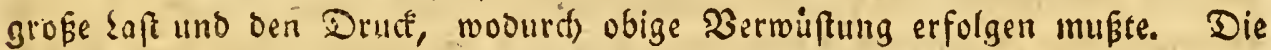
Eiven waren ifgret daangenden $\mathfrak{B}$ lätter wegen nod) aun beften weggefommen.

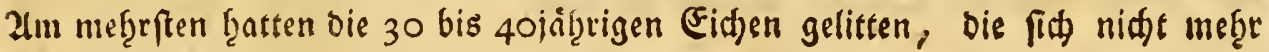
biegen eonnten und abbrechen nußster.

$$
\text { §. } 72 .
$$

Bon Den शRebendingen alt einigen Sadgartett.

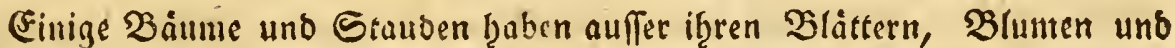
Fructiten auth nod) Dorn = Stacheln uno Briffel uno Satert, die man fämmts

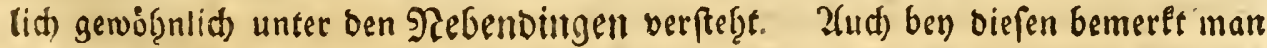

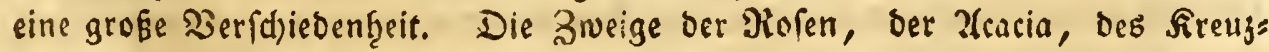
Dorns, ber Stad)elbeere, find auf eine fertr verfdjieberie 2 eife mit Dornen befiset. Einige 2lepfel's uno sp flaumenartent haben nut all Ende ber jungen 


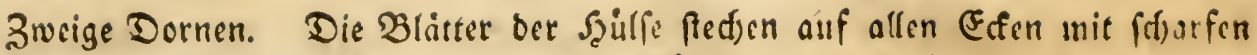

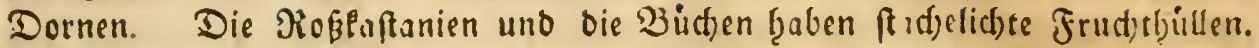

Man finder bie Dornen an vielen Şoljarten boit) nur an ben jingern Zneigen ber $\mathfrak{B a u m e}$ und Stauben; an ben ältern vertroffuen fie und falleu $a b$.

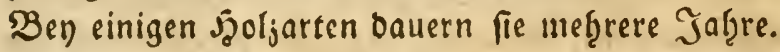

Die Dornen fdeinen aud) nur in ben äuffern Pindenlagen mit einen jels lenartigen Jemebe berbunden ju feyn, wie man es all ber wiloen Piope beym zabrecten ber Dornen aln beften feben Pann. Die Stact)eln aber fino an vielen

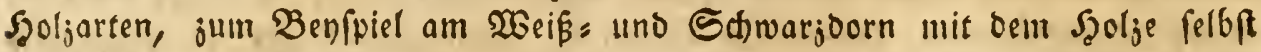

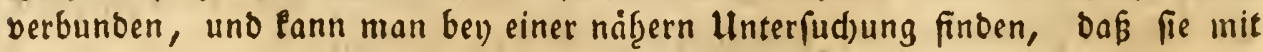

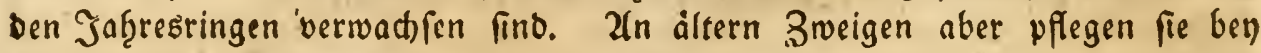

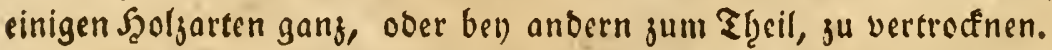

Der eigentlict)e Nukzen biefer Dornen und Stacteln ift uns, fo wie funns bert anbere Dinge in ber $\mathfrak{P}$ flanjenlunde, unbefaunt: fie fdecinen jur $\mathfrak{B} e f(d) j_{3}=$

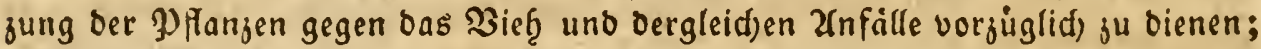
man bemerft baher aud) an einigen Bjemádfen, onk bie Stacteln berfelben auf eine empfinolid)e 2 (rt ftedfen und gleidfam giftig find, wie bas Brennen ber Neffín und bas Stedfen einiger Diffelarten es vermuthen laffen.

Der Nulzen ber an einigen ranlenartigen Stauden befinolidfen Briffer uno Szalen aber ift auffallender, indem fie of̧ne biefe nid)t an andere, if̨nen zur

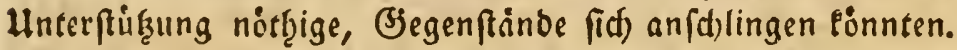

Iln einigen rankigten Stauden fino biefe Jaken lainger und fleifdyigter, wie aIn Weinftocf, an andern fino fie eürzer uno ourrer, mie ain Eptreu. 2alle bers

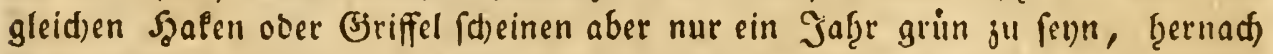
verborren fie, beţalten aber bemolnngead)tet nod) of einige Jabzre lang Jeftigs Peit genug uin ber Staube nüg̨lid) ju ênn.

\section{\$. 73.}

Llnter ber Rinbe befindet fid) ber feftefte und grófefte Theil ber Bäume,

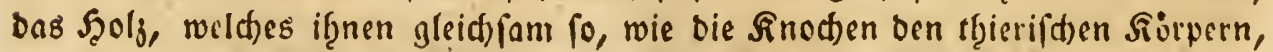

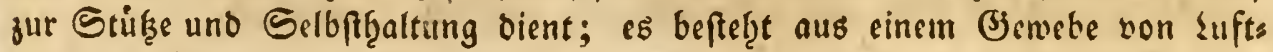
uno Saftrif̧ren. Ilnter ben legtern bemerletman verfajicoene gröbere uno Pleinere, bie zum Theil mef̨r ober meniger, bum Theil bidern unb wäfferigten Saft ents halten, wie man es in ber Saftzeit, befonters in Fribjabt, benm Durd)fdueis

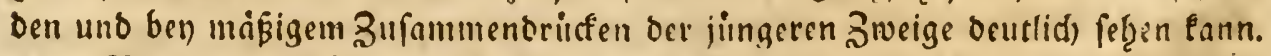

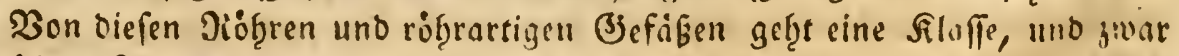

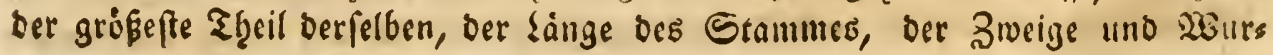




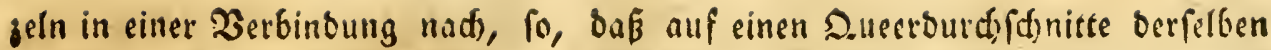

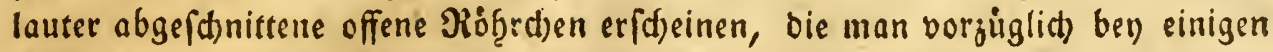
Szoljarten init bloken Zugen beutlid) fę̂en eann.

Zuffer biefen ber länge bes Stammes, ber Zweige uno 2Surgeln nad) laus

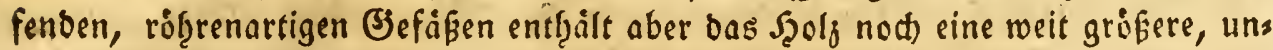
glaublidje Mienge von fibern uno Rob̨rengefäßen, bie ju if̧rer verfdjiebenen Seftimmung unter fich, uno mit allen ibrigen zufammengenebt fino und ben

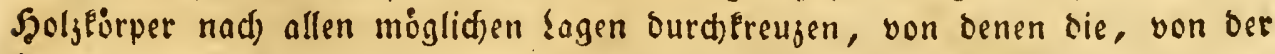
auferen Peripherie bes Stantmes nad) bem Mittelpunct oeffelben lauffenden,

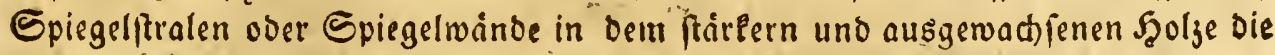

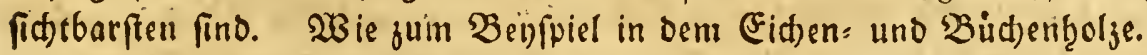

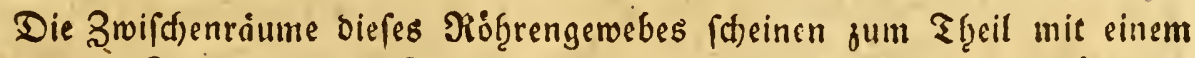
markartigen Stofi uno zum Theil mit Safts uno suftbläsdjen nusgefillet zu

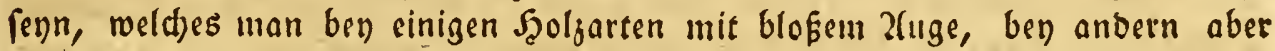

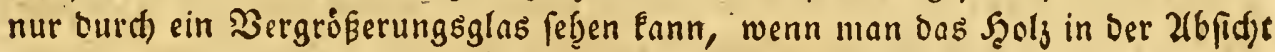

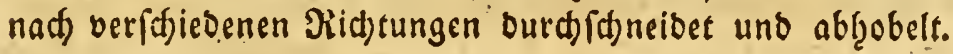

\section{§. 74 .

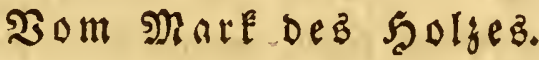

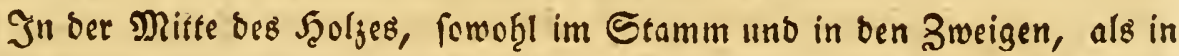

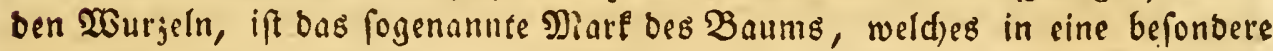

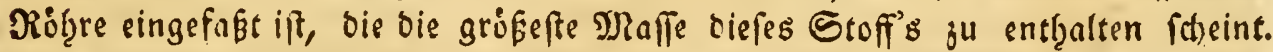
$\mathfrak{B}$ en vielen $\mathfrak{J}_{2}$ of effigt; ben einigen ift biefes Mark weif, ben aniern braun; in ben jungen Trieben waifferigt uno grinlich, in ben áltern Bweigen trocfener, und in oen nod) ältern gewóf̨nlid) ganj verwad) fen uno verborret, woraus man ichliefen

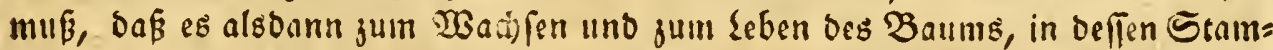
me uno alten Zeften menigfens, fint ben Ulmlanf bes Safts, iberfliffig ift, uno vielleid)t nur, als sin grofer sufteanal bienet. Diefes (d)einen aud) vicle

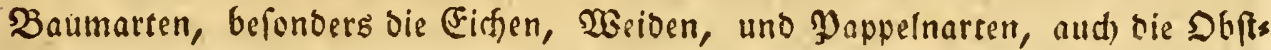
baume fu beftätrigen, als malche alsounn nod) viele Gabire grinen uno wachfen,

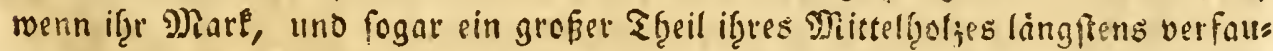
let ift. Bermutblid) aber treten bie ibbrigen, jwifthen belis Giberengenebe befinos lid)en, Markgellen aledarn in teffen Erelle, uno erfeken ben abgang ber mits

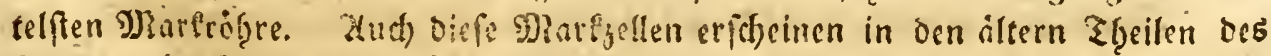
Saums ebenfalls verboret uno berwadjen, weldje bann vermutflid) mit oen, 


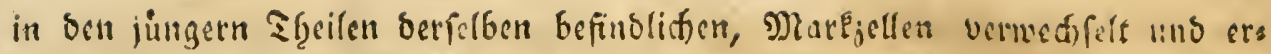
fetzet werden. Diefe Rarljellen verwad) fen alsoann als feftere Szoljmaffr, wie

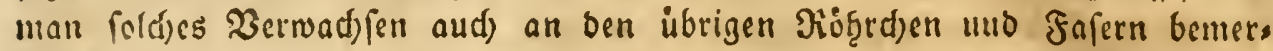
Pen Pann.

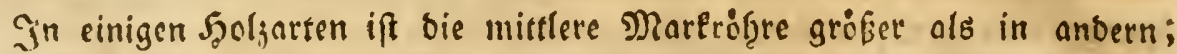

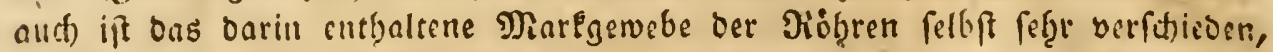

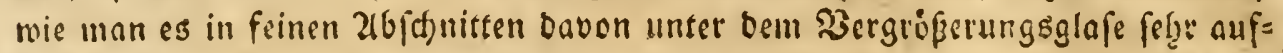
fallend feben Bann.

\section{§. 75 .}

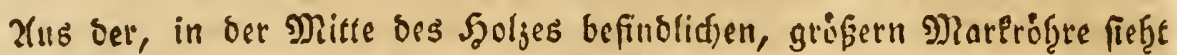

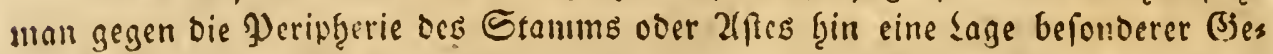

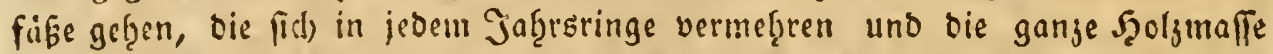
und aud) Die Borfe ourd)ftreifen; man nennt fie bie Spiegel= ober Strab̨lens

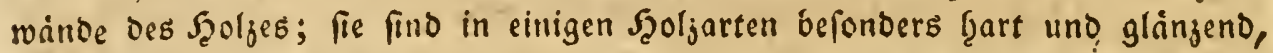
als bey 2 hidhen und (Fichen, ben andern weniger, als in ben sinden, Efpen,

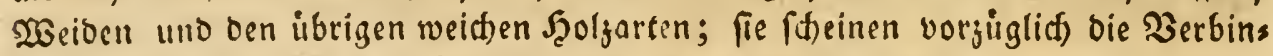
bung ber Gaţrgjirlel ju befeftigen uno unter benfelben einen gemeinfdhaftlid)en Saftumlauf ju befordern. Man lann fie ain beutlidyften auf ber, von troctnem Buddenţols abgefallenen, Botle fef̧en, worauf fie oft sin paar sinien bed aus bem Syolje auggeloft firgen bleiben, und ber Borke bas anfefen eines feinen Dreibeifens geben.

\section{§. 76.}

Sowobl ber Stumm, als bie Zweige und 20 urgeln wahfen ser Tiffe nach, illoent fie wäbrend ber beftimmen jäfrrigen ₹riebjeit cinen Birlel ober Ring ans festen, bie onber bie Jab̨rstinge genannt werben. Diefe befieben aus bell oben benannen Jiofrengeroebe. In Den erften Dionaten ber Sriebjeit, im April uno May, erfd)cinet fold)es wie eine (d)leimigte $F e u d$ tigleit, bie f̧ernad) meb̧rere Confiftenj erfialt und in ben lef̧zen Dionaten, in September uns Detober, incḩe zu feften Sgolje wirb. Sold)e Jab̧rstinge biloen aber fegre felten. formlid)e Birs Eel; fie firto audh nidit nuf allen Sciten von gleidher Didfe. Die Wirfung von Suft, Sonne uno Salte, mef̧r ober weniger ふuftromung bon Saft auf ber eis nen, wie auf bet andern Seite, find bie Urfathen bavon.

Diefe Jafersringe, befonbers bey einigen Ḩoljartert, Ģaben in fid bas Piogrengenebe fefter verbunben, als es mit ben andern Dingen ju fegn fdeint, 


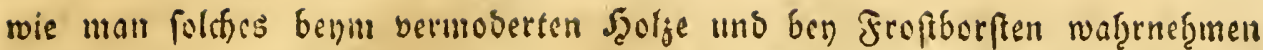
fann, ben weld)en bie alblojung oft nad) Diefen Ringen zeb̧t. Beym Spalten

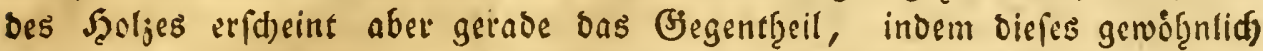
leidter surd) bic Minge von ber Borte nach Dem Mittelpuncte b̧in, als in ber

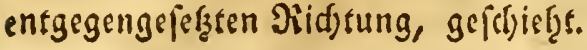

\section{\$. 77.}

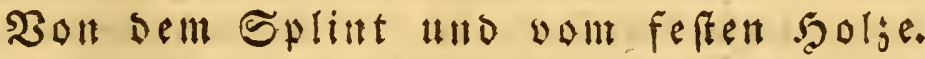

So mie nun wáferend ber jäh̨rigen Sriebjeit aus bem Saft fid nach und

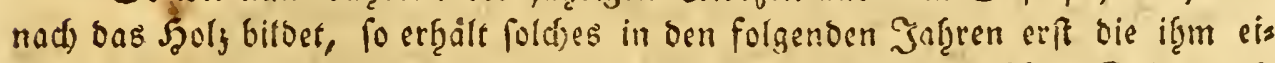

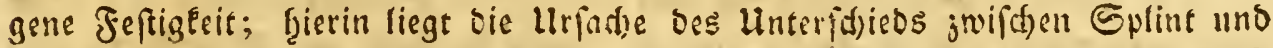
bem feften Sgolje. Der Splint ift alfo Szolf, weldses nod, nidht bie volle Reife erhalten ḩat; berfelbe ift auds, bem zllter feiner Saf̧rringe nach; fefter ober weidfer; ben ben metreften Szoljarten ift fold)er weniger mertbar, bey andern

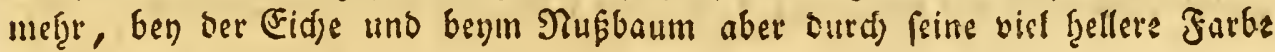
vorjuggtidf fidtbar.

\section{§. 78.}

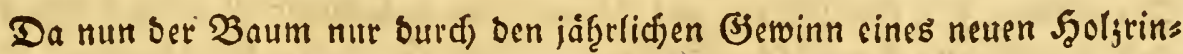

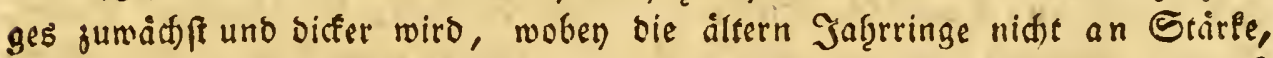

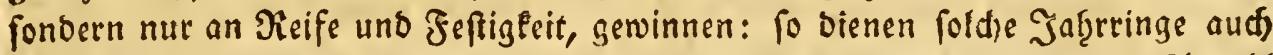

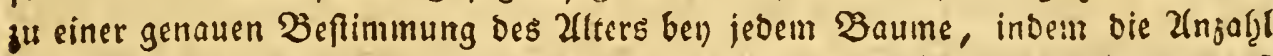

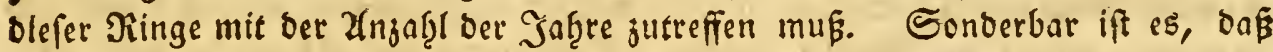
Dicfes lefetere bon vielen Forftmannern, und felbft von foldhen, bie auf theoretis

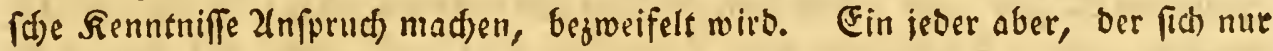

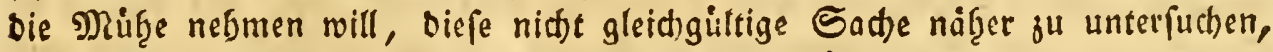
wiro fich von ber Suberlaffigleit berfelben feģr leidft ủberjeugen, uno mit ber gea

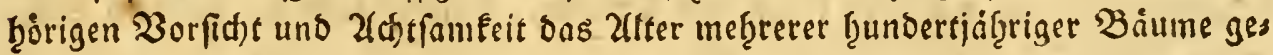
nau beftimmen fonnen, wovon geh̨origen Drts meţreves vorfommen wirb.

\section{§. 79.}

Da nun bie imercere Shartwerbung bes Splintes burd) beffen 2(ltee uns

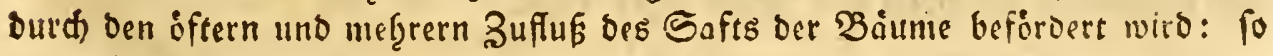

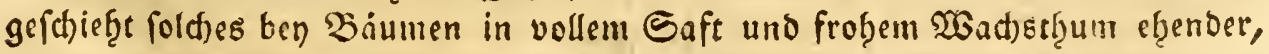
als ber) andern; man findet fogar; bak bey fareen Baillimen ber Splint an ver einen Seite efgender, wis an ber andern Seite erb̧ärtet, fo, dás man oft auf 
ber einen Eeite an einer Eidte nod) orenzejn bis funfjeţn, und auf ter antern Scite nur acht bis jef̨n Jab̨ringe im Splinte zablt. Miegrere oder qrósere 20urgeln ober 3weige, uno sine bafer gríbere 3uftromung von Eaft auf ber Eeite, fund bavon wobgl bie ju vermuthende $\mathfrak{H}$ ráadje.

\section{§. 80.}

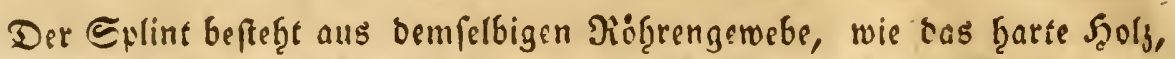
uno feglet if̨m nur bie geţorige Beife, um sie fepte bauerbafte. Eigenfidaft bes

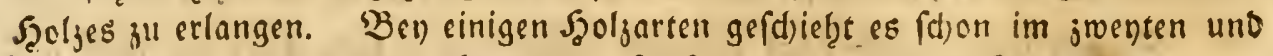

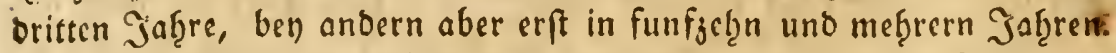

Der Splint unterifteibet fid) von bern feften und reifen Stolje befonbers Durd) eine weiffe, bellere Farbe, uno find oarin bie Suft: und Saftrob̨ren offes

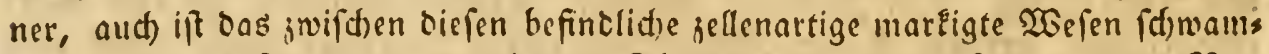
migter. Das Eplinţ̧ols ift baher ber Fin!niß, ocm $20 u r m$ fró gänglid)eit viel mę̧r unterworfen, als das fefte Syoly befferber Baums.

\section{§. $8 \mathrm{r}$.}

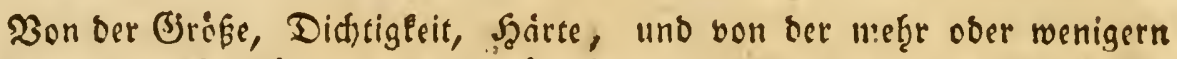

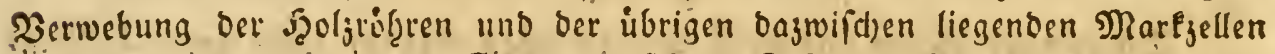

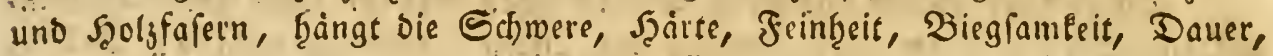
Braudjuarteit jur Jeurung, oder fonftige Eigenfdjaft einer Szolzart ab. Sino

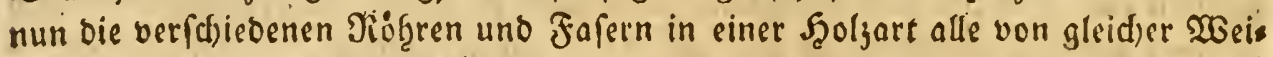

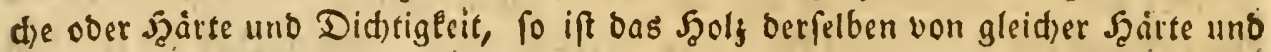
Feinfecit, mie in ben 2 beiben, sinben, Budjsbaun und Ebenfjelf: find aber

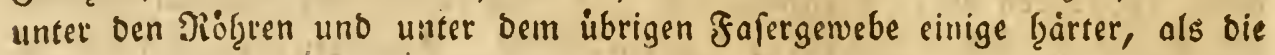
übrigen, ober aud) foldje mit einer ungleid)en Marlmaffe, ober mit grofen fes fien Spiegels und Strab̨lenwanden Durdjogen," fo ift Das Szolz ebenfalls von ungleidern $\mathfrak{R e r n}$, wie man es an Den Sannen, Eid)en, uno an mę̧retn Szolfs arten bemerlt.

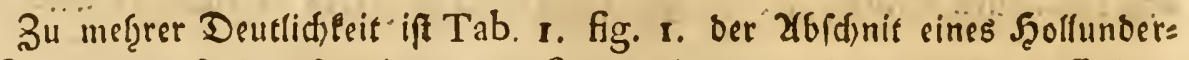

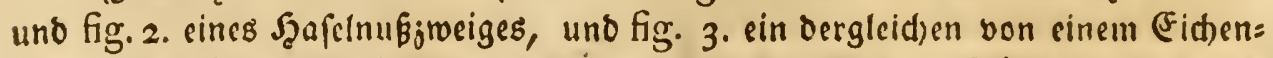
zweige vergrókert abgebildet; worin man bie verfdjieonen Köḩrenftraf̧imänbe und Dergleid)en im Şolze und Mare feḩen Eann.

\section{§. 82.}

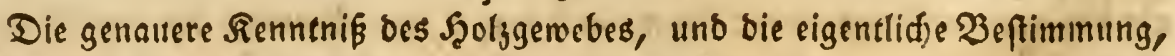

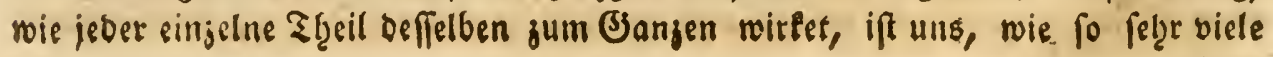




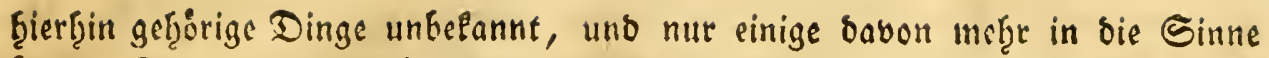

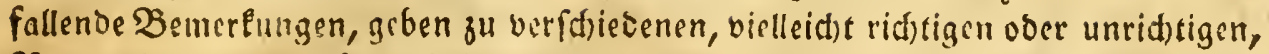

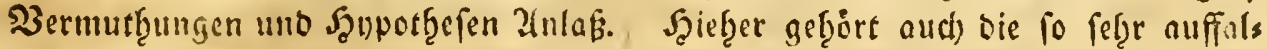

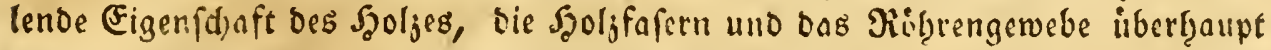
entmeder berm 2lustreffnen mit fegre vicler Siraft zufammen ju jief̧en ober beym

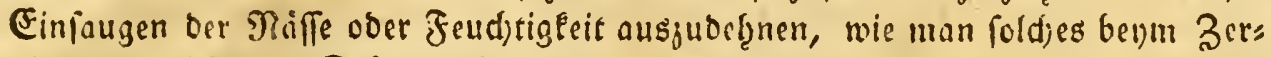

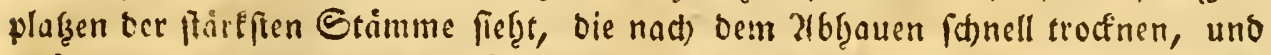
aufzureiffen pfiegen, weil das Snnere DCs Stamms langfumer als bas denfere austrocfnet, wint lezteres nich) ţinlänglid) uad)geben lann. Noch auffallenter aber lann man Diefes lraftuolle 2fusocḩnen an bem betannten Mittel bemerlen, was bie Steinbredier in gemifien Fillen benusen, un grofe Sandfeine boneins ander zu palten, in weldie fie in eingetgauene sid)er Geile von troctinem Szolje folagen, nuf bie fie nadher Waffer giefen, wotauf nad) cinigen Stunoen bie aufaridwolienen Sieile bic Steine voneinanber furengen. Netzrete Dergleiden

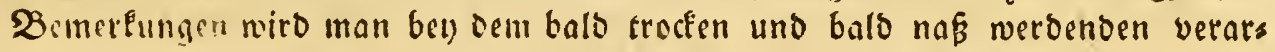

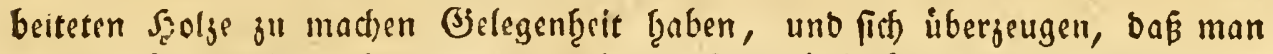
nur ju oft mandiem Şantewetler unbillige Sorwurfe hber bas jur getieferten

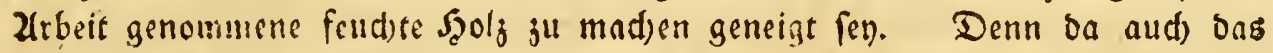
trocenple Syolj ben jeoer Belegenţeit viele Feuchtigleit angieţt, fo ift bas bas

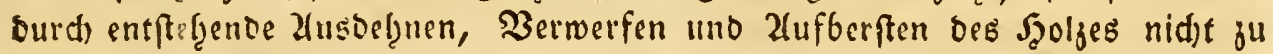

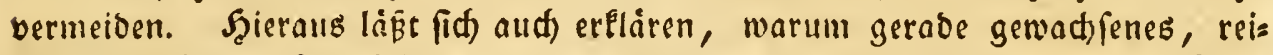

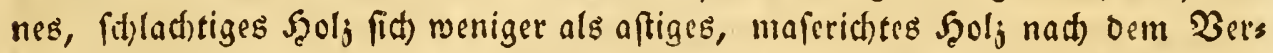
articiten vergiegt; warum man ju foldhen Sachen bie beftindig im Troffnen fid) befinden follen, ganj troffnes, ju andern, aber, j. B. Ju Jenleerrafimen uno bergleiden fein ganj troctines Sgolj nef̧wen misfe u. f. w.

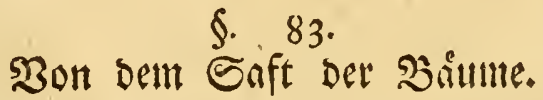

Die fowofgl in ber Borle, als im faften $S_{2} w_{j}$ befinolitye unenditife Menge

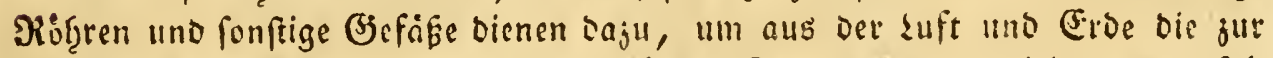

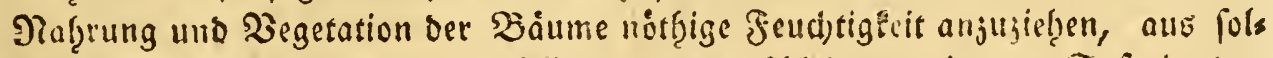
d)en Den fir jede Baum = uno Pflanjenart verjhiedenen eigenen Saft in oen Daju befimmten 2 Berkgeugen abjujondern uno gugubersiten, uno bie iberfliffi: gen Flęile onvon ausjudunften.

$$
\text { §. } 84 \text {. }
$$

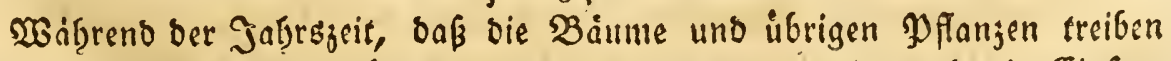
uno wad)fen, ift ber Saft fluffiger, und wirb alsbann aud) ourd) bie Einfaus (Erfter $\mathfrak{T h e f l )}$ 


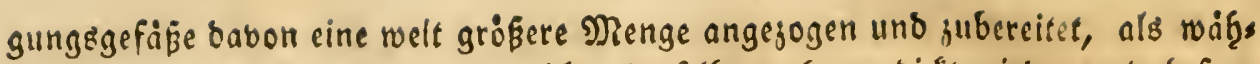
reno oer iibrigen Gaflersjeit, in weld)er berjelbe meţr berdifft miro, uno befons Ders in ben Palten wintertagen, wo er gleidjpain erftart ju feun fdesint.

\section{§. 85 .}

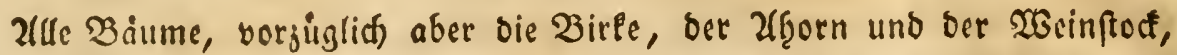

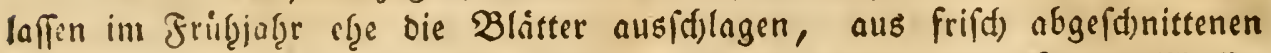
2(eften ober aus 20 unben bie man in ben Etamm mad)t, eine Mienge waffer laufen, weld)es benm 2(ugft)lagen ber Blatter aufgeört. Wabrefdeinlid) wiro

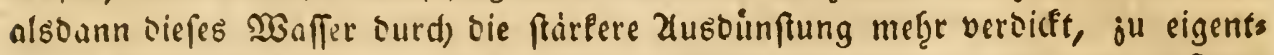
fichem Eajt, uno baraus ber neue Şoljftoff, mie aud) bie ju ben neuen Tries ben, Sinefpen, Slitţen uno Saamen nòtţige $\mathfrak{M a f f e}$ zubereitet uno abgefons bert, fo mie es bey ben animalifhen Siorpern aus ber Naf̨rung berfelben vers ந̧âlteniß̧ıáfig gefdetcen mag.

\section{§. 86.}

In verffiebenen Baumen ift biefer Saft meb̨e ober meniger waifferigt, zufammenjieferend, füflid)t ober bitter, in andern ift er harjid)t, wie in ben Radelg̨olzarten; in einigen iff er gummigt, wie bey Y)firfd): PPflaumen, uno Sirifjenbaumen.

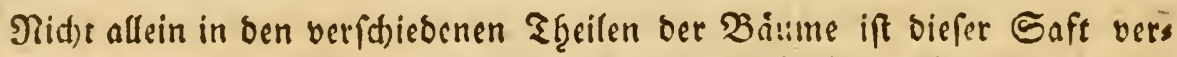
fdieben, fonbern in ben Jrideten felbft. So ift ber Saft oer Bitronen in ben

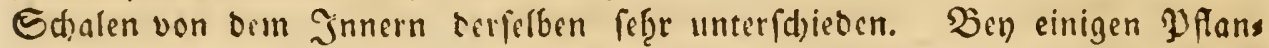
fen ift fold)er mildsigt, bey andern llebrigt, ben einigen gelb, róthlidf) u. f. w.

alle Diefe (Eigenfdaften werten burd) bie, in Din Planjen und biumen veriádietenen Bjefäpe aus den Fenditigfeiten ber Eroe uno ber suft abgefondert,

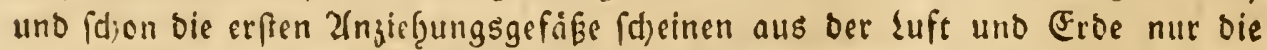

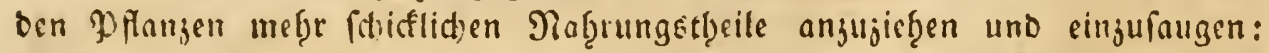

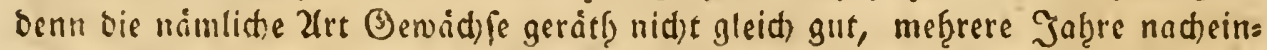

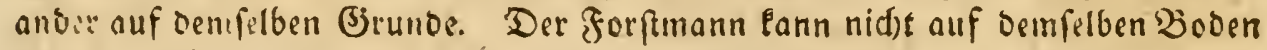
(Eid)en, Büchen, Ellern u.f.r. mit gleid)em গiutzen jief̧en, uno fo liebt jebe

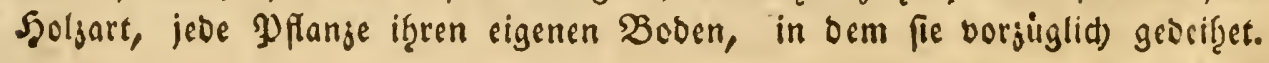

\section{\$. 87.}

Da ber cigentlide Baumfaft aus ber suft uno Eroe angejogen wirb, fo ift

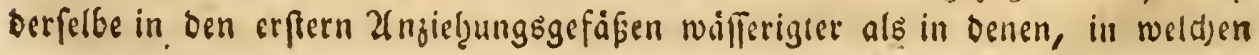




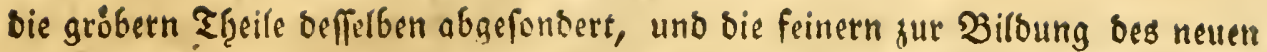
Scoljes, ber 2 litben uno deg Snamens zubereitet werten, man Eann biefes befonoers in foldten Baumen, welde farteried)ente frudte tragen, ain beften waf̧rnef̧men, in weldben ber Saft in ben erften 2uziebungsigefópen nur einen grafigten, in ben feinern Scolfrobren fdoon einen etwas mef̨r bes

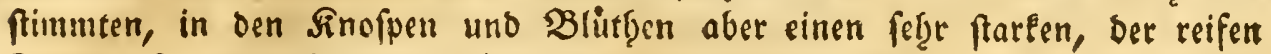

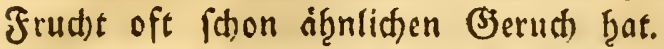

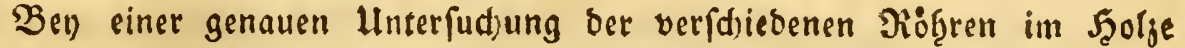
und in ber Dinde witb man bicfe 3erfajedenteeit bes Safts barin finden, fo wie aud fu ben berfdiedenen Saberzgeiten oerfelbe fid in Kidffidt ber Menge, ter meţrern ober menigern Eonfifteng uno Stärle fefcr veränbert. Diefe Saftrogren unterfdeioen fid) befonbers von ben ubrigen burd) if̧re mebrere Weite; if̧rer find aud) nur wenige vorfanden, uno es (d)einen

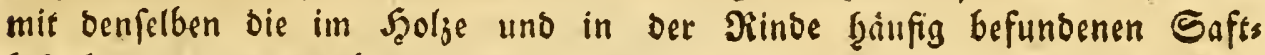
blasden genauer berbunden fu fern.

\section{\$. 88.}

Diefe Saftbläschen find fowoţl if̧rer Beftalt als lage nach in ben vers fojiebenen Syoljartin fefre veridjieben, viele b̧aben melze eine runbe, viele eine

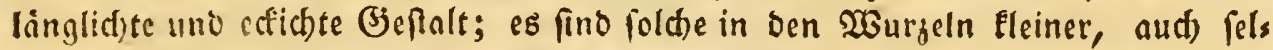
tener, in sem Stamm unb in ben 2leften båufiger uno fdion mefre fichtbar, in

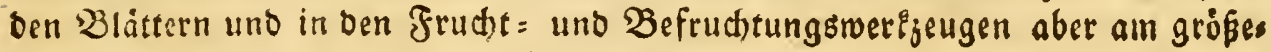
ften ullo ģăfigften, und von feinerem Bewebe.

\section{89.}

Die Eizeniffaft bes Safts ift in ben Şolgarten nuch in Rucficht auf bie Benufzung Deffelben fefer verfdieden. So fiebet man Saar, Ped, Theer, Terpentin: uno Sieriol aus ben Nabelģolgarten. Der Solzgerber gebraudfe bie eidhene und tannene Borle jum Berben bes Sebers, ber Saft bes Seitelbaftes ift aufferft fátarf uno beiffeno, und wird in ber arjened gebraucbt u. f. w.

\section{\$. 20.}

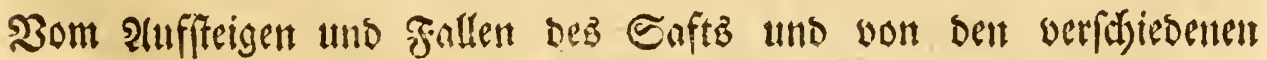
Daben) ju madbenden Benterfungen.

In ben SEintermonaten findet man in ben $\mathfrak{B a}$ atmen ben wanigfen Saft; oie in Şolje befindlidjen Eaftrof̧ren enţ̧alten alsbann nur ned) 
cine verbicfte Fendftigleit, bie für bie Unterf̧altung ber geringen $\mathfrak{J}_{\text {eges }}$

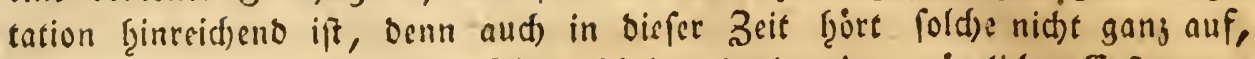
uno nur bei) ganj firenger Silte f(h)int barin sine gainjlid)e Erftarrung einjutreten, bie aber in Den oarauf folgenden gelinden $23 i n t e r t a g e n$ nad,

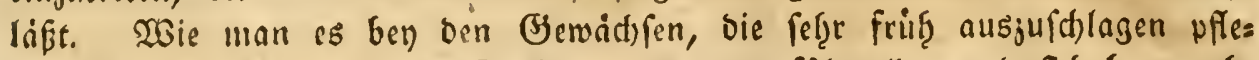
gen, bemerent Pann, beren Sitrofpen alsoann aufidswellen uno (id) bey nad)s beer erfolgter Siăte wieber jufammenjię̧en.

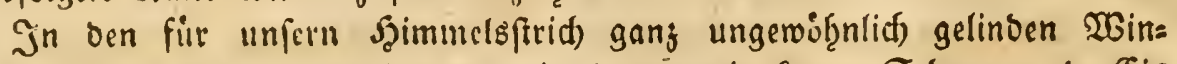
tern von 1789 in 1790 uno 1791 , in Denen wir Paum Sd)nee und Eis

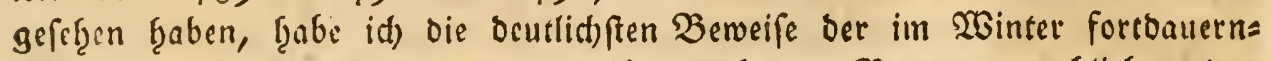

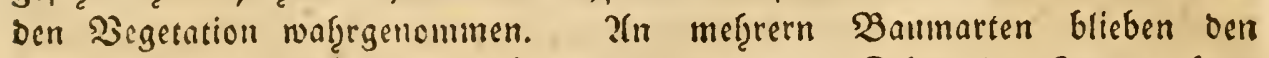
ganjen Wointer iber einige grime Slitter figen. Stjon im Januar fano man in oen Blithefnofien ber meţrften 'Baumarten feŗe ausgebildete

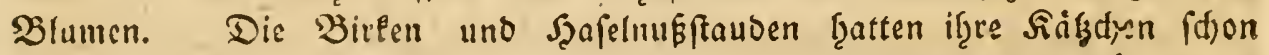
Doppelt verlangert, uno in ben erften Tagen bes Februars blüfete bet

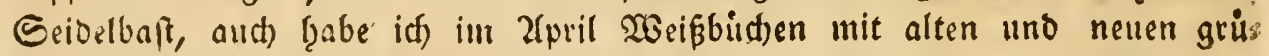
nen Blättern jugleid) gefergen, worauf bie alten aber balb vertroctueten.

\section{§. $9 \mathrm{r}$.}

Die Bewegung bes Safts ift in ben warmen fruftingstagen fef̧r fdinell und frate, bejonders wenn biefe gleid) auf eine lange Bcit anlgals tende trocfene אälte folgen. Der Zufluß ift alsdann fo ergiebig, oas er in grofere Menge vorjiglid) aus einigen Baumarteil, als aus bem Weins

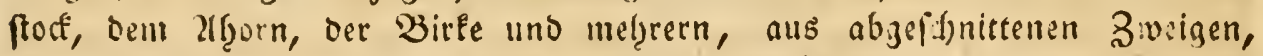
oder aus oen ju biefer Zlbfidt eingeboberten Söchern ausliuft. Sold)es

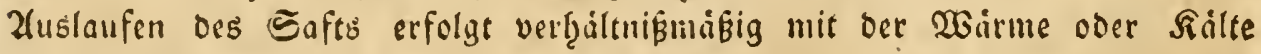

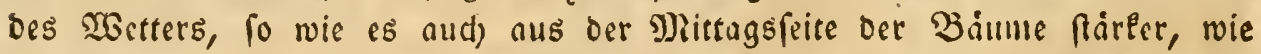
aus oer Norbfeite berferben flest; in oen falten Fagen tiort es ganj auf uno fangt barn wieder in tell folgenden warmern Sazen an, bis bie

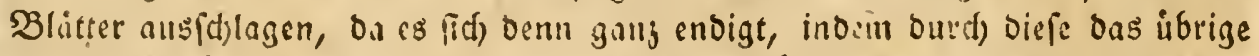

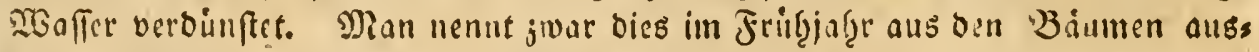
laufende $\mathfrak{X}$ alfer, Saft, es ift abst eigentlid) nid)t viel mebre als ons von oen 2Surzeln angezogene SBaller, aus bem in ben itbrigan Theilen bes baums erft Der eigentlidfe Saft jubereitut wirb. Diefes $\mathfrak{W} a f f e r$ entf̧ált befonders von einis gen Baumarten cine geringe Menge zucferartiges 2 Bifer, wie benn aud) bie

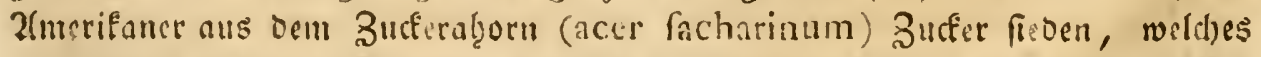
aud) aus oen fiefigen atgorn und der tenne gejdegen fann. Zlus ben Birten 
fann man ben fogeriannten Birlentwein maden, welder ber enthaltenen Buffers

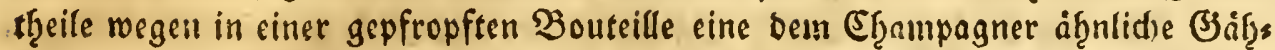
rung annimmt. Das aus bem Weinftodf febre reid)lid fließende waffer foll heilfame Sarrifte haben, uno wirb vom gemeinen Manne zu 2fugenmaffer ges bralldt.

\section{§. 22.}

Dbfjon bas 26japfen biefes waffers genugfan befannt ift: fo pommen Babev) Doch einige Erfheinungen vor, woyon bie Hrjathen bem Naturkindiger

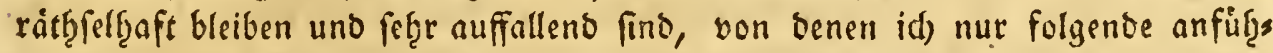

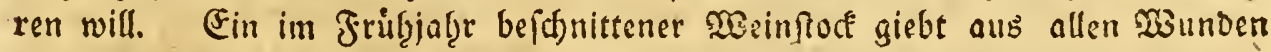
ferge b̨äfig Waffer: Diefes bzoret ebenfalls, aus bemertter Urfache, bann ju fliefen auf, roann bie Blätter ausbrechen. Fin gleiches milfte gefdjef̨en, wenn

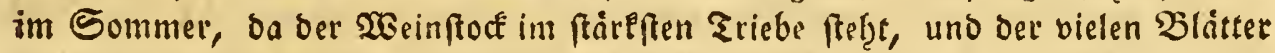
und Erauben wegen eines nod) beăufigern Zufluffes wie im Sribjalgr bedarf, bemfelben biefe Blätter uno Frichte plofifith genommen uno bie Bianlen jum Theil abgefdnitten werben, man bemerft aber bey diefem Berfudse, den id) felbft

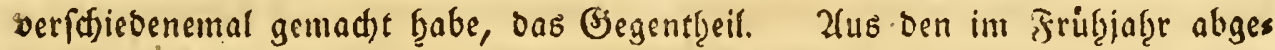

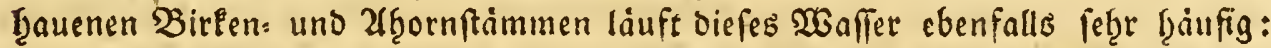
aus ben fpater im bollen saube geţauenen Strimmen aber nicht. Desgleichen

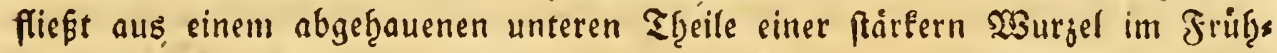

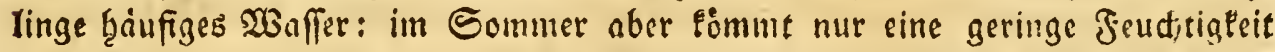

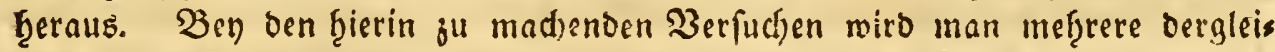

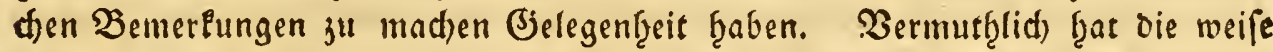
Natur ben Bewaid)fen, nadjoem fie oen Winter uber if̧e Saugungsgefäje ges

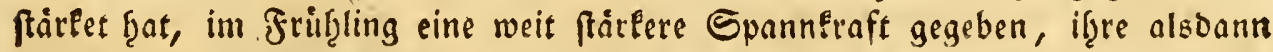
gefd) wino notţige grofe Menge von Maţrung anzugietzen, weld)e fie in ber jpas

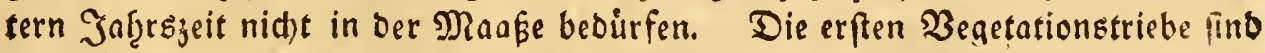
im Frubling fobr ftare uno fduell, man fiebt Blätter, Bblutţen uno neue Gabrs: triebe aus $\mathfrak{s}$ nofpen entfeflen, bie vor wenig ₹agen nod) wintermásig geftloffen

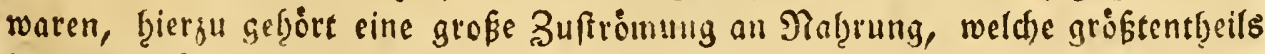
Durd) Den Etamm jugefübret werben mußs. Dahingegen erforbert ser Banm

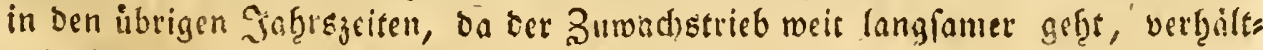

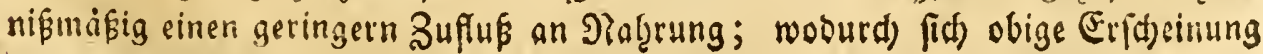
in etwas erflären lípt. 


\section{\$. 93.}

Wie bas 2ufferigen und Fallen bes Safts eigentlich in ben Bäumen unb

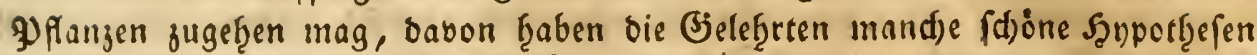
ausgefonnen, bie aber zur Erllärung beffelben aud) nid)t finreid)en. Maan weiß

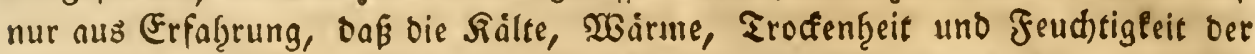
suft uno bie 2̇irkung ber Sonne barauf ben griffen Einfluf f̧aben, uno man

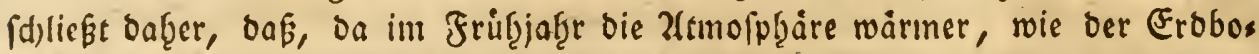

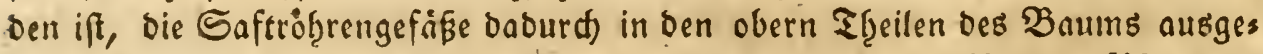

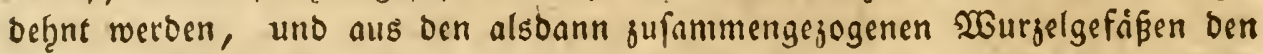
Saft aufjief̧en, fo, wie biefe benm eintretenden Wointer im ungekefrrten Falle gewifiermaken bas Jallen bes Safts verurfadten, ober alsbann eigentlid) auffgos ren, fold)en in grọer Manfe anjujief̧en. Das 2(njief̧en ber obern Saftrỏbs

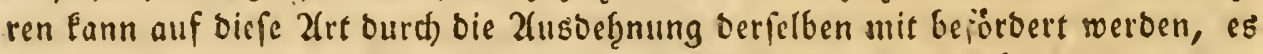

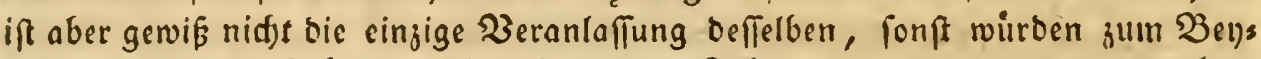
fwiel aus ben ium Jrủ[zją̧r abgefd)nittenen Etäımen, oenen ber ganje obere

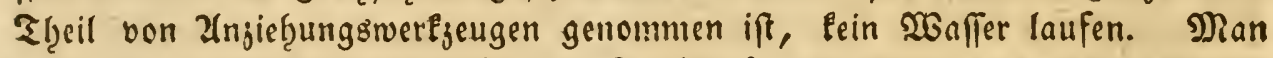
mú alfo in ben $20 u r z e l n$ jelbft eine Eriebtraft vermuthen, wie aud) bie hiers

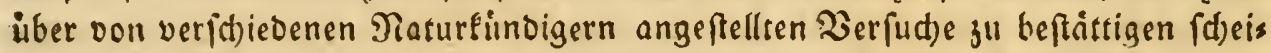
nen. 3. 3. Der f̧ierin befonbers veroienftoolle Szales luttete ouf sine abgeift)nits

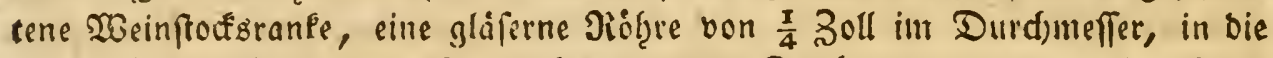
er jwei Soll hod) Waffer goß̈, weld)es von benn Stof, ber bamals nod) nicht ju raufen angefangen bৃatte, eingefogen wutbe; beym Laufen des 2 affers aber

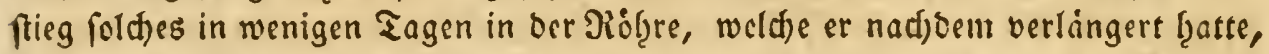

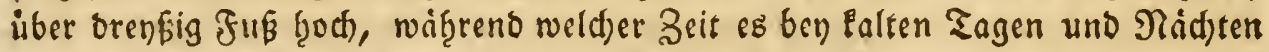
einigrmal wieber gefallen war.

Dicfer finnreifje Berfud berweifet fomoht bie Einfaugung, als großje

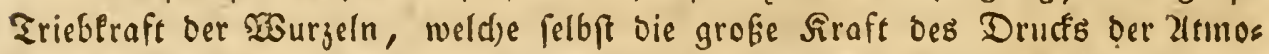
fwhare ibertrifft, als woburd) nur in einer luftleeren Jiöhre bas Waffer auf eis

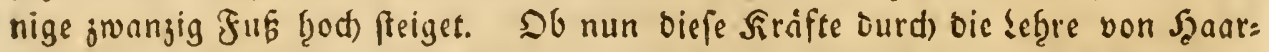
rób̨ren ooer berglcidjen im (Brunde benn bod) Ģier nid)ts mefre bemeifenden

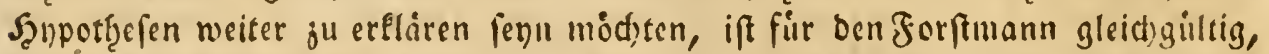

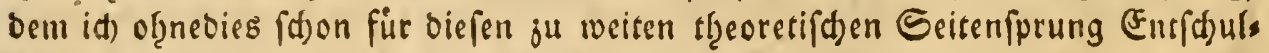
bigung mad)en muk.

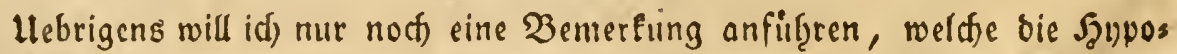

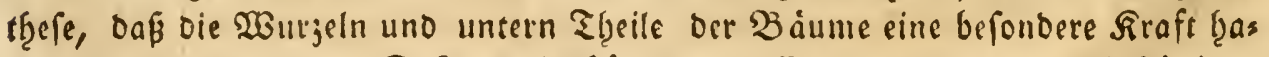
ben, ben angejogenen Saft in bie Şobze ju preffen, noch meb̨r ju beftistigen 
idgeint. 23enn man zum Benfpiel währento bem laufen bes Safts bon einet jungen Birte eimen obern Broeig abfenneibet, uno baraus bas 2 affer balb tros pfenweife heraugquillen fieţt: fo wiro, fobalo man ben Stamın, ober cinen von jenem Zweige entfernten 2 (ft, auf bem er in 3erbinbung geftanden, abges

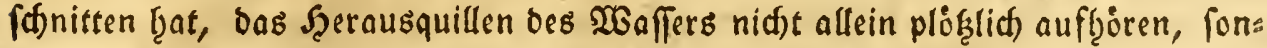
bern aud) felfft das bereits berausgequollene 20 affer in ben abgeichnittenen Zweig

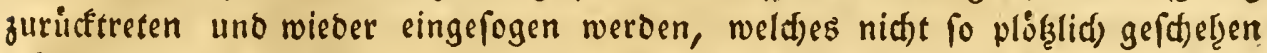
wirbe, wenn das Sgerauslaufen bes $\mathfrak{x a f f e r s}$ burdf ein ju ber Beit in ben Báus men bavon enthaltenes $H_{e}$ bermaak veranlaftet werben follte.

\section{§. 94.}

Da man alls ber Erfaf̧rung weiß́, baß́ veriffiedene Saumarten jum bef: fern Bedeifen if̧en eigenen Brund uno Boben verlangen, als z. B., baß bie Buiche auf faltartigem, bie (Eid)e auf einem mit Sanb vermifdten \{eimboden, uno bie Eller auf einem feud)ten $\mathfrak{B o d e n}$ am beften wädft: fo if die $\mathfrak{B e r m u t h u n g}$

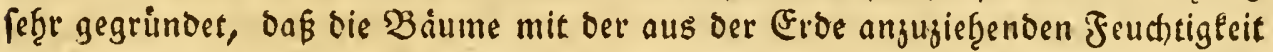
auch bie in biefer aufgelóften Eros uno Salztheile mit anjief̧en uno als eine befs

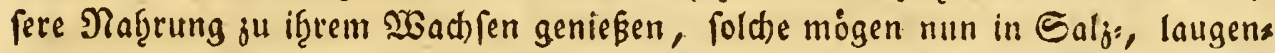
artigen, ober fonftigen Theilen beftefen: indeffen ift bod) bie angemeffene Jeuds=

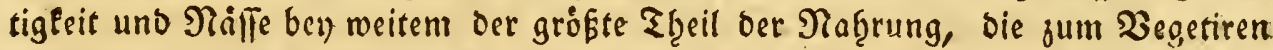
ber $\mathfrak{B a} u m$ uno fonftigen $\mathfrak{P}$ flanjen, notthig ift, uno fogar reines $\mathfrak{W}$ affer ift bins länglid), fie eine Beitlang wadjen ju macten. Bewundernswirrbig jieft

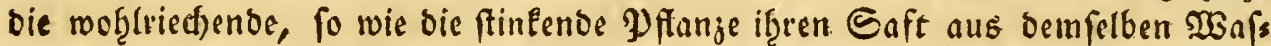
fer, wenn man jum $\mathfrak{B}$ ergleicly bende in benferben ausgewajd)enen uno getrodesnes ten Sano pflanjt uno mit oeffillirten coer Negenwaffer begiépet; es liegt die Zus bercitung Des Safts aljo in Den Drganen ber PPfanjen und in ber Defonomie berfelben, wie foldes gef̧irigen Drts bemertet morben ift.

\section{\$. 95.}

Do nun faton bie Pffanjen jwar aus ber Eroe uno ber barin befindlidene

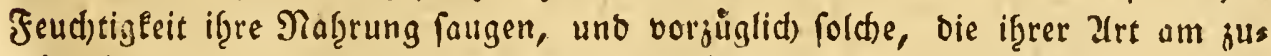

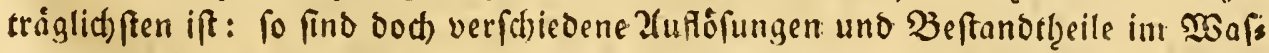

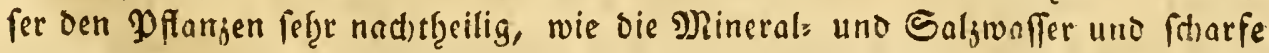
Miftaligen; To wie aud) Das begirsin mit Gartem Brunnenwaffer oen jungen

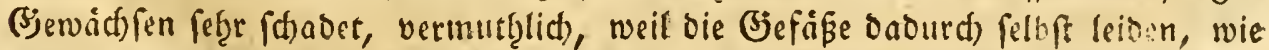
ich es bey ben baburdy getobteten Baumen an ben vorgefundernen. Stocffecfen bemerlt f̧abe. 


\section{§. 96.}

D6 man in ben Pflangen ben Ululauf bes Safts fo bermuthen folle, wie ber Llmlauf bes Bluts in ben animalifden Siörpern burd) bie 2(rtetien ober \$oulss abern bom Şerzen, uno nad) bieferm in ben Benen ober Blutadern Daf̧in zuricf bewirlet miro, oariber fino bie $\mathfrak{R}$ aturfundiger nid)t einig, vermutblid), meil fie mit ber Soee, ben Yflanjen ein gervifles Seben benzulegen, nod) nidft genugfan vertraut fino.

Ja) glaube bie f̧ierin mit cinanber ftreitenoen Szypothefen bereinizen fu fonnen, wenn man fid) Den Lluilauf bes Safte in ben $\mathcal{P}$ Hanjen nur nidjt gerabe

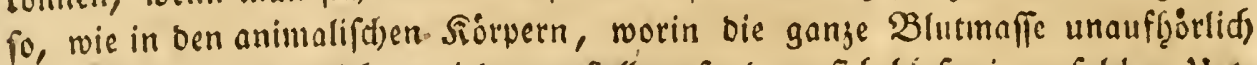

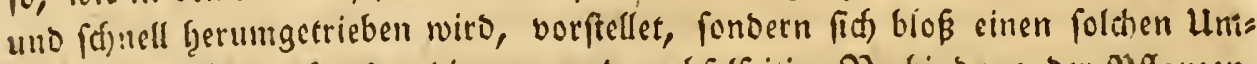
lauf des Eafts benlt, ben bie enge und wedtfelfeitige 3erbinbung ber DPflanjens

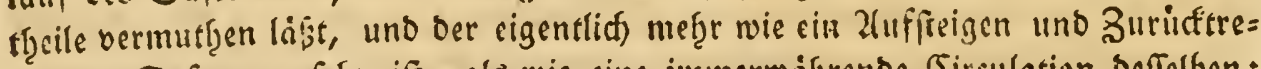
ten bes Safts anjufetrn ifr, als wie eine immermitgende Sirculation beffelben:

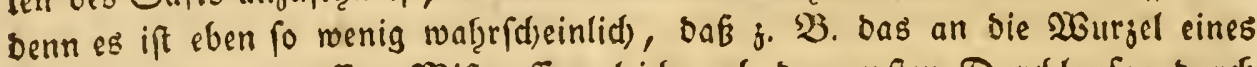
Drangenbaums gegoffene Mifwaifer gleid) nad) bem erfiten Durd)laufen burds bic Şaljfibern gu bem wohlrichenden Saft ben bie Blumen erforbern uno augs

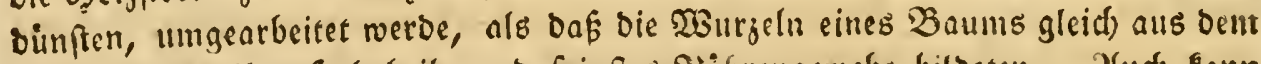

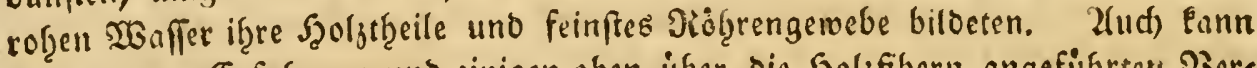

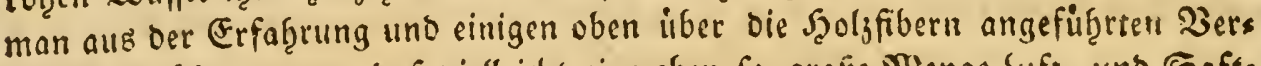

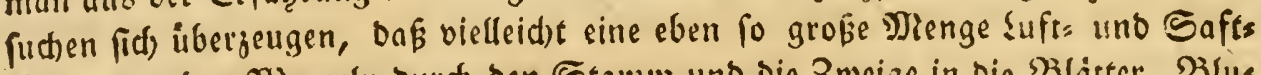

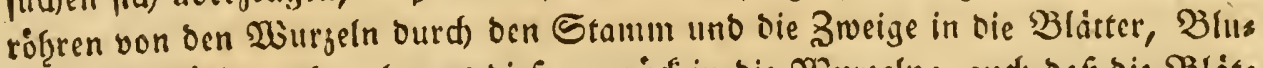

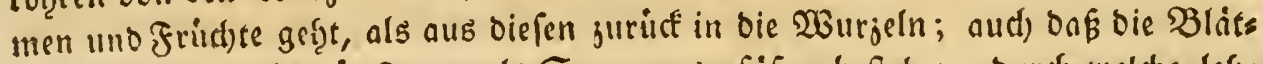

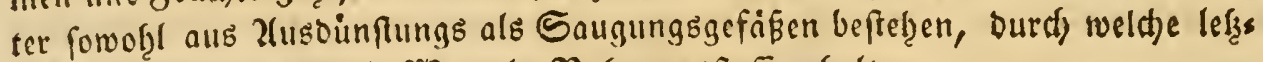

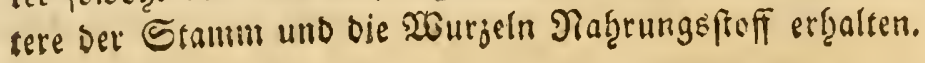

\section{97.}

Ben gevfropfern båumen, bey weldyen ber lleftamm fowobl, wie ber auf oenfelben geferete Theil, immer unverándert bas bleiben, was fie vor ifrec 3erbinbung waren, fd)int bicfer Lmlauf oes Safts etwas Unwaberfdeinlides

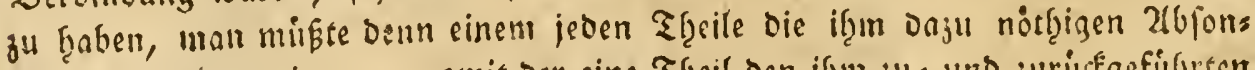

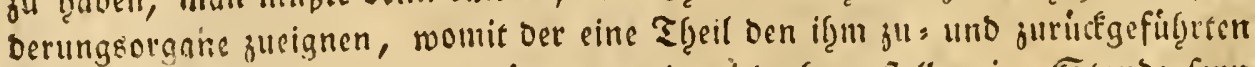

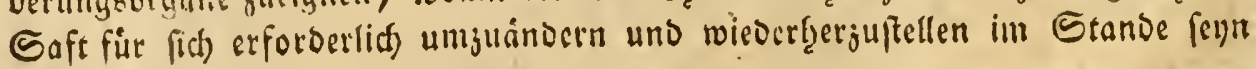
Ponnte.

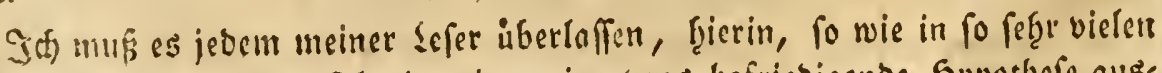
naturliden (Erfdeinungen, fid) cine eigene in struas befriebigende Şypotbefe aus: 
zufinnen, ba es mith) fu meit von bem mir gefegeten Biele obfüfren wirbe, wenn id) aud nur bie von mir jelbft hierin gefammelten bemerfungen anfüberen wollte.

$$
\text { §. } 98 .
$$

Bon ben Şolys uno Frudutentopfen.

Die Rnipfe oder Snofpen fino ber Theil bes Baums, woraus bie B̉ätter ober Blitţen, und bende oft gemeinf(t)aftlid) auģulld)lagen pflegen,

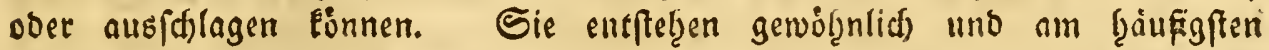
zwijhen ben Stielen ber Blätter an ben jungen Broeigen und Srieben, fo wie fíd) aud) biefe in einen fold)en Rnopf enoigen. Z(ud) énnen bergleidfen Sinopfe an oiltern 2feften, am Stamm uno an ben 2 urjeln felbft entfeften, wie man foldtes bey abgefopften Weiben und Eichen, audf bey abgetgauenen Stäms men bemerken Eann.

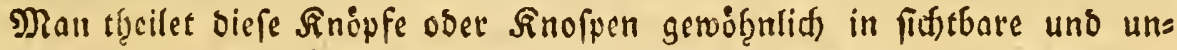
(iid)tbare Sinoipen, iene fino bie, weld)e wir an ben Blattetn bet $\mathfrak{B a d u m e ~ b e s ~}$

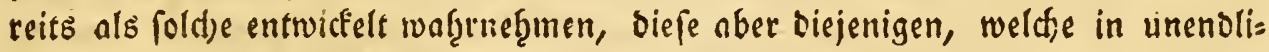
wer Menge in allen Stgeilen ber Rinbenlagen ber $\mathfrak{B a}$ aume verborgen liegen, uno fid) Dann nur erff zu wabren Şeljenopfen bilden, wenn es eine befonbere Beranlaffung ju erforbern (d)einet. Doar beffer, wie jene Ţfeoretifer, welde

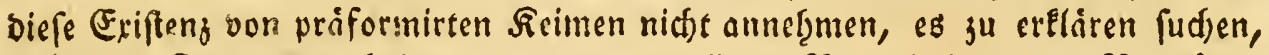
wenn ber Stamm burd) irgend eine baju paffende 2 eranlafiung Das $3 e r m o g e n$

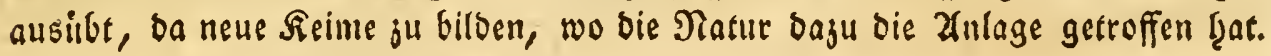

\section{§. 99.}

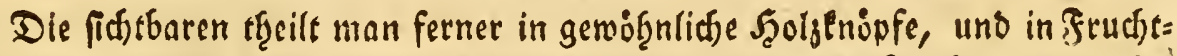
enọpfe ein, aus jenen entfteţen nur Blätter und bie jungen Triése, aus biefer aber bie Blitţen und Jrúchte bes $\mathfrak{B a u m s . ~}$

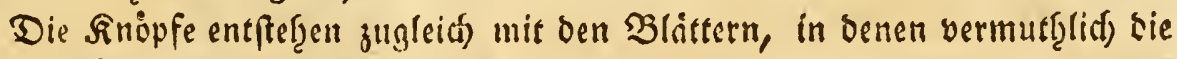
Nâ̧rung für biefelben zubcreitet roito.

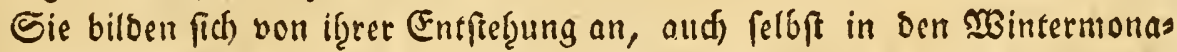
ten, immer melzr aus, wie man bey Unterfudfung berjelben von Zeit 311 Beit wabenefemen fann; Dodf) erlangen nidgt alle bie erforberlidje Dieife und

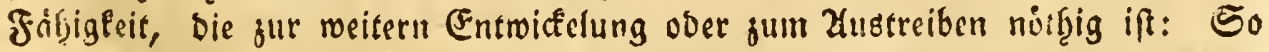

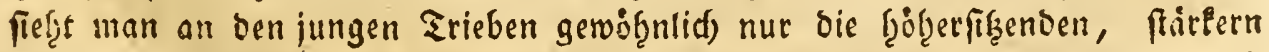
Snopfe austreiben, Daf̧ingegen bie tiefern batan gefdloffen bleiben uno nad) beer vertrodtnen.

(Erfer Theil) 


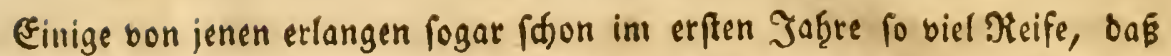
fie alsbann idfon, aber bod) nur geringere Bweige mit (parfanern Blìttern allss treiben, wic man es vorgiglid) an ben Soben ber frarltreibenden Dofteaume fins Det, an weld)en beym Johannistriebe bicle neue Snofpen jü fleillen Trieben

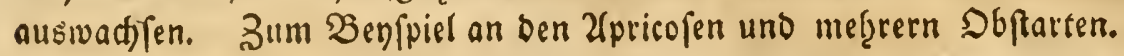

\section{§. 100.}

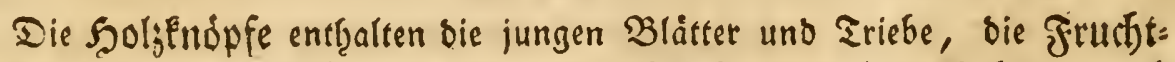
fltofpen, $\mathfrak{B}$ läster uno Blitţen, wie man foltfes bey einer Unterfudfung ourd)

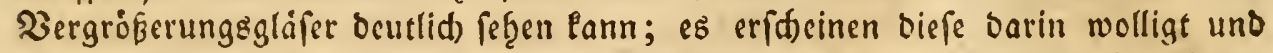
festre oid)t jufammengelegt; fie fino auswendig mit fthuppenartigen loffelförmis

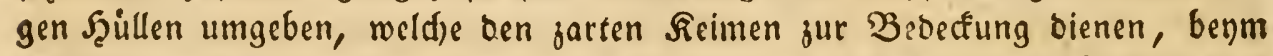
Z(ustreiben berfelben fid) iffnen und bann gewoignlid) balo nad) Entwidelung Der Blätter abjufallen pflegen. Wey einigen Şolzarten bleiben von biefen J̧üls len bie innern lainger figen, wad) fen in etwas in bie länge und fallen fpater, oft erft mit ben Blättern ab, wie ben bem aff̧orn. 2an vielen Şolzarten fino biefe

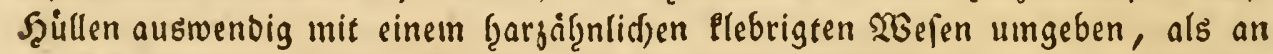
Den Yappelarten und Dióflaftunien, man nennt biefe Ş⿻illen auch Decfblätter.

Die Şoljgnopfe fiken an ben jungen Trieben, wie bie Blätter, an benen fie entftantern fins.

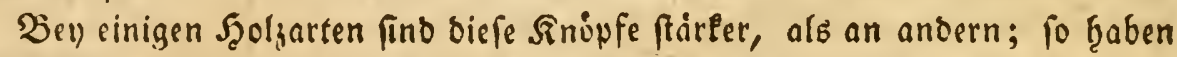

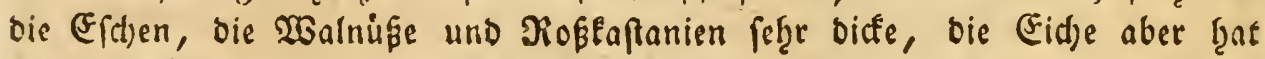
Uleine Sinopfe.

\section{§. $10 \mathbf{r}$.}

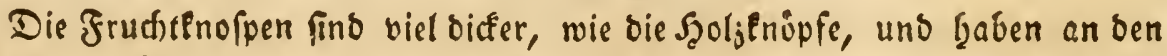
berfdiebenen Sgoljarten aud) verfdicbene Elellungen; bov einigen, wie f. $\mathfrak{B}$. an ben Zfpfels uno Birnbäumen, fteţen fie auf befondern fleinen Broeigen, Die

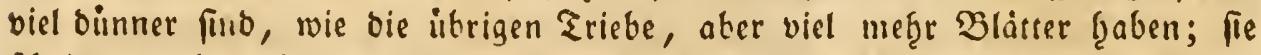
(t) einen aud) meţr alls zellenartigem als aus rôfrenförmigem Giwebe zu bes

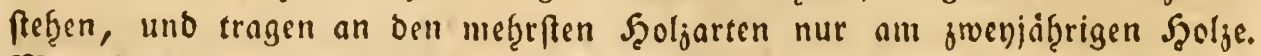
Man pann biefes an ben Birn: uno 2(pfelbäumen, aud) an ben Eiden refer gut bemerten.

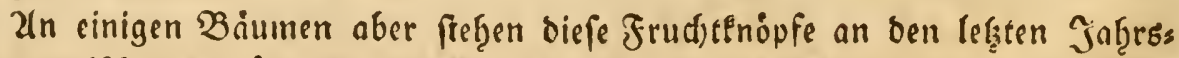

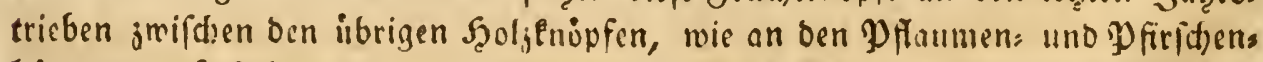

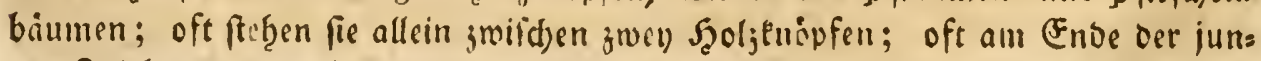
gen Triebe, als am sillac u. f. w. Bey oem Meg̨lbeerbaum (Cratægus ar:a) 
find bie Blumen am Ende ber jungen Zneeige ftion im Sherbfte ferge gekilbet uns

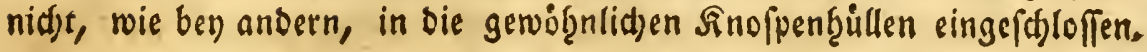

\section{§. 102.}

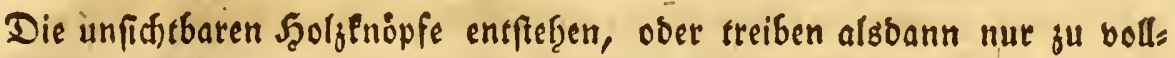
eommenen Szolyenopfen aus, wenn der $\mathfrak{B e g e t a t i o n s} u$ ftano bes Baums es erfor: bert. So felęen wir an abgeţauenen Xeften ober abgefd)nittenen Zweigen, an Stämmen ber abgef̧auenen 'Săume, uno felbft an ben 2 Surzeln berfelben erft Fleine frifd)e $\mathfrak{T}$ eime, Blatter und aefte wadjen, bie po, rie bie ubrigen 2lefte bes Baunt, fortwad) fen fonnen; aud) an ben 2 urzeln und ben Zeften uno úbris gen Theilen bes Stammes lönnen bergleithen verborgene אinipfe als $\mathfrak{W u r}$ geln auswad) fen, wie nir foldjes bey ber $\mathfrak{3 e r m e h r u n g ~ b e r ~ B a i u m e ~ b u r d ~ S t e f ́ : ~}$ linge ober Seflinge bemerlen, immer wad) fen aber aus foldhen unfictibaren

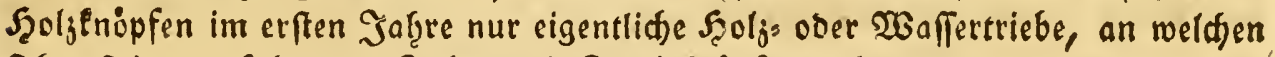
fid) erft in ben folgenden Jaţren bie Srud)tfnopfe ausbilben.

\section{§. 103.}

Einige Sholjarten fheinen ein weit größeres 3 ermogen ju haben, aus bem

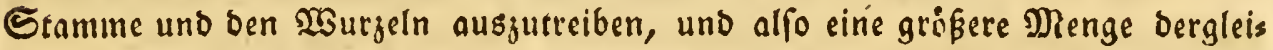
den unfidtbare Şoljenipfe ju bilben, als andere. So j. B. treibt bie Sinbe, bie Eithe, bie 26eibe uno bergleichen Båmme fef̧r leid)t aus abgefdnnittenen 2(es ften wieber aus, andere Gingegen faft gar nidtit, als bie গlabelfidizer, an benen

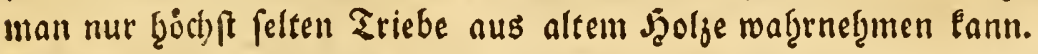

\section{§. 104.}

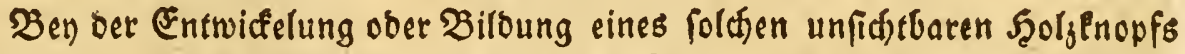
bemerlt man erft eine gemiffe Erthifgung ber Sinde, Surd) beren obere Sagen

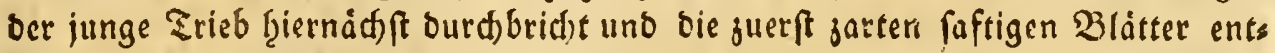

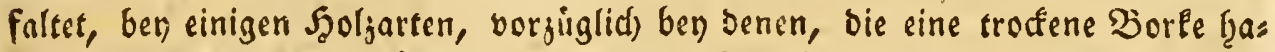

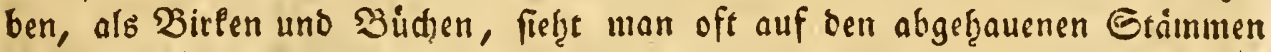

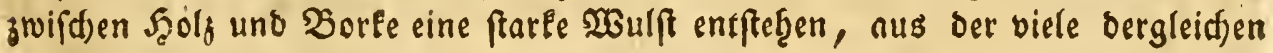
Triebe ausjuwadjen pflegen.

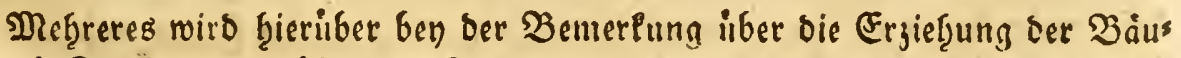

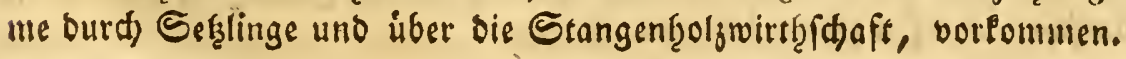




\section{§. 105.}

Da bie Szoljentupfe mit bem Şolje bes Zweiges an weldjem fie entftanoen find, und jwar mit bem Saf̧rstinge, welden ber Zweig in bem Jaf̧re ber Ents ferfung bes Sinopfs bilocte, in 3erbinoung ftę̧en, fo bleibt aud ber aus bem Fnopfe entfandene ajweig in benlelben Puncte vereinigt; uno nimmt bie

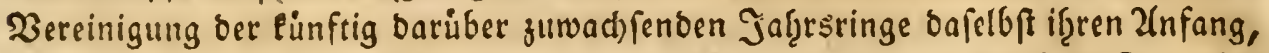
fo, baß man beym Durdfifhneiben eincs frarfen baums nod) ourd) bie Zuwadjs: ringe bas Jaḩr beftimmen Eann, in weldem ein aff baran entftanden ift. Die Jig. 4. ₹ab. I. madf biefes beutlidjer, uno fieţet man, wie ber $2($ ft a, weldjer

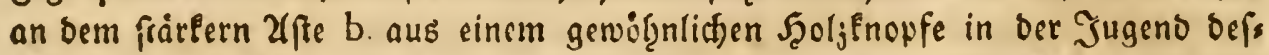
felben ausgewadjfen ift, mit feinen Safzrztingen bis in bas Mark beffilben reis

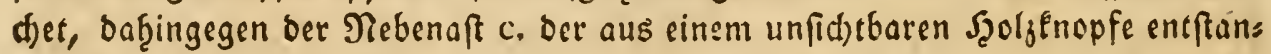

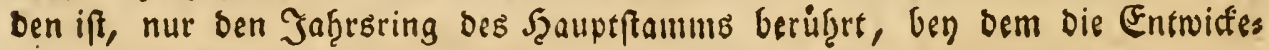
lung biefes Sinopfes Statt gefunden ḩat.

\section{§. 106. \\ Bon Den $\mathfrak{~ l u t h e n . ~ D e r ~} \mathfrak{i}$ åme.}

2fus ben Jrudtethofpen entfalten fid) mit auffallender Sdinelligétit iut Frühjaļr bie Blumen, uno geben befonders einigen Baumarten, ein, leiber: nur ju wenige Tage bauernoes prad)tbolles 2fnfergn; bie Natur fdeinet onut im

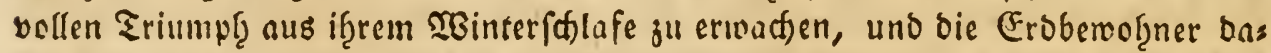
Durdf) von ineuem beleben und mit 刃uth und 2trbeitstrieb befeeten ju rodlen.

Es wurbe für ben bier gewaiglten Plan ju weitlauftig fenn, auch nur bas

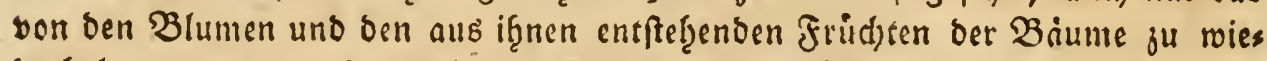
Derf̧olen; ras man babon in ben meţrften guten botaniffen 5 driften finoet; fo viel foll blok bier bemerlt werden, als zu ber beffern Erelärung und Berftänos

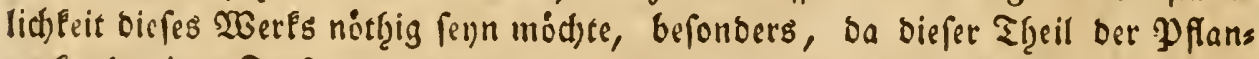
zenlunde einen Forftmann weniger intereffirt, als ben Botaniler, bem es zum Regifter feines Sinneijd)en Syftems bient. Es follen f̧ier nur bie Namen cinis

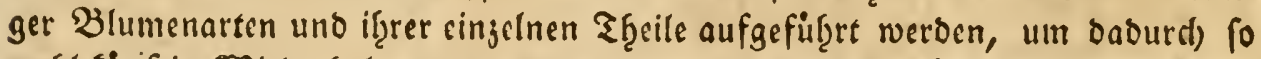

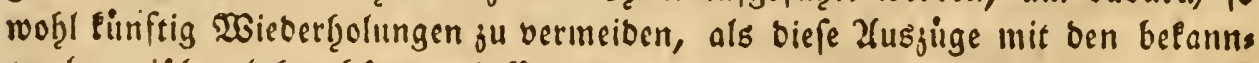

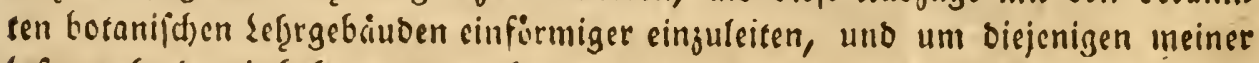
Sefer mef̧r bamit befannt ju mad)en, weld)e fid) in biefem fadje aus ben grófo fern botanifden 20 erlen ferner beleb̨ren wollen. 


\section{§. 107.}

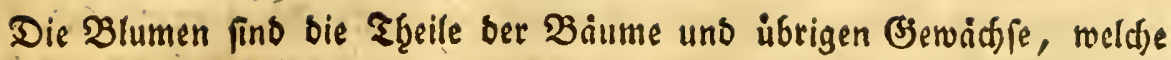
sie Befrudftungswerlfeuge enthalten, bie zur Billoung bes Saamens uno jur Fortpflangung aus beunfelben nòthig find. Man theilet fie in bollemmene und unoollfommene Blumen; bie erftern fino bie, weldfe forobl månnlidfe, als weibs liche, bie lejtern aber, weldfe entweber nut imännlidje, ober nur weiblidje $\mathfrak{B}_{\text {es }}$ frud)sungstgeile ţaben.

\section{§. 108.}

2(n ben volloummenen Blumen fino fotgende Theile fu bemerlen:

1) Die Blluntendecfé (Calix) ober bie áuffere blätterartige, mę̧rens theils grune Bebecfung ber Blutţe, weld)e biefe vor bent 2lufbliţ̨en umgiebt.

2) Die ßlumenterone (Corolla) oder bie gewöh̨nlid) genanuten Blumens bläter; fie ift bie andere $\mathfrak{B e b e c f u n g ~ d e r ~ S h l i t h e , ~ u n o ~ b e f t e f ̧ t ~ a u s ~ e i n c e ~ f e i n e r n ~}$ Subftanj, als bie ákere; fie unterfd)eibet fith metgrenţ̧eils burd) eine andere, als bie grune Farbe, uno ift bie groffefte Bierbe ber Blumen.

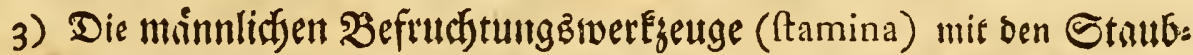
foiben (filamenta) mit ifren Staublolben (anthera).

4) Die weiblidfen Theile, die aud) Stempel (pirtilla) genennt wers ben, mit bem Frudjtenoten (germen), mit bem Staubivege (Atylus) uno Der शrarbe (Atigma).

5) Das Saamenbebåltnif (pericarpium), worin

6) Der Snamen (Semen),

7) Der SBlumen: oocr Frudftboben (Receptaculum floris et fructus).

8) Zuffer biefen Theilen ḩaben einige Blumenarten nod andere, die man als iberfliffig anfefgen lonnte, uno bie ben übrigen 2trten feg̨len; biefe find jum Theil als Safts uno Sgoniggefäbe ju betrad)ten. Sinnee nennt fie nectaria. Die Jnfetten fammeln baraus ben Şonig oḩne Taattheil ber PFlanje. Die Sindenblumen haben aud) if̨r befonderes $\mathfrak{B l a t t}$ am $\mathfrak{B l u m e n f t i e l , ~ w e l d ) e s ~}$ aud) als cin Nebending anjufeteren ift.

Itm biefes beutlidfer bemerfen ju fönnen, babe id) bie atbrilbung einer

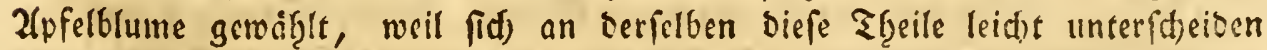

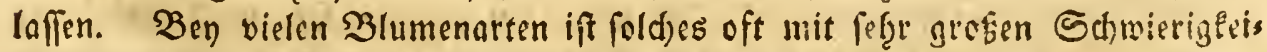
ten verbunden, bie felbfit ber geftjiftefte Botaniler oft nur surd) bis ltebung

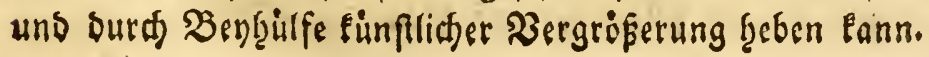


Xn ber in ber 5 ten Figur etwas vergröert yorgeftellten Slume eines Zpfelbaums erfdeint bie in fün Zfusfdnitte getheilte Blumenoecte (a). Die fünfblastrige rothgefärbte Blumenlrone (b). 2(n ben gewojinnlid darin befinos lidjen zroanjig Etaubfäen (c) die Staublolben (d). Der weiblidie Bes frudtungstheil, ober Stempel (e) mit ben Frudtet?noten (f) Der zun Figeil oen Blumenboden (g) ausmatjt, mit fünf Staubregen uno if̧ren Narben (h).

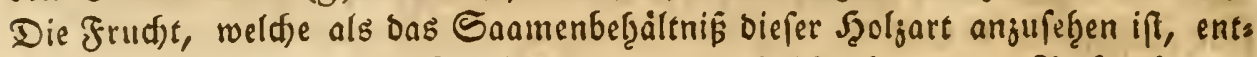
ftef̧t in ber Folge aus bent Frudtetnoten, uno befrált ben if̧er Sieife oben in einer 3erticfung bie alsbann vertrodneten Stanbrege famt einem Fleil ber

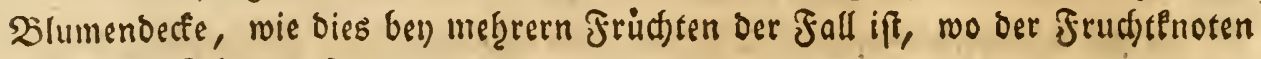
unter ber Blume filgt.

\section{§. 109.}

Die Sllumen find mit ben Blumenftielen und biefe mit ben Frudteltrofpen berbunden, aus benen fie entfanden find. 2(ud) biefe Serbinbung fofeint zels lenformiges Bjewebe ju jenn, wie oben ben ben Blätterftielen bemerft ift. Die Blumenftiele bilben ba, wo bie Blumen frgen, eine 2frt bon $\mathfrak{Z} u l f$, bie als eine Zübef̨nung bes Blúmenftiels anjufergen if̣.

1) Der Blumenftiel wirb einfad) (Pedunculus fimplex) genannt, auf Dem eine Blume figt, roie bie âpfels uno Girfdenblumen u. Dergl.

2) Zufammengeferge Blumenftiele (Pedunculi compofiti) aber, wenn meţrere Blumen auf einem gemeinfdaftliden Etiele befindlid) fino; wie an ben Blumen bes 2f(f̧orns, ber Mofleftanie, bes Şollunders, wober benn communis)

a) ber Şaupt = ober gemeinffaftlid)e Blumenftiel (Pedunculus

b) bie befondern Blumenftiele oder die 2(efte befferben (Pedunculi partiales) uno

c) aud) an ben Zeften der lejtern bey vielen Z(rten nod) bie eigentlidfen Bhumenfield)en (Pedicelli) vorfommen.

Diefe Blumenftiele theilen die Botanifer ber grofen Znjabl Berraidffe

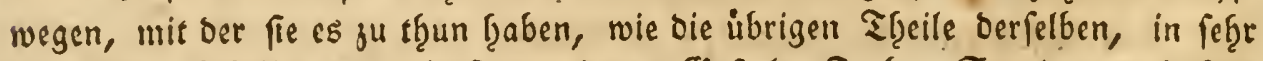
viele llnterabtheilungen, bie fie von beren Bjeftalt, Farbe, Standort und Fons prigen (Figenfd)aften betnefgmen. S(d) will, um meinen Sherren 2(mtsbribern mit Dergleid)en 2ocitläuftigleiten nidft jul langweilig maaken voll ben Blumen nur nod folgenbes anfüberen. 


\section{\$. 110.}

Einige Blumen ḩaben Peine gefärbte Blumenblätter uno bૃeißen (Flores

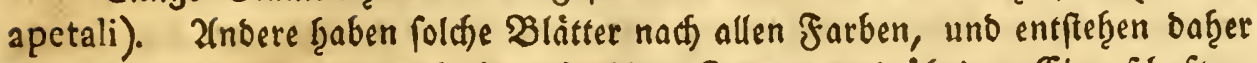
fowob̨l nach biefen, wie nad) if̧ren fonftigen formen uno ibrigen Eigenjathaften, peģr biele Unterabtheilungen: als einfadbe uno Doppelte Blümen, welde

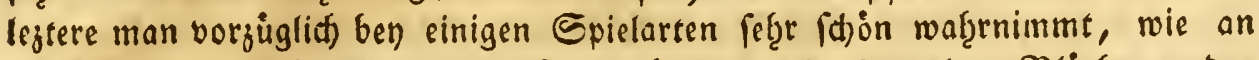

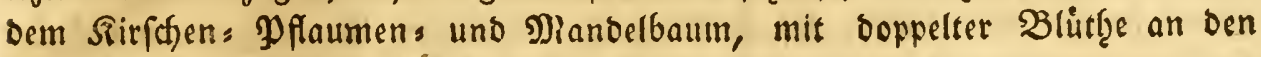
Piofen uno mef̧reen oergleichen (Bewád) fen.

Die cinfadsen Blumen fino:

1) Einblätfrige (monopetali), weldhe nutr ein Blumenblatt b̧aben, bas bem an ben aufferen Enden oft wieser in ein, jwen, orey uno mefrerere Epişen, oft flach, oft tiefer, oft runolid, oft regelmäpig, oft unregelmábig u.f.w. ges

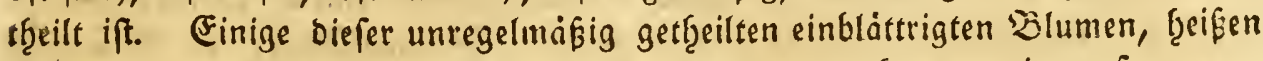
Sippen, oder maulartige, andere larvenartige, andere fappenartige u. f.w.

Die vielbláttrigen Blumen fünnen ber Zaf̨l if̧rer Slätter nad) fowol̨l,

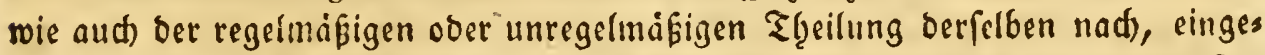
theilet werben in reguläre uno irreguläre vielblättrige Blumen; 34 ben erften gef̧oren bie PPflaumen, bie Felbrofen u. f.w. jur lejten Elaffe der Sinfter, Seis Selbaft, Das Sagpericum u. f. w.

Wenn man nun zu biefen 2(btheilungen ber Blumen aud) jene nimmt, bie auf bie frorm, bie 2 (njahl und ubrigen (Eigenid)aften ber fämmtlid)en obenbes nannten ₹f̣eile, als bet Staubfäben, ber Stanblolben u.f.w. eine Begiefrung haben: fo sann man fid) von ber unendiden Menge Mamen und Treilungen einen Bagriff mad)en, bie ber grobe (innee uno nad) if̧m to viele andere $\mathfrak{B} 0$ s taniler.oft mit fo vielem Bilicf und $\mathfrak{B}$ eftimmung angewendet uno bann mit fo vielen: meifterf̧aften Beywortern zur mef̧rern Erelärung begleitet haben,

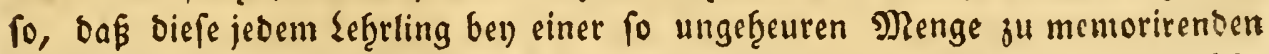

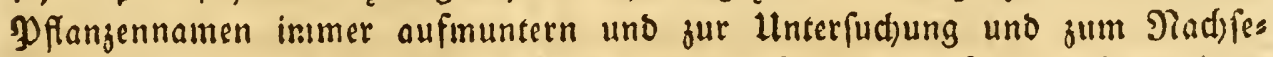
been anfrifden. Fein $\mathfrak{P}$ flanjenlenner wirb j. B. Die Balfamina impatiens noli tangere, wilbe $\mathfrak{B a l j a m i n e , ~ a n f e f g e n , ~ o f g n e ~ f i d ) ~ f e i n e s ~ v e r f t a n d o o l l e n ~ S i n n e e ~}$ mit Dank und 2ergnigen fu erinnern!

\section{§. III.}

Da die Blumen bie Befrudftungswerpgeuge enthalten, bie zur Bilbung bes Saamens borjiglid) beftimmt fino: fo fino biefe Tfeeile befonders merfwurbig, uno verbienen eine uin fo genauere Hnterfud)ung. 
Die Mannliden Theile berfelben find bie Staubfäen mit if̣ren Staubelben; fie fisen gewoigntid zwifhen ben Blumenblättern auf bent 3oden, wie an ben Birnblumen; bery einigen aber aud an ber innern Eeite berfelben, wie in ben PJ firfoblumen; fie beftegen ben berfobiebenen Slumenarten oft alls langern, flirgern, bifern, feinern u.f.ro. Stielen, bie

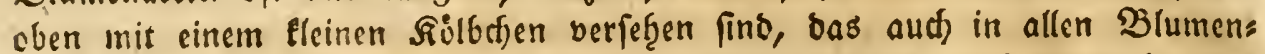
arten fowoht ber Jarbe, afs Form nad) verfdieben ift, auf biefen befintet fich ein ganf feiner ftaubartiger Saamen, ber bey bem 2fufblithen ber Blume nit ciner gewiffen Edjnelleraft uno Eridjutterung in ben blumentelds, und auf bie weibliden ₹f̧eile, auf ben Grudjtenoten bes Stempels, geroorfen wirb und to viefe Theile fdwaingert.

Diefer minnlitfe Dlumenftaub erfdeint unter einent Bergróperungs= glafe theils als ouale, theils als rinsliche Saamenforner, er ift aufferft zart, uno nur unit ftarker 2 ergróferung enteect man oarin 2frticulationen uno förnigte Subfanzen. Db er bie Reime felbpt bes Caamens enthalten

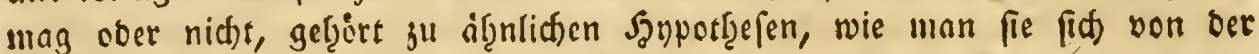
Defdwaingerung ber 2(nimalien mad)t.

Die 2rngaf̧ biefer Staubäben ift in sen Blumenarten ungleicf.

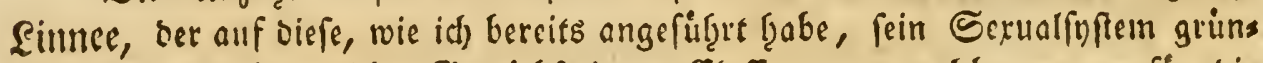
bete, theilt bie fämmtlidjen Eiervadje in 24 Elaffen, von weld)en or 23 fir bie mit beutlid) in bie 2lugen fallenden Slithen, bie 24 fte abor firr bie mit uns Penntlidjen Blutteen, als jum Benfpiel bie Mloofe und Sd,woinme find, annimmt.

Sowohl nad) ber ? (njaf̨l ber Staubfiden, als nach ber verfdjiebenen Etellung uno ben jonfigen Eigenfdaften ocrfelben, fudte er jene 23 Elaften fu unterffjeiben, fo wie er benn audf eine jebe Berfdicoentzcit an ben Saauren,

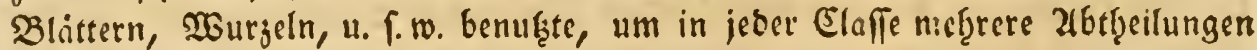
ju beftimunen, uno barnact) bie Biewaict)fe cinguttgeilen unb zu bencnnen. Zum

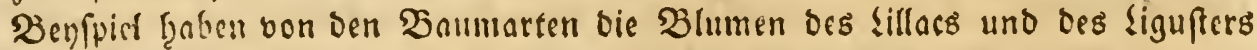

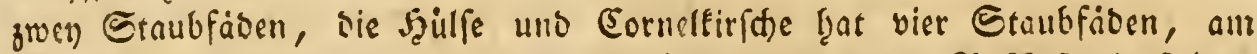
אrenjoorn find pects, an ber Berberiffe cbenfobiel, an oer Moglaftanie fieben,

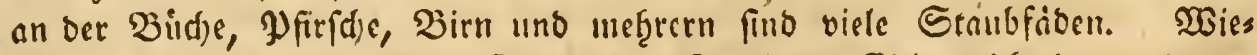

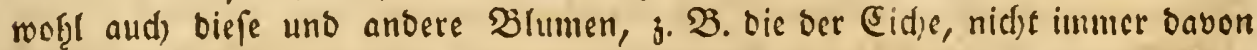

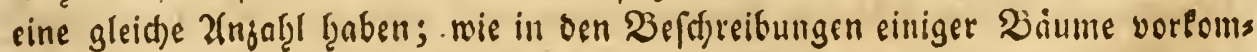
men wirb. 
§. 112.

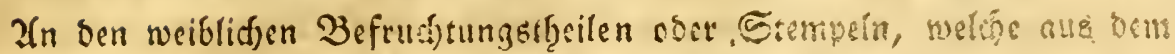
Frudtenoten uno ber Tarbe beftef̧en, fino ebenfalls monnigraitige 3 Bafdies

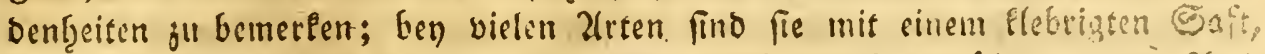
bey vielen ober aud mit einer feinen, oft gefarbten, Wolle ibirjogen. Duds

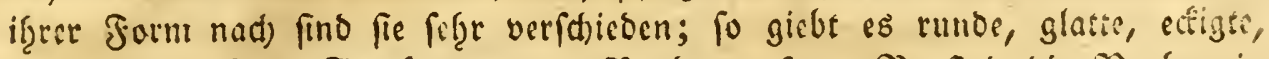
haarigte, flectigte Staubwege und Tarben; fo 8.23 . find bie Thitben in Der Sirnblitbe Trompetenformig u. T. w.

Xud) bie 2tnjagl ber Staubrege ift verfdiesen, fo z. $\mathfrak{B}$. Gaben die

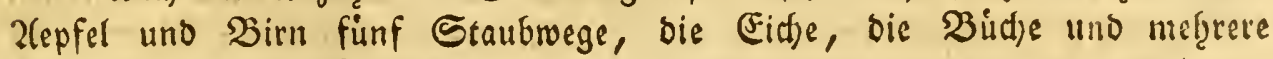
haben nut einen Staubreg.

$\mathfrak{B} \& \eta$ einer mittelınófigen Sergriferung fdjeint ber frutftenoten uns bie Narbe merce aus fellenformigen Driren, Die Staubwege aber aus sincm rogrenartigen Bewebe ju beftetgen.

\section{§. II3.}

Wenn die Befrud)tung gefdeben ift uns bie Slumen fu berwelect anfangen, fo vertroctnen mit biefen auth bie Defrudtungetţeile, fo, baf bie Frudt allein bleibt. Wie wefentlid) nöthig fie gur Silbung ber legtern fins, lönnen wir aus meb̨rern Erfahrungen feb̨en; io jerftort ein bofer

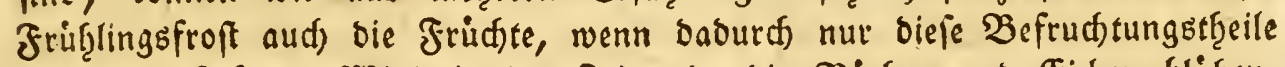

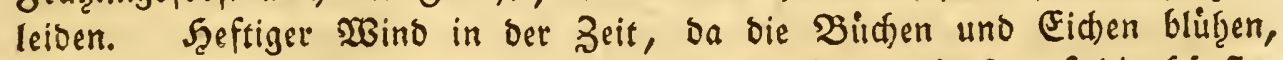
verfindert bie $\mathfrak{B}$ efrudtung uno verminbert oft bie fonft auf bie f̧äufige Blüticen derfelben gegrindete Scofnung ber Maft u. F. w.

\section{§. II 4 .}

Diejenigen Blumen, weldje nur weiblidfe ober nut mannlidfe $\mathfrak{B}$ efrudss tungstbeile baben, werben unvolleommene Blumen genannt. Dian finbet Dergleidgen Blumen auf verfdiebenen Batmarten abgefonbert, wie auf ber

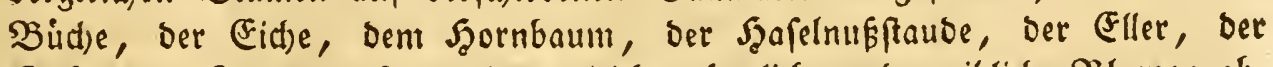
Siefer, Der Tanne. u. T. w. Die jugleid mannlide und wciblidje Blumen abs

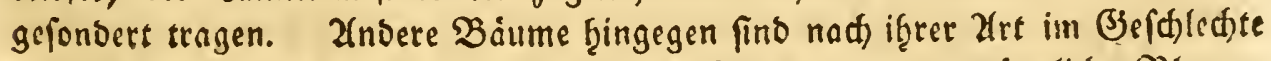
unterfdicben, fo, bak ein $\mathfrak{B} a u m$ nur weiblidje ober nur mánnlidbe Blumen trigt uno alfo nothmendig jwey berfelben fid) naţe ftef̧en miffen, wenn ber, welcher bie weiblid)e. Blume bat, Frudte tragen foll; wie man es an einigen

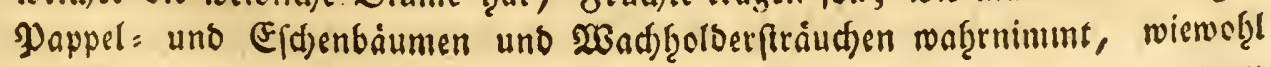




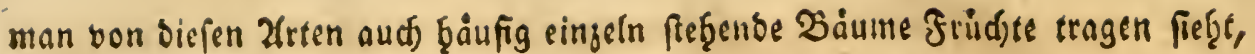
Die Zwitter find, und Blumen von benden (s) fdjledtern tragen.

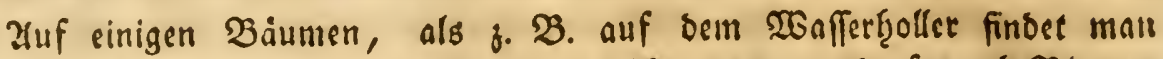
neben ben vollfommenen $\mathfrak{B l u m e n}$ aud) unvolleommene, und oft ald) Blumen

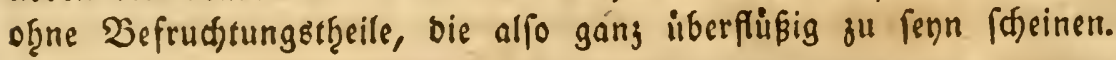

Die an einigen $B$ aumen abgefonbert befindliden männliden Blumen, wie 3. B. an ben Birlen, Erlen, Şafelftuluben, wetben aud) Räkslein, ober saimunchen genannt; fie erfd)einen im Şerbft, bilben fiá) im Winter weiter aus, und bey ben erften warmen frublingstagen bemerlt man barin ben erften

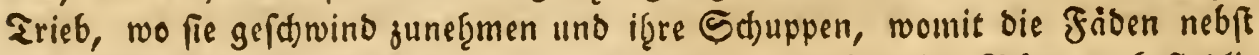
if̧ren Staubtolben bedefft find, jugleid) mit ben auf biefen Baiumen befindli= den weibliden Slumen fid iffnen, uno biefe idwaingern.

Es baben bie Saumarten mit unvolleommenen und abgefonderten männlid)en Blumen eine weit gröbere Nenge Befrudtungsftnub, als bie Baiume mit bollem:nenen Blumen, fo Daß burd) Berúf̧rung eines eingelnen

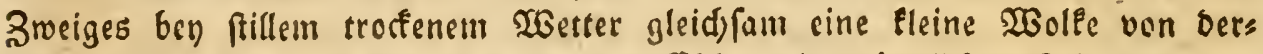
gleidjen Staube entefergt, wie an ber Eidje mit mannlidjen Blumen, an Den' Nabelfgolzarten U. f. w.

Der fogenannte Edjwefelregen, wie id midh an einen bergleidjen bey eis

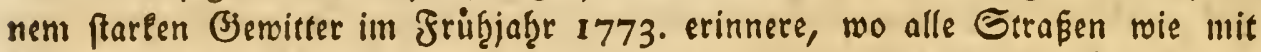
Sd)wefelftaub gefärbt waren, entftef̧t baf̧er, baß biefer Saameniftaub mit Der Feudtigleit ber 2ttmofphare aufgezogen wirb, uno benm barauf folgenden

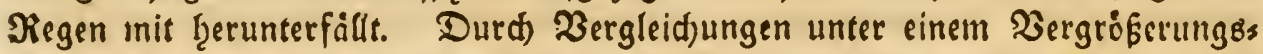

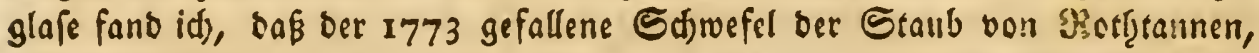
alfo vermutf̧lid) ein Şarjprobuct war. Diefe nur männlidse Blumen fallen nad) Beenoigung if̧res B̈efthafts ab, nur bey einigen 2(rten wathen fie nod) eine Beitlang fort, wie an be!n Szornbaum ober NGeibbidjen, wo fie oft ldjone grune Slumeningnlidfe Duaffre bilocn.

\section{8. $I 15$.}

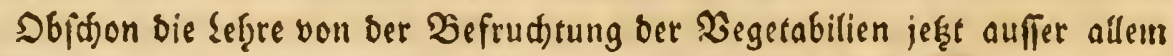
Breifel, uno burd) fef̧r viele Erfahrungen beftattigt ift: To giebt es benn bods einige felbft unter fold)en forftmannern, bie fith auf ifre theoretiftge Senntniffe befonders viel einbilben, weld)e Gieran jweifeln, uno fid) bavon wunberlidje Begriffe machen. Der Şerr Dberforftmeifter von 3 erneck, befien Forftealens ber woḩl nur in biefer Rüffidt) angeführt zu werden verbiem, gef̧ort unter 


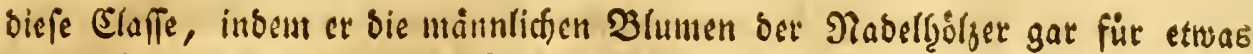

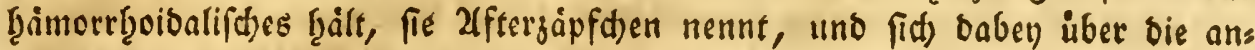

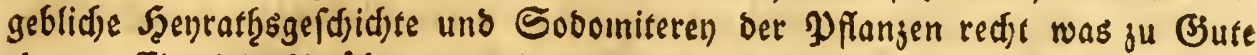

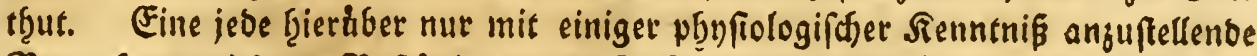

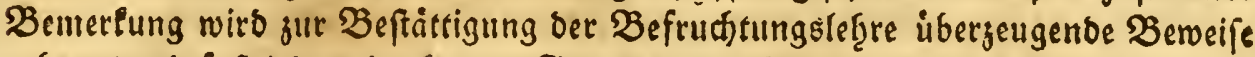
geben; und faft jebem bentenden Bartens und Blumenfreunde find sie Erfag: rungen bekannt, bie man bey jufaumnengepflanjten Melonen obet Pelên burdh bie Daf̧er erţaltenen Barietaten ober Epielarten mathen Bann. Da es abet

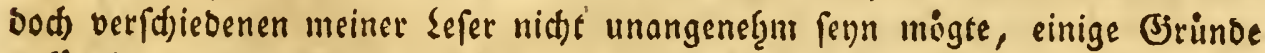

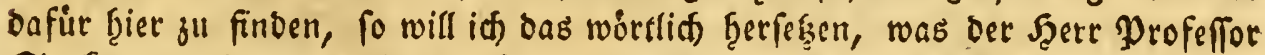

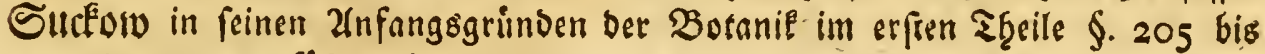
210. bavon angefíţret ţat.

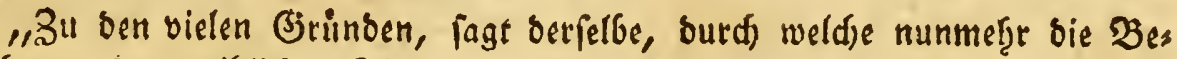
"frudtung ber weiblichen Sţeile, vermittelfit des Saamenftaubs ber Staub= "Geutel, auffer allen Breifel gefegęt ift, geţoren folgende, als bie vorgüglitss

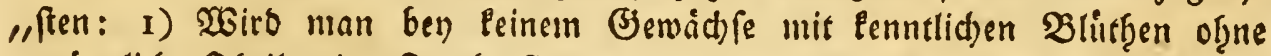

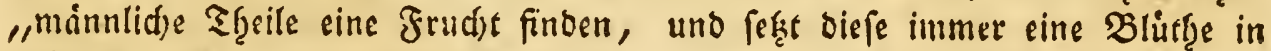

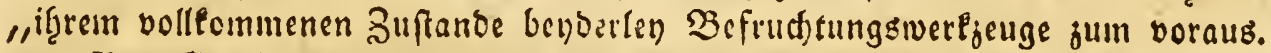
1,2) Bey (serwaidsfen mit ganz getrennten (Befd)led)tern wiro bies nod) bentlis "d)er; ba sin blos mainnlid)er Stamm ecine Frud)te bringt, uno eben fo wenig

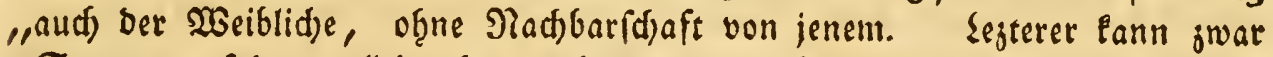
"Saamen anfegen; allein of̧ne vorţergegangene Befrud)tung von beın mánts

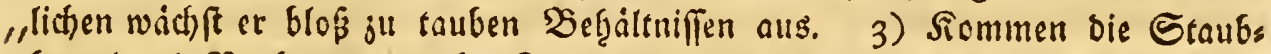

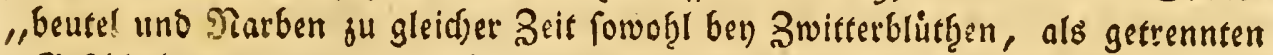
"(Jefd)led)tern, f̧erbor. 4) Deigt bie óefonocre Đeftalt bes Blumenftaubes eine "beftimmte 2(bfid) beffelten, und er eann baher firt feinen bloken zfuswurf ges. "Ghalten werben. 5) Nimmt man einer frifh geuffineten Blitţe, noch ef̧e ber "Samenftanb altegeftreuet worben, -ifge Staubbentel, fo wirb ber Frudjts "Enoten Peinen reifen Sacmen liefern, wenn or nidht etwa ourdh ben Saamens "ftaub anberer benathbarter Blitfen befructset wirbe. Eben fo Eann aud "Der Saame nid)t reifen, wenn inan vor 2lusftiobung ber Bentel bie Tarben "abjofineibet oder jerftoret.

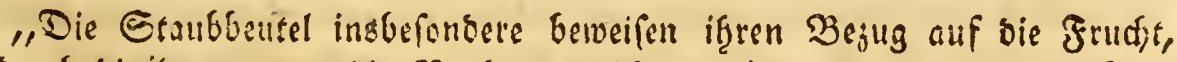

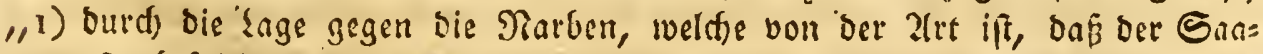

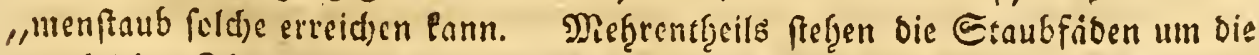

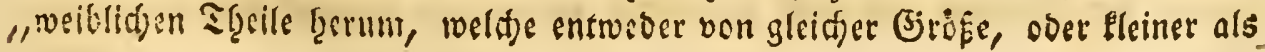


"felbige fint. Sn folden Blitţen flingegen, in welden ber Etaubuag uno "Die Narbe länger fino, als bie Staubfáben, frangt biefe unterwárts, bamit oer

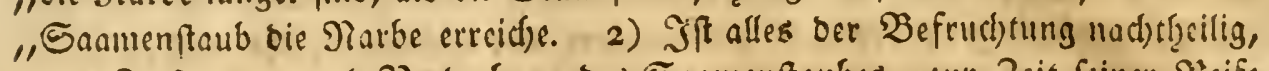
"roas Berftrenung uno 2erberbung oes Samenfaubes, jur Beit feiner Dieife

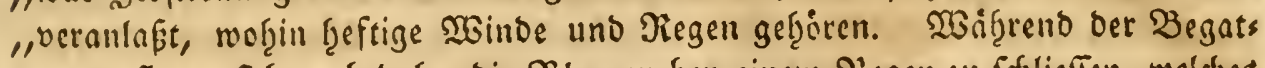
"tung pilegen fid) aud Daher bie Blumen bei) einem Jiegen ju follieflen, weiches

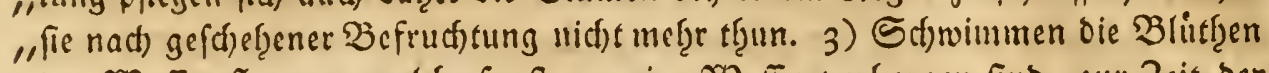
"Der Wanferpflanjen, weldje fonft ganj iun Walfer verborgen find, fur Zeit ber "Oieife bes Gaamenfraubes auf ber Dberfiad)e, uno bie Bhlumenábren folder "(B) "Der 3allisnerie ftȩ̂en einjeln auf fdjectenformig gewuntenen Purzen Sdjáfs "ten, welde fid) jur Blithejeit fo weit verlängern, baß̈ Die Blumendecte

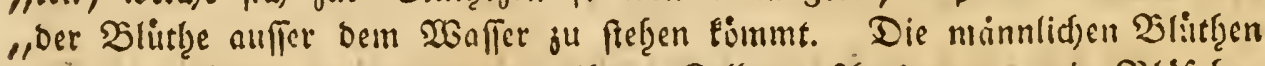

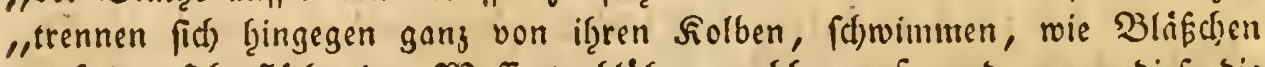
"auf ber Dberflähe bes $\mathfrak{W a f f e r s , ~ b l u ̈ b e n ~ n a d ) h e r ~ a u f , ~ u n d , ~ w e n n ~ b i e f e ~ b i e ~}$ "meibliden Blitben befrud)tet habent, finten leztre zur Beifung bes Saamens "mieber ins $\mathfrak{W a f f e r}$ 4) Berweift aud) ber befondere $\mathfrak{B a u}$ ber Staubbeutal, "und bie 2 (rt beffelben aufjufpringen, ben. $\mathfrak{B}$ ejug auf bie weiblidjen Theile.

"So finben fidf aud) von Seiten ber weiblidfen Theile Berweife, neldye

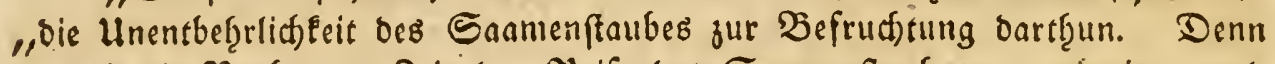
"1) ift bie Narbe jur Zeit oer Reife bes Saamenftaubes ausgebreitet, uno " "d)wişt eine olligte Feudtigkét aus, an weld)e fid) ber Saamenftaub nad)s

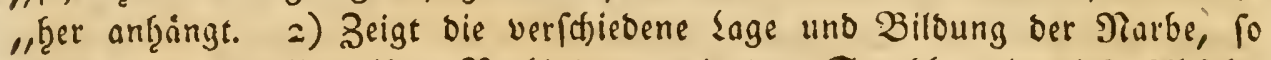

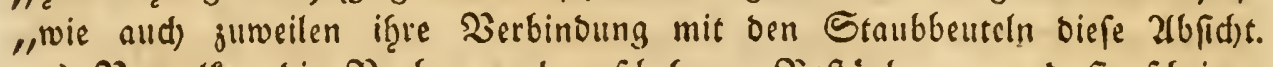

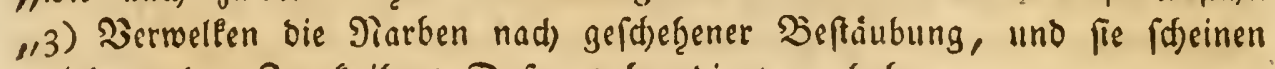
"alsoenn den 3wect ibres Dafernns becnoiget ju haben.

„Car. a Linné difs. Spoufalia plantarum. U Ufal. 1746. Amoen. acad. „Vol. I. Gr.

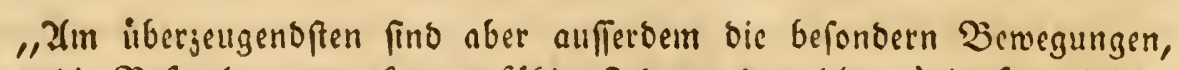

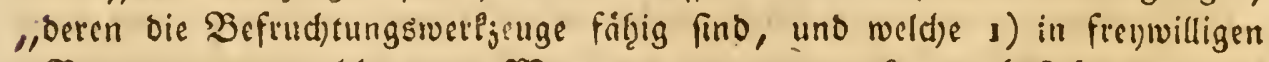
"Bewegungen, weldse man Wanderungen nennen Pant, beftefien; 2) in "folden, weldf)e nut erft auf cinen duffern Dieij erfolgen, Daber siefe Tlgeila

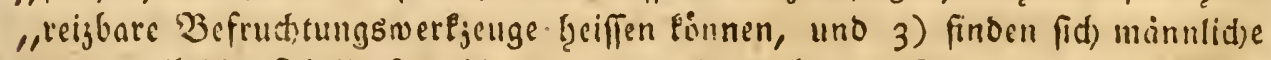
"uno meiblid)e Tgeile forwobl wanoerno als reigbar. Bel) Den wanbernoen "Staubfaben bewegen fid) biefe Thrile von filbft gegen bie NBsibliden, "menn ber Eaamenftaub reif ift. Eie niffern fid) foldjen entweder fulams 
"Men, paarweife ober einjeln, uno legen fid) über Sie Narbe herufer; nad) "I? Iusfriubung ber Bentel jief̧en fid bie Faben aber wieder zurict, uno "anbere, roclde nods nicht geftaiubt, nitgern fits.

"Ein beutliches Benfpiel Gievon liefert unfere gemeine Diaute. EEGen "To berwegen fich mandernde Etaubwege jur Beit ber Dieife bes Saamens "ftaubes gegen bie Staubielben, weldjes man an bell gemeinen Sdjwarjs "fümmel (Nigella fativa) fę̣r beuslid) bemertet.

"Son ranbernoen Staubfaben und Staubregen jugleid) licfern bas

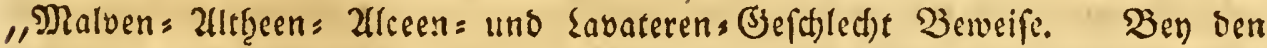
"nid)t walldernoen $\mathfrak{B}$ efrud)tungswerljeugen Eann die $\mathfrak{B}$ ewegung burd) feine „Beriftrung mit Nabeln ober Dinfeln berborgebract) werden. Die faft in "jeden Blitfien fich aufţaltenden Jnferten berwirken gewöhntich diefen Dieiz, "und find nod) baburd) ber $\mathfrak{B e f r u d t u n g}$ beforderlid), dáp fie ben Sanmens "Itaub auf Die Plarben bringen. Bevfpiele von reigbaren Staubbeuteln lies "fern bie Brenneffel uno der Epinat, von reijbaren Staubfäben, ber Saurs" "forn, yon reizbaren Tarben bie Bignonien (Bignonia radicans Catalpa). "2lufferbem findet man aud) wandernde Staubfäben mit reigbaren Staubs "Eolben, wie an bem Spinat, Deffen Faiben jugleid) ebenfalls reijbar find. "Mievicus von ber Mieigung ber Phlanjen fidh ju begatten. In ben Actis "Theodoro-Palatinis Vol. III. phyf. I 16 . 3 . (5). Föletuters Betrad)tuns

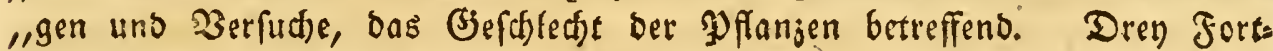
"lȩ̂ungen. Leipzig 176t-66.8.

"So beftittigen nod eine Menge anderer Erfaḩrungen biefe-2(bfid)t

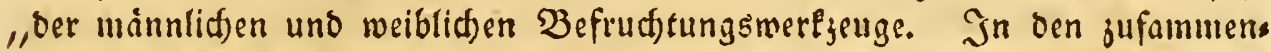
"geferten Blüthen mit verwadpenen Staubbeuteln, beren mittlere röbrige

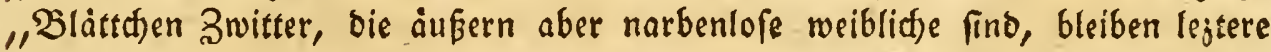
„unfrud)tbar. Ben (Jewad)fen mit vermengten Befdiectern fomms die

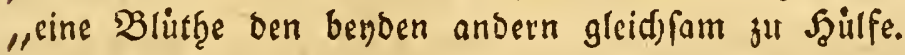

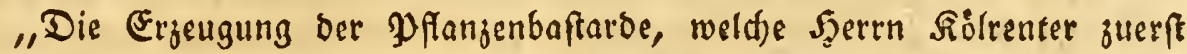
"gluffte, ba er von zwey beridjiedenen 2fiten ben Saamenftaub tiar einen "auf bie Narbe ber andern brad)te, zeigt endich nod) auffallend bie Notf̧s "menoigleit Des Saamenftaubes jur Befrudtung, da cie aus folder $\mathfrak{V e s}$

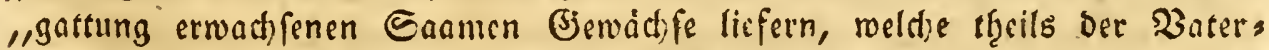

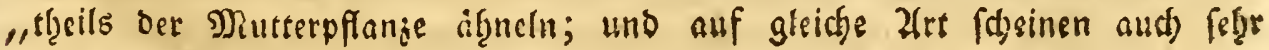
"viele Warietàten jul entfteţen."

ร. 116. 


\section{§. 116.}

\section{Bon Dell Frúdete.}

Die Fridfte find ber Fgeil bes Baumb, weldyer den Saamen fll beffen Fortpflanjung entŗålt.

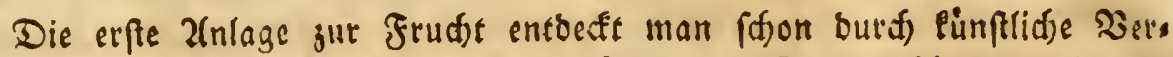
gröserungen in ben Jruhtetnofpen, fief̧e \$. 100. Diefe erfdeint barin als eine wáfferigfe feuchtigkeit, weld)e teym 2lufblithen ber $\mathfrak{B}$ lumen fánell vers grósert uno burd) Die barin befindliden Befrudjtungswerffenge gefdrwaingert wiro, wonad) biefe leģtern an Den mefzeften Sgeljarten verwelfen unb abfallen; boch bleibe bey einigen ein Slgeil von ber Slumendecte firzen, wie auf ben Birs

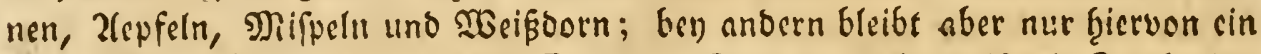
Pleiner Yunet itbrig, wie aup Den Eid)eln. Wen jenen Z(rten ift bie Srud)t ber 2joben ber $\mathfrak{B l}$ lume, ber beyn $\mathfrak{B}$ erwelfen berfelben auffifwillt, bey benen aber, bey welden bie frud)t fid) in ber Blume, als bev PPlaumen, $\mathfrak{P}$ firfden uno bergl. zeigt, fällt bie Blume ab.

\section{8. $I I 7$.}

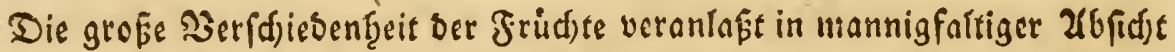

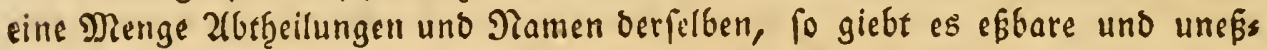
bare Frudfte, Serns und Steinfrinctete: viele nenne man Näfle, viele Zapfen, wie die bes গintelfzolzes, ber Birle, Eller u.f. w. Siele tragen Saamen wie bie Eidje, viele tragen iferen Snamen in siner leberartigen, oft ftad)lidjten Şillle, wie bie Siaftanien und biid)en, viele, und befonders bie Sträudje, Gnban eine 2(rt frủd)te bie man Beeren nennt, bie oft utę̧r ober weniger ges

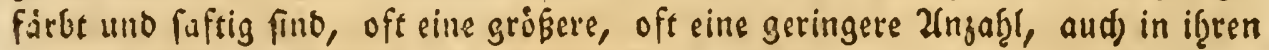
Formen Fef̧r verfchiebene Fiörner tragetl.

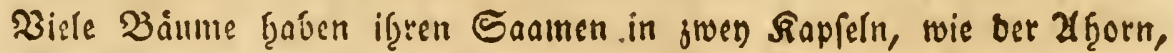

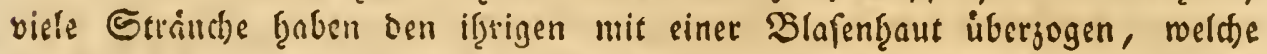
turch) bie barin entḩaltene suft feţr ausgefpannt ift, wie bie Frud)te ber Dimpermufftraduder und bes Blafinbaums, viefe Baiune und Stråudje, weldye botznenartige Slitţen tragen, f̧aben if̧en Eaamen in Sd)oten, wie bie 2racia, viele tragen gefligelten, viele unzeflugelten Snamen, uno bers gieiden. Sich will hiermit utm fo weniger weitlauftig fann, weil bie Jrridste

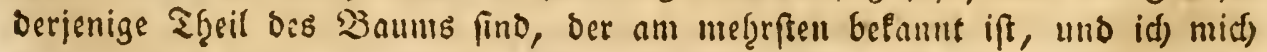
Dod) in eine genaue Zerglisterung unb Befdereibung bicruber nidje einlaffen 
Pant. Sids will aljo nut iu Xflgemeinen ammerlen, baß bas, was wir eigent:

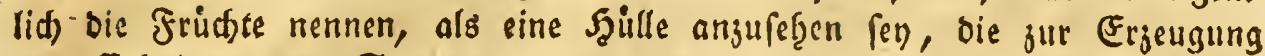
und Erf̧altung bes Saainens bient, indem biefe, wenn bet Saame feine

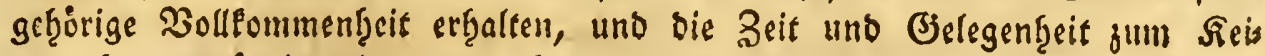
men bुat, verfaulet ober vertrocfnet.

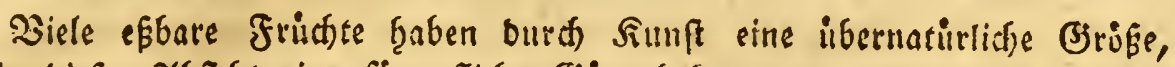
und in biefer afbidft eine fürtreflid)e Biite befommen, als unfere alepfel, Sirnen, Pofirfden u. T. w.

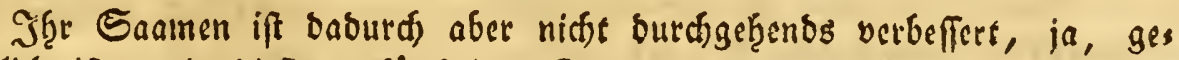
wifhnlith ift or in biefen gefinftelten Sorten weniger vollemmen uno zaf̧ls reid). Die baraus gejogenen $\mathfrak{B}$ äune liefern aud niche gleidi) vollfommene

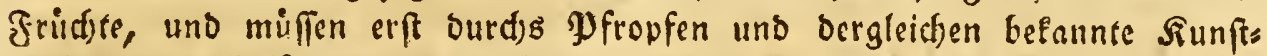
griffe baju getgolfen werden. Der forfhende गatureunbige findet ben einer náfern Unterfutfung ber Fritdfte aller $2($ rt ein roeites Felo jut Erweiterung feiner Sienntniffe uno reiche Belob̨nung feines Sleiffes, vorjuglich) verbient

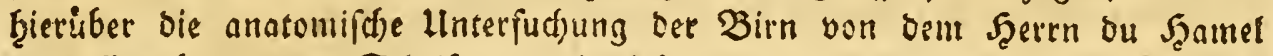
in beffen benannten Sdyriften nadgelefen ju werben, indem biefe ju weis mefgern bergleid)en Unterfuthungen 2(nleitung giebt.

\section{\$. 118. \\ Bon bent Sanment unt befien Reintung.}

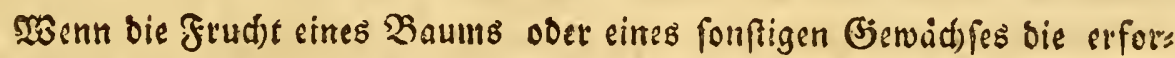

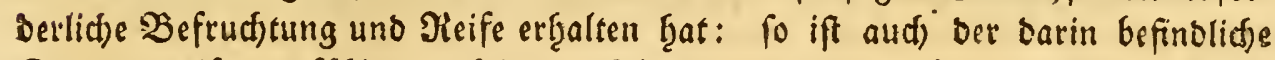

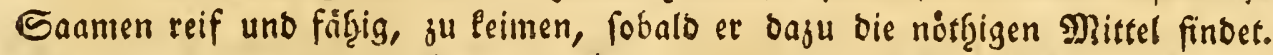
Derfelbe enthält alfo den Feim jut Fortpflanjung feiner 2 (rt, Den man in vers pafiebenen Saamenarten mit frenem Iluge (d) on beutlid) féten fann, wie in sins Den = und 2ffrornfaanten. Die weife Natur ḩat aber jebes Saamenlorn auffer

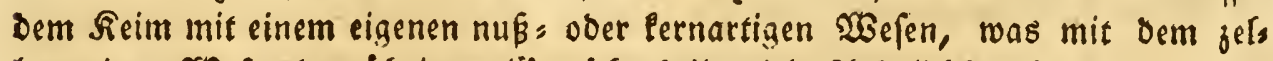

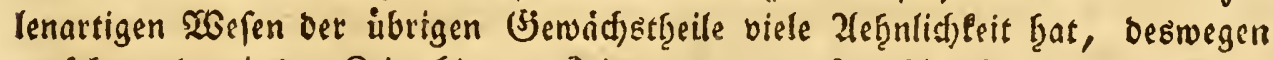

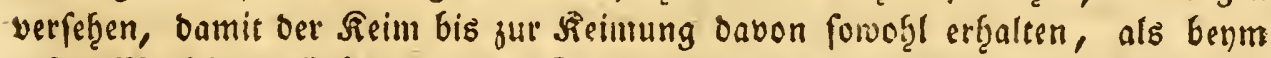

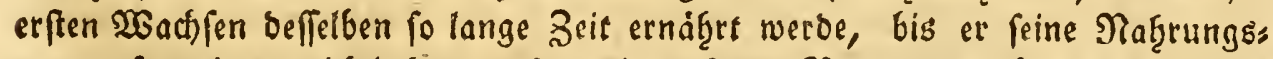

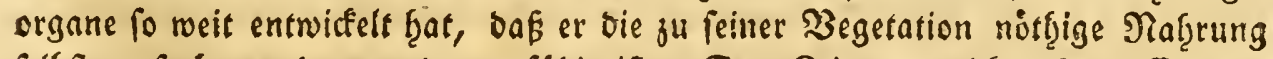
pelbft gu fuden uno gu veroanen fähig ift. Der Feiur, weldher feine Eriftens

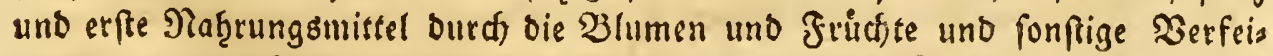
nerunggroge auf bem $\mathfrak{R u t t e r f f a m m}$ vorbereitet erf̧ielt, wirbe ben plófliden Hebergang bon biefem zur robgen Eroe stgne biefe fürforge eben fo soenig erfeas 
getr, als bey ben Ffieten ber Feim eines Embryonen oḅne oie ju feiner Erţals tung notţigen Theile bet Mutter ober bes Eies leben wirbe. Man fann alfo

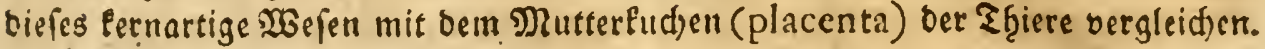

In vielen Saamenarten ift biefes in jwey gleidse Ş̧eile getfeilt, bie man Saamenlappen (lobi) ober Soben trennt, wie bey ben Fideln, Jiüfen, 2(pfefeernen, bey einigen ift es aber anbers geftaltet, als bey ber Jofiaftanie, bel) Den $\mathfrak{W}$ allniffen, bie man nufformige Loben nennt.

Bev vielen 2(rten, als ben bem 2(ḩorn, findet man in beu reifen Ganmen= förnen bie. Saamenólatter gefalten und fef̧r ausgebiloct.

\section{§. 119.}

Sur Feimung bes Sanmens werben meberere פittel erforbert, als \{uft,

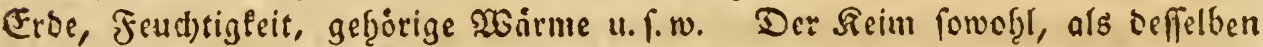
Loben, befinen fitt) fobaun aus, gerreifen bey einigen Saamenarten bie aulfere Scille, bie fid) bel ben fteinartigen Saamen, als bel Tiiffen, Firfiflernen u. f. w. in bell baju eigenen 2(rticulationen offnet, rooraus juetft alsbann bie Wurgel als eine fefre garte Epifze uno nad biefer oer eigentlid genannte Seiu mit feinen Sanmenblaittern erfheint. Bey vielen Saamenarten entftef̧en biefe Saamenblatter (Cotyledones) nus ben Soben, wie bey ben Xepfer, und Birnbaumen, ben andern aber nid)t, als bet (Fid)en, Jioflaftanien u. f. ro. im erften Fall fino bie Soben am Seim mit bem untern Ende, wie Bläter verbunden, in biefen aber fiangen fie unit bempelben buraf cinen befonbern Stiel zujammen, ben man mit ber Mabelfdjnur ber Ffiere vergleidjen fonnte.

Jn beyocn Faller dienen fie bem Sieim ju Nab̨rungsgefäfen als Blatter, ober æaurzeln, uno vertrofnen ober verfaulen, wenn ocr Seiur iberer nid)t mef̧r beonrf. Micḩreres wirb ḩievon bey ben Befdreibungen oer Eidje uno Biidje borfommen.

\section{§. 120.}

Die Saamenblatter (Cotyledones) fino von ben übrigtn 3 lätterm ber

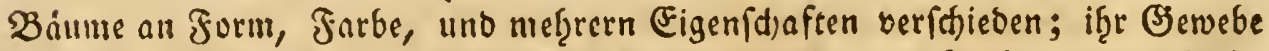
ift weniger róferenartig; fie fino vist bicfer uno sunfler bon Farbe mie bie Bhläts ter Des nadberer entftandenen Sriebes; fie gleichen mef̧e ben Blattern von inmers grunen Baumen, uno bünten beswegen weniger aus, weil es ber jungen Pflanje fonjt nod) an ben jujufifrienden Saften feblen warbs. 
Bey wenigen 2(rten findet man in ben $2(t)$ feln ber Snamenblätter gebils

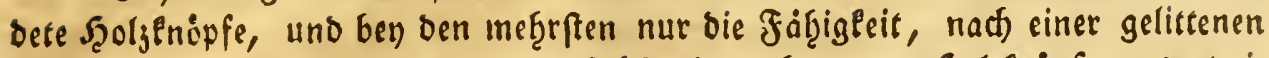

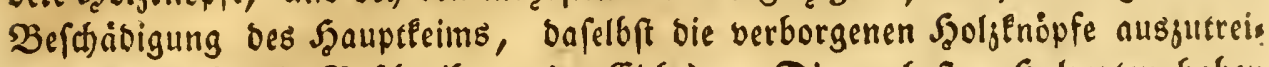
ben (mant ref̧e bie Beffjreibung oer Eidfe). Die mef̧rften Şoljarten f̧aben nur jwen Saamenblatter, einige aber mef̧rere, wie bie Nabelf̧oljarten.

\section{\$. I $2 \mathrm{I}$.}

Wenn bem Saamen bie nöthigen Mittel jum Reimen fef̧len: fo Pann bet Seim fid Darin, mie bie Frudte in cinem (E)e, eine Beit lang, Durd) bie Daju beftimmten Soben erf̧alten, Dod) mus alsbann berfelbe nod) in feinem erften aus fande feun, und wübe if̧n eine angefangene und unterbrod)ene Feimung fos,

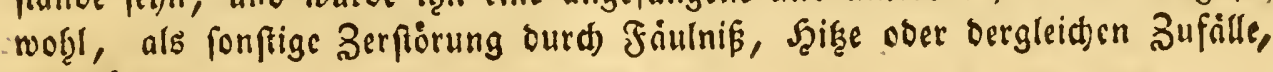
verberben.

Bon einigen Sholfarten erf̨ält ber Saamen unter ginftigen llmftänden

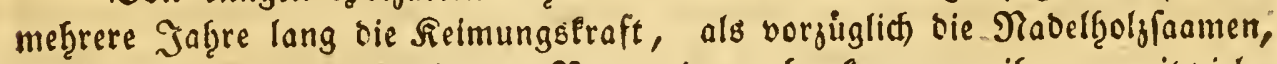
Birkenfanmen und Dergleidten. Son andern aber Pann man if̧n nur mit vieler Borfid)t ibber bie if̧m beftimmte Feimungspericbe nod) elurge Zeit gut erf̧alten,

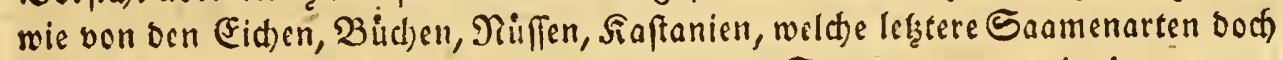
bie färeften Soben ḩaben. Daḩingegen einige Saamenarten, in Denen man

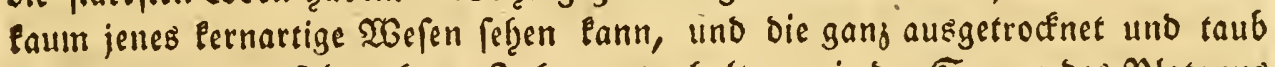
zu fenn fateinen, fid) mef̧rere Jaf̧re gut erf̧alten, wie ber Saame bes Platanus und bes Tulperbaums, ber Birle und metrere, in weldhen man oft erft nad) viergeţntägiger 2lusfaat etwas Sieimfäḩiges mit frenen 2lugen feţen Eann.

\section{§. 122.}

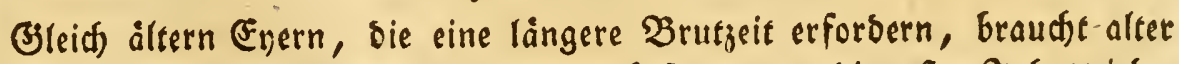
Saamen eine weit lingere $\mathfrak{K}$ eimungejeit; aud) find Davon bie erften Jaf̨rstriebe, viel fawidter, wie bie aus frifhem Saamen. Fir ben Forftmann uno Birts ner ift biefe Bemerkung widtsig, uno mur er alten Saamen oft um fo viel frủber ausfien, wenn er bie baraus ju erf̧altende Pflanje gegen bels winter fidfern will.

Biele Saamenarten leimen gleidh nach) erlangter Reife, uno treiben in

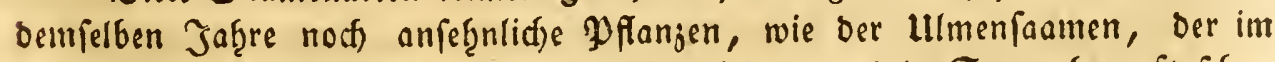
Tan reif wirs, in 2(nfang bes Junitis faton Peimet, und in September oft fifion ùber fect) Boll ḩof̧e Stimmathen getrieben hat. Die metreften Saamenarten

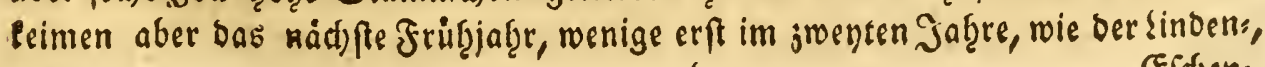
(Evffer Theil) 


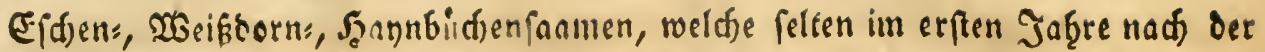
2lusfaat aufjugeten plegen, befonbers wenn biefe Saamenarten eine Zeitlang trefen geligen habern.

Einige Şolzarten tragen sine ungetgeure Menge Saamen, wie f. B. Die $\mathfrak{B i r l e , ~ a n d e r e ~ f i n g e g e n ~ t r a g e n ~ v i l l ~ w e n i g e r , ~ w i e ~ b i e ~ K a f t a n i e n ; ~ e i n i g e ~ f i n o ~ m i l ~}$ feinţäutigen Jlïgeln verfehen, banit fie nad) bem 2 bfollen von bem 2 Binde aufgenommen uno fortgebrad)t wetten fönen, wie bie Tannen, Serchen, Hlls men, Birlen, dhorornaamen; biefe Saamenarten ḩeífen baf̨er geflugelte Saas men. Biele Şoljfacmenarten geben auffer if̧rer eigentlidjen $\mathfrak{B}$ eftimmung nod)

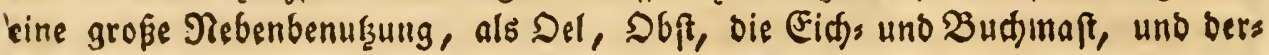
gleiden.

\section{\$. 123.}

Der aus bem Saamen entfandene wargelleim gef̧t bey ben mef̧rften Sjoljarten gerabe ferunter, er treibt im erften Jaf̧e nur figwache und wenige Nebenafte, bas $2 B a d$ fen beffelben ift aber nidjt unterbrodjen, wie bel) ben Blatts

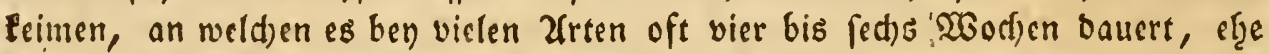
Daran ber jwifthen ben Eotnlebonen befindlidje $\mathfrak{n}$ nopf weiter ju treiben anfängt,

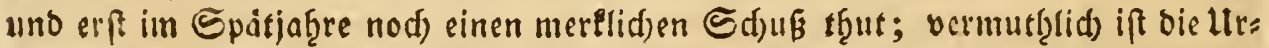

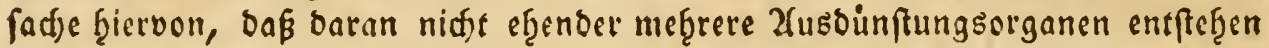

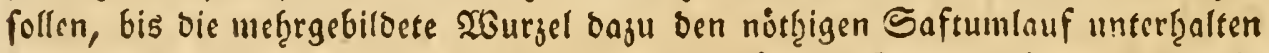
Pann. Die crfte jarte 20 urjel fonohl, wie ber übrige $\mathfrak{R}$ eim verlingert fid nicht allein an if̧ren aubern Enoen, fontern aud) in ber ganjen länge, fo mie bie übrigen jungen Sproffen oer (Jicroad)fe, fo lange fie nod) weid) fino; foldjes

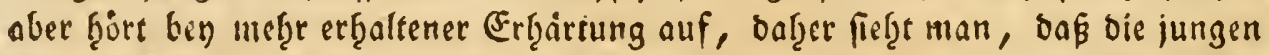
Saamenteime im Shatten reit langftieligter fino, uno bafelbft an allen juns

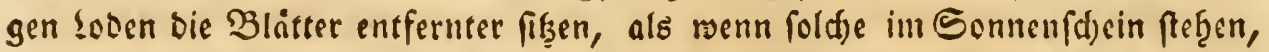
indem bort bie Szoljtg̨cile langlamer erf̨arten und fid alfo ber (änge nad) ausjus Def̧nen meg̨rere Zeit ḩaben: Dabingegen find aber aud bie im Sdjatten fies

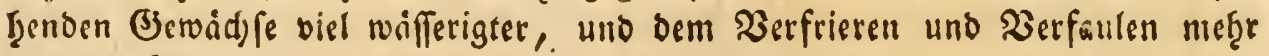
unserworfen.

\section{\$. 124.}

Sdjon bey ben erften Seimen bes Saamens entbect man bie Eigenfthaft einer für jeoen Ţgeil bes Baums ju nef̧menden beftimmten !age. Es jief̨e fid audb bey ganz verlibrter ange bes Saamenlorns, ber Wurzelecim becunter, uno bie Feber oder ber 2 lätterleim in bie Şäbee, felbft bann, wenn bas Siorn auffer 
Der Eroe jum feimen gebrad)t ift: man Eann aud ourds einigemal wieberf̧oltes Uumfefren bes Saamenforns ber bereits aus berpelben gefeimten 2 Burjel eine

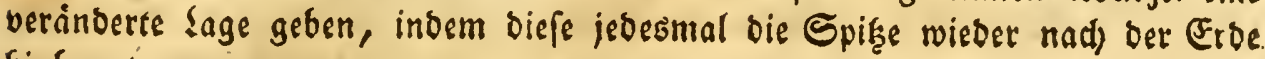
binbeugt.

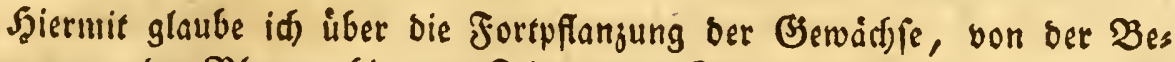
f(f)wangerung ber $\mathfrak{B}$ lumen bis jum $\mathfrak{M}$ eimen bes Saamens fo viel angefithrt ju

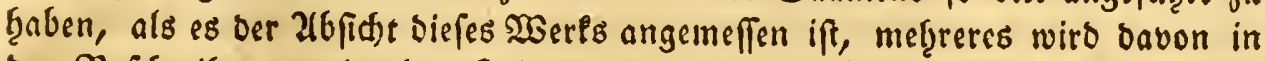

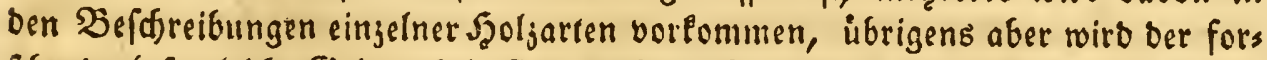

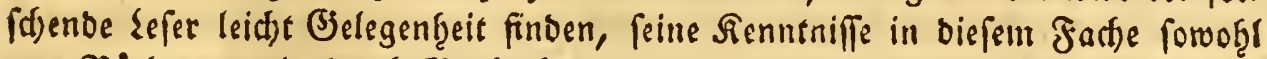
aus Bidtern, als burd) Beobadjtungen ju erweitern, wobey er oft mandfe

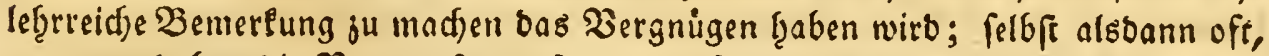
wann er babel) bie Natul, to ju ragen, auf bem Nebenuege antrifit, wie $\mathfrak{c}$

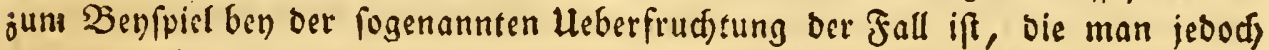
nur felten bey einigen $\mathfrak{B l u m e n}$, befonders bey gefülten $\mathfrak{R}$ ofen findet, aus beren

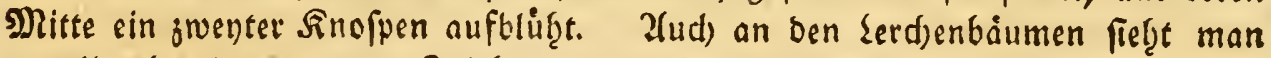

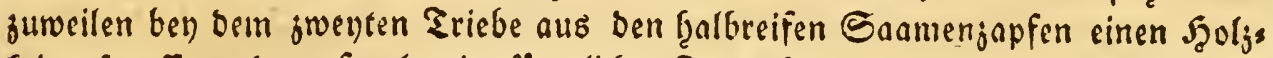
feim fproffen, ber oft als cin förnilid)er Bweig bis jur linge von fedse Zollen wåd) roiffe Itnoollemmenţeiten waf̨rnef̧men, bie ben ungenoif̨ntid)en uno unregets

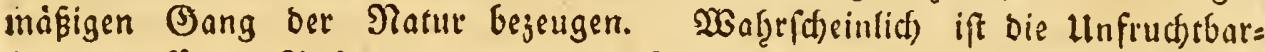
feit ber gefülten Rojen und bes in bem Jalle gevót̨nlich nut mit tauben Saas

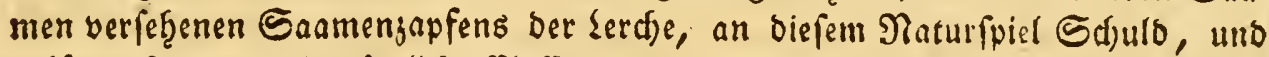
gef̧oren fie unter bie nänlidfe Elaffe von unregelmäß̈igen Erid)einungen, bie man an einigen ibermåkig ausgebef̧nten ungefültten Saamenlapfeln, wie zum Bey):

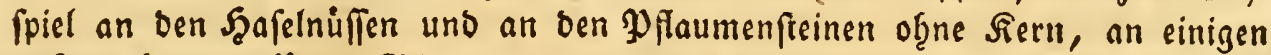
unfrud)tbaren gefülten Blumen, an benen oft bie Stempel ober weiblid)en Sheile ju gefärbten Blumenblittern auswad)(en, uno an ben ourd) ben Stid) einiger Jufectenarten entftandenen Ballen, Eidferofen, und fo weiter bemerlen lann.

\section{§. 125. \\ 2on Den Rrankgeiten Der Båume.}

Die Baiume uno Pflanjen find, wie bie Thiere, verịdiebenen Rtanlf̨eis

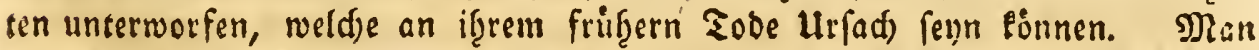

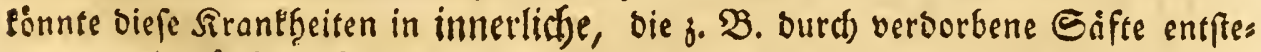

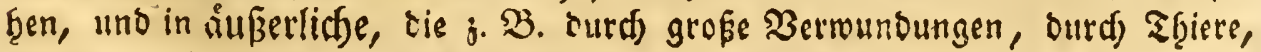
Jneesten u.f. w. veranlaffet fino, ţ̧eilen. 
Sef̧r viele Zufälle fönnen ben Saft in ben Baumen berberben, forvoḩl ein Mangel ber ben $\mathfrak{B a ̊ u m e n ~ n o ̛ t h i g e n ~} \mathfrak{N a t ̧ r u n g , ~ a l s ~ e i n ~ z u ~ g r o ß e r ~ H e b e r f l u ß ~ b e r s ~}$ felben. Sin erfern Falle fann ber Baum nur fdwad)e id)madtenbe Pieifer treis

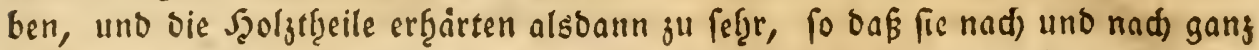
austroffnen uno verbutten. Im jwenten Falle aber treiben bie Bảume ju ftare,

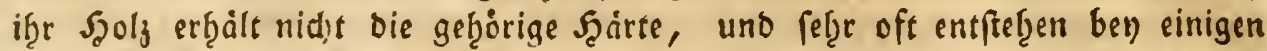
Szoljarten, als bcionbers an Sirid)en uno PP flaumenbaumen baraus Stocfungen und 2lbfäłze zrwifthen Şol uno Borke, woraus ber Saft hernach, als eine 2(rt yon Szarz ober Bjummi hecrausflieहft. Der Drt, mo biefes gefthief̧t, wiro bas bon bransigt unb erebfigt, uno wenn man biefeun $\mathcal{H}$ ebel, befonders an ben Dofts baimmen, nid)t mit 2(usfdjnciben und mit Pf fropfleimen oder Baumnad)s und

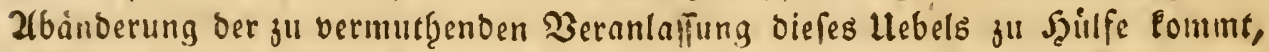

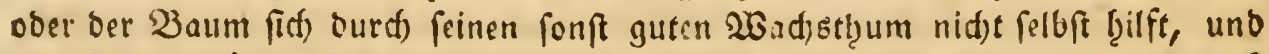

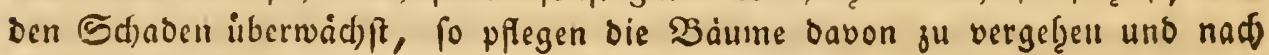
und nad) abjufierben.

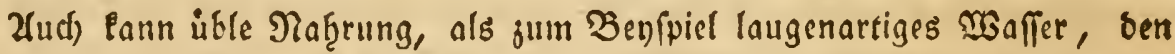
Saft berfelben verberben, uno befonders ben $\mathfrak{S}_{3}$ arjeln nadtheilig werden, vors

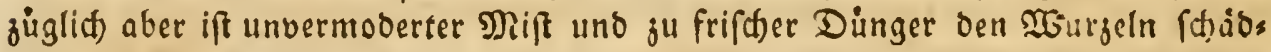

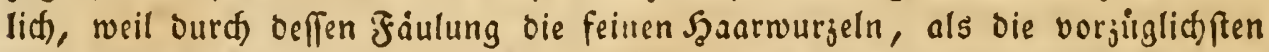
Taf̧rungswerf feuge, oft mit in Faulniß äbergef̧en uno verberben. Sollte man

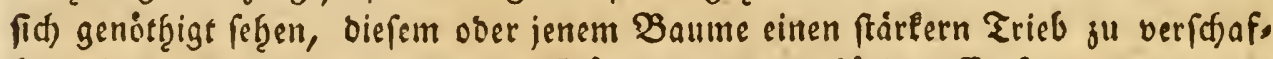
fen, fo mus oeswegen bergleidjen Dänger in ber gef̧örigen Entfernung von ben 2Burgeln angebractst werden.

Xud) ber Mangel an ber nottrigen Suft Pann Bergleidjen Stoctungen bes

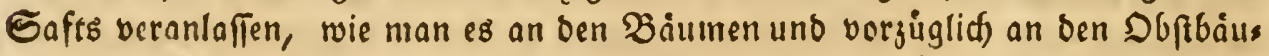
men bemerfen wirt, bie unter andern $\mathfrak{B}$ ăumen unterbrufft fteţen und Daf̧er b̧äfige fogenannte Srebeflecten betonmen, wovon oft ftarftreibenbe Baiune abfterben, wie babon ein meţreres bel) ber $\mathfrak{B} e$ fdreibung ber anjulegenden

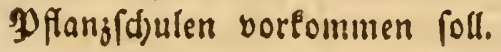

\section{§. 126.}

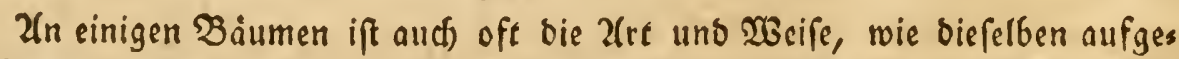

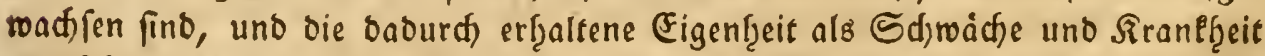
anjufeţn, bie es an fid) nidbt im allgencinen ift; fo ift gu:n Benfpiel ber in eis

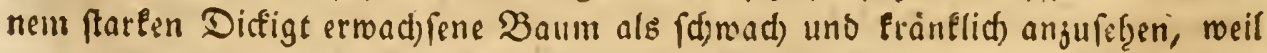
er alls Dlangel ber nötbigen Suft nur einen fdjwaden Etanm uno wenige lefte 


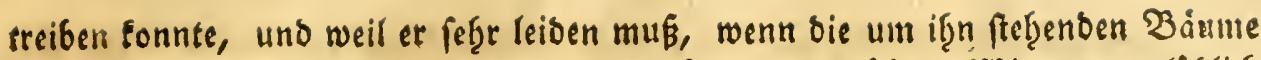
abgeţauen werben, uno er ber freven kuft und ber übeln 2 Bitterung plóglids

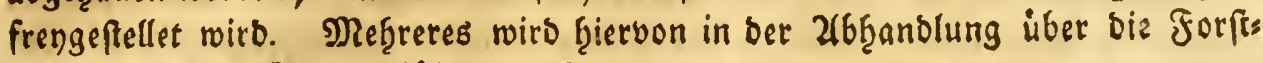
mirtbighaft ber Stangenţdjor vorkommen.

\section{\$. I 27.}

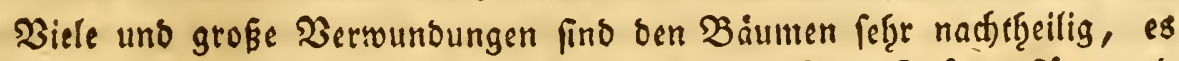

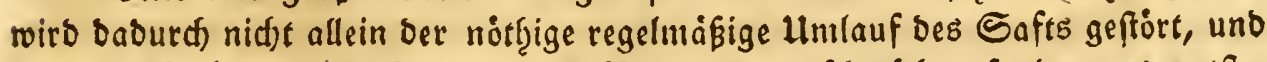

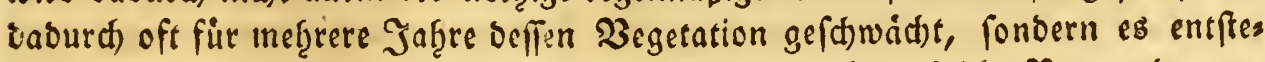

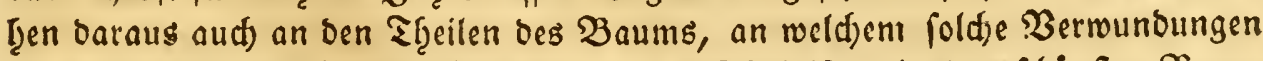

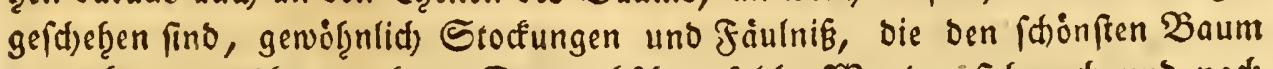
verberben unnutsbar macten: Denn obfhon foldse 2 Sumben fid nad) und nad)

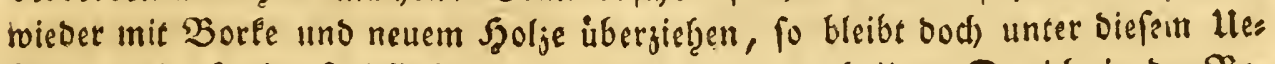

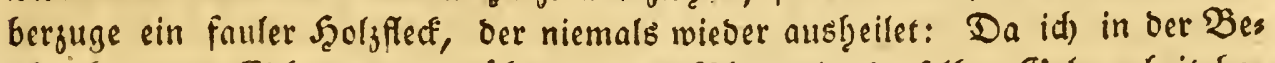

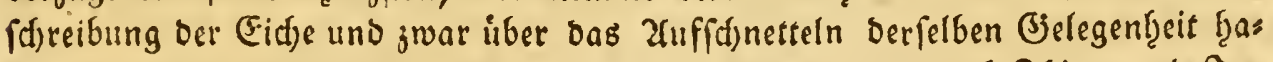

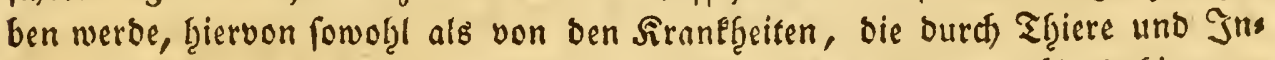
fecten verurfadjet werben, weitläftiger ju fenn; fo will id es bis bafin vers fparen, uno f̧ier nur nod) etras von bem Sdjaben anfüf̧ren, ben bie Båume Durd) ben froft leiben.

\section{§. 128.}

Sn bem berictftigten winter von 1788 in 1789 . Faben wir burd) ben Sroft ben empfindidffer Sdjaben an ben Bäumen gelitten. Hum Brauns forrecig uno in ben benadjbarten Jegenden bes platten landes find alle Defte brume entweber gang erfroren, ober bod) burch ben Jropt fef̧r befdidiget worben, fo, bakes in beun barauf folgenden Seersfte in ben Bairten, wie auf einem abgetriebenen Forforte ausfą, indem bie ronft fo bৃäufigen Dbftbaiume.

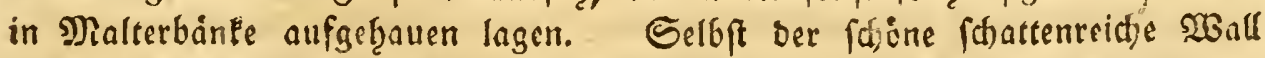
murbe baburd) von feinen alten NuEbeiumen, bie ferbft im Ealten Winter von 1740 fith gut erb̧alten ţatten, ganz entbleş́t. 2(ud) in ben Forften bes platten

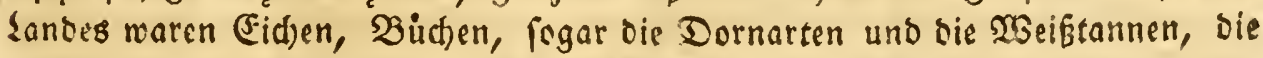
bod) fonft gegen ben Jroft fegtr unempfindict fino, erfroren: Dafingegen was ren bie fonft bel) geringerem Jroft empfindlidjern Bäume, als bie babylonifje Weioe, bie Maulbeerbaime uno bergl, unbefdiobigt geblieben.

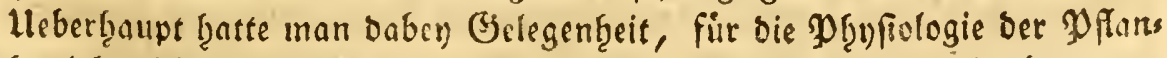

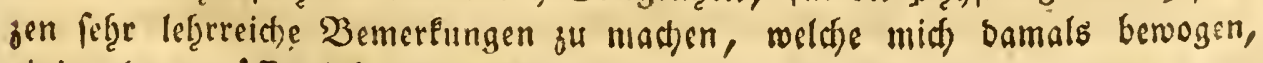
einige bavon offentlid) mitjutgeilen. 


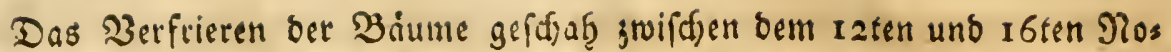
veutber, und alfo nidjt in ber eigentiid)en ftrengen Rälte, weld)e mir barauf iur

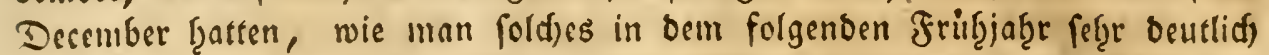

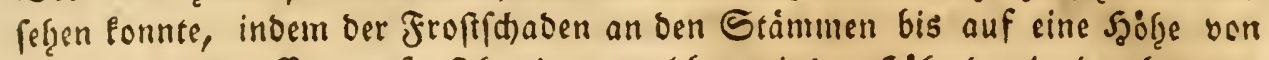
$2 \frac{\pi}{2}$ Jus von ber Erbe auf, fid jeigte, weldjes mit ber Jajife bes in ben benanns till Sagen gelegenen Sd)nees übereintraf. 2futf) Tatten bie verfrornen und bie son bem frofte befdrioigten Båume alle an ber Mittagsfeite gelitten und bie Binbe verlofiren, weldtes von bem ben bem frofte befonders fadabliden Sons nenfdsein ferenaun, woourd) bey Tage bie Mittagsfeite aufthauete, unb barauf mit Bjlattcife ibberjogen wurbe.

Die Sanupturfadfe biefer groben 3 erminfung lag of̧ne Zweifel barin, Dak

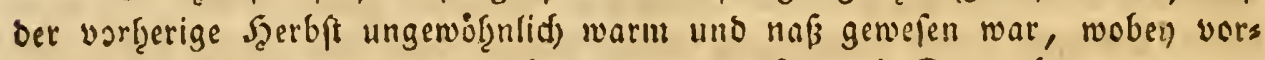
ziglid) bie Dbptbaume, von weld)en einige im Miouath September jum zwens

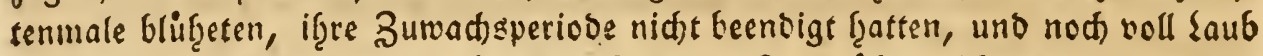
waren, als fie ourch diefen plofflidy einfallenden froft ùberrafdst wurben. Die

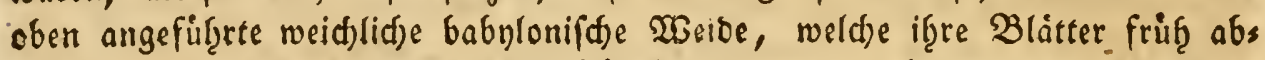
soirft, und ingre Sommetbegetation frür besndigt, ift aud beswegen vom froft,

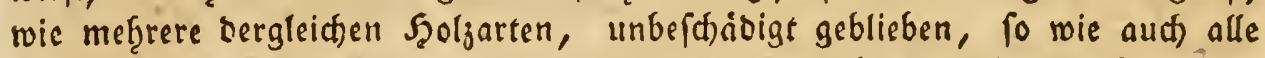

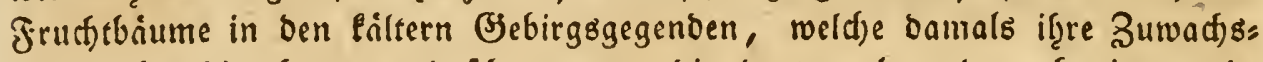
periobe beendigt tratten uno (d)on gegen bie bort nad) und nadf eintretenoe

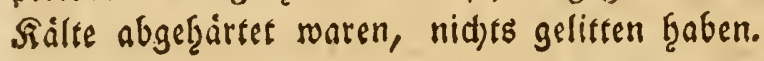

\section{§. 129.}

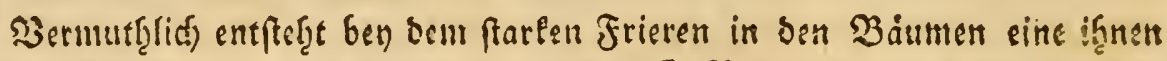

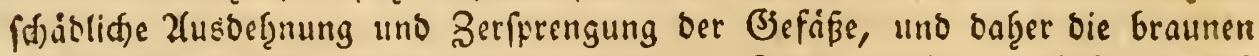
Stocfflecte, weld)e inan in bem Scolje ber vom freft befdoibigten Baiume nad,

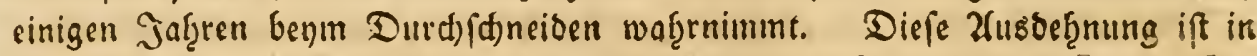

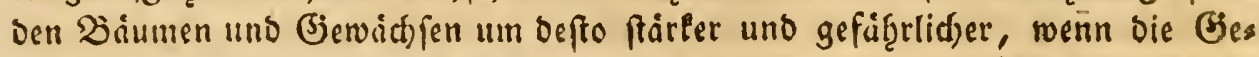

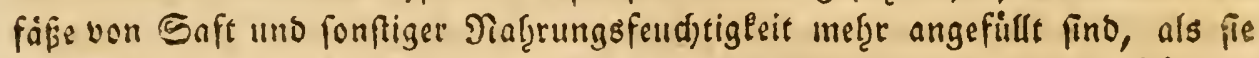

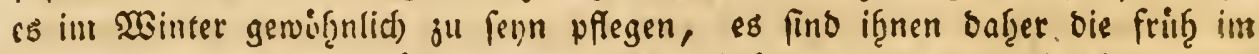
Szerbite ober fpàt ium Friffiaf̨r einfallenden Frofite fo feg̨r fd)iolid, befonders, wenn ben $\mathcal{T} a g$ iber bie Sonnenwárme oen 2antrieb bes Safts unterfinilt uno bie Biefäíe ber Säume, befonders auf oer Sonnenfeite, baunit anfüllt. Dergleidsen braune froftfecten wadfen in ben $\mathfrak{B}$ aummen nidft wieber aus, man funn baf̧er nad) if̧ren Jaf̧rstingen beftimmen, in we(d)em Jaf̧re fie burd) Ben

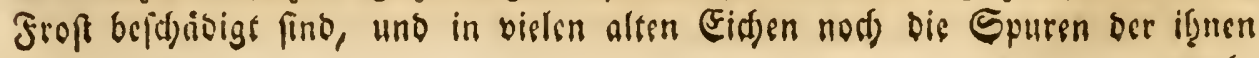
nad) 
nachtbeeiligen Palten 2 inter befonbers bon 1709 und 1740 fefer beftimmt vor: finden. In ben werigen Dbftbrumen, weld)e in ben biefigen (jegenden von

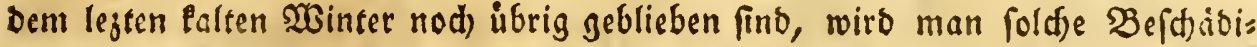
gungsflecfe tinfrig nod) fef̧r beutlid) rab̨rnefimen, uno mantfer feitbem fums merlich grunender $\mathfrak{B a m}$, wiro baburd) nod) vertrocfnen imiffen. 2(ud) bie feit biefem bofen Frofte in ben Forften bes platten Lanbes fo haäufig vorfallenben Winofälle uno Eiffidjoiben fino sime Folge babon, und wito man an biefen bie baburd entfandene Rernfäulniffe und Stodungen bemerfen Eonnen.

\section{§. 130.}

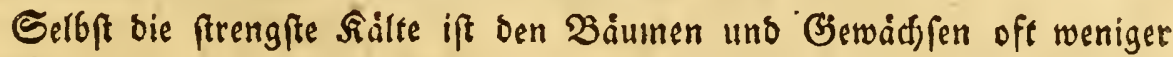
fdjablid, als bie nach cinem geringen Jrofte folgenden Sonnenblicfe, wie man Diefes vorjuglich in ben (Järten bey ben im Şerbfte exfrornen (Sartengemäd)fen

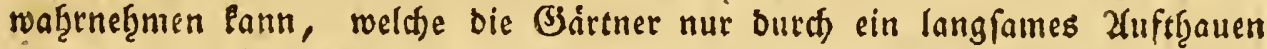
uno mit einer Bedecfung gegen den Sonnenftein gut erfalten fonnen. Der auf oen Bebirgen in ben fujonen ş3inters uno Jrüblingstagen oft bis Mittag

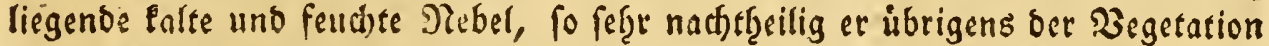
ift, erfiălt burd) bie Zebectung gegen bie tobtenden Sonnenblicfe die Baaume wibet ben froft, und findet man bafeer oft auf ben niebrigen sanogebirgen

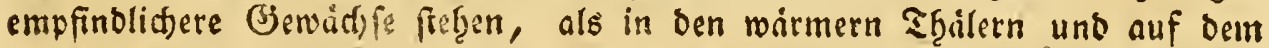

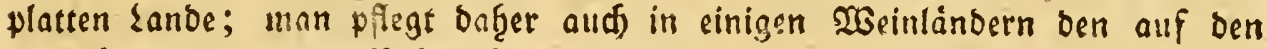
Weinbergen liegenden Rebil oft mit einem outd sas 3 erbrennen von Ranlen, und bergleicten bewirften Raud)e nod) meţr fu veroicten, un Die nach einem gefäbrlidgen Frofte ju befurchtenden. Somnenblicke nod lánger uno beffer abjus Galtem.

\section{§. I3 1 .}

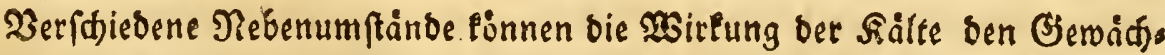

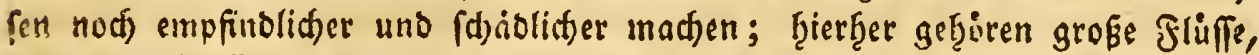
fẹcenves Waffer, naţe liegende feudte und fumpigte Derter, grope flichen von frifhgegrabenem Eroreich u. f. w. Wenn ber barubergefende 23 ind bie

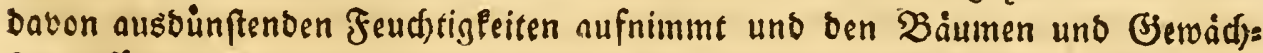
fen zuführen fann: fo leiben biefe alstann ourd) ben Rauhreif mef̨r, uno fonnen aud) fur Ertragung ber Fålte nid)t geţorig austrocfnen. Nan lann biefes befonbers bey ben jungen Baiumen fefen, welche um grobe Teidse uno

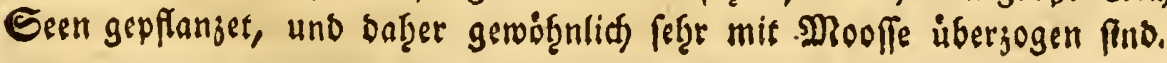




\section{§. 131 .}

Tebft ben oben angefiffreten Hebeln fönnen nod viele andere als Frants beiten ber Bainme angefiten werben, welde alls ben Befdadoigungen von verfdiesenent Infecten und von bem Einfluffe entftefen, ben verfdjicbene Nebendinge barauf berwirlen, woţin man vorjüglid) alle 2(rten bon Sd)mas rojerpflanjen jum benfpiel vom Miftel (vifcum album) uno bem Eptere (Haedera helix) an, bis ju ben geringften Moofen, uno aud alle 2(rten

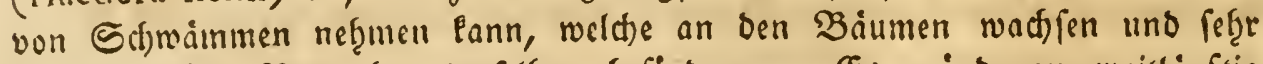
oft bas frübe Serberben berfelben befordern. Es wirbe ju weitlauftig fenn, wenn fier bavon aud) nur bas 2 Befentlidfe angefingrt merben follte; wovon aud) ofgnedem in ber Jolge biefer 26ftandlungen vieles vorloms

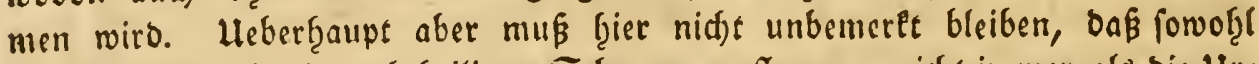
bie Snfecten, als tie naditheiligen Sd)marojerpflanjen, nidft immer als bie Llts fad)en ber Firanlf̧eit eines Baumb, fondern fef̧r oft und faft in Den mef̧rs fren Fälen mur als eine Folge einer barin bereits verffectten Franflecit ober Sd)rade angefefenen werben inuffen, weld)e benn frenlid burds jene nods mef̧r verid)/imumert wirb. So findet man bie Pränflid) und (d)road) madjs

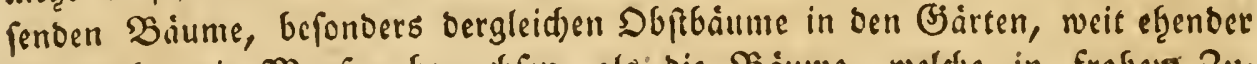
uno mefre mit Mooken bewahpen, als' bie Bàume, weldse in frofent Bus wad) fe fiefenen uno ber fogenannte Meţitţall ober eigentlich bie Brut ges wiffer fleiner fliegen jeiget fid) ḩäufiger auf fränflidsen als auf ftartwad)=

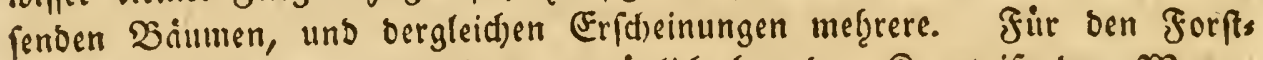
mann ift biefe lejte Semerlung vorjuglid) ben ber Senntnís ber Wourms troffnis oer Diothtanne widftig, woben mef̧reres vorfommen wirt.

Wie nun übrigens aber bie Snfecten und Sd)maroferpflanjen auf ben Baum felbft wirlen, bas ift bey fo vielen Zurten berfelben, und bey ben Sţeis len bes Baums felbft fef̧e verfdieden, ben einigem Nadjoenfen wirb jeber oer fid) nur einige grinolidje Fenntnís ber Naturgefdidate ber, Bäune

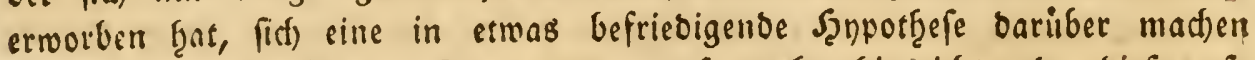
Eỏnnen, weld)es fuir ben Forftmann un fo mef̧r finreidst, ba biefem fo wenige Mittel übrig bleiben, bie Sranflgeiten Der Bäume zu beilen, ober biefen juvorjufommen. 


\section{\$. 133.}

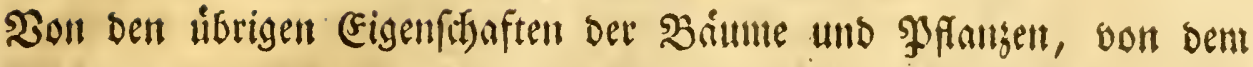

Reben Derfelben und bon ben auf Diefelben wirfenden Dingen.

Zafuer ben übrigen Eigenfdaften, bie, f̧ier von ben Baiumen und Plangen bemerlt find, zeigen biefe bem Naturforider nod) weit mergrere, von benen ich, ber mit vorgenommenen Siurje wegen, nur bie auffallenoften blos anfübren will.

\section{\$. 134.}

Die Woirlungen bes Wetters auf bie Baime uno Pflangen, fo wie ein mef̧r ober weniger frener, luftiger Stano, verurfadjen oft ben benfelben bie refentlidjpe 23eránberung; man fiefet foldjes befonders an ben fatwa: d)ern und fräreern Farben ber $\mathfrak{B l a ̈ t t e r , ~ a n ~ b e n ~ f u r z e n ~ u n o ~ l a n g e n ~ T r i e b e n , ~}$

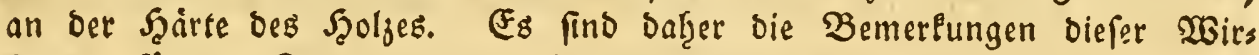
fungen für ben Forfmann von befonderer 2 Eidftigleit, weil fie oft auf bie

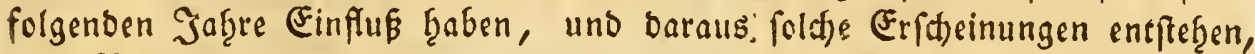

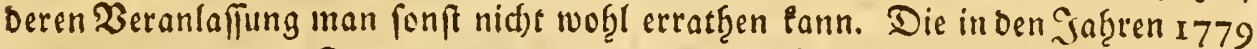
bis 1784 in ben Sommermonaten gerwefene Dirre mit frarfen fogenannten

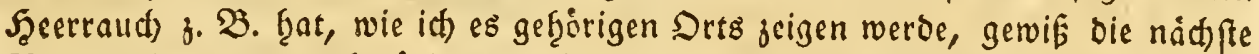

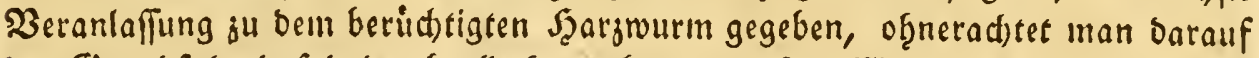

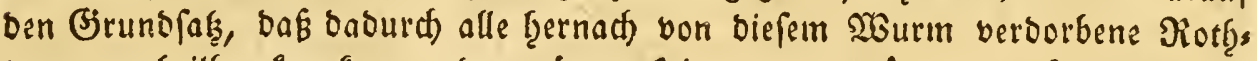
tannen unfeeilbar Arank geworden wåren, Eeinesweges grunden darf, (man fef̧e bie $\mathfrak{B e f d r e i b u n g ~ b e r ~ S i d ) t e ~ o d e r ~ B i o t h t a n n e . ) ~}$

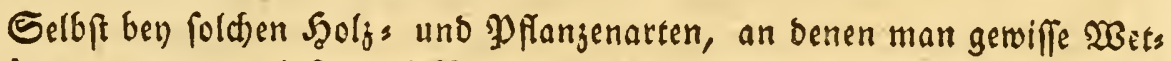
terverảnoerung am wenigften wirkfam vermutţen follte, fino fie $e s$ oft ain ftäts ften. Man fief̧t baf̧er in zu naffen Jahreen auf fumpfigten Stellen òie Ellern, bie jonft fo feģr bie Nâffe lieben, wenig wad)fen, uno auch biefe, wenn

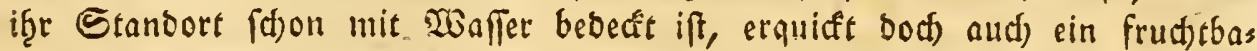

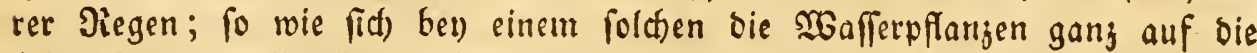

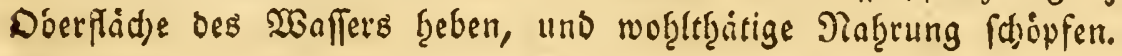

\section{§. 135 .}

Eine iebe Baumart ந̧at bie Eigenfufaft, ig̨ren Stamm, if̧re 2lefte,

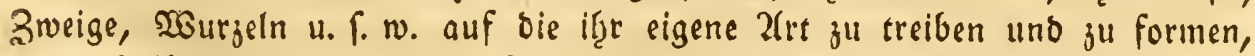

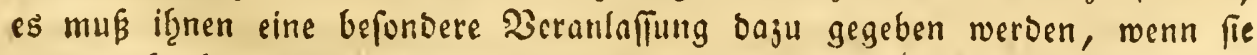

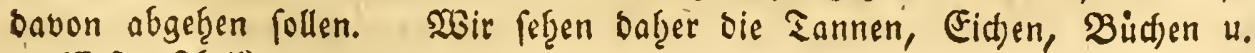
(Erfter Theil) M 
f. w. nut in bet ifgnen eigenen form wadjen, wenn fie auf einem fresen

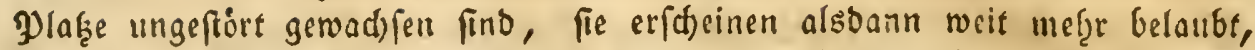
uno weit aftreiffer, aud) wit beffer vertfeilten 2leften, als wenn fie in bein

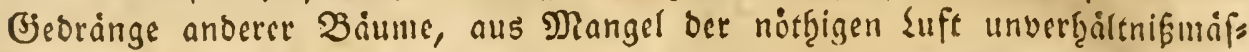
Fige, jul lange und nur fdrwad)e Stamme und unförmige 2fefte gaben treiben miffen, wie wir es an allen zerten yon biaumen bemerlen, bie in ftarten Dicfichten aufgewadfen find, ober bey benen wir aud) biefes burdf jwest=

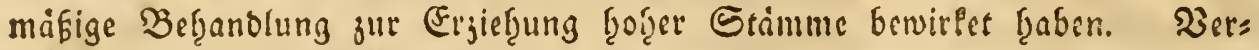
(d)iebene Dinge bemerlen wir aber an ben $\mathfrak{b a u m e n , ~ v o n ~ w e l d ) e n ~ u n s ~ b i e ~}$ Beranlaffungen unbelannt, coer wenigftens nid)t ganj erflärbar fins, biers

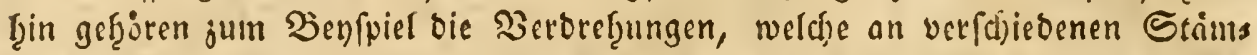

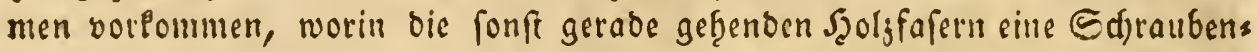

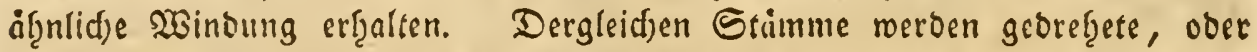

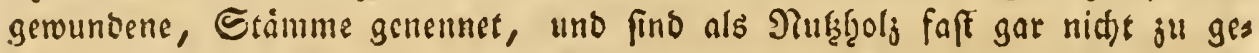
braudjen.

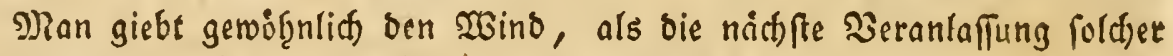
Erfdeinung an, bey einer nåbern Heberlegung aber, wirb man fierrbey ju

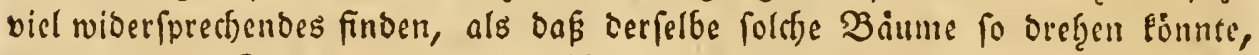
Dak fie in ber Stellung ber ganjen länge nadl fortwadf fen follten. Zfut) Fabe

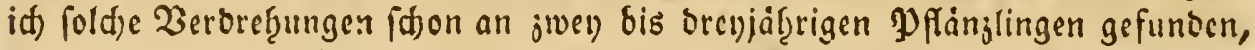

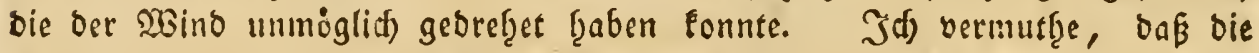
Urfad)e babon in bem erften אeime liegen mag, und daß alts biefem feernad) in berfelben Stidfeung bie fernern Friebe fortwad)fen; ift ber Stamm benn erft georef̧et, fo wiro er es bis zum fiod)ften alter uno bis gur grófeften Etamms ftarke bleiben, weil bie neuen Jafgrstinge ben ailtern in ifger sage folgen.

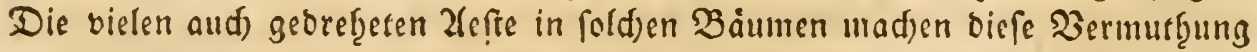

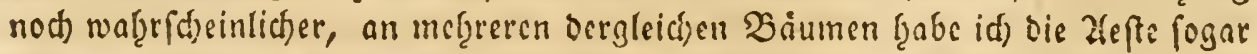
neben einander in entgegengeferter Ridhtung georefict befunoen.

\section{\$. 136.}

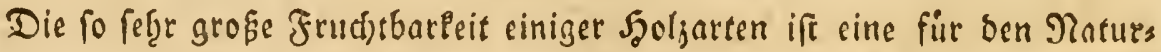
forfder ganj auffallende Bemerinng, befonders, wenn er falbft bie in bie Mils lionen gefgende Yurogreffion in ber Fructetbringung bes Beerfentorns gegen bas

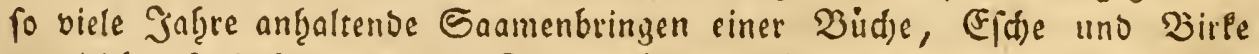
vergleidst, fo baf, wenn alle Sanmenförner aufgiengen, wonige biume bins

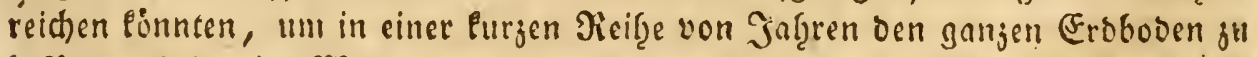

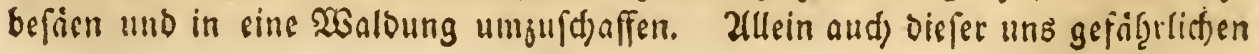
Fruclits 


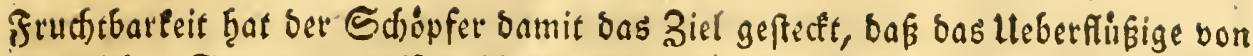

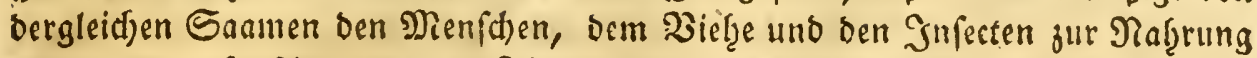
bienen, oder fonftige uns zum ₹Geil nod) unbelannte Enozmecfe erfüllen mus.

\section{§. 137.}

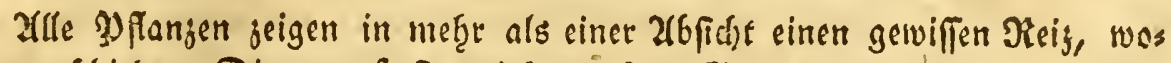

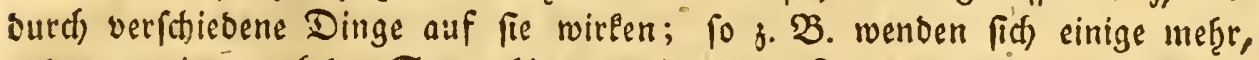
andere weniger nad) ber Sonne bin; bie in einem Simmer gejogenen DJflanjen

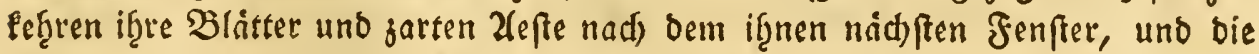

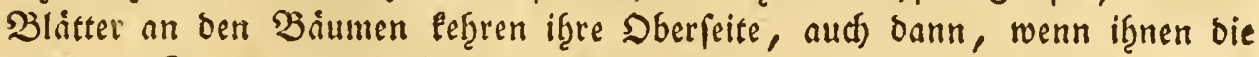

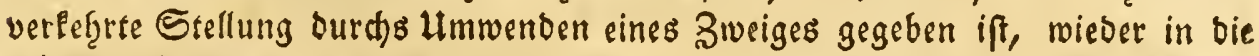

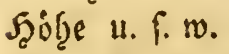

Das Sidfte ber Sonne (d)eint f̧ierbey, wie man aus ben beswegen ant geftellten 2 erfuthen vermutgen fann, nod) ineber, als bie Suft uno Wárme

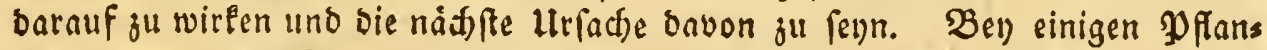
zen earn man ben Disiz jur Befrudfung und jur Fortpflangung ifrer afre beut= lich fefgen, wie an ber Eleinen Sumpfblume (Parnafea paluftris), an bem Sd)warglimmel, an ben Spinat. Einige Wafferpfangen f̧aben nur ifre

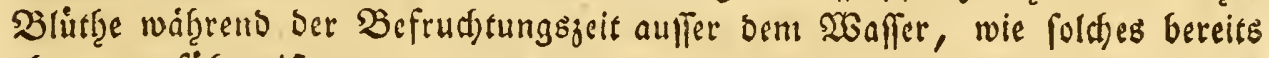
oben angefüfrt ift.

Mefrere Pfanjen, als die Meffeln, laffen uns bey ber Berüf̨rung bers felben einen empfinolid)en uno ang̨altenoen Sdfmerg füb̨len. Wicle Siråuter, als einige Zrten von Solanum uno ber Sdjierling entḩalten bie gefáb̨rlidjeten

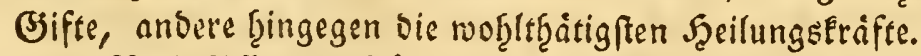

Biele Pfinnjen blüten nur gerwiffe Stunben ben ₹ag über, anbere nut

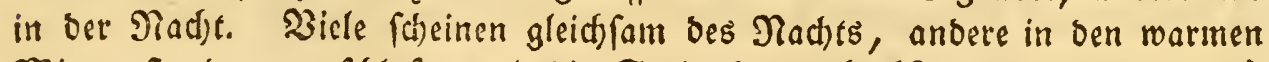
Mittagsftunden, ju fdjlafen, als die Springfaame (Balfamina impatiens L.)

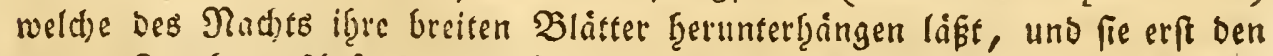
anbern ₹ag benm 2lufgeţen oer Sonne wieder ausbreitet uno aufbebt. Einige

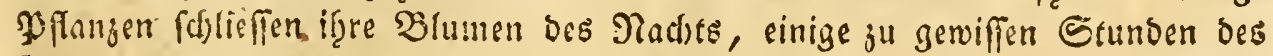
Sages, wie man bergleiden in bem von sinnee bavon aufgeführten Stunbens jeiger finbet. Die auffalleneften Eigenffiaften erfdeinen aber vorzigglid in ber-

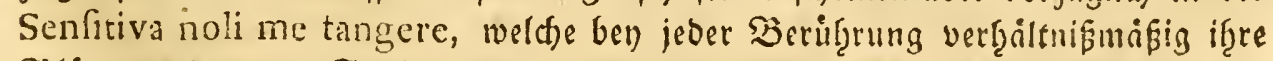
Blatter und jarten Etiele welkeno jufammengiebet, uno foldje euft nad) gefams melten Siräften, ooer nad)gelaffenen Siraimpfen, wieber ausoeb̨ut; fie fobeint

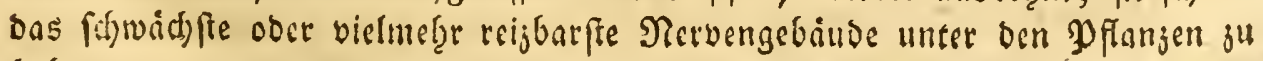
ţaben. 
Dic Dionæa mufcipula fängt surd) cine Bufarmenzief̧ung if̧rer $\mathfrak{B l u s}$ menblätter, bie fids in biefelbe fef̧enden fliegen, uno das Hedyfarum gyrans

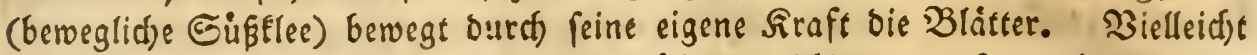

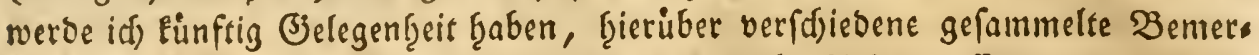
Eungen belannt ju madjen, bie ich, weil fie nidft f̧ief̧er paffen uno midh ju

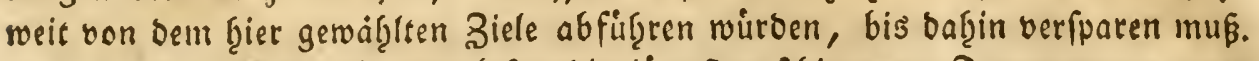
Indeffen aber eann id bem kefer bie jüngft erfdienenen fragmente netherer. Pflanzenfunde von bem Szerrn von Hblar zuverläigig empfeģlen, worin berfelbe

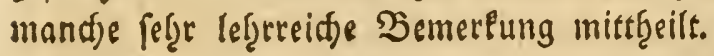

\section{§. 138.}

গRadbem wir nun bie Baiume von if̧rer erfen Entfef̧ung aus bem Saas

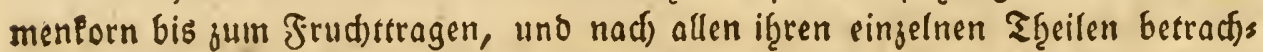
tet haben, mit Rect)t iber bie babey vorkommenden Erffjeinungen erftaunen,

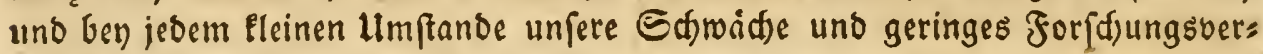
mögen füficen müfen, und unfere ausgedad)e Şgpothefen, wie biefer oder jener

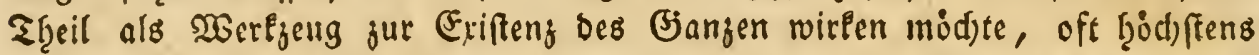
nur bis zur waḩrifdeeinlidjen 2 ernutţung aligjufinnen im Stande fino: follten wir nun wob̨l ben Pflanzen ein gerwiffes seben abfprecten, uno alle nur für Mafdinen halten fönnen? Ein jeber, oer fid) nur bie Miúge geben will, f̧iers uber aud) nur oberfladflid) nactjubenfen, wirb fidf nid)t allein von oem leben Der Y) flanjen vollemmen überjeugen, fondern unter biejen die Brabation eines mef̧e ober meniger vollfommenen bebens unter fíd) fowof̧l, als ben ftuffens

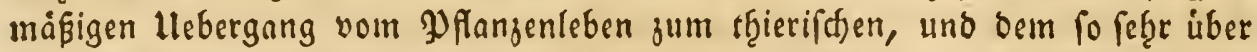
alle erbabenen menfdlidjen Seben, einfelgen. So eridgeinet in POfanjenreide bie Triffel uno ber Cereus ferpens auf einer niebrigern lebensftufe als bie Senfitiva oder die Mufcipula.

Zon ben nid)t werennirenten $P$ finnjen bringen einige ifre keben nur auf einige Monathe, anoere nur auf einige Tage. Die ef̧rmùroige Eidte lebt hins

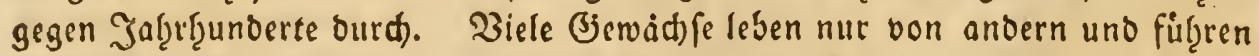
ein waḩres Räuberleben, wie ber $\mathfrak{R}$ iffel und bas Moos, und fino wie begetis rende Snjecten anjureteren.

Einige PPlanjen, die Polnpen, haben ein wahres thierifdes Seben, fino Y flanjen uno Thiere jugleid), uno gleichfain ber Hebergang vom Planjens

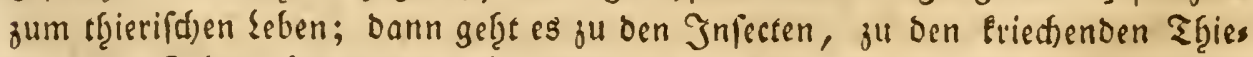

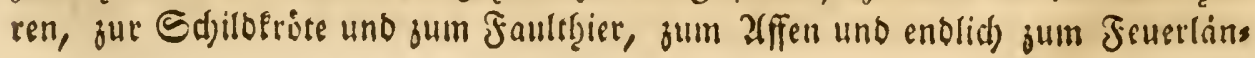


ber utb zum benlenden Menifhen ùber; ber ben Shjopfer alls aller, was er

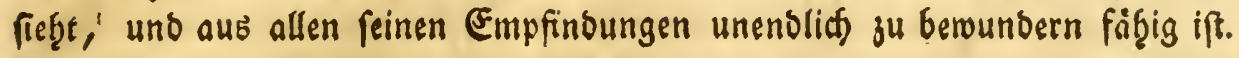

\section{Bierter $\mathfrak{A b}$ fiflit.}

\section{Zon der fanttliden Bebandlung der Bäume.}

\section{§. 139.}

Inter biefer verfteht man bie Bef̧andlungen ber Sảume, durd) weld)e

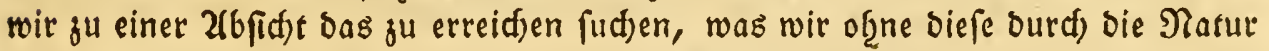

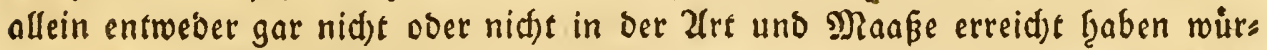

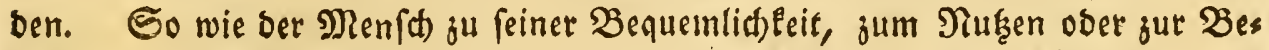
frieoigung irgend einer Brille mef̧rere Dinge in ber Nafur belünftelt, uno

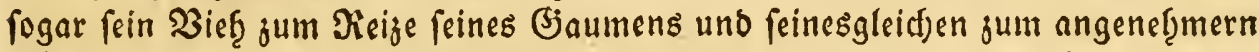

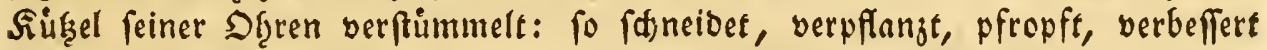
uno miśf̧andelt er auch feine Säume, bod, Eann er biefes alles nur bis zu einem

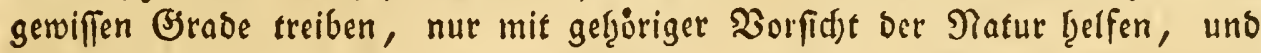

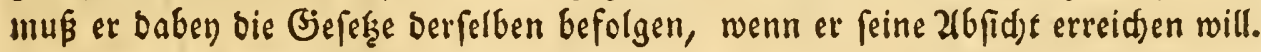

$$
\text { §. } 140 .
$$

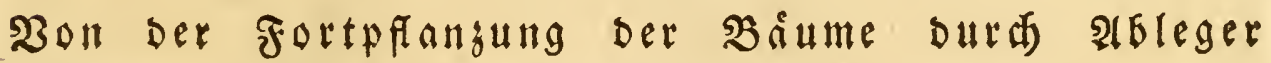
und Sefilinge.

Da fowof̨l ber Stamm, als bie Zweige uno 2 surjeln ber Băume bie

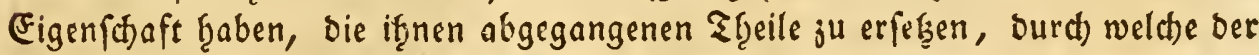
Etamm uno bie Zweige Wourzeln, uno biefe wieber 3weige zu treiben, uno fo

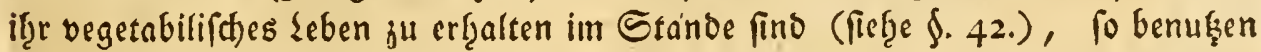
nir biefes $\mathfrak{N i t t e l}$ jur Fortpflanjung fef̧r vieler Sagljarten, die mir entweder

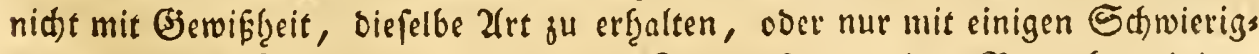
Peiten aus dem Saamen ju erjief̧en in Stande fino, wie z. $\mathfrak{B}$. es bey cinigen

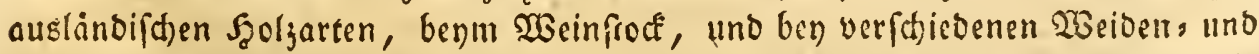
Dappelnarten ber Fall ift, iweld)e wir viel gefdrwinder ourd). Sefglinge, als aus Dem Saamen fortpflangen fornen. 


\section{141 .}

2fbleger nennt man fold)e Buseige, weld)e, of̧ne bon bem Stamme abges (d) nitten zu Fetn, Durd) Einlegung in bie Eroe uno fonftige genugfam belannte Mittel und Sanongriffe erft jum SGurjelntreiben geţolfen, uno bann erft babon abgeidjuitten uno gepflanget werben. Berfolebene neben bem Stamm bels cinigen Syolgarten oft austreibente Sdjóflinge, pflegen fdion von felbft routs

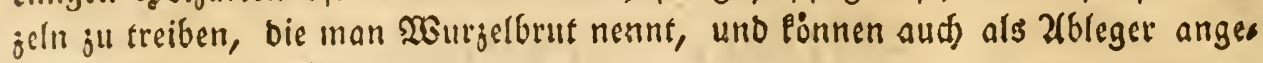
frben uno gebraudet werben.

Sef̧linge, Stedflinge, Edynitlinge aber nennt man bie Breige, welde von ben $\mathfrak{B}$ iumen abgefdjniften, unb in bie Erbe geftectit werben, $\mathfrak{W}_{\text {orgeln treis }}$ ben und wadjen. Man faun aud) ţierunter bie 2 surjeln red)nen, weld)e man von einigen Sholjarten, als von Ellern, einlegt, uno aus weldjen ber einftige

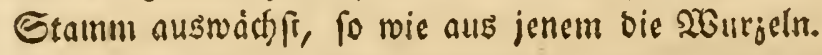

\section{§. 142.}

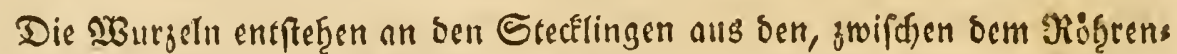
wno Rellengerucbe orr áufern Szoljs und Pindenlagen aun Stamm, an ben

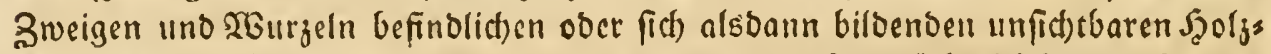

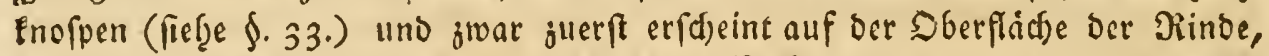

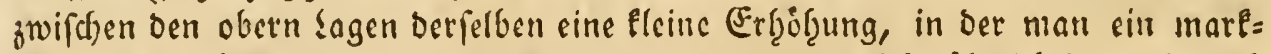

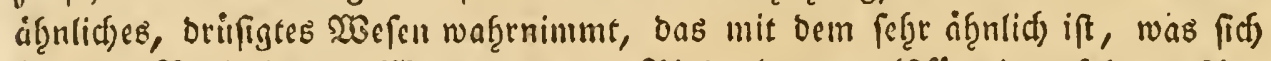

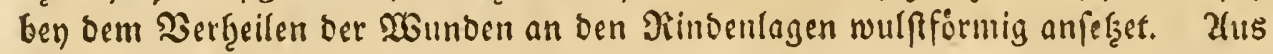

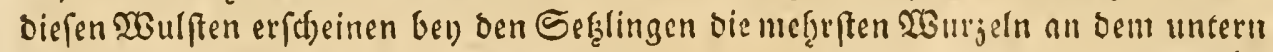
2(b/a)nitfe und ben fonfigen Dindennunben Derfelben, sie nlsoann in Der Eroe

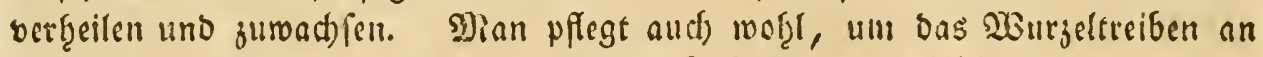

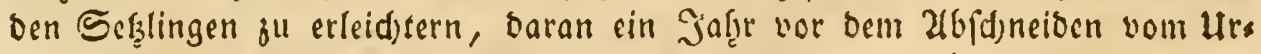

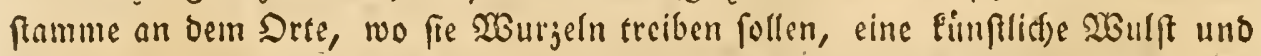

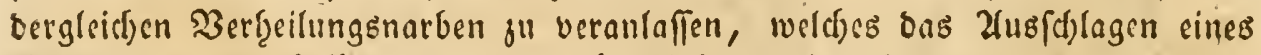

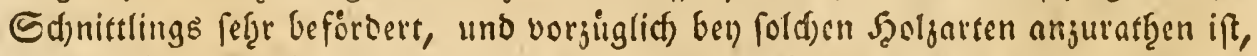
bey welden sicfe fortpplarjungsart mit einigen Edfwicrigleiten verbunden ift,

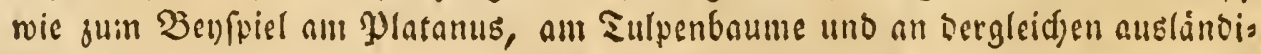
(d) en $\mathfrak{S g o l j a t t e n . ~}$

\section{§. 143.}

Einige Szoljarten laffen fid fef̨r (eid)t surd) Sd)nittlinge vermetgren, als bie scseibens uno Pappelarten, relde man oft jogar viel leid)tet als Stefflinge, als 
rie berourgette Saimme berpflanjen eann; aud felbft einige ber Gärtefien Sgolgars ten, wie ber $\mathfrak{B}$ urbaum und Tajus laffen fid) fo anjief̧en. Znbere aber, wenn fie aud) angegangen fino, pflegen bod) nidft ju fo ftarken Badumen zu wadblen, als wern fie aus beur Samen gejogen fino; weldes id) vorguglich bey ben Sins

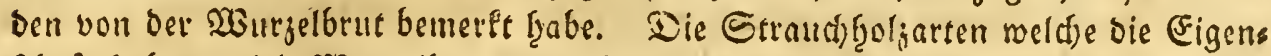

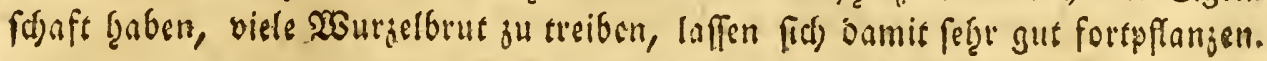

\section{§. 144 .}

Da ber Sefiting obne Wurgeln in bie Erbe geftects wirs, fo miffen bem: felben faft alle Bueige genommen wetben, bamit berfelbe nidjt ju viele Bläter

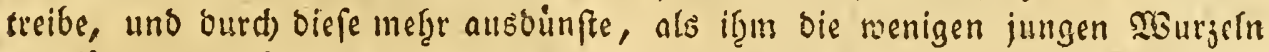

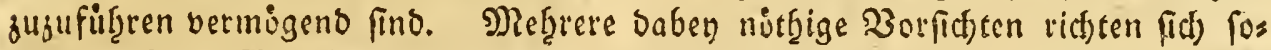

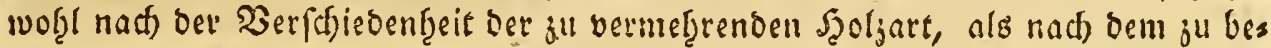

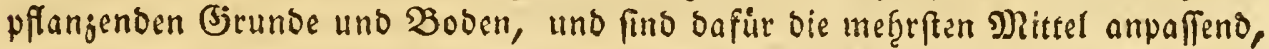

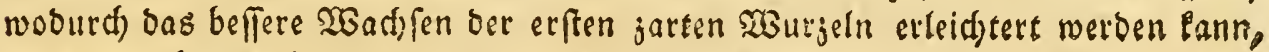
wobon getrorigen Srts meb̨reres borEommen wirb.

\section{§. 145 .

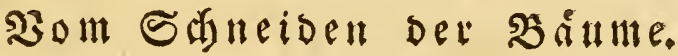

Dard bas Sdneiden ser $\mathfrak{B}$ ăume fonnem ofe geroiffe Dinge auf eine befz

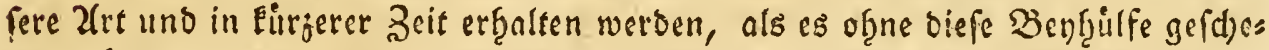

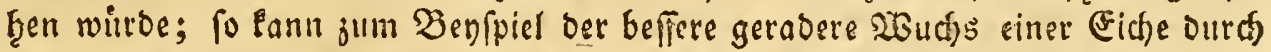
bas abneţmen ber untern Bwaige beforbert wetben, unb eill fdablgeft gewordes ner $2(f)$ ju beffen naturlicfem abwerfen inefrere Sabcre erforbert werben wit:

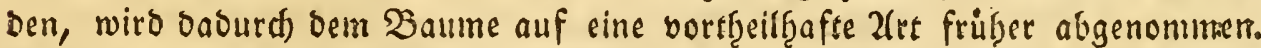

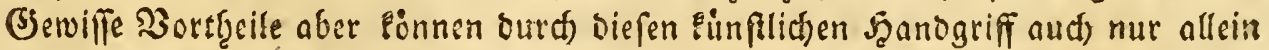
erreid)t werben; fo erjicft ber Forft: und Sanomann aus feinen Eidfen, Scains

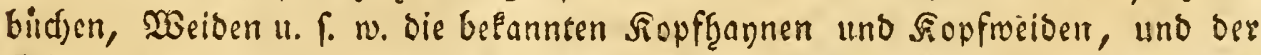
(5ätner feine bid)t belaubten 23 sinde, Sgecten uno feine gefinftelten vergwergten Dbftbåume; To quålt er leiber! ben Tajus uno ben Burbaum ju Dyramiben,

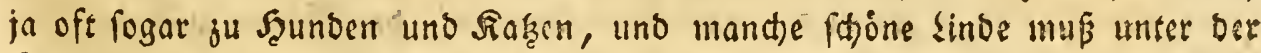
Schere gleichfam jum Egantpignon merben.

$$
\text { §. } 146 .
$$

Daв Befdncioen erftreçt fí) nid)t allein allf bie Blåtfer, Bweige uno

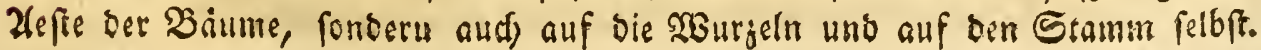


Durch das Befdaneiben wirb bie Benuranung ber Blatter, wie ben ben Mauls

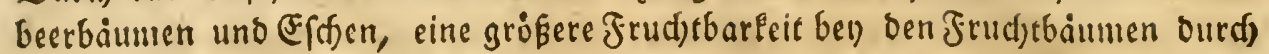
oas alonef̧men bet iberfliffigen fogenannten NGafferreifer, iberf̧aupt bantit

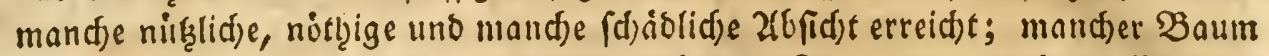
wirb baburd) erf̧alten und mandfer verborben. So werben aud bie wourgeln bevin 3 erpflanjen eines $\mathfrak{B a u m s}$ oft mit $\mathfrak{T}$ ufgen befdjnitten, und viele Bàme

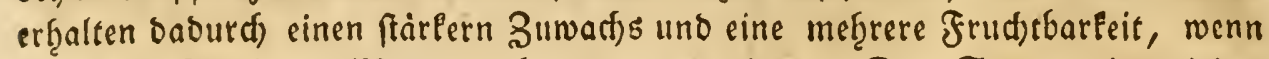
ifrnen ein Theil ber Sourzeln abgenommen wirb. Der Stamm eines jeden

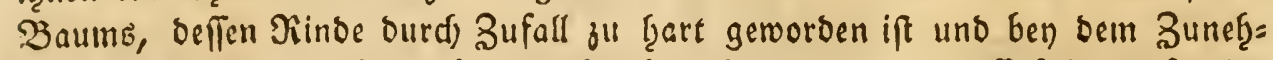
men bes $\mathfrak{B a u m s}$ nidft geţörig nachgiebt, Eann mit gutem Erfolge aufgerizgt

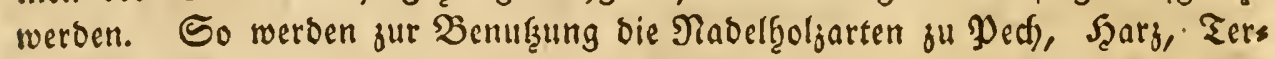

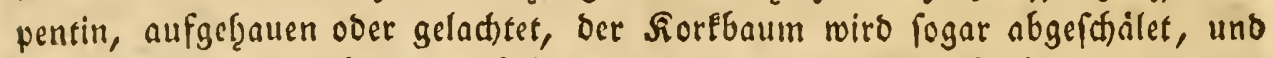
mandjer Baum burd) das 2(uff(jneiben eines fogenannten Sirebsfdabens cber Branoflecters, von feinem Untergange gerettet.

\section{§. 147.}

Da burdh das $\mathfrak{B}$ efdneiben, uno burd) bie naturlide $\mathfrak{B}$ efdadigigung ben

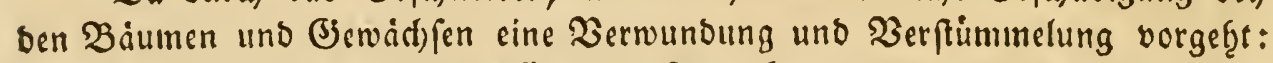

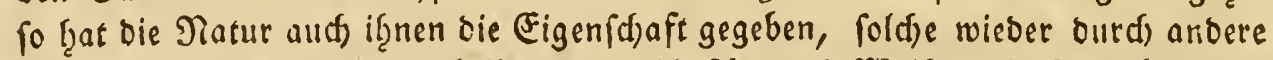
Theile ju erfeçen uno ausjutgeilen; und bie 2 (rt und 2 Eeife, wie fie baben vers

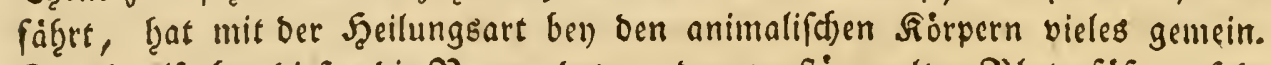
So wie alfo bey biefen bie 2 erwundeten oder verftimmelten Blutgefäße erfefect werben, ourd) welde fatt ber efgemaligen, alsbann ber $\mathfrak{H}$ lmlauf bes $\mathfrak{B l u t s}$ ers bzalten wiro, to gefdjief̧t biefes aud) bey ben Saftrobeen ber Baiume, wie man es bey ber afnatomie eines vormals abgeţauenen, unt nach)feer überwadffenen

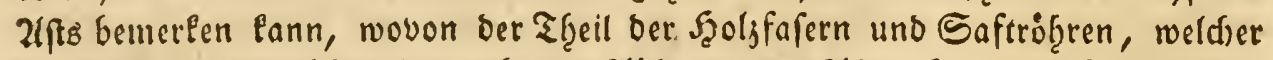
in Stamm verwad)fen ift, nat) bem 2(brauen bes 2fits oft nur aulf ber Dber's flad)e ber wounde affirbt, ubrigens aber ourd) oas Uumlaufen bes Safts erf̨als ten und bem Stamme oafür nüg(tid) wirb.

\section{\$. 148.}

2lus ber bis bief̧er in etwas erelarten 2(natomie ber Bäume unb ocr bar: auf gegrunbeten 2 ermuthungen, wie bie Tiafur ben ber $\mathfrak{B}$ egetation berfelben ju Werle getzen mag, laffen fid) einige 2(nweifungen uno Picgeln Gerleiten, weld)e man benu Befdneiden Der $\mathfrak{b}$ ăume. zu biefer ober jener abfid)t ju beobad)ten

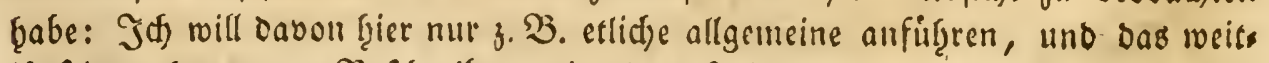
läuftigere Davon jur $\mathfrak{B}$ efdreibung einjelner Şolzarten berfparen. 
§. 149.

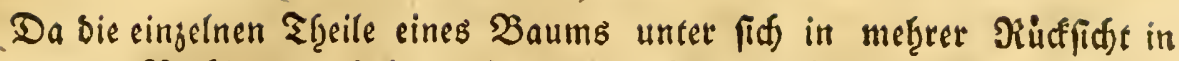
einer genauen $\mathfrak{Z}$ erbinoung ftefen: . To wirkt f. $\mathfrak{B}$. eine $\mathfrak{B}$ efdadoigung ober ein Beffineiben eines 2fftes auf Stamm und Wurzeln, und wenn biefe leiben, fo

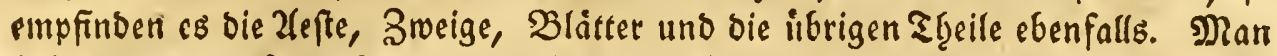
fief̨t beswegen oft ftarle, gefunde biume plöglid) trocken-werben, wenn if̧nen ein ju grofer Theil ber 2fefte ober wob̨l gar bie gange אrone genoumen ift, wie man biefes zum Beyfpiel an ben in ben Baumfdulen durdfs Pyfropfen veruns

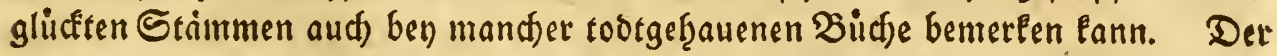

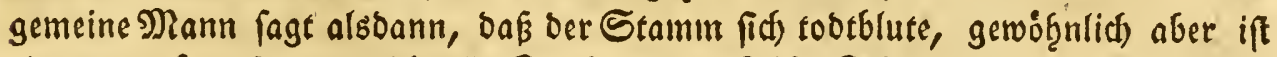
eine barauf entfandene fonelle Stockung ber Sifte Shuld baran. Es gonnen baher einige Baumarten ju gewiffen Zeiten in Jaḩre ein fold)es 2(bfdjneiben uno Sefd)abigen ef̧ender vertragen. Mandfer fdwädere uno in einem geringern

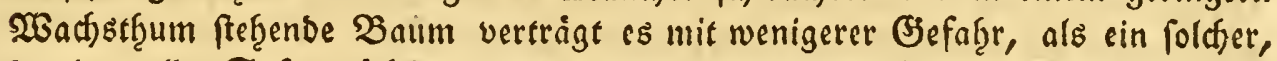
ber in vollen Safte wád) und, etgender werben bie auf bent B̧ebirge und auf

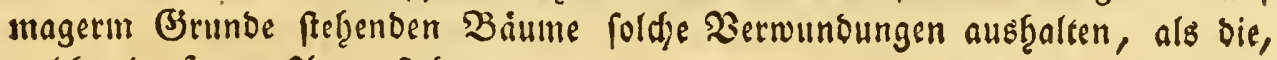
weldye in fetten 2luen fetren.

\section{\$. 150.}

Ein gu ftarles Entblättern ober Befdjibigen ber Blätter burch Snfecten ober bergleidfen ift aud) beswegen befonoers in ber vollen Saftgeit ben $\mathfrak{B}$ aumen

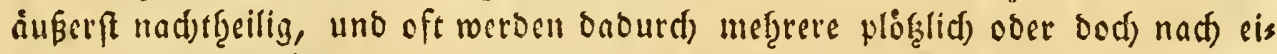

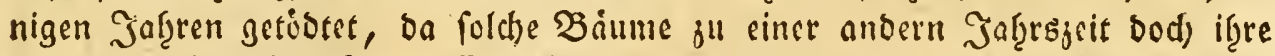
Slätter ferbft abwerfen. (Fin hojd)ft nachtheiliges Benfpiel b̧ierbon geben bie Durch bie bcridttigte Juţrenraupe (Phalena pini bombix) getooteten Futren,

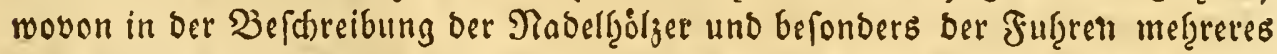
voremmen foll. So wie nun burd) bas befd)nciben in cinem Baume bie vers

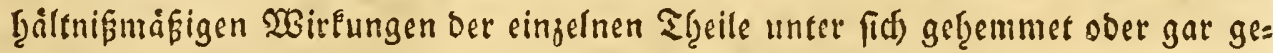
ftort werben finnen, fo werben fold)e aud) in andern fällen baburch gewonnen

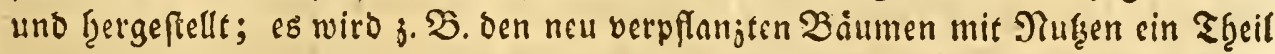

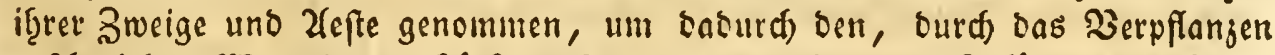

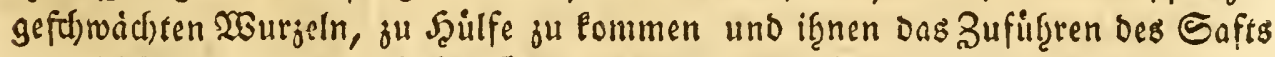

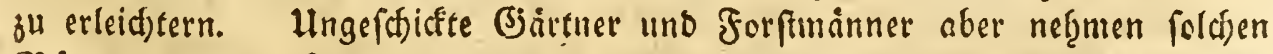

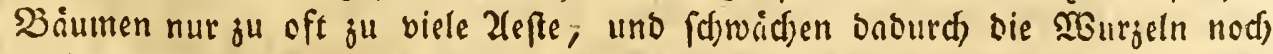

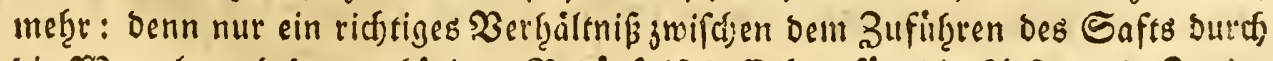
Die 2 Surjeln und bem getgorigen $\mathfrak{B} e$ ürfniß befferben für bie 2lefte und 3weige 


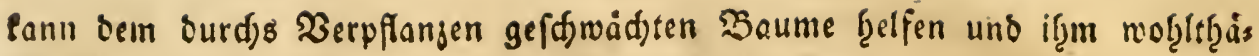
tig finn.

\section{§. 151.}

2(ud) felbft burdf bas Befdneiben einiger Theile bes Baums fann ber gans

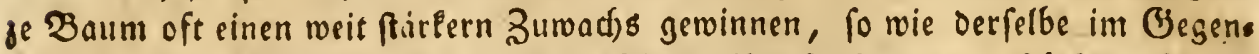
theil aud) baburd) ge(d)wadtet, uno in feinem ifgn fonft eigenen ftärlern Wudds jurüfgetgalten werben lann; biefes firf̨t man täglid) an ben ju Szecfen gejogenen Tannen uno Şaynbudden, aud) an ben Frud)tbaiumen, weldje ber (Şärner fu Dyyramiden und an ben Efpaillere verfwerget, an weld)en er alle ftarfwad) fende

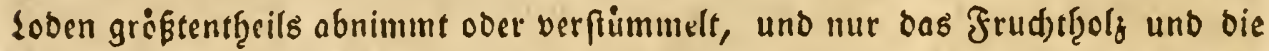
vermaferten und verfrippelten 2lefte läst, jenes aber befonders an fold)en, bee nen er einen Theil ifjes alten Szolges ober ifgrer alten Wuurgeln in ber 2abfid)t nimmt, um ig̨nen onourd) neue Triebseraft fu berfdaffen, indem fie alsbann

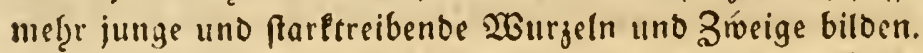

Die Bärtuer nennen biefen Şanogriff oas $\mathfrak{B}$ eriingen sines Bauns, uno wenden iţn oft mit Nutzen bey alten Dbpibäumen an, weld)e bamit nod) auf ei= nige Jafzre erf̧alten werben fönent.

\section{§. 152.}

Eine eben fo fdablide Folge von unjeitigem $\mathfrak{B}$ efdineiden ber Bäume, als bie, welde zur vollen Saftzeit aus oer plög̨liden Stocfung ies Safts zu bes furd) ten ift, Pann aud) Daraus entftelgen, wenn fold)es ju Der Zeit gefdjięt, ba iill Wointer ber Saft in ben Baiumen faft ganj critarret ift, inbem alsoann gleid)s fam aus Nangel an Lebenelraft die von bem abb̧auen entfandenen $\mathfrak{W}$ unden in Fäulung gef̧en, uno nid)t leid)t ausb̨eilen. Diefe Frulungen finb befonbers bey einigen Syoljarten, weld)e ibrigens fdoon an fidh benfelben weniger wiberfe:

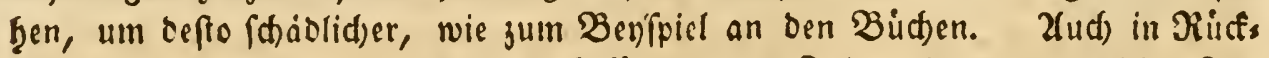
fidbt auf bie von Froft uno Sialte ju befürdjtenden Folgen ift bas unjcirige $\mathfrak{B}$ es

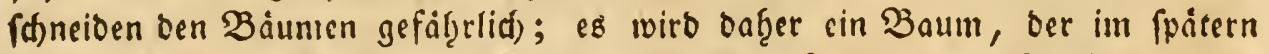
Fribjab̨r oder in Sommer fare befdnitten ift, oft viele neue Triebe imadien,

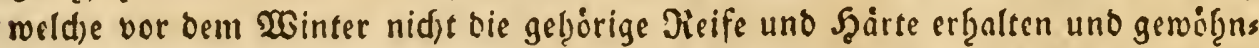

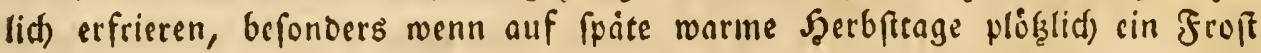
einfillt, weld)er einen fold)en Baum oft gang 3 u tooten pflegt. 2(ud) ein in Sgerbft noch in Sallbe feiner Zworige beraubter Baum if bent

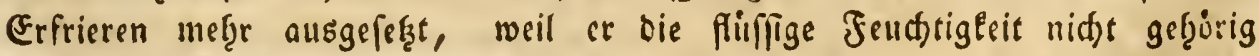
Qusbunften Eann. 
§. 153 .

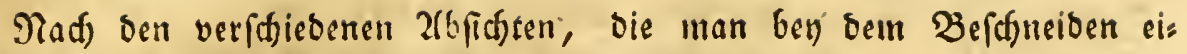
neb Baums zu erreid)en winfd)t, ift bie 2trt beffelben fowoht, wie bie Jaf̧rgjeit bafür, zu beftimmen, und ju iberlegen, ob ber Buwadis bes

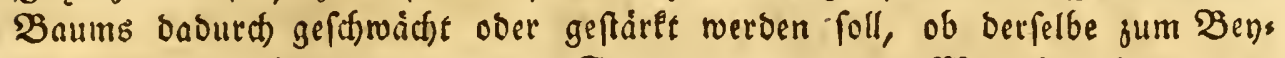
fpiel aus ben Zeften, aus bem Stanme, aus ben Wurgeln wieber auss fdjlagen foll ober nidht. Won allem biefem foll ben einer fid) naiber tafür

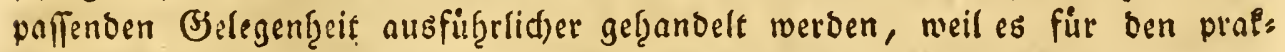

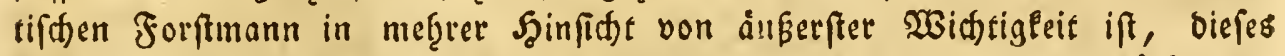
Fatf) grimblid) gu verftefen, uno bie vielen ungereimten Woiberfprutge, bie man bavon begm Forftetrieb nur ju oft biort, blok baburd)getroben werben fönnen, wenn biefe Bef̧andlung ber Natur ber $\mathfrak{B a}$ ame angemeffen beftimmt uno gef̧orig verrid) tet wirb.

\section{\$. 154. \\ Bom Şfopfen Der Såume.}

Eine ber auffallenofen elinftliden Bebandfungen ber Bäume ift bas Pfropfen oerfelben; es Fommen daben to viele Bemerfungen vor, bie für

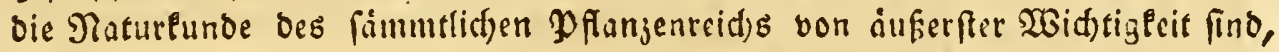
baß ein Geore, ber fid) aud) nur entfernt bamit befthaftigt, uno für bas Nadbenlen uber bie natiurlid)en $\mathfrak{W}$ under nur in etwas empfindlid) ift, oae burd) befonders aufunerefam gemad)t werben inuE; fo wie aud jebem Sars tenfreunde und allen, bie fich mit ber Baumjudt abgeben, if̧re baben anju= wendende Mihte ourd) bie kinftigen, baburd) zu er(zaltenden fridtte reiths

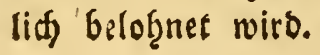

\section{§. 155.}

Unter bem $\mathfrak{P}$ fropfen ber $\mathfrak{B}$ aiume wird im allgemeinen bie Bef̧andlung verftanden, ourd) weldse ein Zweig ober ein Syolgauge von einem Baume

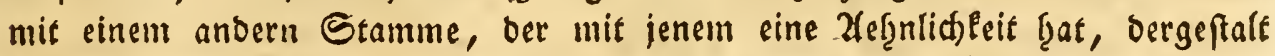

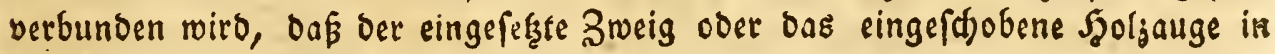
biefen wadt) uno mit if̧m einen $\mathfrak{B a u m}$ bilbet.

Das $\mathfrak{Y}$ fropfen Eann in allen ben Jaf̧rszeiten gefdeften, in weldten bie Baiume if̧re Suroad)glraft vorginglidf geigen, und alfo vom Februar bis Sctober,

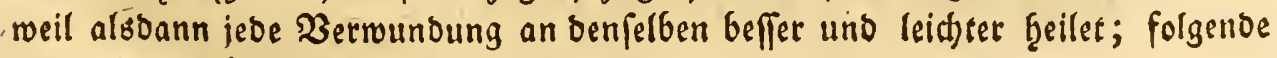
find bie geroobghnlidften Zureen beffelben: 


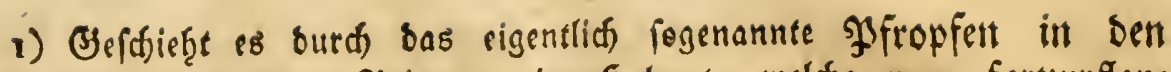
Spalt, wobey cin junges Reis bon ber Şoljart, meld'se man fortzupflans zen nuinfd)t, ain untern Enoe auf benden Seiten platt gefdnitten, uno in ben Spalt bes z"l pfrepfenden Stammes eingefest mitb.

2) Durd das Pfropfen in bie Silnde, wenn sin folffes am urtes ren Ente auf oer sinen Srite platt gefdnitten, uno zwifden bie aufges fohnittene Dinte uno bas Şolj bes äu pfrepfenden Etammes eingefdoben wirb.

3) Durd Das Bufammenfigen, was bie Bärner copuliten nennen, wenn bas Disis uno ber Etumm, weld)er mit jenem faft von gleidjer Diffe

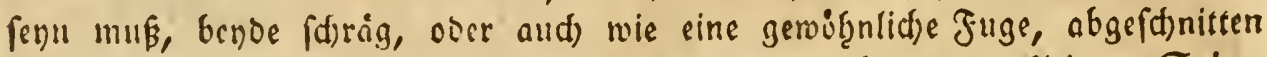
und bufoumen vertunden weroen. Es findet nur bey ganj Eleinen Stam= men obcr auf oen Bweigen fritkerer Stämme Statt.

4) Durd) bas शblactiren, wenn ber ju pfropfende Stamin mit bem barauf ju feseenden Bicipe fo verbunden werben Pann, Daf bas Pieis bon feinem unrfaumme nid)t efger braud)t abgefdnitten zu werben, bis es mit Dem funftigen Stamme binlanglid) vermad) fen ift, in weld)er a(bfid)t man bie zu pfropfenden Stämme einige Jaḩre vorḩer neben den Etamm pflants zen muk, beffen alrt man fortpflanjen mill.

5) Durd) Das Deuliren, wenn von einem jungen Zweige ein $\mathfrak{S}_{0} \mathrm{l}_{j^{\circ}}$ ange mit etwas Pinde abgenommen und zwifden bas feols und bie Piins De bes zu pfropfenden Stammes eingefdoben wirb, man theilt es

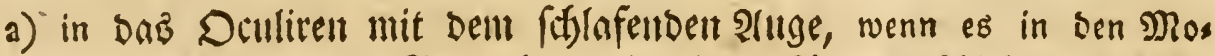
naten 2(uguft unl Eeptember mit einem 2(uge gefd)ieft, weld)es von einer Eommerlooe genommen ift, uno exft in folgenden Jrif̧: jaḩr austreibt, uno

b) in bas Doultiren mit bem treifenten (1uge, wenn es mit einem 2(uge von einem lef̧riáţrigen Mieife in oen Monaten 2(pril und May gefdiefrt, das nod) baffelbe Jaf̧r treibt. Wenn bierben bie

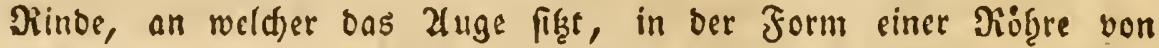
ocm Zweige abgenommen und auf ein, auf gleidfe Weife entblóbtes, Etämmden von faft gleidjer Stärle aufgefdoben wird: fo nennen cs bie Brirtner Nidfreln ober झJfeifellt. 


\section{§. 156.}

Die wirkung biefer benannten Pfropfungsarten ift abrigens biefelbe,

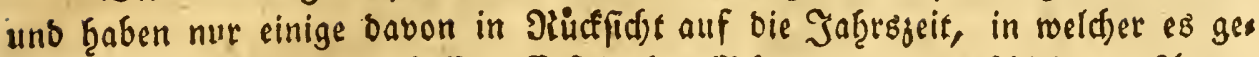

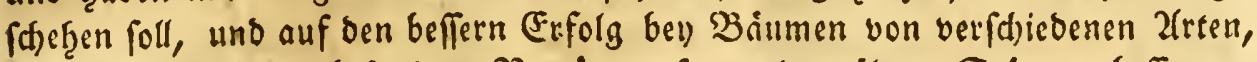

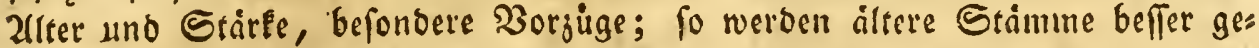

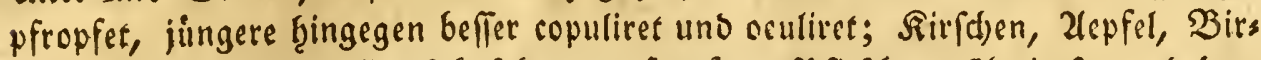

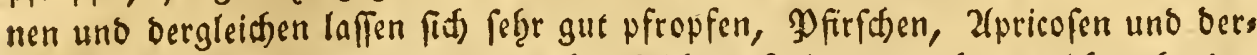
gleidjen aber beffer oculiten, uno bey foldjen Sgolgarten, bey weldjen beydes mit einigen Sdywierigleiten verbunden ift, ift bas 2lblactiren vorjuzieţen, als

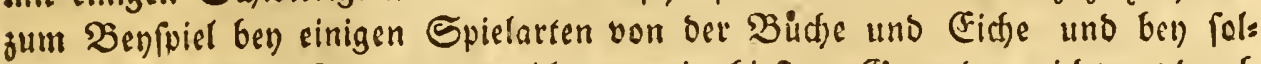
djen auslinnifden Syoljarten, weldhe man in hiefigen Biegenden nid)t gut burds ben Saamen fortpffangen Eann, und bie fid nicht leid)t auf andere ibzres Bileis den pfropfen laffen.

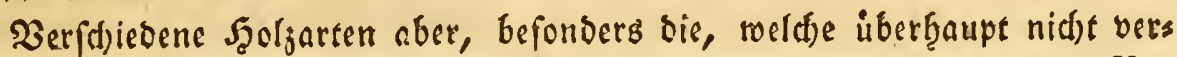

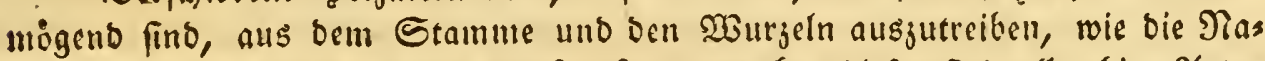
betholjarten, laffen fidf gar nid)t pfropfen, und bey diefen fino alle obige 2(rten vergeblidy.

\section{\$. 157.}

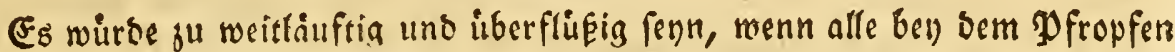

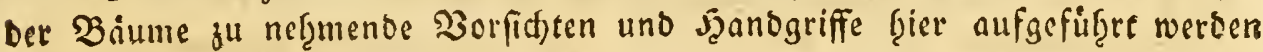

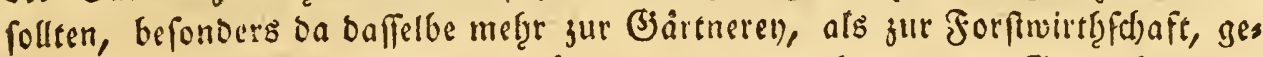
bort, uno in feģr vielen Sd)riften hiber bis Baumjud)t und ben Sartenbau hins linglid befdrieben, aud hibrigens to allgemsin betannt ift, baj ein jeber meis

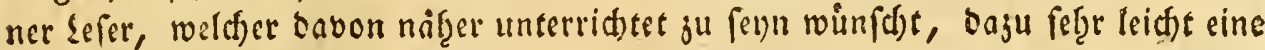
praftifche ?lnleitung finden wirt, weld)e aufferbem, fo wie eine ju erwers benoe Fertigleit, fu einem glusflichen Erfolge bey oer praftifchen 2fusubung vorgiglid) núthig ift. Es follen f̧icr alfo nut now einige Bemerlungen oariber

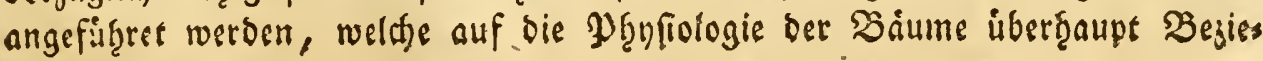
ţung ţaben.

\section{§. 158.}

Die Berbindung und bas Zufaumenwadfen bes gepfropften Stammes mit bem barauf gefersten Sieife, ober mit bem barauf oculiten 2(uge, Bifd)ieg̨t mit einer markartigen Subftang uno einem jellenformigen (jerwebe, wold)es gleid) nach bem $\mathfrak{p}$ fropfen an ben berroundeten Stellen bes Sicifes und oes Stammes, befonders an den beyderfeitigen Rindentagen aus beyden erft als ein 


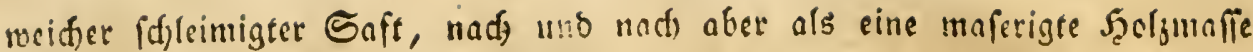
auswaid) fo roie man fold)es aud) bey andern beilenten \$etroundungुen an ber $\mathfrak{B}$ orle unb an bem jungen Şolje ber Bămme wadernimmt: benn bie eigents lid)en $\mathfrak{S}_{2} \mathrm{l}_{j}$ : und Rintenlagen bes Reifes und Stammes verónben fids in bem erften Jaf̨re nidjt unmittelbar, uno nut in ben folgenben Jal̨ren bilben ber

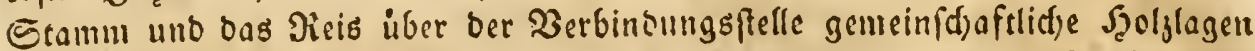
uno Jal̨rsringe. Diefe Bereinigung gefdjef̨t gltid) nad) oem Pfropfen ooer Sculiren aud) nid)t auf ber ganjen 2(bjd)nittsfiache bes Reijes uno auf allen Berüfrtungspuneten oeffelben mit bem Stamme, fonbern mur oft auf sinigen febr Pleinen Stellan, weldies f̧inlänglid, ift, finfrig ein gänjlides 3 ermad) fen fu beforbern, weil bas Riǫhrengewebe ber Baiume, wie bas Berber ber Zuis malien, unter fid mit unenolid) vielen Fafern uno Nebenrobsen in gemeinfdafts

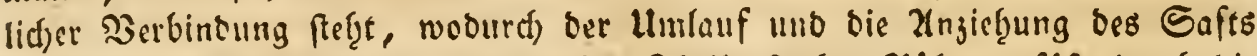

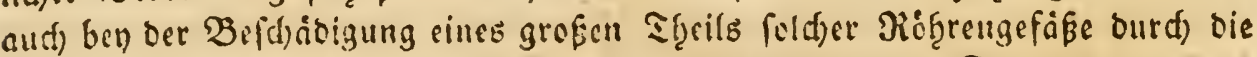
ubrigen unbefudioigten unterg̨alten uno lacrgeffellet wirb. Da nun an einent

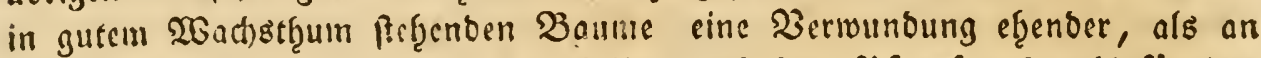
cimem fdroidjlidjen Stamme, ausheilt, unb bas Pfropfen foroofil fur ben

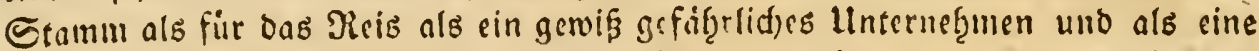
parke 3erwunoung anjufiten ift: fo iniffen aud) benbe cine gefunde Trictss fraft graben, um biefelbe ausjuhalten, uno um bie if̨nen jum fimftigen gemeins (d)aftlid)en Seben notbige 2uereinigung getgorig benirken ju fönnen.

\section{\$. 159 .}

Durd) Das Pfropfen erf̧ált man biefelbe 2(rt bes Baums, bon bet bas aufgefefte Jicis ober 2luge genommen ift, uno man ift nicht in Stande, Damit eigentlid)e 3arietaten ober Epielarten b̨ertorjubringen, wie es in vielen fallen ben Frud)tbáumen ourd) ben Saamen von einer fremben $\mathfrak{B} e f d$ wängerung mö. (id) ift; aud Pann burd) ein wieberf̧oltes Pfropfen sines Reifes auf ben Staum, auf reldsem biefes gerwad)fen ift, bie Zart beffelben nidst veranbert werben, mie einige Gärtuer bef̧aupten, invem bas lejtaufgefegte Reis nue

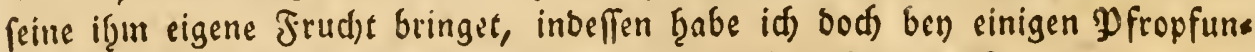
gen, bie id) in ber abfid) gemad)t ţabe, jiemlid) auffallenbe Mitwirfungen oes gepfropften Stanms auf bas Pieis gefeften. So bzabe id) 8. 2. von benfelben Reilern ciner beurie grife bie auf Duittenftämme uno auf $\mathfrak{W}$ Bilblinge aus beın Rern guter Baumarten gepfropft waren, beffere Frudfte erfgalten, als von

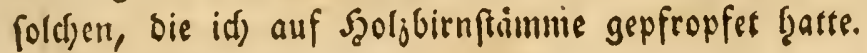


Zlud) nef̧iuen bie Birnen welde man auf ben Bogelbirnbaum (forbus

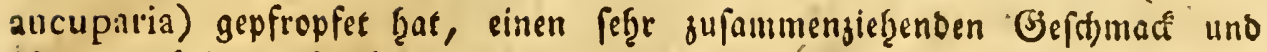
oft eine róthlide farbe an.

\section{\$. 160.}

Da bey bem YYfropfen fid) ber Stamin und bas Neis fo genau verbinden miffen, Daßj bende nur sinen Baum bilden uno if̧re Begetation gemeinfhafts

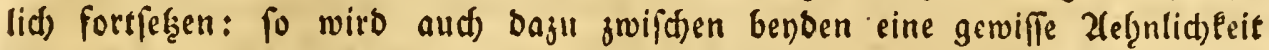
- Der Berwandeffjaft erforbert, wenn foldje 3erbinoung gef̨orig geratben foll.

Man eann baf̧er Birnen, 2(epfel und Duitten fę̧r gutt wed) felfeitig zufammen pfropfen, und $\mathfrak{P}$ flaumen, Pfirfden und apricofen nad) allen 2(rten unter fid) umid)affen, bey foldsen baumen aber, weld)e unter fid) meniget

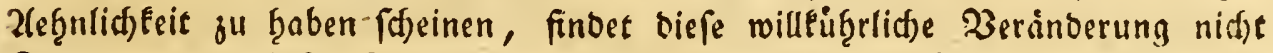
Statt, und alle $\mathfrak{P}$ fropfungen bie man von Eidfen auf Bidten, von Dbftbaus

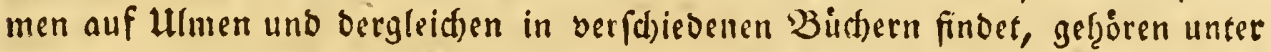
bie Dinge, beren Miöglidbeit nad) einer ausgedadten Sieblingshnpotbefe anges nommen ift, ob̧ne burch practifche Erfab̨rung beftittigt ju fenn. Inteffen

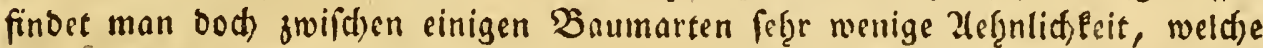
Demoņngendt)t mit cinem jiemlich guten Erfolge jufammengepfropft werden fönnen, als f. $\mathfrak{B}$. Die obenangefúfrete $\mathfrak{P}$ frepfung bes Birnbaums auf ben $\mathfrak{B}$ gelbeerbaum, weldhe fefgr leidte anjugehen oflegt, uno id) folbft cinigemal vers

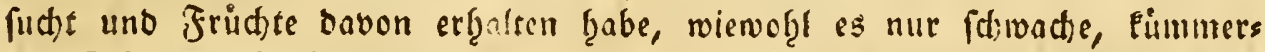

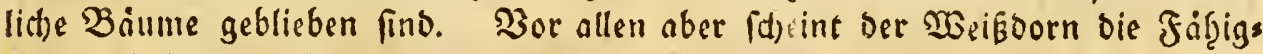

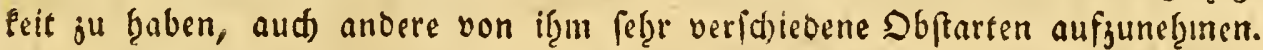
Man pflegt bafzer, wiemofgl mit ciniger Sd)wierigleit, $\mathfrak{P}$ firfchen, Mifpaln, 2lepfel und bergleidsen barauf fll pfropfen, weld)e zroar fleine Stainme bleiben, aber if̧res geringen Wadsthţums wegen balo viele uno gand gute

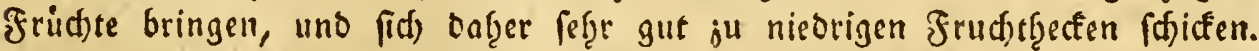

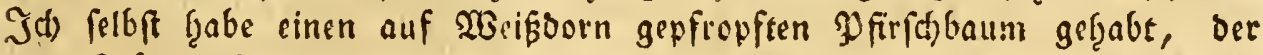
gute Fridte bractite, baben aud ferge wenig ins Szolz trieb, weil fith ber

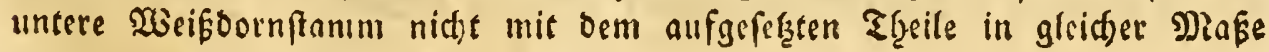
alsbef̧nte, - aber balo verflumunerte.

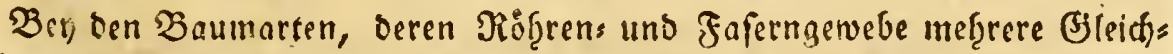
நneit ţat, als 3. B. Den Micifern ber Birn: uno 2lepfetarten, wenn tie auf Etaimme von guten 2lepfel, uno Birnecrnen gefegt werden, gerith oie Bers einigung ober DPfropfung fo vollemimen, bok man nach einigen Jnferen auf 
ber äffern Boorle fo wenig, als 6av' ber Itnterfuffung bes Soljes ouf ber Bercinigungeftelle, bie seringften Unterfdjeosjeiden bemerlen lann; bey Stammen aber, bie mebcr von ber batauf gepfropften art verfdieden find, fint fold)e befto fiatbarer, befonbers, wenn auf einen Stamm, ber nur

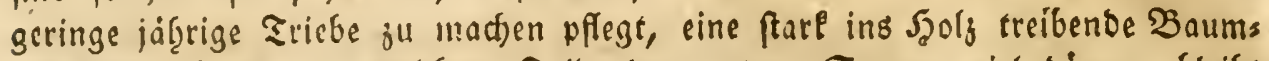
art gepfropft ift, in weldem Salle ber untere Stamm viel bunner bleife

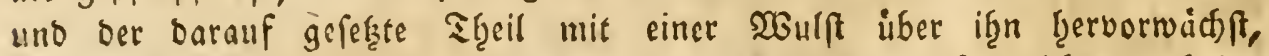

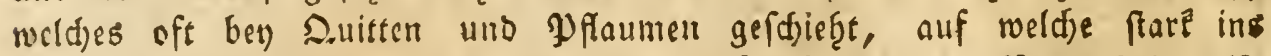

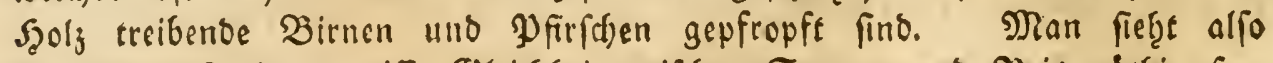

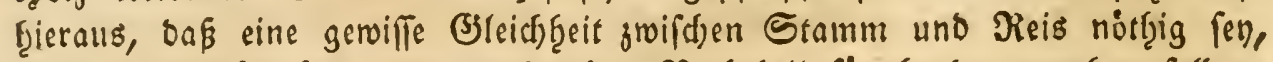

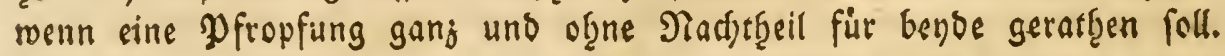

\section{§. $16 \mathrm{r}$.}

Sdjon oben \&. 197. ift es angemerff worben, oaf es nidje roogl fu

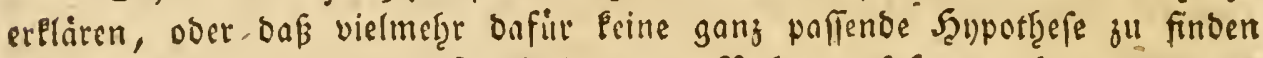

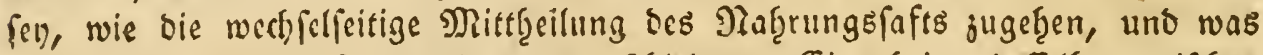

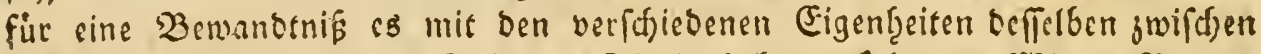

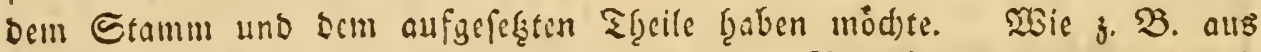
biefem Softe bet untere 30 gelbectoam faure 3ogelbeeren, uno bas aufs

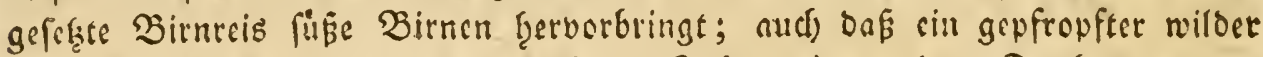
Stamm, ber oft fecfjig und meţrere Jaf̧re cine andere Jrucht getragen Izat, und feit feiner, bev ciner Stärke von eincm Ziertfeiljoll im Durchucfter,

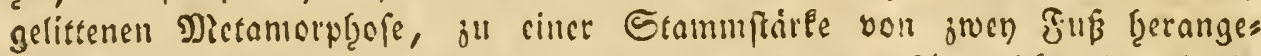

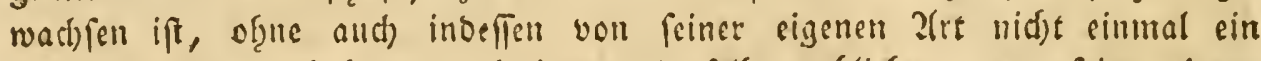
Sllatt gejcigt jll baben, nod) immer berfelte gebliebcil, nur feine cigene

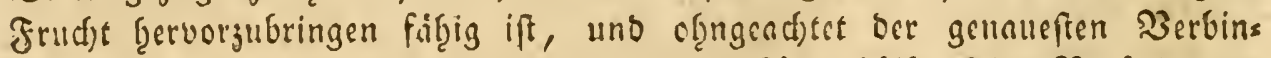
oung mit feiner ig̨m ganj eigen geworbenen Siotperb̨älfte feine Beränocrung gelitten beat, wie man foldes an alten Doftbrumen bemetfen Pann, an benen bie an ben NGurjeln ober an bem untern Stamme hervorwad) fenben wils ben Eprofien die unocranocrte frud)t Deffelben tragen.

\section{§. 162.}

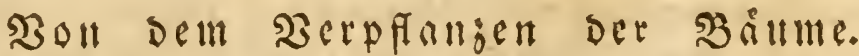

Das Serpflanjen dex Bäume gef̧üt cbenfalls unter bie Eünftidien und nibernatirliden 2 efganolungen berfelben, id) verfpare es aber bis jur Befdreibung ber Eidjen; Dabon ausfübrlidjer zu Ęandeln, theils, reil baben 
vieles, was hier zu lagen waire, wieberf̧olt werben muskte, theils audg, weil

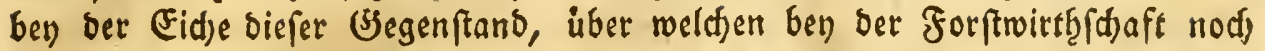

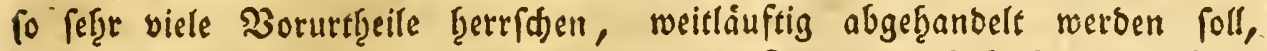

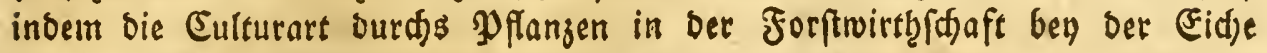
vorgiglid) Staft findet.

\section{Finfter $\mathfrak{A} \mathfrak{b}$ fidnit.}

\section{3on Der Eage einer Gegend, von dem Grtunde und $300 \mathrm{~cm}$, und Den verfdiedenen Erdarten.}

\section{§. 163 .}

Die Lage siner Biegend uno ber Grund und Booen berfelben ḩat auf

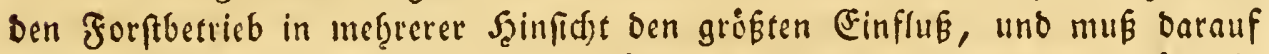
fowohl in Betreff Der Eultur, als bes ubrigen Forfthaushalts genaue Piltefitht genommen werden; es nirb onf̧er, um bey jeber ju beffreibenden Sgoljart

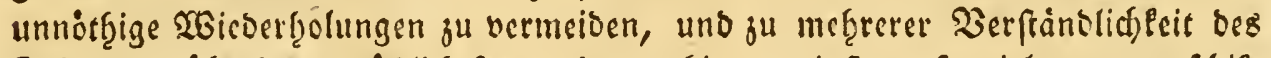

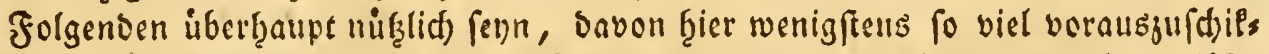

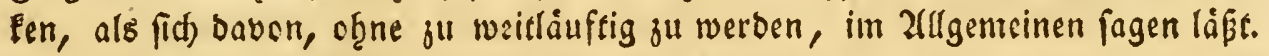

Es giebt fladje und bergigte Bjegenden, erftere Eonnte iman in trocfene, flacke Sanogegenden, uno in tiefliegende fumpfigte, moraftige Biegenden theis len, fo, wie man legtere a) in ḩüglidte (jegenden, b) in niebrige lano: und

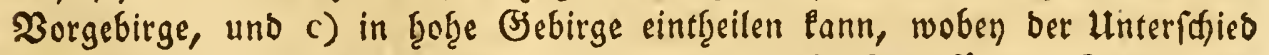
Der lage ber Giebirge nad) ber Szimmelsgegeno ebenfalls für den forftbetrieb suferetit widjtig ift.

\section{§. 164.}

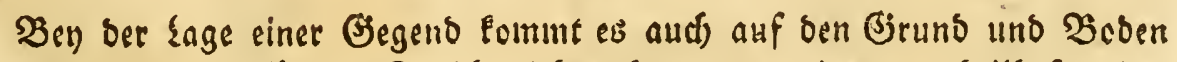
an, woourd biefelbe für ben Forftbetrieb imef̧r oder weniger vorţ̧eilf̧aft witb. Da nun bie Unterfud)ung beffelben einige Senntniß̄ von ben Eroarten erfor: Dert, in to weit fie auf bas forftwefen Begieţung haben: fo ift biefe auds bem Sorftmann unentbeg̨rlid; Dod braudter fid babey nut auf fein Fach eins 


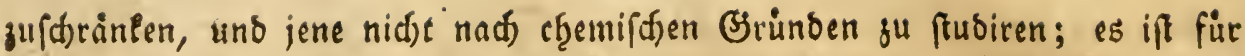

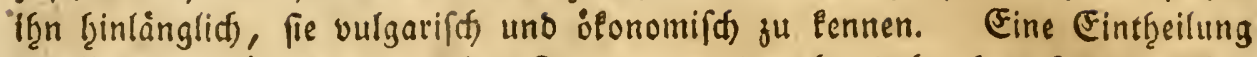
Der Eroarten für ben praftifd)en Forftumann wirb aber bafer bem finftematifden Dineralogen eben fo unbefriebigend penn, als jenent mandfe chemifhe 2(nalype Der Erbarten unnits ift, bie man zum Zgeil felbft in énigen. Sorftfdriften jum gelef̧rten 2anfrtid)e angefüf̨rt findet.

$$
\text { §. } 165 .
$$

Die berffiebenen Erbarten, wie fie beym Jorftwefen in Betradje fout:

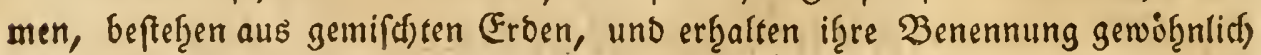

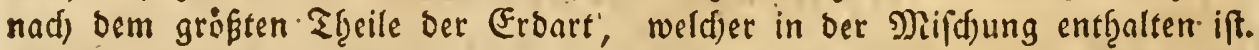
Die Eintheilung ber (Erben in frud)tbare und unfruct)tbare ift für bas forfts wejen bie zrectimábigfte, uno biçe muß̧ für bie fernern Eintheilungen zum Brunde gelegt werben. Sene find bie Erben, worin bie $\mathfrak{B}$ iume und Dyflanzen

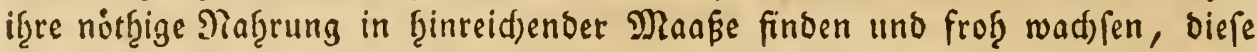
fingegen, worin fie entroeder gar nidft, ober bod) nur kümmerlid) wad) fen Eonnen. Unter bie frudstbaren Erben gef̧oren:

1) \{aub, oder PYflanjenerde,

2) Moorerbe,

3) Ser̨merbe,

4) Mergelerbe,

5) Thonerbe,

6) Sand, wie er in bem naturlifien Buftanbe beym forftrefen betracts. tet wiro und mit andern Erbarten gemifd)t vortommt: Denn nad) feinell eigents lidjen Beftandtbeilen, wie Eleine Steine betrad)tet, getgiort ber Sano ju ben unfrudtbaren Eroarten.

Unter bie unfrudftbaren Erben

1) Feftes Tf̧onlager,

2) Jefter Miergel,

3) Steine aller $2 \mathfrak{r t}$,

4) Schieferlager,

5) Stark sifenfduifige Eroen,

6) Brober ungemifdster Sand oder Brand.

2(uธ biefen Eroen beftę̧en nun die verfdiedenen Mifdungen ber Erbarten,

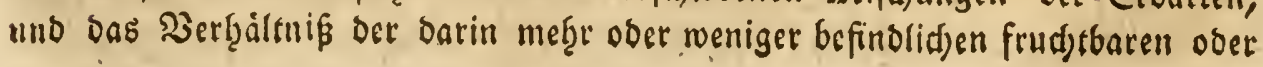




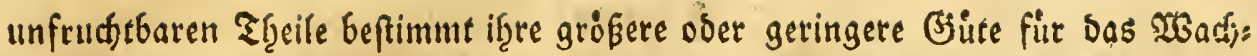
fen ber Bäume. Da nun aus biefen Erbarten unżiflbare Mifchungen bon Eroen entfanden fino, beren (Einfuf auf bie 2 egetation nod) burd) bie lage

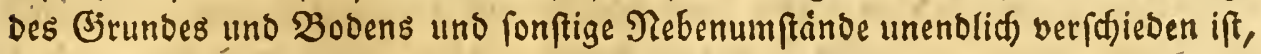

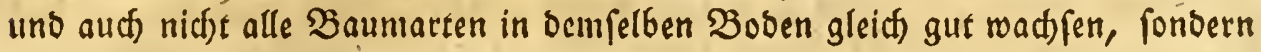

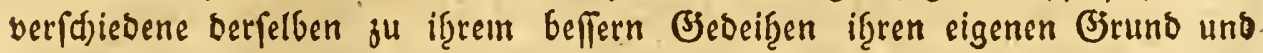

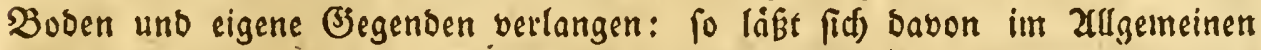

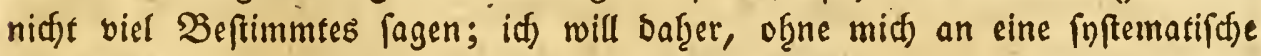

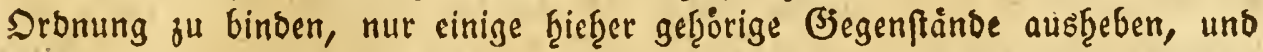

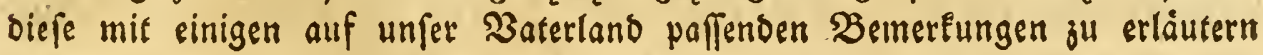
fudben.

\section{§. 166. \\ Bon eitter fladent begend.}

Die Sorften, melde in einer flathen Begend liegen, in ber die grope

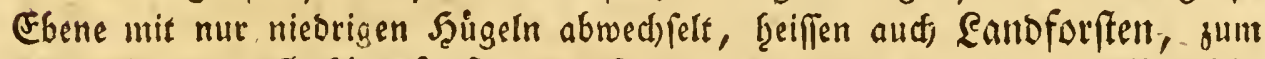

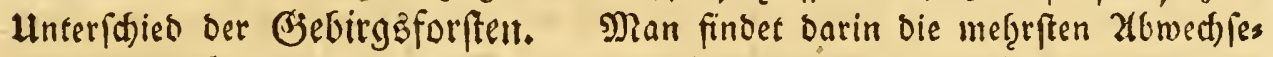
lungen von Brunt uno Boben; als naffe Serter, Moráfte, Seenden, fandigte Begenden, Flugjand und Erbarten nach allen Mifdungen.

Ilnter bie 23orginge ber Sandforften vor Den Bjebirgsforften geţort, bas in jenen einige Baumarten uno bie meiften Straudftgotzer befonders gut wad):

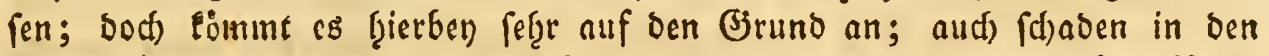
flad)en Begenden, wegen ber bajelbft gemäigtern Witterung, bie bijen Rebel

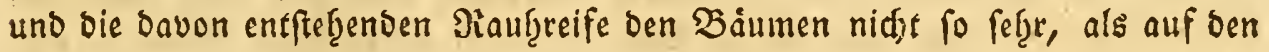

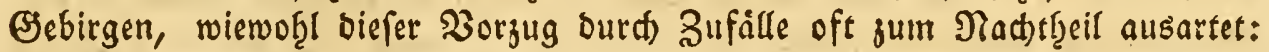

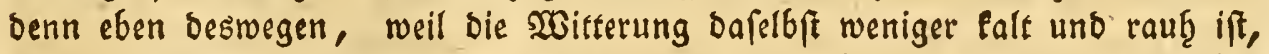
treiben bie $\mathfrak{B}$ aume chender, und leiben baf̧er fef̧r oft von einem fpaten Frif̧, lingsfrofte ben gróften Sthaden, wie man benn aud) in Den flad)en (jegenden viel feltener $\mathfrak{M a f t}$ findet, als in Den bergigten. Die Siafer, Raupen und ber=

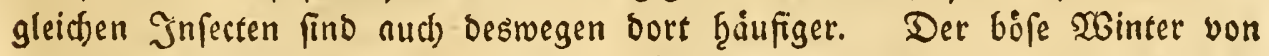
1788 in 1789 . Der nur in ben flad)en \{andesgegenden unfere Dbftgäten und Pflanjungen verf̧eerte, wirb uns bavon nod) lange Zeit eine traurige Erinnes

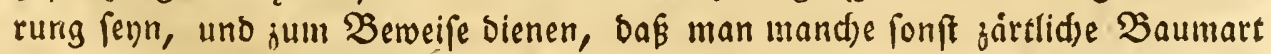
leid)ter auf niebrigen (J)birgen, als auf bem flad)en Lanbe jief̧en Eann. 


\section{\$. 167.}

Bon eiller mafien und moraftigen G̋egend.

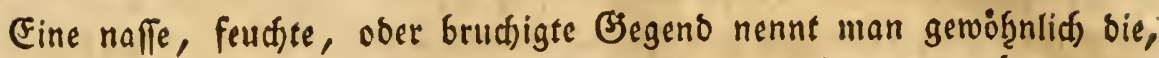
iiber weldje nur in ber naffen Jaf̧rsjeit etwas waffer fiefrt, was aber in ben Sommermonaten abfließst, uno beren Boben bann, hinlinglid) abtrodnet.

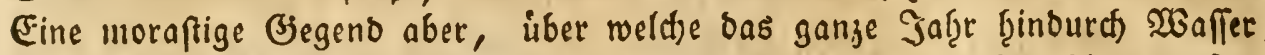

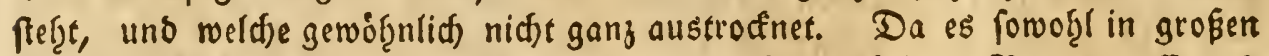
Ebenen uno it ben tiefern Jegenden, als auf oen ḩodffen Bergen naffe und moorigte (jegenden giebt, fo laffen fich biefe barnad) fef̧r anpaffend einţ̨eilen:

Naffe Bjegenden auf ebenem uno flad)em Sande giebtes in ben Forften bey Braunfdrweig, aud in ben Teubricfidjen, Teufjaufer uno Borsfelber Forften, als moraftige aber fonnen bie Dromlingsforften mit allem Red)t ans gefübret weroen, weld)e aud) in ben trocfenften Sommermonaten für ben,

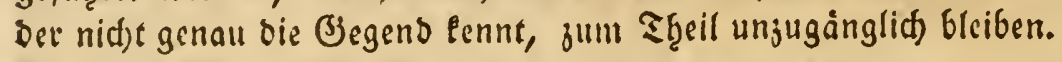

Taffe unb moraftige Biebirgsgegenden finden fidy auf ber Şöhe bes Sols

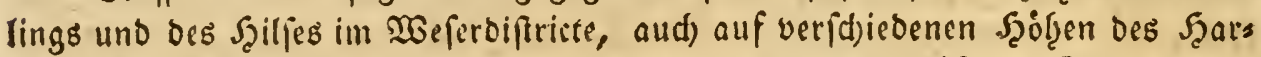
zes, befonders oben auf oem Broden, wo fie von bem oftern Bebirgsnebel Den beftindigen Bufluß von $\mathfrak{x}$ affer erhalten.

\section{§. 168 .}

Der Folptbetrieb in ben naffen unb moraptigen Begenten f̧at ferge viel eigenes, und ift von bem in ben trocéenen Bebirgsforften fefre unterfdieden. Er erforbert befondere seute, befondere Şolzarten, und eine eigne befondere Betrandlung. Jene miffen gleidffaum zu bem beftänoigen Eumpf, und

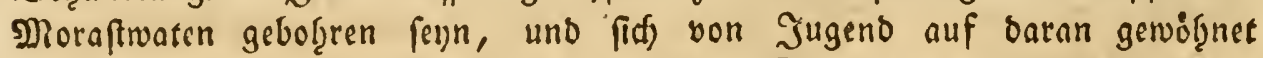
haben, weswegen benn auds bie in foldjen Ëegenden erzogenen Forfetan= bibaten bafür vorjujief̧en find. Ein gleidjes fann man von ben Bäumen unb Eträudjern felbft fagen, benn audf biefe traben in naffen moorigten Begenden von benen ifgrer $2(r t$, bie in Bebirgen wad) fen, ein ferger verfdaies

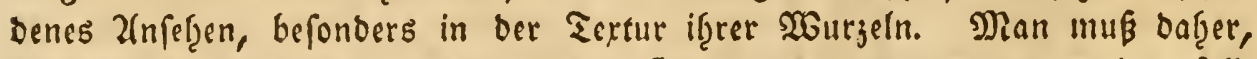
wenn eine Pflanjung in Dergleidjen Begenden borgenommen werben foll, baju auf gleid)em (jirunde gewad)fene Pflinglinge nef̧inen, fo wie aud ben

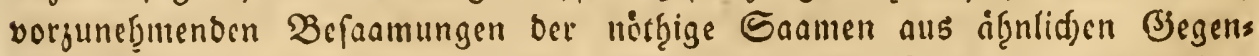
ben vorgujiegren ift, movon in ben ju befdreibenden Forfteulfuten eingelnet Sgolgatten mef̧reres vortommen wirb. 


\section{§. 169.}

In feuchten, naffen (Segenben wadjen einige Baumarten vorguglich gut, wenn ber Sruno if̨nen angemefien ift uno; fum B̉evfpiel, aus einem mit se[cms uno fonftigen frudtbaren Eroarten gut vermifdten, nicht eifens

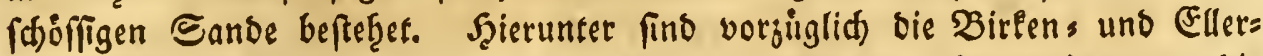
arten und verfdjedene Stråuder. Zuf ben etras erf̧abenen Derfern, bie man in bergleidjen (Jegenben benn geroigchlid) Berge nennt, menn es aud

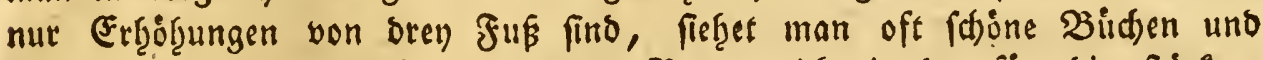

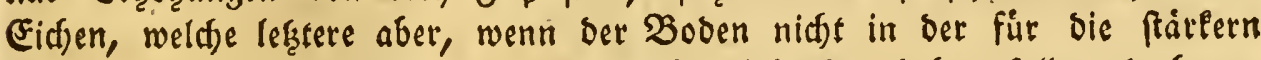
Eidjen erforberlicfen Tiefe bie getcorrige Frudtbarfeit baben follte, bod) nur

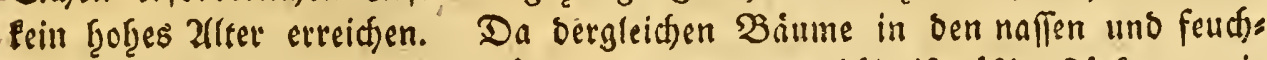

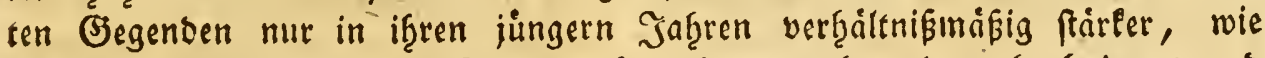

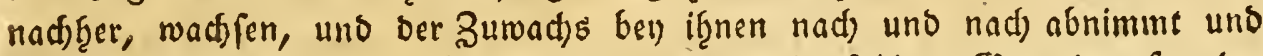
enolid beynahe ganz auffeort: to pflegt jeber, in foldsen bjegenden frembe, Forftinann bie Băume bey weitem uno oft nid)t balb fo alt anjufehen, wie fie wirflid) fino. (jewoignnlid) ift bie verfdjiebene (Site uno lage bes

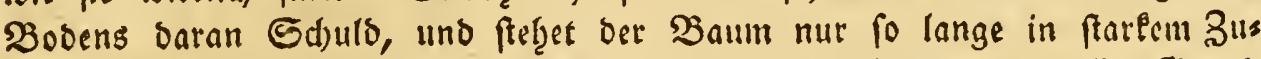

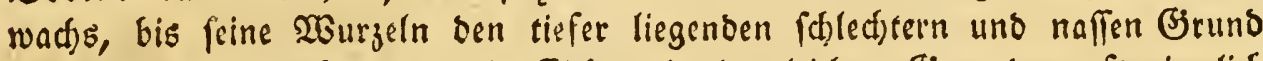

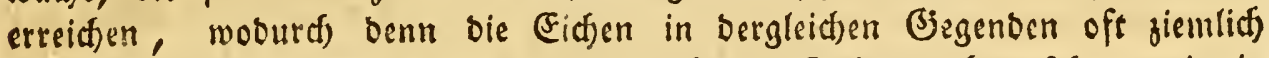

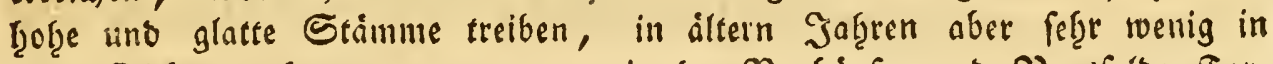

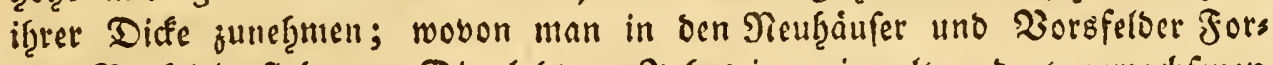
ften Beyfpiele findet. Die lef̧tern Jab̧rstinge in alten bort gewachfenen Eidjen find baher oft fo fein und fo bart verwadjen, daf man fie mits freyen augen faum ju ją̧len vermogent ift.

\section{§. 170.}

Da ber Bruns uns Boben in sen feudten uns naffen Bjegenden in

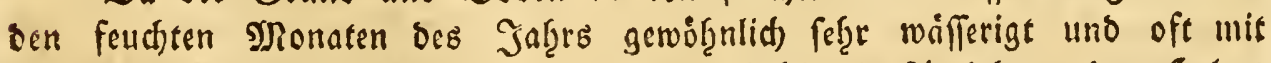

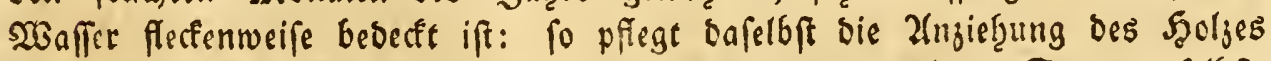
aus bem Saamen auferft mislic) ou fern; inbem fowohl ber Sanmen felbft, als aud bie aus bemfelben entfandene junge soben baburef fefre leiben.

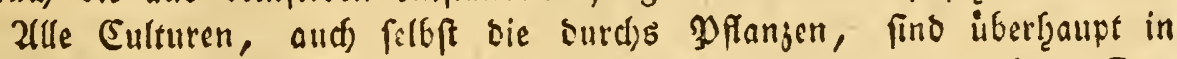
ganj moraftigen Siegenoen fetgr befáberlid), Poftbar, uno miflid). Den Dit fo viel als moglich zu entwaffern, ift zwar oft bas theuerfte aber aud bas guverläfigfte mittel, befonbers weil bas barauf ftefende

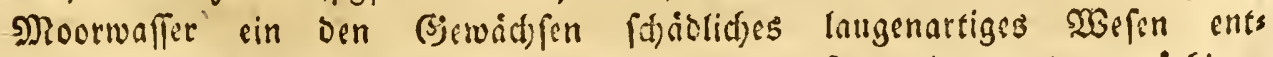

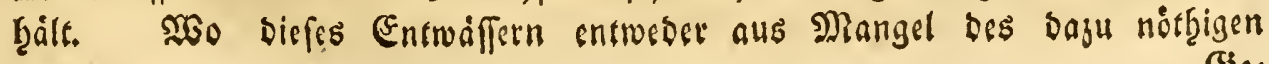




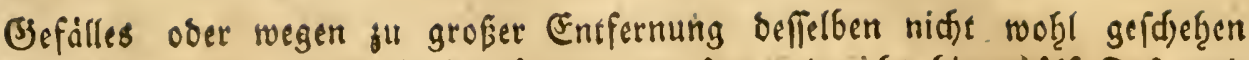
Pann, mus man fids oft begnugen, Den Drt mit act)t bis jwoilf Fuf weit von einanber entfernten, einige Fuf Greiten Jraben ou burdjief̧en, uno auf bie baraus entfanbenen 2 fufwirfe, ober auf jonftige aufguwerfende Saigel junge Ellern gu pflanjen. Die erftere 2art ift zwar foftbarer, aber fiderer, befonber's wenn man bie Braben nach ber Seite jieb̨et, wohin auch nur ein ferce geringes biefälle ift.

Sn (jegenden, wo bas Ellern Şolj gut ju benufien, und aud) nur in mits telmáfigem Preife fteţt, fino berglciden Eulturen folder Moråfte, die fonft nict)ts ober nur áuberft roenig einjubringen pflegen, oft fef̧r vorţ̧eilf̧aft, fo, wie es iberhaupt bey oergleidien mihfamen uno loftbaren Culturen fef̧r auf

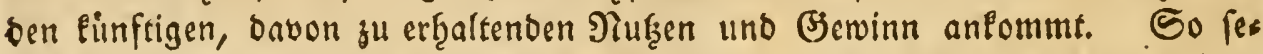

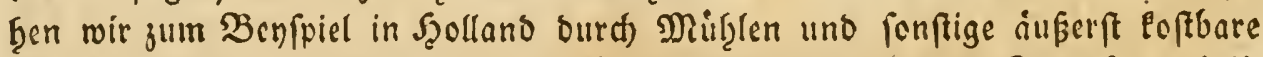
3orridfungen mandien in andern Begenden unbebcutenden Sumpf vortheils haft entwäfletn, und in anbern volfarmen Sanbetn bagegen mebृtere Meilen grope Strecfen Sandes ifrem brudjigten Suftanbe ganj unbenufit überlaffen, bie oft mit einigen geringen (5raben frud)tbar ju madjen wären. Die von ber $\mathfrak{F}$ os nigl. Preufifden Eammer vorgcnommene Entwäferung bes Dromlings in Der

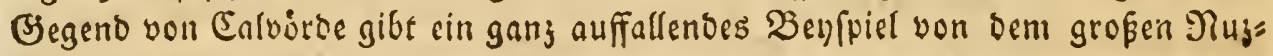
zen folder $\mathfrak{D}$ rud)culturen.

\section{§. $17 \mathbf{r}$.}

Die obere Erblage cinet moraftigen Begend ift faft allejeit cine oft bidgete oft nieorigere Torflage, to wie unter bem Torfe eine thonartige ober fonfrige fes

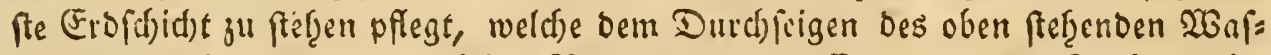
fers wiberftebt, und fo bie nad)fte ßeranfaffung jut Entftef̨ung bes Torfes-giebt.

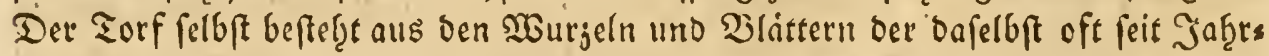
taufenden gewad) fenen sigenen Moctpflanjen uno cinigen Erofioljarten, wold)e, ta fie aflezeit im 2 boffer geftanden, nicfit ganj verfaulet fino. Durd) bie in ben

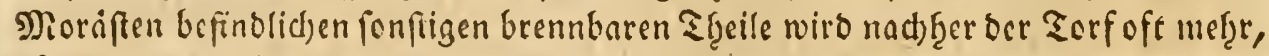

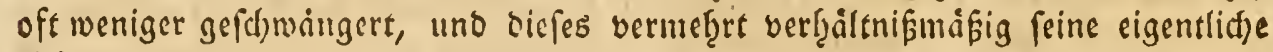

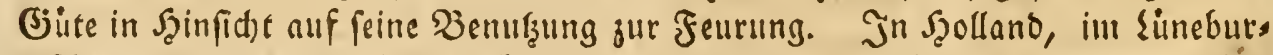
gifden uno bergleidjen flad)en (Jegenden findet man ben Torf oft in einer Saobe von jwanjig uno meb̨r Fuß ftehen, weld)er onun, fo fef̧e unfrudftbar er fur bie

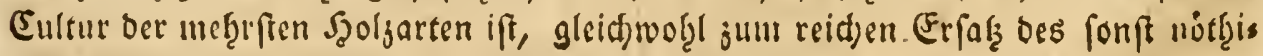
gen Sranob̧oljes dient. 


\section{§. 372.}

Da ber Zorf nun größtentb̨eils aus vegetabilifden Sheilen beftetct: fo ift berfelbe fefer leidat ju guter Planjenerbe umjufdaffen, wenn man mur ben Standort entwáffert, einigemal tief umgräbt, uno sin paar Jaf̨re burch rotten láft. So eann man bie fauerften Moormiejen, worauf nid)ts als Sajilfgras gerwadjfen ift, in wenigen Jaf̧ren ju ben frudftbarfen Feloern uno (Bärten ums antern. Diefes ift auch bas eingige Mittel, in nafien torfartigen Jiegenden Pflanjfdulen anjulegen, welde man benn oft mit Der. Erbe, bie aus ben um

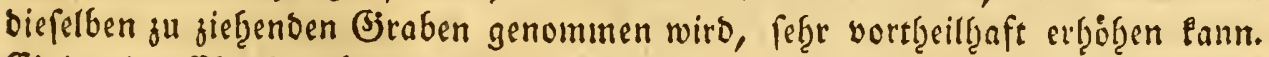
Einige in Egurf̧annoberfden vorgenommene fefre onfefrnlide Entrófferungen

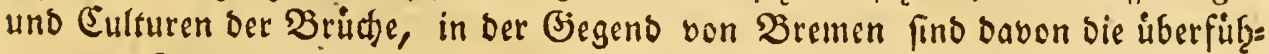
renoften $\mathfrak{B}$ encife.

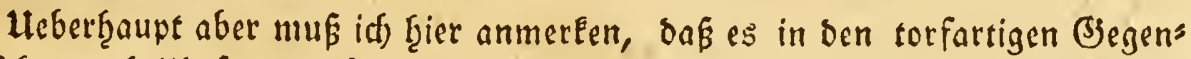
oen fefre vortheilfraft uno oft unumganglid) nottrig fer), bie 3 aiume auf flad)e Sgügel ju pflanjen, uno diefe wenigftens ein Paar Jaf̧re fubor aufrotfen uno sin ober zroenmal burdarbeiten ju laffen, Damit ber Torf Daburd) locfer und ju guter Eroe' umgefdaffen werbe, aud im Pflangen alsoann getrorig bey bie

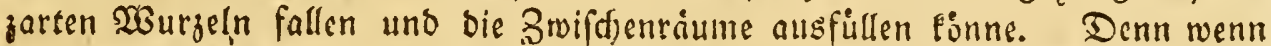

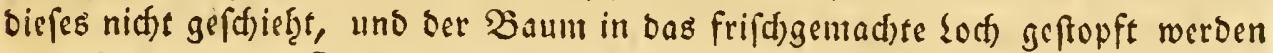
foll: fo merben bie Bwifdenriume der $23 u r z e l n$ nid)t gefullt, indem es oft gainz" lid) an Erbe baju felflt, und bie ausgeftod)enen ju feften Rafen und Torfe wers

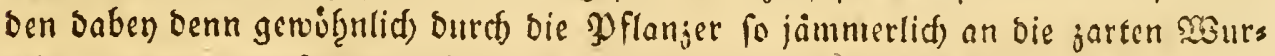

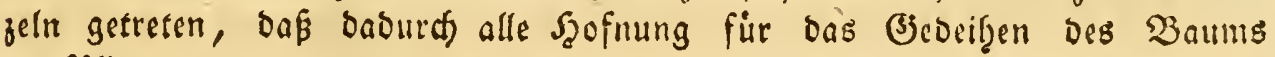
wegfält.

Die Sodser in einet fold)en torfartigen (Begend muffen auth viel grofier, wie gewóf̨nlid), gemadt werben, banit oer ßaum bie enften Jabre befto leichter cinnurjeln foinne, weld)es fonft in bem fo feften Torf nicht leidjt ju gefdefen pflegt.

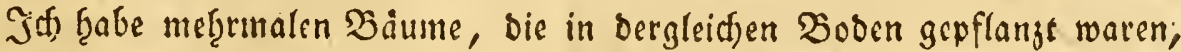

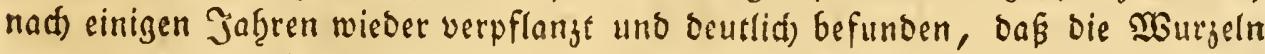
nur dell losgeftodsenen Ţ̧eile ber Eroe nadgegangen waren, und ben ubrigen

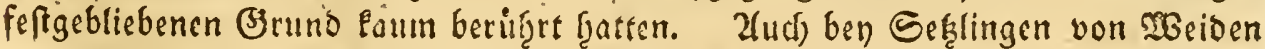
und Dappelarten ift biefe Firforge in naffesn Giunbe febre anjuratgen, uno wit' man ben 3ortheil in wenigen Jaf̧ren fwiten, wenn ftatt ber gewólgnlid)en ?

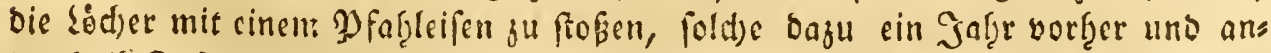
berthalb fuf weit gegraben, ullo Dann bie Sef̧linge bineingeftect werden. 


\section{§. 173 .}

Wenn cin moraftiger Drt cinmal mit Ellern befanben ift und fo erhalten rocrbelt foll, fo mus man fich ferbe vorfetgen, benfelben nicft nuf cimmal zu fart

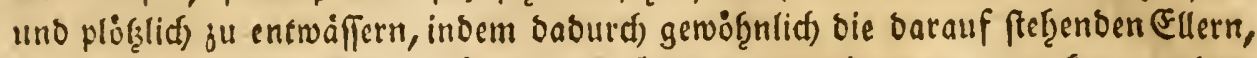
Seren 2 Uurjelgebaube nur fur biefen Jirund gemadit war, troden werben.

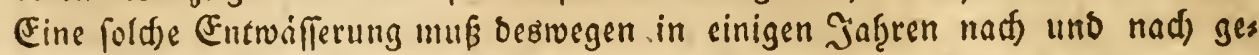

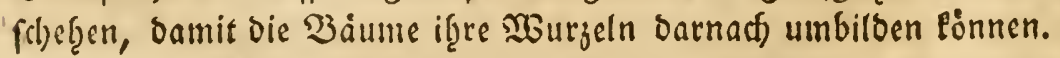

Bey Calvorbe und in mefrern Gegenden, wo grofe Entråfferungen vorges nommen find, im Slciner aud) in ben, burd) ben Canal entwaiferten, Brudien bev) Braunfdrweig fino bavon meferere (Ellernorte aus jener Urfadje vertrofinet finden wirb.

\section{§. 174.}

Die brudjigen Giegenden, befonders, wenn fie eine bृoţe ₹orflage ţaber,

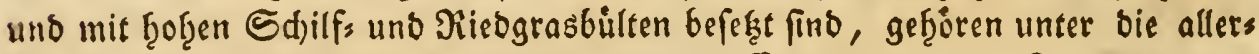

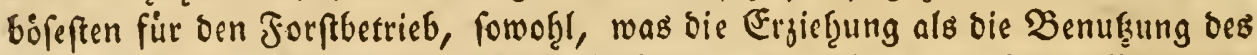
Sgoljes betrift. So minfen oft in Drónlinge die längt bzaubaren Ellernorte

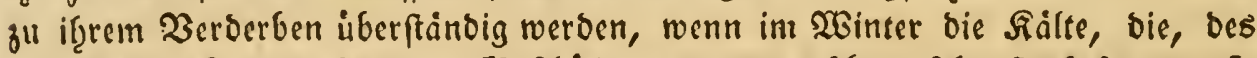

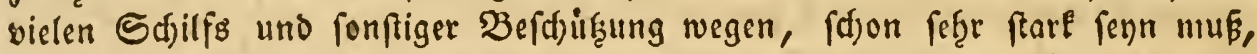
nidf hatt genug, ober nid)t anf̧alteno ift, um bas ju fd)lagenbe Şolj auf bent Eife aus bem 2 rudje ju fdaffen, wie es in ben Jabzren i790, 91 und 92 . Der Fall geweren ift.

Lebrigens ift aber auth in folden (Begenoen ber Forftbetrieb auferft eins fad), weil faft alle finftlid)e Bef̧anolung baben wegfällt, uno, wenn aud Giin "und wieber bariun einige Sulturen vorgunefimen feinn follten, fid foldfe eigents lid) nut allf bie Ellern befdränen, bes Daren Befdreibung meţreres babon borlommen wirb.

Man unus oft aus Noth es gróptentfeils bet Natur uberlafen, was biefe in foldgen unfrudftbaren (biegenden wad) fen laffen will, uno fefcr barauf bebadjt fenn, tak man alle forffwirthfd)aftlid)e Lnternefzmungen berfelben gemás uno

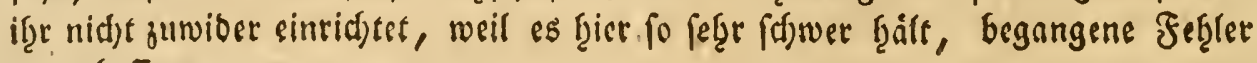
ausjubefifern.

$$
\text { §. } 175 \text {. }
$$

Llebrigens f̧aben aud sie Bridfe, wern fie gę̧orig mit Şolje beftanden fino uno gut beţanbelt merben, vor mandgen ju trocfenem Srte, feb̨r roefentliche 


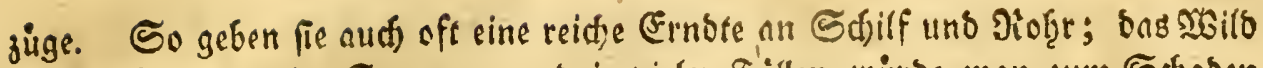
liebt fie befonders in Sommer, und in vielen Fällen würbe man jum Schaben handeln, wenn man foldes Srüd)e entwáffern wollte. Męrreres, was bie forftwifienfd)aftlidje Bef̧andlung oerfelben becrifit, wirb an ben geţorigen Dr: ten vorfommen.

\section{\$. 176.}

\section{Bon fandigten Giegendent.}

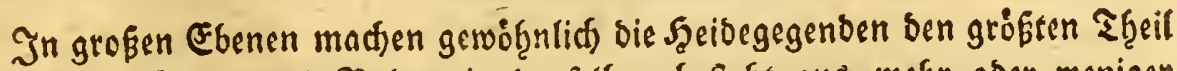
aus, und ber Brund und Boben in benfelben befteģt aus mef̧r ober weniger mit Sef̧ut uno pflanjenartigen Erben gemiid)en Sande.

Mian pflegt bafelbft nach biefer Miftjung ben Erobeben abjutfeilen

a) in blofen Sanbboben, beffen beftandtreile faft ganj fandigt uno grefentheils grobeurnigter Sano find;

b) in gemifdten Sand, welder mit andern Erbarten mef̧e ober weniger vermildst ift;

c) in Mcorerbe, beren Beftandtheile groar mit Sano gemifdte fino, meis ftens aber aus moorigter YHanjenerbe beftethen. Der bfofe Sand beifít alss Dann flugfand, wenn berfelbe fo wenig mit feinern $\mathfrak{3}$ erbineungstf̧eilen verfeget

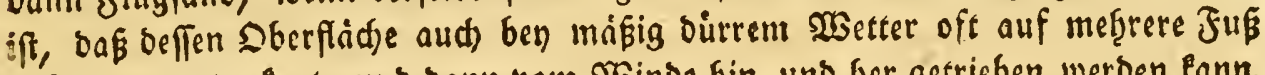
tief gang austroffnet, und bann bom 2 Sinde bin und her getrieben werben fann. Stef̧enter Sand aber, beffen Sberfliche entweber aus ber ifgm eigenen ober jus fälligan nef̧rern 3 erbinbung voun 2 Binde nid)t getrieben werben fann. Zu eis

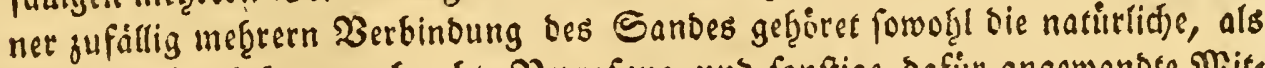

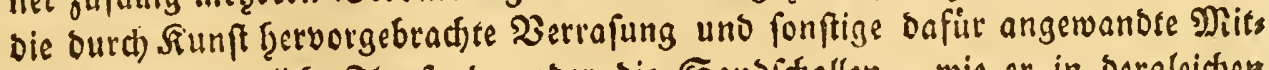
tel. Der eigentlide flugfano, ober sie Sandidjollen, wie er in oergleiden

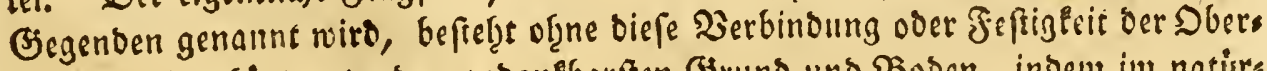
flàde, und gef̧iort unter ben undanfbarfen Grund und Boden, indem im natirs lidgen 3uftande ouf bemfelfen nid)t allein gar nidjts wächft, uns bie Eultur bef

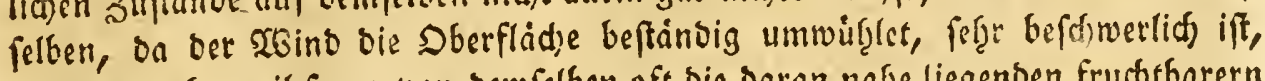
fonbern auds, weil fogar von bempelben oft bie Daran natele liegenden fructitbarern

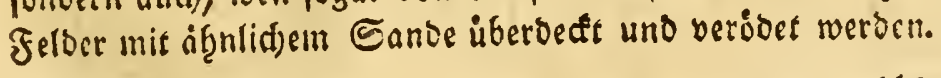

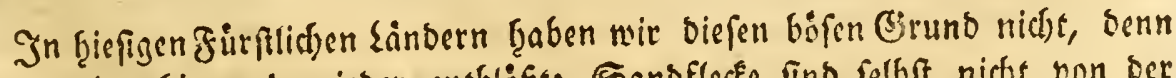
einige menize bin und wieber entblößte Sandflecfe find felbft nicht von oer

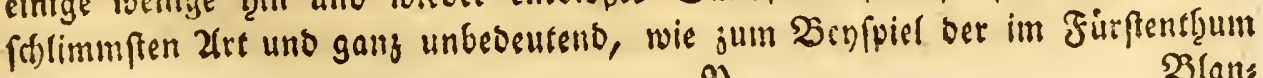
(Erfer Tyeil) 
Dlanlenburg beym Regenfein gelegene Drt mit Flugfand, bet aufferbem ddon gropentbeils mit ben bafur fdicfliden Furen cultiviret ift. In anoern Sandern

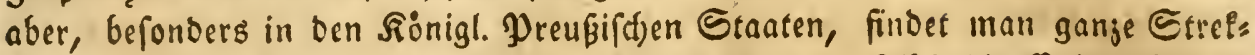
fen und grofe Begenden bon Flugfand, wesroegen bafelbft bie Cultur auberft roidtig ift, uno bie Sienntniffe uno Erfaţrungen, einen foldjen Boben ju bin: ben uno ju Culturen fäbeig zu machen, von einem foiftmann mit Red)t gefors bert werben Ënnen.

\section{§. 177.}

Die getwof̧nliden Mittel, bie Sanofdollen ju binben, beftef̧en barin, Dak bie Dberflactje berfelben gegen bie farten Winde gefidert bleibt. Man pflegt beswegen bafelbft verfdicbene leidte Siune uno flect)twerle gegen ben ftäkften Binojug in angemeffenen Entfernungen von einanber aufjurid)ten, den Boben mit verfdjebenen Bweigen befonders von Furen ju bebecfen, und bann eine $\mathfrak{B}$ efaamung von Birlen uno furen barauf vorgunef̨men, weldfe lef̧tere bafelbft mit ganjen 2fepfeln am beften ju geratfen pflegt. Bu mef̧rerer uno

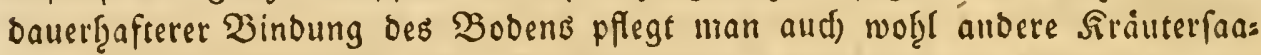
men, als Sgeufaamen, Farrenblätter, Sinfter unb fonftige, in Dergleid)en $\mathfrak{B} 0$ s ben audf nur lummerlidf wad)fende, Sráuter mit barauf zu fäen, un baburch cine linftlitbe 3errafung fu berwillen, uno ben jungen $\mathfrak{j}$ oljpflanjen sinen fes

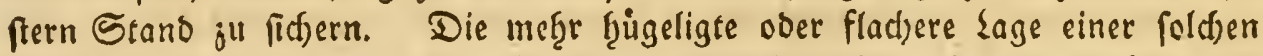
Salibfdolle, aud bie fenftige (jelegentzeit und llinftande andern ficrben biefe verfaiebenen Dittel, aus benen ber Jorfmann bie zreefmåjigften ausjuwåtg: len Gaat.

$$
\text { 8. } 178 .
$$

Der ftẹtende Sand lommt in ben hiefigen füftlitfen Sandern aud nur in

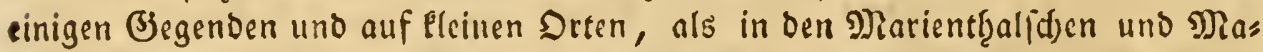
rienbergfden Forften, auth auf oen Sciben einiger (jebirge vor. 2(uffer feiner

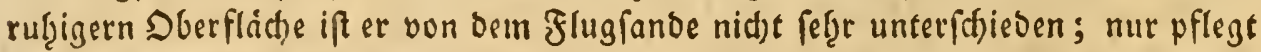
er oft mit meb̨reren bengemifchten feinern Sandtheilen gebunbener zu fentr.

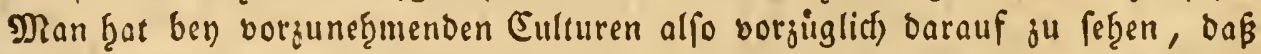
bie Dberflad) beffelben fo viel, als inoglid gegen Wino und brennende Saifze ges fidfert bleibe, uno beswegen bie barauf befinblide ßerrafung, die auf bergleis

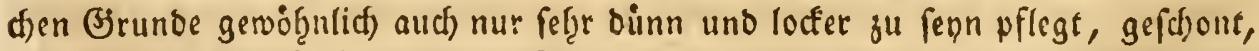
und alfo bie zum Einbringen bes Snamens und jum NBadjen ber jungen Spro\% 


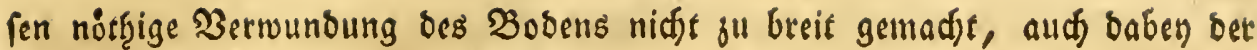
Siruno nid)t ju fef̧r aufgeloctert werbe.

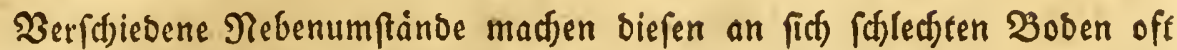
nod) unfrud)tbarer. So ift berfelbe an vielen Drten eifenţaltig ober eifenfduj. fig, mit vielen Steinen vermifd)t, aud) oft mit einer binnen Moorlage und eis

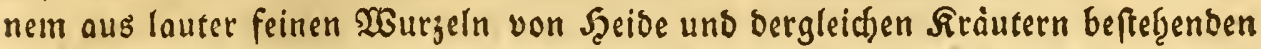
bofen filg ubergogen, roeldes alles fowohl bas erfte Zuflommen oer jungen

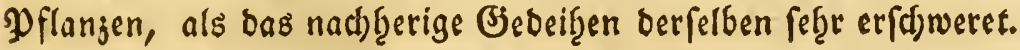

Erftere beybe, uns anbre bergleidien Hebel, bie in ber Eigenfapaft bes Brunbes felfft liegen, laffen fich nun nicht fur ben Forftgebraud verbeffern,

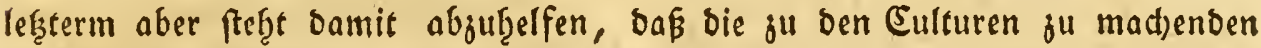
Pläge ober Furd)en bis auf ben Sanogruno tief gemad)t, uno bon biefem fil; in etwas gereinigt rerben.

\section{§. 179.}

Jn einem blofen Sanbboben lönnen mit Nufgen nur Birlen, Fuţren uno Fidten gejogen werden; bie Benufung einiger nur lummerlich radsfender Sträuche ift unbobetiteno, felbft bie Bitle hat barin nur einen geringen $20 u d$ s; bie Fubren lommen oarin nod) ain beften fort. Die Jid)ten ober Rotbtannen pflegen aber nur in ben tiefergelegenen Drten eine unittelmápige Stärle ju ers Galten.

\section{§. 180. \\ Ron gemifd tem Sanbe.}

Die Cjite bes gemifditen Sanbes f̧ängt von ber Miffung beffelben ab, wie fold)e nåmlid für unfere abfidtlid)e Benusung eines folden (Srundes uno

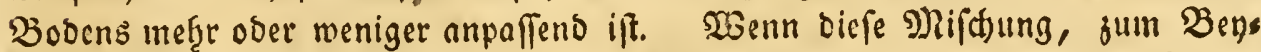

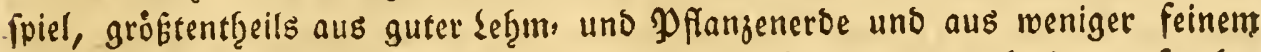

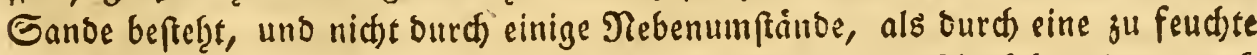
ober fonft nad)theilige Lage, oie if̨m eigene Frudbtbarfeit gefdwoicht mird, aud in gef̧origer Fiefe fegt: fo ift es faft für alle Şolgarten ber glucflid) fte uno befte

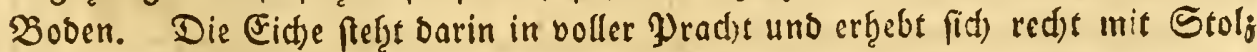
iber ifgres (Sleiden in anberm aud fonft fruditbaren (Jirunbe uno 3oben empor. Sn ben Forften ber furftl. Zlemter $\mathfrak{B a b e r b o r f}$ uno Eampen finoet man bergleichen 


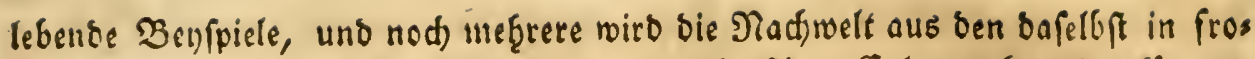

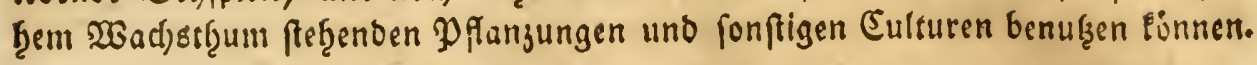

Da nun ber fandigte (3rund und $\mathfrak{B} 0$ den unter fo mannigfaltigen Mifdsuns gen von frudtbaren und unfrudtetbaren Erden, und in unendich) vielen figabli=

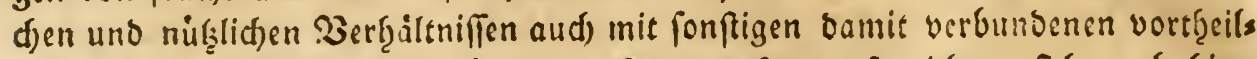
Gaften uno nachtheiligen $\mathfrak{l}$ mftänoen yorloumen Pann: fo rid)ten fid) aud) fiers nad) bie verfdiebenen Benuf̧ungen uno der bafür zu beftimmende forftetrieb,

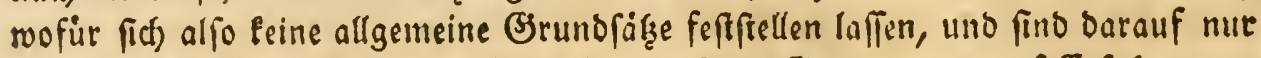

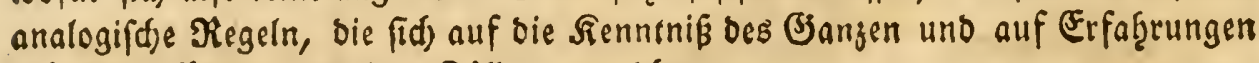
grüben, fïr bie einjelnen Fälle anwendbar.

\section{§. $18 \mathrm{r}$.}

Die Roorerbe, meldje in fanbigten Begenden vortommt, befref̧t gréstentheils aus Pfanjenerbe mit gemifchten Sande, weldse erftere aus ben barauf geroadjenen $\mathfrak{P}$ fanjen entftanden ift. Da fids nun biefe Eroe in ben tiefer gelegenen ober fonft näfern Sanogegenden befinost: fo ift fie an einigen Drs ten if̧rer sage wegen unfrud)tbser, als fie es an fich felbft ift, und eann bas here oft, wenn bie lage berfelben entwaffert, ober fonft verbeffert wirb, fetert

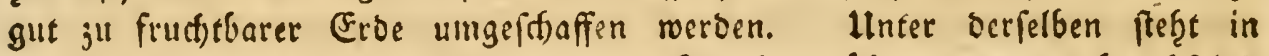

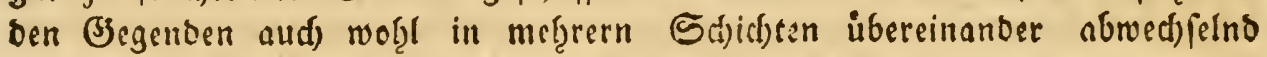
entroder Sand ober tiefere und naffere Moorerbe, weldfes bey vorjuneţ: menden Culfuren unterfudlt werben mus.

2(uf. foldem moorcroigsen $\mathfrak{B} c$ een mit unterliegendem Sanbe pflegen zun Beyfpisl bie Biren. uno Sotf̧tannen redjt gut zu wadfen, uno erfere aud firt oen Stangentgoljbetricb red)t gut wisder aus bem Stanme aubs arftlagen; follte aber bie Mioorerde fegre tief ftefen uno, wie alsbann ges

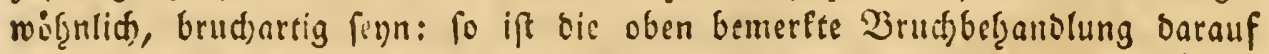
anwendón, uno Daven oft grofier Thiscen ju erwarten.

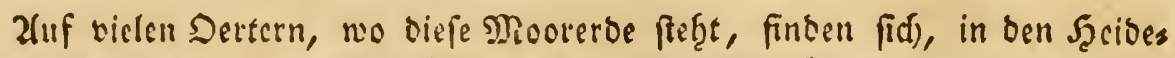

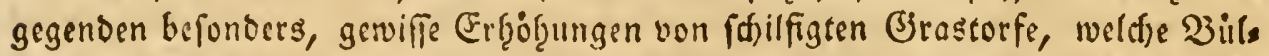
ten gennint weresn, jwiftsen weldyen ber Eroboden oft unbewadsfen ift. Die

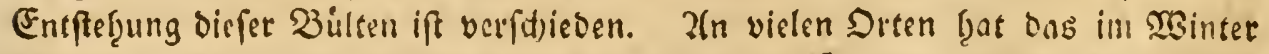

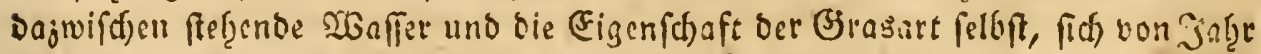

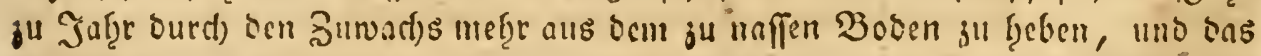

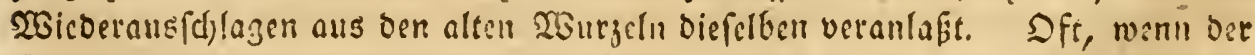
Btrunb uno 20 oen entwáffert werben fann, ober fonft nidft ju nak ift, uno bie 
Bülten entfernt genug von einander ftę̧en: fo laffen fid bajwifthen fef̧e gü bem Srunde anpağlidje Eulturen aufbringen, uno bienen bie Bülten ben juns

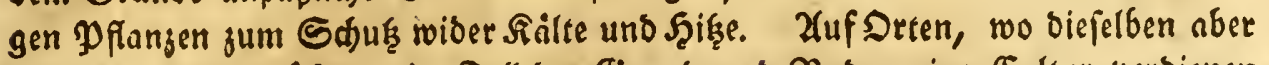

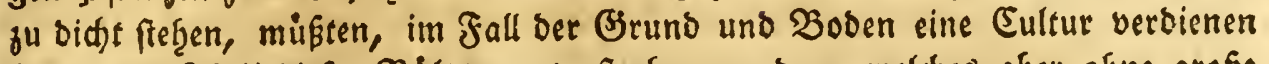
follte, ein Theil biefer Bülten ausgeftochen reerben, weldacs aber ofgne grofé Miufe uno Sioften nidje au gefthetgen pflegt.

\section{§. 182. \\ Bon Den Seidegegenden.}

Sceibeorte ober Seisen nennt man im eigentlidfen $\mathfrak{B e r f t a n d e ~ j e n e ~ B e g e n s ~}$ ben, auf welden, auffer etra einigen fitupfigten $\mathfrak{B}$ çumen uno $\mathfrak{B}$ iffden, nidhts wád)ft als Szeibelraut, Farrenfraut, Şeibegras, uno bergleid)en Sräuter. Im allgemeinen $\mathfrak{B e r f t a n b e}$ aber werben"bie in bergleidfen Begenden liegenden Felber uno beftandenen Stolzorter aud) fo benant; to beiffen bie barin liegenden

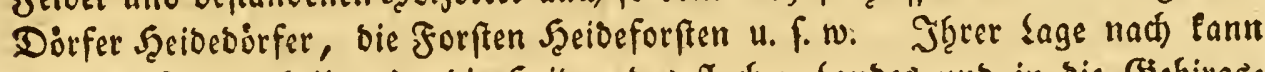

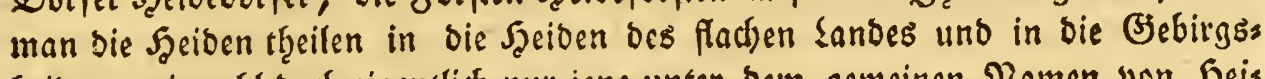
heioen, wiewob̨l bod) eigentlid) nut jene unter beın gemeinen Namen von Şeis Den verftanden werben, uno bicfe babon nur bie analogifdjen ßenennungen erḩalten ḩaben. Ş̧res Jrundes uno Bobens wegen Eann man fie theilen in

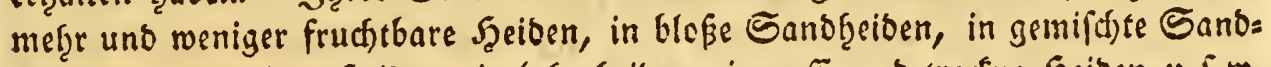

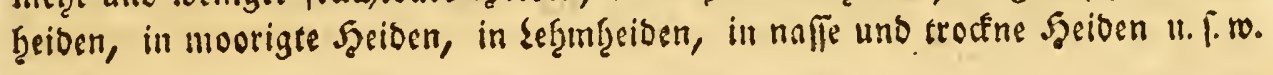

\section{§. 183.}

In 2 bfidft auf ben Forffbetrieb fonnte man bie Fुeibegegenden einţ̧eifen in beftandene und unbeftandene Şeiben. Şur jene pflegt ber Bruno und

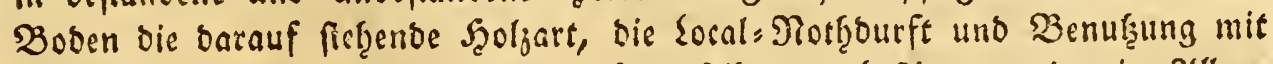
vielerley Nebenumftäneen sen Betrieb berfelben fu beftimmen, ber iur allges uteinen mit bem Setriebe oar hubrigen platten Lanoesforften, wenn es flactics genbe Secioen fino, oser in ben Jievirgsţeiben mit bem forftbetriebe in ben angringenben Jebirgsforften vieles gemein frat. Da man num in ben Seleibes gegenden bes platten lanies auf einigen Diten fefre fructtbaren Srund uno.

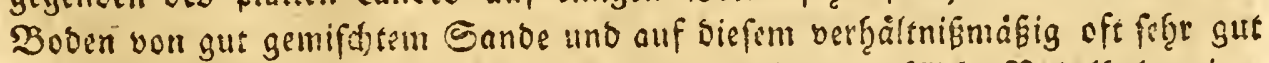
beftandene Bitten: und Eidfenorte, ober aud vortreffiche SRabelfoljreviere

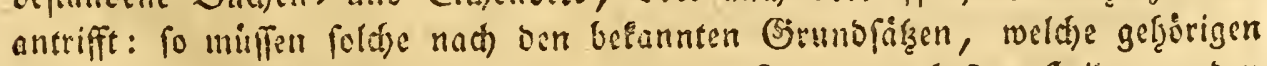
Drfs borfummen follen, behandelt merten. Sn ben mę̧rften seidegegenden

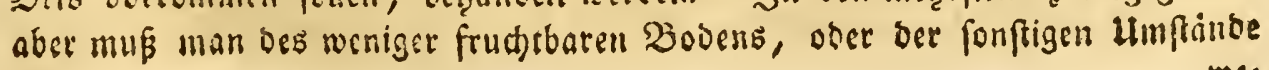


megen, gufrieben fenn, aud) nur oft mittelmásig und fdjed)t beftandene Drte in gleidjem Suftande ju exf̧alten, uno in bem Falle wirbe eine einjufüf̨rende regelmåfigere Bef̧andlung bic Sad)e off nod) mef̨r verfdimmern. Jd)

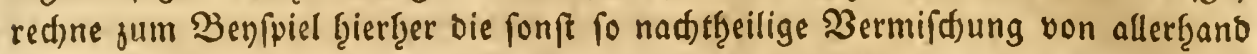
Scolzarten untereinanoer, ben ungleid)en Beftano sines Drts bon Jaf̨ren uno Plák̨en, bas unregelmábige Şauen uno beftindige ausplentern ber feftenden Derter, uno Dergleid)en. Zud felbft ber Jorfmann aus glucflidern Giegens ocn braudft nur eine Beitlang in fold)en Sgeideforften zujubringen, um bers gleid)en Unregelmäbigleiten weniger übel zu nef̧inen; fo wie er fid) julegt aud an bie barin gewóf̨nlid, befindlid)en zwergigten Baiune uno frupfigten Stráus d)er mef̧r und meţr gemóf̨nt, fo fef̧r im 2anfang if̨m biefe und aud bie ervigen Szillen und Madjolderftráudje ecfeln, weil ex fich balo iberzeugen roirb,

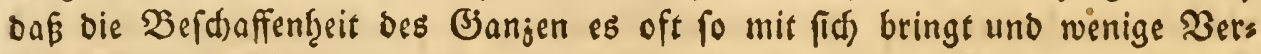
befferungen juläbt.

Xls etwas befonderes muß indeffen f̧ier angeführt werben, dak, da man

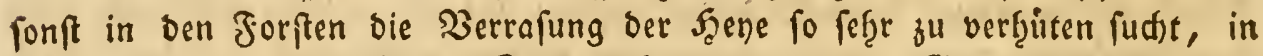

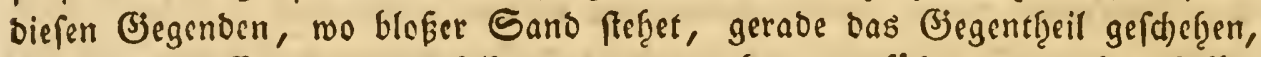
naimlid, bie Erbzaltung betfelben, aus ben oben angefígrten llifad)en befö:s bert werben miffe. Hebrigens fins viele von ien in ber Folge sirfes Budfs,

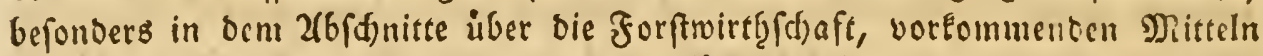

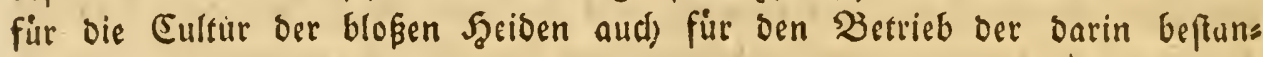
oenen Drte anwenbbar.

\section{§. 184.}

Ron der cultur ber blofien und doen Seidett.

Die Cultur ber Sceiden ḩat auffer ben gewif̨nliden $\mathfrak{B} e f d$ werniffen, die biefe mit ben Eulturen in andern (Segenden grmein bat, aud) nod) if̧re eigene Schwierigleiten, und erfordert bafeer um fo mef̧r anf̧altenden Eifer, llwber=

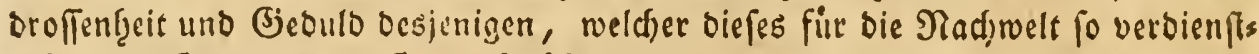
lidfe uno (jectinnoolle (Sij) aft ubernimmt.

Die blofen Sgeiben, in ifrem naturlicfen Zufande fid felbft uberlaffen, bringen foft gar Ecinen 9luţen; auf Taufenien von Morgen fincen of nur

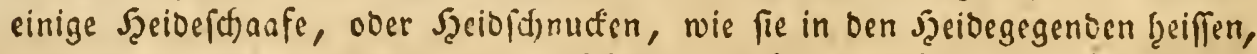
uno bie wenigen zu ben einzelnen Şäufern grb̨origen fïbe ib̨re fummerlid)e

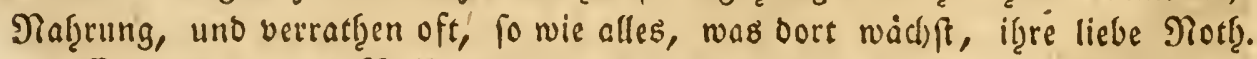

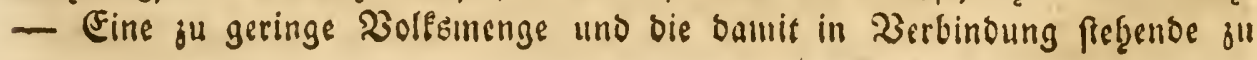


wenige Nuf̧ung ber auf Eulturen anguroendenben Soften unb eine baber ents ftef̧ende unthätige (S)leichgulltigleit b̧aben biefe bis jef̧t an vieien Drten nod) entfernet; uno ba fich in alten Beiten felbft oft keiner um bas Eigenthum bers felben befiummerte, fo fino barauf bie Sioppelfiten uno bergleidten gemeinfidjafts lidfe (jered)tfame entfanten, bie jef̧t fo utandjes gute Bornetgmen barauf vers eiteln, ober Doch feler erfaberen.

\section{§. 185 .}

Diefe Soppelizuten und fonftige gemeinfdaftlide (Geredfffamen auf ben

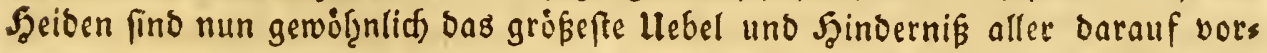
zuneţmenten guten (Finrid)tungen. So leid)t bie Sadje an fid) zu feyn fideint, bie Intereffenten berfelben ourch) eine, oft für jeben unter if̧nen vortgeilfafaftere,

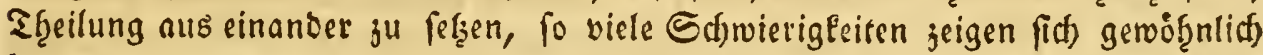

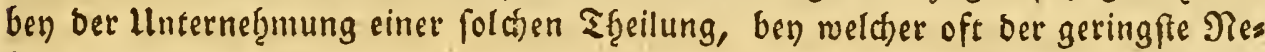
benumftano bie gemeinfd)aftlid)e gute Sadje ricfgaingig madbt uno viele gute

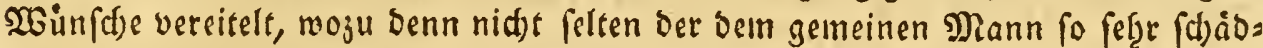
liche 2lovocatenfdarfinn uns Juftijpebantiomus bas mef̨rfte bentrågt. - Es

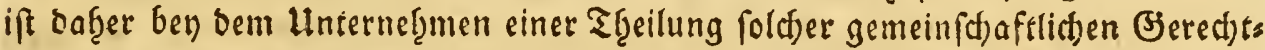
famen gleict im 2anfang, ba not) jeber Sntereflent für bie Sache eingenom= men ift, uno ber Eifer, fold)e ju Stande ju bringen, now) grofécr ju feun pflegt, auch fich alsoannin noth weniger Nebenabficten, Eigenfinn uno bergleis

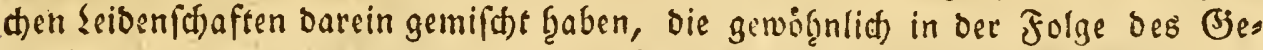
fhaffts baben borjufommen pflegen, bafür ju forgen, wie man bergleiden Hes

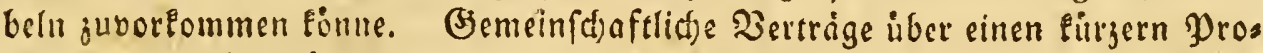

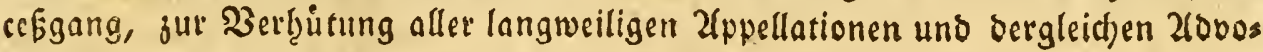
catenEniffe fino die Gierju anwenobaren Mittel.

In länoern, worin biefer (Jegenftand widftiget, wie in ben biefigen, ift, pflegen auch woţl uber bie 2uscinanberfef̧ung folder gemeinfdaftliden (jered)ts famen befonbere Bjefelge ju exiftiren, bie bie 2lbfurgung oer barin entf̣tef̧enden Streitigleiten unb fonftigen Sginosrniffe zum Enogroec ḩaben.

\section{§. 186.}

Zuffer biefen politifdyen Seinoetniffen, welde bie Culturen ber Şeiben ers

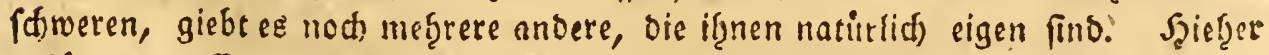
geţören, allfer ber oten bemerten wenigern frudfebarfeit bes Sirundes uno

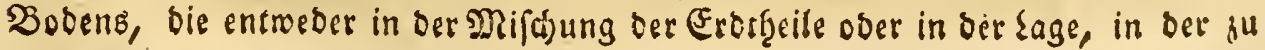




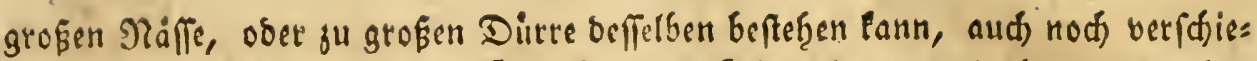
bene Rebenbinge, welde bas Bebeifen ber Sgeibeculturen entreber ganj, ober

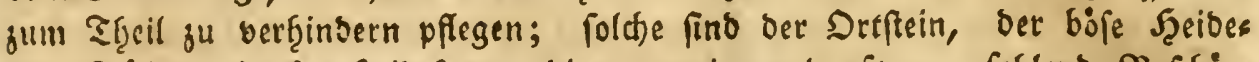

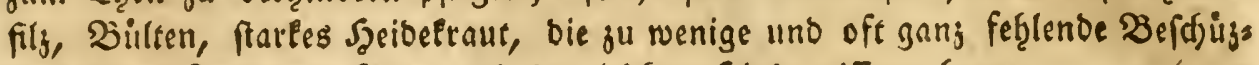
fung gegen Froft uno Şife, uno bergleidjen Şinberniffe meţrere.

Es ift bercits in ben vorf̧ergef̧enden Paragraptenen mef̧reres angefüf̨rt

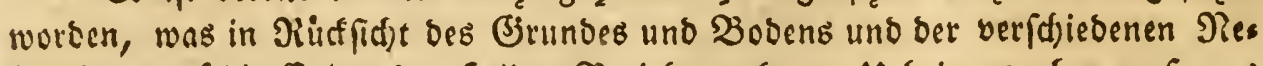

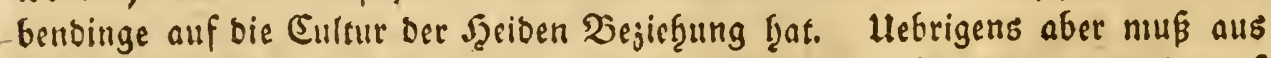
ber Lage und Bribe ber Jgeioen, aus ber vorţeilţaftern Bentęung bes barauf

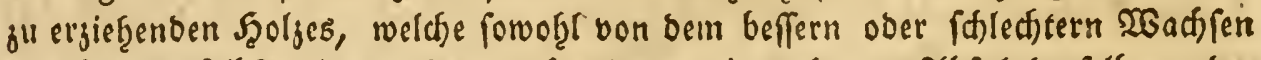

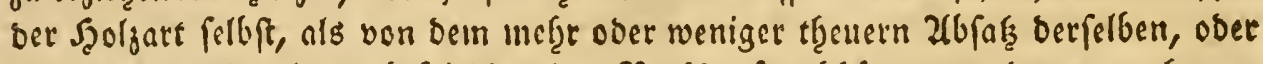
von fonfriger bamit ju befriebigenber Tothourft abf̨ängt, unb aus mef̧reren

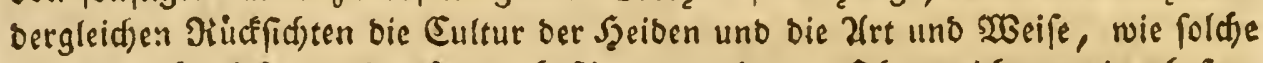
ain beften berwirlet werben Pann, beftimme werben. Şૃne mich an eine befons oere Sronung gu binden, will if f̧iervon nod folgendes bemerlen.

\section{§. 187.}

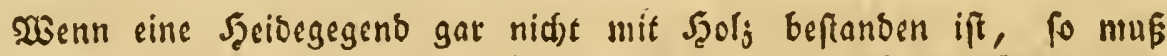
bie Cultur berfelben fo viel, als mogliti, naw cinem auf bas Banje pafs fenben Plane vorgenommen werben. Man beftimm fiu ben verfchicoenen barauf vortommenden Brunb und Boben bie bafit paffenden f̧oljarten; fo rerben fum $\mathfrak{B}$ enfipiel die fumpfigten Derter für sic Ellern, bie tiefer liegenden Begenden mit gut gemifdem $\mathfrak{B}$ eben aus Sandefgm uno Moors erotbeeilen fill bie Rothtannen, auch woh̨, wenn ber Grund und Beden Dafelbft vorguglidg gut ift, fur bie Siidsen und Eiffen, bie trocenen und

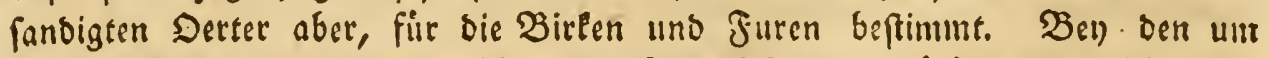
bie (J)ţăge gegetl bas verfdjebene Sceibeviet etwa nothig vorjurid)tenben Befriebigungen, bie bafelbft gewög̨nlid) aus (J)raben mit einem hob̨en fteils aufgeferzten, auth wof̧l mit Birlen bepflanjten ufer ju beftę̧en pflegen,

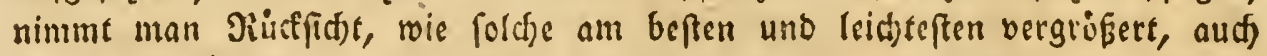

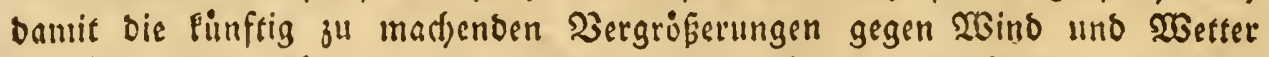

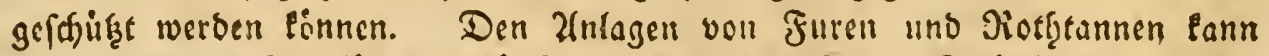

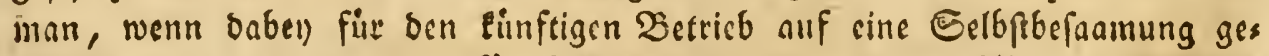
requet rerben folle, bie bafur befamnten Rid)tungen won 2(beno nad) Mors gen hin geben; wobon cin mef̧eres bey ber Befdreibung biefer Sgoljarten vorlominen wirb. 
§. 188.

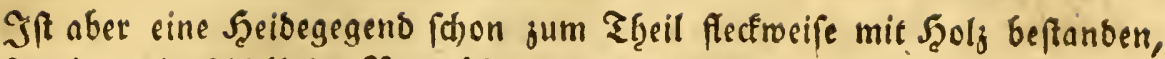

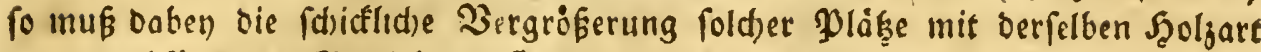

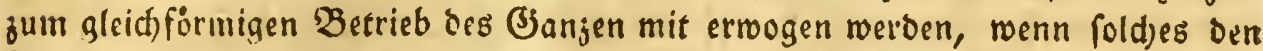
ubrigen llinftinden anpaffend ift. So finbet man Pleinere mit Sannen, Furen ober Birten beftanbene Derter, bie fich burd) bie naturlid)e Befaamung anfeḩns lich bergrofert f̧aben müroen, wenn bas Şeibefraut, ber Sceibefil\}; ober bers gleichen, bas Xfuffommen oes Saamens nich) berf̧inbert f̧ätte, in ben fällen ift oft eine leidte 3erwunbung bes 2 bobens bey einem eingetretenen guten Saa= menjaf̧re das zroectmäpigfte ano befte Mlittel, bie Cultur ju befórbern.

\section{§. 189.}

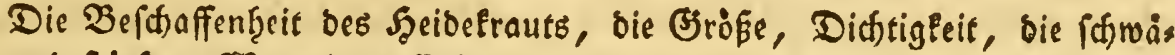

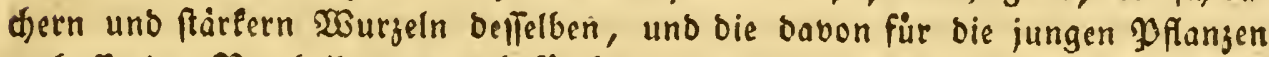
zu hoffenden Bortheile ober ju befürdjtenoen fdäblichen Folgen, beftimmen für

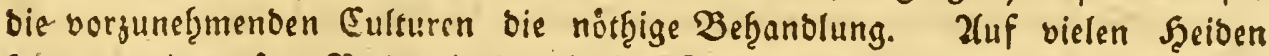
Fann es mit grofem Tutzen in ben ந̧eißen Sommertagen angejunbet und abges brannt werben, wobey man fid) nach bem Winde zu richten, uno bem feuer bie

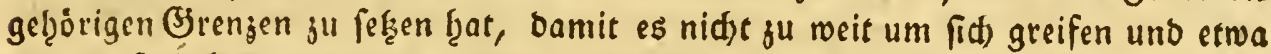
bie mit $\mathfrak{S g}_{\mathrm{g}}$ beftanbenen ober fonft cultivirten Drte-mit berbeeren Eann; foldjes pflegt burd) 2(bgraben ber Sgeibe, burd) eine geborige 2(njab̨l barauf 2(d)t geben= oer Menfach, ooer burd fonftige Nittel ju gefdeften.

(Fin fold)er abgebrannter Jెeiberafen bienet bृernach fum Dinger, uns mus ber Drt alsbann gevflugt und geegget, ober wenn bie ju farken Sceiberours jeln es verf̧inbern, burch ftrid)s ober fiecfenweifes Umb̨acfen jur B̉efaanung vorbereitet werben. In einigen (jegenben pflegt man einen folden abgebranns ten Sceibeort nur mit eigenen baju gemadten (Eggen aufjureiken, ben Snamen bincinjufäen, uno mit Dornbifd)en einjuftreidjen. 2luf foldjen Drten, wo

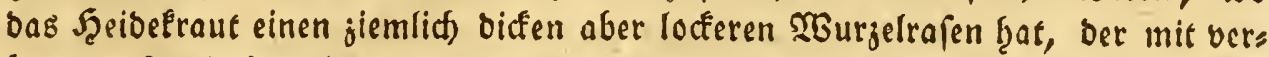
brennt, fo, baf nachber nur wenige $\mathfrak{W u r z e l n}_{\text {in }}$ bem Sanogrunbe fecten bleis ben, ift biefe art bie gefdrwindefte, und ba oft in bergleid)en (Jigenden eine zu ftarle 2luflocferung bes $\mathfrak{B}$ obens meţr nad)ţeilig als vortbeilţaft ift: fo pflegen unter gewiffen Uinftänben befonbers die Nabelfeljbefaamungen in einein foldjen abgebrannten und blok geeggeten $\mathfrak{B}$ oben gut ju gerathen.

2(n ben Drten, wo man bie Şeibe nid)t woh̨l abbrennen Eann, gefdief̧e bie Zubercitung bés Erobobens am beften burd ftrich. ober plaf̧weifes 2ufs (Erfter Thetl) 


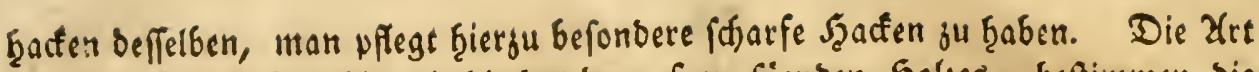
Des Sceibelrauts fowohl, wie bie bes barauf ju fäenden Saoljes, beftimmen bie Breite biefer Stridje und die Entfernung berfelben von einanoer. $\mathfrak{z}$ efurd)tet

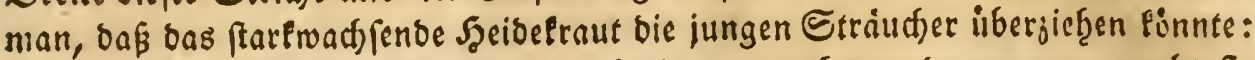
fo milfen siefe Stridje ober Furdjen breiter gemactit rerben; man madjt fie alsbann sin bis zwen Jub breit. Sft ein fold)es Lleberjiefzen aber von bem Jzei: beliaut nidt ju befurdfen: fo fonnen foldfe nur gang fdjmal gemadt roerben,

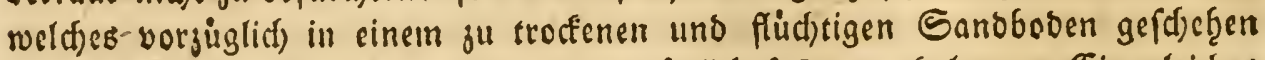
muf́, um Deffen Dberflidse fo viel als moglid) feft ju exthalten. Ein gleidjes hat bey ben zu hacfenden Saamenpläzen Statt, weldje auch nach biefen Umftänoen, oft nut einen balben, oft aber auth auf oren Juß ins 23ierect groß

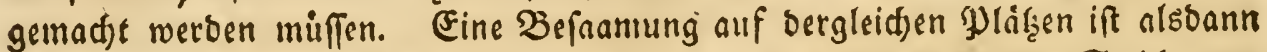
viel wohlfeiler, wenn bie Ulmftande es erlauben, bnf biefe oder bie Striche wes niger breit gemadt werben fönnen, fo wie im Bjegentfecil es bie Fopten pefge

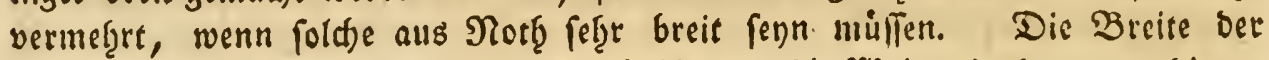
Pläfze ober ber Stride von einanber beftimmet bie Weite, in ber man bic fu fàenden Băume von einanber entfernt Ģaben will, je breiter bie Pláf̧e ober bie Strid)e an fid felbft fino, befto fdmáler wirb alfo ber bajnifden liegenbleis bende Secioefrid fenn. Die Befaamung mus alfo auch fo viel als moglid in ber Mitte ber Pläke obet Stridje gefdetgen, inbem bot) in ber Jolge nur eis

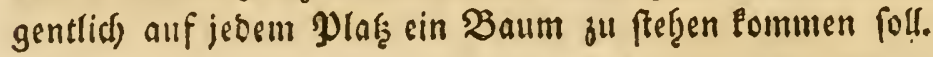

Senn ber auf foldjen Drten fef̧ende Sceiberafen bick uns feft ift, fo miis ren bie 2frbeiter folden abferafen (ober abplaggen, wie es in ben Bjegenden eigentlid) Geist) und an bie Seite legen, fonft aber braudst berfelbe nur elein gefract und von ben grobeften 2 urgeln und Rafen gereiniget fu werben. $\mathfrak{Z}$ en

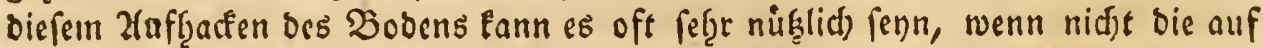
Der Dberflidfe liegende nur wenige vermijd) Pflanzenerbe allein, fonbern mit biefer ber barunter liegende Sano in etwas mit umgefzacft wiro, weil jene als

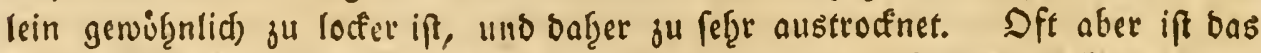

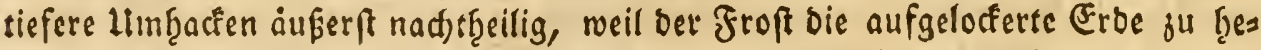

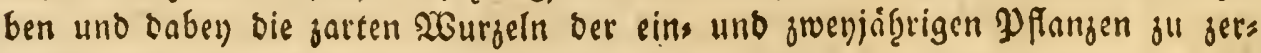
reiffen pflegt.

\section{§. 190.}

Da auf ben Syciben die fdarfen WBinbe uno bie brennende Sonnentitze ben jungen Planjen fo ferte nad)theilig find: fo pflegt man barauf bey biefer Euls 


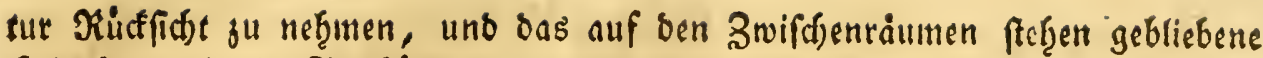

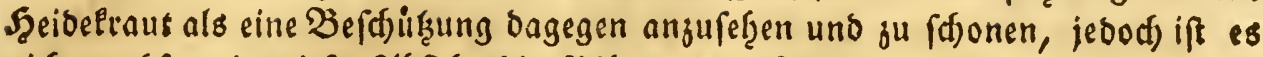

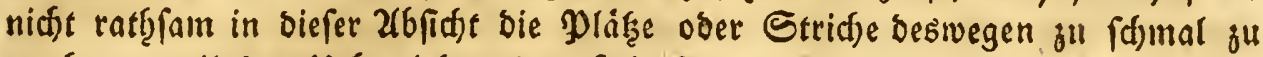

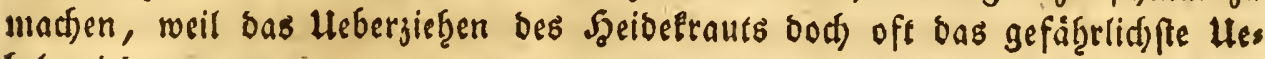
bel wirb.

Diejenigen Seibeorte, welche mit wenigem Sraute bewadjen fino, tönnen nur mit einem $\mathfrak{P}$ fluge in einer Entfernung von fechs bis adt $\mathfrak{F} u \tilde{\beta}$ gefurd)t uno in ben Furchen befäef werben, jeboch muß ber Plas alsbann ganz eben fenn, Doer wenn er ferre abriangig fenn follte: fo müsten bie furchen fo gefübret wers Den, bá̈ bas waffer nidft barin ftef̧en bleiben, ober zu fánell abfließ̧en uno ben Saamen init wegfüf̧eren fönnte, weld)e Borfitht alld bey ben oben anges firberten Stridjen anzuwenden ift; man pflegt baber bergleidjen zu pflugende

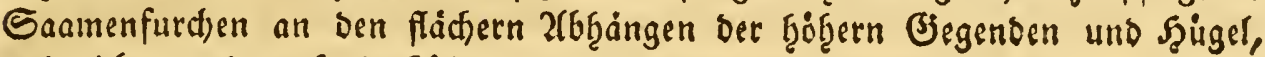

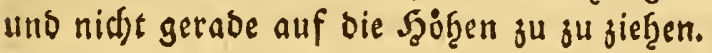

\section{\$. I9I.}

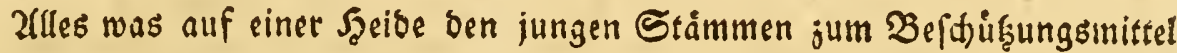

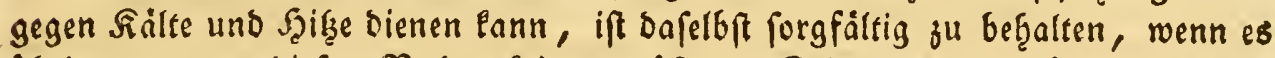

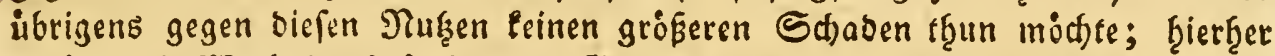

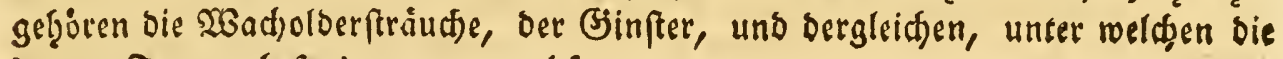
jungen Tannen befonders gut wad)fen.

\section{§. I92.}

Die Zeit ber Befaamung ber Szeiben ridfet fid nath ber Şolzart, bie barauf gefäet werben foll. Dods pflegt man in ben Secibegegenden

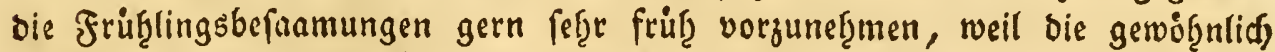
iii May einfallende Durre ben Sceibeboden feģr austroctnet. Der Sanmen miro alsoann auf bie zur Befaamung vorbereiteten Plíg̨e gefäet, in fefterim Boben mit einer leid)ten Sgarle, in locferem aber mit einem $\mathfrak{J g}_{\text {eibefufh ets }}$ was zugeftridjen, uno wenn ber Boden zal locker ift, mit bem fupe feftge= treten, bamit berfelbe befto länger bie geţơrige Feuchtigleit bef̧alten, unt bie jungen Seime einen feftern Stand belommen, aud ber Regen bie Wurgeln beffelben nicht fo ref̧r entblósen lonne. Diefes Feftreten ift ben

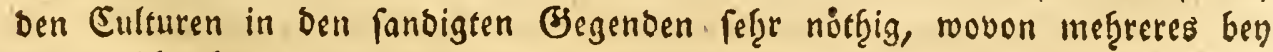
Der $\mathfrak{B e f d r e i b u n g ~ b e r ~ N a b e l f o l j o u l t u r e n ~ g e f a g t ~ w e r o e n ~ f o l l . ~}$ 


\section{§. 193.}

Unter bie bofeften feinbe für bergleiden Befaamungen geţoren bie

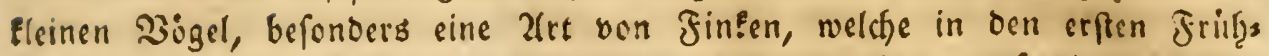

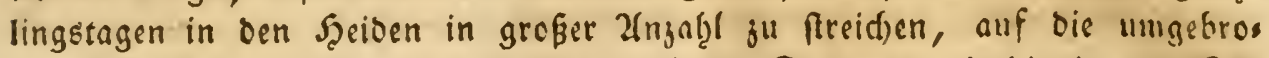
d)enen $\mathfrak{y}$ läke zul fallen, uno ben aukgefäeten Saamen uno bic jungen Sieis me gróbsenthcils zu verjeg̨ren pflegen. Biele warten baher siefen 2 engels

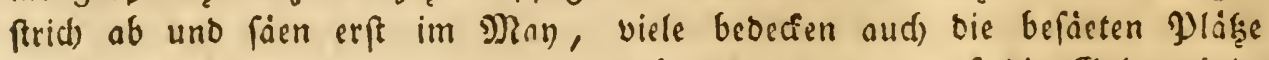
mit Tannenaften und bergleiden, robery benn alles nuf bie Belegenţeit, witterung und $l$ lmftande antommt.

\section{§. 194.}

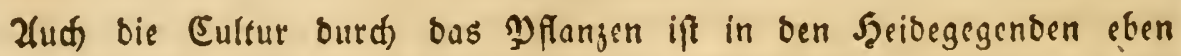
fo gut anwenobar, uno eben fo fegre ju empfeblen, als in andern forfts gegenden. Zam vortheilf̧afteften gefdief̧t fie mit jungen Jurell uno Nothe

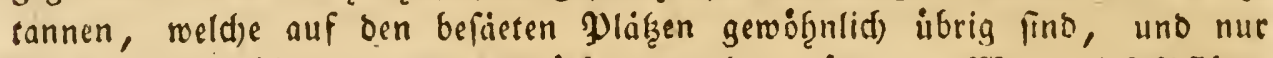

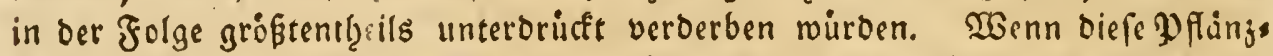
linge, weldle an benfelben Boden gewoibnt fino, mit geţoriger Sorgfolt auss getgoben, uno folde Pflanjungen mit erforterliden fleise gemad)t werben: io pflegen fie feb̨r gut ju gerathen, nur bas erfte uno jwente Sab̨r haben fie,

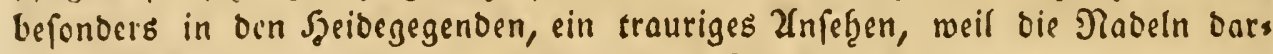
an gelb werden, uno bet groente jährige Zumad)s bey einigen nur wenige Sofnung geiget; biefes mus aber ben Forftmann nid)t irre madjen, inden er fither bzoffen eann, nad) vier bis fed)s Jab̨ren feine Y)fanzung in fros b̧eften Bumadis zul reţen.

Jn ben naffen und bructigten Secibegegenden laffen fíd imit grofem 30 rs theil unt fef̧r gutem Erfolge Ellernpflangnngen anlegen, fo wie oarin alld) alle ibrige Baumarten, wenn oer Brruno uno Boben für fie anpaffeno ifi, fowogl ourd)s Säen, als Durds. Pl flanzen, cultiviret werosn fönnen.

\section{§. 195.}

Die Eultur ber Bebirgeţeiben hृat mit ber Eultur ber Şeiden bes flacten tanbes faft alles gemein, was auf ben 3 rund und Boden berfelben, und auf

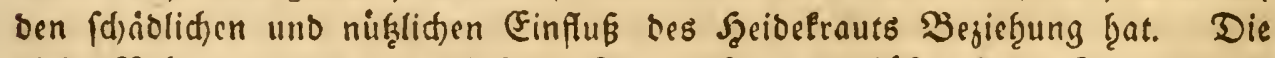
vielen Rebel, oer baraus entftef̧ende Ranţreif uno bie töfen falten Zugminde in ben Bebirgen erfdweren aber bafelleft folde Eulturen nod) meit meţr, und ba man biefen Dingen nidjt gut vorlommen, uno fie nid)t berbeffern eann: fo muk 
ber Forftmonn fid es um fo waniget vitsriafen laffen, wenn er eine bao

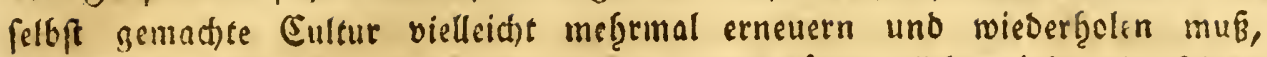
uno befonders in ben erfen Jaberen nur ein Pummerliches leben in feinen

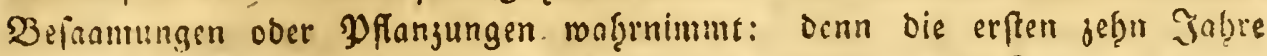

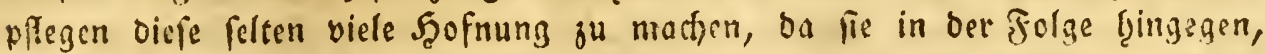

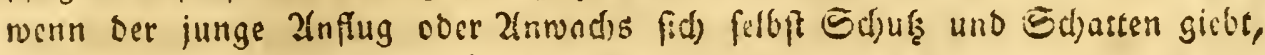
fefte oft alle Erroartungen ibertreffen.

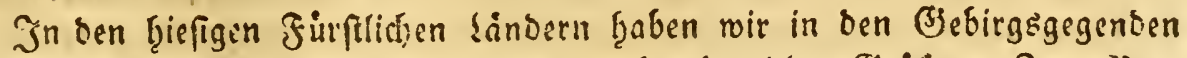

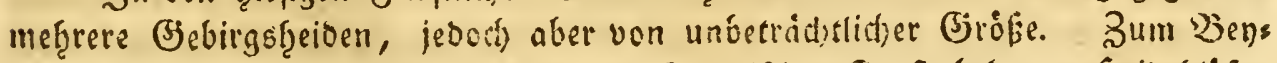

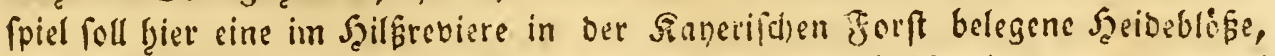
fammit ben barauf vorgenommenen Culturen, mäber befafricben weroen, weil bev) diefer fefre vieles vorfinmt, was aud) auf andere bergleidsen Derter annendos

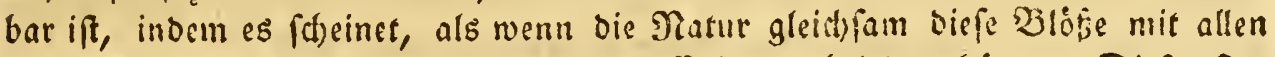
Sainderniffen gegen bie vorjunergmenden Sulturen belaben bätte. Diefer Dre

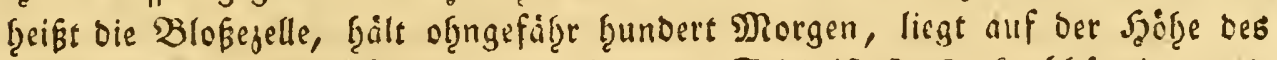
Silfegebirges, nad) Siben bin. In einer Scite ift fie ftarl abbangig, uno jum Theil grengt fie an alte febr bemoofte Budhenorter, bie tiefer in (Srunde liegen, auf Der anbern Seite, fzób̨er am Berge ftef̧en nod) cinige verfnorrete alte Birfen, weldje nad) if̧ren Jab̨rsringen über I 50 Jab̨r alt fenn migen, uno mobon jebe im Durdfithnitt mit ben übrigen gered)net, faum ein Drittel Dialter

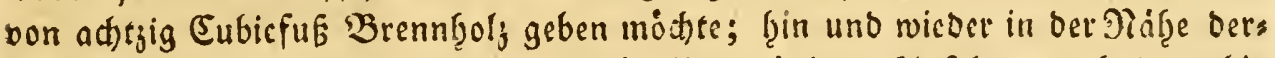

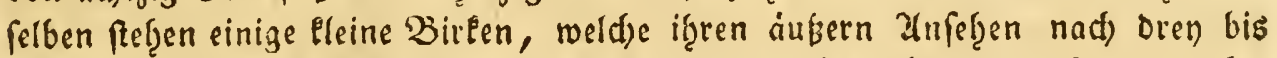

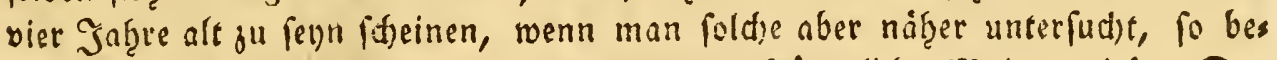
zeugen if̧re Enorrigte Murgeln if̧re vollfommene Erippefid)te Majorennität. Der

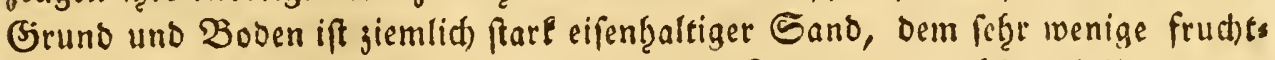

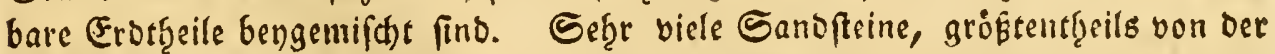
(J)obe ciner Fauft, aud) einige Siefelfeine madhen biefen (Bruno nod) unfrudsts barer. Zuf Diefen liegt eine Sage Torf, Die an einigen Drten uber einen Fuf,

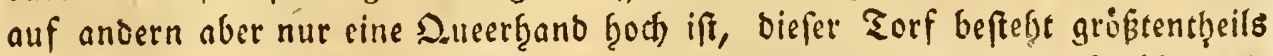

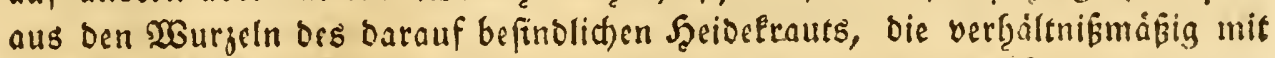
biefem oft pärfer und aud) fefter in einanber geflochten fino, auf vielen $\mathfrak{p l i k g e n}$

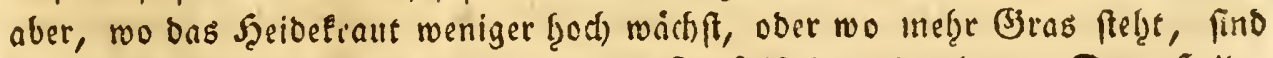

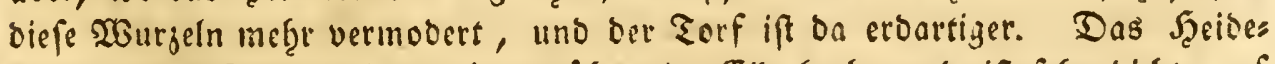

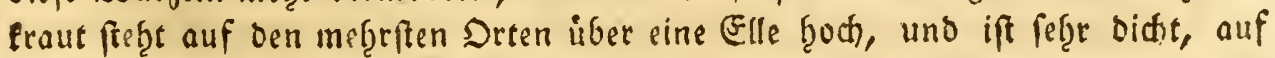

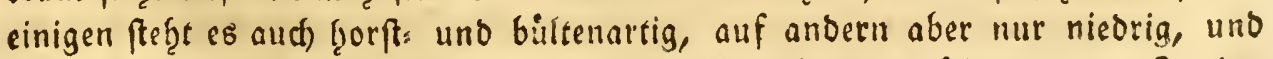
einige Pláke fino nur mit bem belannten bojen Şeibefilg übergogen. In ber 
noffen Taf̧rgyeit ift biefer Torf wegen ber bafelbft alsoann faft beftandigen Bis

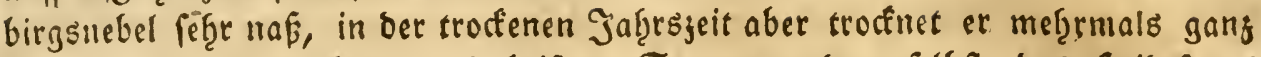

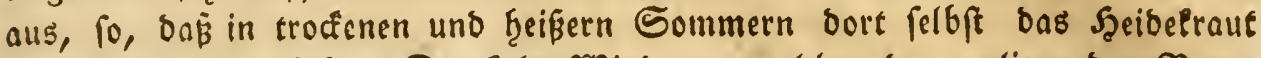
wie verbrannt ausfiçt. Der Palte Windjug, weld)er ber umliegenden $\mathfrak{B} e r g e$ wegen in ber bortigen Jegend herrfdte, ift auf biefer an fid fdjon fef̧r uns

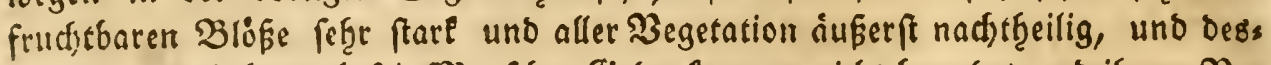

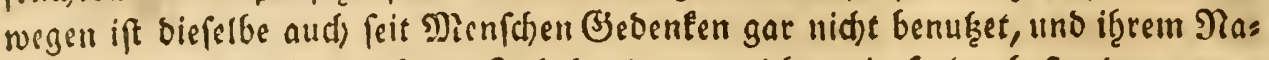
men nad) mag fie feit mef̧rern Safertertuberten nidft mit Sholje beftanoen gerwes fen fenn. Weil nun ifgr natirlidjer Buftand alle Şofmung einet etwanigen Selbfts befaamung entfernet: to wirbe fie of ne eine timftidje Cultur vermutf̧lid) noth Jab̨rţunberte gerabe bas fenn, was fie jef̧t ift.

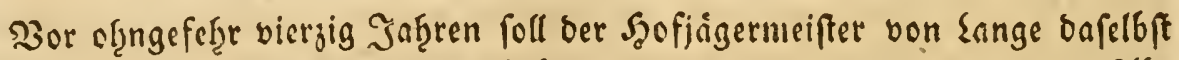
cine Furenbefaallung vorgenommen haben, von ber bie all bem untern 216 =

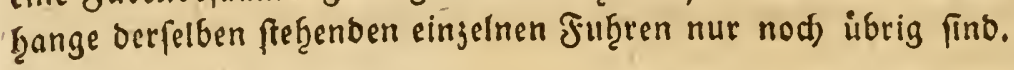

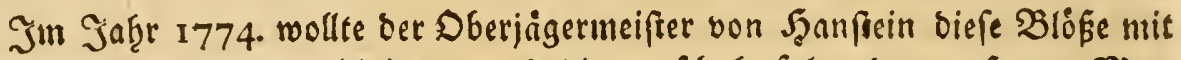
Furen und Dothtannen inltiviren, uno bies geld)af folgendermaaken. Man

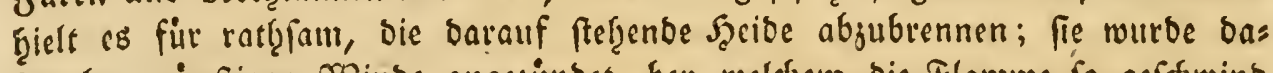
her bey gunfrigem winde angegindet, bey relefem bie flamme fo gefdroino

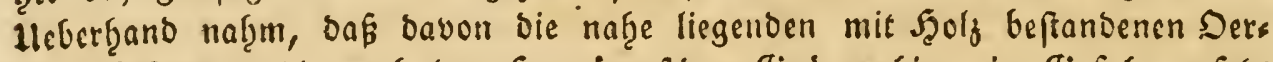

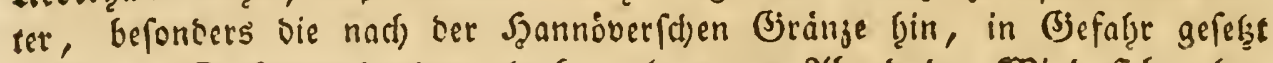
wurben. Diefe wurbe benn bod), als gegen $2($ beno ber Woind fíd) gelegt

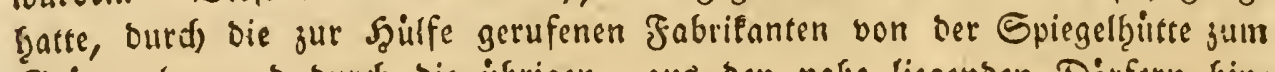
Esrinenplan und Durdh bie iibrigen, aus ben naţe lisgenden Dörfern fiins zueilenoen 2frbeiter abgervendet; cin Llmftand ber zum Belfpiel bienen eann,

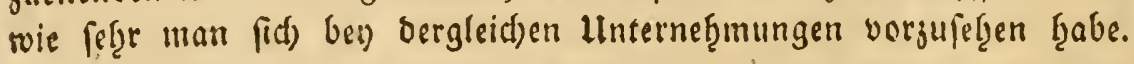

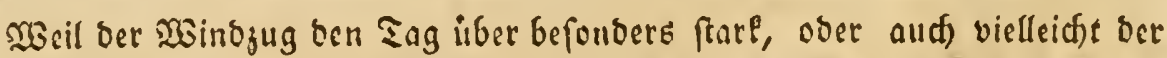

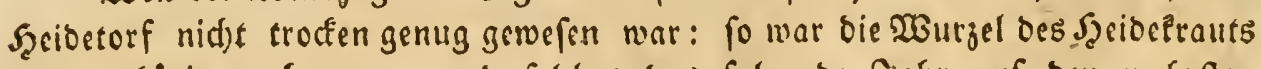

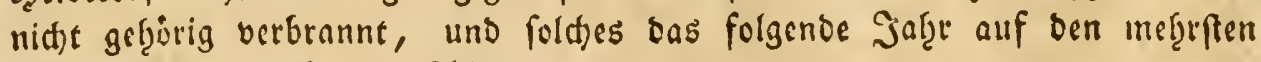
Drten wicber ftart ausgefdlagen.

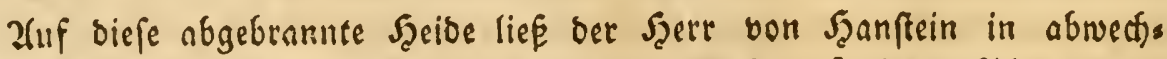
felnden Pieiţen Jutren und Diothtannen fäen, und auf einem Plaţe wurs oen erftere, und auf einem anoeren lef̧tere, nid)t in Reifen, fondern nur fo, wie man Sorn gu fäen pfrigt, fingefäct. Fer Saamen gieng ourd)=

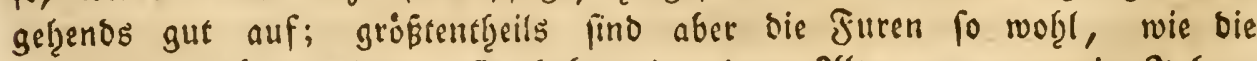
Piothtannen bisdfit elend; fie fraben in einem 2flter bon zranjig Jabren Paum 


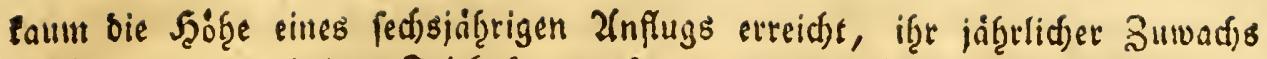

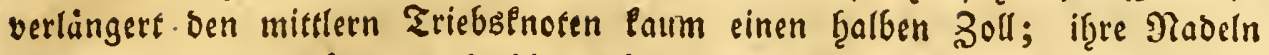
fino gang ausgetrocfnet, uno bie meb̧rften von biefen verfrippelten Pflanzs

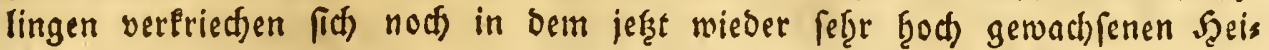
belraute, von bem fie an vielen Srten ganj bebecti fint. In einigen $\mathfrak{i c i s}$ ben bingegen, uno borguglid auf Den Sylägen, auf welden bie furen uno

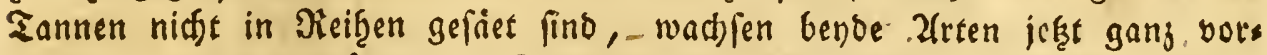

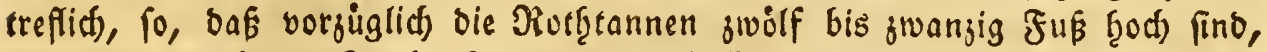

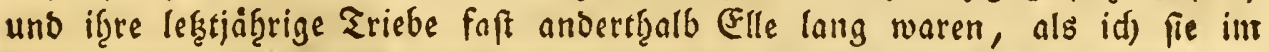
vergangenen Jab̨re faḩ. Dian fief̧t auch von biefen, oafie fie erft feit ben lefeten Jab̨ren in oiefem frobeen 230 d) ebenfalls nur famadteno ifgr seben baben erţalten milfen. Die Sefdafs fentreit bes oben befdriebenen Srumbes und Bobens diefer Blofe bradte

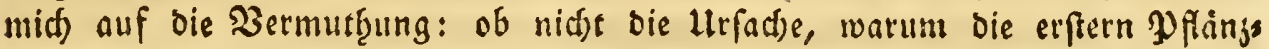

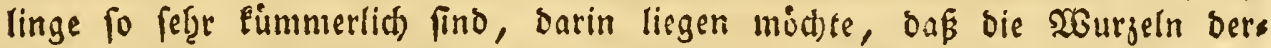
felben nur bie oben aufliegende, meiftens notb aus unvermoberten j̧eis

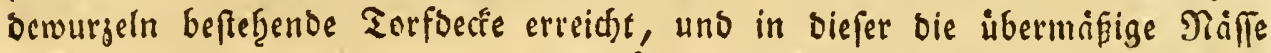

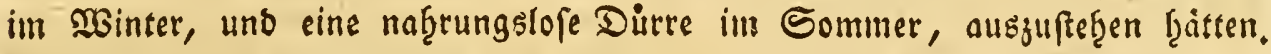

$\Im$ ch) rif einige von biefen vertummerten Pflinglingen aus ber Eroe,

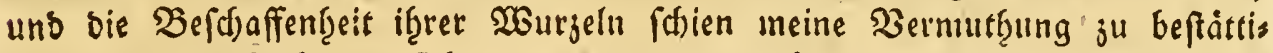
gen: Denn biefe ḩatten fid) nur in ber bort bibger liegenden Torfage aus, gebreifet, und nut renige ber färtern f̧atten ben darunter febenden Sanos boben erreidft; fie hatten bafeer vollfommen bas 2tnfegen von bergleid)en

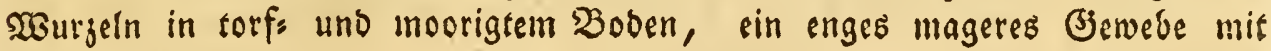
vielen Sinoten.

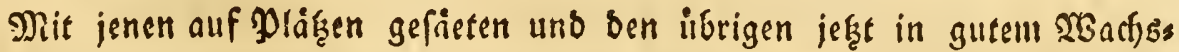
thum ftęcenden Sannen hat es biefelbige Dewallonip. Denn aud biefe

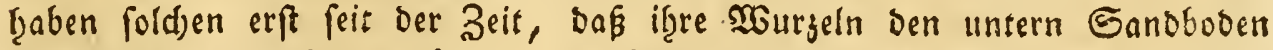
erreicht bzaben, erb̧alten fönnen, weld)es man aud beutlich on if̧ren wours beln fetzen Eann, von benen bie obern elende Mloorwurgeln; bie untern aber in befierm Triebe fefenoc fanobcoenartige 2 Burgeln fino. Da mun auf Der Stelle, auf welder biefe leştern jungen Sannen ftef̧en, bie Sorflage viel niebriger und etoigter ift, fo bzatten biefe, ebe fie, wie bie etft bejdries benen, ganf verfamen, ben unteren, ifgnen zuträgliásen SBoben, norf crrets

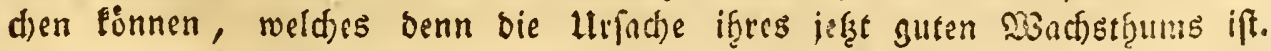
Dit einigen fin uno roieber ftef̧enden Eleinen Bitken fat es biefelbe Bes 


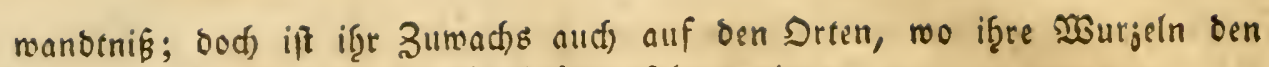
untern Boben bereits erreid)t ţaben, icţr geringe.

Die Meinungen einiger Forftbebienten uno if̧re 23orf̣tåge jur Eultur

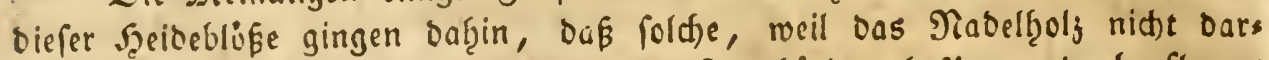
auf radjen wollte, mit Birken uno $\mathfrak{J}_{2}$ aunbuctien bejiet uno bepflanjec werben fónte. Nách náberer Heberlegung aber wurbe aus folgenden Brins oen eine Cultur mit Tabilf̨olje oortheillfafter und, Der lage und dem Srunde und Boden nad), angemeffener befunden:

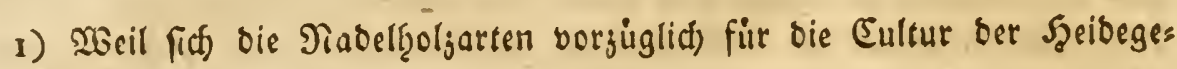
genoen idjicfen.

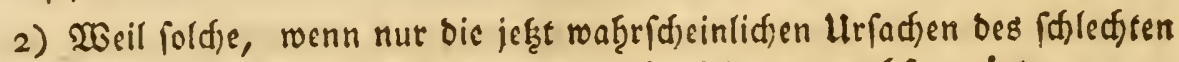

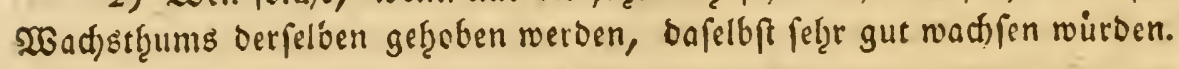

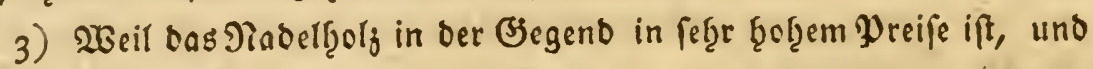

4) Das Birsens und fonftige Brenntgolł bafcibft hingegen äußerft moḩls feil ift, indem das Malter von adtrig Eubicfuß nur ju vier (3rofden verfauft, boer in ber fiofelung genulge wirb.

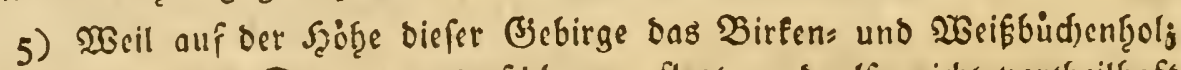
nid)t wieber aus bem Stamme ausjuid)lagen pflegt, und alfo nid)t vortheillhaft ju Stangenţols gejogen werben Ëonnte.

6) Weil bis angränjenden \{aubf̧oljorter in Peinem groben Buwadts fies ben, und bafer ber lünftige Szolgertrag in aller Piucfifid)t wenig eintragen wurbe.

7) Weil aud) einige bereits bort vorgenommene Birkenbefaamungen uno Sgannbưdjenpflanjungell ganj miß̨lungen fint.

Die Cultur ift darauf folgendermafen vorgenommen worben:

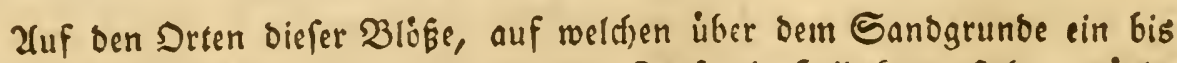

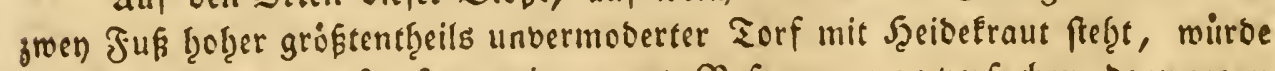
Bs nidte ratbfam gewefen feun, eine gwente Befaamung ju berfud)en, benn wenn aud) bie baju gemadten Plízige bis auf ben Sanbboden vertiefet worben wären:

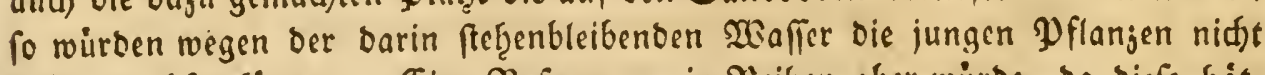
baben wadfen Ënnen. Eine Befaamung in Reib̨en aber wirtbe, ba biefe baát, ten fehre tief gemadit werbell imilfen, fef̧r loftbar gervefen fenn, und an ber

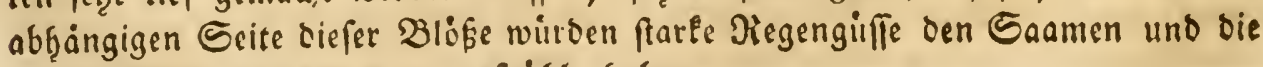
jungen $\mathfrak{P}$ flanjen baraus reggefpubitt ţaben. 
Diefe Drte fdjiffen fid baţer beffer zul ciner Bepflanzung, ju welder Lerd)en barum gewdiblet fino, weil fith folthe beffer, wie bie ibrigen Nabelb̨ölger,

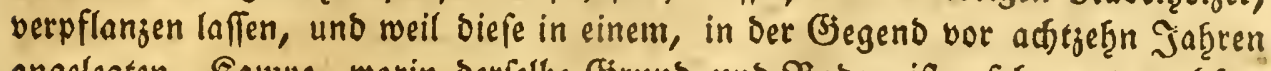
angelegten, Sallipe, worin berfelbe Grund und Boben ift, fef̧r gut wadfen. Es ift beswegen sur 2lnjief̧ung ber Lerd)enpflänglinge ein lleiner 'Ramp angelegt,

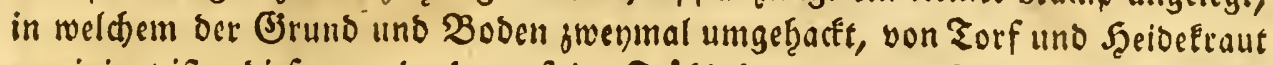

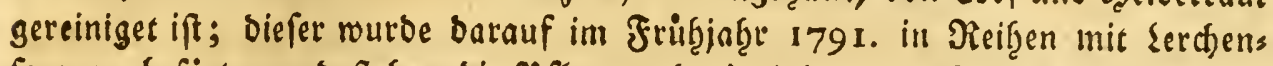

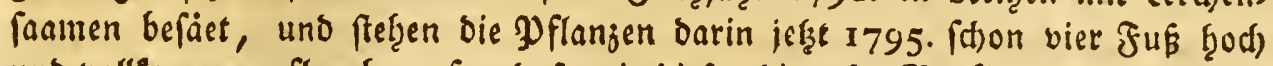
unb volleommen pflanjbat, 10, bak mit biefen oie erfte Bepflanjung bereits in

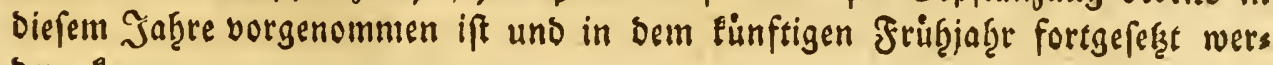
ben Pann.

2(uf ben Sreen biefer $\mathfrak{B l o ̈ \beta e}$ aber, auf weldjen ber Seeiberafen weniger

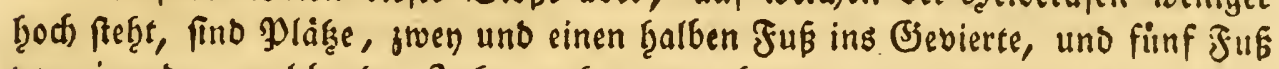

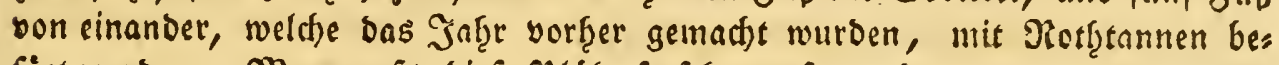

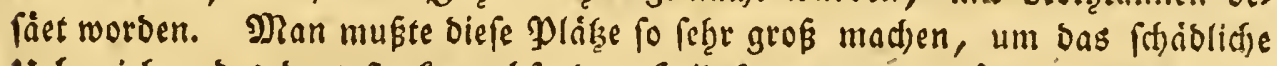

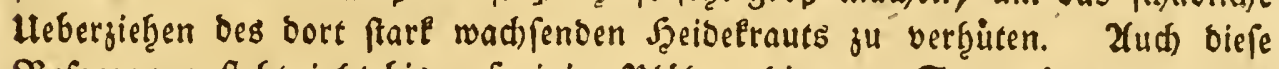
Befaamung ftef̧t jeţt bis auf einige Plâke, bie vom Sonnenbrande gelitten ţaben, feţr gut.

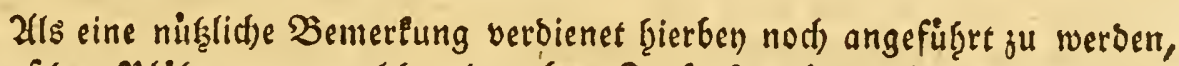

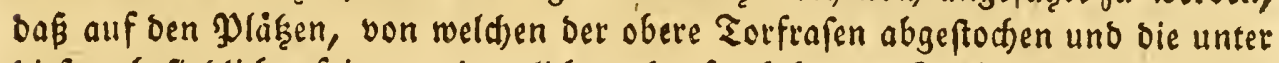
biefen befindictie feine, eigentlid) mehre frudftbare, Forferbe abgenommen worben, bie jungen $\mathfrak{Y}$ flanjen meit beffer feften, als auf benen, auf weldfen man

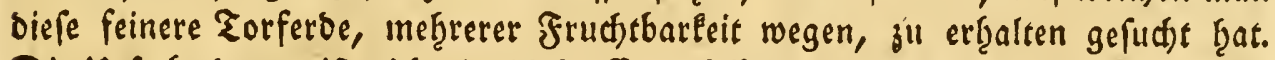
Die Urfadje babon ift nidft in biefer Erbe feleft, fondern in bem Darin burch

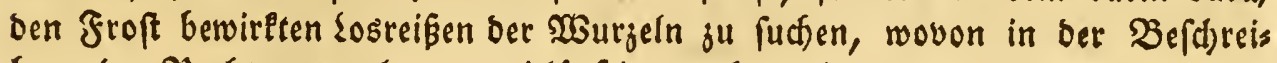
bung ber Rothtannenculturen weifliuftiger geţandelt werben foll.

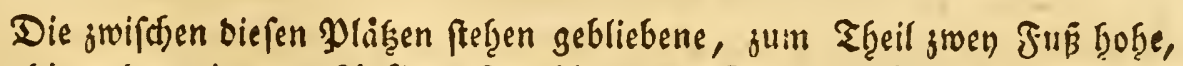

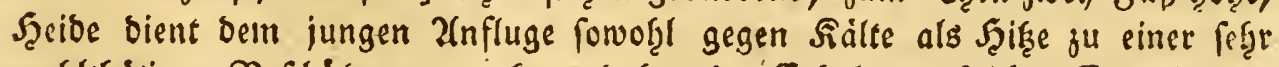

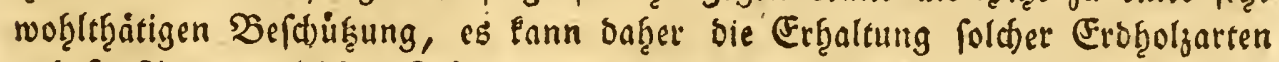

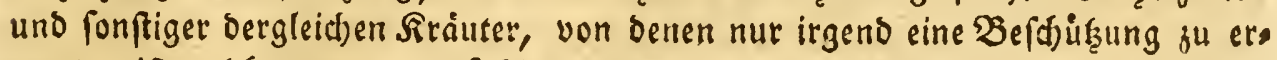
warten ift, nidgt genug empfoģlen werben, uno wenn auth eitre foldhe Cultur

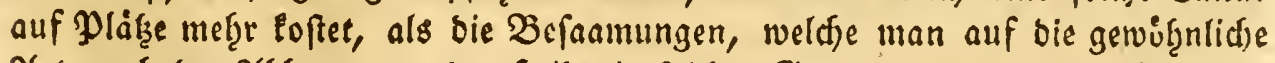

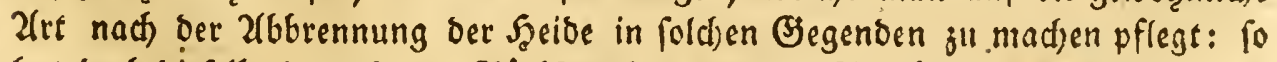

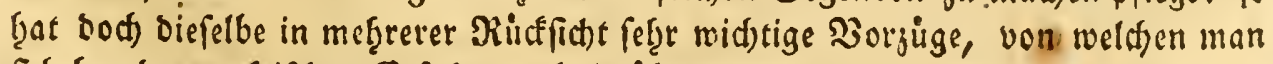
(ii) bey ber praftifden Erfaģrung bals äberjengen wirb. 


\section{§. 196.}

Ein gropes Sginberniṕ fïr bie Planjungen und Eulturen in ben Sgei, ben fowobl, als in ben ubrigen flacten samogegenden, ift ber fogenannte

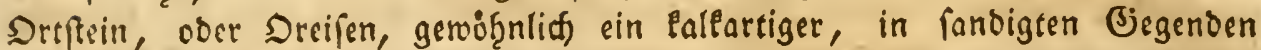
aber cin fansigter oft reid) baltiger Eifenftein; ber fid unter bem Siafen,

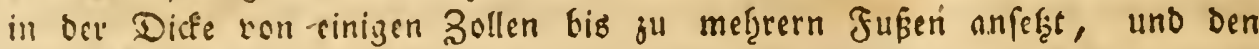
vibrigens oft frudtbalen $\mathfrak{B}$ oden alsbann gall unfructebar macht, weil er folden mit einer feften Decfe ibergief̨t. (Fe foll vorgiglid) um fo leids: tet uno fdjneller entfeb̨en, wenn von cinem fonf̣ mit Bäumen beftanbenen uns befdatteten Beben, ber baju geneigt ift, bie Daiume reggenommen, uno biefer oer Sonne frel) ausgefeft witb, weswegen man bergleiden Drte aucf balo wieter in ben 5 golgbeftano ju bringen bedadet fenn muf.

\section{§. 197.}

26enn nun eine folde (jegend wieber cultiviret werben foll, fo muß biefer Ditftein wenigftens auf jebem glaf̧e, roof̧in ein Baum gepflanjet werben foll, in einer binlingliden Entfernung um berfelben weggenommsn wetben, wibrigenfalls Fann ber gepflanjte Baum nidjt radblen. Da es

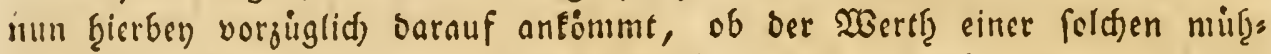
famen uno efoftbaren Eultur, bie Roften belof̧nen, uno ob etwa ber ausjus bredende Eifenfticin auf Eifentzutten, wo er oft als Zufafe mit vielem 23or: theil gebraud) wirb, ober jum Mauern, als Stein oder Mortel, befonders

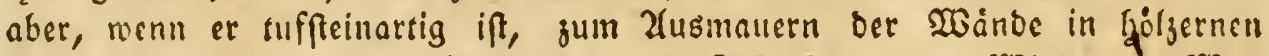
Bebanten, wegen feiner scichtigleit uno Jeftigleit gegell Wino und 23ets

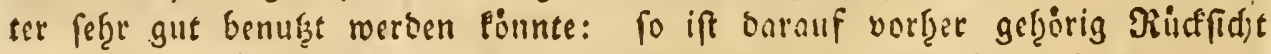

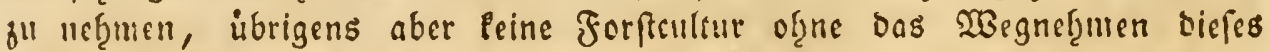
Diffeins auf folden Drten anjuretfen. Zlud felbit bas sobfer und bie

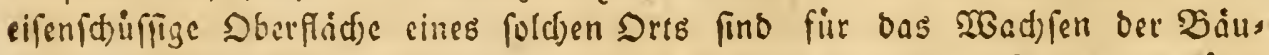

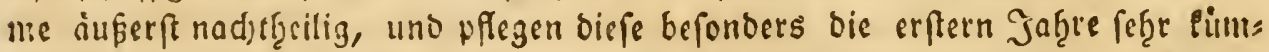
merlid) ju ferben, ood finoet man batauf hin uno wieber alte farte Eis

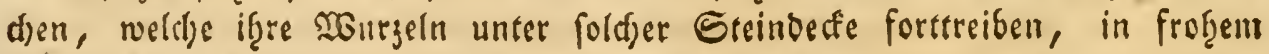
Silfanos.

\section{§. 198.}

Da bie lage eines foldjen Drtfteins nidfe immer gleids ift, und fids siefer oft bidjt unter bem oberen Siafen, oft aber mebgrele Juß tief unter Dems 


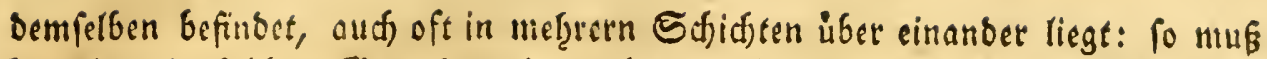

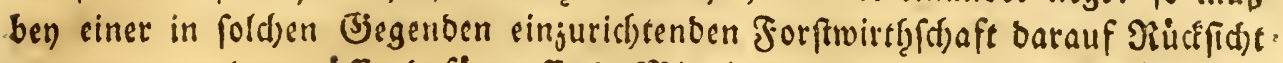
genommen, und es miffen dafür pafferde Mittel angewendet werben. So lápt fid .

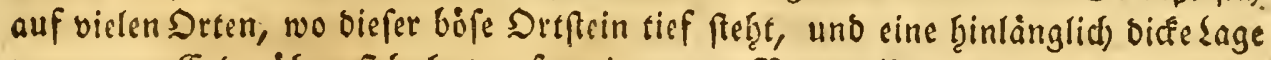

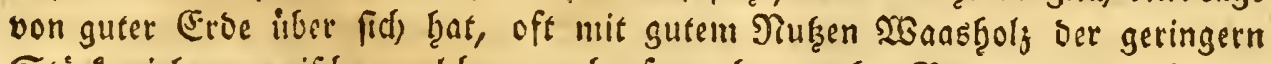

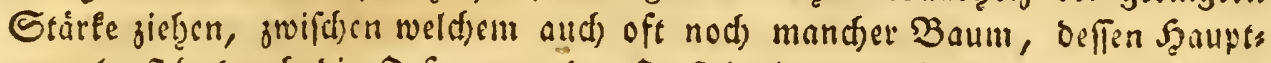
rurgeln fid) Ourd) die Defnungen ber Drtfeinslage surdggemadjt haben, mit aufjuwadjfen pflegt. Llebrigens aber ift es nidjt anjurathen, auf eine tiefere

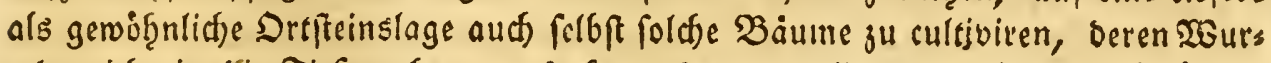
geln nidt in bie Siefe gefen, uno faum den unterliegenden Drtftein berifzen mitrben, als juIn $\mathfrak{B}$ evfpiel $\mathfrak{F i d}$ ten uno Juren fino, weil foldse, befonbers, wenn bie obere Erolage von antraltendem Regen burdgniffet ift, barauf vout

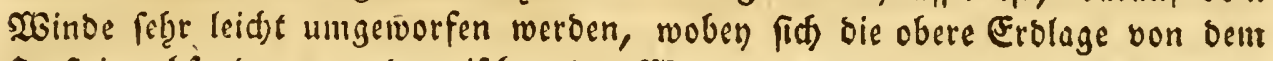
Drtfein abjonbert, uno zroiftoen ben 2 urgeln oer ungefallenen Båume mit umgefdlagen wirb.

\section{§. 599. \\ Bon eiller gebirgigtent siegells.}

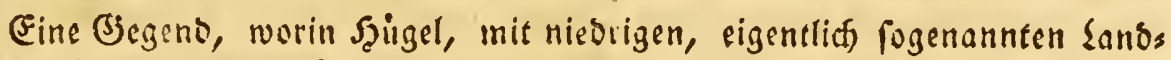
gebirgen abwed)feln, ift fü oen Forftbetrieb in mef̧rerm Betrad)t bie vortfeeils

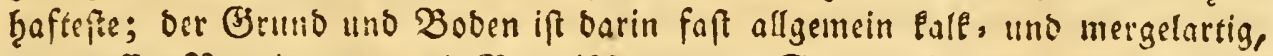

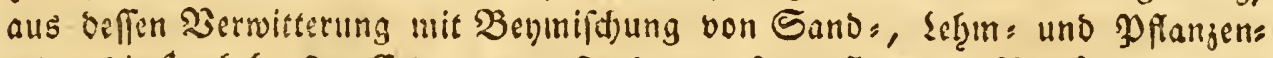
erbe, bie frudjtbarfsen (stsarten entfanden zu fenn pflegen. Sorjiglid) findef man Darin in ben Brinsen ober tiefern Jigenden ben beften unb tieffen Fruf́ts. boden, mosin bis fämutliften Saubf̧olger uno befonders bic (Fid)en in lleberflug

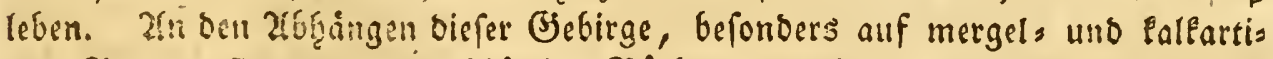

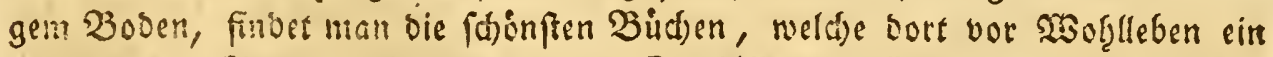

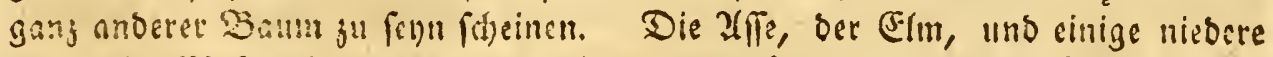

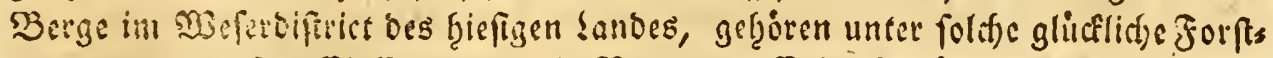

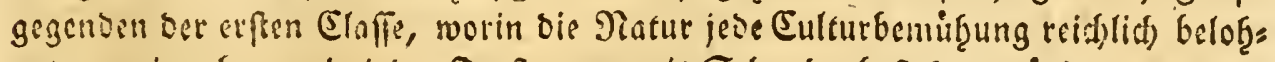

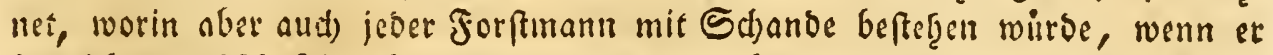

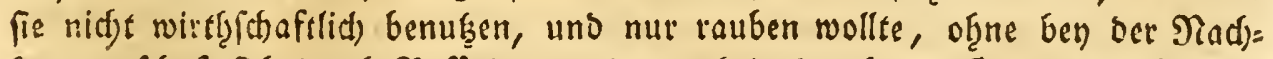

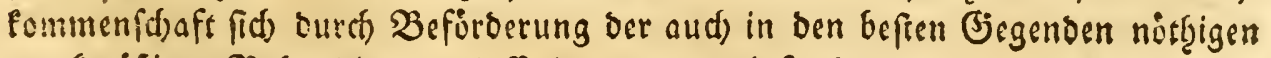
juectmaipigen $\mathfrak{B} e$ g̨andlung uno Culturen ju rechtfertigen. 


\section{§. 200.}

So, wie bie niebern lanbgebirge ju ben fiögern 30 rgebirgen unb bann

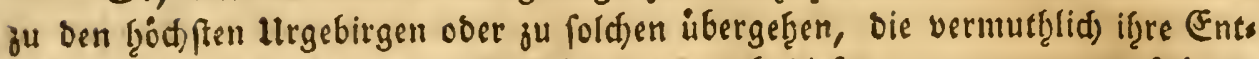
feftrung ber Edjöpfung, uno nid)t einer nach bikfer vorgegangenen fpàtern

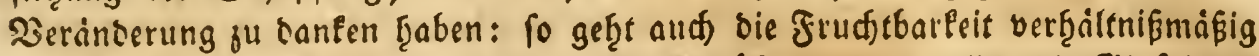

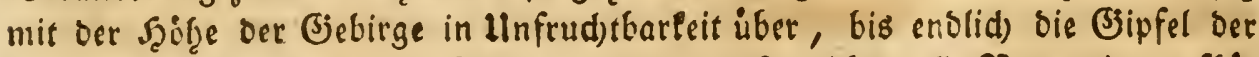

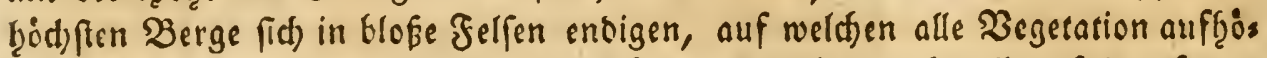

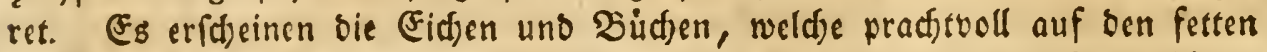

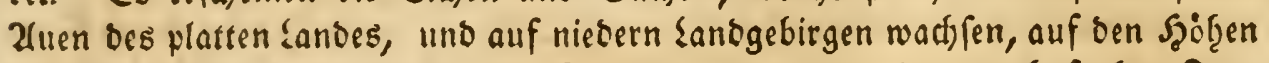
ber 3orgebirge fdion in elenoem Suftande, und bie bort nod) frohen Tane

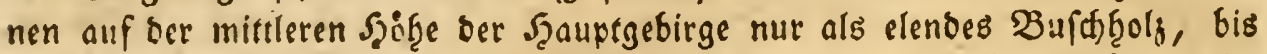

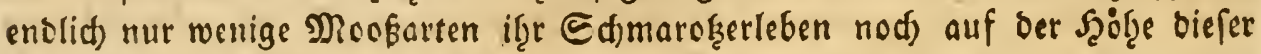
Pnlten Siegenden fümmerlid ju erf̧alten in Stande find.

\section{§. 201 .}

Die nicbern \{and: und $30 r g e b i r g e$ plegen aus Fales und Sandfeinen ju

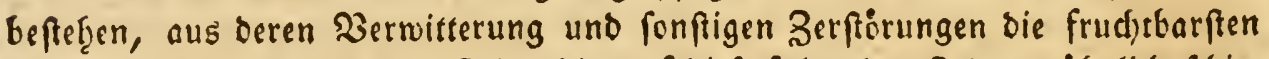
(Erbenmifdungen entfanten find; bie auf biefe folgetroen find gewoilgnlich foles

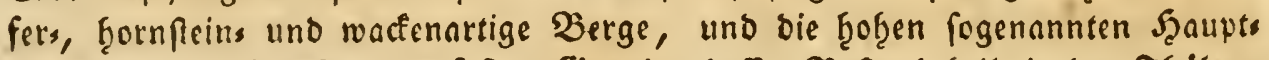
ober Uligebirge beftefien aus feftem Branit, beffen Beftandtheile in ben Ş̧ilern imifden Denfelben in weniget frudtetbare Erben aufgelópet fino.

Es ift alfo in bergleid)en (Jebirgen fowogt ber bafelbft unfrud)tbarere Bruno uno Boben, als bas fo feter viel fáltere uno faft beftänbig naffe Silima

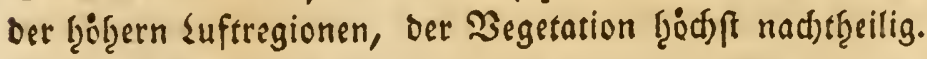

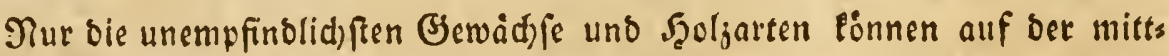

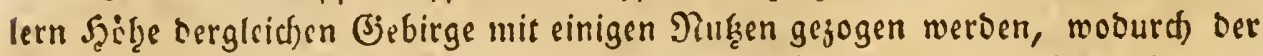

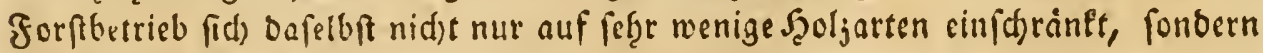

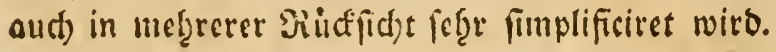

\section{\$. 202.}

In ben berirgen fomme es vorjuglid auf bie lage berpelben nach ben

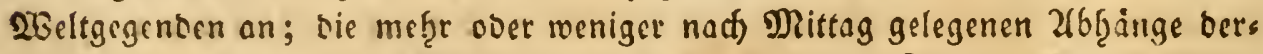

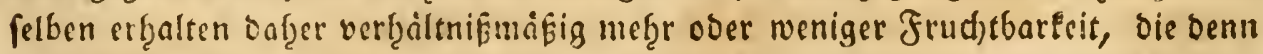
bafelbft surd) cinige, nur ben Bebirgen eigene, Nebendinge vermef̧rt oocr

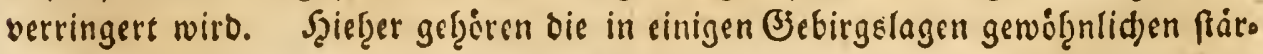




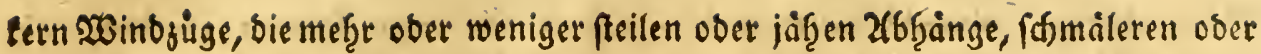

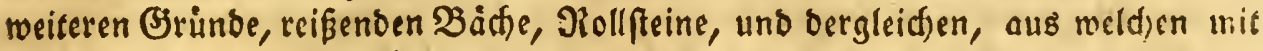

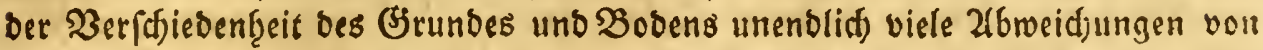
Befdwerniffen für ben Forftbetrieb entftehen. Man lann baber beise feine alls gemeine Srunoregeln anneb̨men, uno nur eine grinolide mit Erfabrrung bers bunbene Renntniß bes Bangen wirb für bie einjelnen fälle ficer abermals jur Znleitung bienen mulfen; wooon weiter am gef̧origen Drte.

\section{§. 203.}

Eine befondere Slafle von Bergen madjen bie vulcanifden Baerge aus, weldfe aller $\mathfrak{W a b c r f d j e i n l i d ) f e i t ~ n a c h ~ e f c e m a l s ~ f o , ~ w i e ~ b i e ~ n o d ) ~ j e s ̧ t ~ f e t r e r f p e i e n d e n ~}$ Berge, gebrannt haben. Es verbienen folde benm forftberieb beswegen bes fonbers angeführt gu werben, weil bie (Segenden, weld)e biefe Berge umgeben,

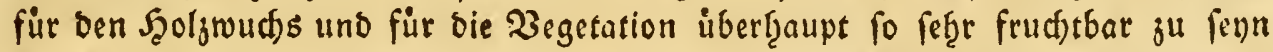
pflegen, inbem ber (Bruno uno Boben mit ber, aus ber bulcanifden 2(fá)e ents

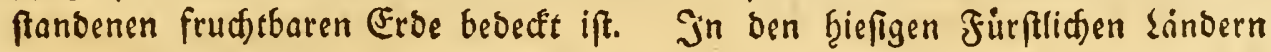
baben wir zraar biefe Berge nid), wohl aber in ben angrenjenben Sanogräflich

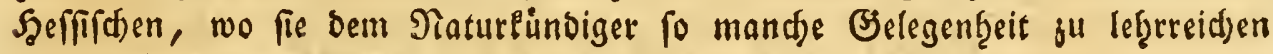
Unterfutbungen barbieten.

\section{§. 204.}

Ilngeadfet bie melcr nach Mittag gelegenen (Bjebirgsfeiten iberb̨aupt weit fruchtbarer fino, als jene, bie mef̧e nach Mitternad)t liegen: fo tam man fols (d)es bod) nid) für alle fialle uneingefdränft annefzmen, benn objdon auf ben Eonnenfeiten bie 2 árme bie 3egetation im Sanjen mef̧r beförbert: po entftes bृen bie Wirfungen des eigentlid)en (Erfrierens ber $\mathfrak{B}$ aume bod) bafelbft mef̨r, wie auf ben norblid)en Eeiten ber (Sebirge. Die Llrfacten bavon fino

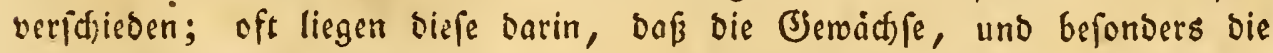
lefrtjäbrigen Soben berfelben, auf ben Sommerfeiten jairtidier uno waiffes rigter fino, oft aud barin, baßs biefe bort in ben lefsten warmen Scerbfts tagen if̧ren jährlidien వuwad) nid) gefiorig beendet, uno bie jungen Soben gegen bie früh eintretenbe Fälte nicht genug abgef̧àtet fino, ober aud),

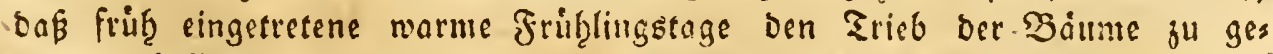

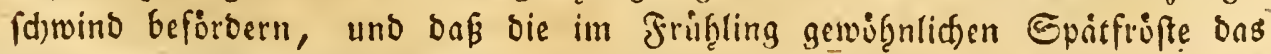
Berfrieren baourd) verurfad)en. Das fdiolid)fe aber auf ben Sonnens feiten ber (Siebirge fino bie früben Connenblicfe bes glorgens nad falten Nadjts 


\section{4}

Nadjtfriften, wiewof̧ biefe in ben biofferen Bebirgen feltener fafaben, als in ben Begenden bes flacten Lanbes, rweil ber in ben Bebirgen gerwif̨ns lith bis gegen Mittag bauernoe Nebel folthe falffie Sonnenblicfe abgäalt. Metreres ift bereits oben boun Erfrieren ber Baiume bemert? worben.

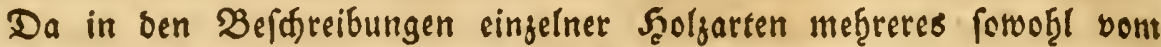
Brunde und Boden, und von ben verfdiebenen Lagen berjelben, als aud von fonftigen barauf rirkenden Nebendingen vorlommen wirb: fo wirb foldses bis Daf̧in verfpart.

Ende Der erftent Tbtbeilung. 


$$
\begin{aligned}
& 11+b \quad \mathfrak{l} \\
& \text { ole }
\end{aligned}
$$

forftmábige (Ergief)ung, Erthaltung und Bentuk̨ung ber borguglidfen

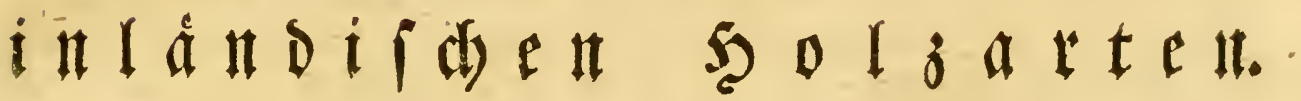

Ereften Sgeils jweyte abtheilung.

$$
\text { Die (E) } i \text { di) } \text {. }
$$



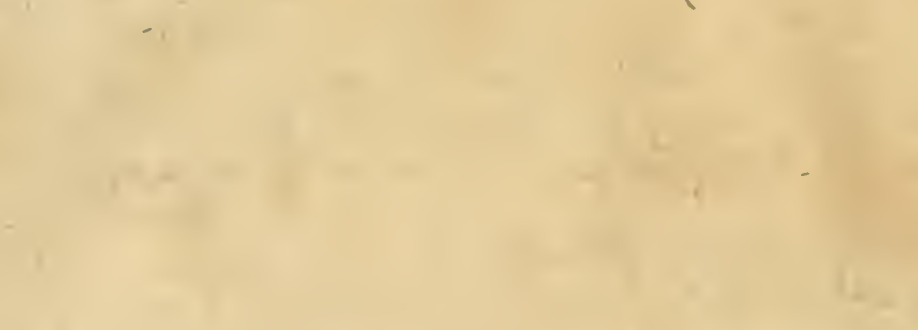

$+2$
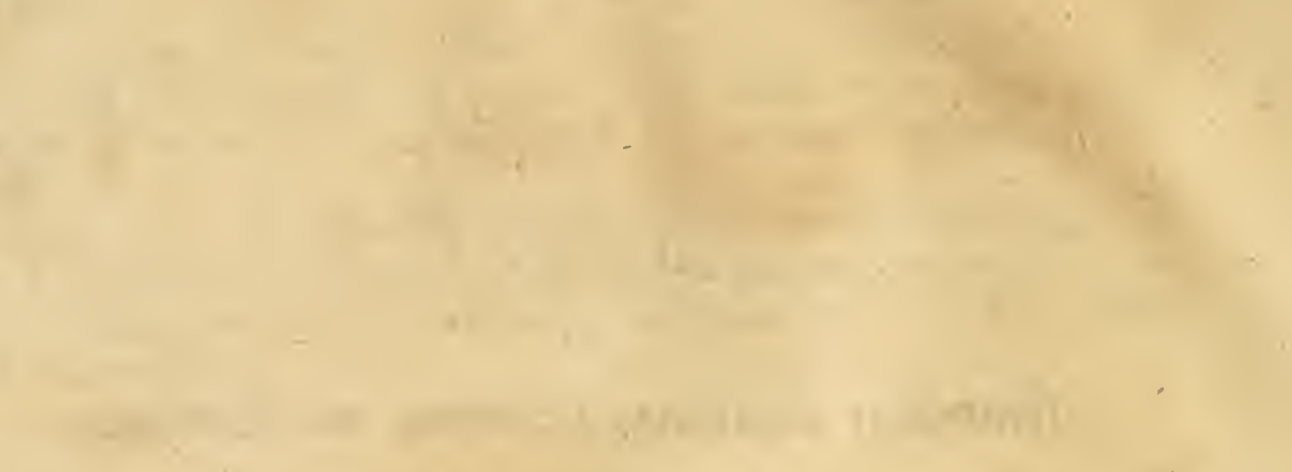

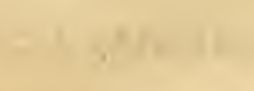

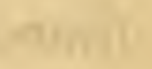

\section{0}

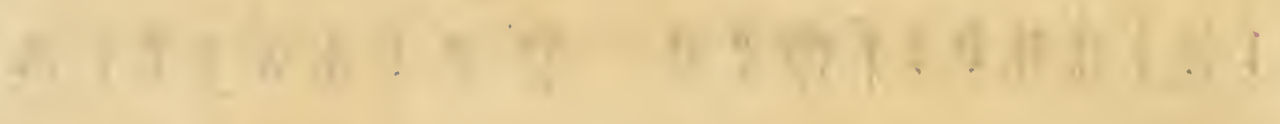

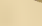




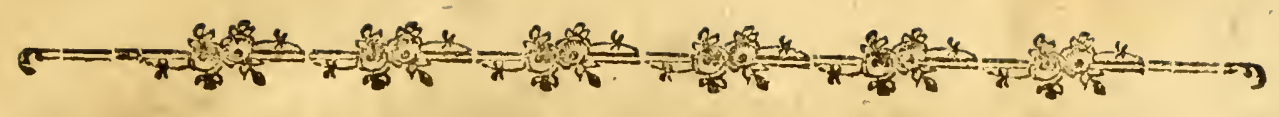

\section{Se(t)iter $\mathfrak{A}(\mathfrak{b}$ (d) nit. $\mathfrak{Z} \mathfrak{a} \mathfrak{d} \mathfrak{e} \mathfrak{r}$ (s: $i$ di $\mathfrak{e}$.}

§. 205.

Da bie Eidfe, if̧rer vorguglicffert Eigenffiaften und if̧res ausgebefrnten

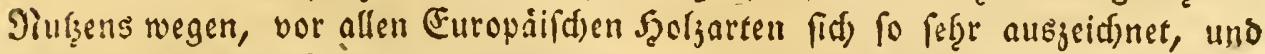

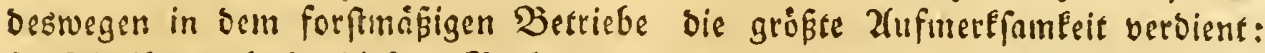

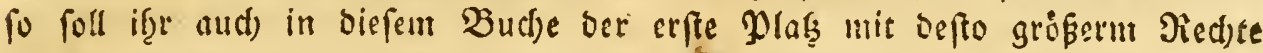
gerviomes weroen, uno weil bavon auth fefré vieles ju fagen fenn wirb, was it

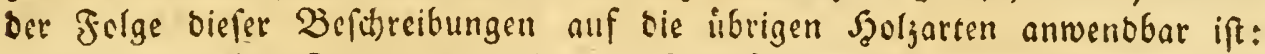
fo foll in fordem falle jebcsmal barnuf juriafigewiejen werben, un unnos thige Sieoerţolungen fu vermeiben.

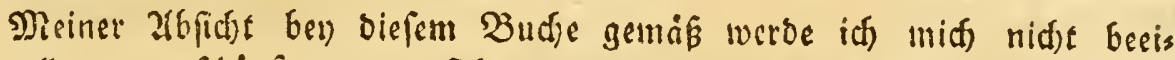
fern, alles zu erfhipfen, mas fid) von ber Eiche Bjelef̧rtes ausfinden und fagen läbt, fonoern ich roill mur bas anjufiufren uns ju exläutern fud)en, was fur ben praptifden Forftbetrieb ocr Eidje vorguglid in ben biefigen Fürptidyen Sindern und in ben angrenjenden Bogenden nuglida fern eann.

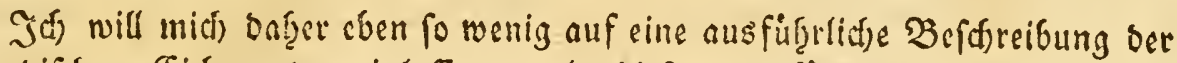
auslindifden Eidfenarten eitlafien, als sicfe nut fir ien Jorftmann bes

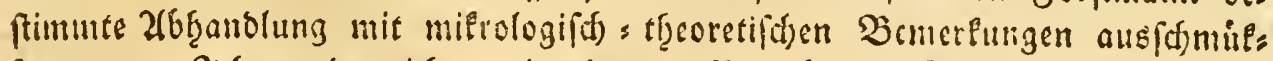
Pen. - Jaf werbe nid)t, wie einct unferer beften Sdyriftetler, bie fid

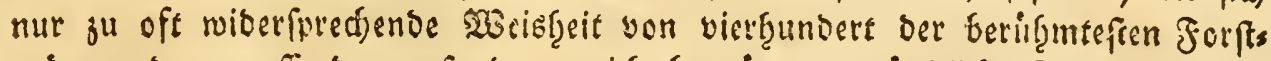
mänter baju aufforbern; fonbern miø begnigen, grüblitje Beovatftungen anjufüf̧ren, wenn es, unt fïr biefen ober jenen biegenf̧tans mef̧reres aus trauen ju geninuen, nusslide) fenn fann.

(jegenwartige abfrandlung foll fich alfo nue auf bie in ben hiefigen

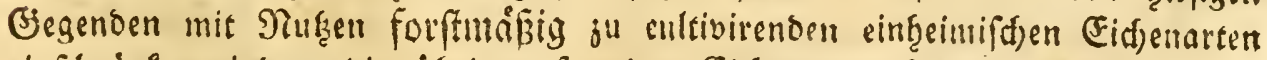

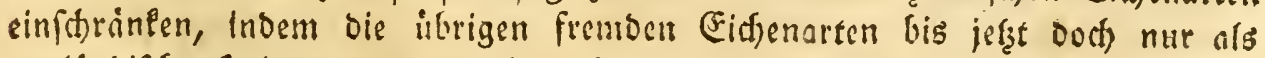
auslänbifde Şoljarten in ben sufwálbern, unb in ben fo genannten Engli= fdeen (bairten gejogen rertoen, und biejenigen meiner Sefer, welde bnyou 


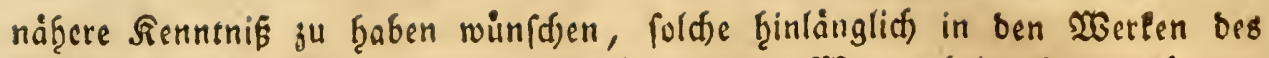
ou Szamel's, ou Pioi, von Burgsborf uno von Wangenfleim finden fonnen.

Sgingegen follen barin alle widftige Bemerlungen, welde in einer ober ber andern Şinfid)t in den verfdiederien Begenden bes hiefigen Landes ben

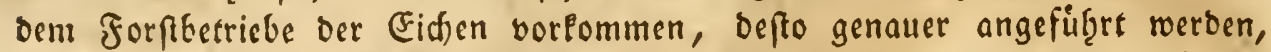
fo wie aud) bie vorgiglidfeten (Eidjenculturen uno bie Namen einiger forfts

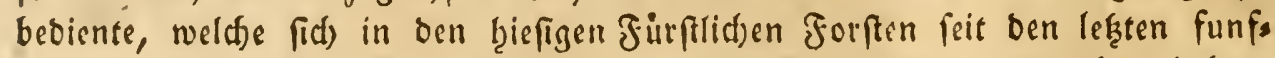
zig Jal̨ren baunit bey) ber Nachwelt befondere Berbienfte ermorben b̧aben, Darin genannt werben follen.

\section{§. 206.}

Die Eidfe, biefe ftolje Bierde unfeler beutidien Forften, ift ju fefre

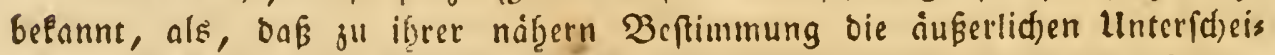
bungsjeid)en oerferben von andern Şoljarten bier angegeben werden follten.

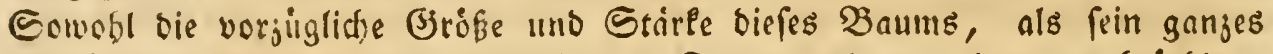

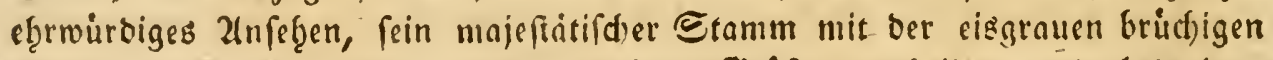
bemooften Borke, uno bie mit maf̧rer Birípe verthcilten und belaubten Zlefte beffelben, heben if̧n weit uber bie andern Baumarten empor.

Eelbft unfern reniger empfindfamen Borfafiren flöpten bie Eidjen eine beilige Şodjadtung ein; fie epferten unter if̧nen if̧ren Bötters, uno bie feners lidftèn Şandlungen wurben unter groben (Fid)en borgenommen. 2(ud) mandje

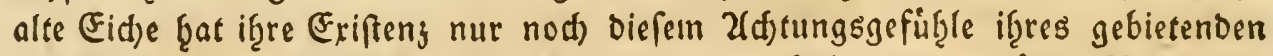
Jorftmannes zu banlen; weldjes fo gar nur ju oft bis jum unnukgen $3 e r b e r b e n$ Derfelben ausgedefgnt wirb.

\section{§. 207.}

Bon Dell verffiebenen arten ber Fidfell.

Die Eidjen fönnen getheilt werben in bie einfzeimifden und fremben (Fid)ens

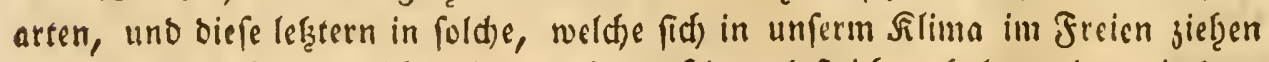
laffen, als bie fino, weld)e wir aus cinem Şimmelsftriche etḩalten, ber mit bem unfern ziemlid) gleidf ift, uno in foldhe, weld)e nur in einem warmern Sitima rad)fen, uno fid) in bem unfern nicht biegen laffen. IInter ben fremben (Eid)en:

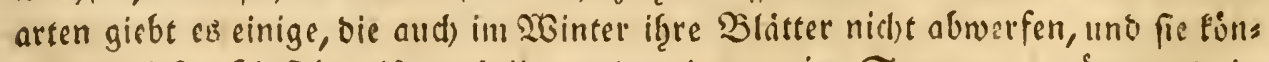
nen in biefer Szinfict) alfo getfecilt worden in nut int Sommter grtume und in allegeit grine Eidfenarten. Sin bem Werle bes Sferrn von Burgsoorf's über 
bie Fidje, werben bie meb̨rften bier betannten Fidenarten mit if̧ren Deutfden,

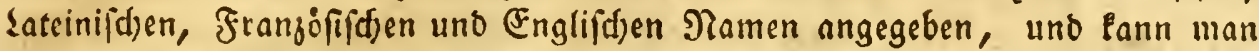
fid) von bemfelben auth ben Saamen und bie Pflanjlinge imandher fremben Fi: denarten verid)affen. Unter biefen fremben (Fid)enarten fonnten aber vielleid)t nur bie bafelbft unter ber füften unb fed)fen Numer angegebenen, als bie Norbames ricanifdes " Caftanienblatteridfe (Quercus prinus) uno bie Sd)arlacfs

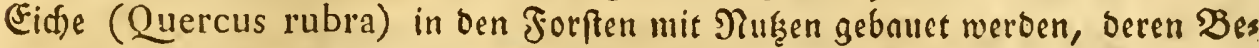
banolung mit ber ber geroobntidjen einbeimifden (Fid)en faft gléid) ift.

\section{§. 208 .}

Infere einfeimifaten (Fid)enarten findet man in gang Deutfalans uns in ben mef̧rften Eurepaiichen Sánbern von einem semápigten Flima, nicht aber unter ben ganj beifín uno ganj Ealten Scimmelsftriden. Selbft auf unfern

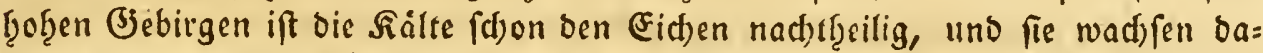
felbft nur elend uno fruppelfaft. Infere niebern Sanogebirge, uno befonbers bie

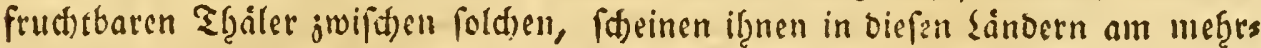

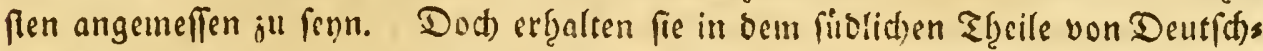

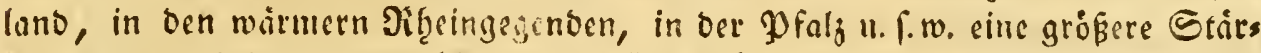

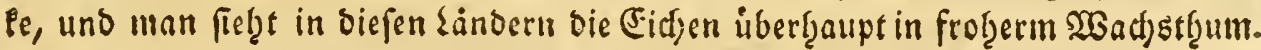

$$
\text { §. } 209 .
$$

Die einţeimifden હidfen fino,

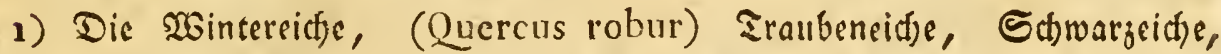
Steincidfe, (3rasidas, Sileveid)e, Furjfticlid)te: (Fiche.

2) Die Sonmereidfe, (Quercus foemina) Stieleidfe, Rotheidfe, grofe Maftciche.

Unter unfern vaterländiffen Fidien fann man nur biefe benden als waţre 2lbarten annef̨men: beren auffaliende linterfacioungsjgiden fino folgende.

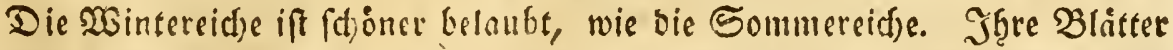

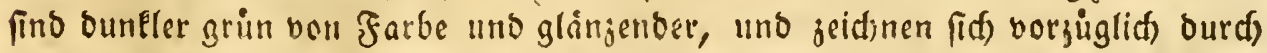
iţre langen Stiele, Eurd if̧re megr wollenartigen Einfdynitte, uno meţrere Breice ber obern Enern aus; fie figsen aud an ben jungen faoljericben mef̧e angelefgnt, und in frikern Winkeln, fie werben viel weniger von ben Jnfecten angefreffen, wie bie Blatter oer Sommercidjen, uns crbalten ifte Belaubung, bie iberb̧aupt bon fefterer Septur ju finn fdeint, lingere Beit grun. Die 


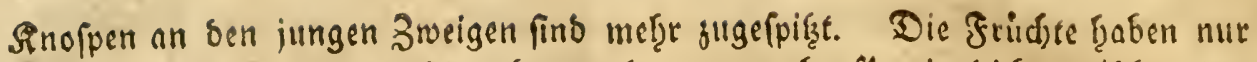

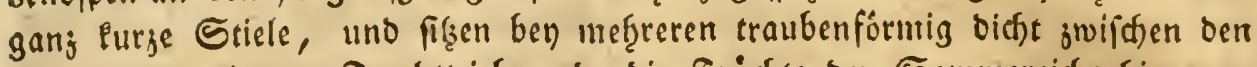
Blätern ber jungen Jrudtstriebe, ba bie früdte ber Sommereidje fingegen zwar bey mef̧reren, bod) cinjeln an einem, ein bis zroci) Zoll langen, gemeins

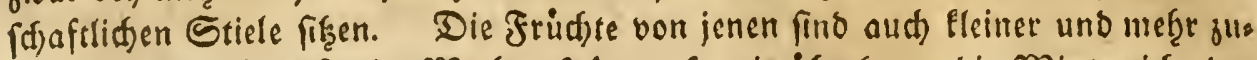

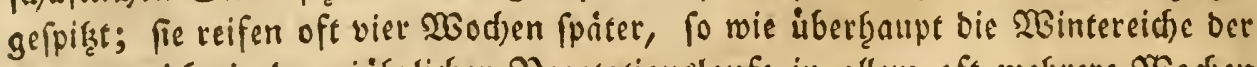
Sommereide in bem jöf̨rlid)en 3 egetationslaufe in allem oft meţrere 20 od)en nad)gerget. Die ibrigen weniger in bie 2(ugen fallenden linterfdicosjeid)en

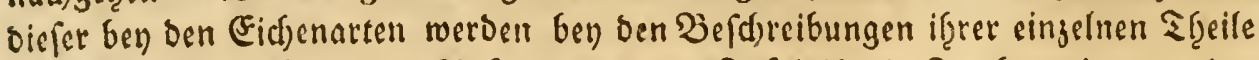
bemerlt werben fönnen. 2luf ber zwenten Safel ift ein Jructstzweig ven ber Gommereidfe und auf ber britten ein folder von ber Wintersidje vorgeftellt.

\section{§. 210.}

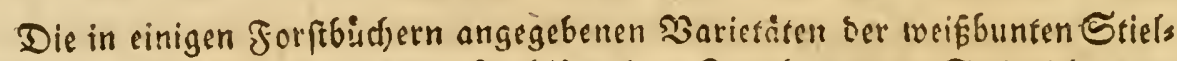
eide mit fdjectigten Slättern, ber feinblätterigen Traubens oosr Steineidje unb bergleiden, find nur als Spielarten anjufetcen, wie man foldse aud bey an= bern Baunarten finbet, bie am fidserften burd) bas D fropfen ouf bie gewoilnnlis den Irten fortgepflanjt werben.

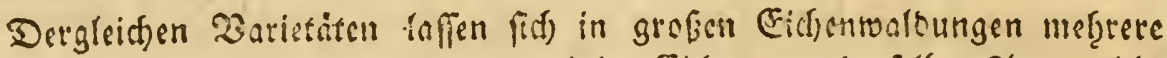

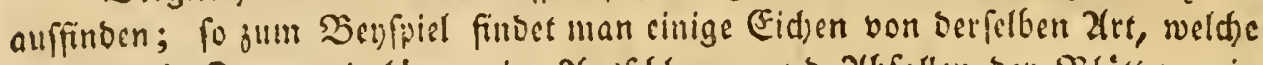

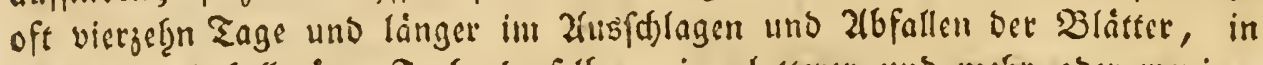
bunkeler und Geellgriner Farbe berfelben, in glatterer und merge ober weniger

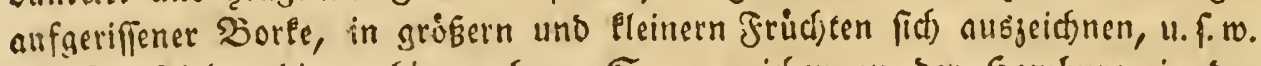
zum Belf fiel vertienen fier metrere Sommereiden an bet Semburg in ber Szallenforft uno auć) cirtige auff bent Brunsleber Jeloe in Sthoniugidsen Dis frrite angefifgrt werden, weld)e befonders fleine lange und fpif̧ige Jrübte

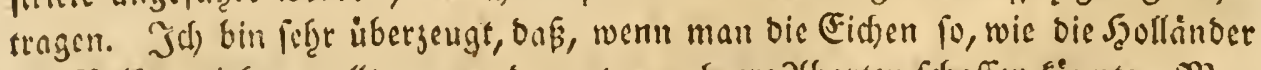

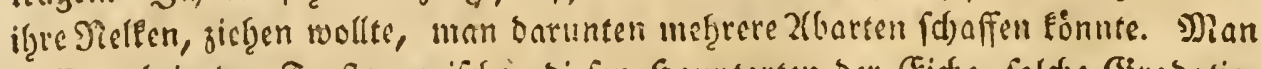

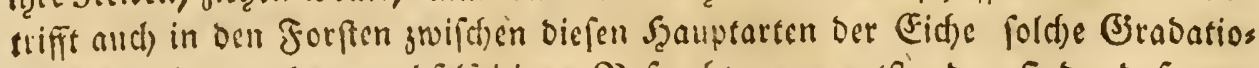

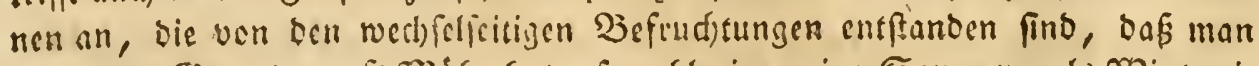

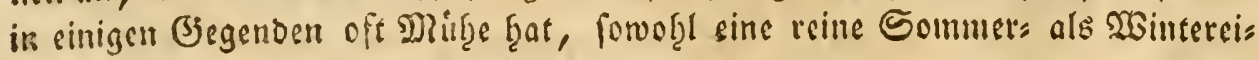
(d) jull finter.

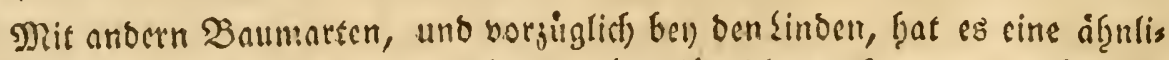

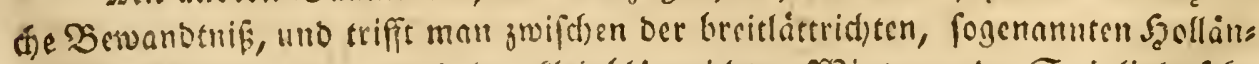

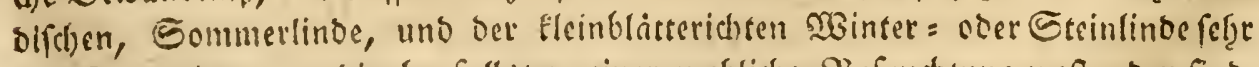

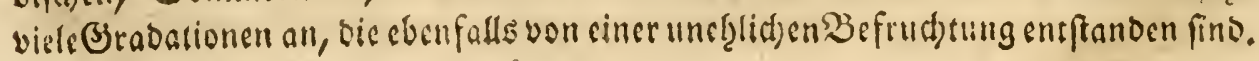




\section{§. $2 I I$.}

Bey forden Baumarten ỉberb̧aupe, weide auf bemfelben Stamme ges

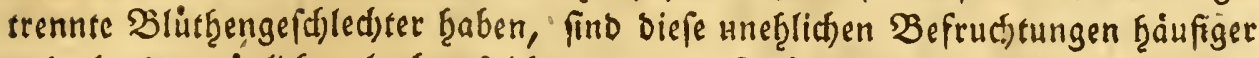

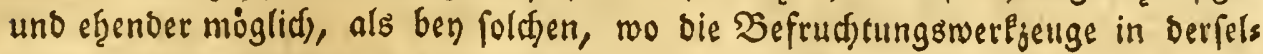
ben shlume enthalten find.

Bey ben Eiffenarten wirt foldjes ourd) verfdjiebene limftande oft nod

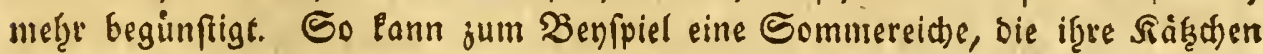
vierjeţn ₹age fruf̧er getrieben, unb baf̧er burd) cinen fpáten frillingsfroft vers

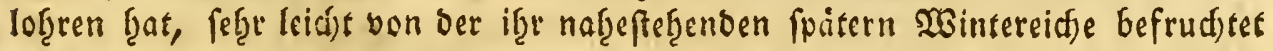
werben, fo wie biefe vielleid)t unter äf̨nlichen aufällen von jener einige ef̧elidge Begünfigungen genieß̌en eann.

\section{§. 212.}

Bende Eithenarsen getgoren in bie erfte Dronung ber in Sommer grünen Bailume, in weld)er fie mit allem Diedtet ben erften Plas verbienen, nach beun Sinncifden Syftem aber madjen fie bie 1 yofte Bjattung aus; fie gef̧oren unter bie Monoecia uno polyandria, benn fie ţaben Betrennte blittengefdeledter auf bemfelben Etamme mit feds bis jef̧n Staubfáden. Fir eine fo grofe

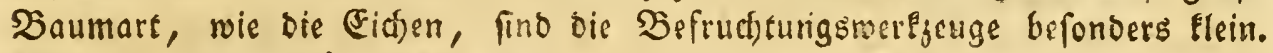

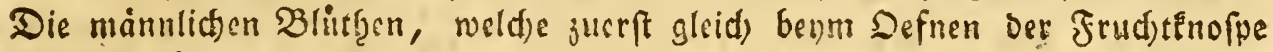

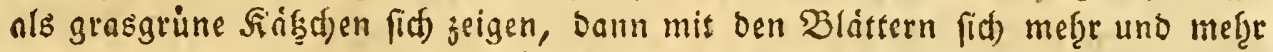

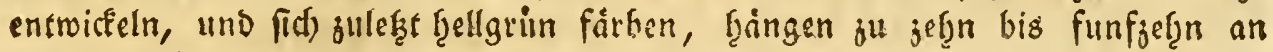
einem ein bis jwen Zoll langen fabenaltigen Stiele; bie Staubfaben find fe Furg. Die gelben Staubbeutel nad' bem Zerf̧ältniß ber Blütge aber finto bick uno

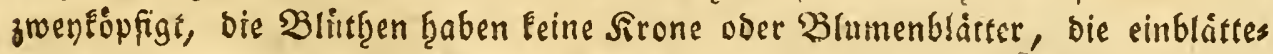

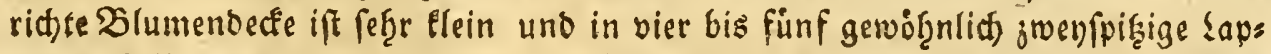

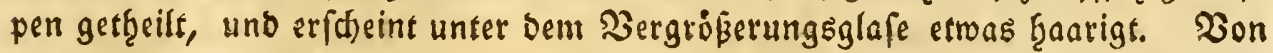

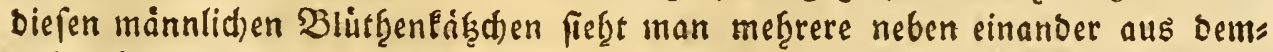
felben Frudtetnotell, und fie bleiben gerwothnlid) auf bem Brunde beffelben figen,

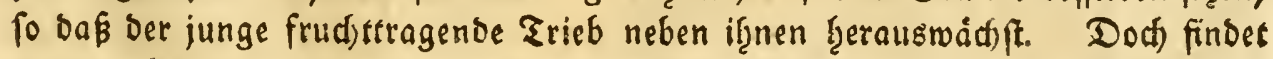

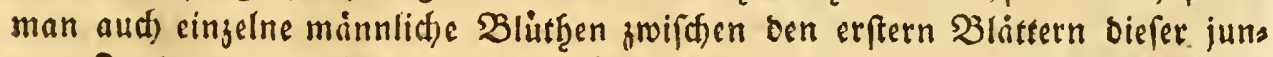
gen Zweige; es pflegen diefe. Bluthen alsbann aber meniger vollenmen in fenn. 


\section{§. $2 I_{3}$.}

Die weibliden Blitţen erfdseinen an Den jungen Trieben ber Frudteflros fpen jnifden den Blättern; fie haben audf leine Sitone uno leine Blumenblats ser; fie fisen ben ber Sommereict)e ben jwen, oren und meţrern an einem oft ein bis zroen Boll tangen Stiele, bev) Der Mintereidje aber an einem foum merélidjen Etiele, bey mefgreren traubenformig jmifd)en oen Blättern. Die einblatteridjte Blumenbecfe ift bey beyten (Eid)enarten fünfipaltig, halb fugelfơrs

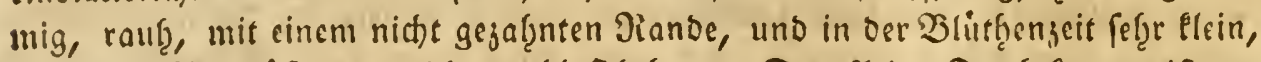

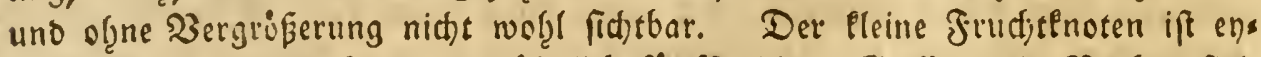

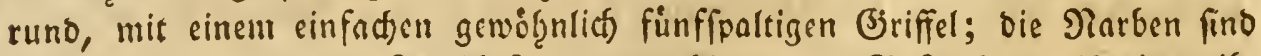

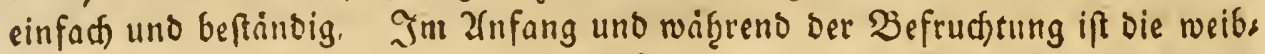

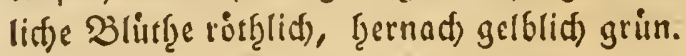

Die Siguren auf ber vierten ₹afel erllären biefes alles beutlid)er, man fief̧et auf berfelben die minnlide blittle in ter Fig. x. uno bie weiblidse in ber Fig. 2.

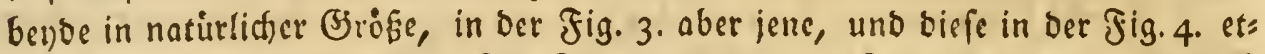
was vergrö́pert vorgeftellt. Die Fig. 5. Peflt einen Frudtzweig vor, ben ids iin bergangenen Jaḩre von einer Eid)e, Die auf Der Jुỉhe bes Sollings auf eis

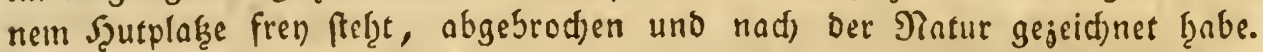

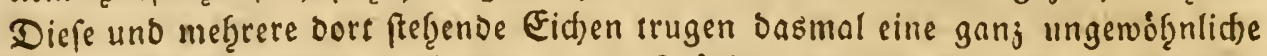

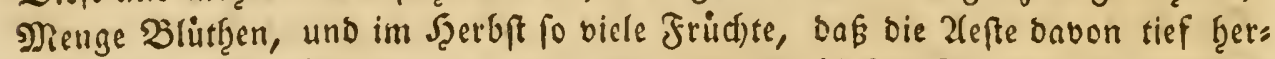
abf̧ingen. Bey a) fieţt man baran bie jarten weiblichen Blumen zwifhen ben ausbred)enden Blättern f̧erborftef̧n. Einige bavon f̧atten in Şerbft ad)t bis zeţn reife Sruddte an fünf bis fed) Zoll langen Stielen f̧ängen.

\section{§. $2 I_{4}$.}

Die Frudft ober viefmefie ber Saamen ber Eidan ift enformig und Pern. artig. Sie beftef̨t aus groen gleid)en Theilen, bie mit bem, jwifhen if̧nen am obern Ende befinoliden, Reime verbunden find. Diefer Kern if mit einer

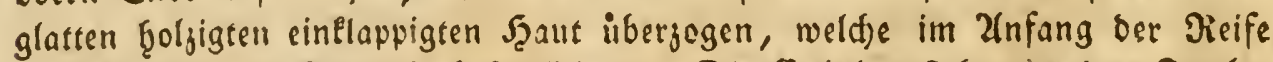

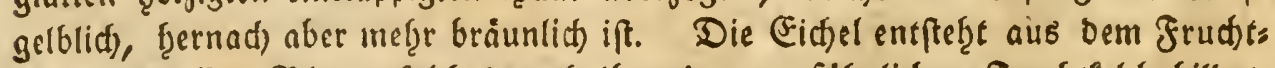

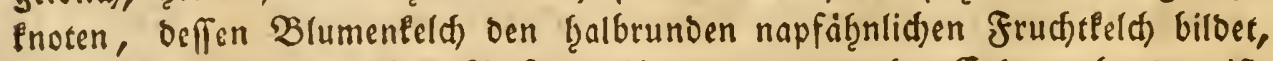
mit weldjem fie bis zu if̧rer Reife an if̧rem untern raufen Enbe verbunden ift, fich alsbann ba ablojet und abfält. Die teeren Frudtsteld)e bleiben nadffer nod) eine Beit lang auf oem Baume fifsen, uno fallen erft gewóg̨nlid) mit ben Blättern ab. 


\section{§. 215 .}

Bevbe Eidfenarten fetęen in unfern Leutfden Jorften vermifdet, bod, wirb man $_{i}$ in einigen (jiggenden meţr Sommercid)en, in anbern ţingegen mef̧e Wointereifjen finden. Die Urfache biervon liegt vorgäglich in bem frùtgern ober

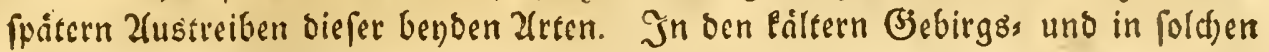

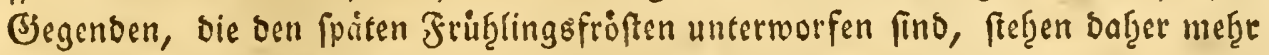
Wintereidjen. 2luds wirb unan, wenn man genau barauf acftet, in cineur Jaf̧= Ie oft in ben Forften mef̧r von ber Sommereide, als von ber 2 Sintereidse, ein

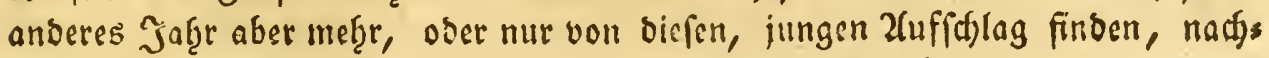
bem naimlidj biefe ober jene Saamen getragen ţat ober nidft.

\section{§. $2 I \%$.}

Bott Der Blithe, Don Der Fruti, vont Reiment DeB

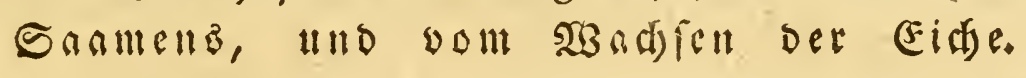

Die Zeit ber Blutţe und Befrudsung ber Sommereidje ift gervig̨n: (id) ber ?nfang bes Maymonats, und bie ber Wintereidje alsoann vierjef̧n Tage fpater, bod) frängt biefes bey benben 2rten, fowohl von ber sage

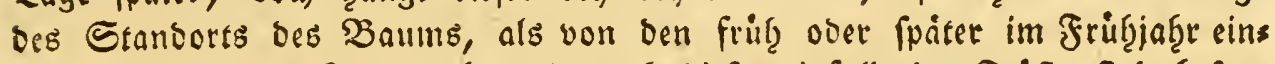
tretenben warmen Tagen $a b$; bie nad) biefen einfallenden Frofte find befons bers ber Sommereithe gefóf̨rlita, und vereiteln bie Scofnung einer anfafeis nenber: reicfen Maft nux ju oft.

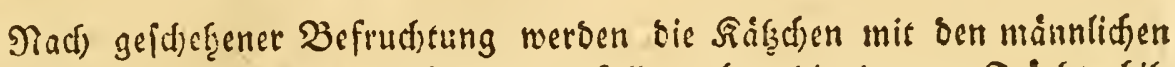
Blithen briunlidit, fie vertrodfuen uno fallen ab; bie jungen Frudde bils ben fifh bemnid) ft aus ben weiblidjen blitferen, beren Stiele mur an ben

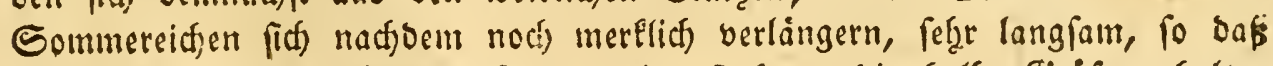

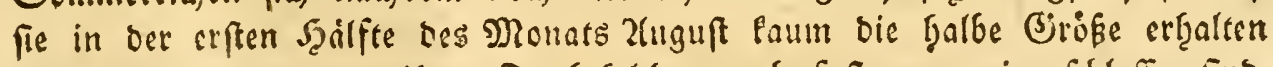

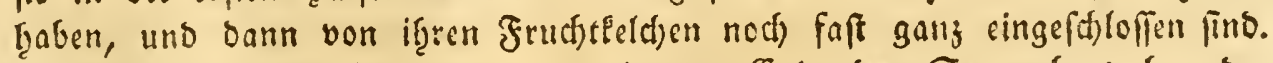
Defro gefdumber aber ger̨t es Damit jum Ende Des Sepember's bey ber Sommeicicise, und bis jum Enbe bes Tovembers bet) Der Sintercidje, ju

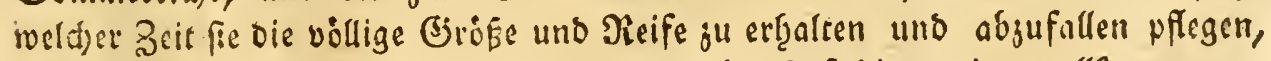
wovel) es, wie bey) anderen Seoljarten, jugeţe, daß́ bie weniger vollemmenen, bon ben Injecten angefreffenen, ober fonft nothreifen zuerft, und bie guten

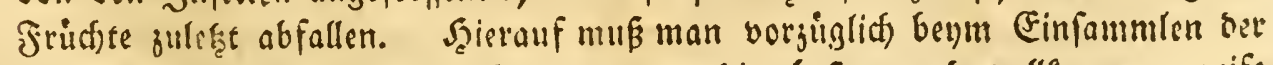
(Eid)eln ju Befanmungen ad)ten, woju bie beften und vollemmen reife Srust)e genom:nen rocroen miffen. 2(ber aud) biefe eann sin nad) anfialtenber (Erffer Theri) 


\section{4}

Dürre lurf bor ber Reife ber Eidjeln eingefallener frarler Regen, monad) bie äufere Sdjaale aufjufpalten pflegt, fo frate befdadoigen, bak polde zur Befaas mung untauglid, werben, befonders wenn man gejwungen ift, bie Eidjeln eine

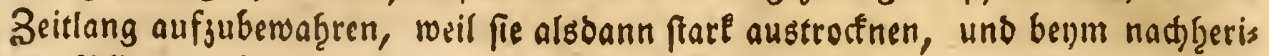
gen Pllanzen faul rerben.

\section{§. 217.}

Die Eideln ber Sommereide fino of̧ngefïber einen Zoll lang und oft brens viertheil Zoll biff, bie ber Wintereid)e fino etwas fleiner und oben weniger juges

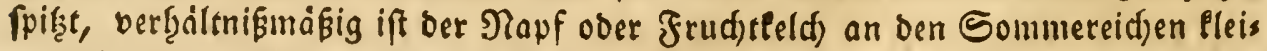

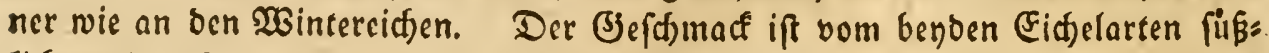
Jid)t uno jufammenfieg̨eno. Die Sernpticfe Der Eidgel beftę̧en, wie andere nufartige Sanmen, aus einem jientid) feften, marligten uno óligten Rellenges wëbe, weld)es als ber Mitterludien bes $\mathfrak{R}$ eims und ber baraus entfeffenden jun:

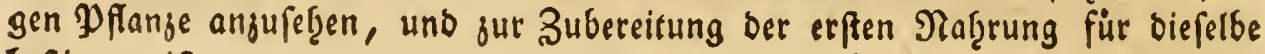
beftimmt ift.

\section{§. 218.}

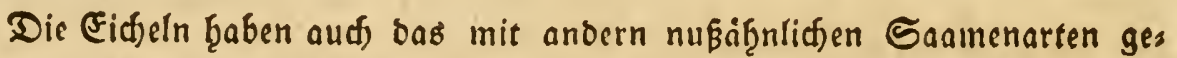

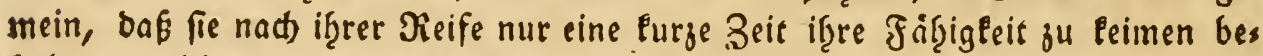

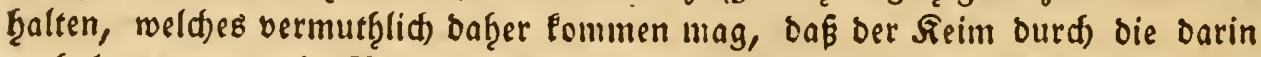

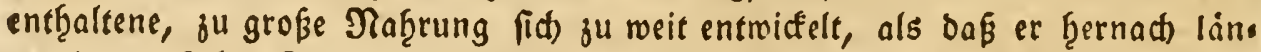
ger in bempelben Buftande gut erf̧alten werben fönnte, of̧ne aus ber Erbe boju

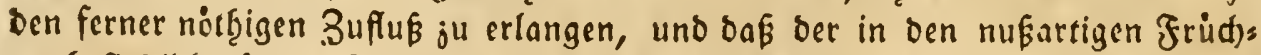
ten befinolide óligte Saft ranjigt wirb, weld)es man an ben auf ben Eidjeln fid) jeigenden braunen Flecten fo wobl, als an bem 2 elfen und Stoden bes innern Serns peţen Pann.

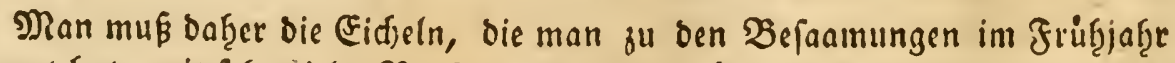

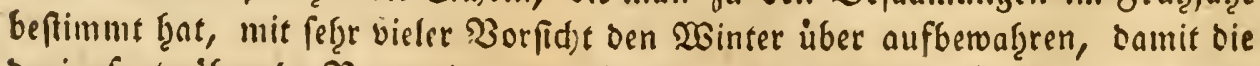

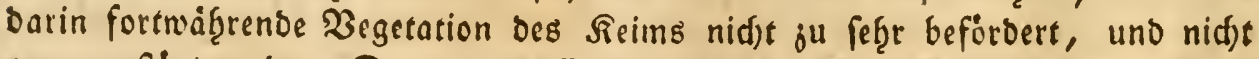

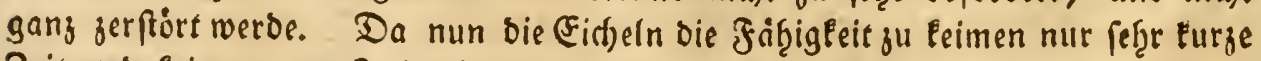
Beit uno lein ganjes Jaf̧r beţalten: fo bef̧aupten viele forfteute fef̧r irrig, Dak von ben gefäcten Eidjeln viele erft in bern zwenten, uno felbft in bein britten Jaf̧re, wie man foldhes wob̧ bey andern Baumfanmen finbet, aufgingen, in.

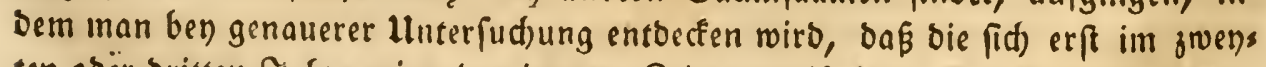
ten odër britten Jaf̧re beigenden jungen Feime gewí̄ Esine Rernfeime, fondern folitie 
polde fint, meldse aus einem Snofpen, ber im erfen Jaf̨re bereits entftans ben, aber burd) Zufall unbemerlt geblieben ober verbifien ober abgeftopen ift, ober aus berfrornen Siernfeimen ausgefdlagen find, man wirb alfo an ifnen leine Rernfiutcte entbecten, wie es ber Fall fenn wübe, wenn ber אeinz unmittelbar aus ber Eidjel entfitanden wäre.

\section{\$. 219.}

Der erfite Reim und bie Wurjelntriebe fino in ber reifen (Fidfel pajort gebilbet, weldfe nad) bem $2(6$ fallen berfelben ben Winter über fid) meţe uno mef̧e entwicteln, fo baf man bey vielen Eitheln faton iun December ben erften

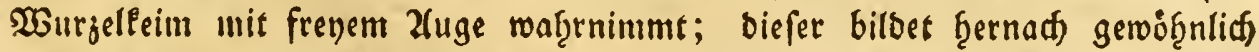

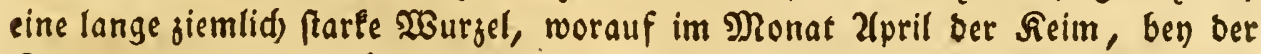

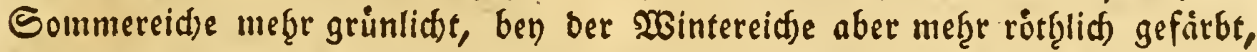

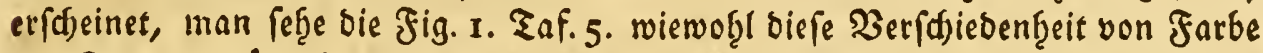

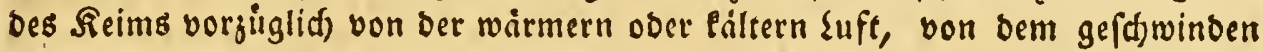
ober langfamen Ficimen, und von ber flärfern ober tiefern lage in ber Erbe abf̧ängt. Zlus biefem $\mathfrak{K}$ eim treiben nad)her bie erften $\mathfrak{B l a t t e r}$ aus; bie benden Siernftucfe ber Eidel bef̧nen fidf bey dem Reimen auseinanber und zerfprens

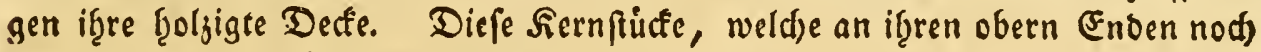
bis in bas zrente Jal̨e ourd) eigene Fafern mit bem $\mathfrak{F}$ eim uno ben 20 urzeln verbunben bleiben, verwandeln fich nicft, wie bey einigen andern Sgolsfaamen in bie fogenannten Saamenblitter, fie bleiben beym $\mathfrak{B} a$ adfen bes $\mathfrak{F}$ eims in Der Eroe, bod) erfutlen fie benfelben Zwect, und find baburd als wafere Eotys lebonen ober Saatnenblätter anjufę̧en. Bè siner gänflidten Berplaf̧ung ber

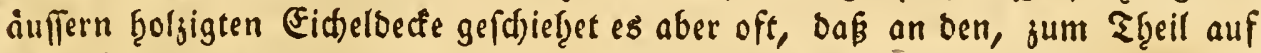

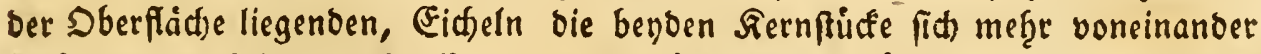
entfernen uno fich als waf̧re Eotnlesonen aufţeben nno grünlith färben. Die nach Der Natur gegeidjnete Figur 3. auf ber 5ten Tafel frellt einen foldjen unges woignnliden fall vor.

\section{§. 220.}

Det aus bem Seime entfandene junge ₹rieb pflegt bis but Mitte bes

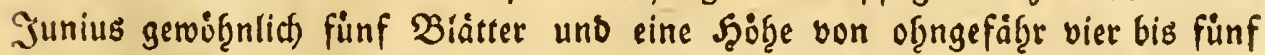
Boll zu erf̧alten, in oer Fig. 2. ber 5 ten Tafel ift ein folder orenmonatlider Trieb abgebilbet. Begen bas Ende bes Julius fdseint berfelbe fid nur zu ers Ģarten, uno ftatt bes grafigten ein neţr f̧oljigtes 2 Eefen anjunef̧men, alsoann erţált er mit ben juenten Triebe bis gegen saz Enoe bes 2lugufts nod) wob̨t

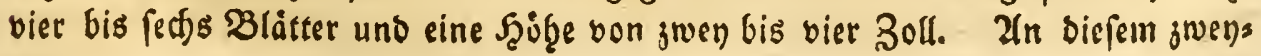


ten Friebe, ben aber nidft alle junge YOFlanjen machen, und ber bey vielen fid nur auf eine ctwanige Deffnung und auf bas Differwerben ber imittlern Snofpe

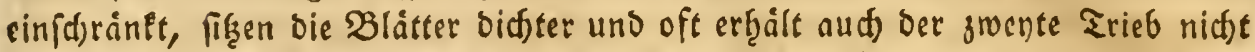

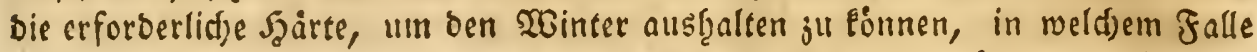
Der Trieb bes zwenten Jaf̧rs aus den Finofpen bes erftern friblingstricbes ents

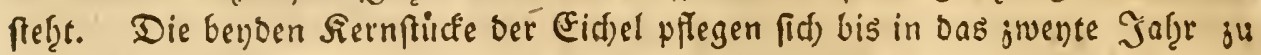

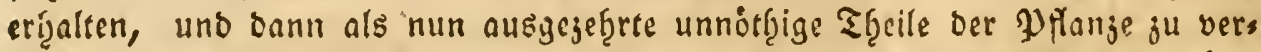
trodnen; fie hinterlaffen bann gleidffain an ber Poflanje eine Tabelnarbe juricf, bie mit bem oritten Jabere verwaidft.

\section{5. $22 \mathrm{r}$.}

Edjon an ben jungen Saamenleimen ber Eidfen erpdieint bie foft

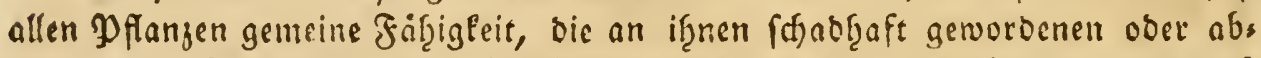

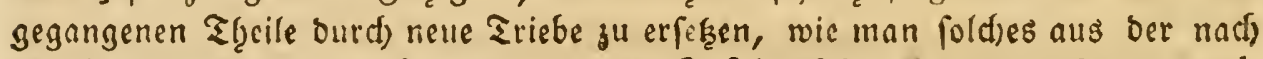
Der Natur gejeidfneten Fig. 4. Der 5 ten Fafel erfeţen eann, wo bey a uno b

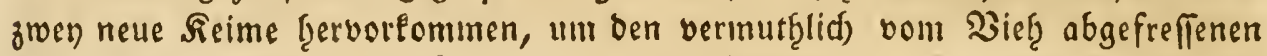

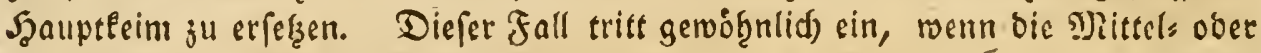
Şauptétime ourd) bie fpäten Früflingsfrófte, ober ourd) ein fonft wibriges

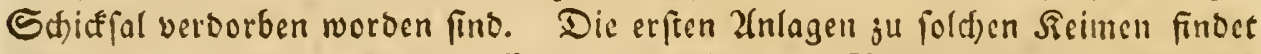
man fhen fen jeber gefeimten (Fid)el, jwifhen ben Berbindungen ber fleinen Stämuthen mit den beyben Fernfticfen ber Eidel. 2(ber aud) bey biefen to

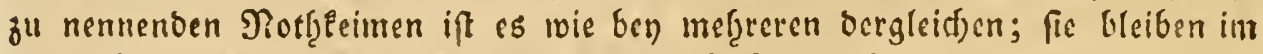

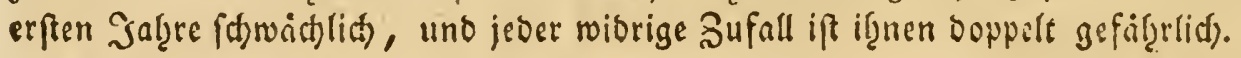

\section{§. 222.}

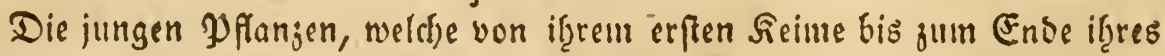

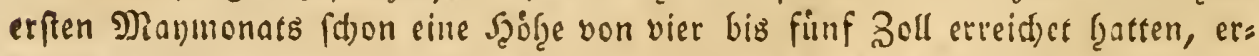

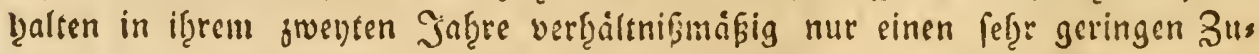

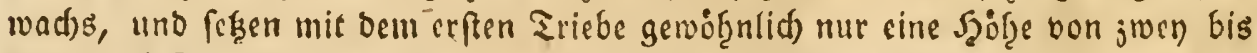
viertebyalb Zoll auf; ber iunge Jrifflingstrisb ift baben felge mager, uno hat

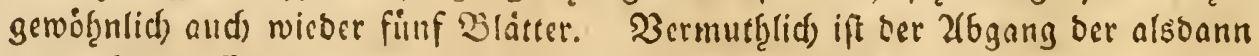
vertroffneten Eotyleconen und Das Entwifgnen von biefen ful Dem gribern unjus

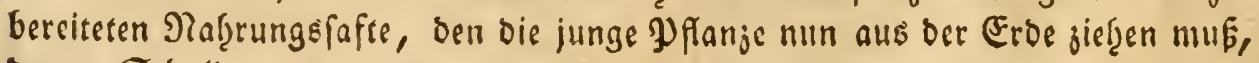
Daran Ed)ulo.

\section{§. 223.}

In ben folgenden Saf̧ren erf̧altẹn die jungen zarten Y̧fanjen immer

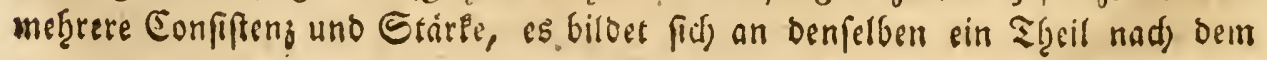


anbern mef̧r aus, fie zeigen fid) idfon mit Stamm, 2(eften und Zweigen uns erreiden' in einem guten SBoben, in facten lanbe ober auf ben niebrigen Lanos

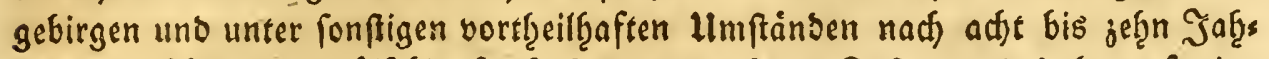

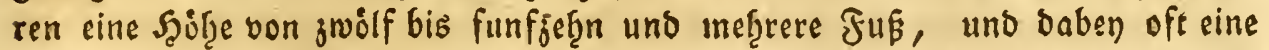
Stamundicfe von anderthalb Boll; ba fie bingegen in cinem folectenten Brunde

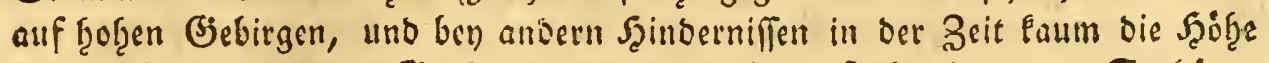
Des unn fie heer ftę̧enden Grafes, ober von ein yaar Fuf erlangen. So hångt

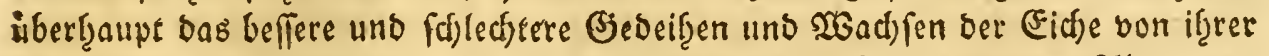

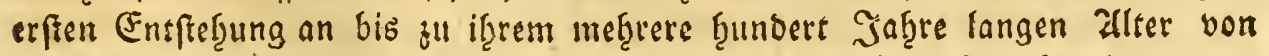

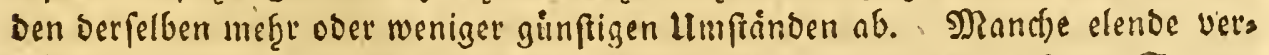
Prippelte Eidfe auf einem moorigten Birunde, Deren !urjer vermaaferter Stanm

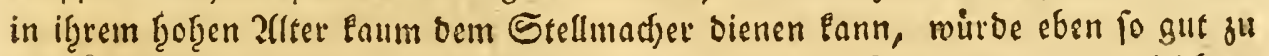

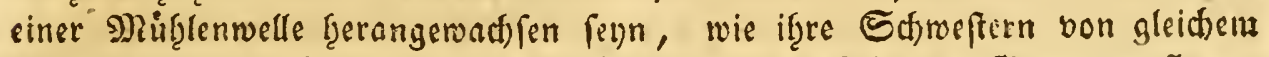
2llter, weldye bie כorfid)t meţr beginftigt uno auf beffern Biruno gepflanjet

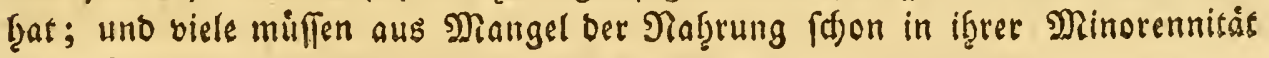
Ģinfterben.

\section{224 .}

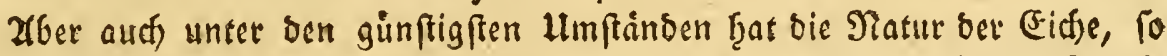

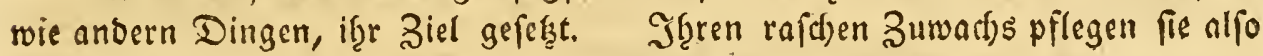

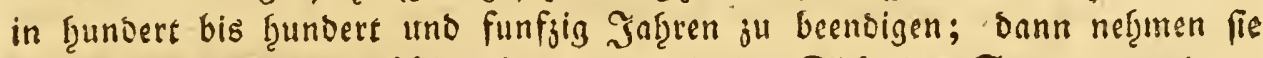
nidft meger ftare an ber Sajoge, fonbern nur in ber Dicfe bes Stammes uno an Zleften ju; fie haben alsoann gleid)fam if̧re Mannbarkeit erlangt uno bringen

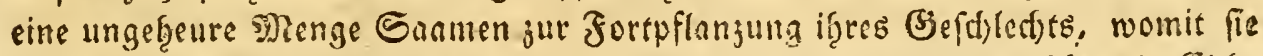

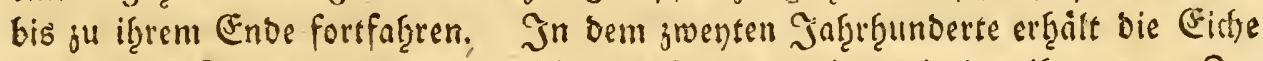

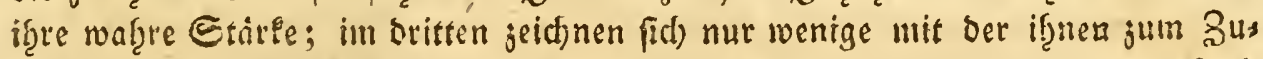

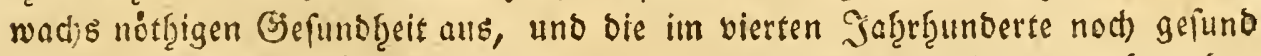

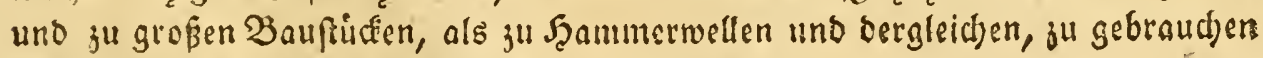

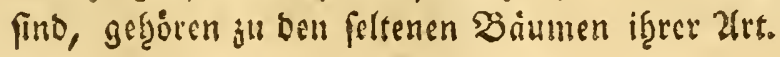

\section{\&. 225 .}

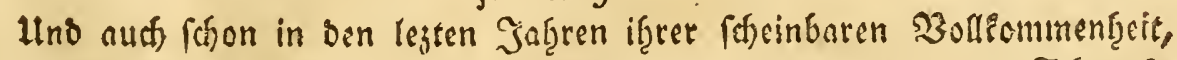

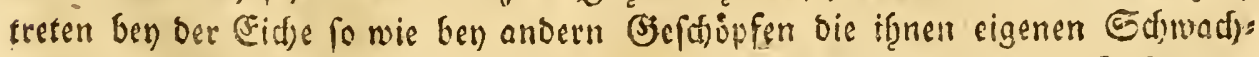

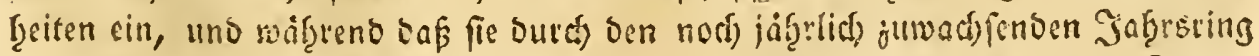

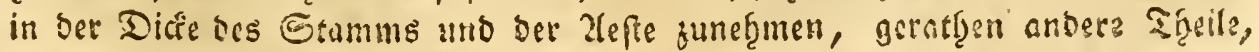
befonders in oer SJitte bes Etamms in Stoffung, uno getien nact und nact) in Bermoderung uber, in weld)em Zufrnoe aber sie (Eidhe uno befonders bie

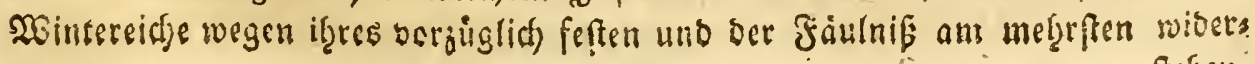




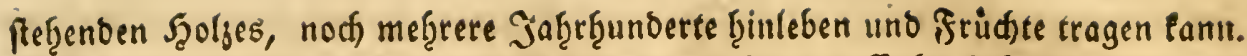
So pef̧en wir auf Triften uno 2 seiben mand)e alte Eid)e ftef̧en, worin bie

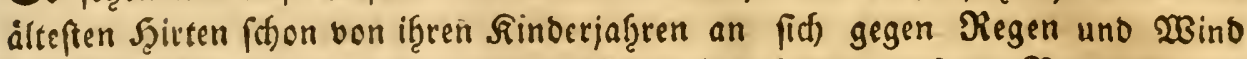

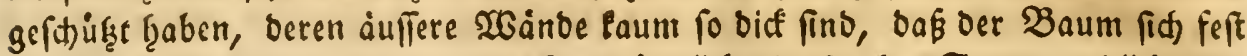
bamit erb̨alten lann, wie benn aud) gewoifnnlid) ein ftarler Sturm endlid bem lummerliden Seben foldfer Baiume ein (Enbe mad)t. 2als etwas befonderes ift

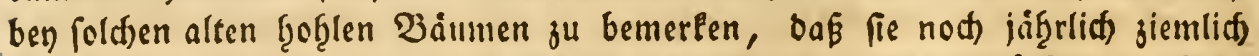

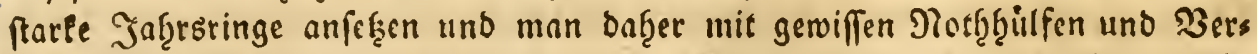

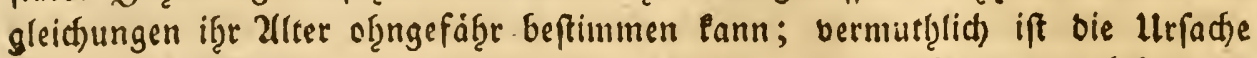

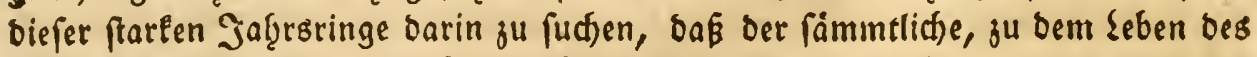
oft nod) grofen Bauns notthige Eaft allein burd) bie auffern nur gefunden

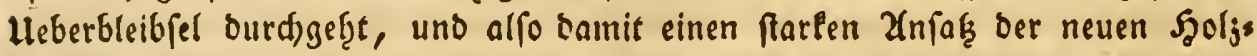
triebe veranlaffet. Şiermit laffen fid) aut() bie reeiter unten vorfommenten ftars

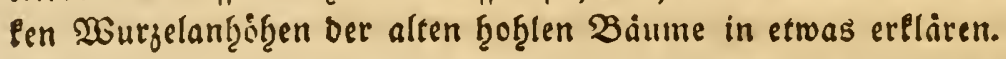

\section{§. 226.}

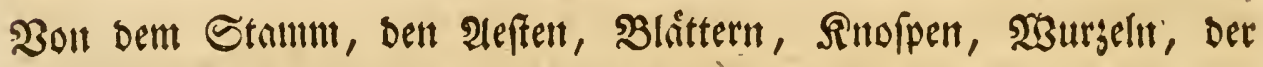
Borfe, Dem Splinte, Den Marferffien, Dem feften bolge uno Dent fluffigen Theilen Der Eiche.

Der Stamm der Eidjen nimmt fid) wegen feiner befonbern Groöse unb

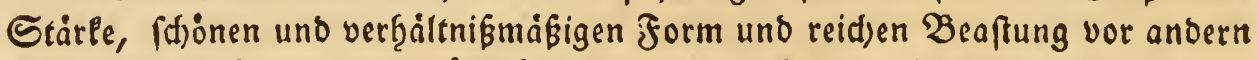

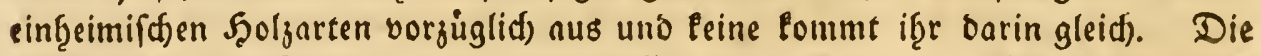
Zlefte ferţen am Stamme nicft fo gabelförmig wie an ben Buidsen und meths

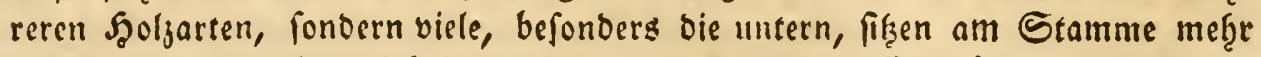

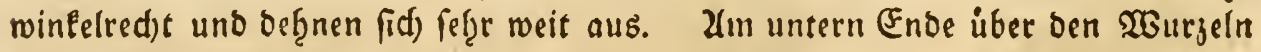
ift Der Stamı anfeţnlid) biffer uno bey alten (Fid)en bilben aud) bie Wurjeln

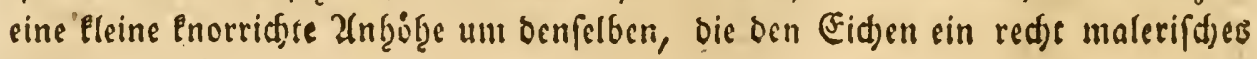
2nfẹten giebt.

\section{\$. 227.}

2n ben Staimnten und 2leften junger (Eid)en, befonders an foldeen, welde

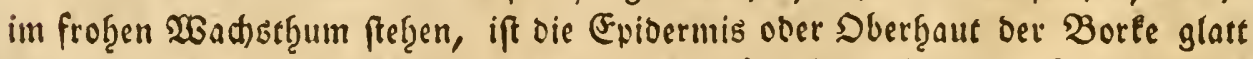
uno glänend, bey ber Wointereidje meber ins grinlid)te, bey ber Sommereid)e aber mef̧r ins filberfarbigte falleno. Benm Zelter: uno Diderwerben ber Eid)en verliert aber bie Epibermis iţre Defrnbarkeit, fie fpringt ber Sánge bes Etamms nad) auf, woburth bas unter berfelben liegende Bellengerwebe mit alfs geriffen wird, uno nun entftę̧t bie ḩolgigte ftark aufgeriffene enotigte uno trocfene 
Borte ber alten Fidjen, beren obere trocfene Sagen in bem Zuftande if̨r nur

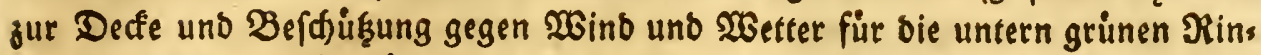

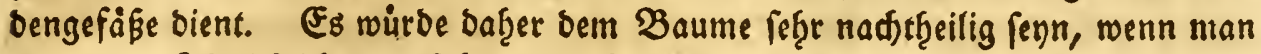

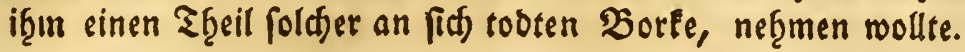

\section{§. 228.}

Sowoḩ das Zellens als bas fämmtlid)e Rófrengenebe in ser Borle ber

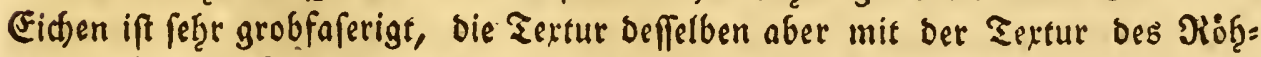
rengenebes im Splint uno in feften Şolje gleidförunig. Z(ud) bie aus ber Mitte bes $\mathfrak{B a u m}$ nad) Deflen Peripherie Ģingeţende Strahlen: ober Spiegels. wainde ftreifen allf gleidhe Weife burd) Die fämmtlid)en Borlenlagen. 'In den Saft: uno suftrif̧ren ber innern grunen Rinocnlagen lann man beutlid) maf̨rs

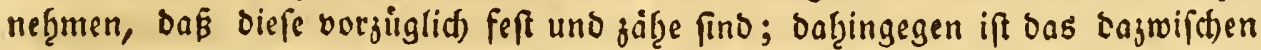

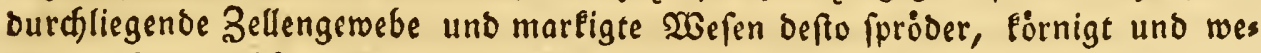

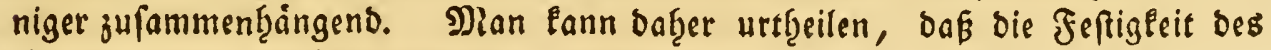

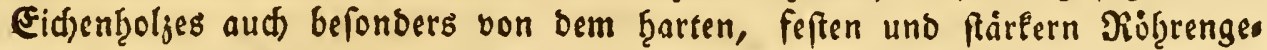
webe beffelben hertomme, wie benn aud) biefe Röbren barin fẹr grof uno offen fino, und man in ben Eiđjen beswegen bie Jaţrstinge Deutliduer, wie in ben weid)en Şoljarten, feţen fann, befonders da in jenem bey jeoem Jahresringe die

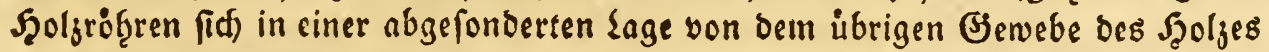
beutlich unterfdeiben, (fief̨e fig. 3. auf ber erften Tafel, weld)e einen 2(bid)nit eines zwavjāhrigen 3weiges vergróbert vorftellt.) Bey ben Wintereidjen ift es etras feiner uno meţr verwebet, aud) fino bie marfigten Fafern barin Gairter, bie Spiegel: und Strahlenwainde aud nidgt fo groß, als in Den Sommereidien.

\section{§. 229.}

Befonders bidt und feft ift aber bie Teptur ber Eidenţoljfafern ben Etraḩlens ober Spiegelwainben nach, ober aus bem गnittelpunft bes Baums

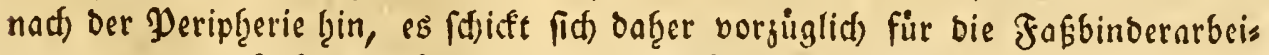

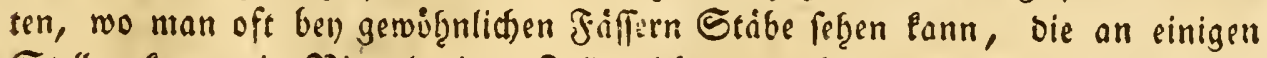
Stellen laum ein Biertel eines Bolls oiff uno baben bod) fef̧r luftoidt fino.

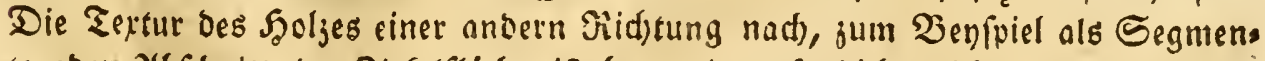
te ober Ybfdnitte Det Birfelflache ift bey weitem fo bitht nid)t, es fpaltet bas (Eid)enţoif alsbann aud) nidjt fo gut, als ben Strab̨lenwänoen nad.

$$
\text { §. } 230 .
$$

Die Rinbe ber (Fid)en ift mef̧r, wie bey andern Şoljarten, mit unfid)tbaren Scoljfnofpen befręt, man fief̧e foldjes befonoers an ben viclen jungen Trieben 
bic aus einem alten Stamme neben einem abgef̧auenen Xfte betborfproffen,

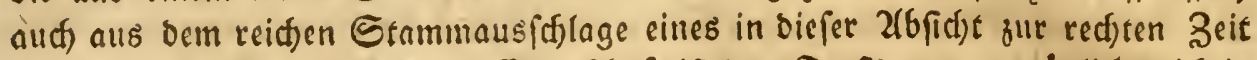
abgeb̨atienen Baums. Diefe Eigenfd)aft ift bem Forftinann vorguglid, widftig zul bemerfer.

\section{§. $23 \mathrm{r}$.}

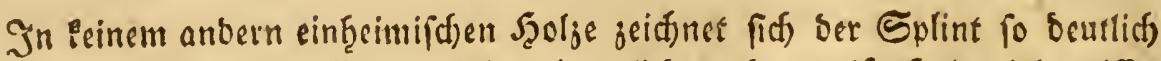
aub, als im (Fict)entzolje. (Fs ift biefes eigentlich nod) unreife Szolj viel weiffer. an Farbe, als bas reife fefte Şoly. Die Saft = und suftröhren find barin viel offener und bicfer; es ift aud) weider und prober. So wie ber Sirnno und Boden und bie áage Des Standorts ber Eidgen fef̧r viel auf bie mefrere

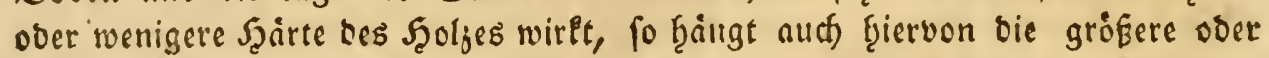

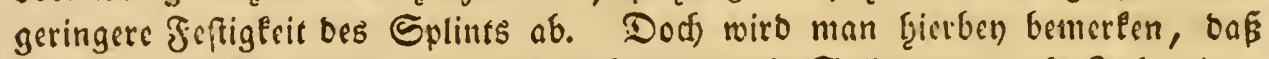

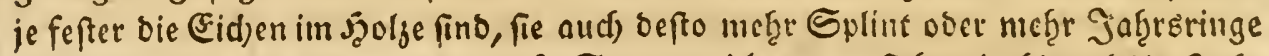
im Splint b̧aben; fo wiro man oft Sommereid)en von frebenjig bis ad)rzig Jaţ:

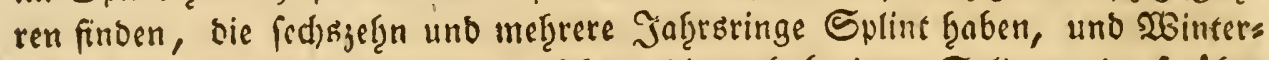
eiden habe id) von ben Jab̨ren gefefen, bie nod) breitern Splint uno oft uber jwangig Jaḩrstinge barin bृatten. Dahingegen finben fid alld) auf anbern

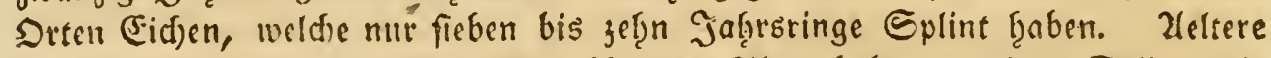

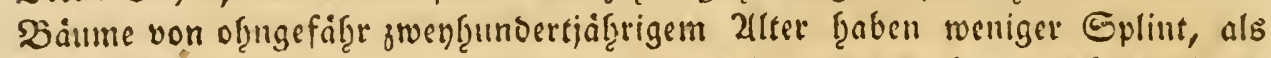

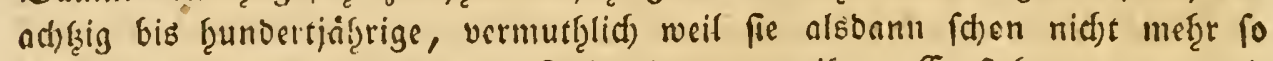

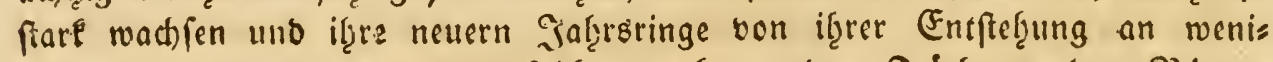

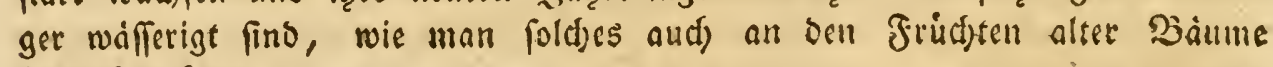
bemerten lann.

\section{§. 232.}

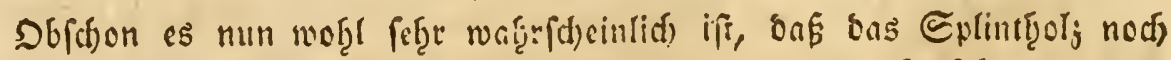

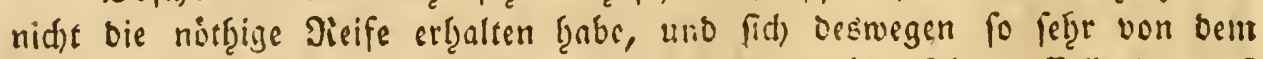

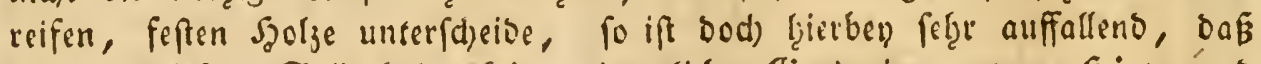
man in biefem Eplintíolje Esine sigentlid)e Bratationen won Sgaite uno

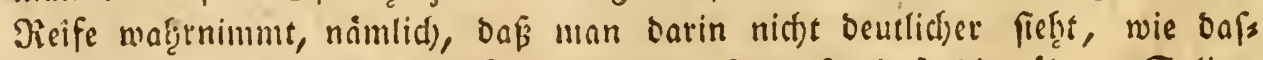
felbe von Jab̨r ju Jab̨r reifer geworben fey, to bas bie altern Gylints

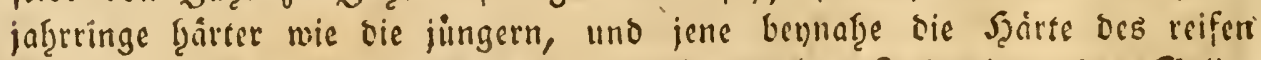
Şoljes jul haben fdueinen, fondern die fámmtliden Jaf̨rstinge bes Gplin=

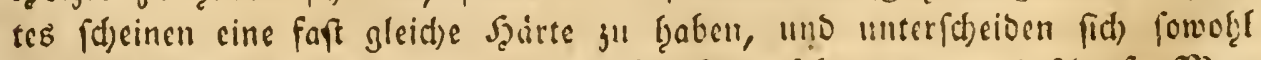

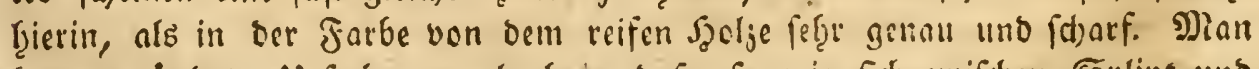

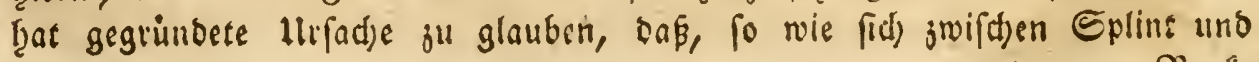




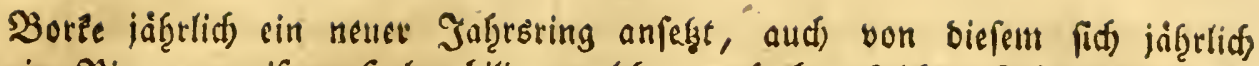
ein Ring zu reifeur Sgalje bilbe, weldjes aud) bei) foldfen $\mathfrak{B a d u m e n , ~ b e r e n ~}$ Jaḩrstinge an einer Seite viel frâteer wie an ber andern zuwadjen, Statt findet.

Die geringere Feftigleit und Scärte bis Splintes verrith fít befons

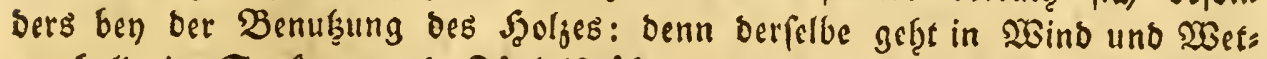

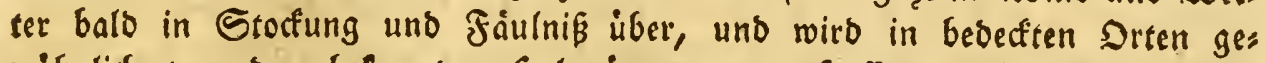

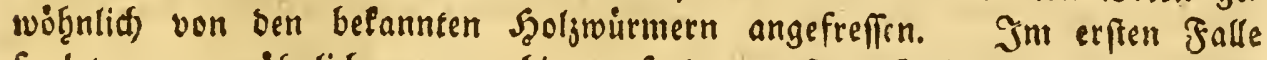
faulet er getwognnlid) genau bis auf ben erften Jab̨rsting bes reifen Saljes weg, und berweifet bamit ebenfalls ben auffallenden fharfen 26 s,

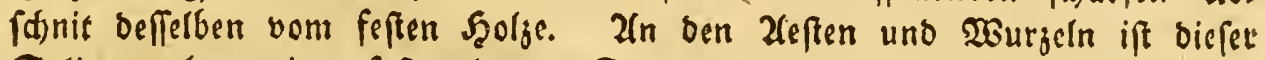
Eplint noth weniger feft, als am Stamme, fo wie bas $\mathrm{Szl}_{3}$ iberbaupt an biefem, uno vorziglidf aum untern Ende beffelben, ţäter, und fefter ift, wie an ben übrigen Ţ̧eilen bes Baums.

\section{§. 233 .}

Die mittlere Marfréble erfdjeint in ben jüngern aweigen ber Eidje

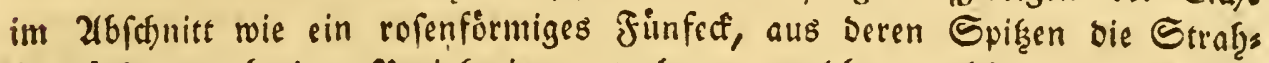

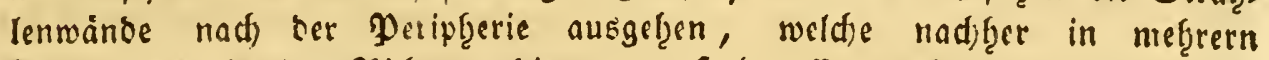

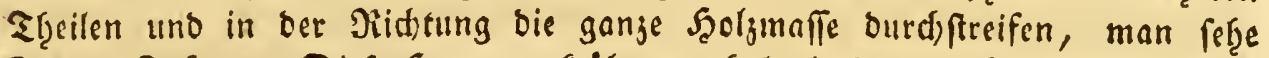
Fig. 3. Taf. 1. Diefe Szauptmarérỏhre vorf̧oljt in bem verilterten Stamme, Den 2leften und $20 u r j e l n$ ber Eid)en, wie in alldern Sedzarten; fie vers trodinet zulezt ganj und giebt die nádffe Seranlaffung ju ben innern Stockungen und Jåulungen bes Baumb.

\section{§. 234.}

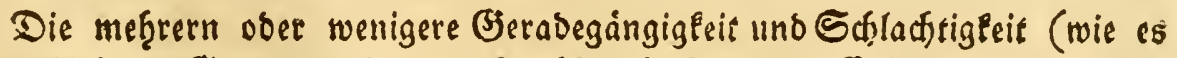

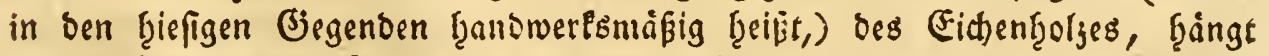
to wie bey andern Seoljarten von bem inetzern ober wenigern Unterbredtent

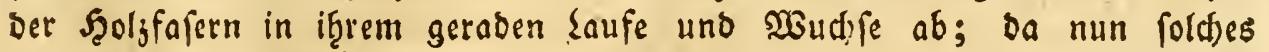

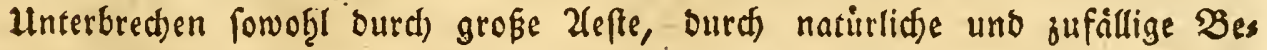

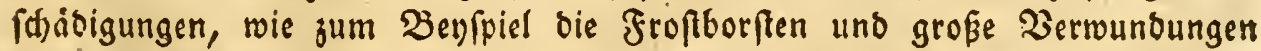

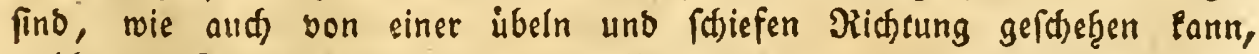
weld)e ber Baum bey feinem erften $20 u d$ s genommen beat: fo liegen bierin bie Ulrfacten, warum einige Baime febrr gutes gerabegängiges, (h)lactitiges, andere ţingegen frummes, aftiges, majerigtes, verwachjenes, veroreţtes $\mathfrak{S g}_{2} l_{5}$ geben. Heberḩaupt ift bie Eidje ben in ber Eintcitung \$. I35. vermutḩungss (Erfter ₹̈beil.) 
weife erflärten Stammberbreḩungen mę̧r, wie anbere Szolzarten, unterwors fen, uno baher manafer bem entfernten 2(nfd)ein nad fdjoner (Fid)baum zu verfdiebenen Beburfniffen unbraudbar.

2ud felbft bie beffere uno geringere, gleid) und ungleich anfinaltende Frud)tbarkeit bcs (Jiundes und Zobens wirlen auf bie Eigenfdaft bes Eis d)enfedjes, uno man geat bey Seurticeilung Derfelben, wie alld bey ber Beftimmung bes Solges ju biefem ober jenem (jebraudse, bierauf vorjug= lid) zu adjell uno Pritffid)t zll nefgmen; movon weiter unten bie náb̨ern Sennjeidjen vorlommen werben.

\section{§. 235 .}

Das Eichenteoly bat bor antern einţeimifafen Soljarten fefre viele Sorgige; es idjift fid), wie bereits bemerft ift, feiner vorjiglidfen Did)s tigfrit megen am beften für bie Jabbinberarbciten; es wiberftebt inef̨r, wie

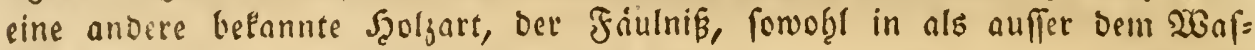
fer; Der Wurm ftid) bas fefte Scolj faft gar nid)t, es moggte benn barin

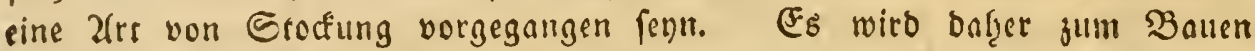
aller 2urt, bey Miublen, Saiufern und Sdbiffen uno fo meiter vorgezogen. Fs bat bey feiner feftigfeit cine fef̧r grofe ふieglamfeit, befonoers im Sernḩolje junger Stamme, bod) jeigt es weniger Elafticitát ober feber= fraft als sas Tannens uno ibrige Nabelfely, weswegen, fo wie aud) wegen feiner eigenen Sdrwere, es fid) weniger ju Ballen ober ju folden. Sticfen fdjicft, weld)e in einer frorijontalen lage saften tragen follen. Es wirft uno vergief̨t fid) weniger, wie andere fefte Soljarten, weld)es ebcufalls von bef fen feften Jiogeren uno Fafernfyftem, auf weld)e Suft uno Foud)tigfeit wes niger wirken fönen, fertommen mag; beswegen trocḱnet es abcr áulerft langlam, und gef̧en nef̧rere Jangre ocrauf f̧in, bis ein gchauenar (Fid)s baum austrocfinct. Nad) jwölf und mebrern Jaf̧ren wirt man bey einer im Jrenen gelegenen unbearbsiteten Fid)e von mittelmäjiger Etárle die laugenartigell, fauern Sifte nod) jefre feudf wabgrnefgimen fonnen, wann fie surd)gefdnitten uno bearbeitet wirb.

\section{§. 236 .}

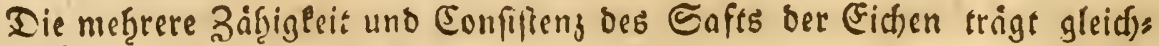

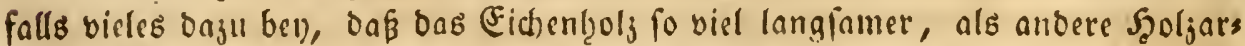
ten, alstlocfnet; welches mon befentoers Daraus fd)liefen fann, Daf oas in ber Saftzeit gefälle Eid)enlyolz viel gefd)winder austrodinet, als foldjes, was 


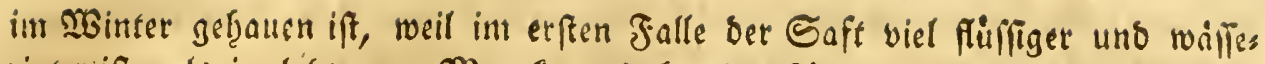
rigter ift, als in lefgtetn. Man faur oafer bas 2fustrocfnen beffelben onourch fefge beffleunigen, baj man frifhe eidjene Dielen uns bergleidjen grópere Stucfe nad) bem Sdjnciben ober Szerarbeiten nus bein Sroben eine Beit lang

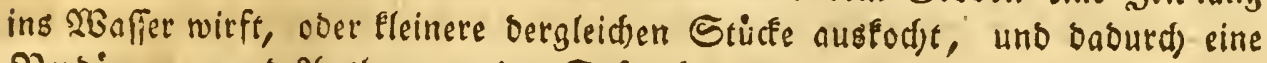
ふerbinnung unb 2luslaugung bes Safts benirft.

\section{§. 237 .}

Siele unferer forftgelef̨rten, vorgiglid bu Scamel uno von Burgg:

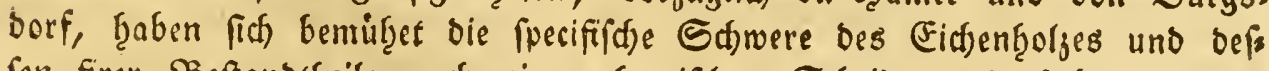
pen firer Beftandtgeile nad einer chemifhen Sdgeibung berfelben anguges

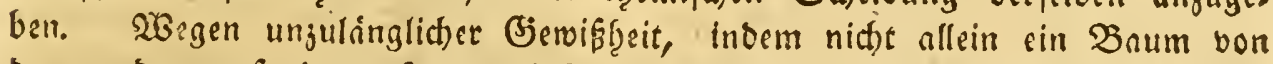
bem anbern, fonbern fogar bie verffjebenen ₹lecile cines Baums unter fid), nadjoem fie mef̧e ober weniger verwad)fen ober vermafert fino, am

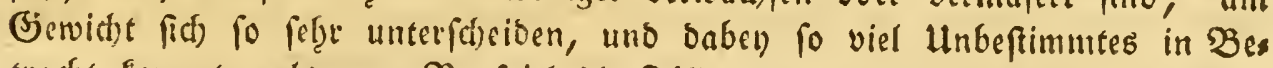

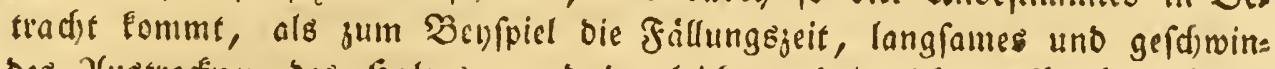
bes afustroctnen bes joljes, uno bergleid)en, balte id, es für uberfluffig,

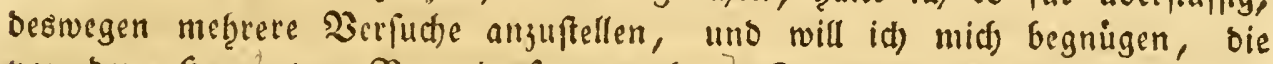
von bem Sgerth von Burgsoolf angegebene Sdwere eines Ribeinlänoifden Eubicfupes, von frifdem Eichentzolge folgendermasen bier ju bemerlen.

Bon einer Sommereide

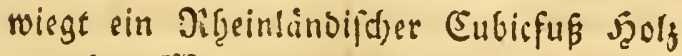

vou ber 20 urjel

- Dem Stamin

- Den 2eften

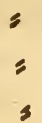

3on ber Wintereide

bon bet 20 urgel

- Derir Stamme

- Den areften
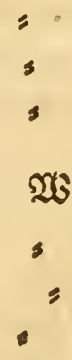

3

5

3

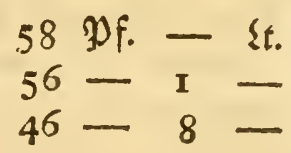

58 Pf. - \{t.
$56-1-$
$46-8-$

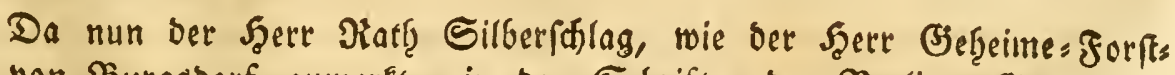
rath von Şurgoborf anmerte, in ben Sdyiften ber Berliner Befellidafe

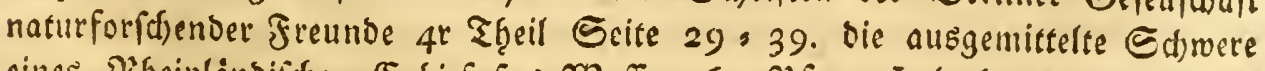

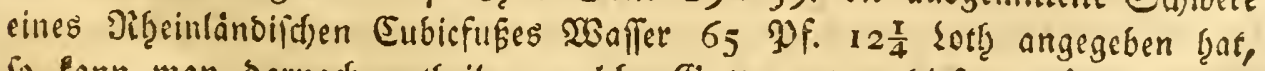
fo lann man Darnach urtbeilen, weldge Bsattung bon diefem grunen Syelje, 
auf bent waffer idjwimmen wübe ober nidat, und baf man nut ausges trocfnetes Eidjenţolj mit gutem Erfolge fiösen fonne.

\section{§. 238.}

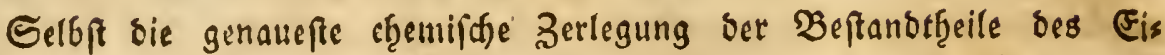
d)entzolzes Ponnte für ben pratefifden forftnuf̧en nidsts geroiffer beftimmen, als ber täglidfe (J)braud, bes Stoljes, und bie in bergleidjen Dingen alles geltende Erfaf̨rung uns folden Eennen lef̧ret. Denn eine Berfog̨lung ober 2luslaugung bes Laugenfaljes zum Benfpiel, bie ber Ȩ̧emiler in feinem las boratorio mit ber grojiten Bjelef̨rfamleit Gerborbringen und uns mit aller

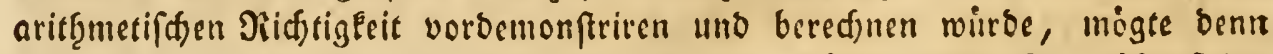
bod) wof̨l wenig init ben Piefultaten unferer Siobler uns Pottafdenfieber ỉbercin treffen. Wir wollen alfo unfere funftige forftmápige Bered)nungen

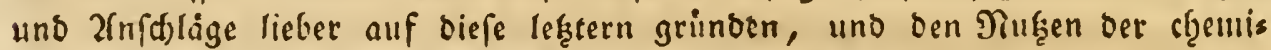
fden IInterfuchungen ben 2potfectern uno Sd)eibefunftern iberlaffen; Diefe mogen fich Damit bis auf's Caput mortuum luftig mactien.

\section{§. 239.}

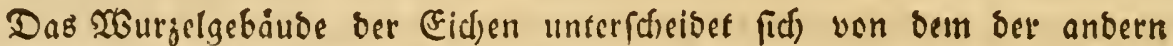

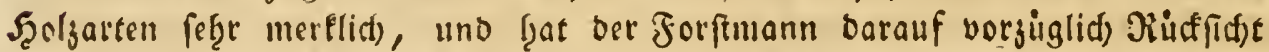

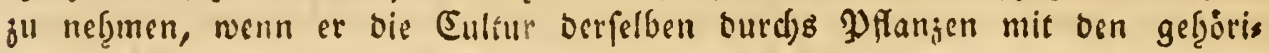
gen Siafafregeln beforgen will; biefer Begenftano foll bafier bier befto weits lainfriger abgefandelt werben, bod) aber nur in fo weit, als foldfes bas bet (Fid) bcfonders Eigene betrift, indem ber Lefer bas llebrige, was bie (Eid)e bzierunter mit anoern Baumarten gemein bzat, in ber oben ausgugsmáfig

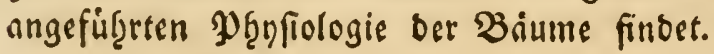

\section{§. 240.}

Sifon ber erfte Murjelleim Det aus ber Eidfel vor bem Pfanjens feim auहfdlagt, bat cine genviffe Şärte uno Stäre, bie anbere bergleidjen Caamenfeime in bem (Jirabe nidit baben, und in ben erfen zroen bis bren

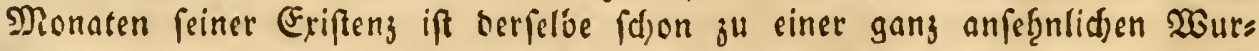
gil berangeradjen, wie bie Jig. 2 und 3. Der 5. Saf. jeigen, welde in ber Plicffid) fefre genau nad) bur Natur gejeid)net find. Man Pann bereits

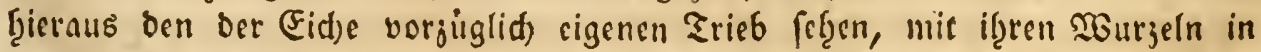
bie Tiefe bes Eroboocns einjubringen, uno bie fogenannte Yofalilwurgel zu treiben, weldye aus beil erften 23 urjullecim ber (Fid)el entftef̨t. 


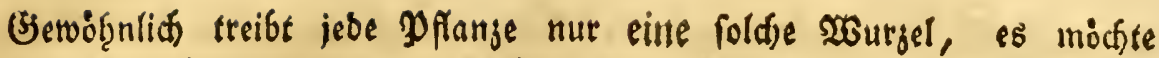

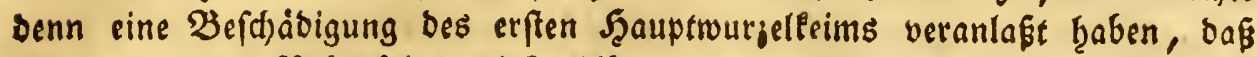
zwen ober bren Rebenleime biefen 2lbgang erfergten, uno eben fo viele auds in bie ₹iefe geţeribe $\mathfrak{Y}$ faf̧itwurgeln bilbeten, weld)e alsoann bünner und mit

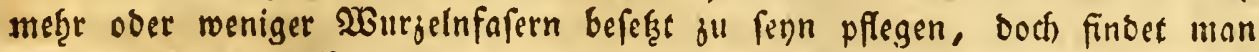
zuweilen Peimente (Eid)eln, woralls zwey Şauptwurzeln zugleid). aubgetrieben fino, mie Fig. 1. ber 5. Tafel. Nur in ben jugenolidjen Jaf̧ren (d)eint bie Eidje vorgiglid bie Eigenfafaft ju ţaben, mit if̧ren Wurjeln in bie Tiefe Der Erbe ju getgen, und sine lange, ftarle $\mathfrak{P}$ faģlourgel ju treiben, befonders in einem tief frud)tbaren (Brunde, hernat) aber boch) burd) bie obern Nebenmurs

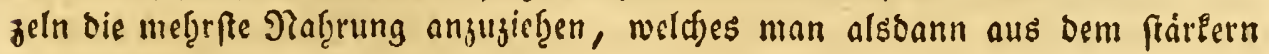
Zuwadjs berfelben ferten fann.

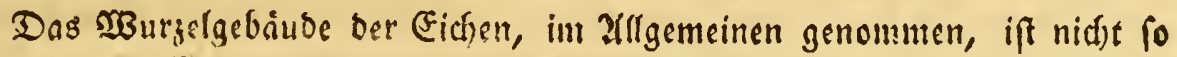

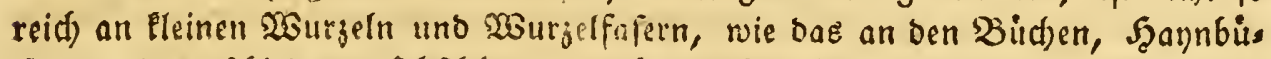

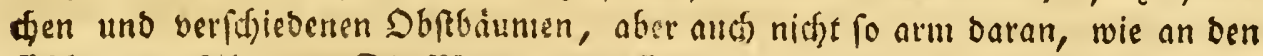

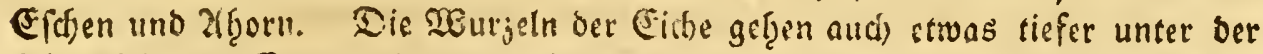

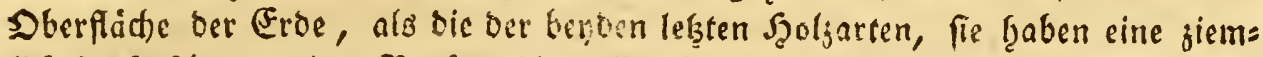
lid) ftarke fowammigte Borke, bie voller mourzelecime fenn muB, weil fie ben

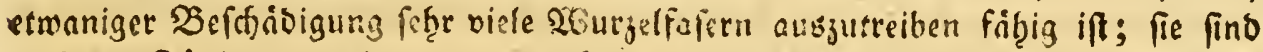
nuch) Der fäalung weniger unterworfen, als bie Wuurgeln anderer Baumarten,

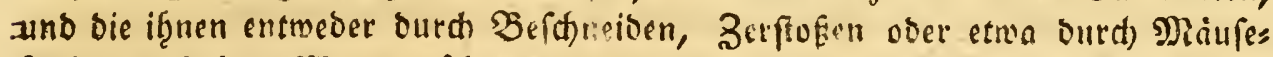

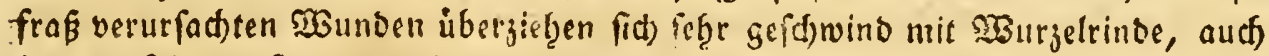

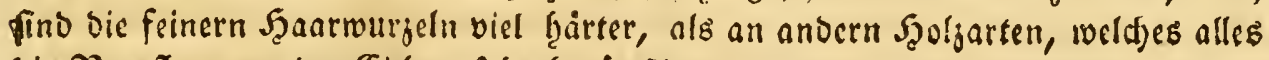
Die Berpflanjung ber Eidjen feb̨r beginftigt.

\section{§. $24 \mathrm{I}$.}

Die Lage bes Standorts und ber Grums und Boden, auf welden bie Ei:

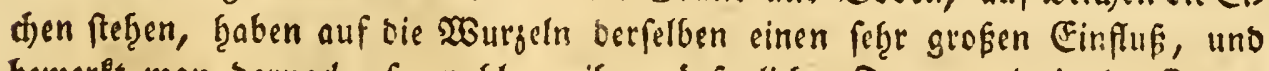
bemerlt man barnach, fo wob̧l an if̧rer suberlicten Form, als in ber Teptur

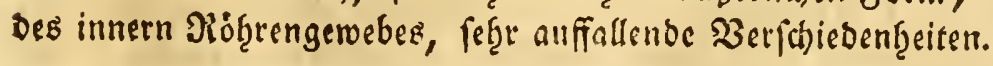

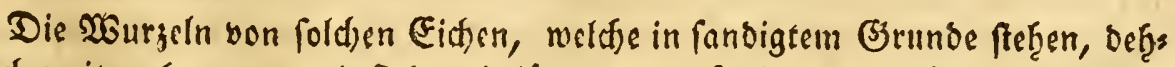
nen fict) weit mefhr aus, und finb weit länger uno faoigter, aud) init wenigern

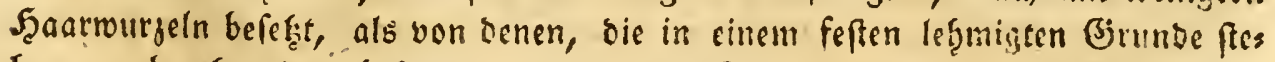

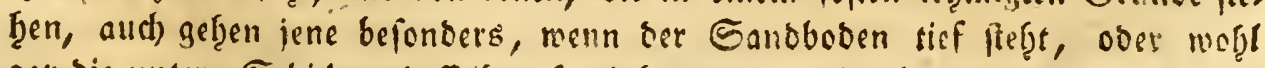
gar bie untern Edid)ten Eefferben frudhtearer, als bie oberen fino, meit mefer

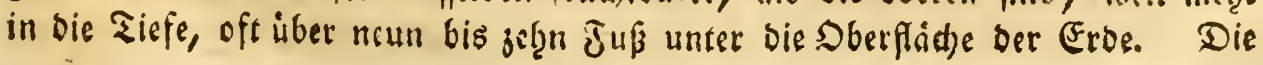




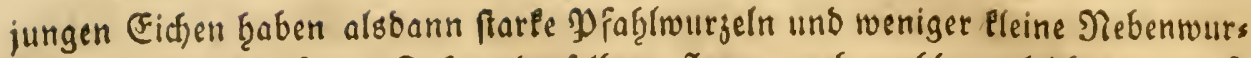
jeln. Siele ber feinen Fafern berfelben pflegen aud) woht ungleid), und oft an ifrem vorbern Enbe biffer, als an bent anbern ju fenn, uno fo, wie bie meģrere oder wenigere Dirre ober Näffe uno Frud)tbarkeit bes Standes ein frárkeres over geringeres $\mathfrak{W a d}$ ) fen bes $\mathfrak{B}$ aum

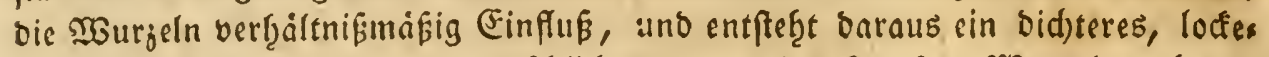

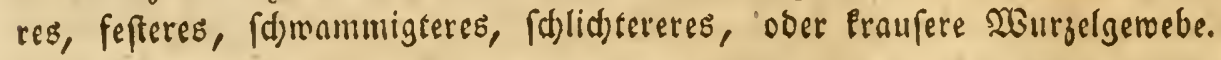

\section{§. 242.}

Die Eidfen, weldye in einem feudten, moorigten ober noffen Grunde fies

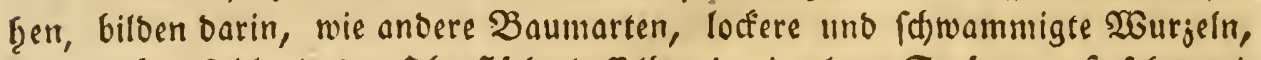
uno treiben foldhe in oer Dberflad)e beffelben in einjelnen Straingen oft Felgr weif aus; fie fino aud) mit wenigern Wurgelfofern beferget, ven meld)en fefgr viele berfaulen, wogegen fid bann wieber neue anferzen; wie biefes aud) ben) andern

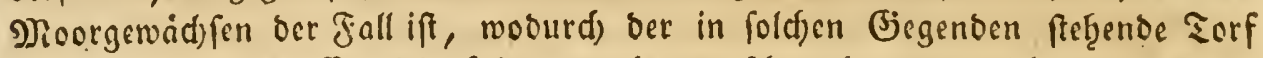
mit erjeugt wito. Ein fehre feftes, trodfenes, fdjmachtendes, bidftes uno prat:

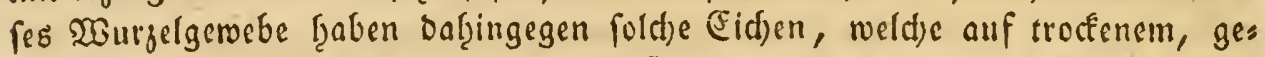
birgigtem, mergelartigem oder magerm (Stunoe fref̧en, unb fo, wie fold)e auf

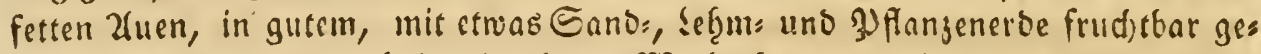

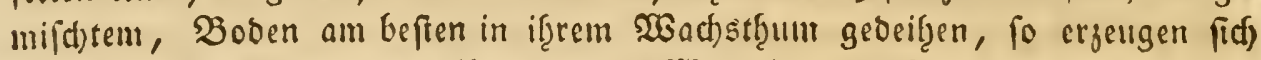
audf) Darin bie beften und vollfommenften 2 Surjeln, und fann man nad) biefem,

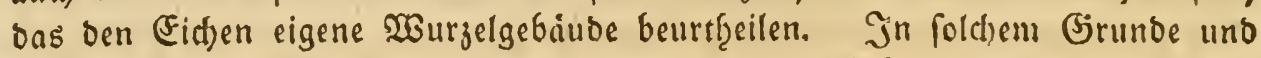
Beben traben fie oft peine, ober bod) nur geringe Yyfablmurjeln, aber befto

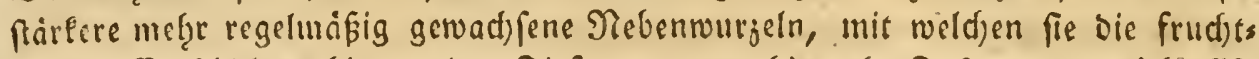

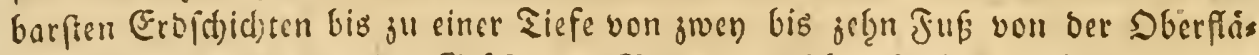

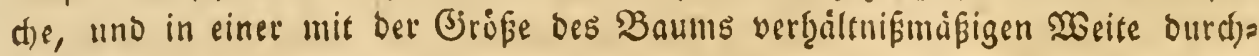
Pried)en.

\section{§. 243.}

Da bie \$̇urzeln ber Eidien fo, wie bie Der anbern Baumarten, in ber Erolage uno in oen (Erojdichten an ftarffen wadfen, worin fie bie

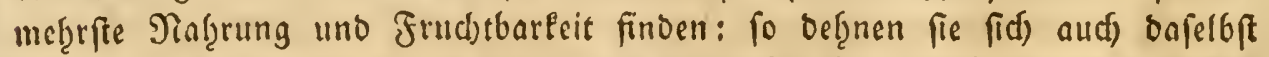

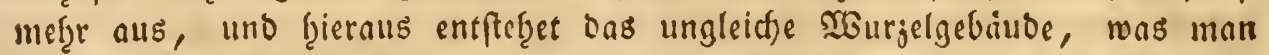
an mand)er (Eid)e findet, uno was oft an ber einen Seite mef̧r wie bops pelt to ftark, wie an ber andern Eeite ift. 2fn Baiumen, bie an ber eis nen Seite einen guten, fefien Brund laben, an ber anbern aber etwa einen nafs

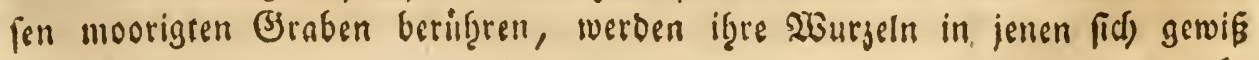
meţr 
mef̧e ausbef̧nen, als in biefem, fo wie man in biefem Falle an eben bems felben Baume ein an fid) fef̧r verfdjebenes wurgelgewebe wahrenef̨men

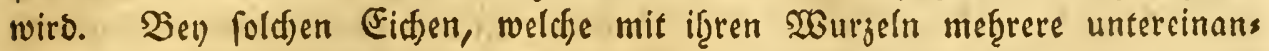

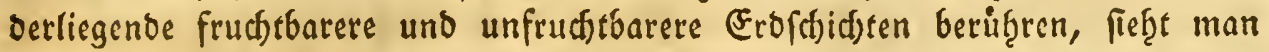

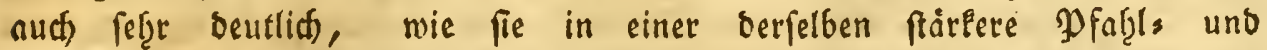
wenigere nuth geringere Nebenwurjeln, uno in anoern bingegen fef̧r gerin= ge uno oft gar Peine phab̨ltwurgeln treiben, wie man es an einer (Fid)e,

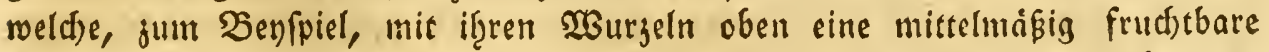

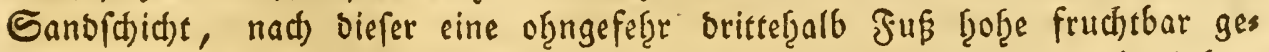
mifdte sefrmlage, uno tiefer wieber einen ber obern Sandlage äţnlidjen Girund berubrt Gat, bemerfen wurde.

\section{§. 244 .}

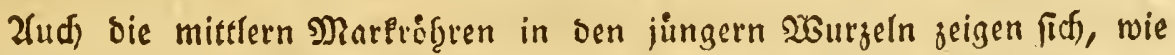
in ben Zweigen, im 26fdynitte als ein funfectigtes fternartiges Jiosden; bies erfiált fich in ben 2 urgeln längere Seit grim, als in ben 2leften, und auch in jellen finbet man juerit Epuren bon Fáulung on bemielben, bie fith von ba in bie ubrigen Tgeile oer 2 Gurgein uno fo weiter von ben al= ten Şauptwurgeln in bie fleinen jüngern 2 Wurgeln ausbef̨nt, bis ber $\mathfrak{B a u m}$ ganj austrocfnet uno abftirbt.

\section{§. 245 .}

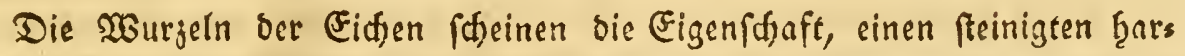

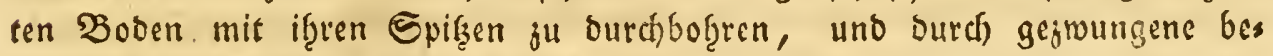
(a)rerlicte Biegungen ju ourd)fthlingen, wie man biefes bey andern $\mathfrak{B} a u m=$ arten, auf fteinigtem, felfigtem (Jirunbe wabrenimmt, in sinem geringern (Bstas be zu beben; fie gebeifien batzer aud auf foldem Boben meniger, als iene, fie pflegen barin nur fummerlid) ju wad)fen, uno ifgre SOurgeln fino wenig ausgebef̧nt und trocfen.

\section{§. 246.}

Bey alten (Fidgen, befondel's bev foldfen, welche in ben lefiten Safiren

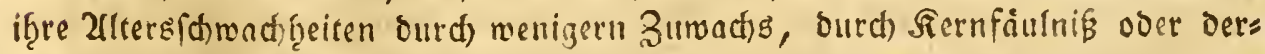

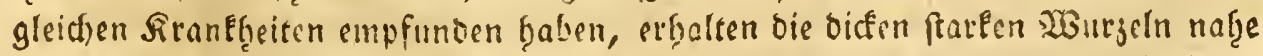
am Gtamm einen ftirlern, unregelmáfigen Zumad)s, woourd) fie fid) gleidy fom aus ber Froe feben uno eine antioge von unförmigen, Enotigen uno Rernfaulen 20 urjeln biloen, bie oft eine $\mathfrak{P}$ cripherie von jwanjig uno melgrern $\mathfrak{f} u \bar{s}$ weit 


\section{8}

um ben Stann erreidt. Es ift biefes ben Eidfen meţr, wie allen anbern Däumen, eigen, bed finder man es aud) ben alten Efd)en unb Biiden, jebod nid)t fo ftark, vermutblid) weil leine Baumart in bem eben bemertten 3uptande ifre seben nod) folange ju etrialten im Stande ift, als bie Eidjen. Das 2unferzen bet

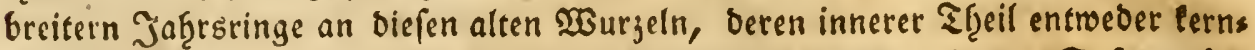

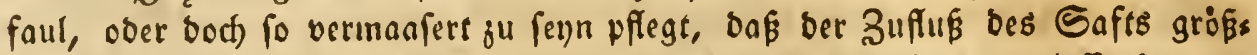
tentheils burd) bie jungern Ja[zrstinge bewirft werben mus, veranlaffet ben uns gleid)en Sumadje bicfer unformliden Wurjeln, uno verurfadet bas fdeinbare zuffeben berfelben.

Das äufiere Şoly an biefen burd) ungleidjen Sumadfs gleidffam aus ber

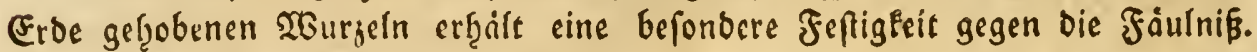

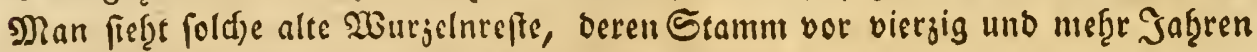
abgetzauen ift, oft noch in ber (Erbe fteţen.

In folden Bisenben, worin bie (Fid)en nidje vorguglid, fark wadfen, find

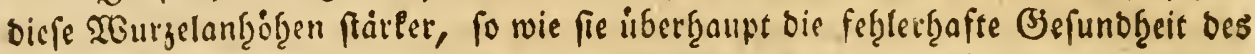
Baums anjeigen, und if̧n in meţrerer 2(bfidjt verbảd)tig madjen.

\section{§. 247.}

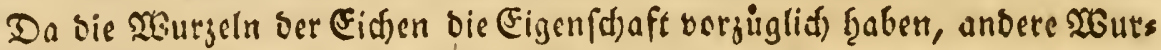

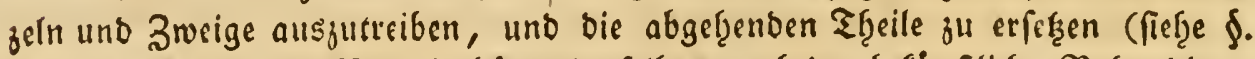
229.) To Eann bas $\mathfrak{W}$ urgelgeboiube berfelben aud Durd) Eunftlid)e Befrandlung in mefrer Siluffidt verbeffert werben. Fs wirb baf̧er eine Eidje ber, jum Bevfpicl, beym ßerpflanjen bie \$faf̧lmurgel mit ber gef̧öigen ßorfid)t genom:

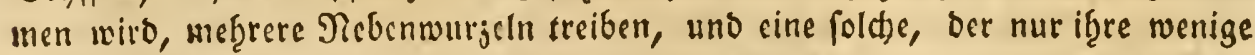
ftarle Picbenwurjeln abgefdnitten werden, cin Brauferes und mit mefrern

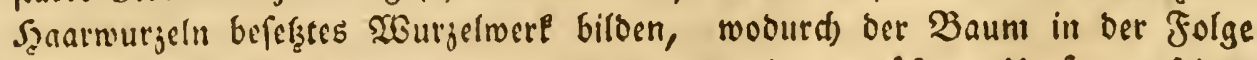
wcit mef̧e Frud)tbarleit erf̧alten, uno aus einem gröferm limfange feines Stanborte Tab̨rung an fid ju jief̧en im Stande fern fann. Es ift baf̧er ber, bon cincul grofen Theile ber nur gewóf̨nlid) praftifhen Forftleute angenommene,

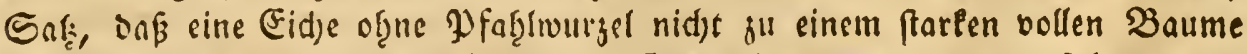
Getanmadfen werbe, ainferft falfd); in (jegentheil wirb jeoer, ber fid nur eine geringe Miibe geben will, fid) praftifd) iberjeugen fönnen, baf fowofgl (Eid)en,

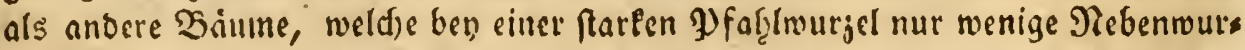

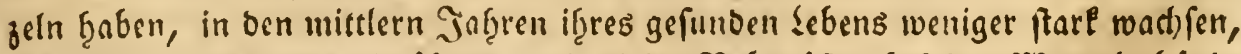

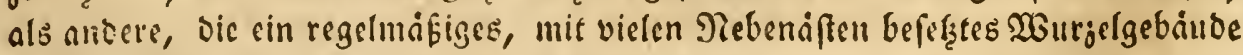

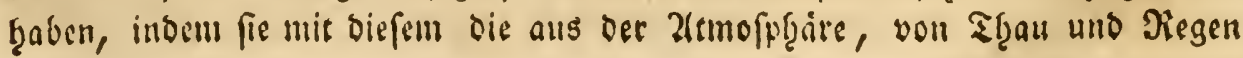


nur bis auf cine geringe Tiefe unter bie Dberfiàdse ber (Frbe täglid friff cins oringende, vorjuglid) frudtbare Nab̧rung reid)lid)er geniefen, babingegen bie

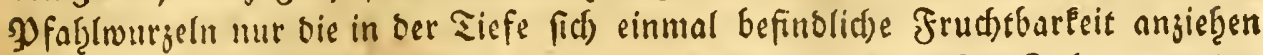
Eonnen. Dian firbet baber aud) nur it ben erften jugendlid)en Jab̨ren an ber (Eid)e farle Pfablwurgeln, und befonbers an benen, weld)e auf einem tief frudts

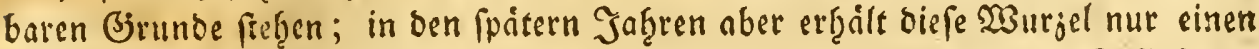
geringen Buwad)s. (Es berftäten fid) alsoann burd) ben melurern Buflus bes

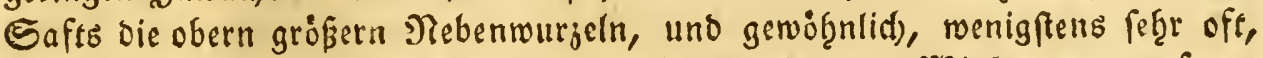
ftirbt vie Pfabllwurgel ganz ab, welthes id an vielen voin 2 Sinde umgeroorfenent uns an ausgerobeten (Fid)en uno anderen $\mathfrak{B}$ ăumen bemert ţabe.

\section{§. 248 .}

Die (Eid)en, weldse von ifrer Jugens an ein freves, ungef̧inbertes uno gutes 2 ad) weit aus, uno bilben alsoann fefre aftreide Fionen; boch find biefe nid)t fo bidft mit Zroeigen beferst, uno aud) locterer beblättert, als es bev äbnnliden Ums

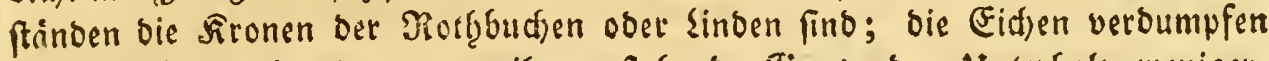

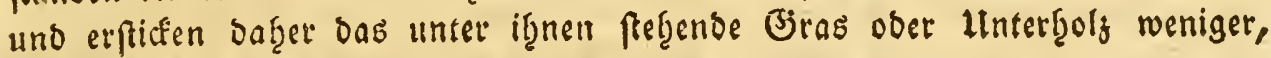

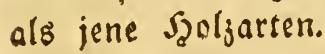

Siele, befonbers bie ältein untern 2lefte vongeringerer Stäte, fifen an beit Stamme in einer Lage, bie fich oft bem rechten SBintel feftr náfert, fo, wie ¿berhaupt bas ganje jactigte aftwere einer bejaf̨rten (Fid)e, viele fdarfe Wins

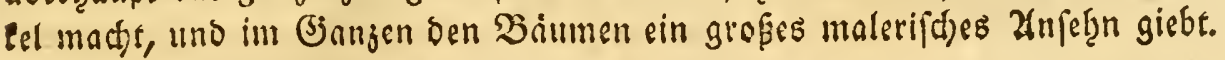

\section{§. 249.}

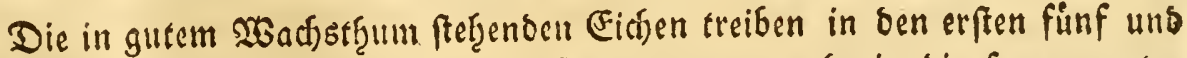
jwanjig bis funfjig Jaf̨ren, wie alle Baumarten, mef̧e in bie fo genaunten

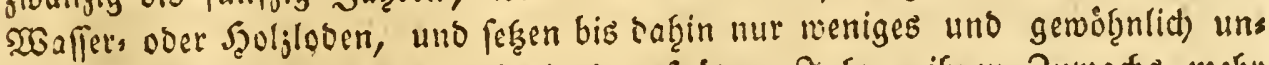

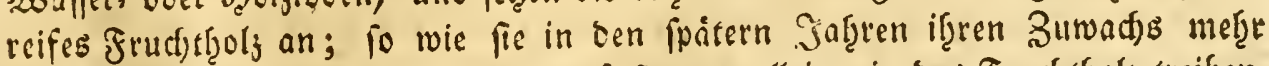

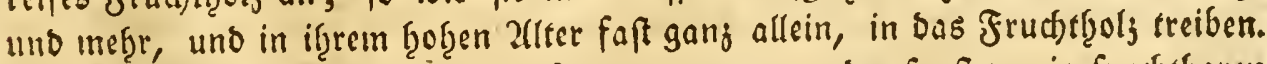

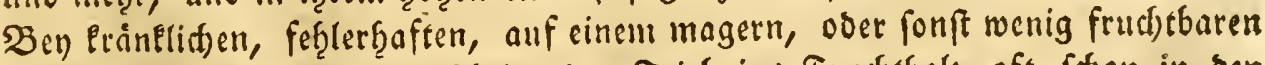

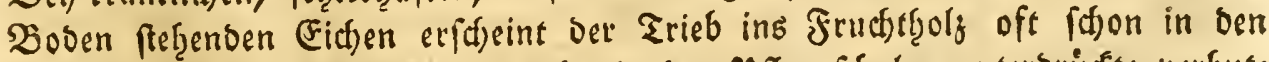
erften Jab̨ren, uno finoct inan felbft in ben Pflanjfdulen unterorickte verbuts

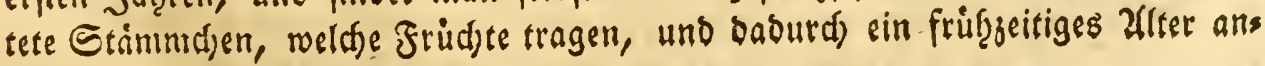
zeigen. 
In ben eigentlidjen Sgoljloben ift ber Suwad)s ftirfer; er bauert wie bey andern $\mathfrak{B}$ siumen vom 2 (usfd)lagen ber $\mathfrak{B l a ̈ t t e r , ~ n a d ) ~ r e l d ) e m ~ b i e ~ j u n g e n ~}$

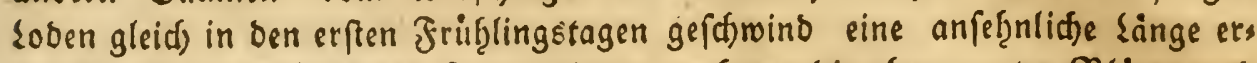
langen, bis jum Enbe bes May; alsbann nef̨men bie obern jarten ßlatter uno Sinofpen eine mef̧rere Confiftenj ober Feftigleit an; bie Loben felbft verlängern fidf aber bann nid)t efcer, bis im Julius bie jrente Triebjeit eintritt, in weld)er

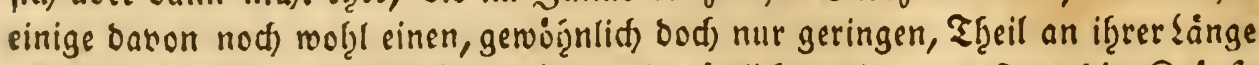
zuferzen; biefer jrente ₹rieb ift aber weit joirtlider als oer erfte; Die Sinipfe babon fino weniger feft uno die 2 latter feiner uno binnf̧äutig. Ueberf̧aupt aber ift biefer zroente Trieb bey ben Eidjen feltener uno geringer, als bey viclen andern $\mathfrak{B}$ aumarten. Bey jungen in vollem Triebe ftefenden Baiumen entfies bृen biefe Şoljloben sin f̧aufigften aus einer, uns gewoif̨nlit) aus ber obern

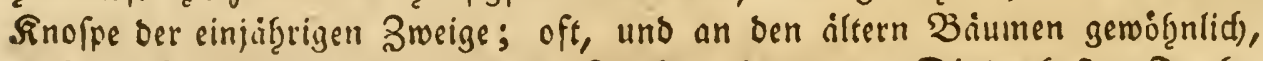
treiben neben biefen einige gevingere frudtsweige aus. Die meţrften fructsts

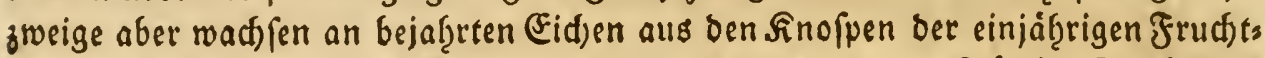
zweige uno bilben an ben lleinen zactigten Xeftden ganje Büfdel Frudjtholg. 2us bem Sinofpen, woraus bie jungen Frudttriebe entfefen, Eommen neben biefen gleid) beym Defnen berfelben bie inannliden Blitţen ferbor, fo wie an ben jungen Frudjttrieben jwifd)en ben $2(d)$ feln einiger $\mathfrak{B}$ lätter bie weiblichen Blutţen erfd)einen. 2(n biefen Frud)ttrieben find bie Blätter viel bicfer, ountler grin von Farbe, gläjenber uni fefter, wie an ben Waffers oder Sjoljloben, bis Snopfe babon bider, uno fifzen fold)e nát̨er zufamınen.

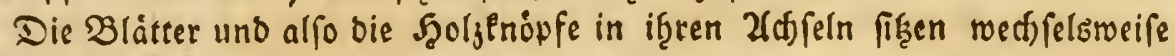
in einer Spirallinie, fowoḩl an ben jungen frudt: als an ben $\mathfrak{s}$ oljtrieben. Das $\mathfrak{S g l}_{\text {olj }}$ ber erfern ift viel fprober; eb beftef̧t aus meniger gerabelaufenden

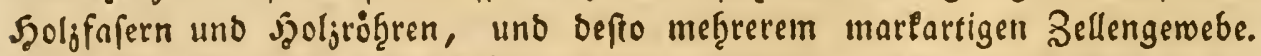

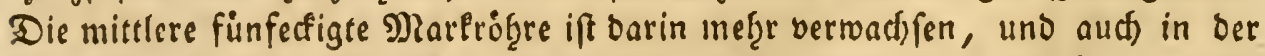
Rinbe find fie nuf gleidfe 2frt von ben Şoljtrieben verfdjeden. Diefe Şoljs triebe, weldbe befonbers bey alten (Eid)en jäb̨rlich nur eine fę̣r geringe singe

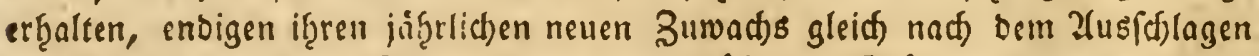
Der Blátter in wenigen Tagen, uno in oer hibrigen Brumungsjeit oes Jaf̧rs merben biefe Frudtjoweige, bie baran befindidten Frudte und ber funftige Frudtetnoten nur zu ber if̨nen nötrigen Reife ausgebiíbet, of̧ne baf folcte nod)

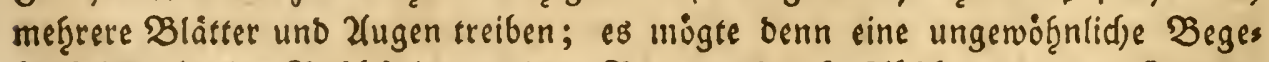
benleit, als cine $\mathfrak{B} e\{d$ ábigung bes $\mathfrak{B a u m s}$ burd) 2(bfdneiben ber 3weige, ober burd) eine ftarle $\mathfrak{B}$ efdábigung ber blätter ourd) Infecten es verarlaffen, bas einige Jrudttriebe bey ber jweyten Saftjeit von neuem austreiben, in wels 
dem Salle foldhe, eigentlid) wibernatirlidje, getinge und (d)wäblicfe Sproflen

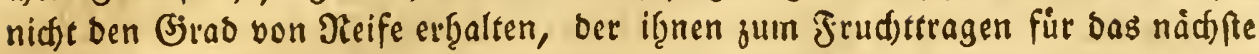

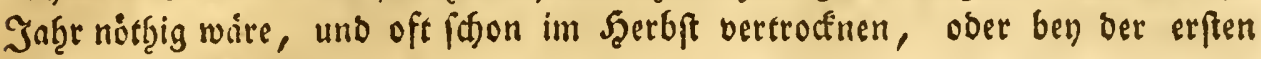
Sälte verfrieren.

Durd) ben jäb̨rlicfen 2 (nwad)s neuer Frud)treifer entftef̧en in einigen Jaḩren an ben (Fid)en bie befonders zactigen und mit feinen Reifern reids bes

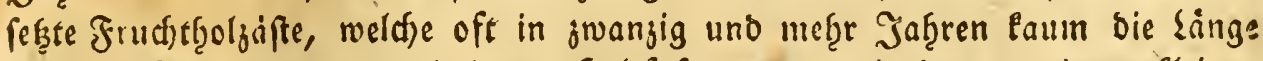

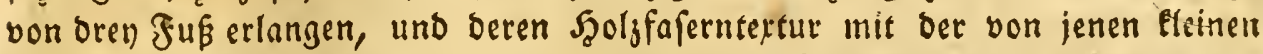

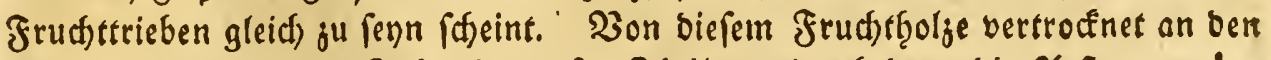

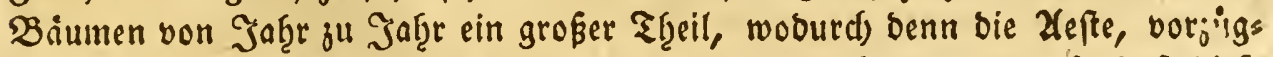

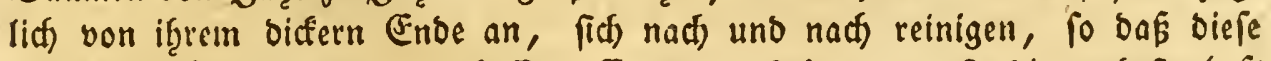
Frudtholjbuffhel nur an ben suffern Enden berfelben, wo fie bie metrifte suft baben, langfain fortwadjen.

\section{\$. 250.}

2fn ben geringern abgeworfenen Jructifafteden finbet man an bein Srte if̧rer eb̧emaligen 3 erbindung eine gewiffe rofenartige 2friculation, die volleommen berjenigen gleidtt, bie man an bem untern Ende ber Eidtel und auf ben Sticlen ber in voller Peife abgefallenen Jricteten waf̧rnimmt. Mit biefer 2lrticulation fdeint bie Natur alfo bas 2(bwerfen bes überfiluffis gen Jrud)ţolges erleichtert zu ḩaben.

\section{§. 251 .}

Das Şolz von ben Zeften ber. Eithen ţat bey weitem nicht bie Şärte,

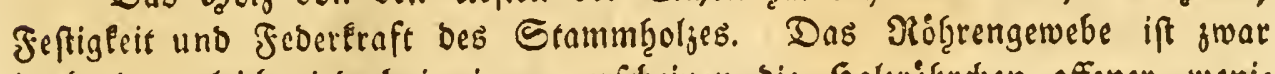

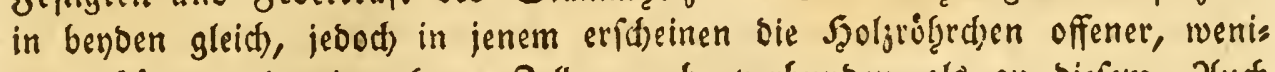
ger erf̧ärfet uno mit mę̧rerm Bellengenebe verbunde!n, als an biefen. 2luth ift an ben 2leften verb̨altenifimábig mefreres uno an fid viel unreiferes Splintholz, als an bem Stamme. Das 2fftgols ift úberfaupt nidts to ges rabegángig; es läft fid nid)t fo glatt verarbeiten; es wiberftefgt ber Saauls

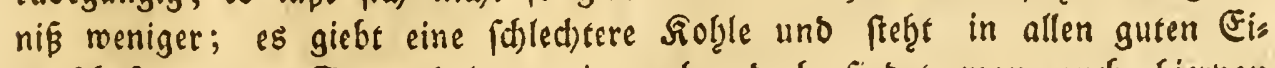
genfajaften bem Etammbolje weit nads; bod) fritbet man aud fiervon jowohl unter ben 2lefien eines Baums felbet, wie aud an ber 2art ber Eidjen, einen fefre merellidjen llnterfidied. So find bie untern grof́ert, ftarken, oft gabelförmigen Zlefte ober fogenannten Zwielen einer bicfen (Eid)e biel f̧árter wie bie obern geringen 2lefte, uno an Büte fef̧r wenig von

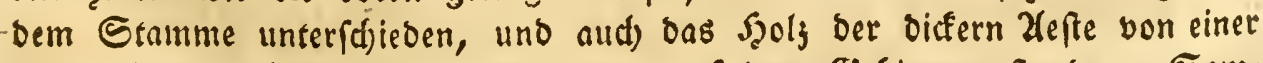

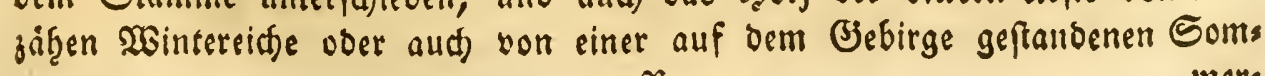


mereidfe - ift viel fefter unb hiarter als von jungen Eidfen, bie auf fetten 2(uen und gutem Brunde geftanben find und nod) nidft bie vollemumne Saarte erlangt b̧aben.

\section{§. 252.}

2/n ben 3weigen ber Eid)en fann man ben B̧efundf̧eitşuftand berfelben

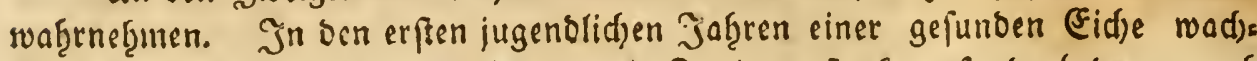
fen befonbers anf ocn obern aeften und Breigen ftarfe gefunbe Soben; nad)

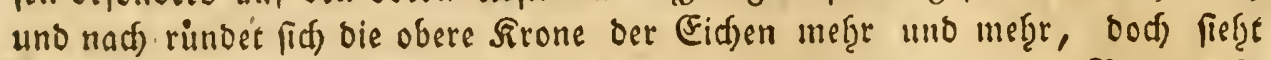

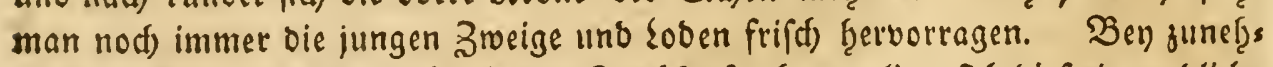
nendem 2flter unb bey nadjaffender Triebleraft aber verliert find biefe jugenolid)e

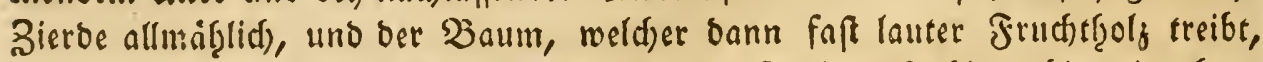
erţâlt baunit jeine obere Sirone nur nod) eine Beitlang fo f̧in, bis bie obern 3reige berfelben yon oben heerab ju vertroefnen anfangen, uno alfo ein Beid)en ber fdjon mef̧r eingefretenen Stfwadje abgeben. Es ragen bann aus ber bes laubsen Frone fold)e vertrocfnete 2lefte gleidf fam wie Şirfh)geneibe ţerbor, bie

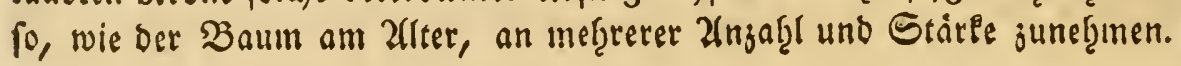

\section{§. 253 .}

Die Blatier ber Sommereide find auf ber zwenten, und bie ber 2 Sinters cide auf ber oritten Runfertafel abgebildet; jene ţaben längere Etiele, fie fino bunfler grin von Farbe, glätter, uno if̧re Tertur fajeint bicfer uno fefter zu fenn. Diefe fino oben breiter, als bie Blätter ber Sommereiffe, uno if̧re Eins fdinitte fino wellenartiger, aud) bie untele Seite efwas blaffer grin. Sm Wointer bleiben an ben Wointereid)en mef̧rere Blätter trodfen fif̧en, als an jenen. Dak

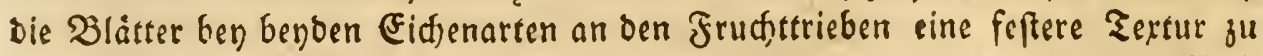

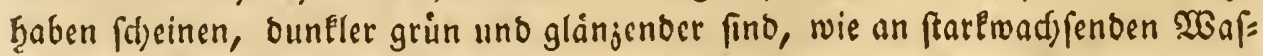
fers ober Şoljloden, ift bereits fdjon angemerlt.

Die Blätter des jwerten Triebes fino weniger tart und feft, als bie bes

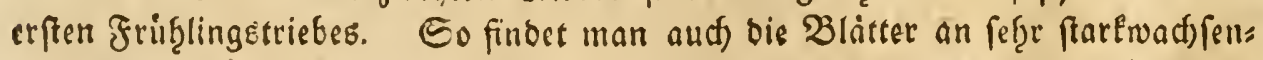

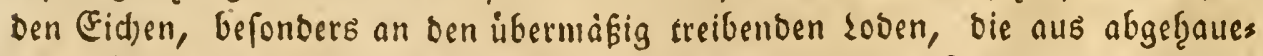

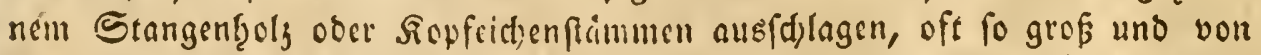

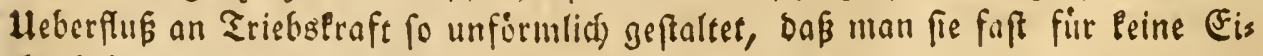
đenúlatter balten follte.

33on ben auf ben Eidjenb!ättern befindlidan Ballapfeln wirb unten von Den Jinfecten metreres vorlommen. 


\section{§. 254 .}

Die Senukgung ber Eichenblatter ift fefre getinge uno fortäntt fid auf ben Forftoinger uno auf bie \$ieffireuung ber ben Eidentwaloungen benadbarten armen Beroof̧ner ein. Das 2 ief frift fie nidjet gern, bodj pflegt es bie zars ten Soben eines jungen Eidjenfiolzes fef̧r gern abjubeiffen.

Das 2lbfallen bes Eidfenlaubs f̧ängt fef̧r von ber woitterung und von ber

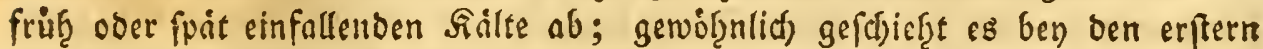

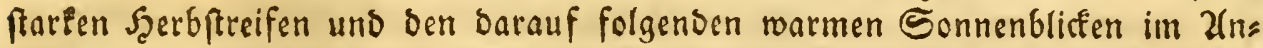

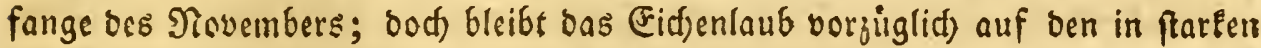

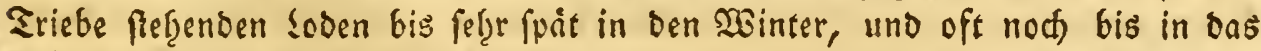

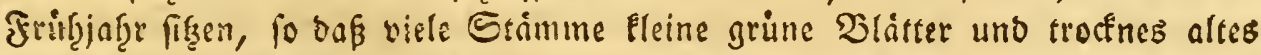

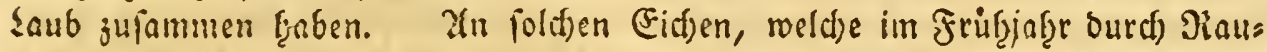

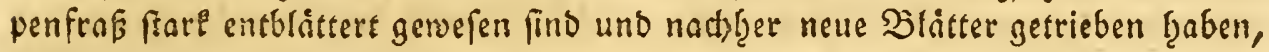
phegt bas kaub bis refre fpat in ben Szerbft und bey gelinben Mintern oft bis zum neuen Triebe grü ju bleiben. Mefreres f̧iervon ift in ber Einleitung vom 2 bfallen ber $\mathfrak{B l a t t e r ~ i b e r f ̧ a u p t ~ g e f a g t ~ r o o r b e n . ~}$

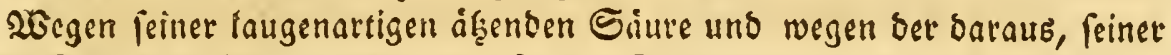
lïngern Dauer halber, entftetgenden feftern Decfe ift bas abgefallene Eid)ens laub bem Brafe nad)tfeiliger, wie bas \{aub bon anbern Baumarten, uno fieţe

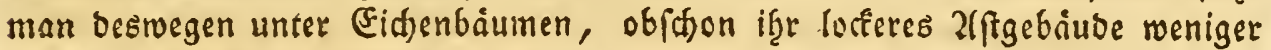
erfticfend und luftiger ift, bod) weniger (jras warffen, als unter andern Baums arten, bie weit ftăr fere uno bidfter belaubte Frenen ţaben.

\section{§. 255 .}

Der Baumfaft ber Eid)e ḩat eine jufammenjief̧ende, laugchartige Sảure,

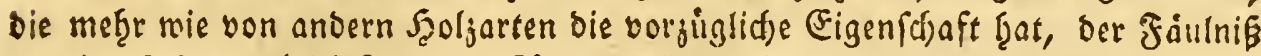

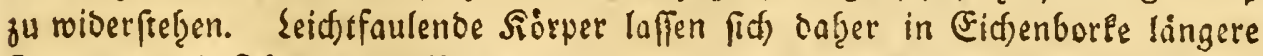

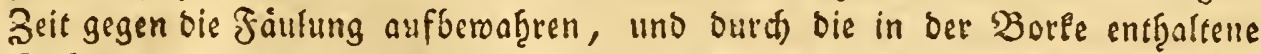
Saftlauge wirb eigentlicf) burd) bas (Jierben ben Şäuten bie geţơrige Feffigfert gegeben. 2(n frifd) gefpaltenem oocr gefdnittenem $\mathcal{H}_{\text {golje }}$ eann man biefe Saure

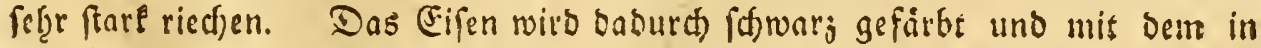
ben Balläpfeln entţaltenen baumfaft färbt man Dinte. 2(ud) fino bie úbeln Folgen belannt, weld)e baraus zu entftefen pflegen, wenn bas gefiorige 2lus:

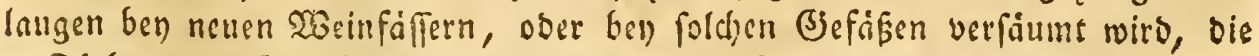
zu Färberenen, Sbleidjercyen oder bergleidfen gebraudte reerben follen.

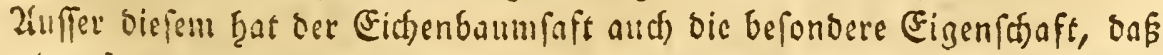

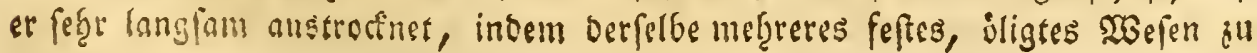




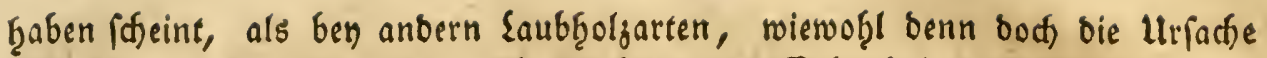
von bem to jef̧r langfamen 2ustrocfnen bes Eid)enţolges eigentlid) in bent feften unb bidfen Rög̨rengewebe beffelben zu futfen ift.

\section{§. 256.}

Die nähere Beftimmung. ber Beftandţeile bes Eidjenfafts ift für ben Gorftmann iuberfluffig; folgende Frage oaruber aber ift für benfelben ju erörs tern befonbers wid)tig: nàmlid, weldjen $\mathfrak{U n t e r}$ (d)ieb ber mef̧r ober meniger in Dem Eidienţolje enthaltene Saft auf oeffen mef̧rere ober wenigere Feftigleit uno Dauer berwirlen möcfte. Da nun biefer Begenftano in bem britten 2(bjd)nitte

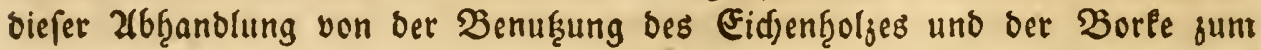
Berben vorfommen wird: fo wirb ber Sefer baf̧in verwiefen; bas ibrige biers von aber wirb berfelbe in bem erften 2(b/d)nitte von ber Naturgefdidfte ber Bäume gefunden traben.

\section{§. 257.}

\section{Bon Den Rrantheiten uns wibrigen Zufôllen Der Eidye.}

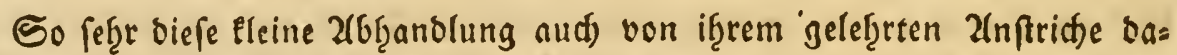
burd) verlieren mag, onE fie bie Siranlf̧eiten uno mibrigen Sufälle ber (Eidfe

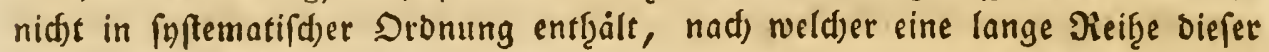

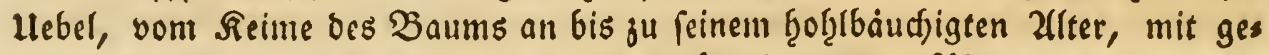

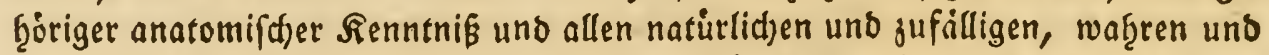

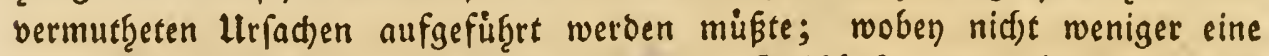
grunogelef̧rte Sifte von allen baran freffenden Befdjopfen vom Şodjwilbe uno Sindviefe an, bis zu ben geringften baran nagenden und batauf eriedjenden Infecten, uno allen baran wadjenden Sdmaroferpflanjen, Schwämmen,

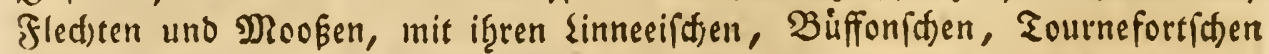
Tamen uno fonftigen gelef̧rten 2 erjierungen, (fo wie es in ber von $\mathfrak{B} u r g s s$

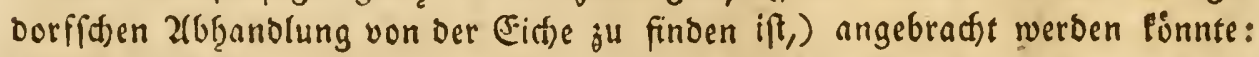

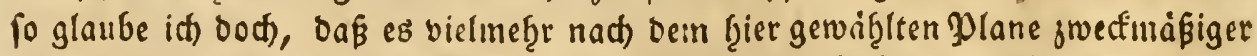

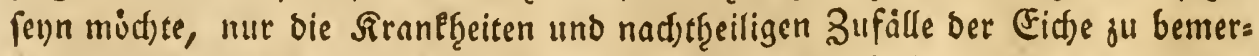
Pen, weld)e man burd) practifdanwenbbare Mittel jul heilen, und benen man Durd) gefiórige Maafregeln vorgulonmen im Stande ift, ober beren genauere

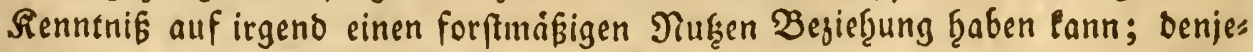

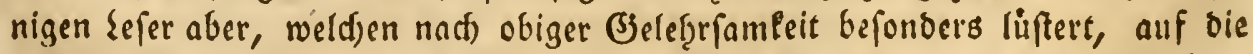

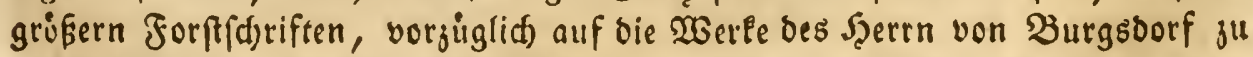
verweifen. - Mandjer alte $\mathfrak{W}$ seidemann witb es fo fdjon fatt ḩaben, wenn 
er biefes $\mathfrak{B u d f}$ lieft; und fänóe er barin vollends alle Sateinifaen und Briect)is iffen Coleopteras, Lepidopteras, Hemipteras unb wie bie verfdjiebenen Flaffen von fliegenden und eriectenden Infecten, bie man an ben Eidfen findet,

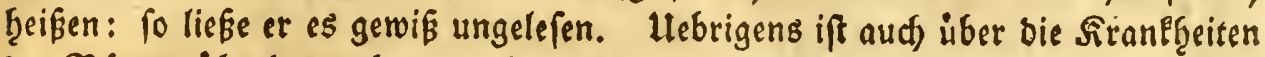
ber Baiume úberţaupt bereits oben meţreres yorgefommen.

\section{§. 258.}

Soldfe Franlfgeiten ber Eidfen, bie man bey einer vernunftigen Forfts

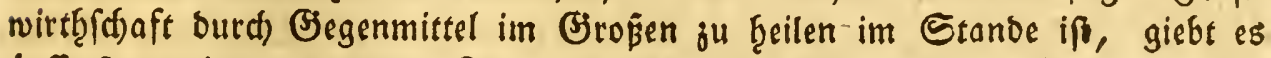
aufferft menige: benn ber Forftmann eann nidft ro, wie ber Ssartner, feine

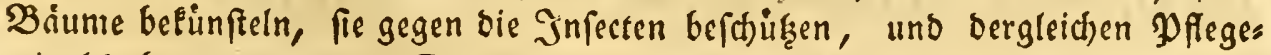

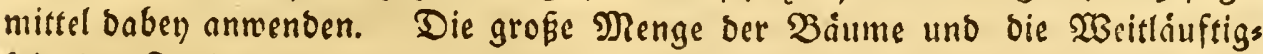
leit ber Forften geftattet ben (Bebraud) foldjer Mittel nicht; und felbft ben Pflanjungen unb Baumffulen find biefelben beswegen f(h) on fef̨r eingefd)ränt. Man follte es baher beynaḩe für eine Satyre balten, wenn ber Şerr Şofratḩ Jorfter in feiner lleberfeģung ber von willfelm Jorinth in Englano beraubges

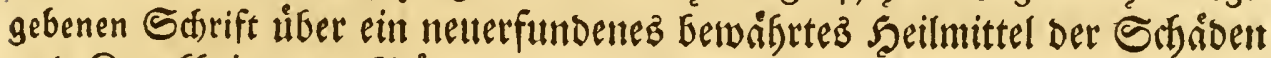

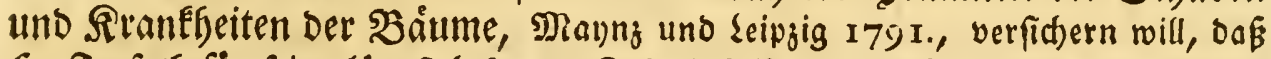

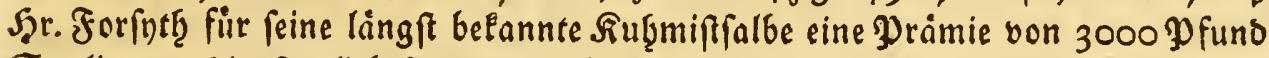
Sterling verbienftuoll befommen ḩaben foll; weil er bamit grofe lodjer und Fäulniffe an alten Eidjen curiret ந̧abe!!

\section{§. 259.}

2lls Şeilungsmittel, weldte in einigen Fälten forftmápig anjumenben fint, fönen folgenoe angefergen werben.

Die ju bidft ober unter großen baumnen unterbrüft ftebenben jungen Eidfen wadfen gu idwad) uno ju langftammig, verbutten uno vergeţen julejt gröstentheils; biefen ift oft ourd) ein gefdicftes 2(usplentern ober burd 20 egs nef̧unen ber gropen Baiume noh) ju helfer.

Den burch Froft oder Miaufefrás uno $\mathfrak{B}$ erbeiffen bes $\mathfrak{3 i e t z e s ~ f t a r t ~ b e s ~}$

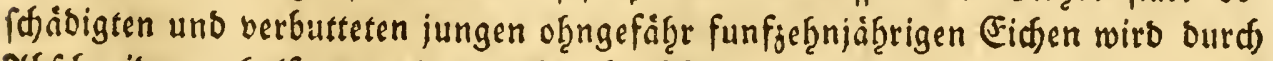
Zbfdjneiben geţolfen, uno mandjer befódibigte uno beswegen niebrig uno ju viel in bie Zefte wad) fende junge brenfig bis vierzigjä̧̨rige Baum lann ourd

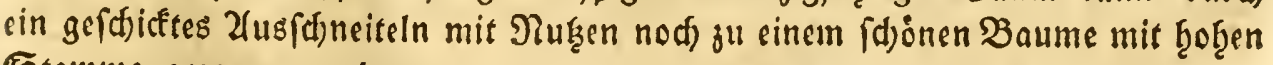
Stamme gejogen rerben.

Bey Den Baumfdulen und (Fictenlämpen, aud) bey Eleinern Pflanzuns gen, an beren Erryaltung und Eebeif̧en oft vorjughlich gelegen ift, laffen fid)

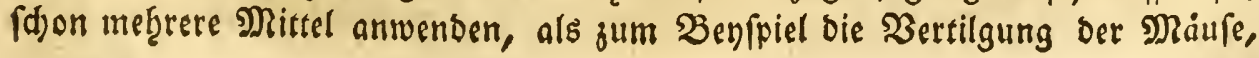




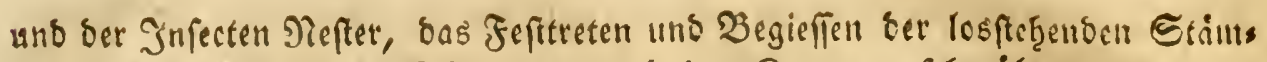
me, bas 2lustrauten unb Jäten ber ourch bas Fraut ju feb̨e überjogenen juns

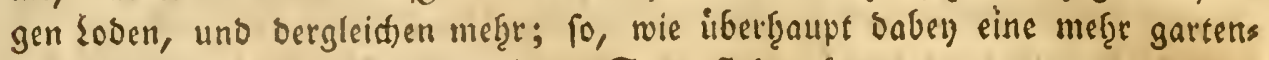
ntópige Beforgung und Interb̨altung Statt finden fann.

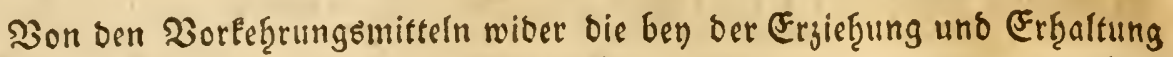
ber (Fid)en ju befürd)tenden ubeln Folgen fönnten bier weit meb̧rere angeführet

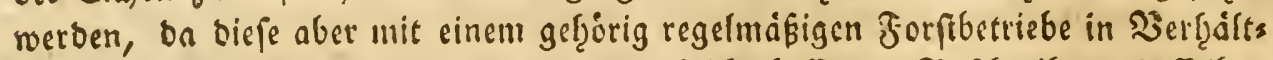
niß̧ unb in ßerbinoung frefen: fo werben fold)e beffer jur Befdreibung oeffelben

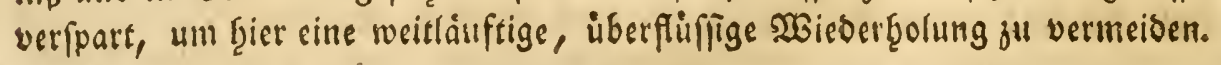

\section{§. 260.}

3ur Erflärung einiger an ben Eiden vorfommenten Erfdeinungen, bie

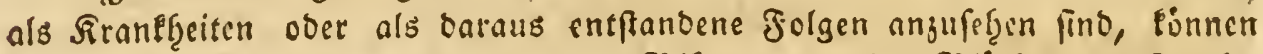
hier angefüb̨rt warben: Die alr einigen Blättern, an ben Slithen uno Frud)t:

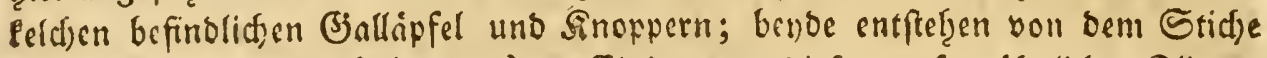
einiger fliegenarten (Cinypes). Einige von biefen wefpentignlid)en fliegen fted)en obel vernmoen bie Rippen ber untern Scite ber Blatter, anbere die Stiele ber Blätter, anbere bic jungen Snofpen, andere bie mainnlicken Blithen,

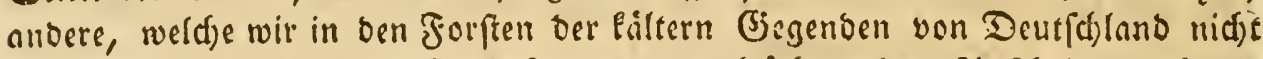

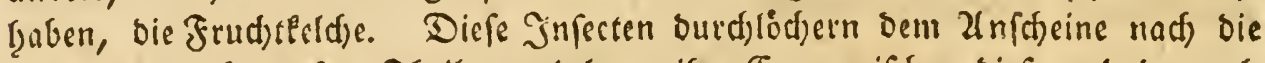
Dberfzaut ber bemerlen Theile, uno legen ifgre Ever zwifhen biefe und bas jels lenartige Semebe berfelben; biefe, obgleid) wegen bes felir feinen Stiajs nur

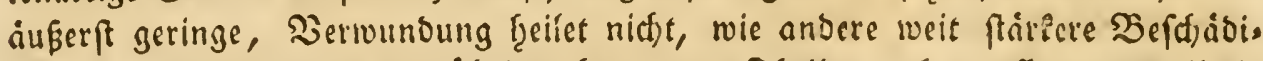

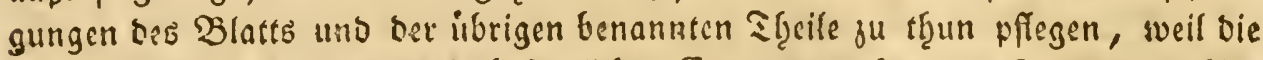

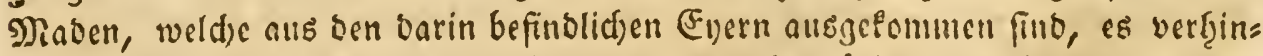
bern. Es entfteft baraus eine befonbere 2(rt 2fuswithfe, weld) man an ben

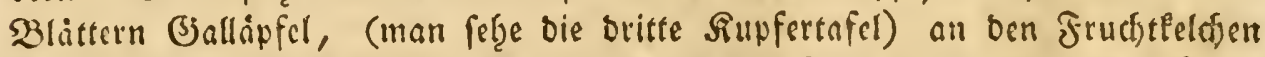
Sncppern, an ben Sinofpen, Eidjelrefen, Jig. 2. Sob. 2. uno an ben Sluthen

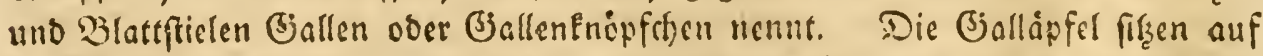
ben Jippen ber untern Seite Des Blatts, oft cin bis zer̨n auf einem Blatte, mit ocm fie buref sinen fefre dinnen und furzen 2(nf̧anz zientlid) feft verbunoen fino; fie graben bie Form und erreid)en jum इheil bic Briffe von einer ein, bis zwey lotbigen Sugel; viele find gelblid, viele rotflida gefärbt; einize fino auf

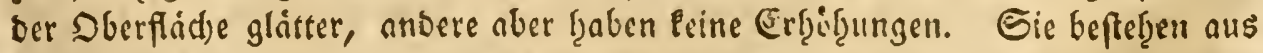

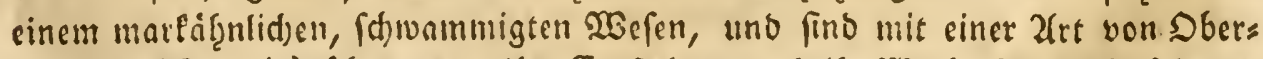

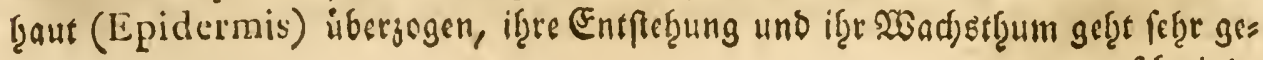
fajoino, 


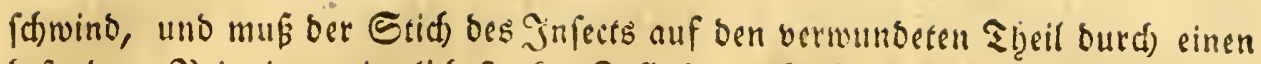
befonbern Dieij einen jiemlict) forfen Buflus von Saft berwirken: Denn an Blats tern, bie mit fed)s bis jef̨n Ballapfeln bef̧ängt fino, findet anan nur fefre gerins

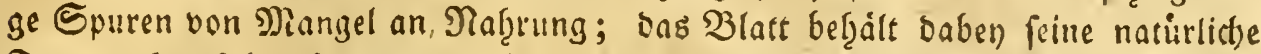
Form, of̧ne fid) jufammenjujiefzen, uno nur bey cinigen pflegt die grine Farbe

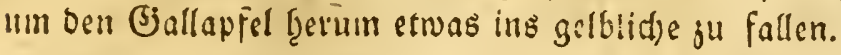

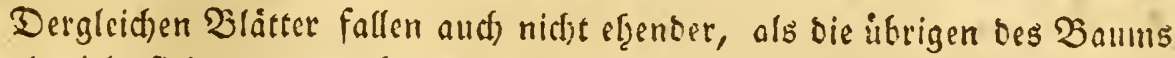
ab, uno visle firbet man nod) bayon fpat im Minter auf ben $\mathfrak{B}$ aumen figen.

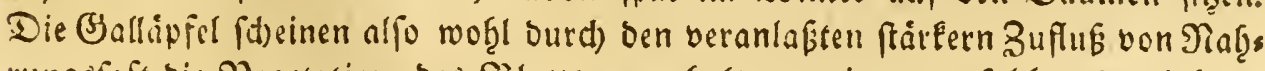
rungsfaft bie 3 egetation bes 3 latts ju erţalten, wie man fildes beutlith an

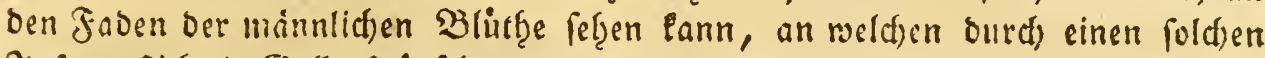
Jnfectenftich ein Gallenenopft)en entfanden ift, inbem fid berfelbe baburd) nod)

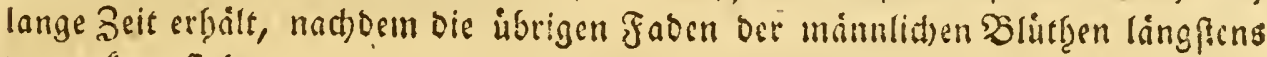
vertroctnet fino.

In ber Mitte ber (jalläpfel ift eine, aud woh̨l maţrere, Fleine länglid)t

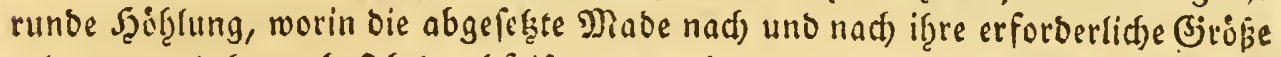

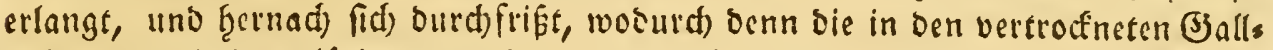
ipfeln ourd)bohrcen sodfer entfteţen. Diefe Balläpfel merben wegen if̧reb vielen uno befonders feimen (Eid)enfafte jur Dinte und jur Feirberey gebraud)t. Mit

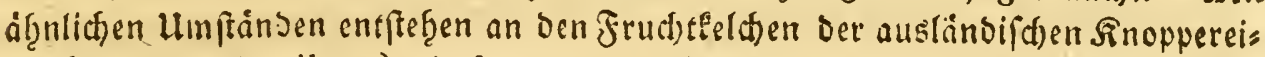
d)e (Quercus Aegilops) Die fogenannten Sinoppern von einer 2(rt ffliegen, die fid) in Den wairmern (jegenoen in Franfreid) uno Spanien aufgált, wo biefe (Fis

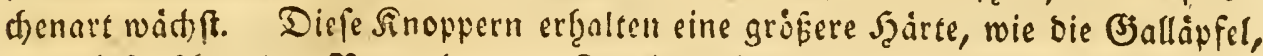

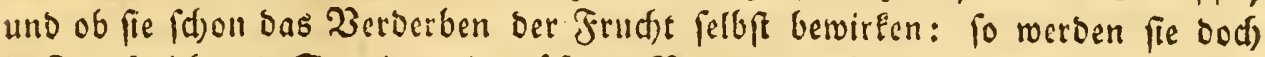
in Frantereich uno Spanien mit gróperm Nukcen jur Färberey uno feinen Bers berey) gebralld)t. 2ud) giebtes an ben inlänbifden (Fid)en, auf ber untern Seite

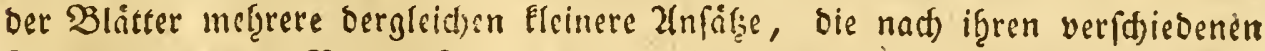
Formen unter ben Namen Tellerd)en oder J su!en belannt und die Folgen von

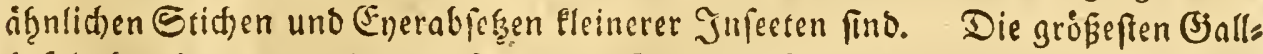
ipfel aber findet man in ben Jjonaten Mial) uno Sunius an oen lejtjighrigen Los

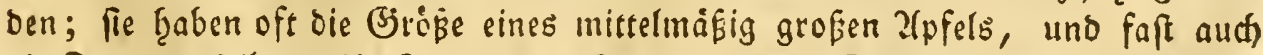

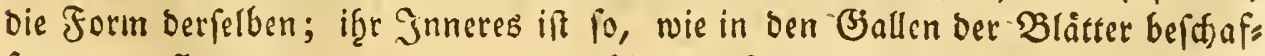
fen, nur pflegt es etwas bidjter uno jäfeer ju fenn; man finoet barin mefzrete Maben, jede in einer befondern eleinen Szjgle liegen; die fidf im Monnt Julis us burdjfreffen, wonad) oiefe Gjallen abfallen. In biefen grofen (jallen finben (id) oft mefrere alten von Maben uno fliegen, fo wis audf bis, weldje aus (erfter Tyat) 
ben nad) gerigen Stidgen einer art Sd)lupfwefpen, bic barin if̧re Enet ablegen,

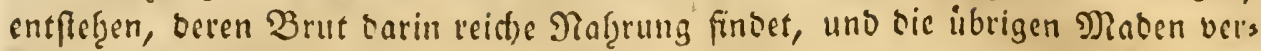
octrit. 2fn einigen immer grimen (Fid)enarten in oen wármern sänbern erbalten bieje fämmtliçen arten von Gallen eine weit grêßere Scärte und sine gewiffe art Dieife, die ben in biefigen (Bjegenden gewad) fanen (Ballen fef̧lt. Die Materia: liften laffen bafer tie fremben (jallapfel Eommen, bon benen bie Surfifden aus ben Begenben von Ginima die beften fino, und nur felten werben bie einf̧eimis

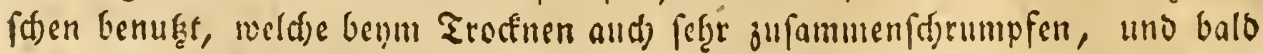
mit ben Blàttern verfaulen.

\section{§. 261 .}

Zut Senntnif ber Whiberwärtigleiten ber Ficfe, beren nifgere Seftimmung

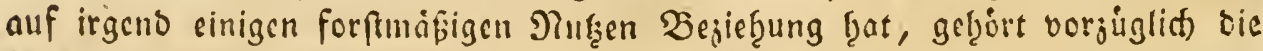
Befanntfd)aft mit ben Infecten, aus beren im Jrübjaf̧r vorb̨andener gribern ober geringern Mienge Der Jorftmann bie Şoffnung ber bas Jaf̨r ju erwartens Den Maft und Befaamung, nebft andern babey in Erwägung fu jief̧enden llm: ftanden mit bered)net; von biefen aber foll in bem \$. 366. von ber INaft, bas Rotbige vorlommen.

\section{§. 262.}

2uch gef̧iren bief̧er bie Wirlungen bes Froftes und bie baraus entftandes nen nact)tgeiligen folgen, fo woht ben jungen loben, als ben alten Stänmen; aber aud) f̧ierbon wirb linftig nod) oft bie Rebe fenn. 2llfo mit Zuructweifung auf bas, was bavon bereits bon ben Báumen uberb̨aupt gefagt ift, uno nod gefage reerben wirb, babon nur folgendes:

Wie ber froft eigentlid) auf bie (jemadsfe wirle, ift nod immer, wie fo

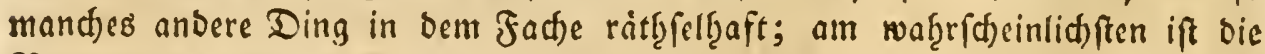
3ermutḩung, baßs ourch bas Frieren bes in ben (Jewad)fen befinolictien Safts

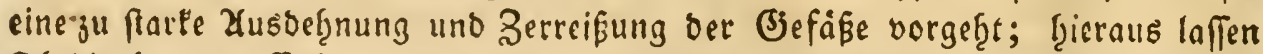
(id) bie ben ben (Fid)en vom frofte berurfacten Erfdeinungen aud) am beften erflären, befonoers bie weiblid)ten, róthlichten, aud) fdrwärlid)ten Streifen und Flecten, weld)e man ţäufig in Den alten Fidjen, vorneţmlid) in ben (Ses birgsforften, finbet.

2ud) bie Eisllifte ober Froftborften fino die Folgen eines, entrocber befons bers ftarfen, ober unter nattefeiligen llmftänen eingetretenen, Froftes, bey weldem ber Sramm der Bàume, und vorgüglid Der Eidjen, oft mit einem 
Een Sinull von oben bis unten aufreift. STenn mun foldfes 2(ufreisen nad ban

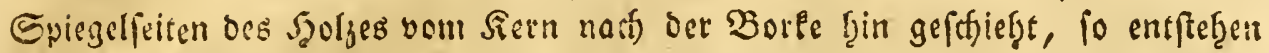

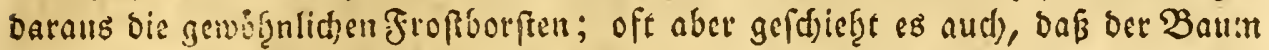
auf ber 2lufenfeite aufipaltet, tiefer im Szolje aber auth nod) baben eine Sers

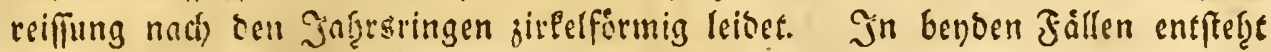

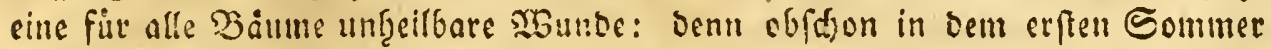

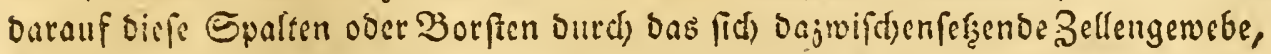
wie mef̧rere $\mathfrak{B e f d j o b i g u n g e n , ~ f u f o m m e n t y c i l e n : ~ f o ~ r e i s e n ~ f i e ~ b o d ) ~ w e g e n ~ g e r i n s ~}$ gerer. Fefrigleit bet) jeber Jusbefgnung eincs, aud nur mittelmäßigen, froftes

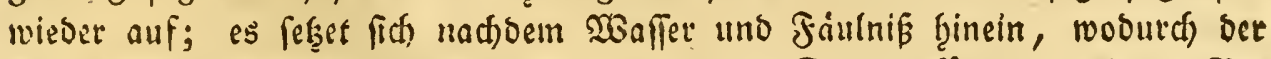
$\mathfrak{Z}$ aum feimen gefunien $\mathfrak{3}$ แchs verliert, und oer Stamm für bie inebreften $\mathfrak{B} e s$ "1แßzungen unbranbbar wirb.

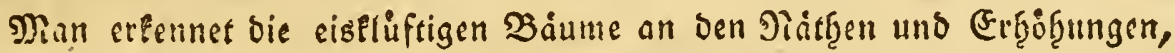
welde fid ben Epalt nad) auf ber Borte serfelorn nad) und nad) bilben, ben welden ber forftmann fid) crinneru mub, einen foldyen Baum je ę̧ender je bef fer ju benufsen, insem er von Jaber ju Jal̨r nur nod fdjaof̧after wiro. Daf man an ben (Eid)en vorjiglid folde Jroftborften finbet, bavon liegt bie Itrjadfe woht in bem feftern, gröbern uno weniger nachgiebigen Roberenges mebe berfelben, uno aud barin, bafie fie fid bey einer folden farfen Bes fd)abigung lángere Beit, wie andere Ballmarten, in weldjen barnus weif

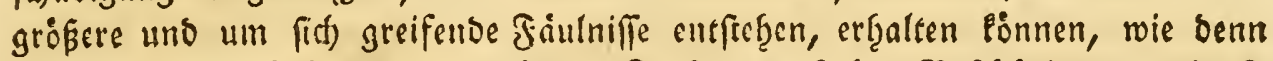
iberf̧aupt ben (Eid)en alle burd) oen Jroft verurfadte Beffibigungen in to weit reniger madjtgeilig fino, weil fie bamit noch viele Jaf̧re grünen Ëns nen; jebod) Gecilen fie bicfelben felten ganj aus, uns bie (Fid)en, weld)e

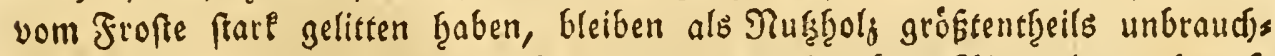
bar. M̉enn aber fold)e $\mathfrak{B} 2$ fdadoigungen nur bie obern Rindenlagen betrefs fen, wie es oft an jungen Eidsen ber fall zu fenn pflegt: fo find fie eben

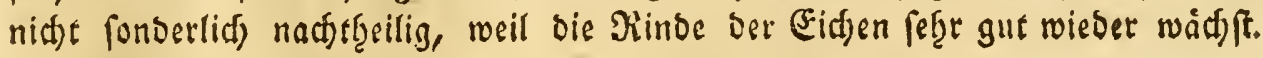

3on ben übrigen ben ben Eicfen vortommenden Befdábigungen, wels

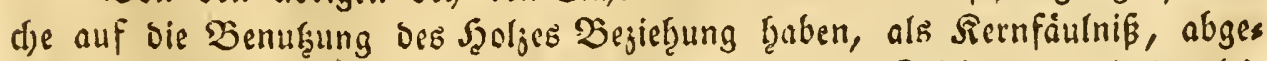
nommene grofie 2lefte uno bie saraus entfanoenen Sajáben, uno oergleis d)en, wiro in bem \$S. voll ber Senufsung bes Sgoljes ber Eidje meţreres bemeref werben. 
§. 263 .

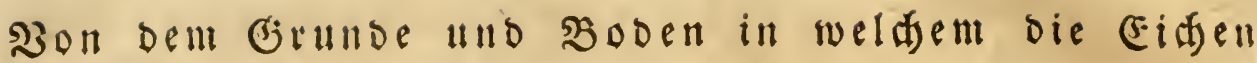
vorgliglith gut wad)

Somofr die Eroenmirdung bes Grrundes uno Bodens, auf bem ber Baum frefet, als bie Siefe uno bie sage beffelben nad) ben f̧immelsgegen: Dell, oder in Diudfid)t nuf Berge uno Tháler, auf Dirre und Näfe, auf meţrere und wenigere Sidjerţeit gegen 2 ind und $\mathfrak{W e t t e r , ~ u n d ~ a n d e r e ~ b e r s ~}$

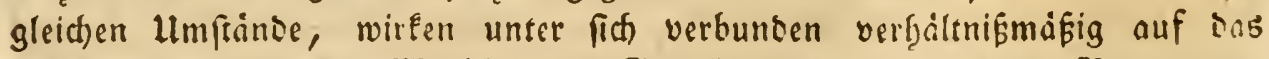
ftàtere ober geringere 20 ad) fen und (J)ebeifen ber verfdjiebenen $\mathfrak{B}$ aumarten.

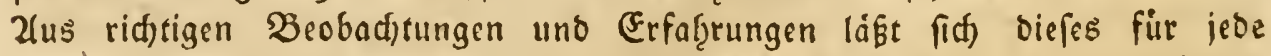
Baumart genaner befiummen, und nad) biefen weís man, baß́ bie (Eid)en

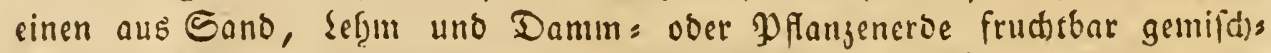
ten, fo genininten Nittelboden, vorjuglid) lieben, uno barin auf bem flas

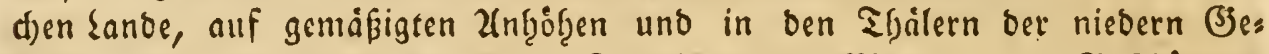

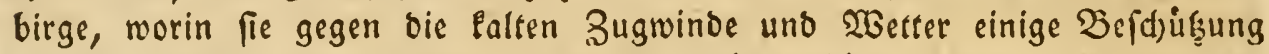

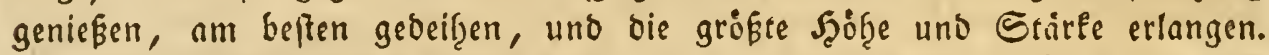

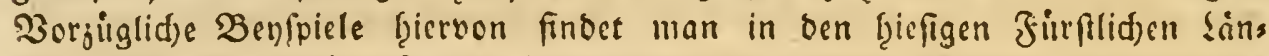
Dern, in oen fladen Sandforfen bey Braunfdyeig in oen 2(emtern Campen uno

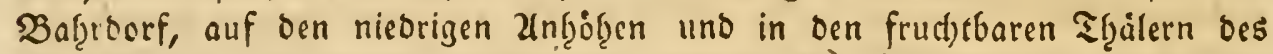

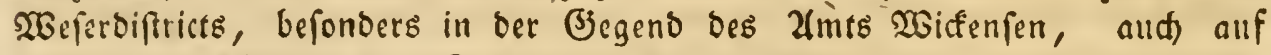

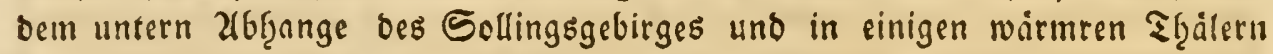
Der Llnter: Szarjgebirge.

\section{§. 264 .}

Dbfdion die Eicten auf ben eigentlitsen naffen und moraftigen Orten nidft, ober bodh nur erippelidt), fortfommen, fo findet man bod) in bergleiden (jegens ben auf ben geringen, in etwas trocfenen 2 unfiogen alte (Fid)en bon ganj ans

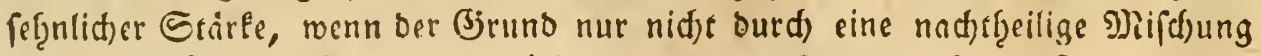
von eifenfhujfingem Sande, und Dhreifen, wie biefes bort oft ber Fall ju fernn pflegt, ifgnen juwioer ift. Dergleidjen (Eichen fiefet man auf ben ctwas erf̧abs

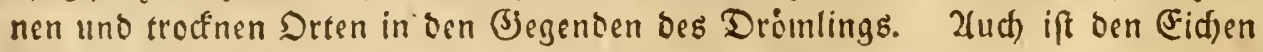

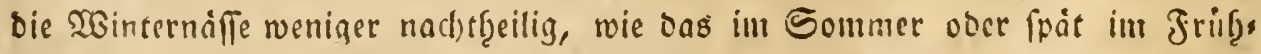

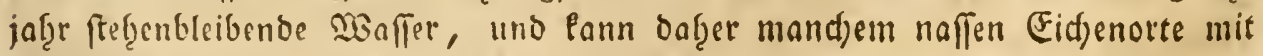
ableitung bes maffers fȩ̣r geţolfen werben. 


\section{§. 265 .}

Der Palefteinartige Sruno uno Boben ift ben Eiđen nid)t vortheilhaft; man finbet baber auf bein Eim, auf Der affe, uno auf bergleiden Ralfgebirgen, wo

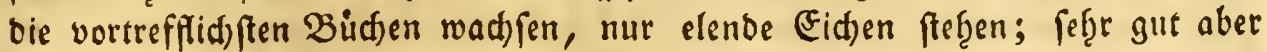

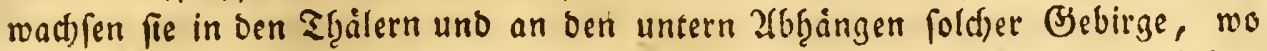
Der Jiruno auf bie erforberlide Tiefe aus ferge verwittertem Jiergel init Lef̧m= uno Pflangenerbe gemifat ift, wie jum Beyfpiel auf bem Elje, auf ben tiefern

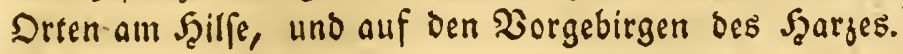

\section{§. 266.}

$\$ 6$ man nun aber gleid) ben eigentlid) fo genannten Mittelboben, oer aus oben bemerter Nifichung befrebt, als ben frud)tbarften uno zutriglid)ften fur bie (Eid)en annefrmen lann: fo finbet man bod) in Den Sanogegenden, wo ber Sano bey weitem ben grópeften Fgeil ber (stomifhung ausmaht uno biefe nur

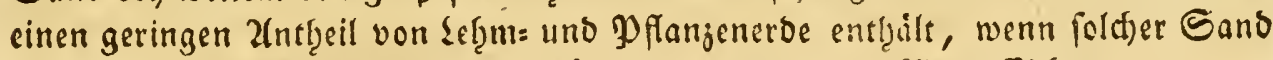
nur nidgt ju groblieficht uno eifenjabffig ift, ganj vortrefflid)e (vid)en.

Zuffallende Benfpiele fiervon fiefct man iu Mänfterftien, in ben frudftba=

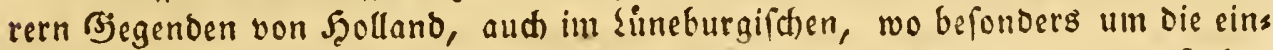
zeln gelegenen 23 auerb̧ófe bie fdónften uno ftäfften (Eid)en fteben, bie oft bey einer Diffe von fieben bis ad) $\mathfrak{F} u \tilde{B}$ in Durdweffer nod) allf oen oberften 2(eften vollen Suroad)s jeigen, uno jäbrige Sooen treiben, bie man fonf̣t nut an junget Eichen jul reben gewobnt ift; Die (Fid)e fdeint Dafelbft ein gang anderer Baum

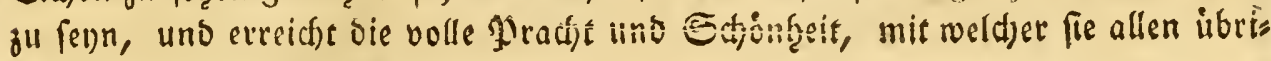
gen Furopåifdjen Báumen vorgeb̨t.

\section{§. 267.}

Die oben gerifgmen Forfen oer 2(emer Campen uns Baf̧rborf gaas ben einen foldyen frudtoaren (Eidhentoben, weld)er aber in ben ubrigen biefis gen Sanogegentoen fiut oie (Fid)en nid)t fo glieflid) gemifd)t ift, worin man bie Marienbergfden, JRarientbaliden, Suerenţorfter uno Meubăufer Forften red)nen laun, in welden froar bin uno wirbar cinine ftarle Eidien febcen, die aber grofetentbeils feglerţaft find uno Bervelfe genug an ben

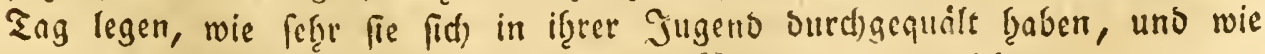

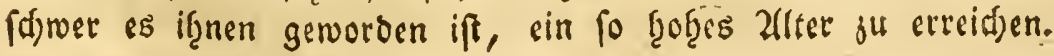




\section{§. 268.}

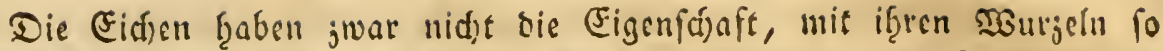

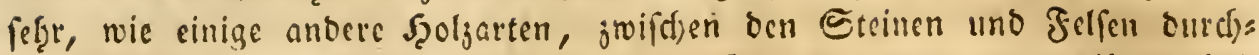
jufd)lingen, inoem fie damit mef̧r in bie Siefe gef̨en, uno ju if̧rem befs

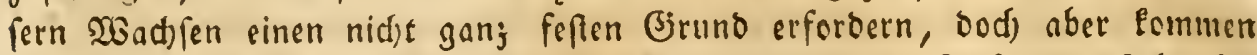
fie -in einem freinigten Booen, wenn er nut auf die Siefe bon fedfs bis

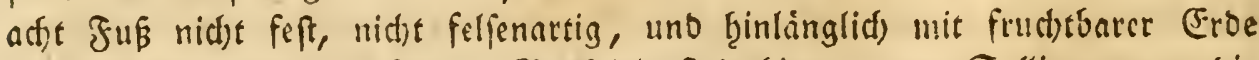
gemifdt ift, feģr gut fort. Devfpiele find bierbon am Sollinge, wo bie Eidjen auf einigen Drten, im rotb̧fanoigten Sirunde feb̨r gut wadjfen.

\section{§. 269.}

Eine or vorjigliaften Eigenfáaften eines für bie Eidjen fruthtbaren Bobens ift die erforderlid)e Siefe ocffelben, welde unan nad) oen limftins ben ber Darin ineḩrern oeer wenigern Feftigleit, Näfie ober Durre, jwis

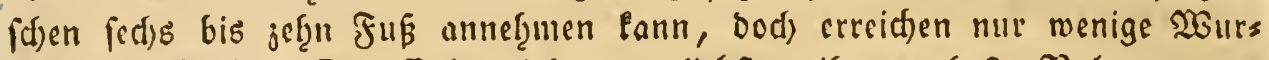
jeln biefe Tiefe. Die Eidje jief̨t am liebften if̧re meţrfte Iaţrung aus

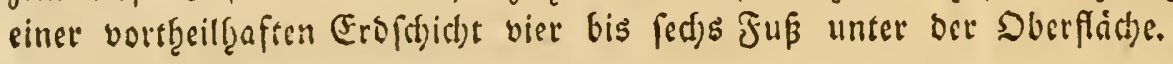

\section{§. 270.}

Det von ben Forfmninmern faft allgemein angenommene $S_{a}$ : baż auf

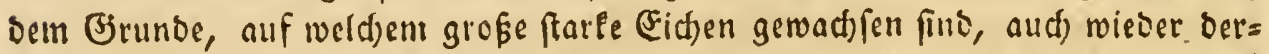
gleidfen wad)fen lonnen, ift nur mit einigen Einfdrantungen ridiftig, bie auf

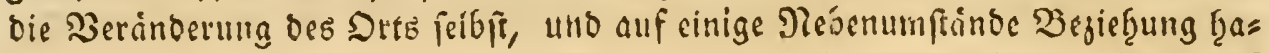
Eell. 23eranderungen bes (Jrundes uno Wobens laffen fich auf einem Dite, auf

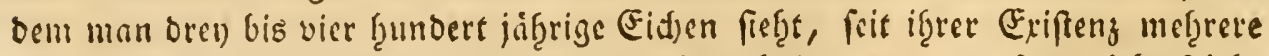
geoculen. Es fann ein, in ber Deit mit Szelg beftandener, auf oer Dóerfliche feft genefener Sanboosen feine fefte Decfe verloren b̧aben. Ein bamals trockes ner Drt eann jeft iberfdwemmt, ein anderer ourd) bas von Zeit ju Zeit fid

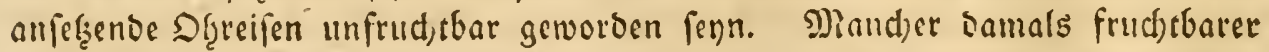
26 bृang bes niebern 3orgebirges fann indeffen feine gute Danmerde burd) WBaf:

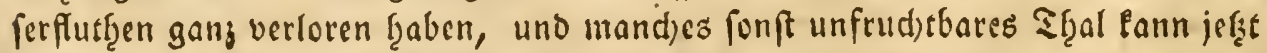
Damit angefitlet feyu, uno bergleid)en Seraindetungen mef̧rete. Suben, von

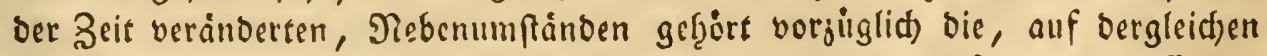

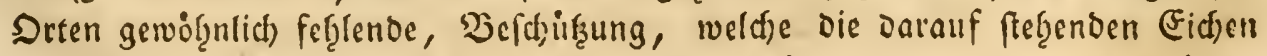

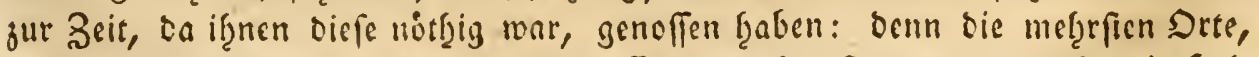

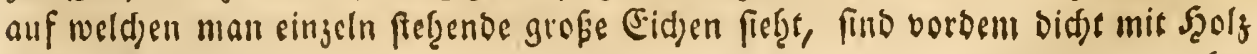




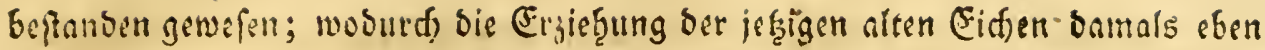

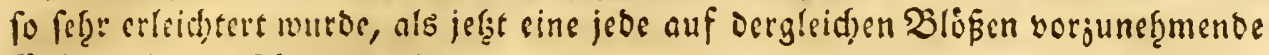
Eictencultur erjicfweret wirb.

In fo weit nun, als bie nad)tbeiligen Serainberungen, weldje fid feit ber Exiftenj ber auf oen Diten ftę̧enden (Fid)en fü ben (Siuno uno Boben ereiguet haben, fich zum 3ortheil Det vorzuneţmenden Culturen wieber geben laffin, uno

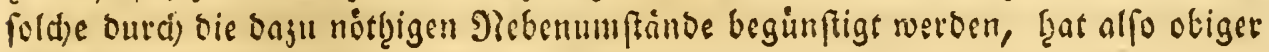

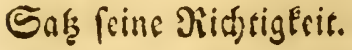

\section{§. 271 .}

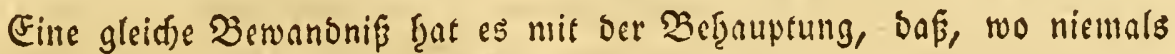
Eidjen geftanden wären, man nud) leine jię̧en míb̆te.

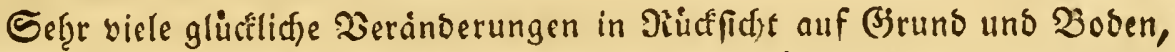

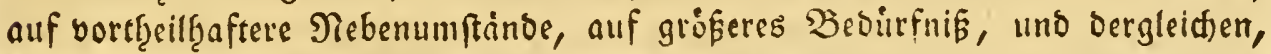
fonnen biefe befrauptung unrid)tig madhen, fo wie fie bingegen in vielen fallen

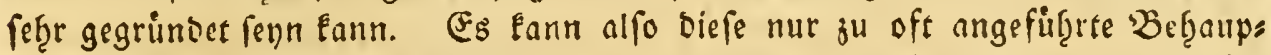
tung an fid felbft nid)t gelten, uno nur bie nåfzer unterfudten uno rid)tig bes funbenen (Grunse, ob es rathfam fen), auf einem fold)en Drte (Fid)en ju cultivis ren ober nid)t, fann biefen oft gemisbraud)ten Ferftef̧rfał berid)tiger.

\section{§. 272.}

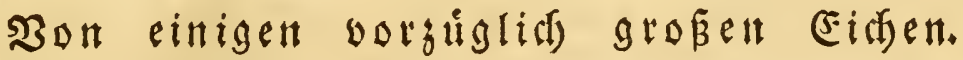

20enn bie Fichen auf einem fir fie fruditfaren Boben uns unter fortbaus etnben güntigen Llmftinden aufroadfen: fo lönnen fie eine, yor andern Baums

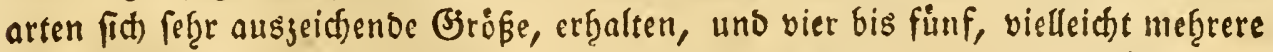

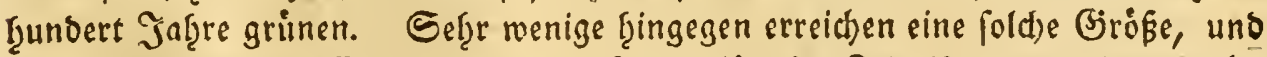
bie mebcrften ftarfen Eichen bringen oft bie längfte Zeit if̧res vegetirenben bens mit sinem geringen Zuwad) auf ber äusern Seite zu, woitgrens, bafi fie an wefentlidter Stärle burch) Siernfäulnif verlieren, biefe pflegen baher aud,,

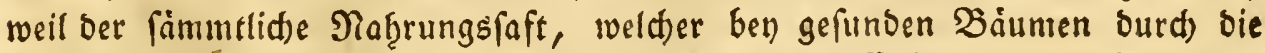
Sgoljröţren bés ganzen Stamms geb̨t, in ben leof̧len Eithen nur ourch ben ges

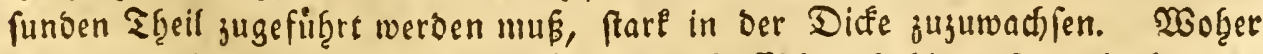

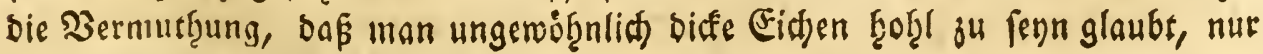
ou oft beftåtigt roiro. 
Beyfpiele von fefte grofien (Fid)en findet man in beul mef̨rmals gerifgenten

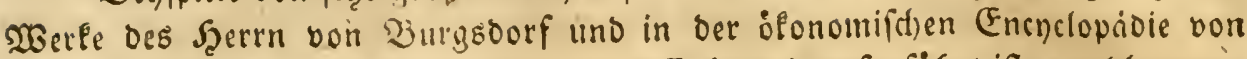

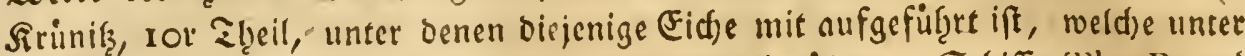

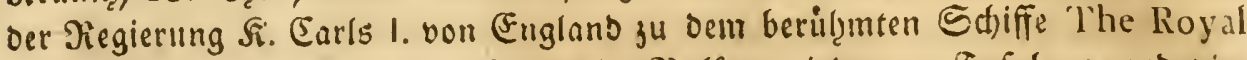
Sovereign burd) einen Freuj fdnitt vier Balfen, jeoen 44 Fuf lang uno vier

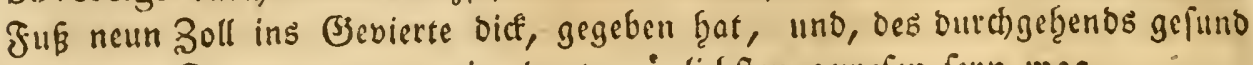
gemefenen Stanms roegen, eine bel vorgiglid)ften geroefen feyn mag.

(Einige Fidjen bev Boomte im Scannoberfífen, von benen ids cime, auf finf

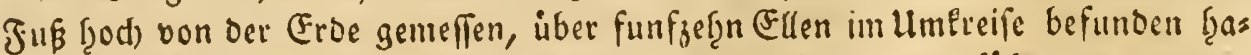
be, pflegen in ben biefigen (Jiegenden als groge (Fid)en angefithrt ju werben,

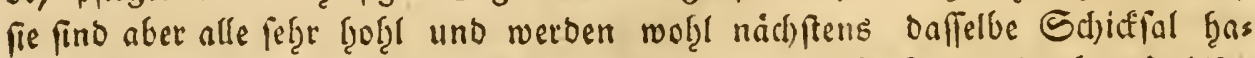

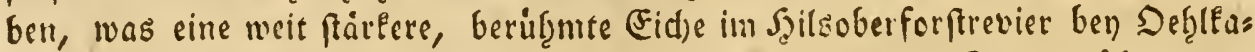

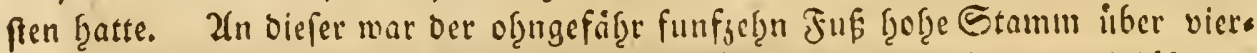

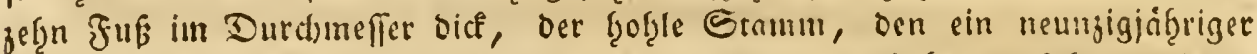

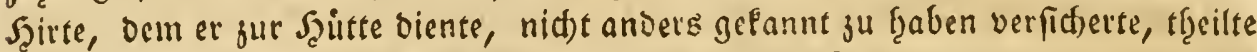
fid) oben in oren fzohe gefunde alefte, vor funfirf̨n Sab̨ren wurben bon biefen

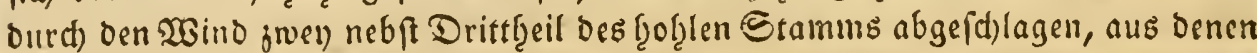
eine grobe 2(njabl gefunder Stänoer gefdnitten ift, ben nod) ubrigen Sbeil bat man aus ad)tung fur biefes forftmonument ftefenen laffen, und vor ein $\mathfrak{y}$ aar

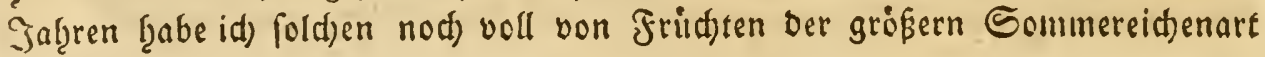
gefelcen.

Jin Sdjoningfdien Dberforftrevier, bey Frelftebt, ftę̧t nod) eine ref̧e grobe (Fid)e, Deren Stamm unten uber jef̧n Jus in Durd)meffer uno baben

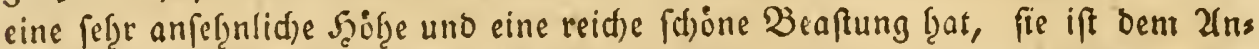
fefen nad) in Stamm nod) gefund, uno verbient if̧res feltenen fdionen 2 Wudf fes regen mit Sied)t bis ju ifreen naturlidjen Tobe gefdont ju werben.

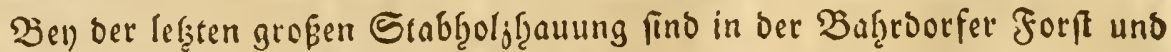

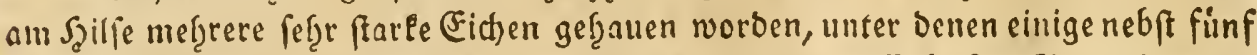
Ecjocf großzen Stäben über breubig Malter ju adjtjig Eubicfup Drennfeolj ges geben labert.

\section{\$. 273 .}

Bon Der forftmázigen Ergiefung Der Eidfe.

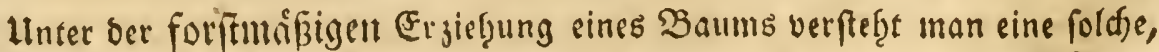
bie bei) einer grofen 2 (njabl von $\mathfrak{B}$ áumen in weitläuftigen Drten uno $\mathfrak{B a l o u n s .}$ gen aum vortbeilgaftepten alrwenobar ift. 
Sie ift alfo von ber gartenmábigen Ergief̧ung ber Sảumte fef̧r uns ferfdieben, uno ber Forftunann wirb baburd) befajränlt, von ten Mitteln, welche firr bie Erjictrung einer Baumart bie beften und nutglid)ften find,

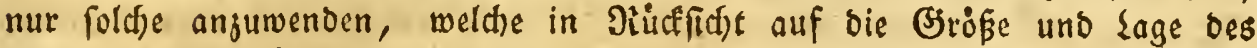

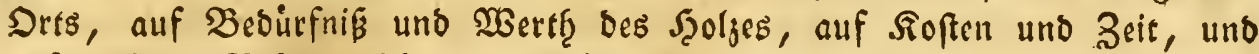

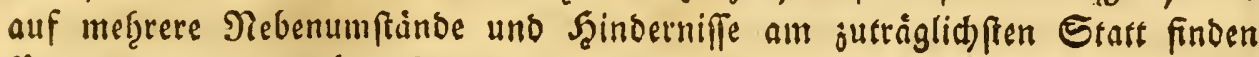
Ponnen und anwendbar find.

\section{§. 274 .}

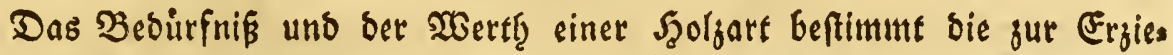

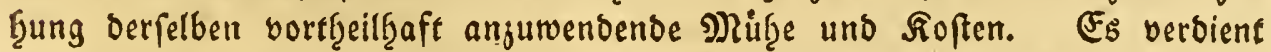

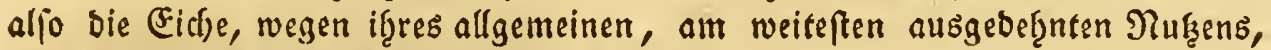
eine múf̧amere uno poftbarere Bef̧andlung, alb jebe anbere weniger ges

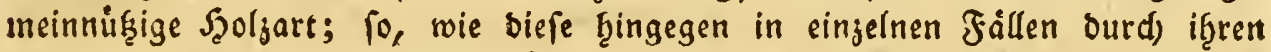

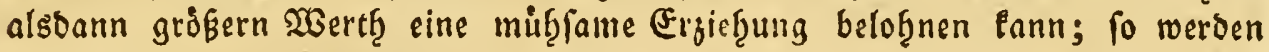

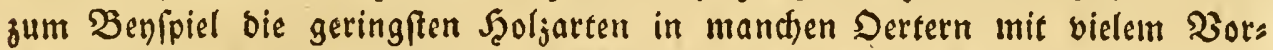

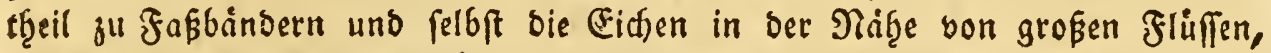
oder wo fie fonft einen grófern werth haben, mit mef̧rerem Fleiß̧e uno Foften gejogen, als in ben holgreidjen Begenden, wo man fie oft ungern nur als Jeuerf̧el benuf̧en ênn.

\section{§. 275 .}

Die Erjief̧ung ber Eidjen Eann man in bie natiorliche uno kunfitliffe eins theilen; jene ift siejenige Ergief̧ungsart, wo bie Eidfe aus bem, von ber Tatur Fingeworfenen, Eaamen entfanden ift, uno po, bon if̧r beginftigt, nad) uno

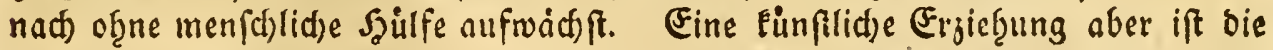

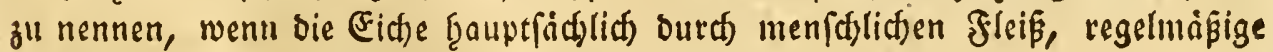

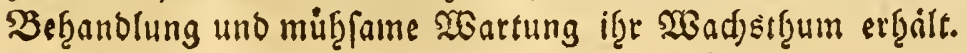

$$
\text { §. } 276 .
$$

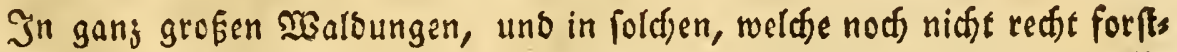
mápig beţandelf werden, wadjen bie Eidjen fo auf, wie es in bein erften $2(6=$

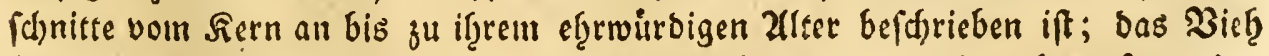
frift ifre Maft, uno oer Menfdh haulet fie $a b$, wenn er ifrer beoarf; weiter wiro fid gar nidst um fie belimmert. Dergleiden Eichen aber, wenn id eis

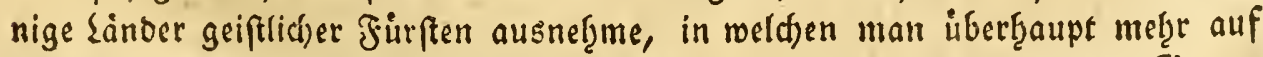

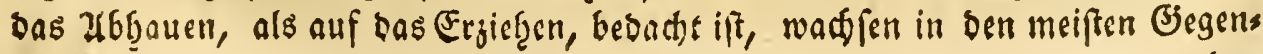




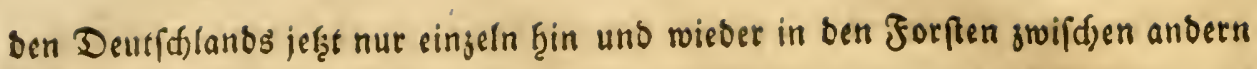
Sgoljarten auf.

Da erfennet jef̧t ben Werţ biefes vortreffitiden Baums, ber es bors

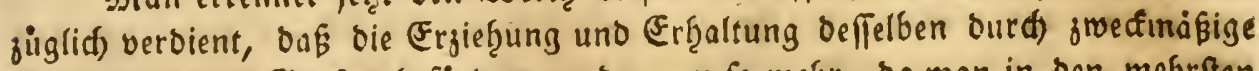

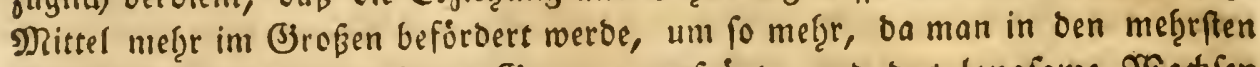

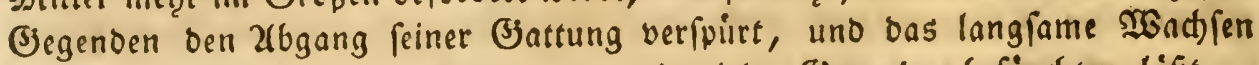
Der Eidjen einen fiunftigen Mangel baran in vielen Begenden befirtaten läét.

\section{§. 277.}

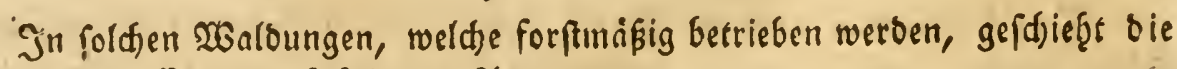
Erjief̨ung ber (Eid)en auf folgende $2(r k e n:$
1) Durch bie naturlitte Befaainung in ben Berbảgen und Bufflägen.
2) Durd) bie Einflithe $\mathfrak{B}$ efaanung.
3) Durd) bas Pflanjen.

\section{§. 278.}

Da bie bey ber Erzier̨ung eines Baums anzuroendende lünttidfe Bef̧anos lung nur als eime Bengiulfe anjufefgen ift, woourd) bie Natur fo zu fagen unters

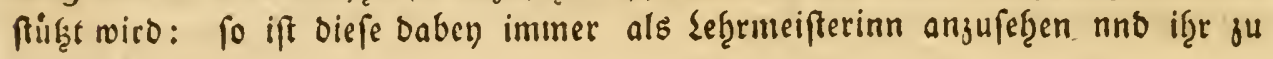
folgen.

Hlebrigens fino bey allen naturlidsen und elunftidfen Fidfenculturen forgens be Duncte in lleberfegung zu jichenen.

1) $\mathfrak{D b}$ es bortheilfaft fey, ben befimumten $D r t$ mit Eidjen in ben Beftand zu bringen, fo wob̨l in Riuffid)t auf Deffen Bruno nno Boben, als auf bas tünf: tige Beourfnis uno ben $\mathfrak{W e r t h}$ ber (Fid)en.

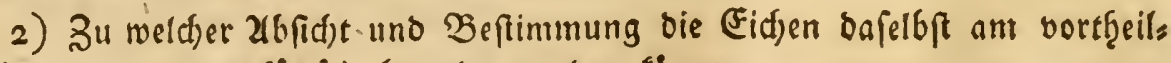
bzafteften erzogen und fiunftig benukget werben fönnen.

3) Woldhe Culturart für ben beftimmten Drt ain jrecfmábigften fen, uno

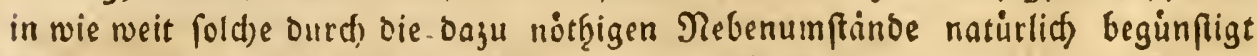
werbe, ober ourd) Sinft beroerfftelligt weroen fönne.

\section{§. 279.}

Die Beffimmung bes erften Puncts gefdief̧t durd) cine juberläfīge unb

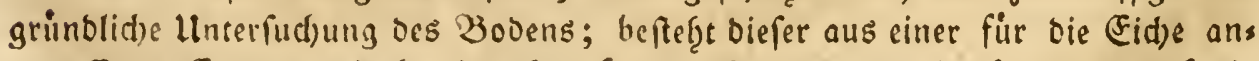
gemeffenen Erbart, wie bereits oben $\$ .263$. bemerlt ift: fo fömmt es suf bie 
mefrere ober wenigere Frud)tbarkeit beffelben an (woju oft bie Fiefe ber Erolas gen bes Drts uno bie mitwirfenoen Dinge bas mebrefte bentragen,) of (id) init einiger 3uverláffigleit f̧offen láft, baf bie auf bem Drte angulegende (Fid)enculs tur ber Erwartung entfprectien werbe ober nidft. Die Hnterfud)ung Des (Jruns bes uno Bobens ift ju ben (Fid)enculturen um befto widtiger, ba bie (Eid)en einen beffern Booen verlangen, ols viele ber übrigen Scelgarten, uno biefer aud nod) bon ber Sefd)affentzeit fenn mus, daß́ bie Jrud)tbarleit beffelben eine lange Reibe

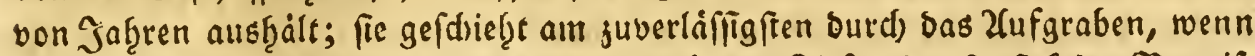
auf bem Srte fonft leine offine Stellen in geţüriger Tiefe oder fonft teine Beweife baruber vorf̧anben fino. Da nun in bem flad)en Zanbe bie Erolagen weniger, wie in ben gebirgid)ten (3egenben abred)feln, fo ift in jertem bas 2ufgraben an ein ober. jwey Stellen oft für einen Drt von mef̧rern f̧undert Miorgen binlänglié, in biefen aber imus cine foldse Unterfuchung an mef̧rert orten, wo man eine verfhiebene Erolage verimuthen Fann, vorgenommen merden. Dá foldjes bis auf bie nithige Tiefe gefdefere, verftef̧t fid) von felbft, ubrigens aber foinmt es fier nur auf bie ofonomifde Renntnif ber Erbarten an; und was man in einis gen Forffid)riften bariber für bie (Eid)enculturen von chemifden Unterfud)ungen vorid)lägt, geb̨ort gróptentl̨eils jur geleţrten Ȩ̧arlatanerie.

\section{§. 280.}

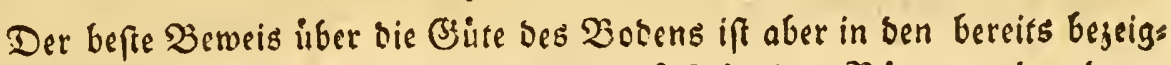
ten SBirlungen Deffilben, an Den etwa barauf ftebcenden $\mathfrak{B a}$ aumen ober beren

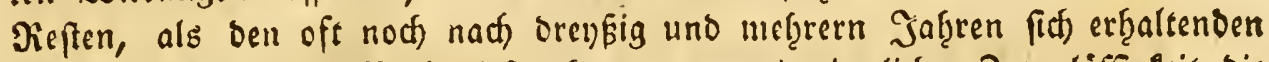
Stulen ju fuden. Nad) biefen Eann man mit jiemlid)er Suberlaffigleit bie jwecfmápigfte Eidfencultur beftimmen; jeood b̧at ber forfmann feierbey nuf alle bie, bey ben vorbzanoenen Baumen eingetretenen, gunftigen unb nact)theili: gen Nebenumftäno, und in wie fern bicfe fü bie Bufunft Statt finden mód)en, oder nid)e, fef̧r genau ju adten, babey fein llttheil in vielen Fadlen nur gerabe auf bas, was ba ift uno nid)t auf bas, was ba nod) jeyn Eonnte, cinjufdrånéen, es

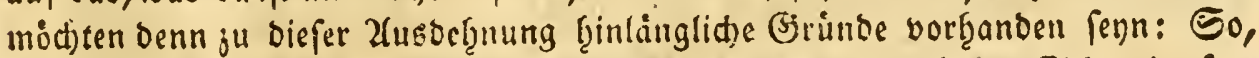

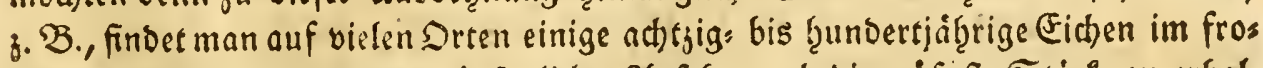

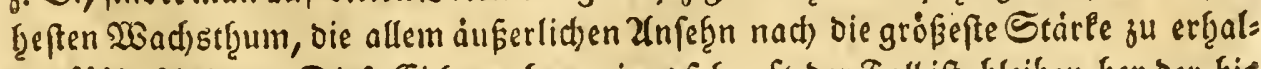
ten fäbrig fdeinen: Diefe (Eid)en aber, wies fef̧r oft ber Fall ift, bleiben bey ber bis

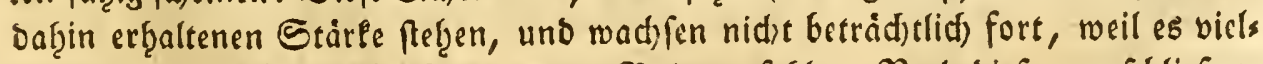

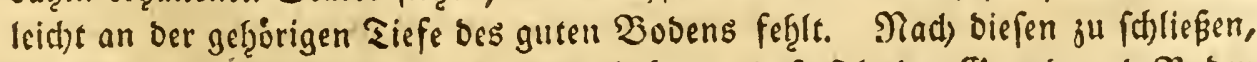
wurbe man bod) nun irrig bebauptet b̧aben, bafi fid) ber (Jiruno uno Boben jur Ergieb̨ung ber ftärften Eidben fdjicfe. Man fiefge sies vorjuglich in ben ล 2 naffen 


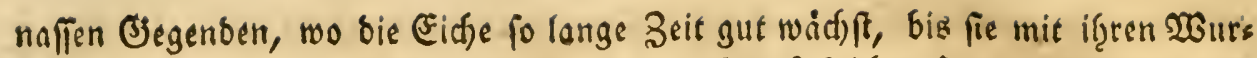

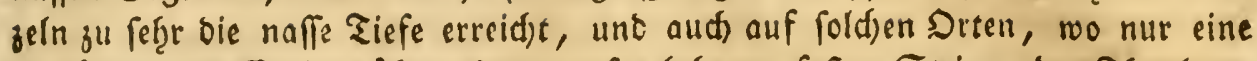
jul binne gute Erolage über einem unfructitbaren feften Steins ober Fţonlaget befindlid) ift. So fetęen im Begentleil auf vielen Drten nur furzftimmige, uns anfergnlide (Eid)en, welde oft eben fo wenig als ein Beweis angefüfret merben

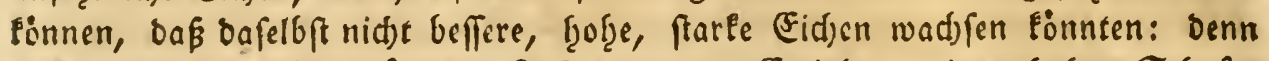

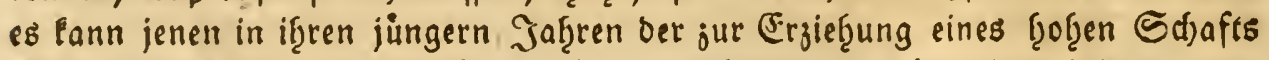

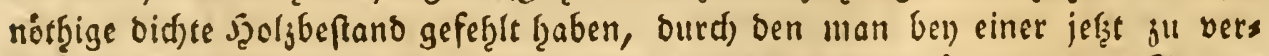

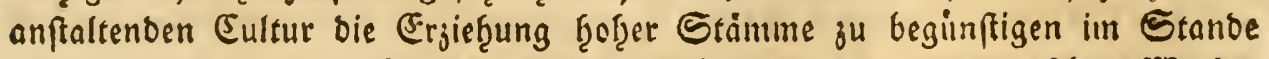

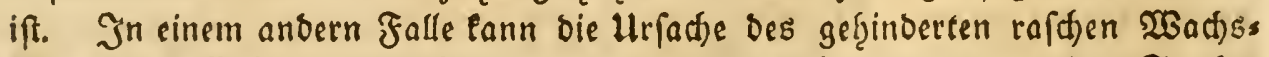
thums einer Eidfe in if̧e felbft liegen, wie man es ben oen, alls alten Studerer

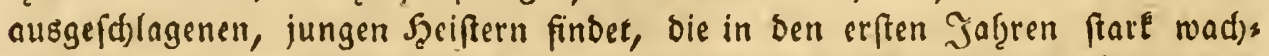

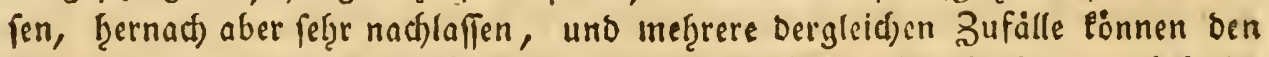

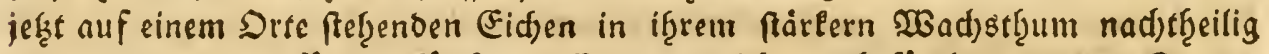
gervefen fenn, bie für bie Pünftigen Eulturen nidbt zu befürdten find. So wie

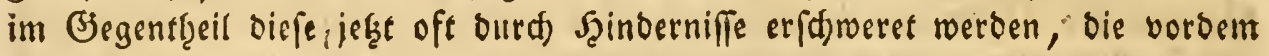
nid)t ba waren.

Da nun bereits $\$ .263$. von bem Birunve und Boben, welden bie Eidfen vorjughlid) lieben, bas notbige angefitgert worben ift: to wirb bie Msiebers trolung f̧ier vermieden.

\section{§. $28 \mathrm{r}$.}

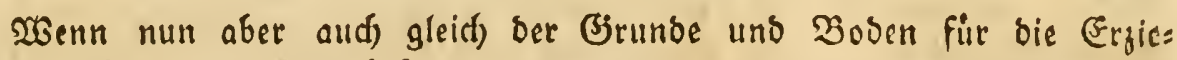
bzung ber (Fid)en (d)iffich befunden ift: fo ift ood) nod) in Şinfid)t andes

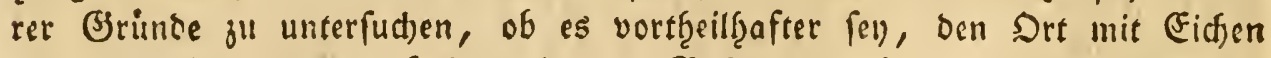
oder mit einer anbern Szoljart in ben Beftand ju fefeen; denn obfdjon bie

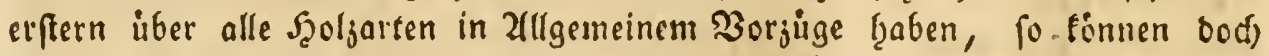

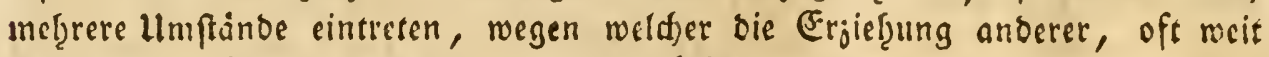
geringerer, Şoljarten ratffamer fenn modfte.

So ift zum Benfpiel oft in foldjen Begenden, wo bas 9?abelfiols in

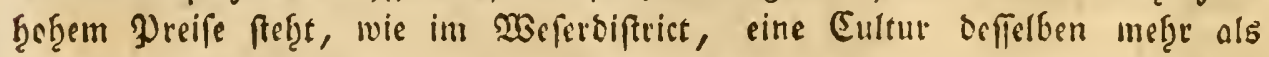

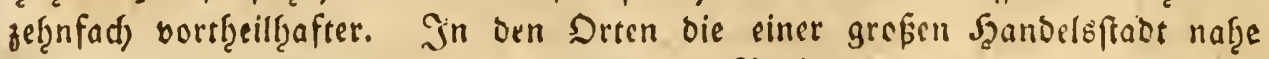

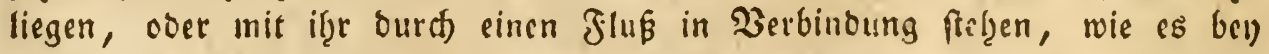

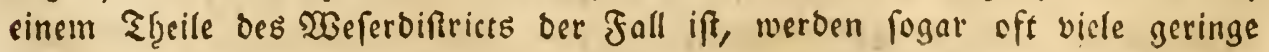
Şoljarten bis auf bie Szafeln uno Trsiten ju Banofioffen fo theuct bes

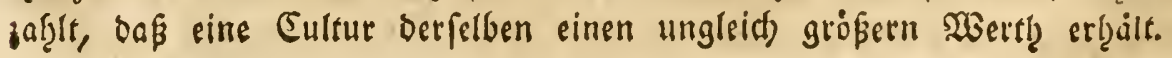




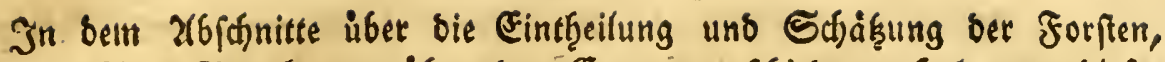

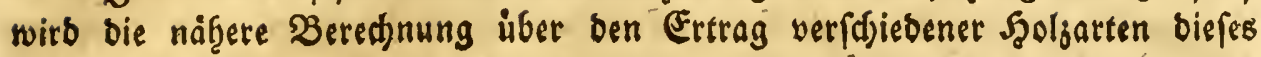
meţr etläutern.

Dod muß fich ein Forftmann auch burch biefe Britunde nifft allfeit verleiten laften, bie Eidfenergief̧ung mit wenigerm. Eifer zu-betreiben, uno nid) in jebem galle ben Ertrag einer grópern Belofiumme als Den einjig

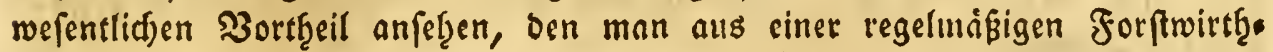
(đ)aft ermarten finne. Denn es treten vorginglich in landesterrliden uns in foldjen Forften, aus weldfen meţrere Bebirfniffe, und biefe oft in eis ner fortbauernden Reif̧e von Jaf̨en befriebigt meroen miffen, folde tlus fände ein, oaß man barin bie Forffwirthefhaft meţr nad) biefen, als auf eine fünftig grösere unt reidere baare 2(usbaiute, einjurid)ten f̧at. Unter biefe geţoren, zum Benfpiel, bie Erforderniffe des Brenn: und Nutzholzes

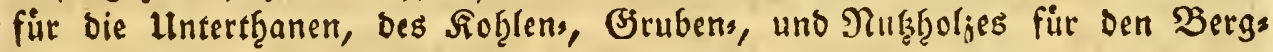
bau, verffjiebene Eoreen Şorg jur Errfaltung Der Jabrifen, und eines einmal eingefüfiten Syandels und bergleiden. Dft find aud baben ein

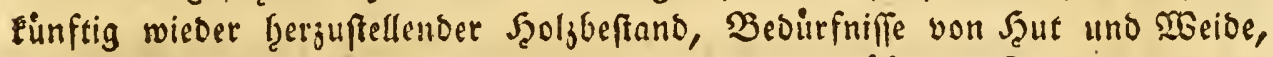
gewifie. Servituten, vortbeilfaftere Benufgung ber übrigen Jorften uno ber naf̧e babey gelegenen Nieviere, in Erwàgung jt zief̧en.

\section{§. 282.}

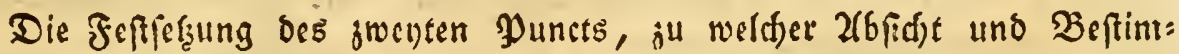
mung bie Eidjen nuf cinem Drte am vortbeilf̧afteften erjogen und benutgs

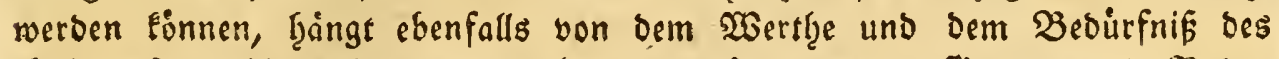
Syoljes fo woḩl, als von ber lage bes Drts, vom Grunde uno Bober beffelben, uno von viclen babey vorlommenden Nebanumftänen ab, wenr bieje Dinge zufanmmen erwogen werben: io lápt fich Darnad) mit einiget Suverläfifigerit beffinumen, weld)e 2(te Eidjen barauf am beften gejogen wers

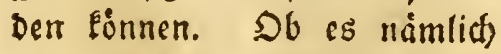

1) bortheilf̧after uno forfmáfig móglid fen, auf cinem Orte grofe ftarle Eidten ju Milfilenwelter, jum Echiffbau, und ju folchen Besirfnifs

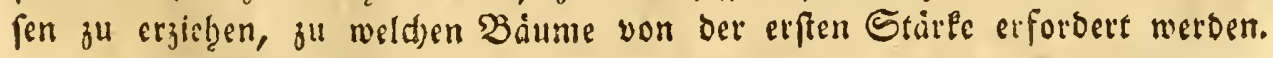

2) Doer os man barauf nur (Fid)en von Der Bróse ergief̧en folle,

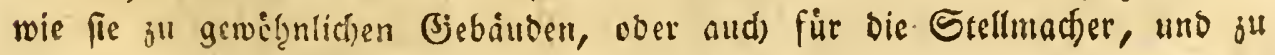
Derglitiden geringern Boburfniffen notgig fino. 
3) $D 6$ es vortfeillyaft fen, bie Eidsen als Srenn: uno Siof̨lf̨ols ju benufien, aud) in weld)em Falle es als jef̧n. bis funfjeftns ober aud) als brenfigs bis vierjigjäbriges Sdlagloly gezogen merbe, woben benn eine cinfache oder boppelte Wirthichaft Statt finoet, nach meld)er entweber auf einem Drte nut eine Şoljart, wie jum $\mathfrak{B e n f p i e l ~ n u r ~ f u n f z e ̨ ̧ n j a ̊ g r i g e s ~}$ Sd)lagholy aflein, ober mit biefem aud) nods grofere àltere Băume, ober aud Eidfen, Bid)en, und meţrere Şoljarten unter cinander jugleid, erjogen werden.

\section{§. 283.}

Die Beftimmung oes britten Puncts: SHelde von ben benannten Eulturarten auf einem gerwifien Drte am zrectmógigften fev, gefdief̨t ebens falls nach obigen 23orausferiungen, inbem siefe fid fo mob̧l nach ber vors

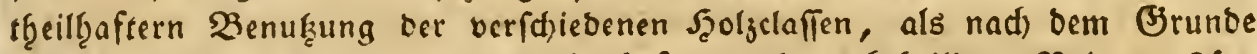

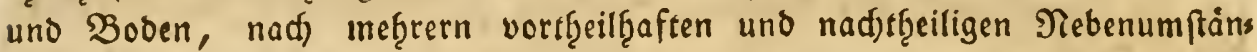
ben, uno nad bem grofern und geringern Wertte bes ju erjieb̨enden Sgols jes richten mub.

Diefe ferner mun genauer ou beftimmenbe Punlte find biberf̨aupt uns ter einattoer gemeinf(d)aftlich berbunden, und fönnen nid)t mob̨l getrennt in einer gewiffen fiftermatifden Dronung einjeln vorgetragen werben, of̧ne bas ben vicle roeitläuftige Wieberf̧olungen fll begefren; fie follen alfo gemeins fhaftlid ber Gegenftand bes Folgenoen feyn, uno unter ben verfádebenen Heberfariften abgeb̨anbelt werben.

\section{§. 284 .}

Bolt ber natirliden Ergiebung ber Fidfen in ben

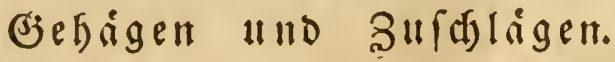

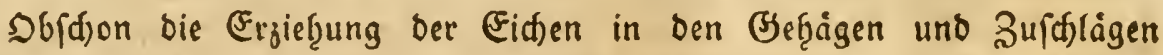
als bie natirtichfte uno midtigfte Ergiefrungsart berfelben fier vorguglid

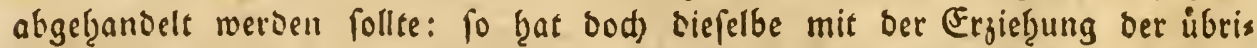
gen Seoljarten ju vieles gemein, uno ba fie mit ber Forftrirthfafaft übers baupt in fef̧r enger Serbinoung ftef̨t, to wiro fold)e, um alle unnotbige Wiederf̧olungen fu vermeiben, bequemer in bem zwenten Theile, in bem

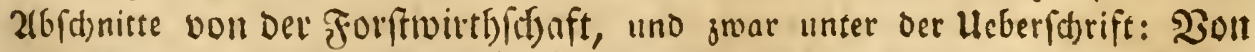

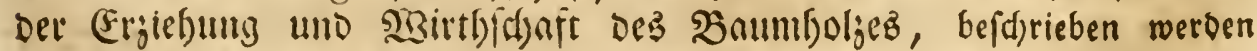
Ponnen, wo Der geneigle efjer bas $23 e f e n c l i d e$ bavon finden wirb. 


\section{§. 285 . \\ Bon Der Éluftiden Ergiebung ber Eiden Dura Die Berpflangung.}

Die Natur ennt Eein $\mathfrak{B}$ erpflanjen ber Băume yon einem Drte auf Den anbern, benn fie láft foldhe nur ba aufmad) jen, mobin oer Saamen gefallen

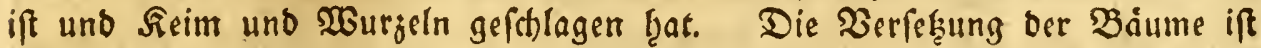
alfo eine wibernaturlidfe Şandlung und erforbert daf̧er eine befondere $\mathfrak{B o r f i d}) t$ uno 2(d)tfameeit, wenn ber verfégte Baum baben nidte zu fegre leiben, uno in feiner $\mathfrak{B e g e t a t i o n}$ nidjt jul lange Beit geftort werben foll.

\section{§. 286.}

Der veränderte Stand bes Baums, in Rủffidt auf ben (jrund und Bos

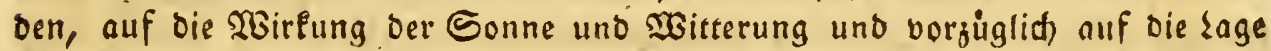

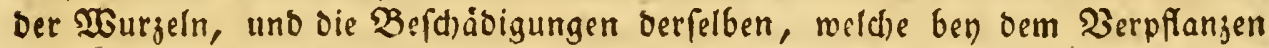
faft unmóglich ganj verb̧utet merden Eonnen, uno oft fo gar bey beir gróbeften

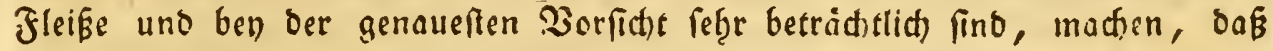

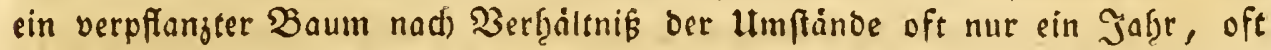
meferere Jaf̧re, oft aber aud) fo lange er eriftirt, meḩr ober meniger Erant ift,

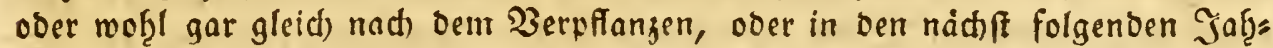
ren vertrodnet. Berfdictene bierben vorkummente miorige coer güftige llums

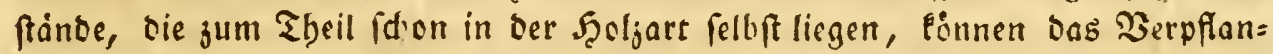

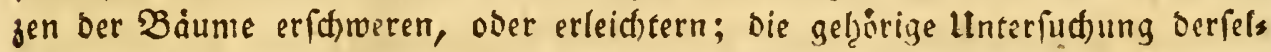
ben muf es bafeer beftimmen, in nie weit wir biefe an fid) widernatürlidje Şands lung bey unfern forftulturen nufslich anwenden fönnen oder nidts.

\section{§. 287.}

Ben ber Eidfe findet bas 3 erpflanzen in ber Forftwirthiffaft, befonter

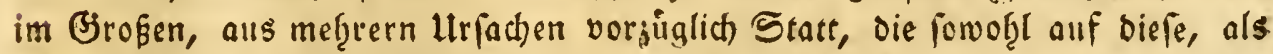
auth auf bie gute (Eigenidjaft, bafs biefe Banmart fidh leidher, wie viele andere

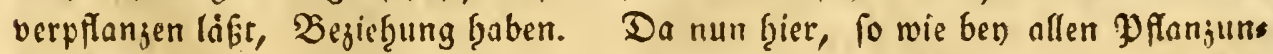
gen uberbaupt, ber mef̧r ober weniger gute Erfolg fo wob̧l von ben natirlid)ent

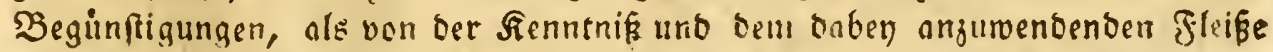

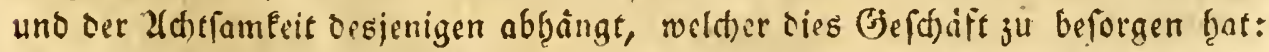

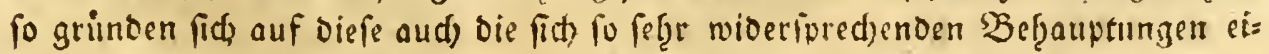

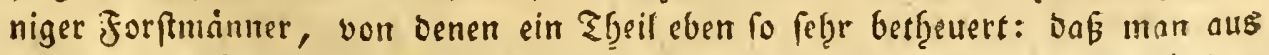

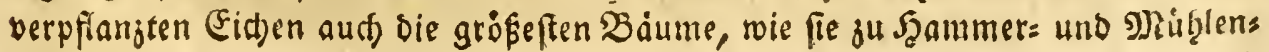
wels 


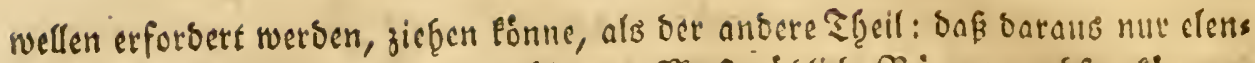

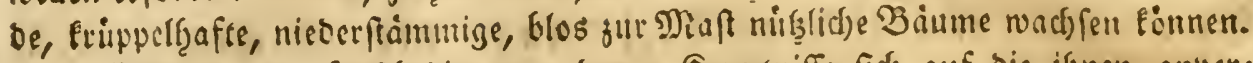

Einigen $\mathfrak{l n t e r f o r f t b}$ bienten, beren Sicnutniffe fid) allf bie ifrnen anvers traueten, oft für bie Eidjentultur wenis paffenden Forftrebiere befdyranfen, ift

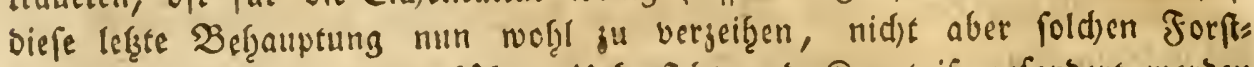
mänern, von benen cine goblere Hleberfidjt und Senntnís geforbert werben

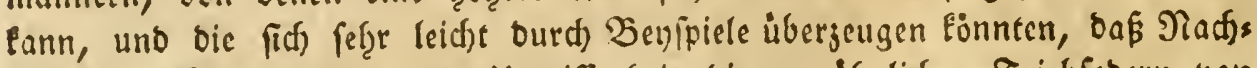

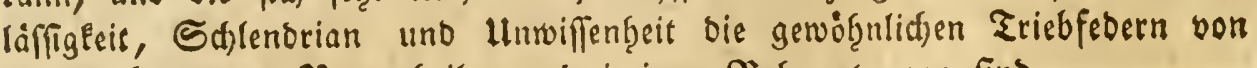
folden bequemen 3orurtgeilen uno irrigen Befgauptungen finb.

\section{§. 288.}

Fir bie Tef̧te Bef̧auptung, fo wie fitr alle gegrundefe Borutţeile biefer 2(rt, finten fid) freilid) leiber! in allen ḩecfigen Forften nutr fu viile

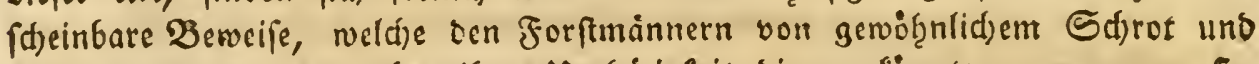

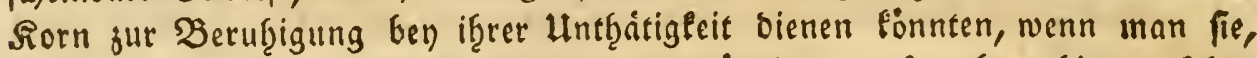
of̣ne fie einer genautern 2(d)tfamleit fu roirbigen, fo oben fin anfehen wollte:- bey einer naifern ilnterfudtung aber werben biefe gerabe bas Jes

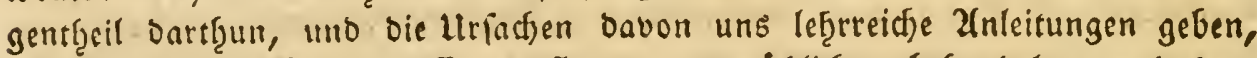

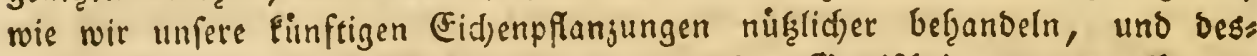

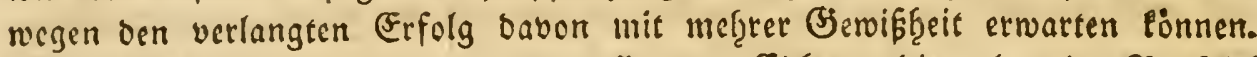
Man benle fids nur fiatt einer verpflanjten (Eidje, bie als ein Benfpiet gegen bie Berpflanjung aufgeftellet vito, auf bemfelben Srte eine aus bem Eaamen aufgewacisfene, weldje, außjer bem Serpflanjen, alle bie wibrigen

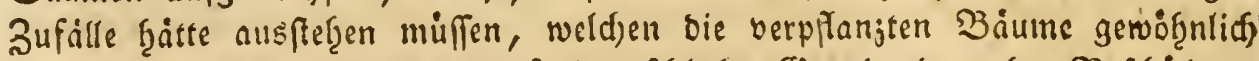

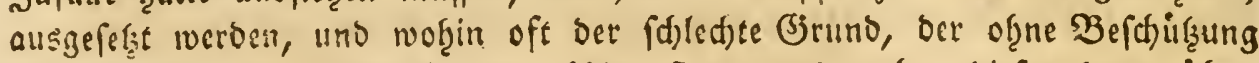
freie Stano, uno bergleidjen zu zäblen fino, uno redsne biefen bann übers sies nod) bie bey bem $\mathfrak{3 e r p f l a n g e n ~ v o r g e f a l l e n e n ~ M i s t r a n o l u n g e n ~ j u ~ g u t e , ~}$

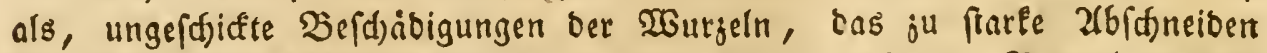
ber 2lefte, und abtopfen bes Stammes, Die in mefirerm Setrad)t wibers naturlide 2fuswabl bes yplinglings, bie fadablidfen Dinge, bie biefem ben einer nut fu gewoig̨nlidjen Tad)láffigleit in ben erften Jaf̧ren nad) ber 3erpflanzung ju begegnen pfiegen, und bergleidjen mefgr: fo wirb man fid

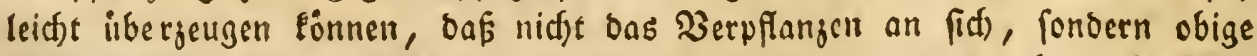

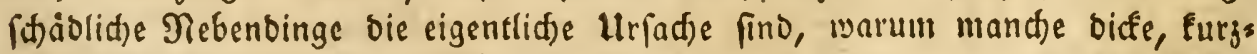

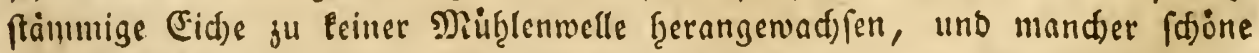
junge Szeifer alfo blos burd) wiorige Bef̧andung benum $\mathfrak{B}$ erpflangen vers Prippelt ober gar rertrecfinet ift. 
Zuf vielen Drten, wo roga: nativitife Şinberniffe bie Ergief̧ung bee

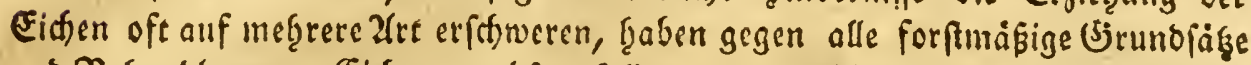
und Befgandlungen, (Fid)en wadjen follen, von welden bie gegen bas $\mathfrak{B e r}=$ pflanzen eingenommenen Forfminner alfo Wunterbinge vetlangt baben, uno bie fie folglid feģe ungered)t jum Dewsife if̧eer unbilligen Meinung anfüh̨ren.

$$
\text { §. } 289 .
$$

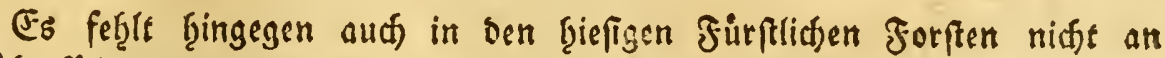

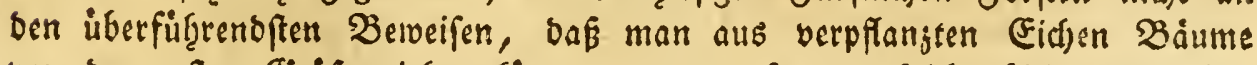
bon ber erften Brófe jief̧en Eonne; nur muß man foldje billig ba auffus chen, wo biefe mit ben unerpilanzten $\mathfrak{B}$ aiumen gleidhe Beginftigungen ges noffen baben, mit benen fie verglidjen werben follen. Selbft aus ben äls tern Beiten finden fid fiervon in ben Forften bes Sollingg, und in ein: gen Drten bes Shilsteviers bereits ausgewadsfolte Mithfienwellen ber erften Gjute und Bróke, an welchen man Das 3 erpflanjen nidjt verkennen Pann. Ilno fef̧r viele jüngete Pllanjungen bafelbft jeigen uns bie zuverláfighte

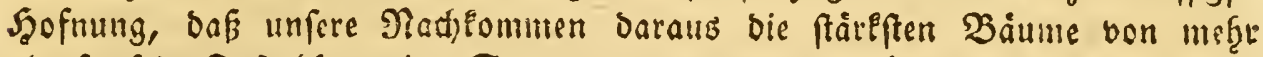
als funfoig fus sänge im Stamme werben nuf̧en fönnen. Sa) ratge es

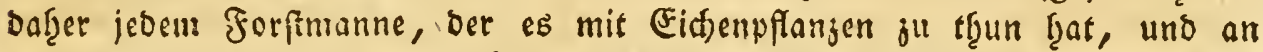

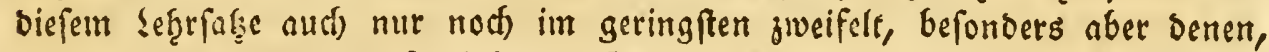
weld)e in oen meniger frudtebaren Begenden ber biefirgen uno angrengenden

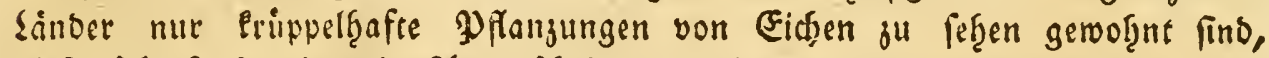
biefe Dberforftreviste in Zlugenfechein zu nef̧nen, und zwar unit beut feften Berfprecten, baßs fie gewiś von ber Suberläffigleit beffelben werben über. jeugt werden; an we!dfer llebergeugung oft füt bas gute Bierathen einer Pflangung fo feber viel gelegen ift.

\section{§. 290.}

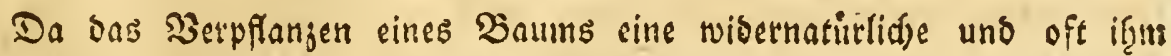

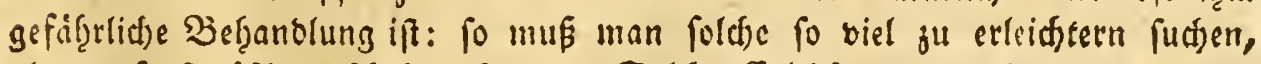

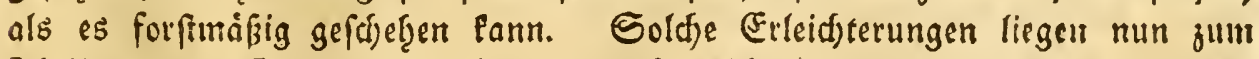
Theil ill bem Brunde und Boben, auf welden gepflanjt werben foll, uns in bem ju verpflangenden Stamme felbft, oder in ber dabey anjuwendenden Bef̧andlung und in ben fonftigen Sairfsmitteln. 


\section{§. 291 .}

Wenn ber Brund auf bem zu bepflanjenden Drte ben Eiden vorjüglids

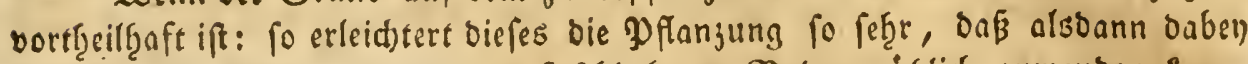

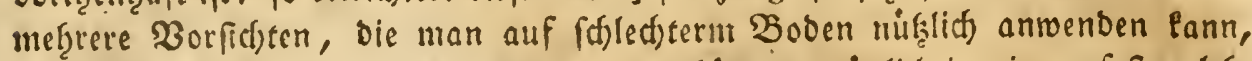

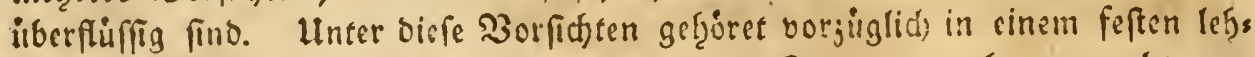

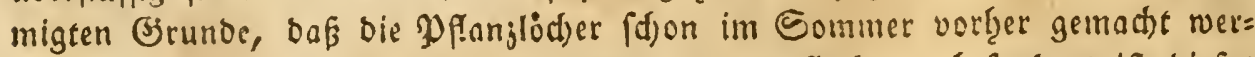
ben, Damit bie (Erbe fid) meţr burd)liege und aufoctere; befonders ift biefes

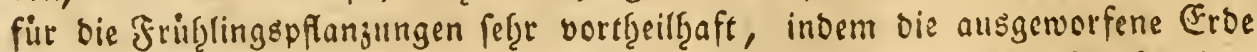

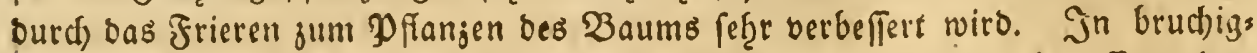

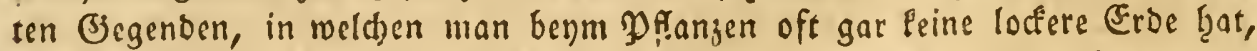

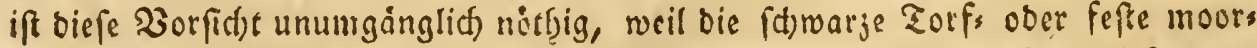
artige (Erbe nad) bem Frieren in feine PPlanjenerbe gerfällt; bod) if biefes nur firr bie barin paffenden Szolzarten zu verferten, indem bie (Fid)en eigentlich) nidfit in bergleidsen Soben gepflanzt werben follten. Sn feudseen uno naflem Dos

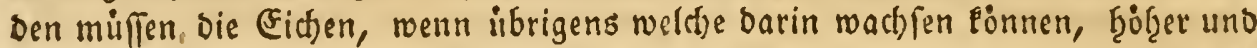
oft nad) ben Ulmftänoen in aufgeworfene Şigel gepflanjt weroen, wie fold)es in

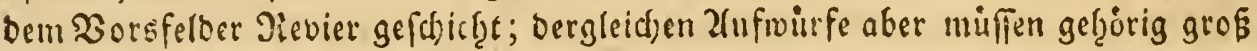
gemacht, uno feffgetreten werben, weil fie fonft im Sommer fefre fart ausjus trocinen pflegen und ber Pflingling barin nid)t gef̧örig feffftefen wirbe. Man

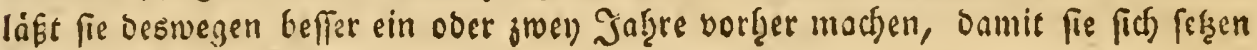
und burdjlirgen Eonnen.

\section{292.}

Die Berpflanzungselfeidferungen, weldje in bem Stamme felfit liegon,

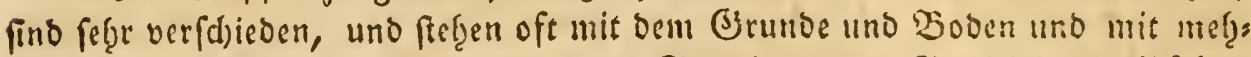

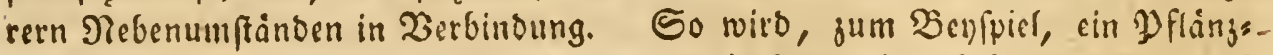
ling, welder in feudferem Boden gejogen ift, leidfere fid auf fenchten, als auf troffenen $\mathfrak{B o b e n}$ verpflanjes laiten, unb einer in ben wärmern Tybilern gejos

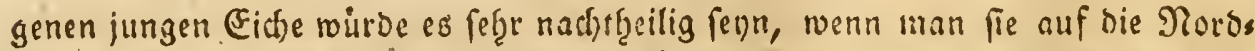
feite ber Päfern Gjebirge planjen wollte, weil in benden fällen ber $\mathfrak{B} a u m$ feine 3egetationsart umainoern muk, weld)es denn audf bey Den PPfanzen, fo wie

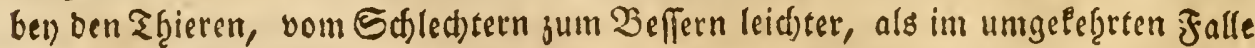
gefdief̧t. Es wirb Daher ein auf mittelmágigem Booen gejogener Pflanjling fid) in frudstbarerin Boben beffer, als ein foldfer befinben, ber alls einem fetten Boden in cinen magern gepflanjt wirt.

Eine (Eid)e aus bent Biebirge läpt fíd ontzer auth gut in bie warmen Sands

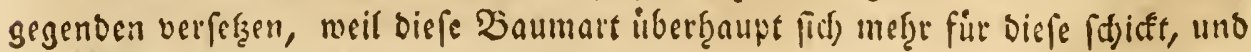


barin zu gröperter Stärle gelanget; im entgegengefergten Falle aber wirb eine

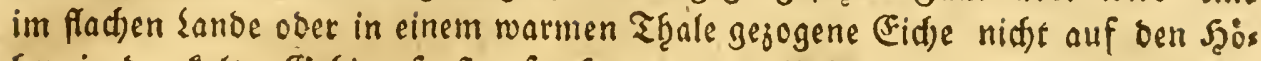
fen in ben ealten Sebirgsforfen fortlommen, weil fie barin nidft gegen bie lals ten 2 inde gefdujųt ftę̧t.

\section{§. 293.}

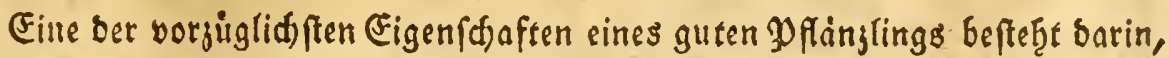

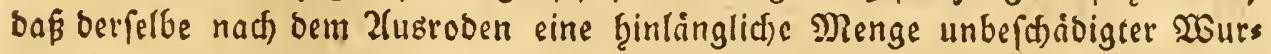

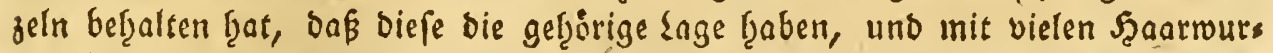

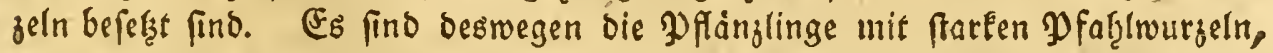
- bee mit cinjelnen nur an einer Seite berausgewad) fenen farfen ఇebenmurgeln

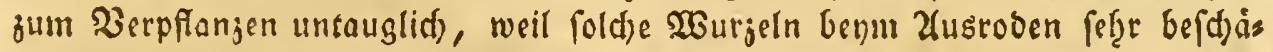
bigt uno gewoig̨nlid) faft ganj abgeţauen werben múfen.

Dergleidhen ftarle Şauptrourzeln b̧aben aud naţe am Stamm nur menige

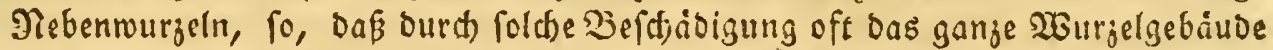

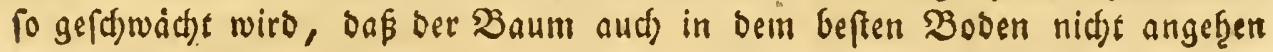
lann.

\section{§. 294 .}

Der Stamm cines Prlanj̧eifters muś jung, gerabe, gefund, unbejdjàs bigt, ftämmigt, nid)t ju lang uno nidfs ju fdjwanfend fenn; alle Erumme, vers

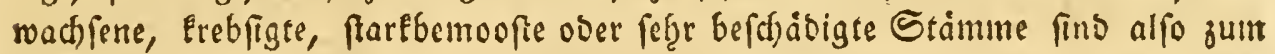
3erpfangen ju verwerfen, weil baburd) bas ifgnen bereits eigene Hebel nur nod inebr verfd)limmert werben mübe. Die ju langen, fdywantenden Stamme,

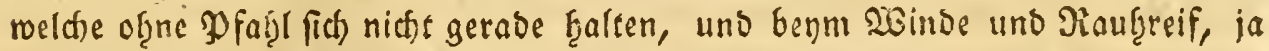

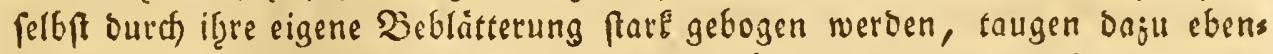
falls nid)t. Bor allem aber mus man fich giiten, alte, vermaaferte, unters

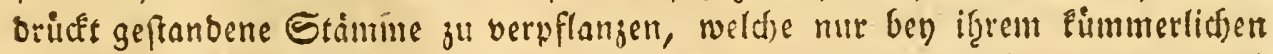

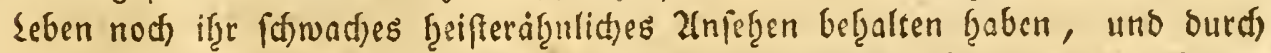

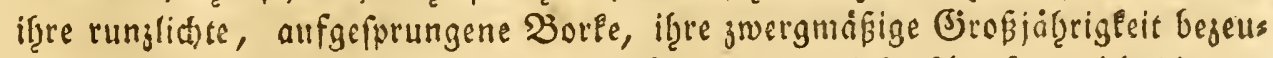
gen. Sum Beyfpiel von unfinnigen \$ftanjungen biefer 2tre Eann id bie ans

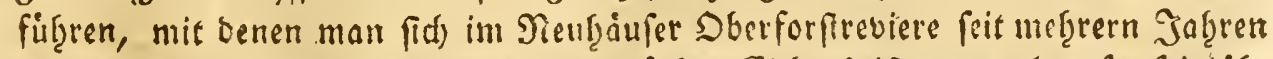

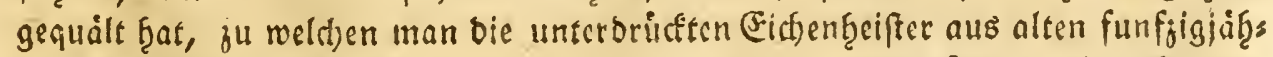
rigen Zufthligen genommen, uno, weil fie oben und unten faft gleidh biff, uno iuber brengig Jue lang find, auf bie Szalfte abgeţauen, uno dann in ben bortis

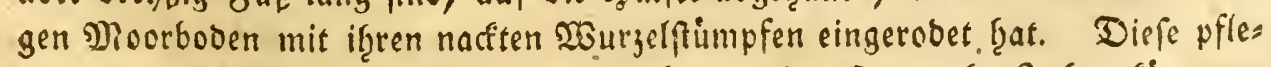
gen alsbann, wenn fie nidft gleid) vertroffinen, bie erftern obef̧n Jaf̧re fimmers 


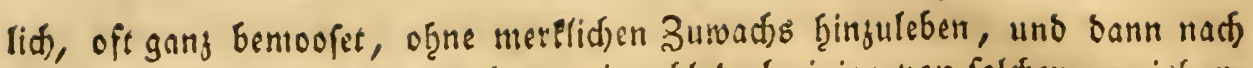
uno nad) gróftentf̧eils ju vergetren, wienofel bod) sinige von folden gemishans

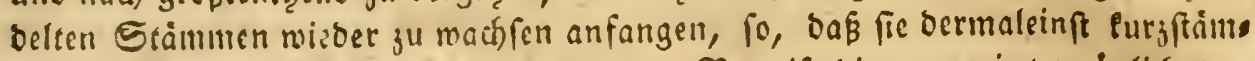

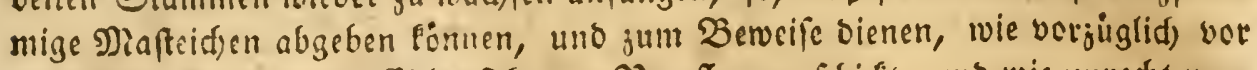

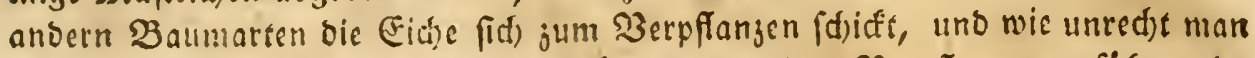

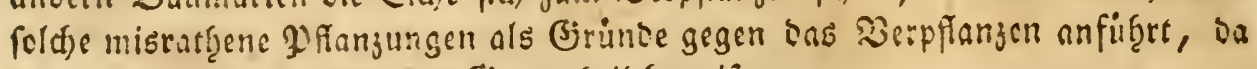
fie bod) cigentlid) geraoe bas biegentf̧eil berweijen.

\section{§. 295.}

Zllen Forftbebienten, uno nllen, weltise fich mit Baumplongen abgeben, mú́ bie genauere llnterfudfung ber erforderliden (Figenfdiften eines Dfling:

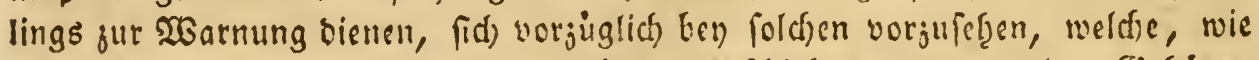

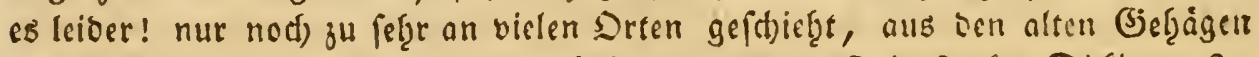
und Bufthlagen genommen werben, befonders, wenn fie in ftarken Diffigten fies

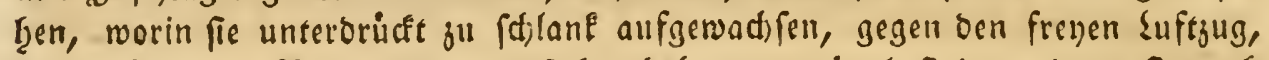

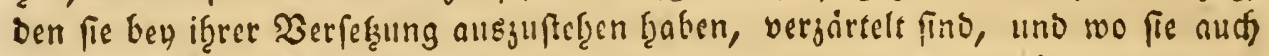

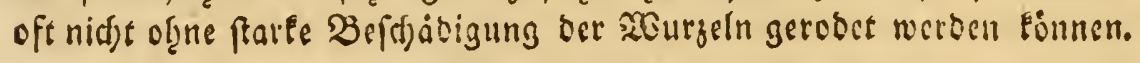

\section{§. 296.}

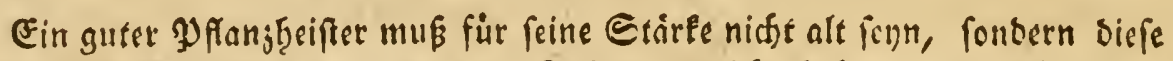

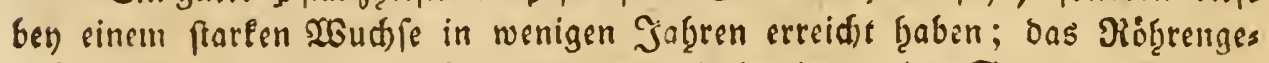
webe beffelben ift alsoann offen, weniger, als in cinem alten Stamme, verf̧olzt,

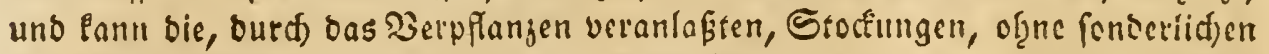
Naththeil iberfteten. Dafingegen ift bas $\mathfrak{B e r p f l a n j e n ~ o e n ~ a l t e n , ~ a u f ~ m a g e s ~}$

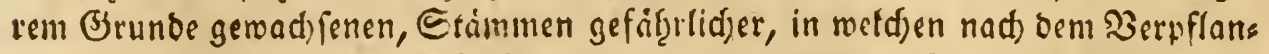
zen burd) bie Stoffung bes Safts bie naţe am mittelften Marf liegenten Şoljs

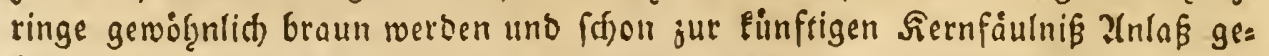
ben; wie man foldfes ben oen altell mager geftandenen Stämmen in einigen Jaḩren nadj bem 3 erpflanjen betjelben beiterken Eann.

\section{§. 297.}

Nad) ben verfdiebenen 2 (bficheen bey siner $\mathfrak{P}$ flangung Pann man bie Etäre ber $\mathfrak{P} f l a ̈ n j l i n g e$ beftimmen. Die fräreften yon ob̨ngefel̨r jef̧n bis funfs

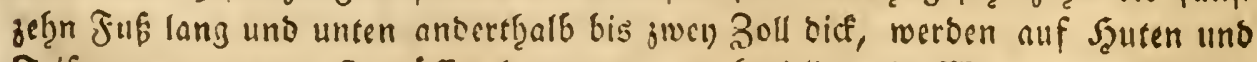
Triften genemunen; fie milfen beswegen gute freitliegende SOUtrefn fiaben, bas mit fie befto fefter frefen, und gefdjwinder anwadjen fönnen. Die geringere 


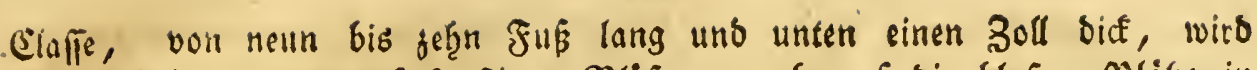
ou ben Yflanjungen auf fonfigen Blösen, auds auf bie bloken Pläke in

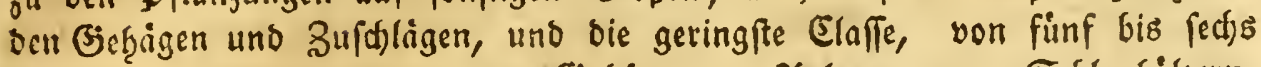

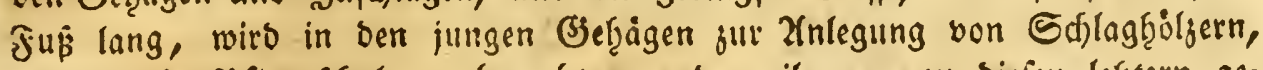
uno in bie Pflamjfhulcn getraudft, uno weil man zu biefen lefetern ges

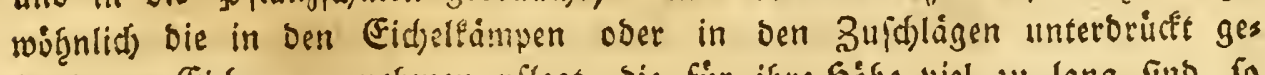

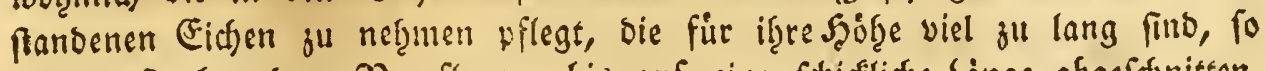

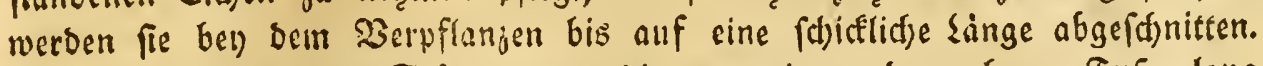
Ben grofen ftarlen Stámmen, die jwanjig und meţrere Jus lang und am Stamme iber brey Soll bic fins, ift bas Berpflanjen Peinesweges

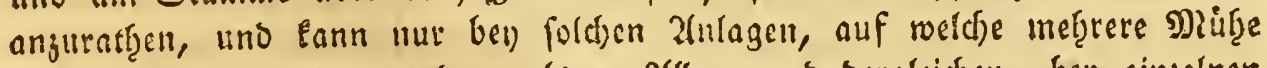
unb Foften verwenbet werben, als ju Zlllecn und bergleithen, ben einjelnen

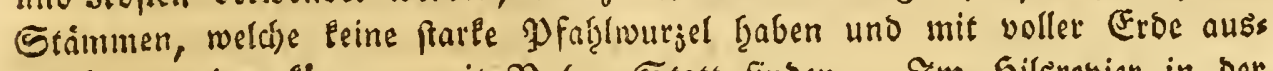
geţoben werben fonnen, mit Nukzen Statt finben. Sm Shilsrevier in ber

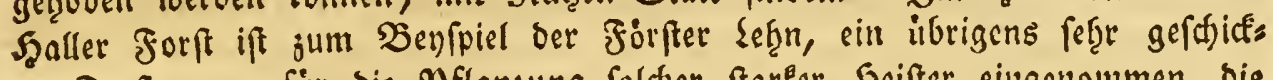

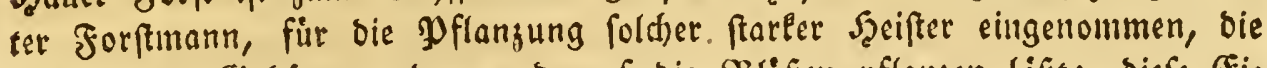

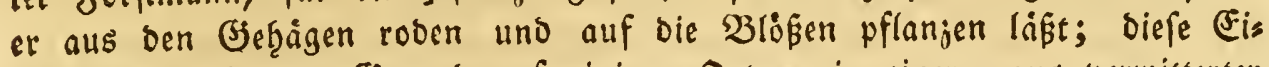
d)en, weld)e in oer biegeno auf einigen Drten, in einer, aus verwitterter Fale, Mergel: und guter Y Plangenerbe entfandenen, fladfliegenden Damms

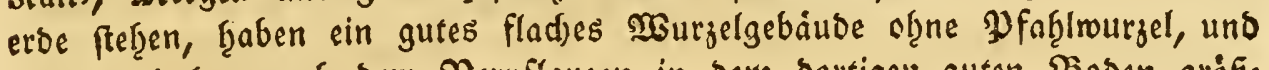

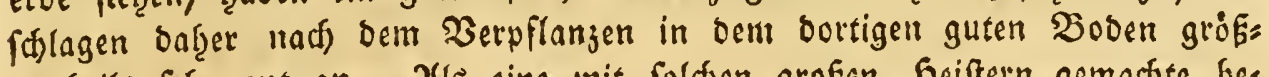
tentheils feb̨r gut an. Zlls eine init fold)en grofen freiftern gemadite bes

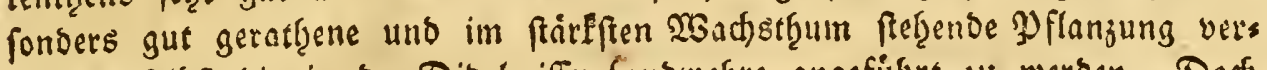
bient bafelbft bie in ber Dibelmifler \{anoweţre angefübrt ju werben. Dod) ift biefe 2art ou pflanjen feţr befdnerlid, und allenfalls nutr mit vollen

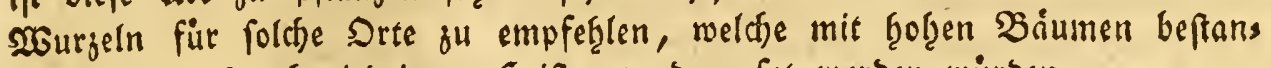
ben find, woburd) niebrigere Şeifter verbumpfet werben wurben.

\section{§. 298.}

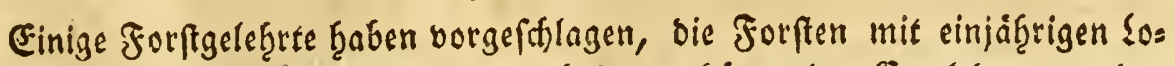
Den, bie mit voller Erbe fammt ifgren nod Daran ţängenden Eotylebonen, ober Sernftucten, aufgenomumen werben follen, ju bepflanzen, wovon mail aber fdwerlid) einen guten Erfolg erwarten Eann, fo fefre fie aud) biefe Pflanjungss art burd theoretifate Birinde empferten.

Hum hin und wieber in ben Forftorten eine geringe Blofe bamit auszubefs ferm, mag biefe Spicleren mit einigem Nukzen angewendet werden Ënnen, bie im (stopen aber nidjt Statt findet, weif folde junge loben bod) allen wiorigen 


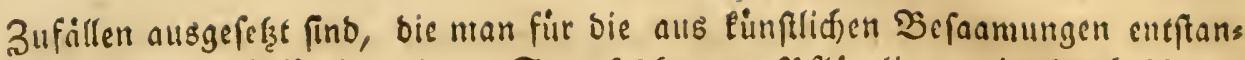
benen Soben ju befürdften ţat. Statt fold)e zarte Pflänglinge mit aller befthwers lidten 3 orfid)t aufjunef̨umen uno einzupflanzen, Pann man fie weit leidjter uno fuverlaffïger burd) Die Befaamung felbit erziefren.

Das ibrige hiervon, uns wie man fí) gute Pflanz̧̧eifter verifaffen

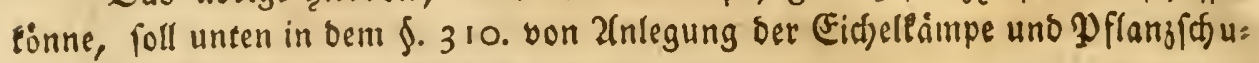
Ien ausfü̧̨rlider gefagt werben.

\section{§. 299.}

Das Berpflangen ber Baiume gefdief̧t gu ber Zeit am beften, mann bie Siegetation berfelben gering ift; alfo vom 2lbfallen ber $\mathfrak{B l a f t e r , ~ b i s ~ z u m ~ f t a r s ~}$ eern Frülitingstriebe, wann bie Sinofpen merflid) bicfer zu werben anfangen.

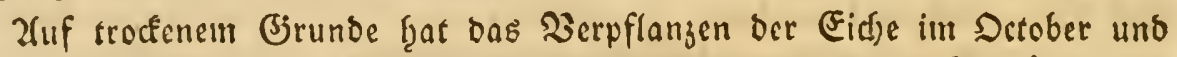
November, befonders im Broken um . Beit ju gewinnen, einige 201 jige; nut

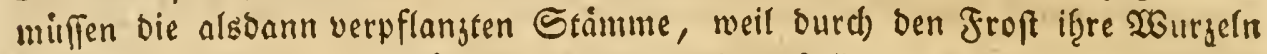
aufgeţoben werben, im Frủhjaf̧r wieber gerabe geftellet, uno angetreten werben.

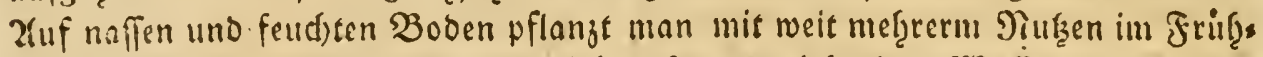

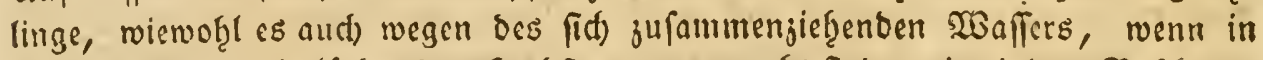

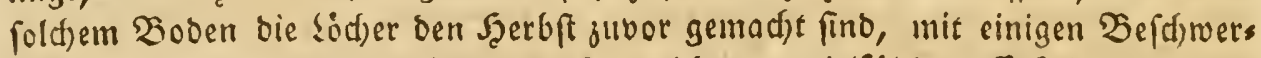
niffen verbunden ift. Uleberb̧aupt eann id) aus vielfältiger Erfab̨rung verfis d)ern, Daf fiur bie Pflanzungen in ben Forften, und befonders fiur bie Eis d)enpflanzungen, ber februar und Mairg bie befte Beit fev, nur wirb man bes fonders in Den fältern (Sebirgegegenden voin Frofte, und Durch bie bernach) ju

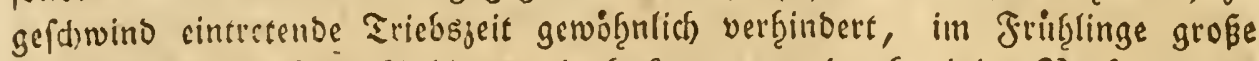
DJilanjungen ju berverffelligen, bod) Pann man burd) einige 3orforge uno 3orarbeiten folche fdjon im voraus fef̧re erleidfern. 2(m renigften aber ift bas Eidenuplanzen in ber lejten Şalffe bes Decembers ober im Senner anjuratgen, weil in oer Beit oie $\mathfrak{Z}$ egetation 34 geringe ift uno bie feinen Saarmuryeln nact)

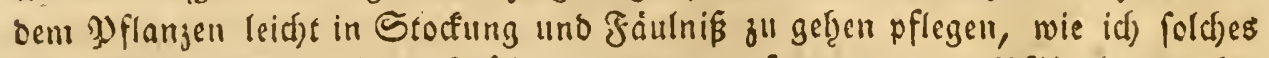
ben mefreern in nadjpten frifgling wieber aufgenommenen poflinglingen bes merit haabe.

\section{§. 300.}

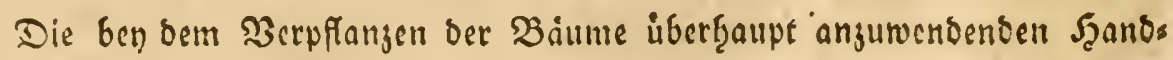
griffe uno Sciulfsinittel find folgende:

1) bey Der Zlusrodung bes Pplänjlings muiffen, fo viel als moglidf, bie

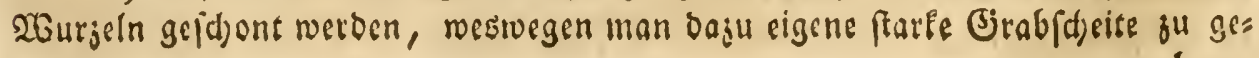
braus 


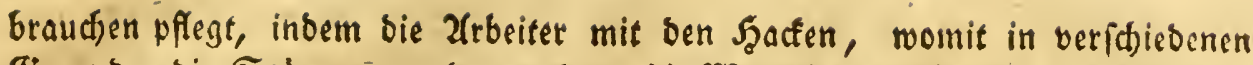

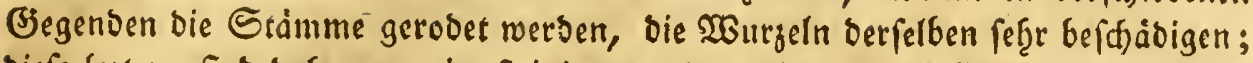
biefe lejtern find baber nur in fteinigtem ober mit grofen 2 burjeln Durchjoge:

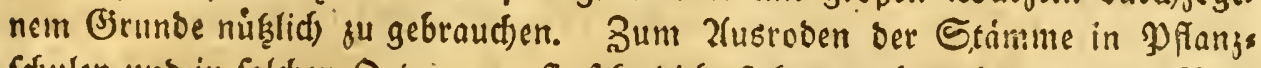

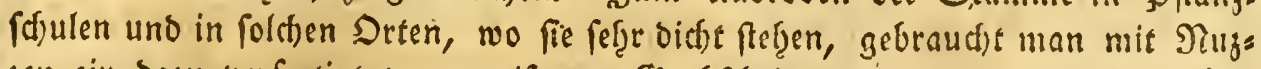

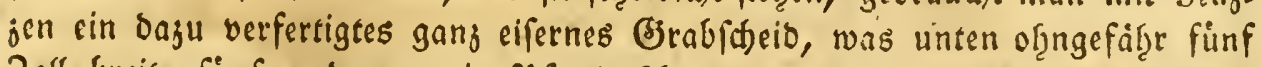

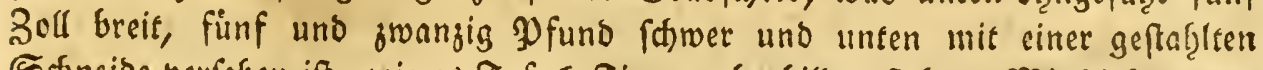

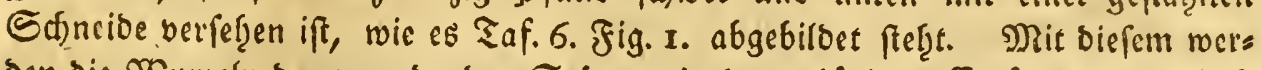

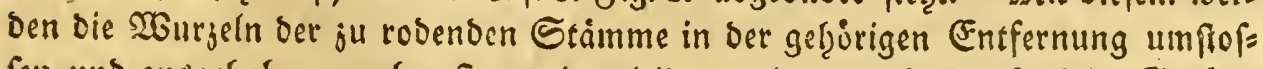
fen uno auggelgoben, wobey fie weniger leiben, als wenn fie ourch vieles (Jraben uno Biegen verborben uno befonbers bie Jinsen berfelben abgefdunben werben.

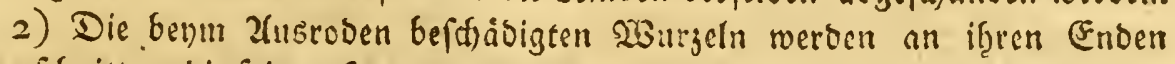
glatt gefduitten, bie feinen Sgarrourjeln aber babed foviel, als moglid), gefdont.

3) Zon ben Zeften uno Zrosigen wirb oer gef̧orige Theil ebenfalls abges fdiniten, weldes bevbes in bet Folge weitleinftiger befchrieben werben foll.

4) So viel als móglid, ift bey jober Pflangung bafitr ju forgen, bak die Pflänjtinge nid)t ju lange Beit anffet ber Erbe bleiben, befonders aber, baf indeffen bie suft und Sonne bic feinern $2 u r j e l n$ nid)t austrocfne, obet aud), baf ber Siegen bie feinere (Froe nn benfelben nid)t ganj abipuble. Man fudft Dafere bey grofen Pflanjungen bie gerobeten Gtämme eingufálagen, und nidje mef̧r roben ju laffen, als man benfelben Sag wieber einpflanjen laun; and ift

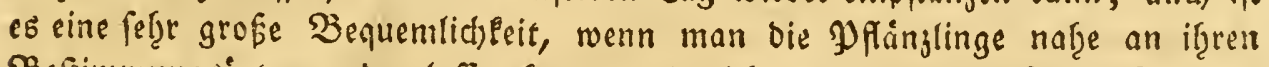
Beftimmungsorfern roden laffen eann, uno niche erft, wie es oft Der Falf iff,

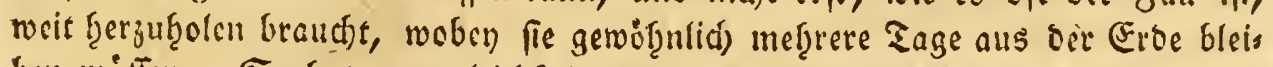
ben millen. So bzat man gleid)falls ju forgen, bak bie 2 Surgein an ben gero,

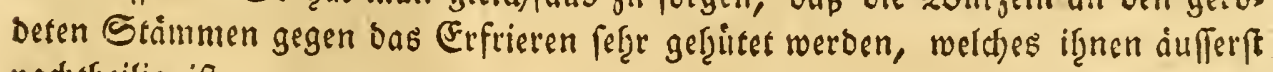
nad)etreilig ift.

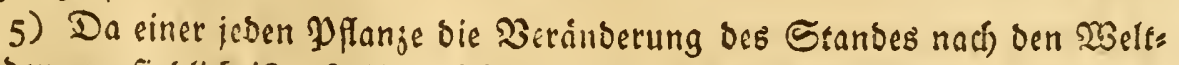

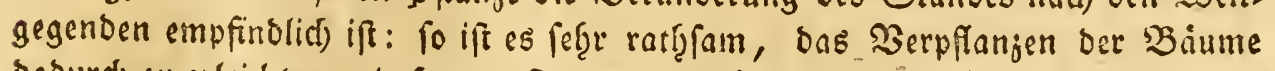
baburd) ful erleidtern, cáp man fie vor bem 2(usroben, nad einer beftimmten

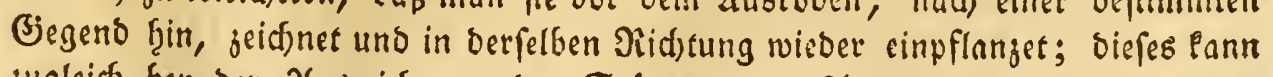

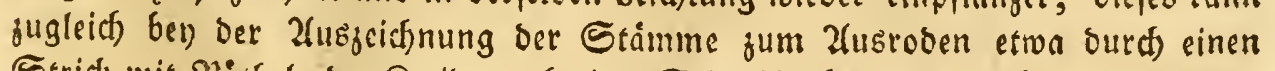
Stric) mit Mothel ober Ireibe nad ciner Srite bin, bequem mit beforgt merben.

6) Bey ber Einfef̧ung ofs Pfläjlings ift vorgiglid) satauf ju feţen, bab

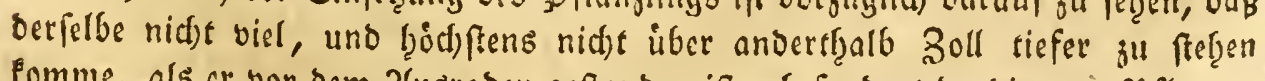
fomme, als cr vor bem 2fusroben geftanden ift; befonders ba die jum plangen

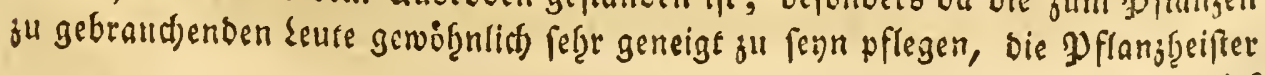




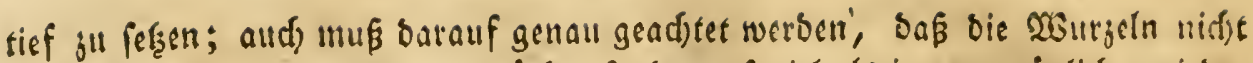
in einen Slumpen jufammengebrucft, fondern, foviel als immer miglid), wieber in bie ifnen naturlid)e sage gebrad)t werben, fo, baf bie bajwifdenfallende loctere Erbe, alle Swifhenröume ausfillen lonne, unb jebe ftarfere Wurgel in ber Erbe einjeln liege, in roeld)er abfidgt man ben Stanm wäbreno ber Seit, baß bie loctere Eroe auf die Murjeln geroorfen wirb, einigemal auf und nieber fduttelt, uno bann erft mit Dem Jupe in ber Entfernung von bren bis viet Sollen vom Stamme ab, befrutfaum antritt.

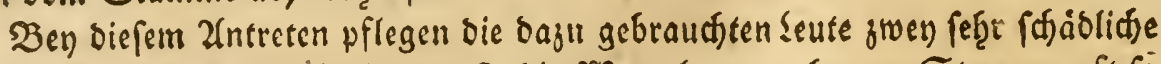
Fef̧ler zu begeţen, einmal, inoem fie bie sourgeln ju nabe aut Stamme of to antreten, baßj bie an benfelben befindiden feinen Şaarwum jeln babon abgeriffen werben; befonbers, wenn bie untere locfere (Etbe babev feht. nachgiebt, wobon man fich überzengt, wenn ein eingefefęter Stamm etwa gleid) mieher auggeb̧oben wirb; uno zwentens, inben fie bie Erbe in einem feften Brunbe uberf̨aupt mit

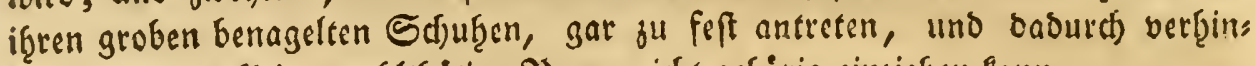

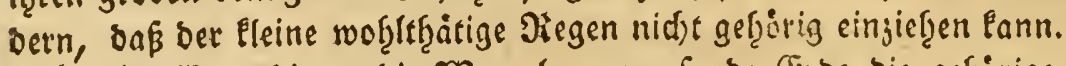

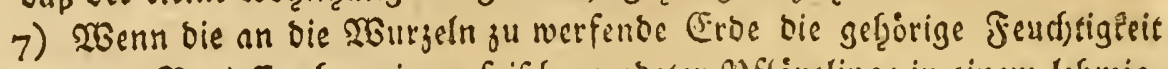
hat, fo ift bas Begieffen bey einem frifá) gerobesen W flinglinge in einem lef̧migs

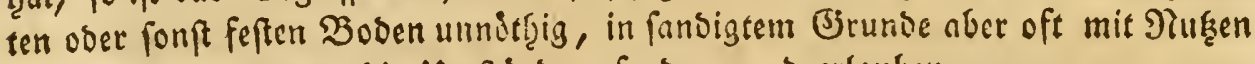
anjumenden, renn es bic limftinde eiforbern uno erlauben.

8) Das von einigen Forfminnern fo fef̧r angetriefene Finfolámmen ber Pflänlinge, wobey in die Wf!enjlodser fo viel Waffer gegeffen werben foll, baß bie locfere Eroe gleidfam ju Bren wiro, uno fo um bie Ņurjelnifliefen

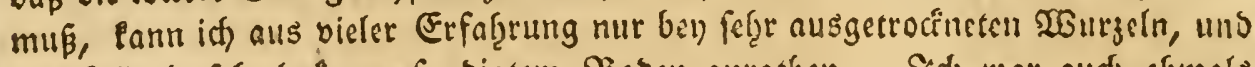

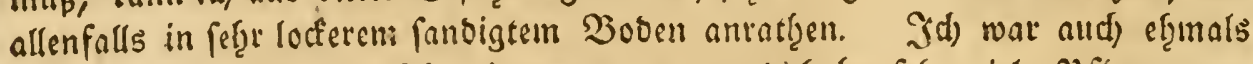

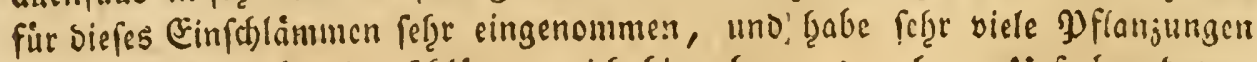

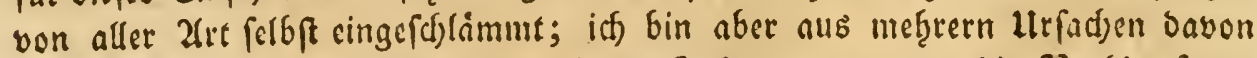

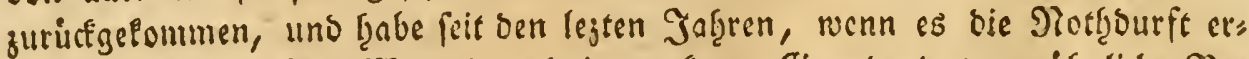

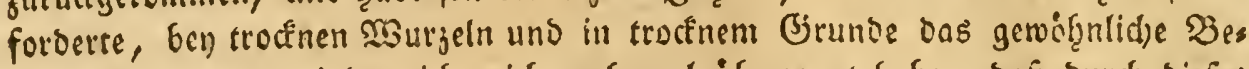

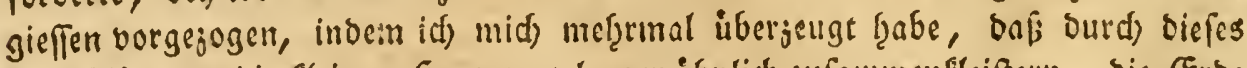

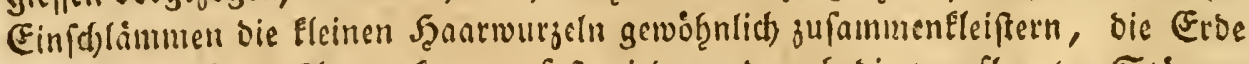
um biefe!fen beym atustrodnen ju feft wits, uno auch bie verpflanjten Stámme

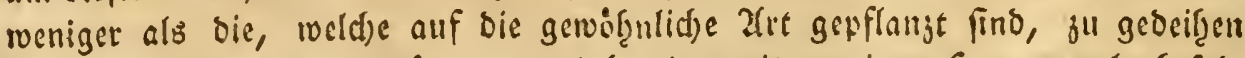

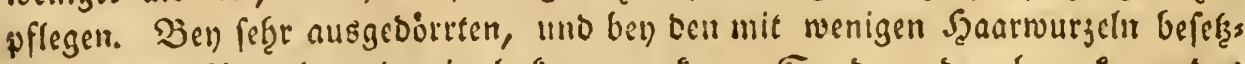
ten grofern Mürgeln, ober in locferm trofnem Eanogrunbe aber lann bas Einfalämmen in vielen fällen vortbeillgaft feun, nur ift genoen mit Sioften uno ßefdimerniffen verbunben. 
9) Das Feftefęen eines verpflanjen $\mathfrak{B}$ aums ift ein fef̧r wefentlides Ers forbernif, und man bzat barauf un fo mef̧r ju achten, wenn bie berfegten

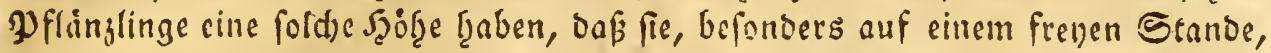

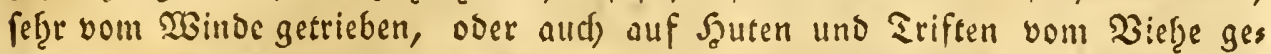
rieben und gebogen werben Eonnen. SJan fud)t biefes Feftfefien auf verfdieone 2lrt ju beforbern. Jn einigen Biegenten werben an bie verpflanjten saiume

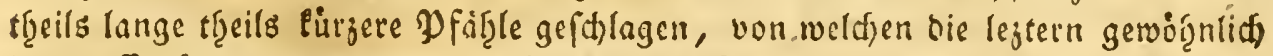
in ber Entfernung von anderthalb Juß bom Stamme ab eingefert, und fdreg mit bem obern Fnoe an ben Zaum gebunben werben. Das anbinden felbft

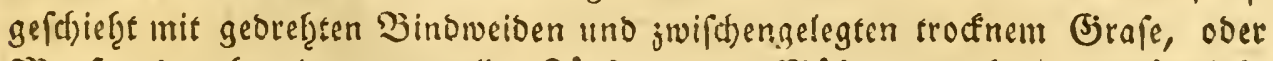

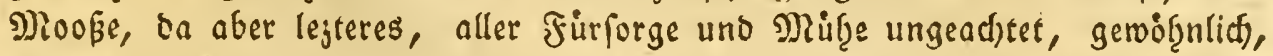
roenn es trocfen geworben ift, bajwifden ausfält, uno bann ber Stamm bom Winde gerrieben wirb: fo mug man biefes 2(nbinben an Pfäf̨len nur in folffen Fålfen wảf̨len, wo man zur Befeftigung ber $\mathfrak{B}$ aume fein anderes Mittel ủbrig bat, als jum Bevfpicl auf Scuten uno Triften, wo noth ubetbies bie neuvers pflanjten $\mathfrak{B}$ ciume oft aud, mit Dornbifdsen-bebunben werben imiffen. Sn vies

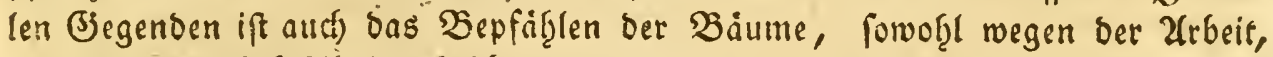
als wegen bes \fabllicoljes foftbar, und, wenn baju leicht ftocfende und faulende Soljarten genommen merben, wenig bauerf̧aft uno in ber Folge fđadoliđ, benn felbft auf J̧uten uno Triften leibet ein bepfäḩlter Baum burd) bas Pieiben bes Bieţes oft incler $S_{\text {d) }}$ ben, weil er fid) nid)t gut wieder aufrid)en, und meniger, als ein frenftebzender Stamm, nad)geben Eann. Man futht Daber biefer in meţrerı Betrad)t nad)tţeiligen Befeftigungsart, fo viel als móglidf, entubrigt ju fenn, uno ben neuverpflanjen Stámmen burd) 2lnfiảufung ber Eroe, uno Llulegung mit Rafen mebgrere Standbefeftigung ju geben, weldes befonders in fefterm Boben uno bey Ståmmen mit guten gef̨origen Wurjeln auch bas fichers

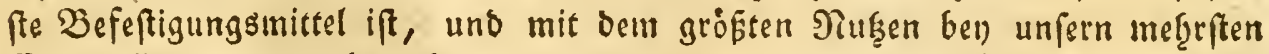
Eidjenpflanjungen gebraudt roiro. Diefe fogenannte Bef̧igelung muE nut

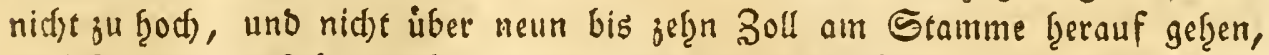
weil fie fonft semfelben nathtgeilig ift, uns eine 2rt Fäulung veranlafen Pann.

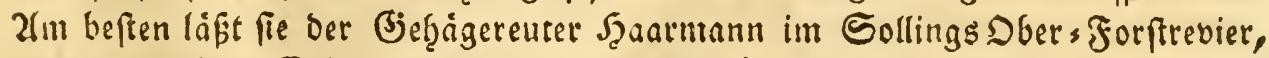
ber als ser befte (Fid)enpflanjer nod) oft angefüb̨rt werben wirb, in ber erften Szoljminoer forft madjen, mit vier befonders baju geftodjenen Mafen, von melden jrey neben bem Stamm uno jwey queer auf biefe gelegt uno angetreten werben. Durd) diefes Bef̧ügeln wirb-dem gepflanjten Stamme nebit bem

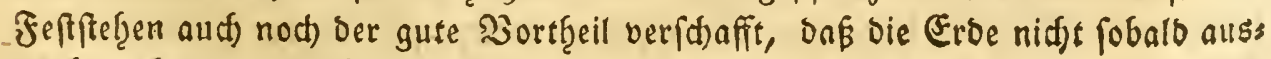
trocfnen lann, und langere Seit frudtbar erbalten wirs.

(Erffer Theil)

236 
Zuf Şuten unb Friften pflegt mant aud woḩl biefe Szuget breiter zu mas

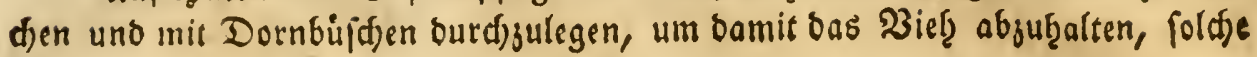
Şugel nieberzutreten.

\section{§. $30 x$.}

Woenn cine Pflanjung geţorig geratfen foll, fo muß foldfe in ben exfen

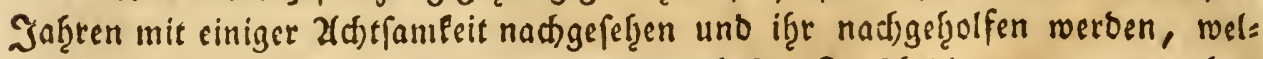
d)es nur zu oft verfäunt wirb, indem bie mefreften zorftbebienten genug gethan gu Ķaben glauben, menn fie einen Plas einmal bepflanjt ḩaben, uno fíf bann

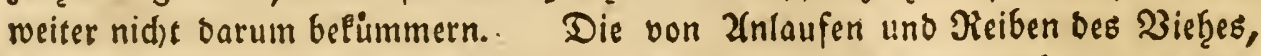
ober vom Sturm gebogenen Strimme, minfen mieber gerabe geriftet, bie etwa vertrocfneten ober fonft befdrobigten, in ber folgenden PPlanjjeit mit andern ausgewectfelt, bie baran, befonters in Maftigeiten son ben Edjweinen unge:

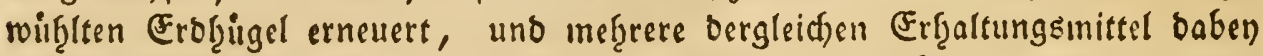
angervendect werben, miewof̧l von bicfen bey feģr groken Pflanjungen nur wenige

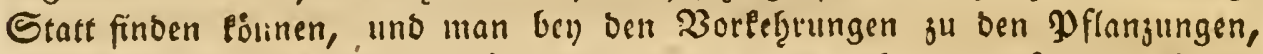
unb bey biefen felbft fáion bafiur forgen muß, Daßs Dabey alle fernern Erŗals tungsmittel, to biel als miglid), wegfallen. Unter biefe gef̧iort vorziglid bas bon vielen Forftgeleferten vorgefd)lagene. Begicffen bel) frarfer anf̧altender Dürre, weldes, fo nirglid) es aud befonders in leidtem fandigtem boben fenn eann, uno aud of̧ne ßerluft bes Pflänglings oft nid)e verfäumet werben barf, ben

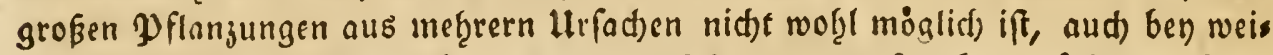

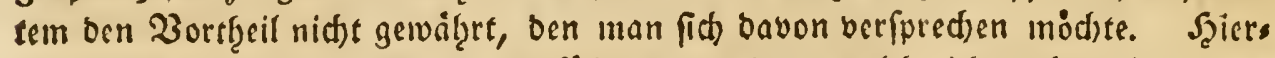
bey verbient sine Bemerfung angeführt ju werden, weld)e id) mef̧rmal zu mas den (j) elegentzeit gef̧abt uno nod) in oen lezten Jaḩren beftättigt gefunden ţabe,

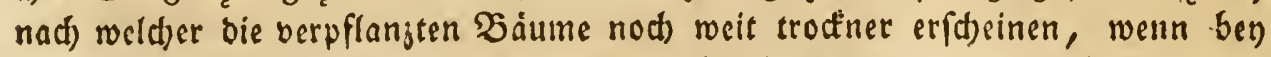
fortbauernder Dirte bas Daran gegoffene 2 affer wieber ausgetrocfnet ift, als wenn fie gar nid)t begoffen fino; eine Erfdeinung, bie fidf alts ber burd) bas

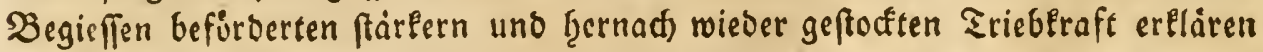

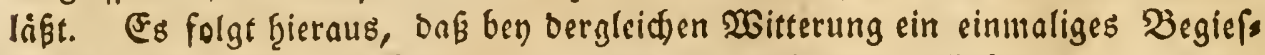
fen ben Pflinglingen nad)theilig feyn eann und daß man baffelbe, wenn es ans gefangen ift, wieberfiolen mus.

Ein Sleides wirt man nad) cinem einjelnen Regen bey wieber eintretens

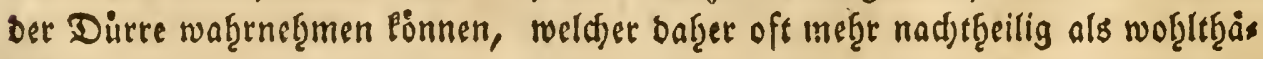
tig Fenn Pann.

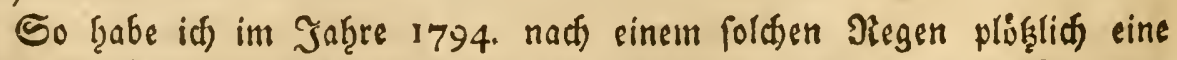

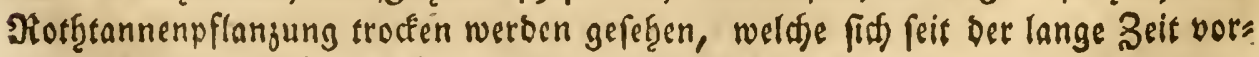
Ger anţaltenden Dürte grim erţalten hatte. 


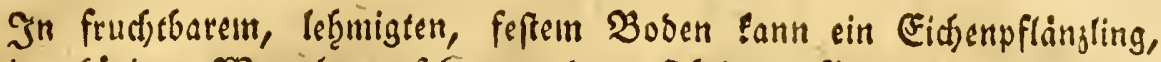
ber mit gef̧origen 2 ourfeln verfeţen, und vorfictig gepflangt ift, fdoon eine

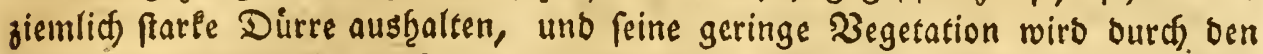

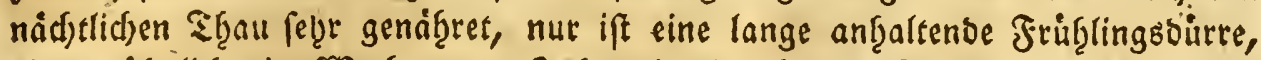

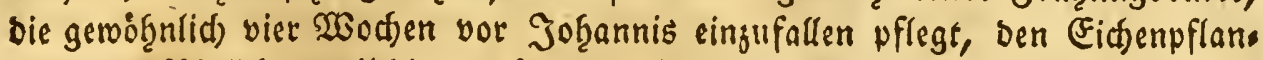
zungen gefäbrtids, weil bie verpflanjten Stämme tann erft ju tteiben pflegen,

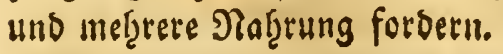

\section{\$. 302.}

Da bey allen burdf eine lünflid)e Forfteultur gu erreidfenden $2(6 f i d)$ ten bie

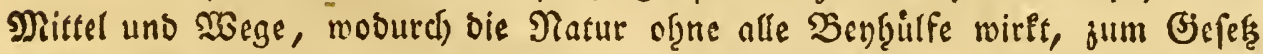
unb gur beften Zfnleitung bienen: fo miffen nir auth biefe bev bem $\mathfrak{P}$ flanzen um

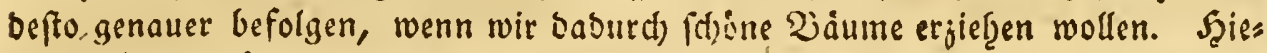

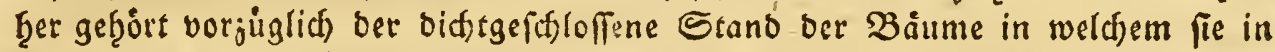
ben naturlidf oid)t bewad)fenen Forftorten in hoben geraben Stanumen aufzus wachfen gegrungen werden, oa fie im Bsegentţeil in einem freyen Stande, wenn

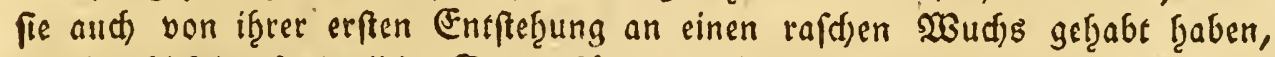

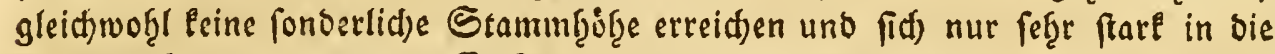
Zefte ausbreiten werben. Es folgt hieraus, baß alpo aus verpflanjten Baius men aud nur bann fdjone, bुoţe, aftreine Stånme wachjen werben, wenn fie

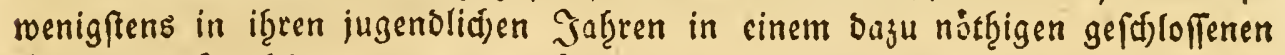
Stande aufroadjen; und man fúf̨rt baf̧er auth in biejen Puncte fef̧r uns red)t gegen bas כerpflanjen ber Eid)en an, dak bie auf Blö́pen, weits låuftig gepflanzen alten Eidjen nut ju furjftammigen Mafteiden benuf̧t soerben eonnen.

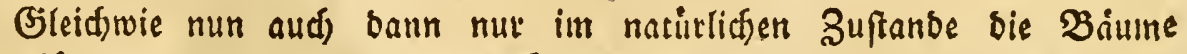

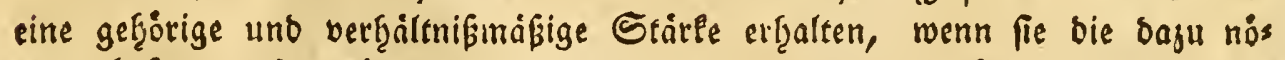
thige Suft genießen Pönnen, uns nid)t ju bidf fteţen, fo folgt auth ţieraus,

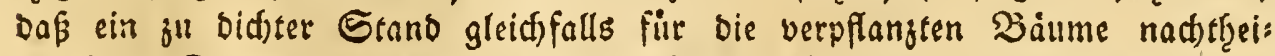
lig fen. Die verffiedenen 2(6fidften für bie funftigen Benufungen oer zu pflanjenten Eidjen miffen baf̧er bie Entfernung beftimmen, in weld)er fie voneinander gepflangt werben follen, wenn man babey nidjt auf bas Şor

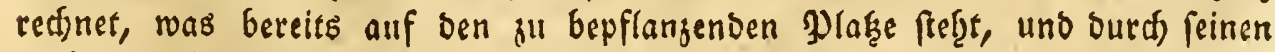

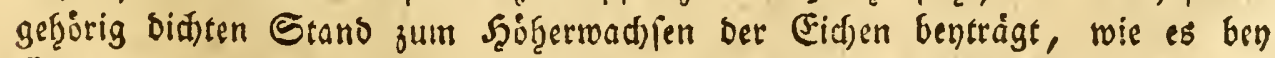

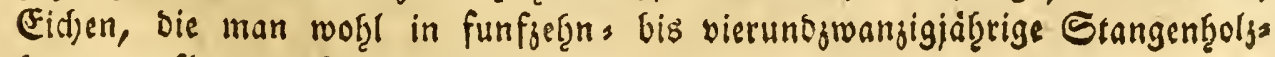
fiene zu pflanjen pflegt, ber Jall iff. 
§. 303 .

Nad) biefeur Grunblase alfo wirben foldje Fidjen, weldje ju feb̧r langen fammerinen Baimmen radjen follen, und ju Baleen ober jul bers

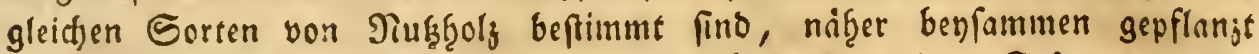
werben inuffen, als bie, aus benen man lügere, bicfere Stamme ziebzen will. Derglididen eigentlid) ju enge Pflanjungen fincet man auf einigen Drten im Şilsoberforftreviere, uns in oer Def̧rentb̧aler forft am Sollinge, aus ben Beiten bes fel. Sberiagermeifters ven Rangell, befonders in ber Flfden (Sirund, in weld)er bie (Fid)en auf adje fub voneinander in sinien ftefen uno bey einer Stammftarle von einem Jub eine Stammbicte von funfzig bis fedjsjig Juk erreid) baben, fo, bak foldje einander unterbrul: fen wurben, wenn nid)t ein Theil, wie es nädjfens gefdef̧en wiro, hers ausgeţauen wurbe.

\section{\$. 304 .}

Die Entfernung, welde für alle Eictempflangungen, aus welden Baiume uno fein Stangentzoly gegogen werden foll; all beften paft, ift

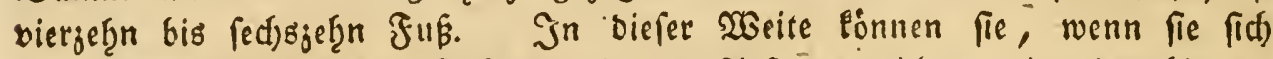
nad) ben erften jwanjig Jaf̧ren mit ben 2(eften erreid)en, einanber bis jur

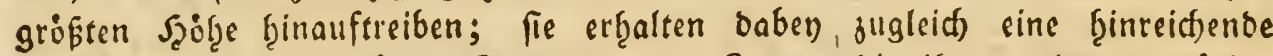

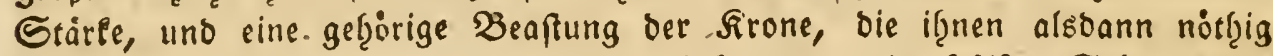
ift, wenn, nachoem aus ciner fold)en Planjung Die Sadifte Stàmme ges

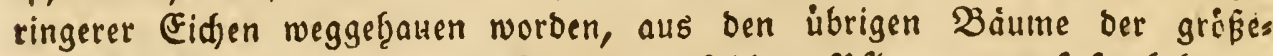
ften Stinke mad)fen follen. Bey einer foldhen Pflanjung auf frudtbarem Boden mit guten Stammen müfen benn aud) bemnid)ft alle Siunfteleyen bon felbft regfallen, bie man bey folchen anjumenden gezroungen wito, in weld)en die Stamme vierzig und meţrere Fußs voneinander entfernt ges

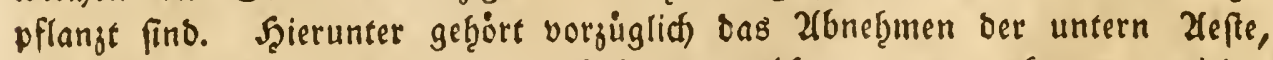
bas fogenannte 2(uffaneiteln ber Säume, rold)es unten vorfemmen wirb.

\section{§. 305 .}

Da nun aber bie Eidenpflanjungen auf J̧uten und ₹riften vorgüg: lid) Statt finben: fo lommen oabey verfdiebene Uinftande vor, welde bas Raf̧epflanjen ber Baiume verf̧indern, befonders auf foldjen Srten, auf

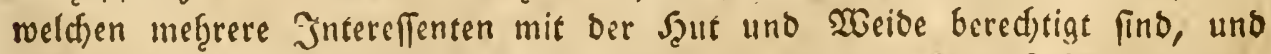
aif roldjen feit langen Jabren nur wenige ober gar leine Zaiume geftans ben fino. Diefe Sgutintereffenten pflegen fich gewob̨nlid) iber bas Nab̨epflans zen Der Eid)en, weil Dann unict iţnen nur fef̧e wenig, und wenn fie erft 


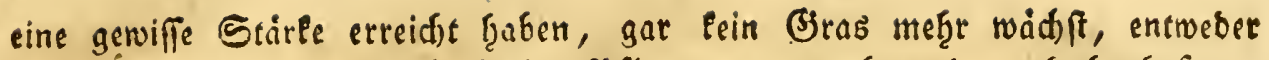

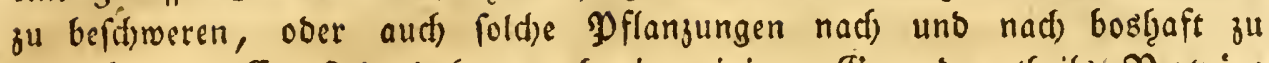
verberben. Es fino baleer aud in einigen Bjegenden theils Berträge

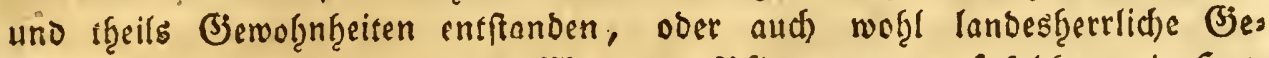

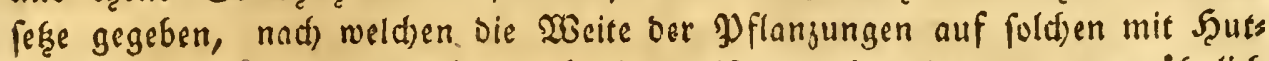
geredfigleiten befd)werten Siten beftimmt ift, woben benn nur gerwöbnlich

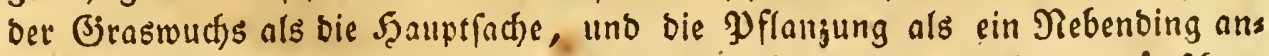

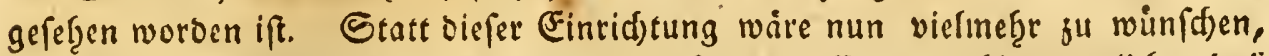

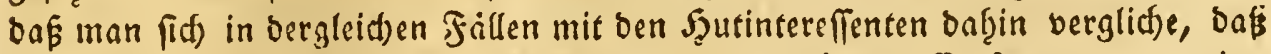
ein ₹geil bes ju bepflanjenden 2 eeibcorts in ber geţörigen Entfernung von vier: zef̧n bis fed)szeg̨n Juk bepflanft wirbe, ber andere Theil aber bagegen gang zur

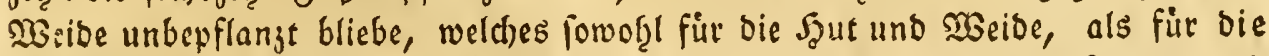
Dflangung ratbfamer feyn wirbe, als eiren foldjen Drt ganj, oft brey und

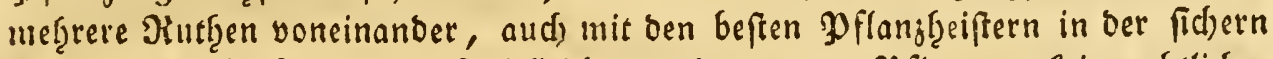
- Suverfid)t zu bepflanzen, baß́ viefleid)t aus ber ganjen Wflanjung Pein red)tlider Baum wadjen fann.

Bon fold)en fdjabliden weiten $\mathfrak{P f l a n j e n ~ t ̧ a b e n ~ w i r ~ i m ~ W e f e r b i f t r i t i t e ~}$ Benfpiele genug, wie oie grofe Eidjenpflanjung auf $\delta \mathrm{cm}$ Dutfelde, alif ben

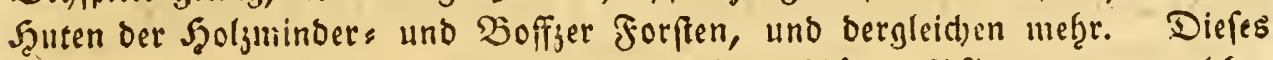

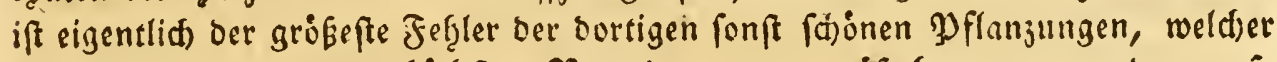
aber freylid leiber! ben ţöchfen 3 eroronungen gemä. begangen werben muB́.

$$
\text { §. } 306 .
$$

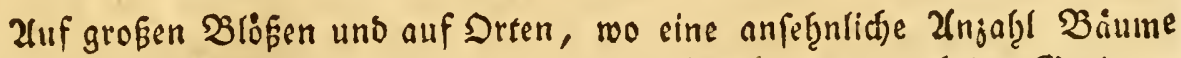
gepflanjt werben lann, pflegt man biejelben in Reifien uno aud ins Bevierte, ober mie es bie Sranjofen nennen en quinquonce zu pflanjen, bas ift, in fols d)er Dionung, worin bie Baume nad) allen Seiten Ģin in geraben Reifen ftes

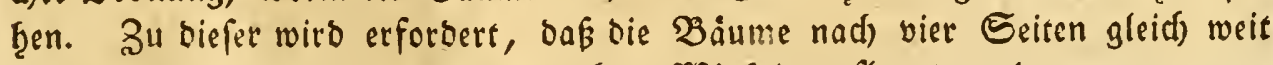
voneinander, und geṇau in einem rechten Winlel gepflanjt werben, wojul man

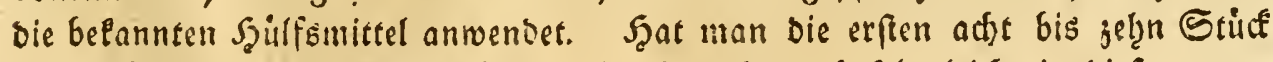

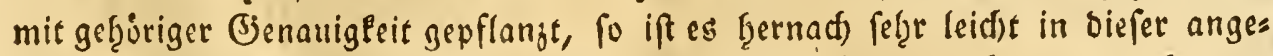
fangenen Dronung fortjufaberen, wenn nur bie Stämme niche gat zu Prumm fino, und ber Drt nid)t zu ungleid) iff. 2(ud) Inffen fich ju biefer bie Forft gies

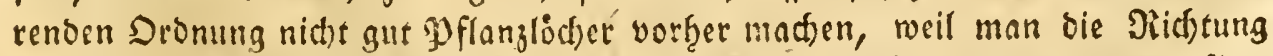
nidft of̧ne bie Etánme ober Etangen zu nefamen im Etande ift; man pflegt (iid) bafer genoignlich ju begniigen, bie Steifter nur in gernoen Sinien uno auf biefen in gleicher 2 seite ju pflanjen. Das in Sinien Pyflanjen ţat auffer bem 


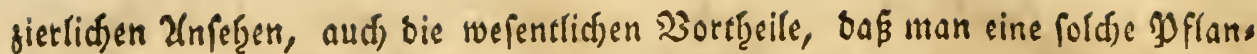

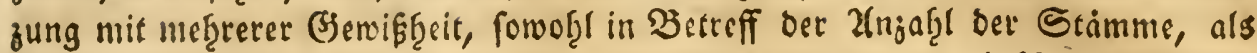

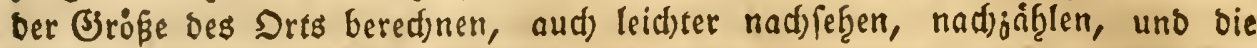
Darin beffadoigten Baiume beffer bemerten tann; zugleid) ift es bas auffallenofte

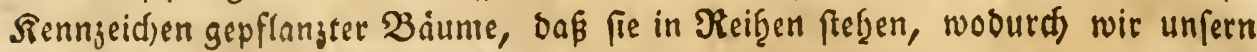
Siadjfolger an bie Erkenntlidpleit fir unfern Jleiß erinnern.

\section{\$. 307.}

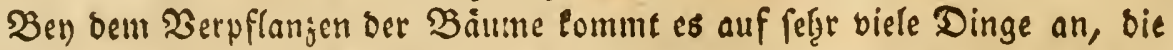
babey nur unit cinem gewiffen $\mathfrak{Z}$ ergnigen uno einem eignen Briebe besjenigen, weldjer bie Pflanjung zu beforgen ḩat, geḩorig erreidjt werben; uno Panur

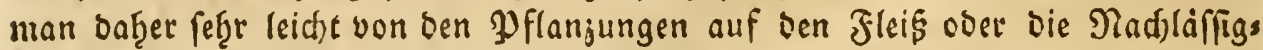

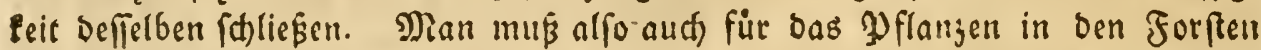

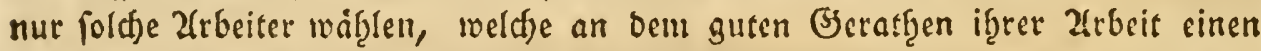

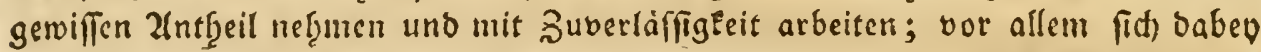
aber für bie Frof̧ndienfte, Forftoerbrecter uno bergleid)en mit waidermillen bies

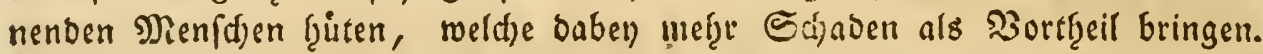

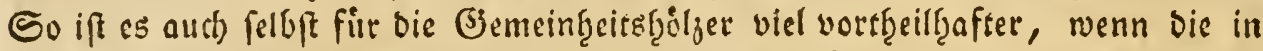

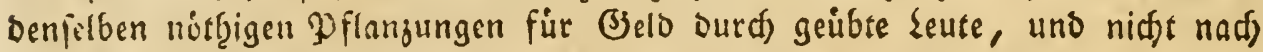
Der fogenaunten (jemeindereife gemad)t werben.

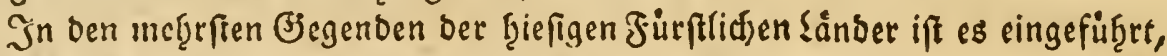

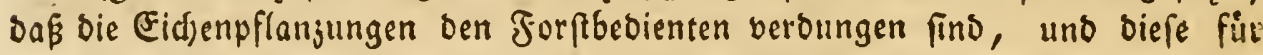
jeben Seifter bey ber $\mathfrak{P}$ flanjung sinen (jutengrofden, unb, wenn er nach orell

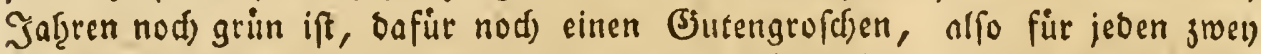

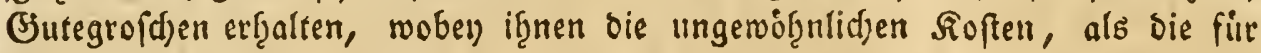
einen entfernten Zranfport befonders bezalgit werben; biefe Bablung ift frenlids in bem falle ju theuer, wenn bie Poflänglinge alls grof́en wof̧leingeridtes ten Baumfdulen genommen werben fonnen: ba fie aber zugleid) als ein fur bie Y Planjungen ermunternoss Zlesibenj anjufetgen ift, fo ift oicfer eleine

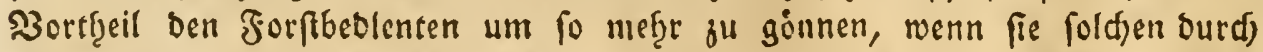

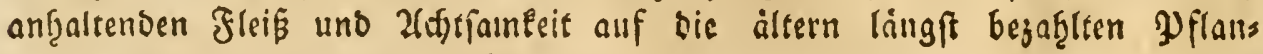
zungen mit ju veroienen fudjen.

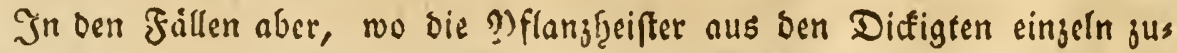
fammengefud)t warden muffen, wie wir bavon leiber in fef̧r vielen Jürftlidjen Forften ned) Benfipiele fiaben, if bie PJflanjtare nid)t zu theuer, weil von fols

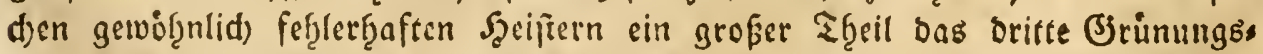

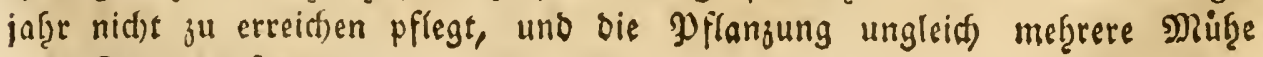
und Roften erfordert. 


\section{§. 308.}

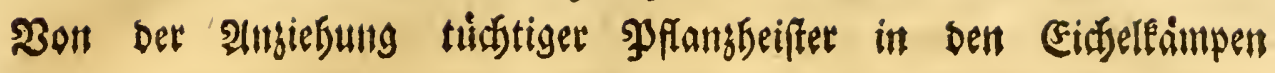
uno B̧aumichulen.

Wenn bie zu einer Plfanjung erforberlidjen Eidfenţeifter bie geţöris gen Eigenfdaften bुaben follen, fo miffen fie von if̧rer exfen Jugend an Daju vorbereitet und angejogen werben; foldjes eann ain beften in ben Eidjellämpen uno PFlanjldulen gefdef̧en: Denn wenn man audi in ben

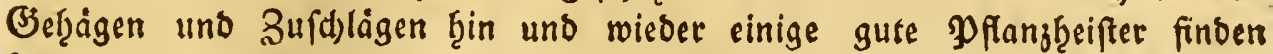
follte, wie es unter gemiffen Utmftänoen fef̧r oft ber Jall feyn tann: fo werben bods bie barin aufgewactjenen Sceifer nur felten untabelfăft jenn,

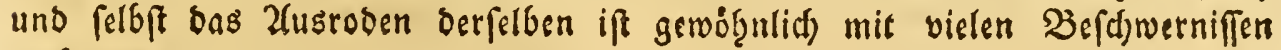
verbunden.

Die 2fnlegung ber Eidfeleampe und Pflanffoulen ift onfer befonders für foldfe Begenden, in weldgen große Eidfenpflanjungen Státt finden, von feter groker widt)tigleit.

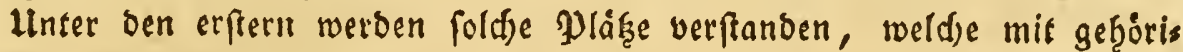
ger Befriedigung verfeg̨en fint, und worauf bie Eidfeln gefäet, bis zue Berpflanjung gewartet, und gef̧örig erjogen werben; unter ben Pllanjfdjus ten aber foldfe Drte, auf weld)e unter ben gefeorigen Beginfigungen Fleine Eidenftäammen gepflanjt uno bis zur Grö́̈e eines pflanjbaren Saeifters angejogen weroen.

\section{§. 309.}

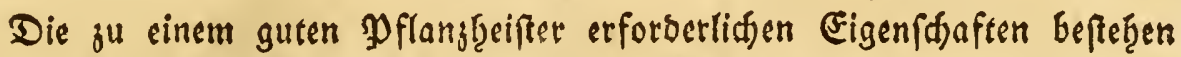

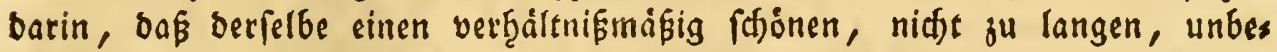

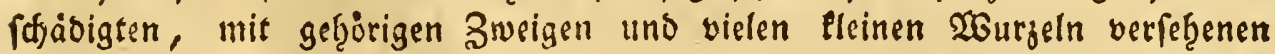

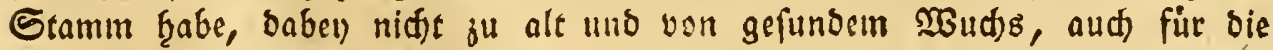
Segent feiner lunftigen Beftimmung idicflity fey, auf meldje Erforberniffe alfo ben ber Zlnlegung eines Eidjenfamps oder ciner Pflanjfdjule notţmens big Riuffidte genommen metben mus. Die Sig. 2. Tab. 6. ftellt einen

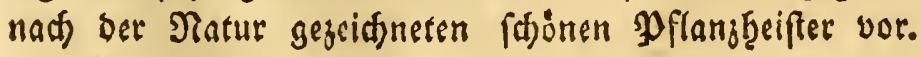

\section{§. 310}

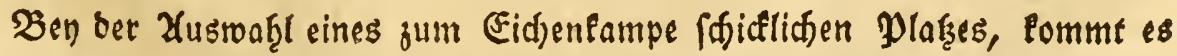

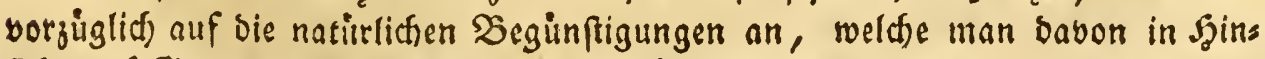

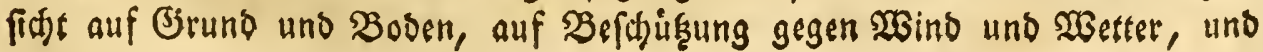


auf verfdiebene Bequentidjeciten fir tie finftig von ba aus zu beforgenden Pflanjungen mit gegrindeser \ermutb̨ung etwartsn ?ann.

Der Brund und Booen mú in einem Eidjelfampe von foldfer Befdafs fentreit feun, bás bie barin aus bem Saamen gejogenen Eid)enloden in gef̧öris

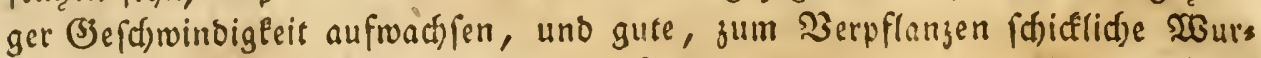
jeln fdlagen lónnen; wern es alio auf einem baju beftinmenten Drte nod) an finlänglid)er Frudt)tbarkeit bes Bodens feften, oder wenn man fitr gut finden follte, foldye zu vermefyeen: fo fann man nad) den llmptinneen bazu bie ges

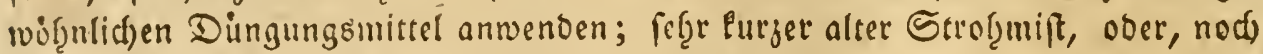
beffer, ber in cinigen Syoljgegenden vorfallende Laubmift ift baju fégr gut, bod) mus eine foldje Dingung cinige Jaf̧re vor ber Befamung vorgenommen wer=

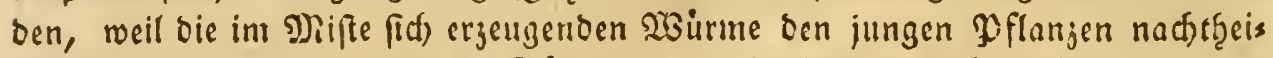

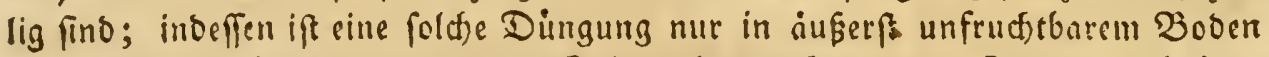
anjuratfen, auf weld)em fonft bic Stämmden auf aul lange Beit (d)wach bleis ben wirben. Da man nun bie Eidhellaimpe befonders allf folden Drten anju: legen pflegt, wo bie linftige $\mathfrak{P}$ flanjung baraus gefótehen foll, uno wo ben ber

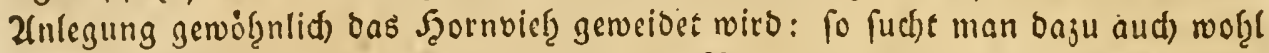

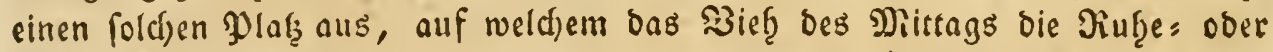

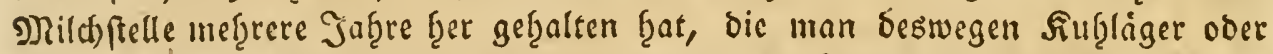
Siuffeflen zu nennen pflegt; ober man weifet ben Şirten eine jum Eidfeleampe beftimmte Stelle cinige Jaf̧re vorheer baju an, uno benutzct biefes für die Ei.

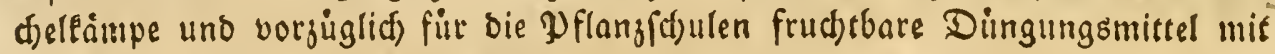
fę̣r geringer Miţe unt of̧ne Soften.

3or alle:n aber, und befonbers an Drten, auf weldjen ftarler Brastafen

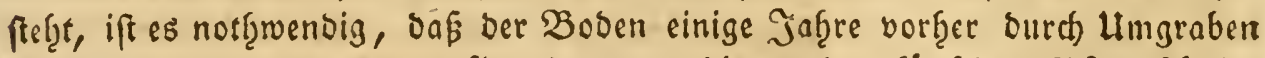
urbar gemad)t werbe; man pflegt beswegen bie zu ben tunftigen $\mathfrak{D}$ flan; $\{$ d)

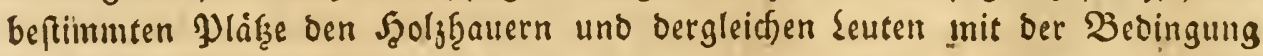

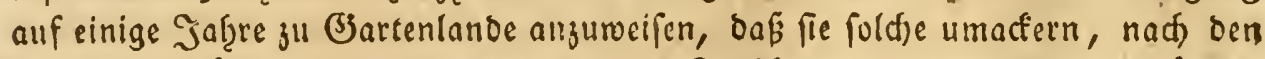
Ulmftinden büngen, und bann wieber zur Forftbenuşung liegen laffen müffen; bie Eeute pflegen ein fold)es Zanerbieten gewoinnlict) gern anjunef̨men, wiorigen: falls man ifgnen aud) nod) wolft einige '(Jrofd)en für jeoe Butbe jugeben mag. In fefer vielen fallen aber ift die gute Damms uno kauberbe, bie befonders auf vormals ftare mit Laubfrols beftanden gerwefenen Drten befindich) ift, oer befte natirlidje Diunger, und wirtoe cs aud) oft (d)iolid) fent, einen fold)en (Erobos

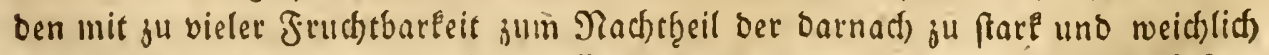
wad) jenden looen, zu veroerben. Es tommt alfo auch bierbey auf bie Erfafes 
rung und B̧eurtheilung an, bon weldjer uberf̧aupt fo vieles bey allen sfonomis

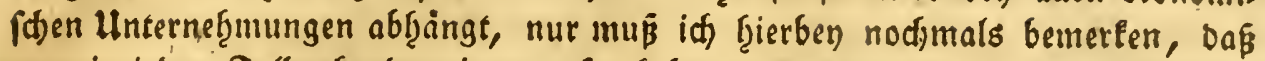
man in jebem falle ef̧enber einen ju frudftbaren, als ju magern Boben fur alle

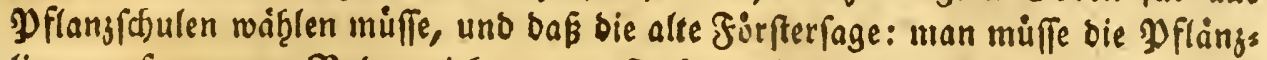
linge auf magerm Boben gief̧en, un fie ţernad) in beffere Eroe verpflanjen

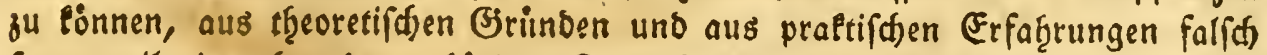
(en), weil ein, bey ber geţörigen Frudtbat Esit aufgewachfener, Jgeifter bas Zerpflanjen, aud felbft in einem (d)led)ern Boben, efgenber vertragt, als ein fummerlia ergogener, vermaferter älteter Stamm; wovon unten nief̧retes bors Commen roito.

\section{§. 3 II.}

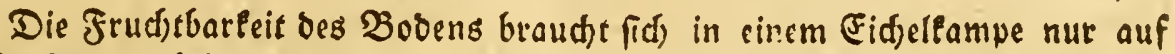
eine Tiefe von hiddftens anbertḩalb Fußs zu erftrecten, uno es ift beffer, wenn bie tiefere Erolage unfrud)tbar, hart, ober wohl gar fteinigt ift, reeil alsbann

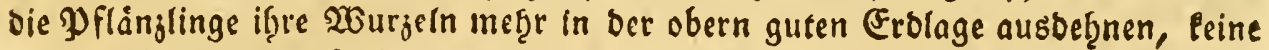

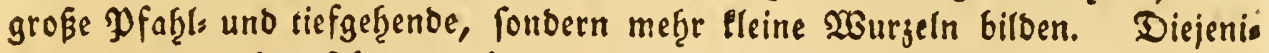
gen ţandeln baf̧er fef̧r unred)t, reldbe einen jur Baumfoule beftimmten

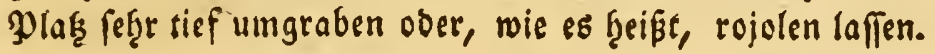

\section{§. - 312.}

Bey ber Xusmaḩl eines Mlaţes jum Eichelfampe esommt es auffer bem nod) auf verichiedene mitwirkende Nebendinge an, auf reld)e man befonders in Den gebirgigten (jegenden genau ju adten f̧at. Daf̧in gef̧ort bie, gewiffers mafen für bas beffere $23 a d)$ fen vorţeilf̧afte, für bas leid)tere 2erfrieren ber jungen Soocn aber jugleid) gefäh̨rlid)e, Lage nad ber Morgens uno Mittags: feite ber Bebirge, movon bereits oben mef̧reres gefagt morben ift. Da nun allf) in ben (srunben bie jungen loben oft ef̧enber boin frofte ju leiben pflegen,

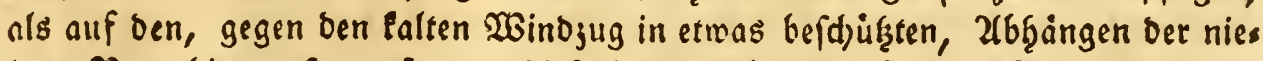

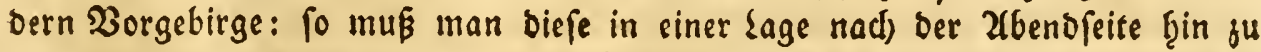

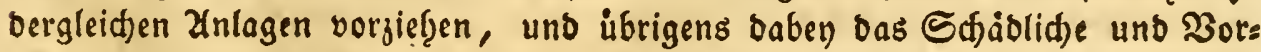

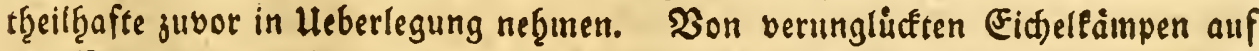

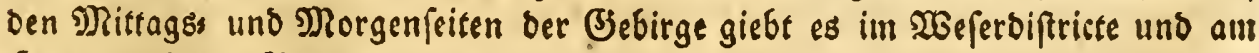
Şarje meţrere Benipiele.

In den Jaf̧ren, in weldjen es viele Màufe giebt, pflegen fid biefe im Şerbft gern in. Die Şolgungen, Der Darin gefallenen Maft wegen,

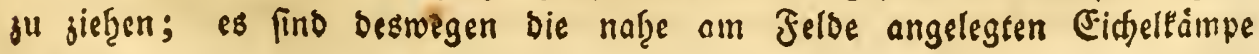
(Erfter ₹gell) 


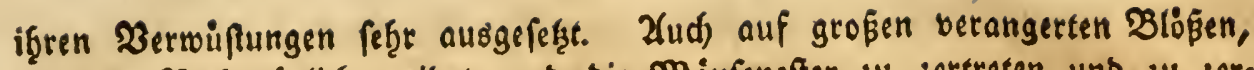

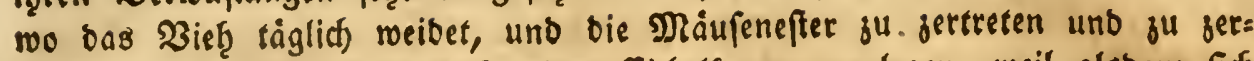
fioren pflegt, ift es bebentlif, einen Eideleamp anjulegen, weil alsoann fid bie meḩrften Mäuse, bet Siderbeit wegen, in ben befriebigten Eidelleamp zief̧en, und Dann in Wointer bie jungen Soden an Stämmen und SBarbeln verberben; wie es jum Benfpiel in ben Eidteltimpen in ber. Şaller forft auf bem orffeloe und bey meţrern bergleidsen ber fall ift.

\section{§. 313.}

Weil bie zu ergieţenben Pflanj̧eifter für die lunftige Bepfanjung

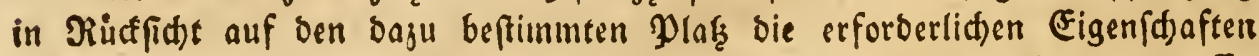

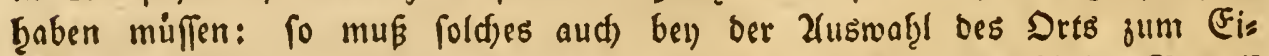
delfampe erwogen werben; man fudft baher in biefem fo woht im $\mathfrak{B}$ ctreff Des Brundes uno Bobens, als aud) Der faitern uno wärmern sage befs felben mit Der baraus ju bepflanjenoen Blöpe cinige Ġleidftgeit zu finden,

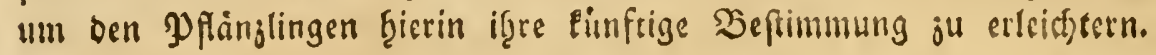

\section{\$. 314.}

Die Eidfelfimpe müfen bey if̧rer erften Ifnlage nidit ju groß ges nommen werben: 2luf einem Plake von einent ḩalben Morgen tönnen febe viele PPlinglinge wadjen, und man eann fold)en in ben folgenden Jaferen,

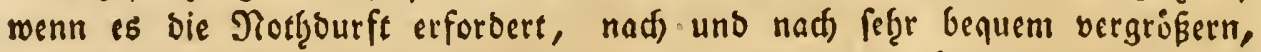
und an ber einen Eeite mit ber Befriebigung weiter riffen, woourd) bie

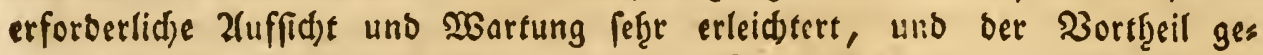
wonnen wird, Daß́ bie YPflänflinge nid)t auf eimmal, fonbern erft nad) und

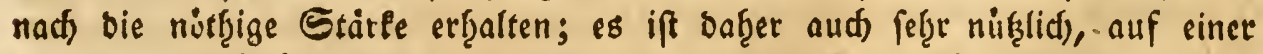

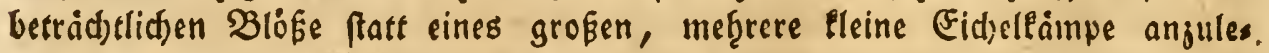
gen, weil ben ber fünftigen $\mathfrak{Y}$ flanjung bie Sceifter nàf̧er an ben Drten if̧̧ rer Beftimmung find, alfo ourd) weites Tranfportiren nid)t fo fefer befda ás bigt, und gefdrwinder wieber eingepflanjt werben fönnen. 2(ud) lauft man mit mef̧rern fleinen, von einanber entfernt gelegenen Eidf)elfónpen weniger

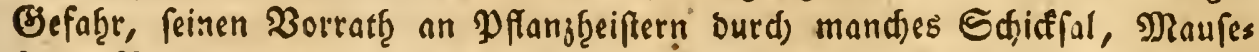
fraß, Berfrieren und bergleiden, ju verlieren, als bey einem einzigen grofs Pern Eidjeltampe. 
§. 315.

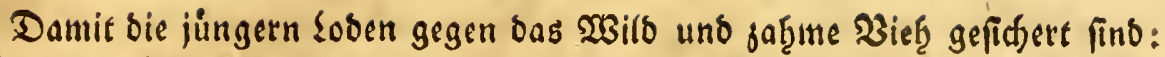
fo múfen die (Fid)elfämpe befriebigt rerben; foldes gefdieb̨t nad) ben Beburf: niffen und Ulmftänoen auf verfdiebene 2 seife; in viclen Fallen if ein etwas breiter Sraben mit bem 2ufrourfe binteid)end, oft lann auf biejen nod eine Scefe gepflanjt, ober aud), wenn bie Sidjerung nur einige Jaţre bautern foll, ein trodener Saun gemadt werden; weldhe Befriebigungsarten auf grofen Seibeblöpen und in foldjen Siegenden, wo bas ftirlere Şolg theuer ift, bie ges wöhnlidften find. Man pflegt bafelbft aud) init vielem शuFen auf bie 2lufs wirfe Sannen und Fuhreen zu fäen ober zu pflanjen, weil foldje bie jungen Eis

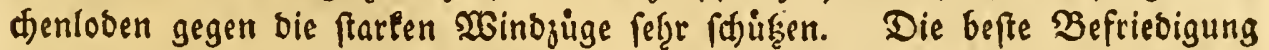

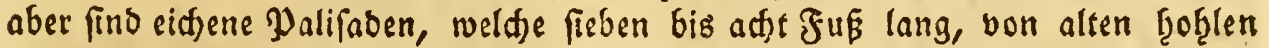

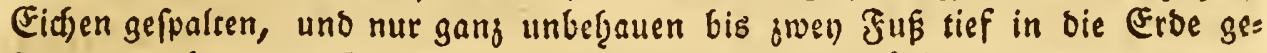
Pefzt, und oben, ber (selegenţeit nach, mit tannenen, budfener, weibenen, uno bergleidjen Zneigen fufainmen geflod)ten, ober aud) an eine Latte genagelt wers ben. Wenn aud eine folde $\mathfrak{B}$ efriedigung in etwas theuer ift, fo werben bas Durd) bod) bie Rampe am beften gefid)ert; fie fonnen aud mif einer geringen

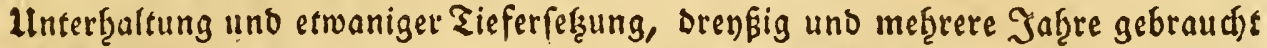
uno bas Scolj bavon nad) bem nod) als Brennf̧ol grofitentheils benufgt rerben, [0, Dap oie eigentlid)en Soften babey feţr unbedeutend fino.

\section{§. 3 I6.}

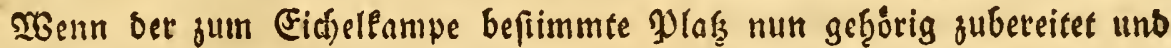
befriebigt ift: fo muf berfelbe befaet werben; biefes gefdieg̨t entweber ourch blopes Einwerfen ber (vid)eln in bie frifd gepfligten ober gegrnbenen Furd)en, in welde fie fiernad eingeegget ober eingegarket werben, ober in jroen bis orey

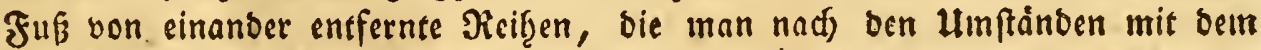

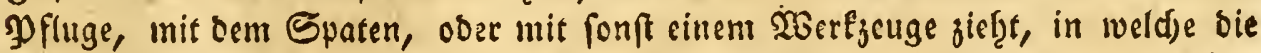
Eictseln eingefäet uno mit weniger Erbe bcoecte merben muifen. Jn vielen Bies

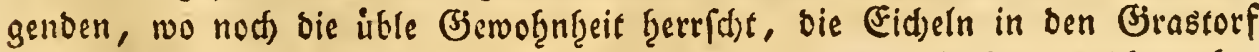
einjufzacten, werben aud) auf fold)e 2l't bie Siampe bamit befäet, weld)es aber God)ftens nut in einem fanbigten, locfern, nidft fare berafeten Boben Statt finden follte. Zu ber Befaamung in Reifen wiro weniger Saamen erfordert, als wenn biefer nad) ber erften 2lrt nutr als Forn gefäet wirs; aud bृat biéfelbe regen ber, in ben erften Jab̧ren in einigen Fällen nothigen, Reinigung, wegen

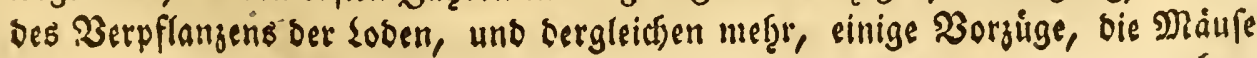


aber, weld)e in ben Reif̨en bie Eidgeln fệt leidjt finben tönnen, pflegen eine fold)e Befaamung oft in eurzer Zeit faft ganz zu verzę̧ren. Es ift baher in

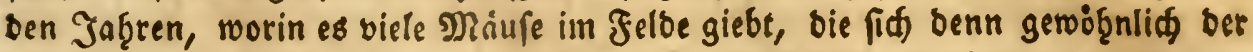

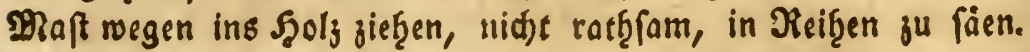

Die Befaamung mus nidft fparfam fenn; man redinet, wenn fie nidft in

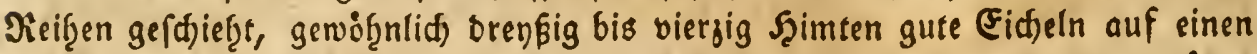

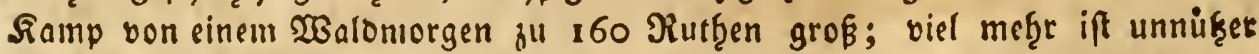

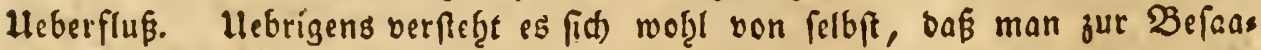

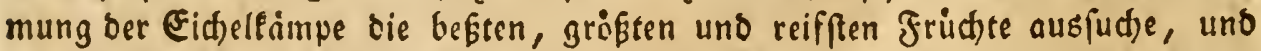
Dof man bey bem Einfamineln berfelben barauf acteen muffe, nad) ber verfdies benen 2(bfid)t entweber reine Sommers ober reine Wointereid)en zu erf̧alten. Nact) ber Befanınung im Sęerbft ift es fef̧r vortheilf̧aft, ben Siamp einen ḩalben

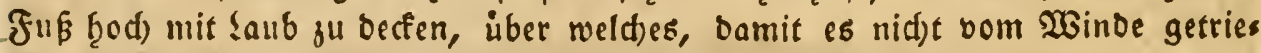
ben werben eann, Zweige gelegt werben múfen, bie inan, nadjoem fid) bas

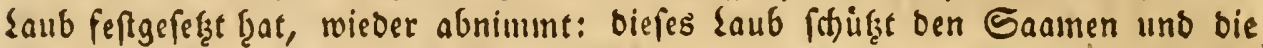

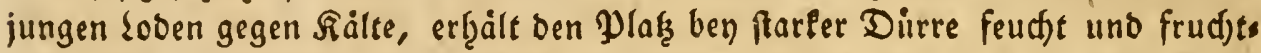
bar, uno verḩindert, bak in bem folgenden Jaḩre bas 1 ln lraut bie jungen Pflanzen nid)t ibergief̧en und veroumpfen eann, gewaithrt alfo gleidjam ber

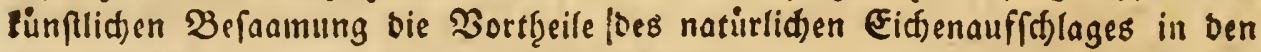
beftandenen Forftortern. Da fid) aber bie Maufe aud) unter bem Laube jufams

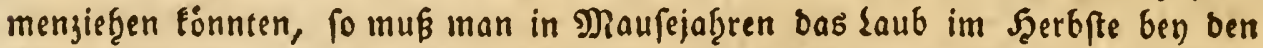

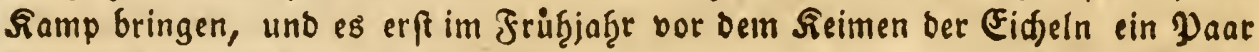
Finger tiod) Daraufwerfen laffen.

In viclen B̈egenden pflegt man bie befäeten Eiđfellämpe und Beß̧ảge init Forn zu beftellen, weldes aud in ben ţiefigen forften vor ungefäf̧r vierzig

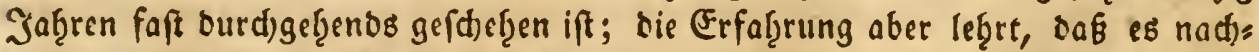
theilig ift, theils, weil bie Máufe baburd) angezogen nerben, theils aber aud), meil bie jungen Eidjenfeime unter bem Forn zu mager und zartlid aufivad)fen, und beswegen ben bem 2lbmąten bes Forns leioen.

\section{§. 317.}

Weil bie Ratur jur Eid)clfaat ben Şerbft beftimmt f̧at, fo ift biefes audf of̧ne Breifel bie befte Zeit; jetod) iff bie Şerbfteidelfaat aud einigen mibrigen

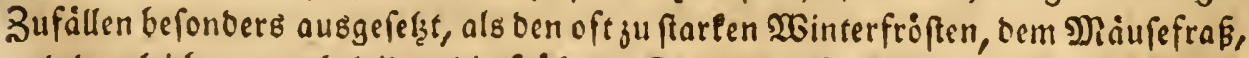
uno bergleidsen, aud) leiben bie frủbern Fieime ber Şerbffaat oft burd) Dic fpas ten Jrüb̨lingsfröte. Fü biefe Jälle ḩat die Befaamung in Früb̨linge 3or 


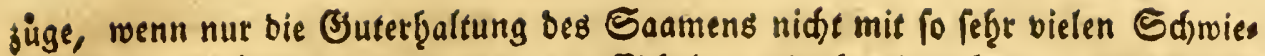
rigfeisen vertnupft wire; inosm bie Eidjeln, wie bereits eben angemerft ift,

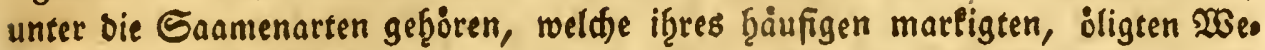
fens roegen feţr leid)t ranjigt uno fledtigt, uno bann für bie Saat untauglidf werben.

Sollte es bennof̧ngeaditet bey gewiffen umftänen nothig penn, fo wie es audf) bev zu befird)tenden Befhibigungen von Maaufen uno bergleidfen, fu etwanigen 2(usbefferungen ratţiam fevn mod)te, eine geringe Menge

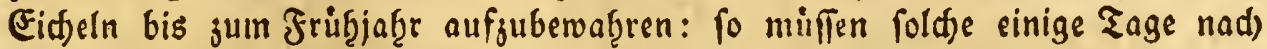
Der Sammlung luftig, nidst bidf an einen trodinen Drt bingeffiüttet, uno, bamit fie fich nid)t brenneli, in ben erften vierzeţn Tagen säglid) einmal umgewendet wetoen; man fonn fie bann wobl an einem mittslmáfig trocts nen Drte gróstentheils gut erbaltert. Siele rathen, fie aud) mit bajwis fdjen gefduttetem trodenem Sande in Saften ober Fäflern aufabewaţren, meldfes id) aucs einigemal mit fef̧r gutem Erfolge getf̧an babe: am beften aber eann man bie (Eid)eln erţalten, wern fie auf sinem trectenen, freven,

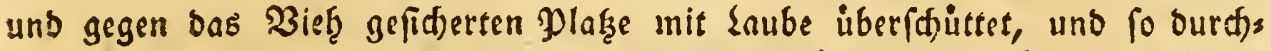

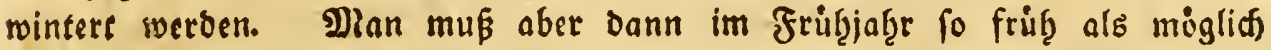
bie Bsfaanung bamit vorneţmen, weil bie Eidfeln fonft ausfeimen und ganj mit if̧ren Reimen fidf zufammenjalingen würben. Biele Forfiges

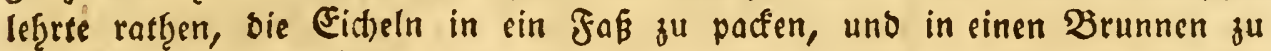

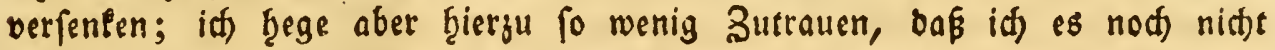
habe verfucten mogen.

Dab von einigen Forftfdriftftellern angegebene Mittel: man folle ben

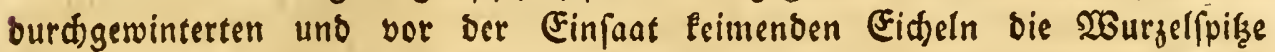
nef̧men, um baburch ju verhindern, baß bas junge Ståmmaten Peine Pfahlwurgel triebe, getiort ebenfalls unter bie theoretiften Spielwerfe: benn, menn man ald) foldhe Wurgeln abnef̧men wollte, fo witben baran balo andere Pfab̧lwurzeln austreiben, wie id es feb̧r oft an Eidfeln und ans bern Saamen erfaḩren f̧abe.

\section{§. 318.}

Dft pflegt eine mit aller $\mathfrak{B o r f i t j t}$ boforgte Befaamung in ben Eidfels

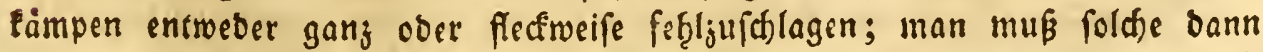
das folgende Saber, weun es nidft an Saamen fef̧lt, erneuern, ober auds mit jungen SP flänjlingen ausbeffern. 
Sollte bas zwifden ben jungen Eidjen aufwadfende Straut benferben

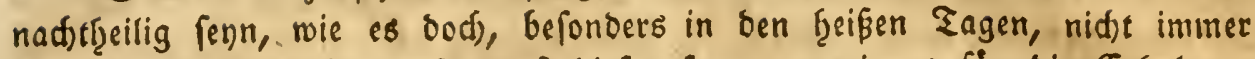
ber Fall zu renn plegt: to mus biefes fo gut, wie es fir bie Errģaltung ber Yyllanjen moglid) ift, weggefdjaffit werben. Die ibrige ben einem Eis derfsompe vorfallende wartung ift nad) ben Ulmftanden veridieben, und ber) einer gut getroffenen Einridstung unbebeuteno, wenn man nur ben id)isticfen Dingen baben to gut wie moglid vorgutommen futft.

\section{§. 3 s9.}

Die in einem Eidfelfampe aufrod) fenden jungen Stämmden minfen nidjt ju biaf ftehen, weil fie fonft ju fafwad) uno ju lang in Stamme werben, uno

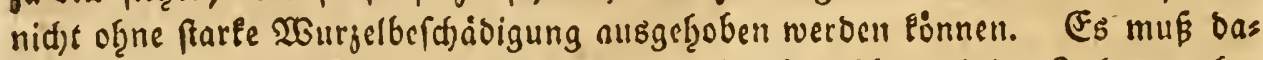

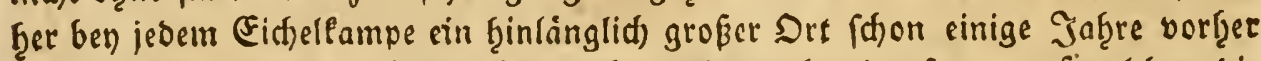
zu einer $\mathfrak{P}$ flanjidsule auf oben befdjriebene 2 (rt vorbereitet (eun, anf weldyem bie jungen Pflänjlinge, bie nact) und nad) jwifdeen ben jul bidf feţenden zunef̧men fino, in orey Juß von cinander entfernte Ricifen eingepflangt werben milfer.

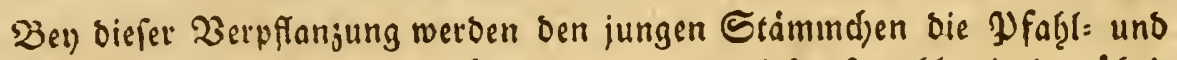
fonftigen ou fenten গebenwurzeln abgenommen, und biefen forobl, wie ben ủbris gen, im Sampe ftefgengebliebenen, nur fold) Fleine Nebenäfte abgefdnitten, weld̆ge bas (jerabewad)jen bes Stamms verḩindern, wohin vorzüglid) bis obern Sabeln geţoren. Man fef̧e ben \$. 326. uno bie folgenden.

\section{§. 320.}

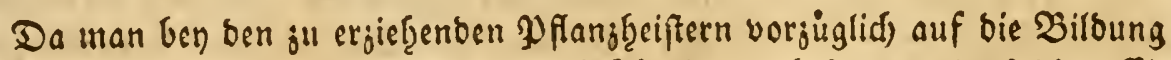

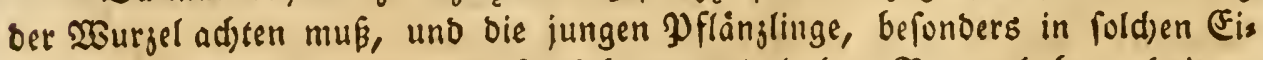
d)enéampen, weld)e einen tiefen frud)tbaren uno lockern Boden baben, (nie es faft in allen fanbigten Begenden ber Fall ift, Felgr ftarle und nacte, oft rubens

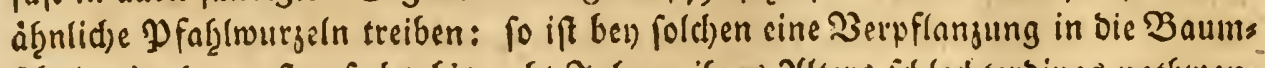

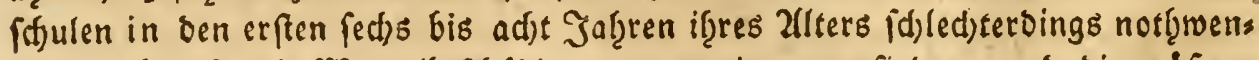

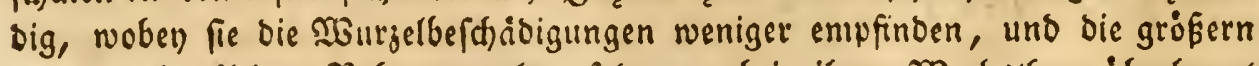

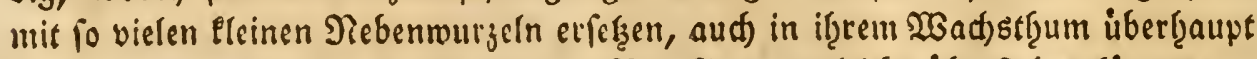

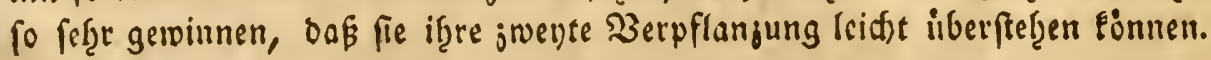

In feftem, und mur anf eine geringe Tiefe locferm Grunde ift biefes $3 e r s$

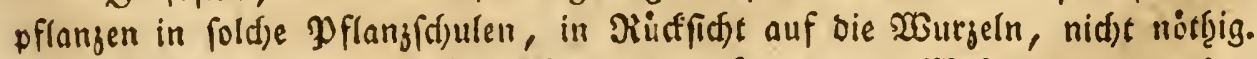

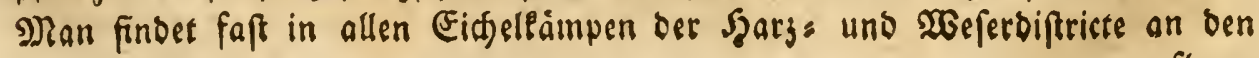
pflangs 


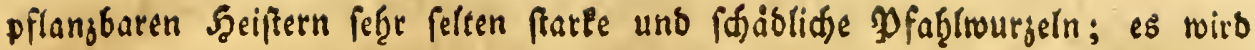
Dore baf̧er nur bey foldjen Sgeiftern mit Nufzen angerwenbet, weldje man auf Triften uno an bie Wege beftimmt, woju ftirtere Strimme crforbert werben, Die man of̧ne biefe 3orlef̧rung nidjt anders, als mit if̧rem Sdjaben, verpflanjen lann. Defto nothiger aber ift ein foldbes Serpflanjen junger Soben in bie Pflangfdulen faft in allen biefigen Forften oes platten Lanoes, wo bie unvers pflanjten Sceifter feţr ftarke $\mathfrak{P}$ fab̧lourzeln gu treiben pflegen.

(Fin jeber, oer fid) aud) nur etwas mit Banmpflanjen abgegeben bृat,

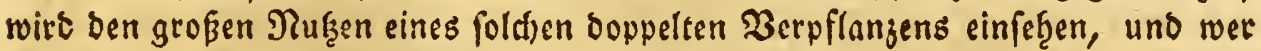

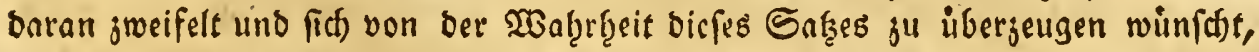

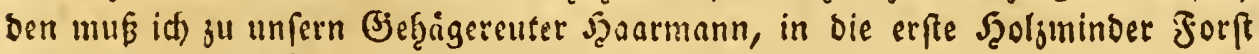
verweifen, wo er uberfüfrende $\mathfrak{B}$ eweife bavon finden wirb.

\section{§. 321 .}

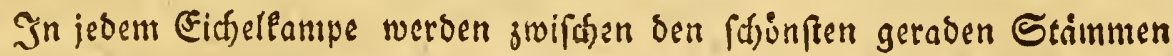
audi) biele frumme, verwathfene, unterbiucfe juridfbleiben, weldje bey bem

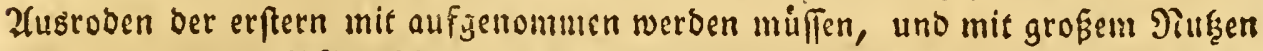
reifenmeife in die Pflanjld)ulen wieber gepflangt werben fonnen. Diefe werden babey anderthalb bis jwey Fub lang abgeidnitten, und bleiben dann jwey bis brey Jab̧re ftef̧en, während weldjer Beit fie wieber viele frifche Triebe uno Wuijeln gefolagen b̧aben, worauf fie im oritten ober, vietten Jab̨re lurg vor

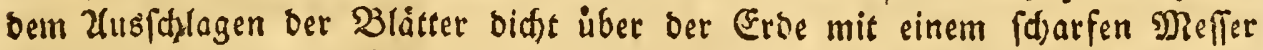
abgefdnitten retben mitfen. Stierauf treiben in bem folgenoen Sommer aus ben Ståmmen meb̧rere ftarle Soben, von welden sie grobefte, nadjoem die ubrigen bas folgende Jaf̨r abgefanitten worben, Den lunftigen Stainm biloet, und in menigen Jabgren an Starle felbft oft bie ibertrift, weldfe als bie beften uno farteften auf ihrem erften Stanbe fefren geblieben fino.

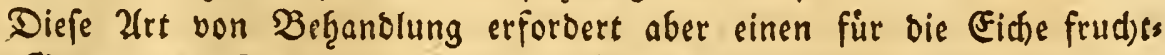
baren Gruns uno Boden, wenn fie gefiorig gerathen foll. In fifled)term Boben, toenn man benfelben nidft in stras berbeffern fonnte, muffen bie Stämme aud wob̧ um ein Jab̨r langer-unabgefdnitten pef̧en bleiben, bamit fie erft mefrere Triebsfraft erreidjen. Nach biefer von ben berufgm: ten ou Scamel vorjuglid) angepriefenen uno unter bent Ramen von Rece:

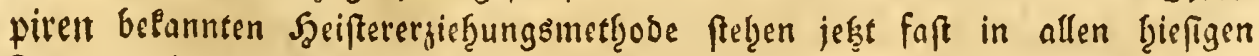
Forften, in weld)en bie Eidjenpflanjung mit Eifer betrieben wiro, goffs nungsvolle $\mathfrak{P}$ flanjfatulen uno vorjuglid) in einigen Fidseltaimpen ber erften

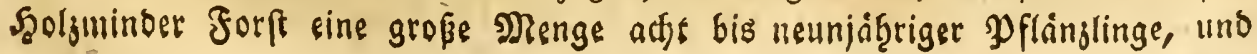


bereits fef̧r viel berpflanjte Stämme, bic man in allem Betradjt als maf̧re

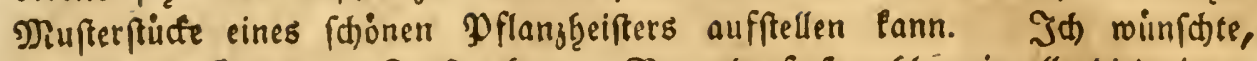

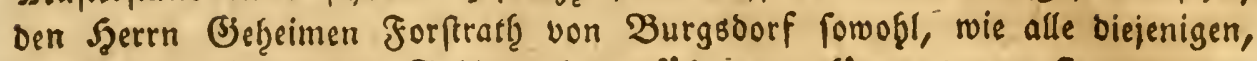
bie ifgum nadjbeten, im Sollinge ţerumfithren fu fönnen; um fie von bem Begentheile if̧res Eak̨es in biefem Yuncte übergeugen ju Eönnen. Die

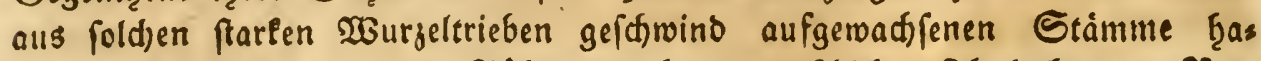

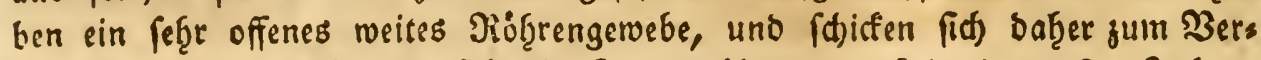

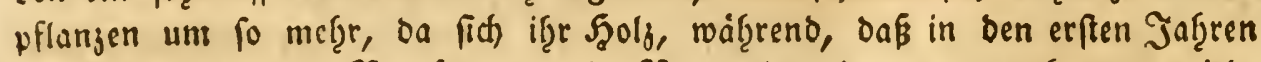

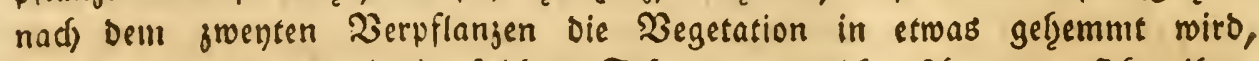
weniger vermafert, als in Foldten Stámmen, weldhe idfon an fidf, ifres langfamen Wadjens wegen, ein enges verţoljtes Rührengewebe ந̧aben. Die von einigen biergegen gemadte Einmentung, daß aus cinem Şeifter, beun in feiner erften Jugend einmal fein Şauptfamm genommen fen, Pein grofer Baum wadjen tönne, uno bie b̧icrben von if̧nen angefüf̧rten Bebenflidséten iber bie burch das 2(bfdneiben veiurfad)te 3 erwundung, melche ganj uno gar auswaddf, werben burch oie practifthe (Erfaf̨rung ges nugfam widerlegt; und fanwerlich witroe man wohl einen alten Eidfbaum finben, ver in feinem seben nid)t einunal feinen J̧auptfamm burd) irgenb

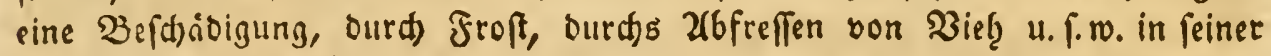
Jugeno verloren haitte.

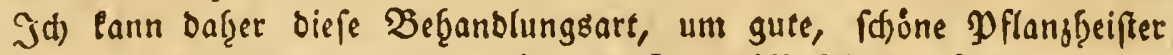
zu ergiefzen, einem jeocn mit ber größeften Zuberläfirgleit empfehten, befons bers zu foldyen Yflanzungen, fu weldfen man gern grobe farfe Stamme 6̆ nef̧men wünf)t.

\section{§. 322}

Sowoḩl naturlidje, als zufállige Befdadbigungen fỏnnen bie jungen Ståmme in den Eidfeléämpen und PFlanjfdulen entweber gang ober aud) nur in fo weit verberben, baßs baraus, wenn fie of̧ne Benfiulfe fid felbft uberlaffen bleiben, feine fdjone Stimme wadjen fönnen; ḩierb̧in geţort bas $3 e r f r i e r e n$ ber jungen Sooen, ober auch woţl gar ber ganjen Stämme, bas abfreffen ber

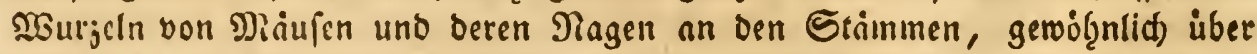

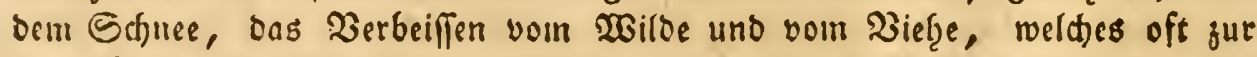

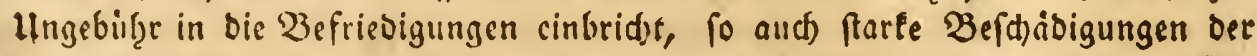
jungen Soden Durch Snfecten uno Meţlthau, uno meţrere Dergleiden. Die

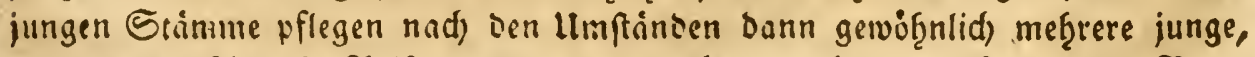
geringe uno [d)wad)e Pisifer wieder ansjutreiben, woben es auf eine gute Beurs ţeilung anfoumut, ob man in folgenden Jrübjaţren Durd) 2(bfdneiben ber uns 


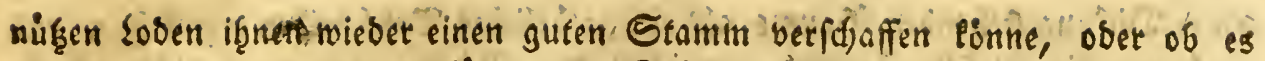

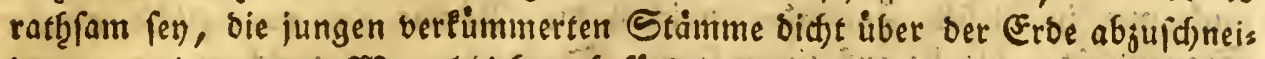

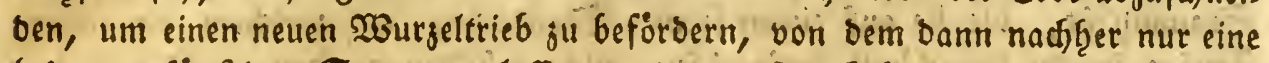

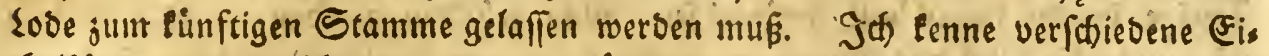
deleámpe, in weldhen aus oen verkimmerten Soben nach einein folden 2 (b, fdneiben bie fdjönfen Stämme geroatjfen fint.

\section{§. 323.}

200as man íbrigens in cinigen Forftefriften voun Fortpflanzen und Erzies

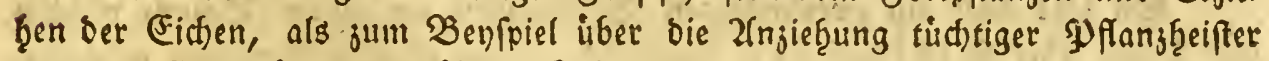
aus ber 20 urzelbrut bon siltern Ståmmen, burd) bas Einjenlen ober Einles gen ber 2lefte, burd Das fogenannte Stecfen abgefdhnittener Eidfenzweige zus ben Eulturen im bructigten uno feudten Booen, uno bergleiden findect, gef̧ört

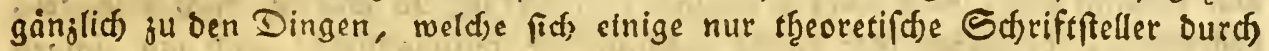

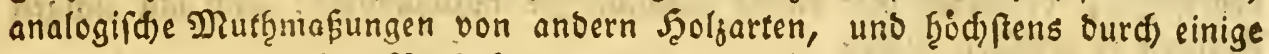

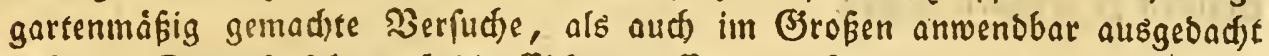

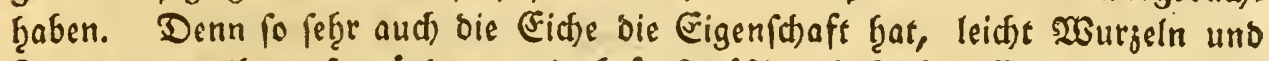
Zweige sul treiban, fo wurbe man bod) forftmåsig mit foldhen Eulturarten nichts ausrid)ten, fie fonnen alfo Godditens nur für bie Fortpflanjung einiger Spiels uno frember (Eid)enarten Statt finden, wiewoht für biefe aud) bas Jortpflanjen burd) Das belannte $\mathfrak{P}$ fropfen ober Dautiren vielmeţr ou empfeg̨len ift.

\section{§. 324 .}

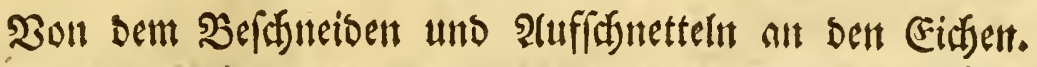

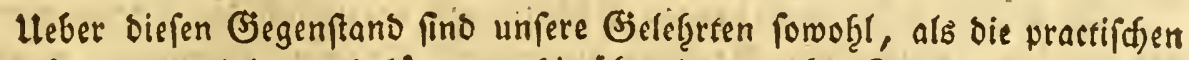
Sorftmainner, unsinig, uno ḩort man f̧ieruber in mand)er Forftgefellifhaft eben fo lebtraft für als gegen bie Sache freiten; gerabe 10, als es úber bas $3 e r s$

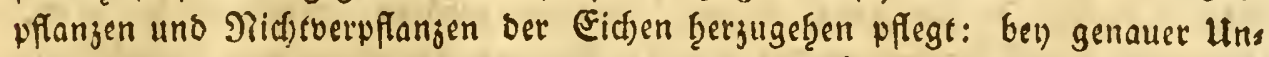
ferfucfung aber wirb man finden, bas, wie es getwónnlid) oer Fall ift, bende

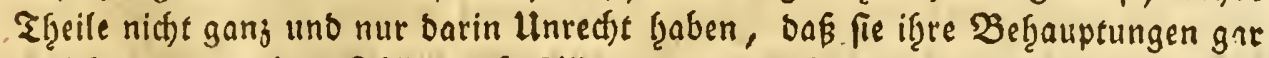
bu fetre von einzelnen Fällen aufs Zlllgemeine ausbef̧nen, uno aus einem einmal

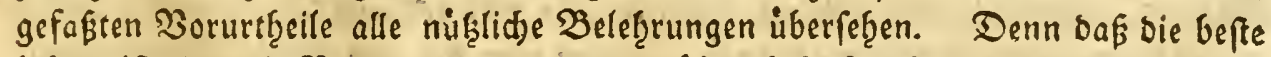

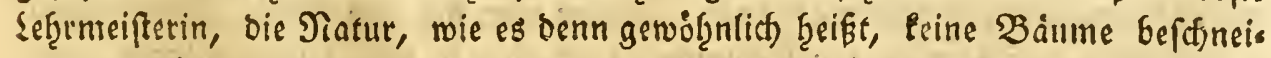
bet, bas lann bod) woḩl nidt als ein allgemeiner bemeis bagegen angefüf̨rt merben, weil biefelfe fich anber Mittel bebient, um gleide 2 Sirfung herborgu= bringen. So if zum Beyfpiel bas Bertrodenen ber untern 2lefte, an einem in (Erfet Thell) Do

einer 
sinet Didung ftehenben Baume als ein naturlides Befdineiben angufeţen, uns oud) nur in biefent Suftande erreid)en bie båme bie vorjuglid)e serabe Stammbobze, bie fie auf einem frenen Stanborte, auf roldfem die untern 3reige immer baran mit fortwathen, nid)t erf̧alten wurben. Die Natur zeigt uns alfo felbft bas. Mnittel an, roeld)e wir jut Erjię̧ung folder Strimme onjumenoen baben, an weldjen wir ju unfern verid)iebenen 26 fid)ten burd) bie Sunft Das erreiden fónnen, was uns bie Natur Daran jufällig verfagt.

\section{§. 325 .}

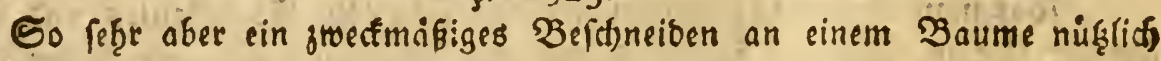
fenn eann, eben fo fdablid ift es bemfelben, wenn es of̧ne Renntnis gefdiebet. Beybes lann forobgl an jungen als an alten Stäminen Stott finoen. Da nun biefer midtige (Jiegenftano in unfern rammtlid)en Jorftid)riften, foviel mir bas bon befanut finb, noch nid)t genugfam erlautert ift: 10 mill id) mid) befonbers befleißigen, benfelben hiêr etwas reitläuftiger nbjuţandeln, uno mit einigen figuren fu erllären fud)en.

\section{§. 326.}

Ben allem Berpflanzen ber Eichen frmotel, wie ber librigen Baumf̨oljs arten viberbaupt wiro barauf gefeben, dak fie in oen erfien Gatgren nad) Dent

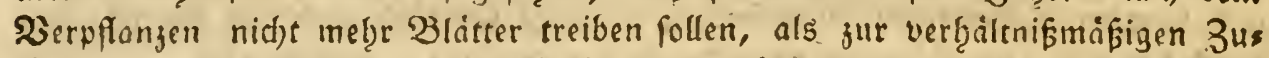
fiibrung uno atusbinftung hes Safts, jwifden bieien uno ben ourdis $3 e r=$ pflangen gefdrodiden uno aus guten 2(bfid)ten oft aud) befdnittenen 2 Burgeln notḩiß fino, wie babon in oer Einleitung über bas $\mathfrak{B} e$ fdneiben oer $\mathfrak{B}$ aume meţreres vorgetommen ift.

Es miffen baber oen jungen Pुfänglingen vorguglid bie 3meige genoms men werken, welche ain Stamme eine farte Srumme veranlaffen roirben, weil babil) auf ois Ergiefung fdjoner Ståmme mit Riúffidst genommen voiro, wie Fig. 3. Tab. 6. Der Jweig a uno b f̧ierf̧in gelgoren, vorginglia) bie oben,

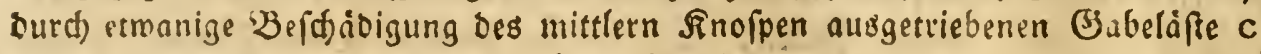
und d von weld)en ber weniget fdoone abgefdnitten werben inuf, wonact) bies fer Sgelfter nie jig. 4. elfdeint. Da nun aber bie metrete Stärle eines

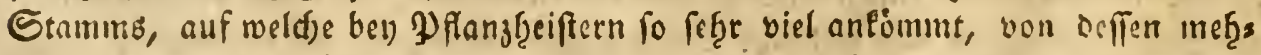

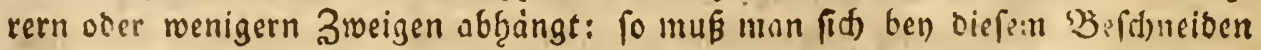

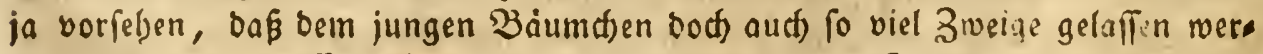

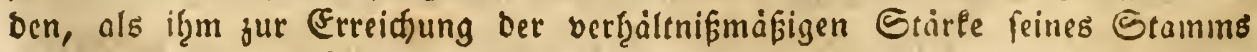
nuthig fino: man wurbe babger feģr unrecht beandeln, wenn man sinem folden 


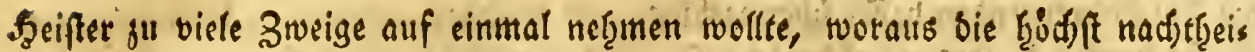
lige Folge entfteben tönnte, bas ber Sgeifter bielleicht unten wieber einige geringe fdimadjende Sproffen, oben aber mefzrere farke uno reich belaubte Broige treiben, uno mit biefen lopffdwer in Sonmer fid Erunmen, uno im $\mathfrak{\text { Winter }}$

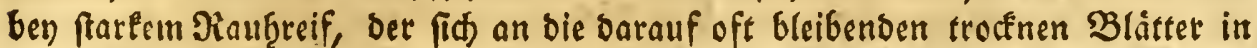
grofen laften biangt; fich ganj biegen und vielleidfe gat bredjen twirbe (in bet

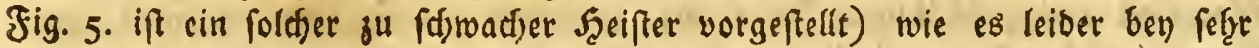
bielen fđönen Szeiftern, vorgüglid in ben Gebirgsforften bet Fall ift, welde

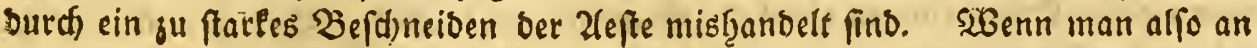
einem jungen Szeifter einen in ber Folge fádolidjen 3weig aus Furchi, ifn im Stamme zu fdwådjen, abjufd)nciben. Sebenlen trảgt: fo mus man foldem

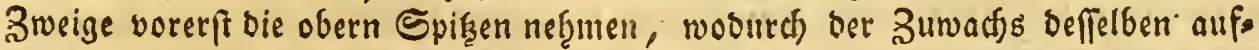

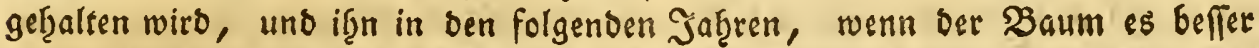
vertragen lann, erft ganz abfonneiben.

\section{§. 327.}

Das $\mathfrak{B}$ efdneiben ber jungen Pflanjlinge in ben Caats unb Pflanjfdus len muß einigemal, nadbem es der meţr ober weniger gefdjlofiene Stand bet Pflänlinge, ober fonftige Seranlaffungen es erforbern, wieberf̨olt werben, wobey es als ein nidyt ju überfhreitenoes Beferg gelten mus, lieber auf einmal

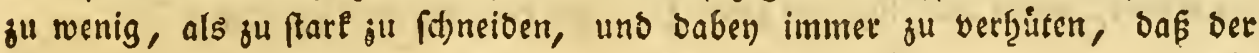
Stamm nidjt ju lang und (d)wad) aufidjeßse, weldjen feb̧ler man nidjt leidjt mieber zu verbeflern im Stande ift. Es mus bafer ein Forftmann, ber fid bie

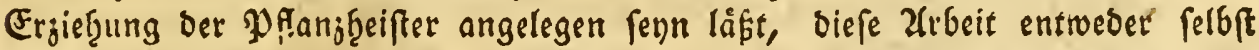
thun, ober bod) renigftens in feiner (5)genwart verrichen leflen, uno bafu nut foldfe Mitarbeiter gebraudfen, weld) baran einigen antheil nef̨men, unt bie er aud zum Pflanjen uno Dergleicten forftarbeiten ju nef̧men pllegt.

\section{§. 328 .}

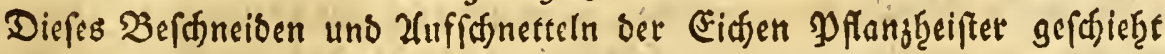
am beften in Jruf̧jaf̨r Purz vor bem 2ustreiben bes Laubes, wenn man juit bem SPlanizen in ben Forften fertig ift, ober aud gleid) nacf Jof̧annis vor bem zweyten Rriébe, inoem bie von bem 26fdyneiben ber 3weige verurfadten 23 un: ben alsoann un befto efrenber verwad) fen, als ben Winter uber, wenn es iut

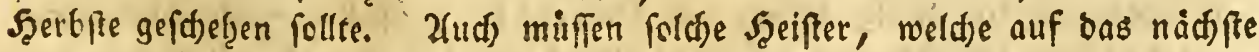

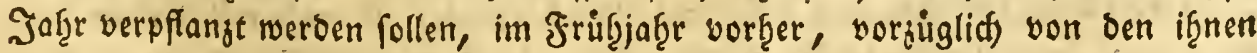
nađtţeiligen grösern 2leften gefäubert werben, weil fie vor bem Berpflaizen 


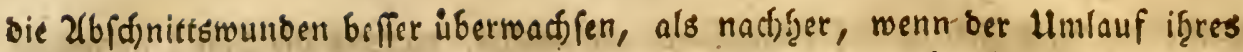
Eafts burd)s 2(ufroben gefdwad)t ift, uno man i[̨nen aud fdjon boraus eine beffere Form zum frenftehenden Şeifter geben Eann.

$$
\text { §. } 329 .
$$

25enn tie vor einigen Jaf̧ren in ben Forften gepflanjten J̧eifter fu if̧rem

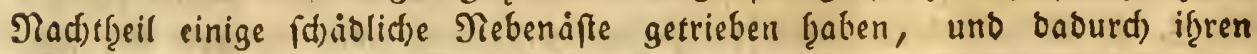

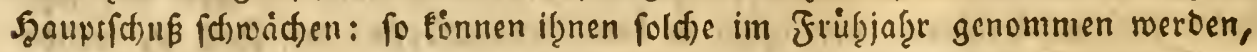
wobey obige Erinnerungen ebenfalls Statt finben müfen. B̉e Y)flanjungen,

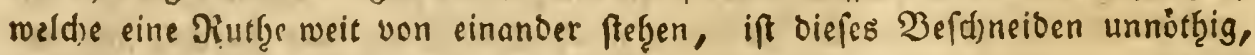
weit fie fich in oer Folge felbft oon if̧ren untern 2 eften reinigen, und einander auftreiben: ber) folden aber, von orey uno mebrern Jiutfen weit, mie man oft all Şuten zu planzen gezmungen ift, wirbe niand)er fdoje Sgeifter nur einen

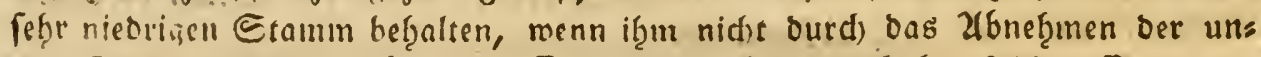

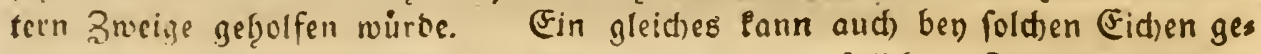

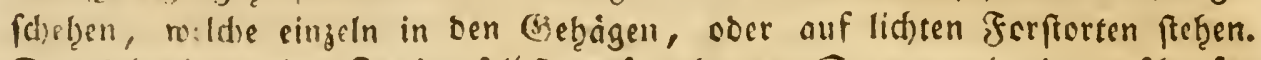

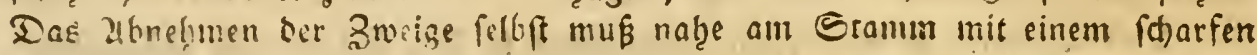

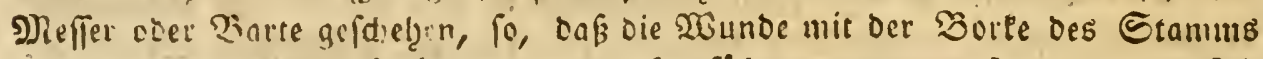
gerabe ift, mobey ber Şieb von untell auf gefübret weroen muß, bamit ber fals lende 2 ft mit feiner 5 d)were die untere Borke nid)t lofreife, weld)es gefdjes ந̧en wirbe, wenn man if̧n von oben b̧crunter f̧auen ober fducioen wollte.

\section{§. 330.}

Da bas 2fonef̧men eines 3weiges eine- Bermunbung aim Stamme verurs

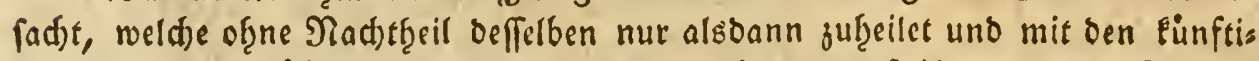
gen Saf̧rstingen übergogen wirb, wenn fie nidft fu großs ift, uno ber Stamm

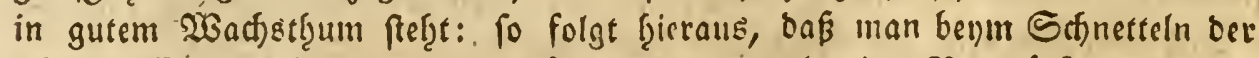

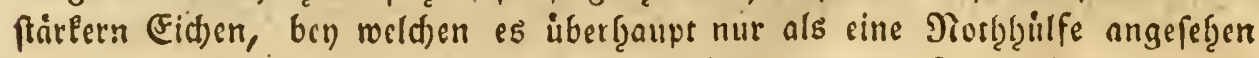
werben muE, nur bie flcinern Zlefte bon bृidhftens bren Soll bicf, nid)t aber foldse ftarle abţauen barf, welde, wenn fie aud mit Borle gang uberwadden

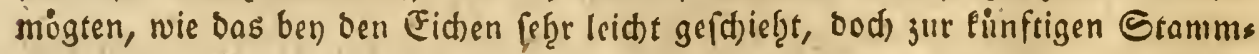
failnis bie nåd)fe (B)elegenfzeit geben würben; mobon man fid) benm Rerarbeis ten uns Durchfdunciden alter (Fid)en fefre leid)t uberzeugen fann.

Die Ulrfad)e ber Faulnís eines abgenommenen aftes liegt in ber Con=

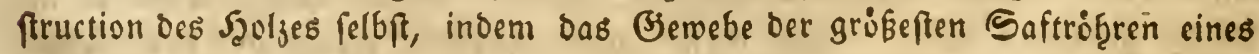

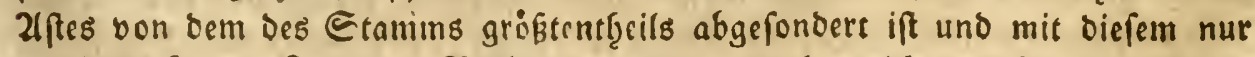
ourd) bie feinern Jafern in 3erbinoung ftefgt, ourd) welde es aber nur in ben 


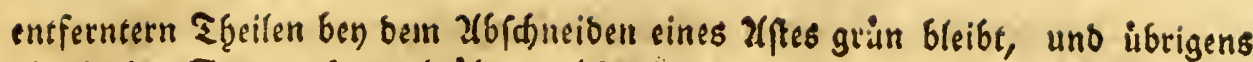
als ein in Stamm ternad) úberwadjpener tobter uno nach uno nadj faulender Siorper frecten bleibt, wie es bie fig. 6. weldfe einen überroadfenen $2(f t$ im Durd)iffnitte bes Stanms vorfellet, beutlid)er zeigt. Es ift baf̧er oas $216=$

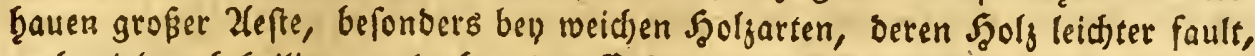

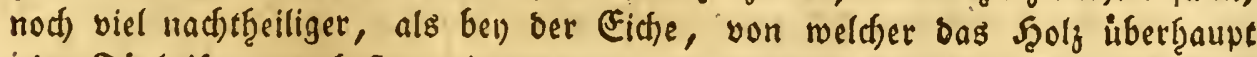

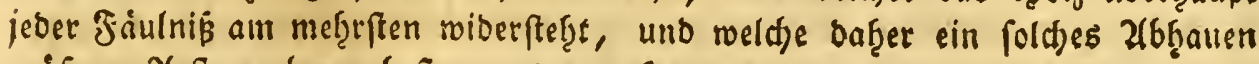
gróferer 2(efte nod) am beften vertragen eann.

\section{§. $33 . \mathrm{r}$.}

2n foldhen Eidien, weld)e unfere 3orfaf̧ren vor fectjig und fiebenzig Jaḩren auf J̧aten weit von einander gepflanzt, und, wie es bamals Sitte war, Dabey gelopfet haben, ift bas Zuffidnetteln und 2lbf̧auen ber unsern 2lefte faft

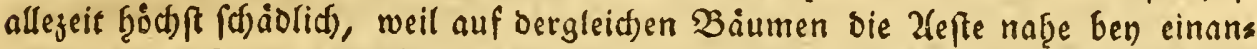
Der als eine Frone gewadjen fino, unto baburdy im Snnern bes Stamms ein gar ju grofer fauler Stoljeórper entfteg̨en wirbe. Diejenigen Jorftbeoiente, meld)e alfo if̧ren unnükęen Dienfteifer an foldfen Bäumen oft of̧ne Barmţers

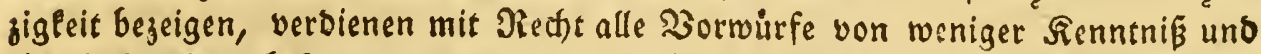

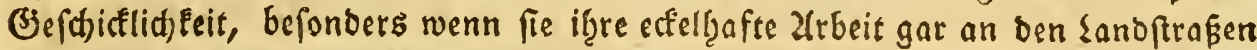
zur Schau betreiben, wie bavon an ber Seejenfthen Sanoftrase im Syilbesfeeimis

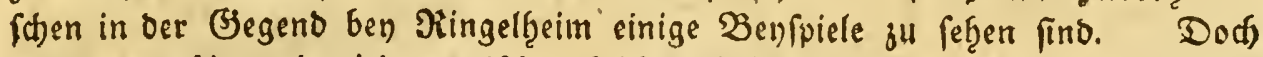
finoet man hin und wieber zroifden foldfen $\mathfrak{B}$ aumen einige, weld)e einen für

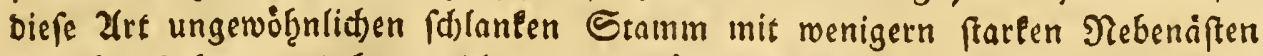
getrieben ḩaben, uno bey weldjen ein vernüftiges Sdjnetteln fȩ̣r nüs̨lid ans gervendet rerden eann.

\section{§. 332.}

Bey allen grö́sern Eidjen, an weld)en mef̧rere 2(efte abgeţauen werben

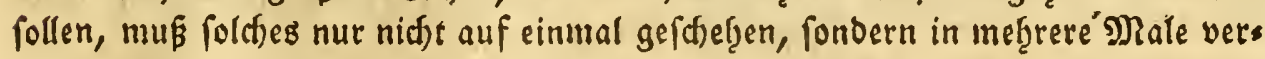
theilt merden, jwifhen meldsen bann jebesmal nad) ber Stäke und form ber

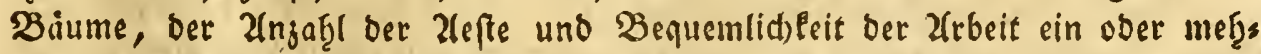
rere Jaf̧re gervartet werben mus, woben aud) ber Bortheil benugat werben Eann, baßß man benım erften Schnetteln ber untern Zlefte faton biejenigen,

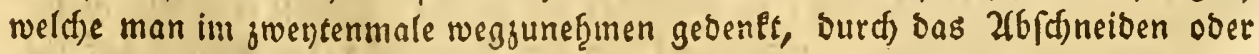

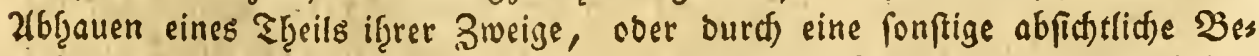

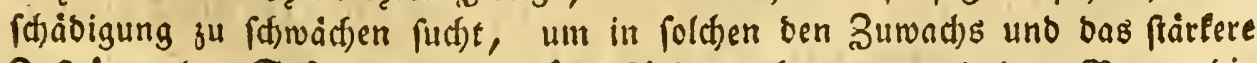

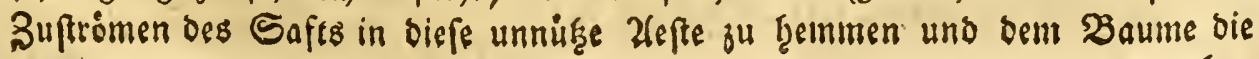


bey) bett tünftigen 2(b6hauen erfolgenden Stofungen ju erteidtern. Sin vies len forftidsiften ift oaher, um ben Baum voraus an ben $\mathfrak{B e r l u f t}$ feiner

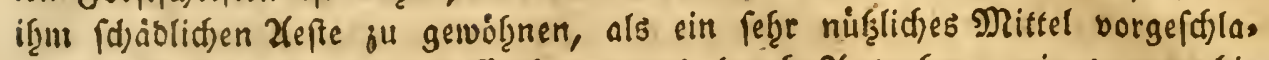
gen: man folle biefe ourd) Einf̧auen uno burd) 2(usnef̧men eines jwey bis oren Zoll breiten Borkenreifs, ein ober ein paat Jaf̧re vorb̧er abferben mas den, und bann erft ben alf ganj am Stamm abpurzen, weldes Mittel ges wißs mit vielell Brüben empfoblen ju werben verbient, nur aber in fef̧e vielen fillen ben grofen, weitläuftigen Yflangungen mit cinigen Stjmierigs Eeiten verbunbent ift, uno ebenfalls, aus oben angefüb̧ten (Bründen, nid)t

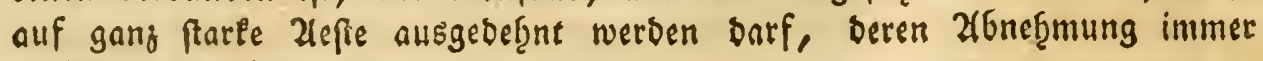
nađțţeilig bleibt.

\section{§. 333.}

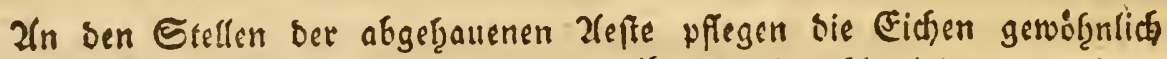
meţrere frartmad)fende Wafferrsifer ausjutreiban, micmob̧l alsoann weniger, wenn bas Sdnetteln fut red)ten Zeit, nainlid) um Tothannis gefdieţit. Dies fes 2fustreiben ber Wonferteifer wirb befonders von benen, weldje bef̧aupten,

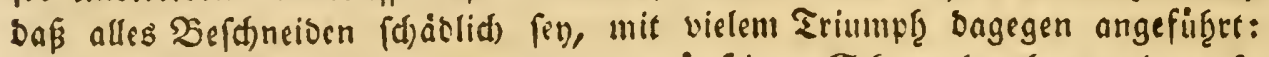
es ift aber, bey einen gemáßigten, verninftigen Sdjnetteln, bey weitem to (d)ätid nid)t, als man es angiebt, es beföroert vielmetre bas beffere Hes

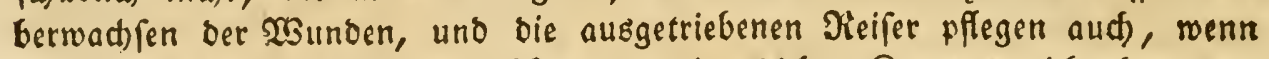

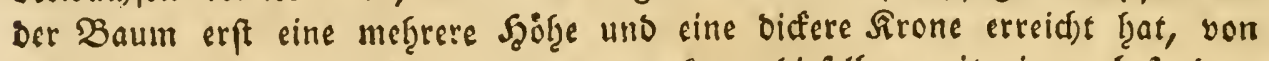
felbft wicber ju vertrodnen, ober man fann biefslben mit sinem befonbers bazu gemadten Eifen Jig. 7. mit geringer Rithe abftofen, weldes audh bev) jüngern Eidjen für fleine Bweige nilf̧lid) gebeaudjt retben fann.

\section{§. 334 .}

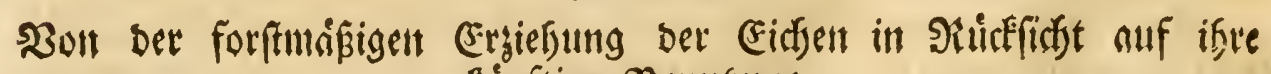

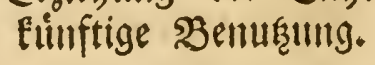

Da bie Benuferung ber Eidjen, vor allen andern Shoigarten fo vielfact) uno

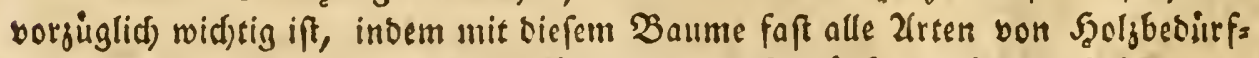
niffen am beffen befriebigt werben fonnen, biefe Beburfniffe aber nad) Solalvers

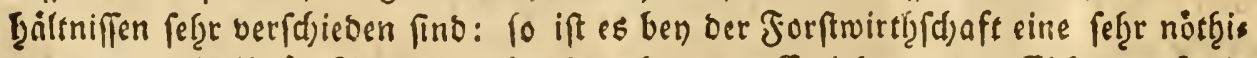

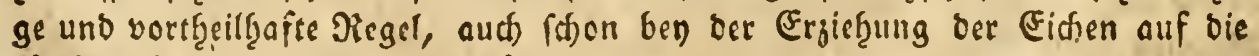

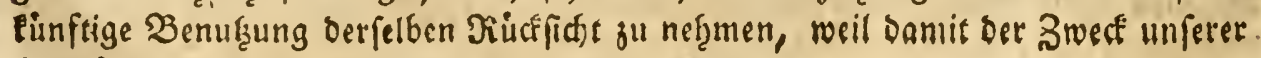

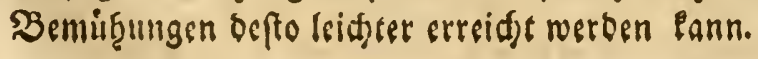


Die Bennf̧ung bet Eidje und bie nađ biefet einjuridjenben Ergief̨unges

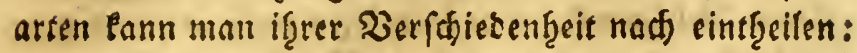

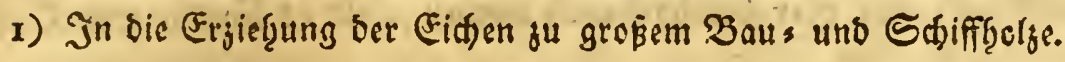

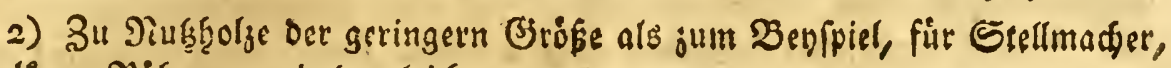
ju Ballen, Röb̨ren, uno bergleifjen.

3) ลu Foந̨len, uno Feuerţolze.

\section{§. 335 .}

Sur erften Elaffe gefiuren alle Eidhen, weldfe wir in ber $2(b f i d f t$, baj bars

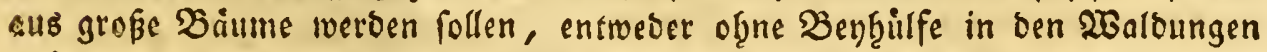
aufwadjen laffen, ober auch barin fäen uno pflanjen, wobon bereits bie Erjies bungsart abgefrandelt ift, uno nod) verfdjiebenes in ben \$\$. von ber Benuf̧ung ber Eidfen berif̧rt werben wird.

Sur zwenten Claffe gefgort ein grofer F̧geil ber ju jener erfern getechneten (Eid)en, nämlid bie, weldhe bie abfidstlidse Stäre nicht crreicten, weil es if̨nen entweber an bem baju erforderlid)en Bumadje gebricht, weil fie $\mathfrak{B}$ efdadoigungen

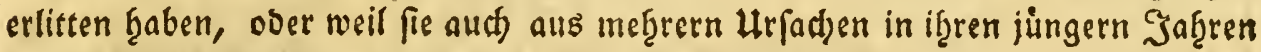
abgetgauen werben.

2(ud) giebt es meţrere 2(rten yon Eidfen bet geringern Bröse, auf melde

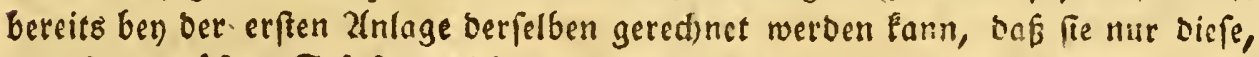
uno feine grösere Stärke erreidsen follen; als foldhe, weldje auf cinem flactern,

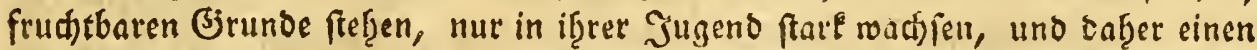

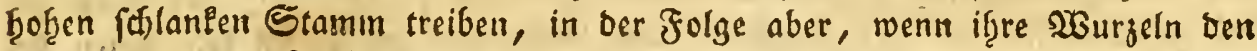

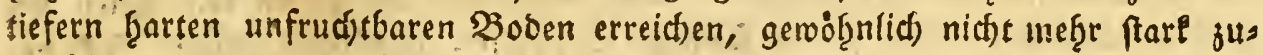
wać) (en, und in ber bis baţin erreidten Stärke fteţen bleiben; bergleiden

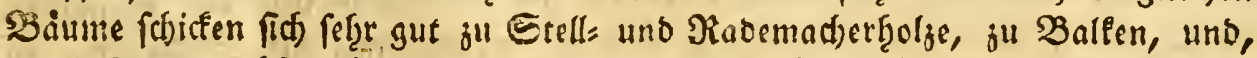

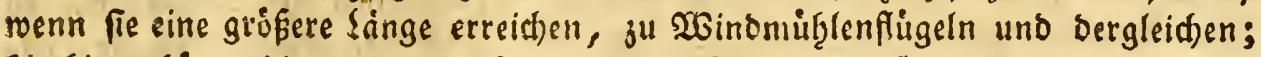

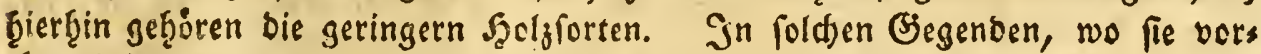

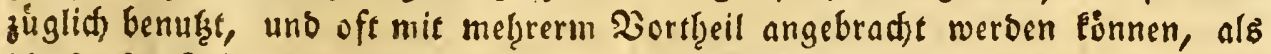

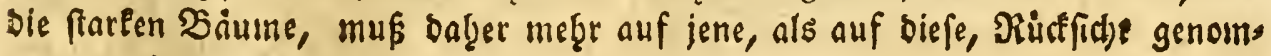
men werben.

\section{§. 336.}

Die Cultur biefer zmenten Elaffe ift gróatenţ̧eils mit ber Ergief̧ungsart

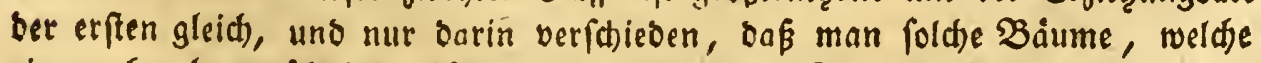

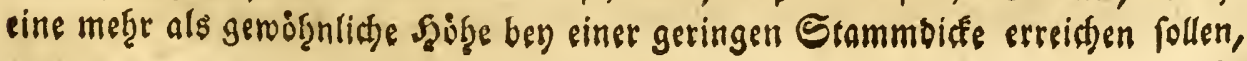


in einem boljoidten Gtansorte aufrodjpen lábt; wenn fie alfo in naturlidien, ooer aud) mit ber Saano befäeten (Beljaigen ftef̧en: fo muffen biefe nidjt fo ftar uno lidft geplentert ober burdjgefgauen werben, als es für bie exfte claffe ges fdjerien múfte.

Die DPfanjungen berfelben müfen enger fenn; man fäst uno pflangt fie beswegen aud robgl zroifden andere ftartroachende fgoljarten, als jwis fifen Tannen, Serdfen, in bie Rothbüdfen, uno vermifdten Derter, weld)e

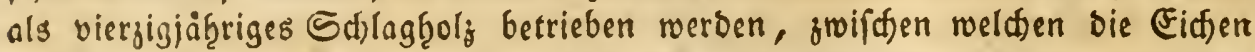
eiucn fefce langen aber aud) an fid) fdroadien Stamm treiben, oben eine geringe $\mathfrak{B}$ eaftung Gaben uno beswegen bie Stäle ber erften Elaffe nidjt ers

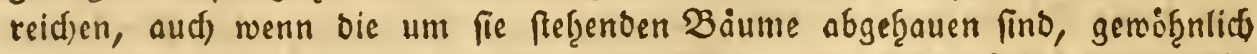
an Zuwad)s verlieren uno oft burd) ben Wino nievergemorfen roerben; fóls d) Båume fino in einigen àltern Pflanjungen in ben benoen 2 Beferbiftriften aus ben Zeiten bes Dberjägermeifters bon Sangen und in mef̧rern Forften in

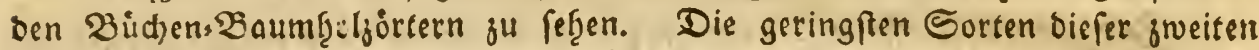
Elaffe fino bie, weld)e ju grofien Bibbenreifen, zu seiterbsumen, Deidjeln, uno bergleidjen gebraud)t werben, weld). jum Theil in bid)t beftanbenen (Eis d)enortern, als von anoern unterbricft, vorfallen; jum ₹leil aber aud fef̧r

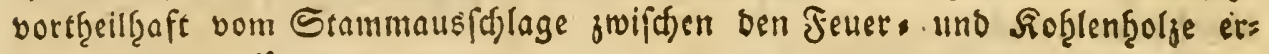
$\because$ ani weroen Ënnen.

\section{§. 337 .}

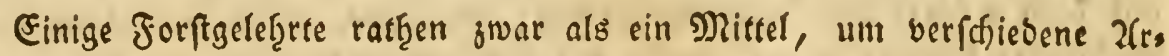

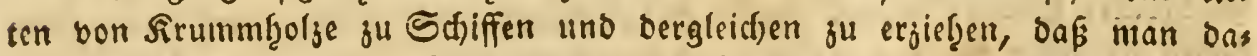
gu bie Stamme in if̧rer Jugens ourd) 2lnbinsen an bie neben. ifgnen fte. Genoen Baume, ooer burd) fonftige Benfiulfen gewóf̨nen folle: Jri ber praftifdsen 2(ukubung aber lann biefes nur ḃöfftens bey ber geringften Elafle von foldten Şolzarten Statt finden, welthe etroa die Stellmadier. jul if̧ren 2rbeiten gebrauchen, uno id fę̧e nid) wohl bie Miogliḑeit ein, wie

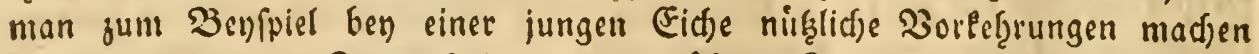

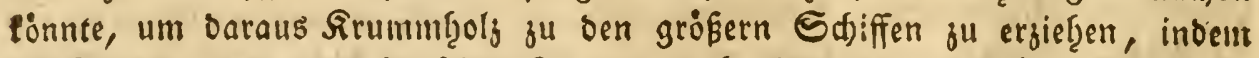
ber $\mathfrak{B}$ aum, bem man in feiner Jugeno aud eine paflidje Sirumme baju ges geben fiätte, fold)e längftens verwadjen, uno fid, gegen bie 3eit roieber ins Sierabe gefefte fraben wirb, da st ju feiner Beftimmung bie erforderlicfe Etirfe traben wutoe. Das Einjige auf weld)es f̧ierbey mit vielem Sortheil Rüffid) genommen werben Eann, beftę̧t batin, bá man beym Zusfid)ten

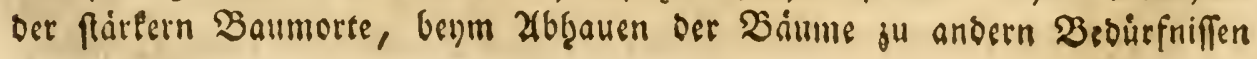




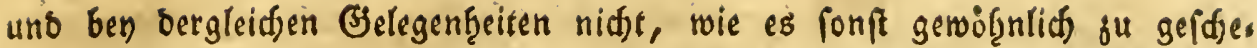
ben pflegt, immer bie Erummen uno ungleich beafteten Säume of̨ne Unters fdies wegnefime, fondern foldje alsoann vorgiglid fdone, wenn baraus roes gen bes gebogenen Stamms ober ber fofiflid)en grofen 2lefte ober (Sabeln,

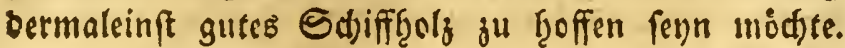

In ben fiefigen Füftlidjen Lanben, muß fierauf in ben Wefers Dbels forftoiftriften vorgugfich geadtef werben, weil bafelbft bas Sdjifficols, wes

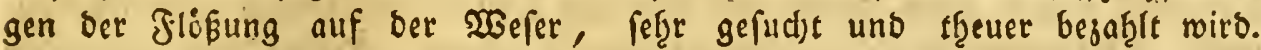
Die bortigen forftbebiente miffen fid alfo mit bergleiden Sgoljforten auds befonders belannt madjen.

\section{\$. 338 .}

Die Erziebzung ber Eid)en ber britten Elaffe ju Siof̨l: uno SBrennfioly, Eann man mit ber von anoern ju biefen $\mathfrak{B}$ chuf beftimmten Soljarten eins theilen in bie Ergief̧ung ber Fiden aus bem Saamen, wohin aud in bies fem Berfande das $\mathfrak{P}$ flanjen ber aus bem Saamen entfandenen Soben gef̧orf, und in bie Erjiefrung aus bem Stamms und Wurgelausfalage, rold unter bem eigenen Namen ber Eidjenftangenf̧oljwirtbfd)aft begriffen ift. In ben fiefigen Furftlicten Sanden find mir feine Drte belannt, in weld)en bie Eis den aus Saamen und ourd) Pflanjen mit ber eigentlidfen 2(bfic)t gejogen roiren, baßj fie zu 3 rennfioly benufgt werben follten, weil man bierzu braucf)= bareve Syoljarten wäb̨len, und bie (sid)en vortfeilfafter vernufen lann. Das,

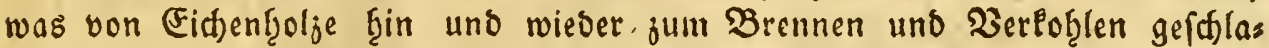
gen riro, ift von foldsen Baiumen, weld)e befdibigt, abftindig, ju গlukss biolje untauglict) waren, ober aud etwa andern beflern Baumen jum Sdjas ben, oder von biefen unterdrucft ftanben; bas Berbrennen uno Berlof̨len

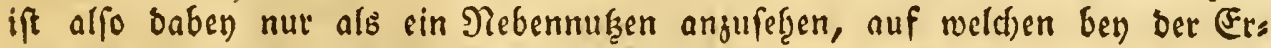
jief̧ung ber Eichen leine befondere Niuffidyt genommen warb. In bem

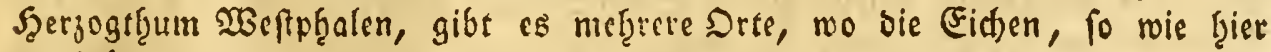
Die Buthen, ju Brennizoly aus bem Saamen gejogen werben.

\section{§. : 339 .}

2(ud) Die (Fid)enftangenf̧olgmirth(d)aft, bey welder bie Stamms und 26 urs

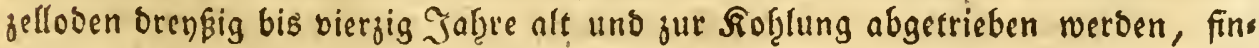
Det bis jef̧t in ben bृiefigen Jirrflid)en Forften nur mit eingelnen Strimmen Statt, bie zroifden ben andern Şolzarten ftę̧en. Zwoilfs bis. funfzeb̨njąg̨riges 


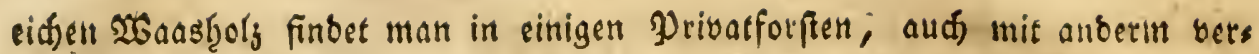

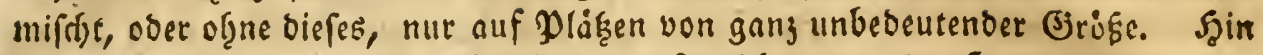

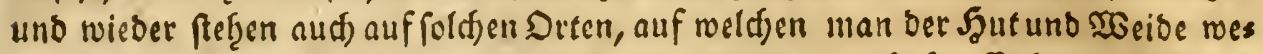
gen bie fogenannten Sopfgannen ju jichen pflegt, getippte Eiden; ju biefen

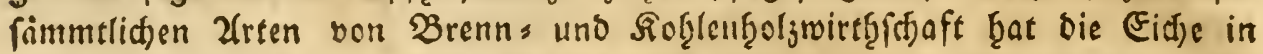
mef̧retm Betracht feţr grofe Borgige vor vielen andern Syoljarten, fowolgt in Betreff ifgrer guten Jeuerung uns ifgrer nidbt ganj idfledten Fob̧le, als

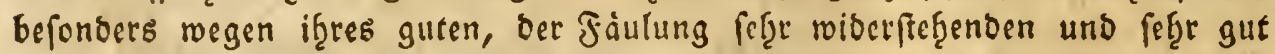
wieber ausfalagenoen 20 urjelfaums ober Jriebels. Daben treibt bie Eifje

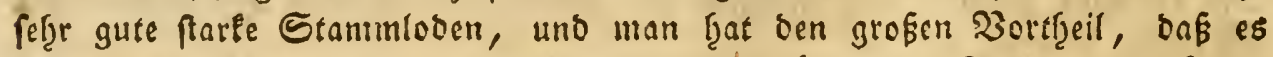
Dabel) nidtt to ganj genau, wie ben ber Rotg̨udde ober Birle, carauf an:

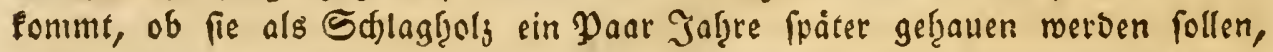
weil bas Sgolj felbft fid) alsbann meniger jum Sdjaben fteht, wie es ben ber Birfe ber fall ful fenn pfirgt, uno weil ber Stamm fitherer, als ber

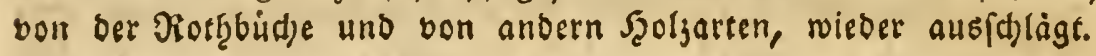

\section{§. 340.}

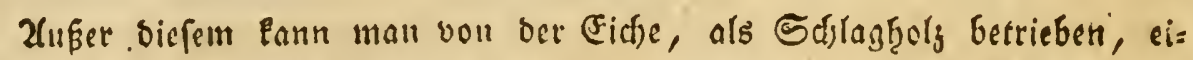
nen feb̨r grof́ell uno tighlid) junrbusenten Thufgen gewinnen, ourd) bie zum Berben nòthige Borle, wovon nadbber weiter.

In einizen benadjbarten Sintern frat man bieje, aits einet Eidjens

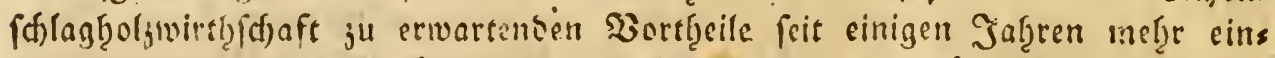

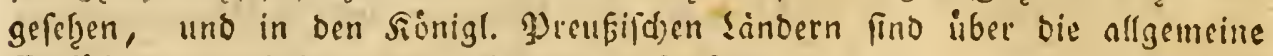
Einfitgrung berfelben einige befondere 3 efelgle ergangen, Deren Befolgung

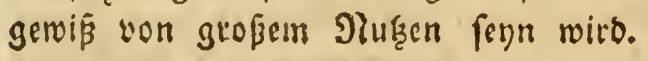

\section{§. $34 \mathrm{r}$.}

Die Znlage zul einem cidfen Stangsntorge gefdief̧t auf bie naimlidse

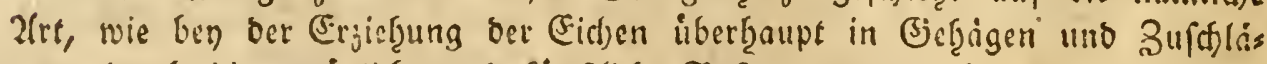
gen, surd) bie natitrlifje und funftidse Befaamung, woben benn bie Daju

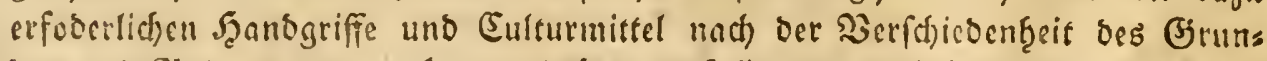
Des uno Bobens uno llad) Den babey vorfallenden nachtfeiligen uno ginpis gen Llmftinden ebenfalls Statt finden. Dahin getgort aud) bas bepflanzen folcher Stellen, weld)e ouref bie Befnamung nid)t oen gefgorigen Sgoljbeftano

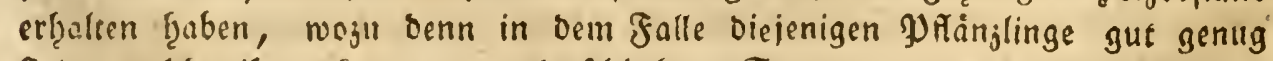
fino, weldje ilgres frummen uno fdled)ten Stamms wegen zu den übrigen 
Pflangungen nifft gettommen werben: Diefe werben benm Pplangen ein

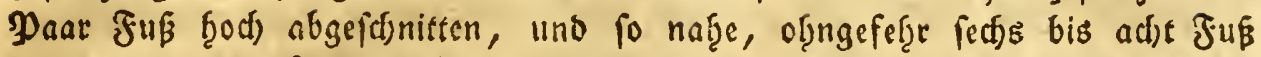
von einander entfernt gepflanjt, wie uran den eunftigen Stangenfigljbeftano j" நृaben wimfdt.

\section{§. 342.}

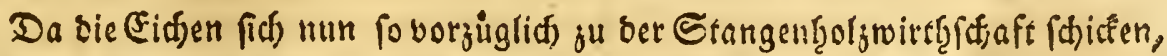
und fid) beffer, mie fefre viele Szolgarten, verpflanjen laffen: fo lünnen bas

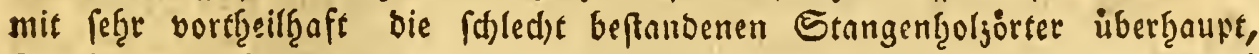

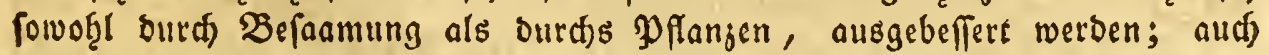
wito aus ig̨nen bann ofgnebies nod) mandfer fdjone Saum unter bem in folden Dertern mit ju erjię̧enden Sherţolje aufwadglen.

\section{\$. 313.}

Bey) Der 2(nlage cines cidjen Etangentroljes eann eten $10^{\circ}$, wie bey ans

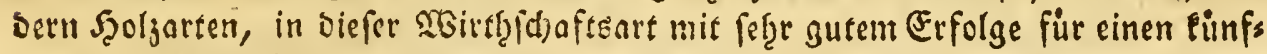
tigen guten $\mathfrak{H}_{\text {gl }}$ beftand geforgt werben, indem man bie jungen jwölf: bis adjts

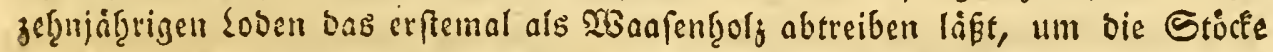
zum beffern und juberlaffigern Stammausfd)lage fïr bie lunftigen vierjigjątris gen Şaunngeparivoell vorjubereiten. Die $\mathfrak{B}$ efdreibung Der $\mathfrak{B i t d j e}$ mirb uns

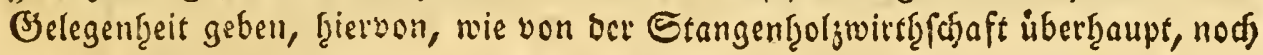

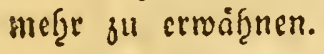

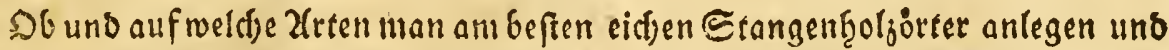

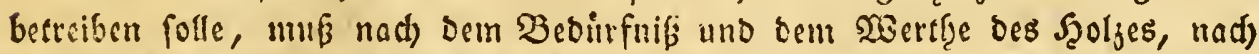
Dem Brunde unb Boben, und den ibrigens damit verfnupften $\mathfrak{H}$ mfrinden ents

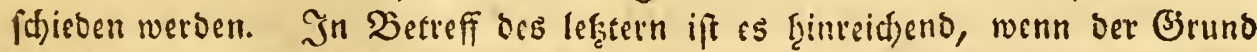

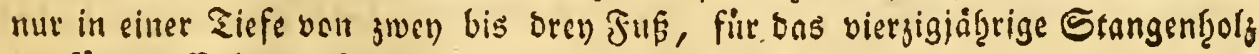

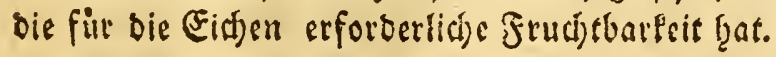

\section{§. 344 .}

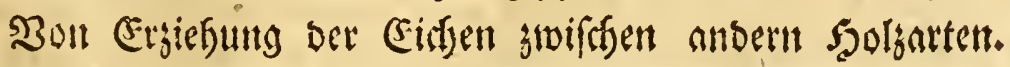

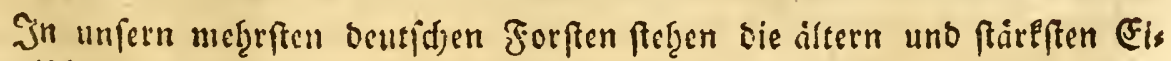

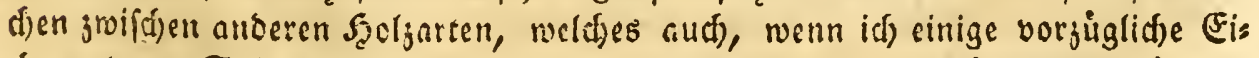
chenorte am Sollinge und cinige Plcine alte ciften $\mathfrak{B}$ aumfroljöter uno jüngere

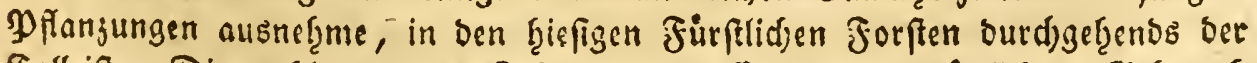

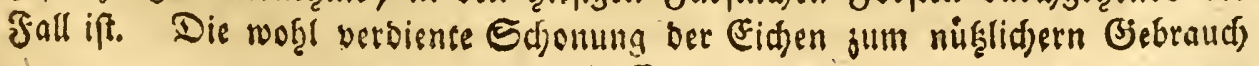




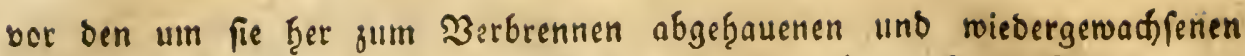

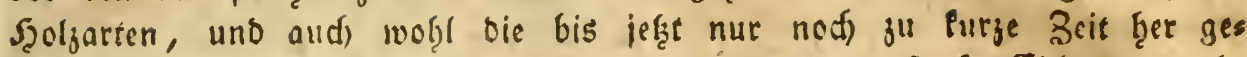
füfrrte beffere Sorftwirthf(t)aft, feit meld)er nod) feine farfe (Eid)en gerwads

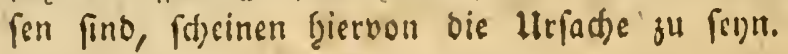

\section{§. 345 .}

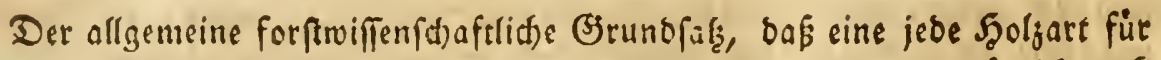
fid), und nid)t mit andern gemiít)t, gezogen merden foll, finbet vorjuglid auch bey) Der Eidse Statt. Es erleidtert Diefes die erfte Erjief̧ung berfelben forohl, als tie baben notffige Wartung uno $2(d)$ ffamleit, fo wie aud bie $\mathfrak{B}$ eftimmung

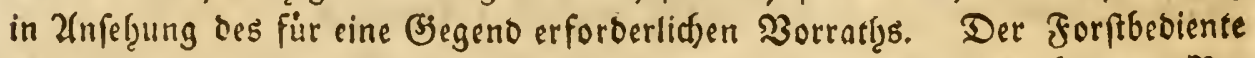
miro baburd in ocn Stand gefergt, ben jeber Belegenţeit Die nưtḩigen Bes Dürniffe mit mef̧rerm 3ortbcile ju befriebigen, als wenn er einen geforderten

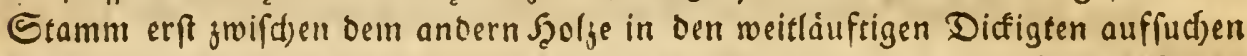
muk: aud) felbft bie Controlle wird genauer uno beftimmter, das Jällen, Bears beiten uno 2tbfaţren ser nothigen Baiume if mit wenigern Sdjwierigkeiten

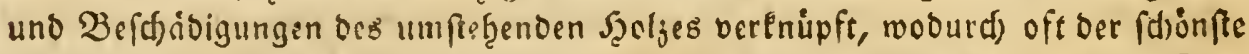
(Eid)baum mitten in Did)t mit andern Şoljarten beftanbenen Srte zur Zeit,

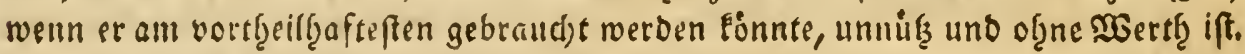

Bev einst guten Eintheilung eines grofen Forftreviere, in weldfent, wie

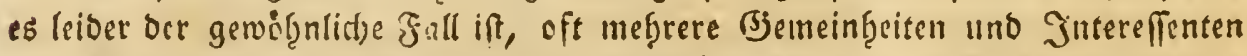
mit ber Scut berechtigt fino, fo daj benfelben ein gerwiffer Tigeil ber ganjelr Forft baju úberlaffer merden muk, eann man audy oft in Betracht oer fü bie

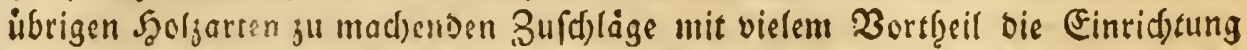

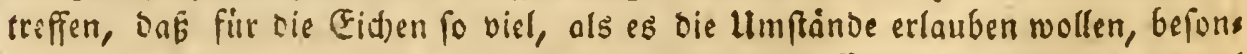
bere Drte beftiunmt merben, bie Dann, wenn bic Eidjen barauf erft einmal

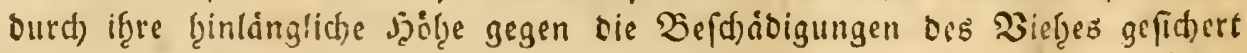

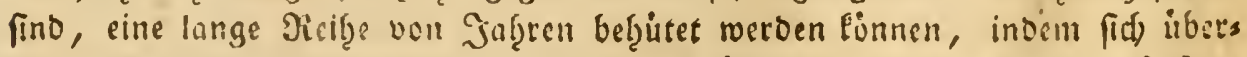

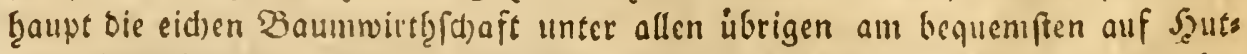
orten betreiben lást, fowobl wegen ber YPflanjung als ber Benufzung ber bes frandenen Dite jelbft, weil bic Eid)en nidte, mie andere Baumarten, auf eins

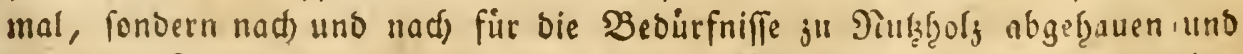
bie leeren Stelien darauf nad)gepflanjt werben lönnen, 10, Dak ein fold)er Drt

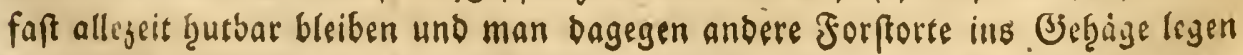
tann. 
2(ud) ben ber Tajation und Betreibung ber Maft ift es cine grobe Bes quemlid)eeit, bie Eichen gröstentţeils in einer Begend ber forft jufaımen pefgen ju f̧aben, als wenn fie einjeln zerfireuet finb.

Die (Eid)en werben aud) auf einem für fie allein beftimmeen Drte von

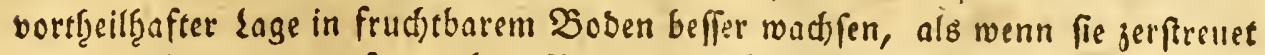

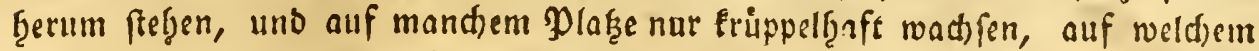
eine anoere Banmart inbeffen vielleidst jwen Bienerationen vollfommen beenois gen Punnte.

\section{§. 346 .}

Es ift aber barunter, oak bie (Fid)en nid)t mit andern Sgoljarten bers

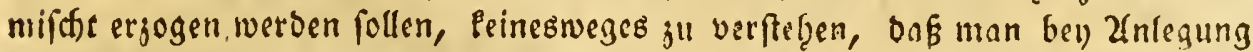

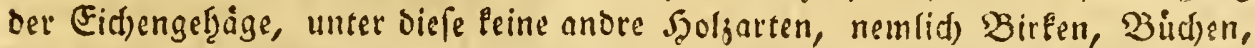

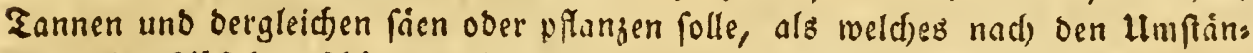
ben in ber 2(bfid)t, fdoine, robje Etamme zu ziefgen, oft mit been beften Er:s folge, befonders in ben weniget frud)tbaren Sandgegenden gefdiebet, uno als

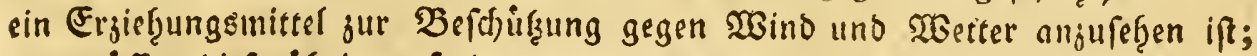
nur múfen biefe úbrigen Syoljarten, wenn iman bamit feinen Endjwect ers reidft uno finlänglidf Eichen gejogen bुat, nad) und nad) ausgeplentert uno ber Drt von nun an als ein blofer Eidjenort bef̧andelt werden.

\section{§. 34 ?.}

2(ber aud) bieje Tiegel ift nid)t og̣ne 2(usnaf̧me, unb wie cs in allem Betrad)t fogat nidft rathjam fenn mógte, eine ganj regelunápige fortits

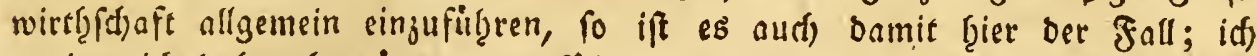

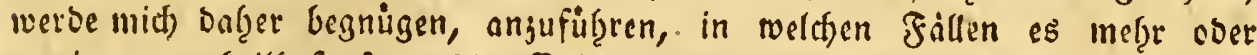

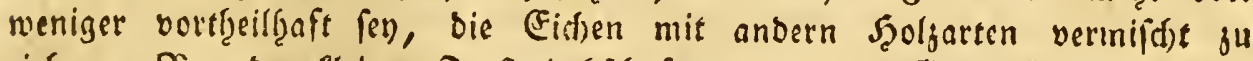

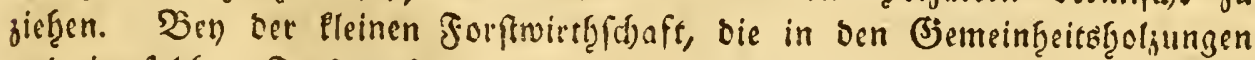

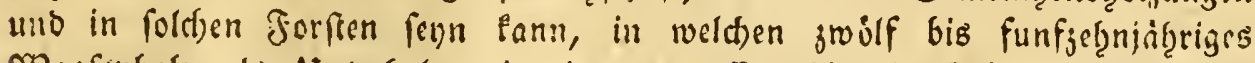

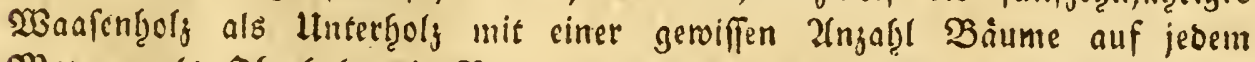

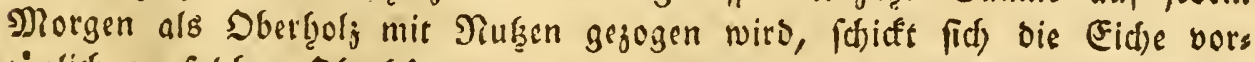
ginglid) 3" Folden Sberbaumen, menn anbers ber Bruno und bie ibrigen Ilunftande fie beginftigen, indem fie mit if̧rer wenizer bidtsbelaubten Frone

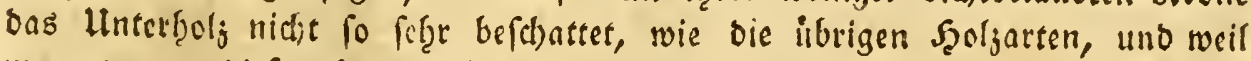
man wegen biefer fuijen Saaungsperioden feler oft im Stande ift, bie

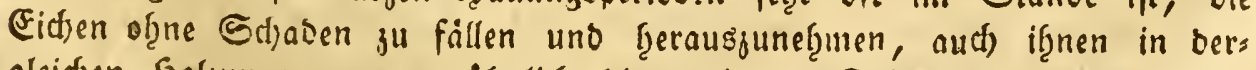

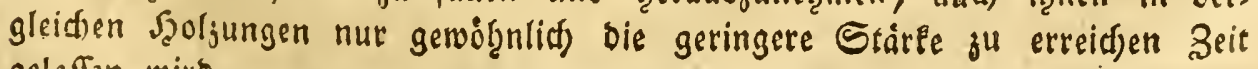
gelaffen wirto. 


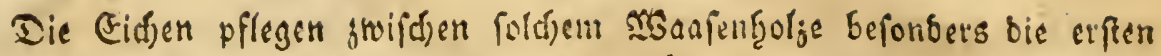

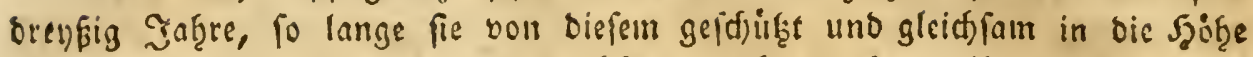
gatrieben werben, felge gut zu madjsen, nadjoem Pann ifgnen ourds bers ninftiges Sdunettell gefrolfen toerben, oamit fie unten nidfte ju biele 2lefte (d)lagen, und baburd) finftig bas Hntertigoly zu felgr veroumpfen.

\section{§. 348 .}

Bwifften bem fogenannten vierzigjä̧̨rigen Stangenţotje, beffen Setrieb

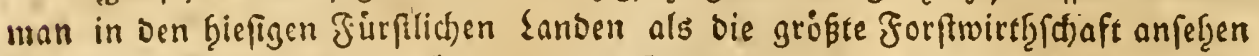

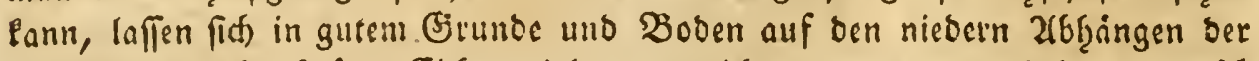

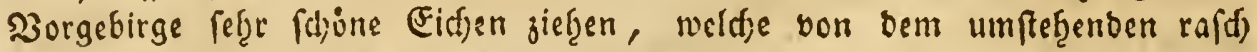

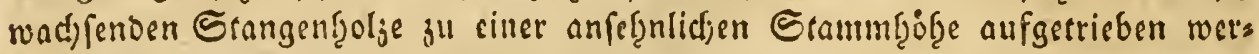
ben. Man pflegt alid) bel siefer jorftrietthfdhaft, von weld)er in cinem bes foltbern 2(bfd)nitte weitlauftiger gefgandelt werden foll, ju ben belannten SaFs

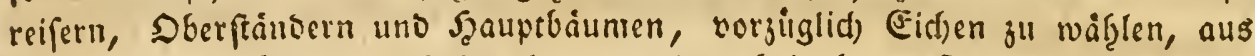
Der oben angeführten $\mathfrak{H} r$ fadie ifrer weniger belauten Sirone, und wegen

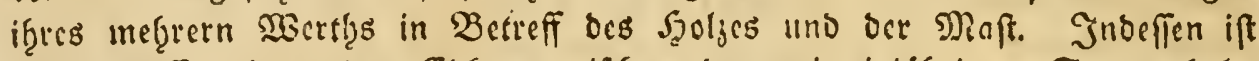

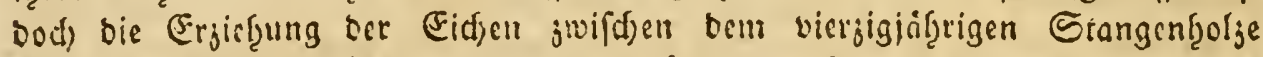

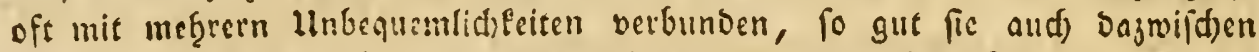

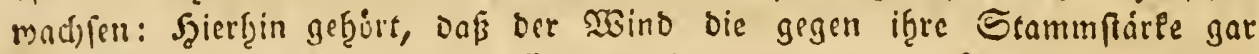

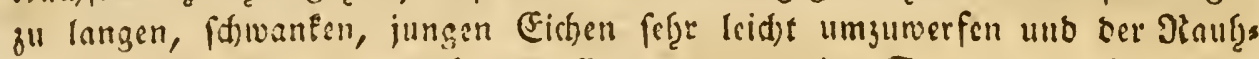
reif bie jüngerll nieberjubrüfen pilegt, wonn ein Stangenort abgetrieben wiro, uno bie Eid)en alstann unvefdlifget fich allein İalten follen.

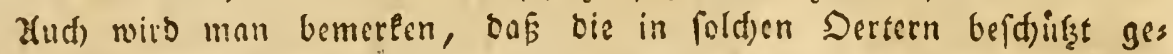
frantene (sid)en an ifgem Zurwadys fegre leiben, uno oft burd) bie befanns ten Froftborften ganj virborben werben, wenn bas un fie fiefzenoe Etans

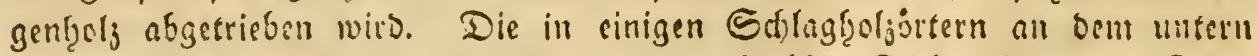

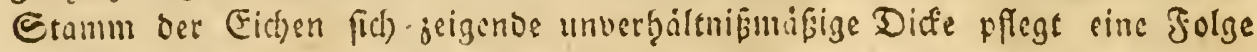

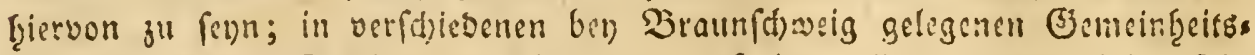
holjungen, fum Bevfpiel in Beobinger Şolje, finock man biefes fof̧e baaufig, uno es ift als ein fidjeres Beidjen anjuferfen, baş foldhe Eidjen

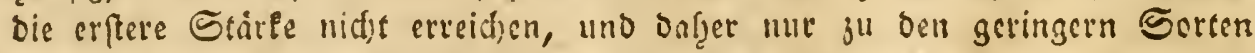

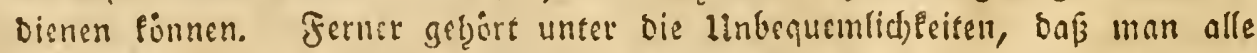
virrjig Jafere, nur to lange Beit, als es die jungen Stammloben geftatten,

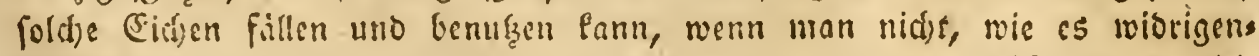

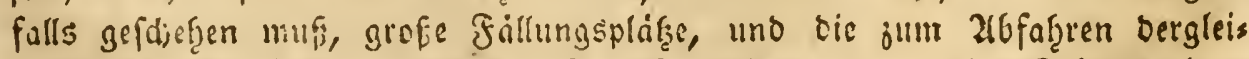

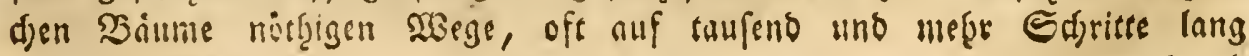
bull(i) 
burd) bas fajonfe Stangenfigls Gauen will; wobon man im Slanlenburs gifden und in ben untern. Sgargrevieren, aud) am Şilfe ben ber. gropen

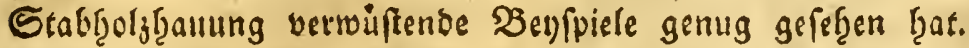

Wie injmiffen biefem in etrons vorgupommen fer, wito unten bey

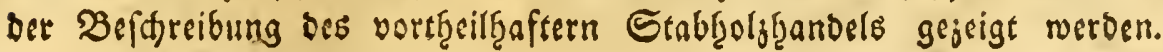

\section{§. 349.}

Die Sefdnerlichteit, mit ber man bie zroifden bem Stangentrolje

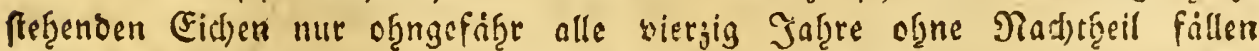
Eann, ift alsbann nod) grober, wann fis in folden Büdens Dertern fertan,

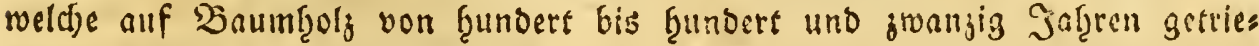
ben metben; es ift baber nid) rathfalm, Fiden, aus benen $\mathfrak{B}$ aume ber

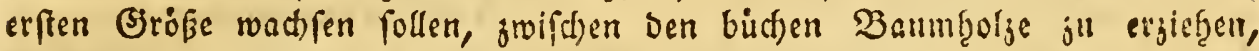
fo leidfit man aud) burd) ben befonders (d)onen, fd)lanlen 2 Guds berfelben auf einell fitr fie und fur bie $\mathfrak{B}$ itde gleit) frudjtbaren Dosen baju vers

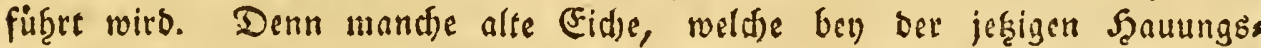

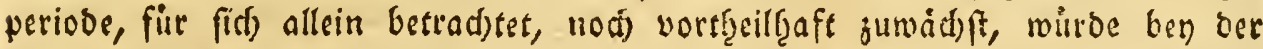

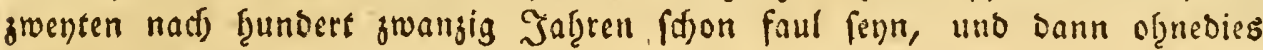
in vielen Fällen an ben Büdjen mef̧r, als ifgr boppalter 2 Berth betrigt, veroumpft haben.

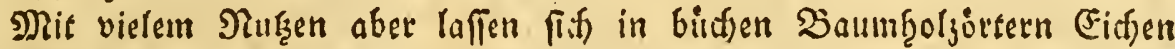

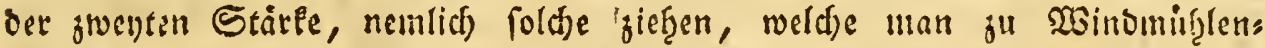
flugeln, ju Şalen uno ju Stellmadjerḩolze beftimmt, meil biefe, mit ocu

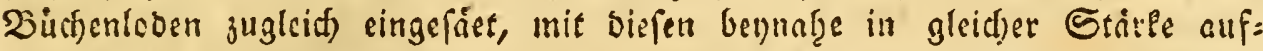
wa(b)

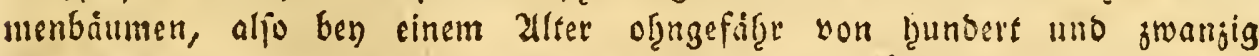
Jab̨ren gebzauen werben Ponnen, fo bổ allf bem funftigen jungen Sgene

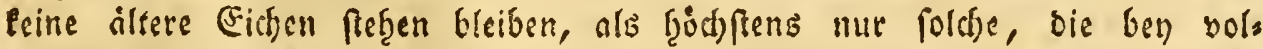

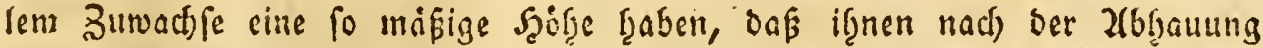

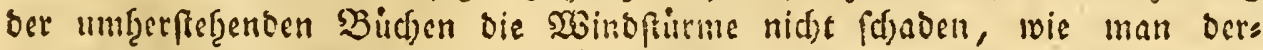

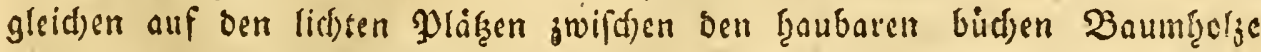

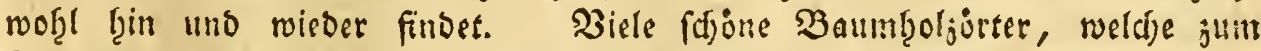

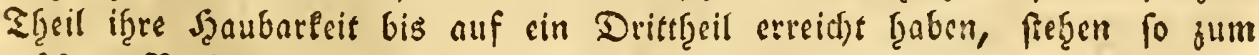
grofiten Nadjtgeil mit alten (Eid)en, vermifdst, die man ogne fie gu benuss zen, if̧rem 2erberben uberlaffen mus. Beyfpicle bicrbon fino in ben beyben Weferbifticten, aud) am Dorm unb Elf̧e in Edjoningiden Rebiere fu

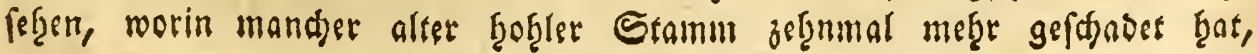




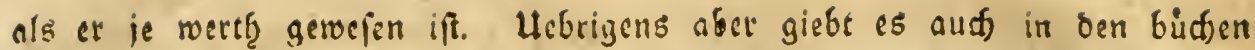
Baumb̨olgorten Pläke uno Etellen genug, auf welden farle (Fid)en mit

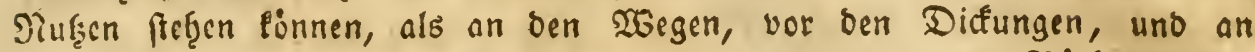
- Folden Dertern, mo man fie ofjne ourds die umftefenden Budjen gef̧ins bert ju werben, allegeit fällen fann.

\section{§. 350 .}

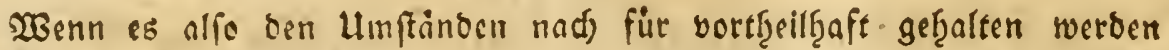
follte, in einem bidden baumfgoljgene aud (Fid)en von geringerer Stårle ju ziefen: fo müfien, nadjoem man ben Saamen baben lann, entroeber ben Szerbft vor bem erfen anf̧auen bes beftanoenen Drts, ober in bem barauf nådjffolgenten Jaf̧re bie Eidjeln jur Befaamung eingef̧adf mers

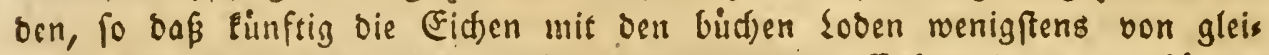
d)ent 2lter fino. 2(m beften aber fann man bie Fid)en in einem bichen

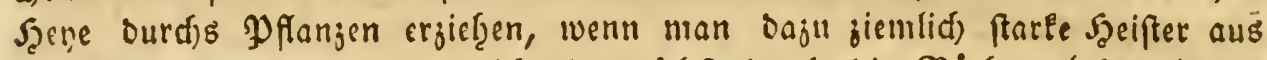
ben Eidjelfampen nimmt, weld)e beinnäd)ft ourd) cie Bidfen, loben in bie Şífe getrieben werben, uno babey einen gerwiften ßorgug bor ben Budten beţalten.

\section{§. 35 I.}

2uf Şuten unb Sriften werben an verffiebenen Drten bie (Eid)en

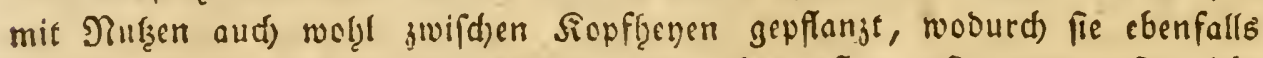
fefge in bie Sgebe gerrieben werden; julegt aber pflegen fie, wenth fie nidft

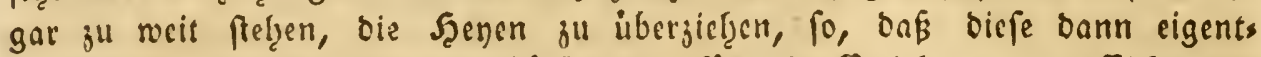

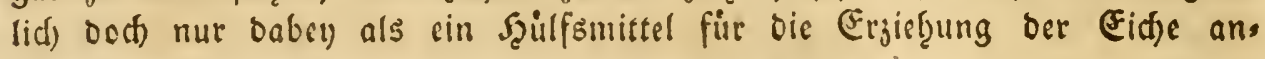
jufergen fino.

In folden sinbern, in weldsen bie Forftwirthid)aft mef̧i, als in ben

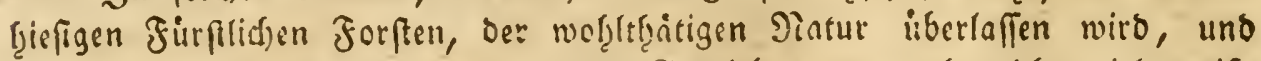
wo man bon eigentlidsen beftimmten Betriebsarten nod) nicht vicl weí̈, fonbern nur ba meghauet, wo sas mefrefte ftebt, leine eigentlidbe Saeve

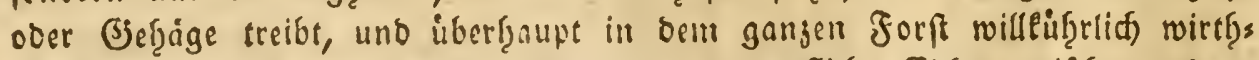
id)aftet, findet man hin uno nieder ganz vortreflid)e (Fid)en jwifd)en anbern

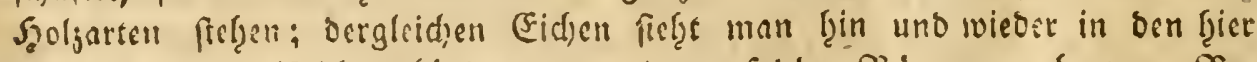

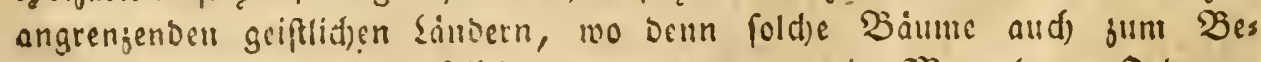
weife sienen, mic fefer sajelbft Das, was man mit Jangel an Dronung

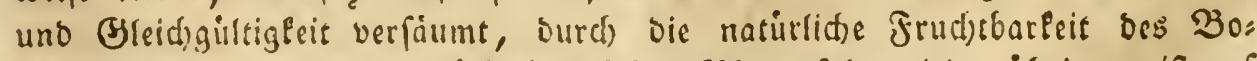

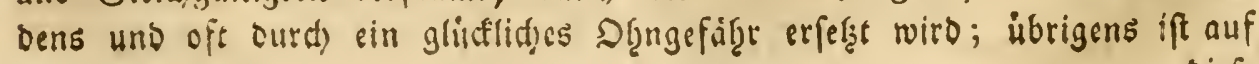




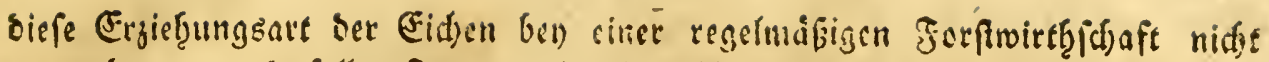

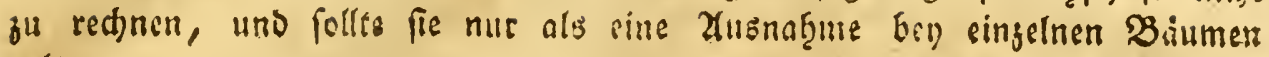
gelten.

\section{§. 352.}

\section{2on ber forfmåpigen Sieife unb Saubarfeit ber Eitfe.}

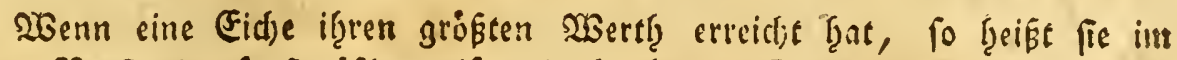
weitern 23 crftande forftmígig reif uno baubar. Diefer 2 Bertf ridfet fith

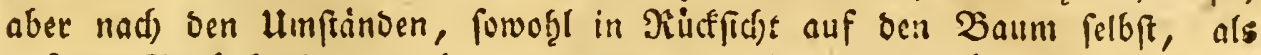
auf bie Beburlfnife, welche entweber gegciwartig ober éninfig bamit vors theilf̧aft befriebigt werben fonnen. So ift, jum Benfpiel, eine unter einer

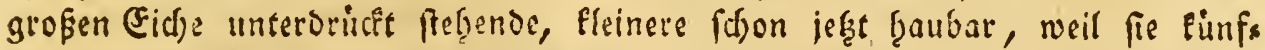

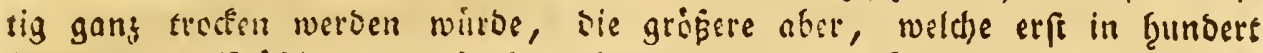

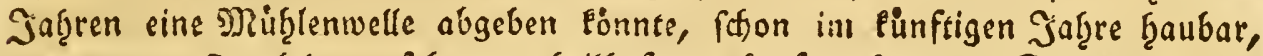
wenn man fie alsoenn feg̨r vorţ̧eilf̧aft verfaufen eann. So Pann man

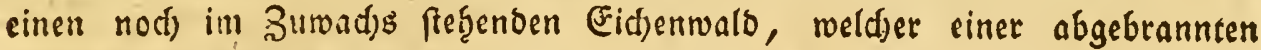

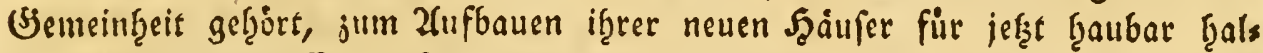
ten, ba er es auffer biefer eingetretenen Nothwendigkeit nid)t gervefen feyn wirbe U. f. w.

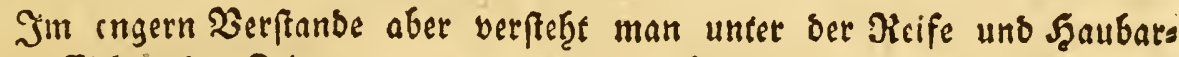

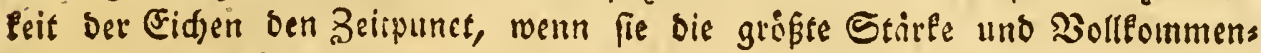

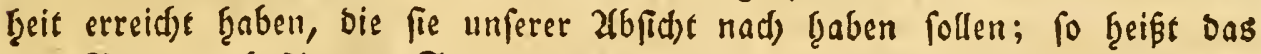
zum Brennen beftimınte Stangenţolj nad) vierjig Jaf̨ren, uno bie Bàme

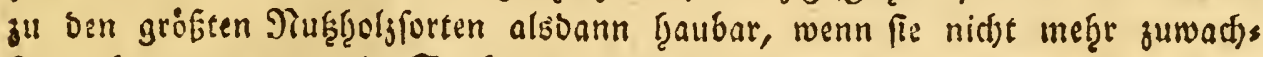
fen, of̧ne bagegen mit Etectungen uno Sernfäulniffen wisoer an ig̨ret ins nern ङiute zu verlieren.

\section{§. 353 .}

Die Benufzung Der Eidjen ift ju imannigfaltig uns ju wicftig, if̨e

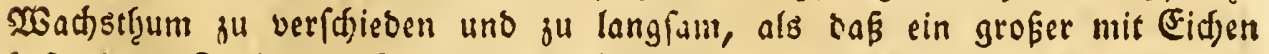
beftandener Forftort auf einmal haubar feun und gefället werben follte, wie es bey ben Buiden und andern vorjuglid) jum Brennen beftimmen Syol jars ten gefdief̧t: Das 2lbf̧auen Der Bäume in einem Eid)enorte, weld)e zur Bes friebigung ber Beburfniffe nad) und nad) herausgenommen reerben, ift bas tzer eigentlid) als ein fortbauerndes 2(usplentern anjufeten, mit weldem nad) ben limftanden balo ein frarler ober geringer, balo ein hadffammiger ober (Evifer Theil) Ff nies 
- niebriger, bald ein ganj gefunder ober ein juin Theil fabob̧after $\mathfrak{B}$ aum bes nuft werben fann, uno weggenommen wird; wobey fü bie beffere Benus=.

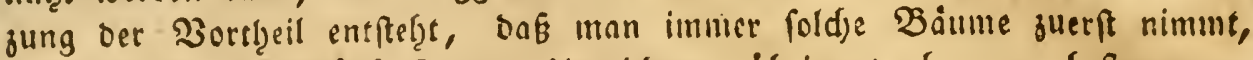
weld)e für bas Debirfuí, jwar frinteid)en, ibrigens aber am beften wegs Pommen Eonnen, als folde Etämme, bie ourd) Wint uno 2 Better obet burch einen fonftigen Bufall befdioigt fino, meld)e frofts und Eistlufte has

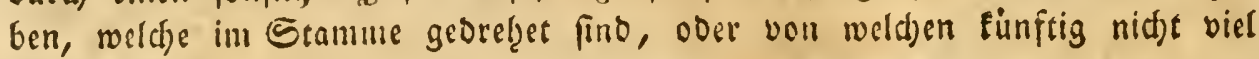
su groffen ift u. f. w.

\section{§. 354 .}

Itnter biefe lef̧ten aefeoren befonbers bie Baiume, welde ibren ftätern

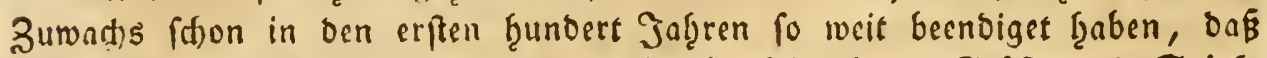

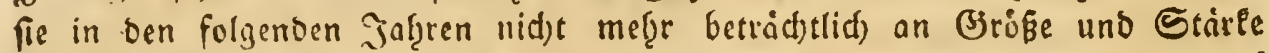
zunefgmen, roie man ons vorguglid) an foldsen Bảumen findet, weld)e auf

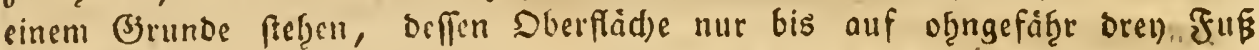
₹iefe für bie Eidhe fruchtbar, in mebrerer Siefe aber, etwa megen Iáife, ober megen einer fefen witrigen Erolage, unfrudtbar ift, wo bie (Fid)en alfo nur in ifgrer Sugeno iur IBobllleben, Jecrnad) aber nur (d)mactiteno wad)s fen lonnen; oder aud) on fold)en Baimmen, weld)e in ben erften. Jabren eine gute Bejd) mit biefen verloren baben, ober auf beren Standorte ber Gituno uno 20 s. ben burch grope $\mathfrak{W}$ nferfutben ober fonftige 3ufälle eine nad)tbeilige 3erindes rung gelitten bat. Jn allen biefen uno åf̨nlidjen fällen ift es rathjamer, bie Fid)en alsoann, wann ifre gute Bumadjsperiobe beenoiget ju jebn (d)eint, ju fallen, und ju ben Beburfniffen ber geringern Şoljforten, ju Ballen, zu Stellmadjerbolje, zu Pobren uno bergleidjen ju benutgen, uno fatt if̧s

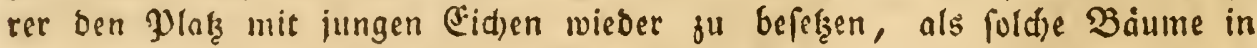
if̧ret jwebten (d)winofúd)tigen Periobe fid) uno oer Forft jum Sdjaben läus ger feben ju laffen.

So tritt aud) bey folden (sidjen, weldse zrifden bem bidjen Baum,

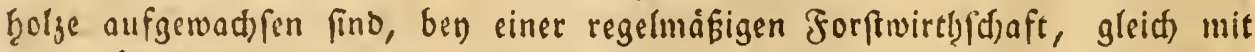

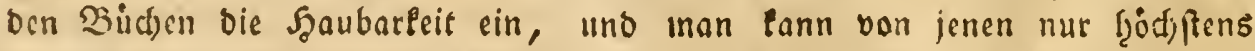

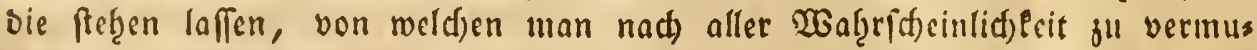

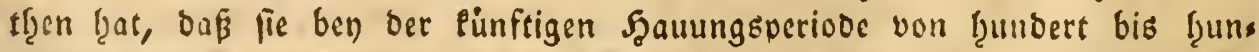

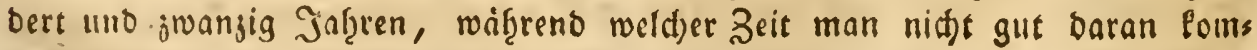
men lann, nod) gefund und braudjbar fenn werden. 
§. 355 .

Bey oer 2(uswah̨l, weld) Büune aus eimem beftanbenen Eiffenorte als reif angejergen uno geţauen werben follen, ift es befonders in ben Bes

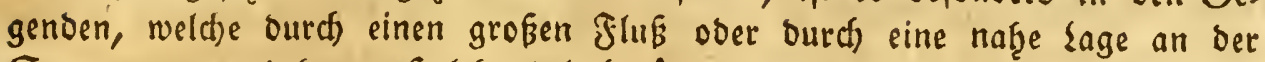
See zum ausgedeb̧nten F̧oljhandel begunftigt fins, von bein wefentlichften

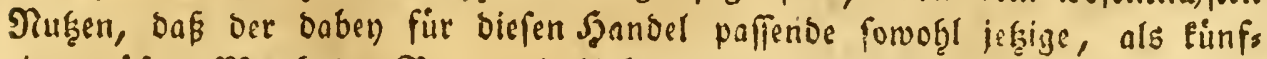
tige grofere $\mathfrak{Z}_{\text {erth }}$ bes $\mathfrak{B a u m s}$ in $\mathbb{H}$ cberlegung genommen werdz, woben es

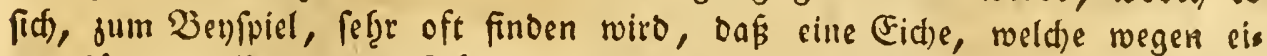
ner bृod)ft unförmlid)en Sirunme ober eines grofien afts für oell gewoihnlis

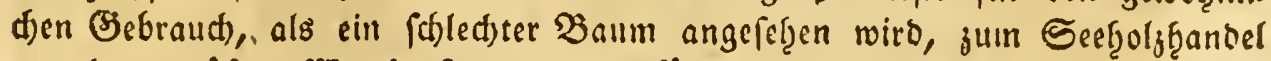
von bem gröften Werthe feyn, und bafur exft in fpatern gabren, oder ben einer anbern Sielegenţeit, als ḩaubar angefę̧en fu werben veroienen Pann.

\section{§. 356 .}

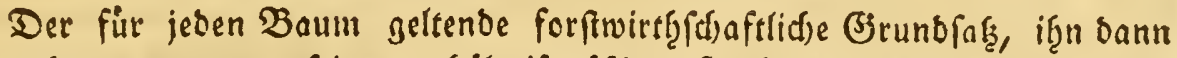

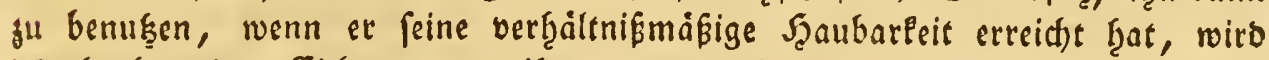
jebod) bey ber (Fid)e wegen ifgres ausgedef̨nten Tukenens und langfamen

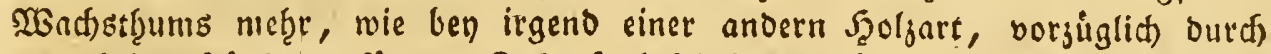

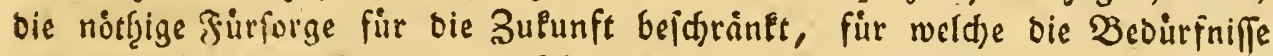
in vielen gällen nid) voraugzufefcen fino. Fs muß onger nach ben vers fdjeoenen Umftanden bierauf befonders Xiúfid)t genomınen uno freilid) oft

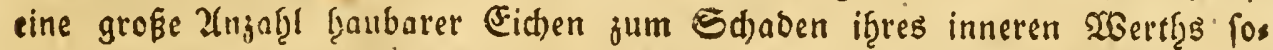

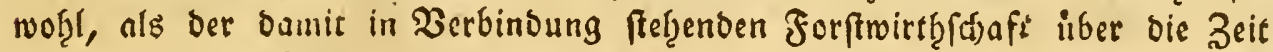

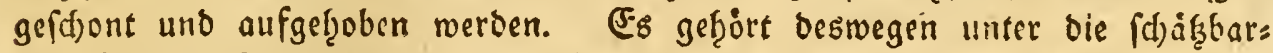

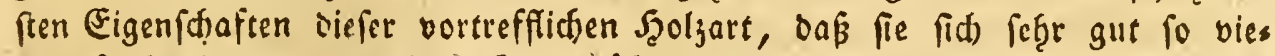

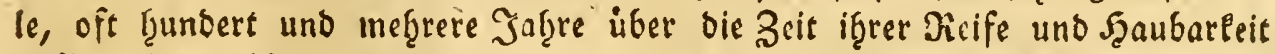

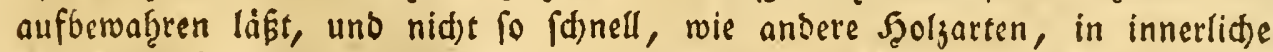
Etocfung ibergeţt, weld)es befonders bev ben gróften Seljforten fü bie

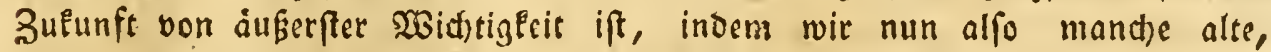

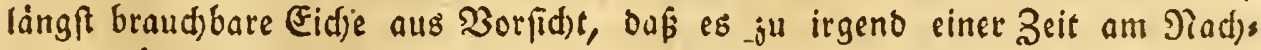

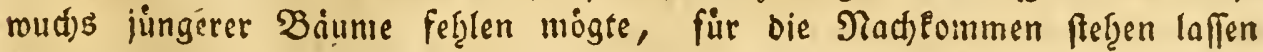

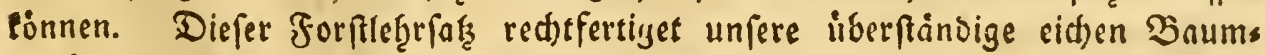
boljorter in ben Campenithen und Stjoningfoen forften, weldi)e als gute

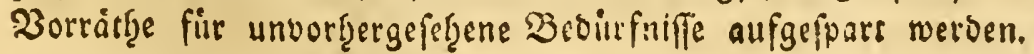




\section{§. $35 \%$}

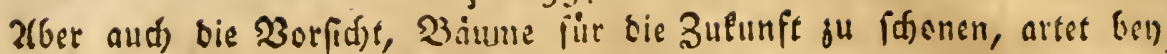
Peinet Szoljart fo ferge ins llebertriabene aus, wie bey ber Eidje, und es ift

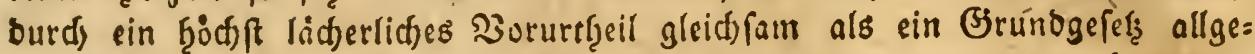

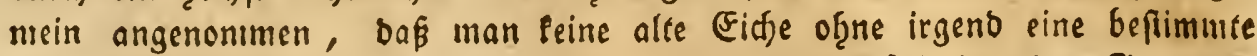
Beranlaffung abbaulen milffe. $\mathfrak{N a n}$ findet baher faft in allen Begenden

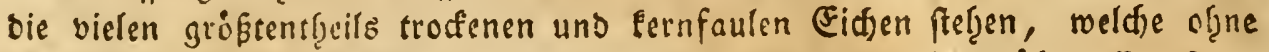

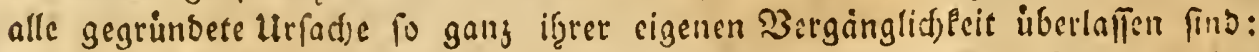
olgngead)et benn bod) von Derglsidjen Biumen nod) ju feiner Zeit mand)es

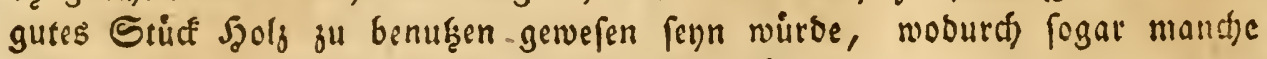
geţauene junge Eidge bृatte gefdgont werten fönnen.

\section{\$. 358 .}

Die von vielen Forftbebienten angefiţrte lltrache, bas man bie alten Eiffen ber Maft wegen fdjonen miffe, ift, wern man bie Seltentrsit ber Raftjag̨re, uno was bagegen von fold)en alten (Eidjen in vielen Fällen an jungen Şolje veroumpft witb, berefinet, gewiß oft ein ju unbedeutenoer Nug̨en, als ba man folden als einen Bervegungegruno ju einer fo jwedfwiorigen Sdjonung

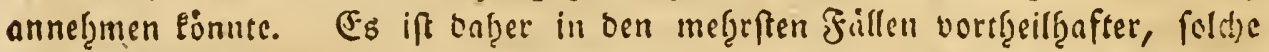
Bảume, Deren Etämme gröbtentyeils ternfaul zu forn pflegen, aud nur als Brennhyol zu benufgen, wenn tie ju nid)ts beffer ju gebrauden fenn mods:

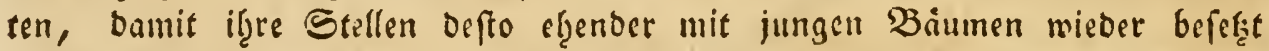
weroen fönnen. Sef̧r oft fino fold)e alte abfränoige Eidgen jum Theil

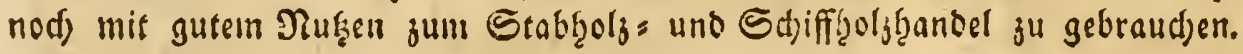

\section{§. 359.}

In folden Fällen, in welden bie alten Eidgen zu Beweifen ber Brrens sen, ober fonftiger Berectefame bienen, wirbe es frenlidf nidft ratbjam

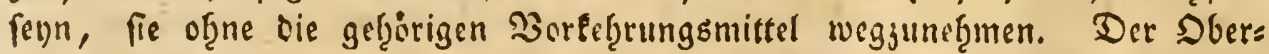
fërfter Sdjomburg nannte beswegen bie alten Eidfen un গReuţaus uno Dans Dorf, weld)e feit ben lefiten zwanjig Jaf̧ren zum Tgeil weber knub now Borle getragen baben, fcine getreuen Poffefíonsabvoiaten, jum Berveife, dak

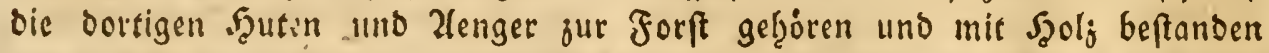

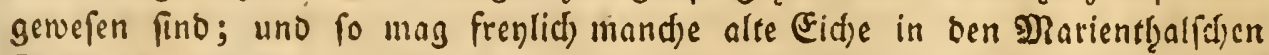

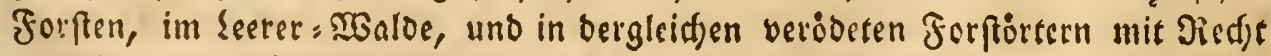
unt in vollen Efgren verfaulen.

2uct) in ben Şarjforften, wo bie Laubf̧oljörter mefer, wie bie Nabsls

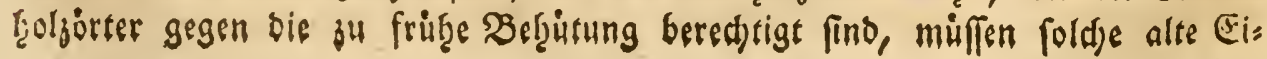




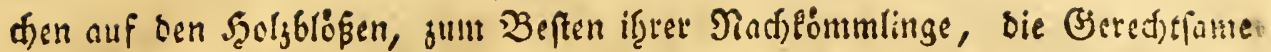
verwaferen; aufferbent aber mus man biefe Dionumente ber vegetabilifa) en 3ergänglideseit nidft oulben und es immer für einen Misftano ber forfit an=

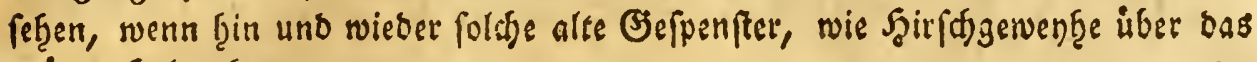
grine $\mathfrak{S g l l}_{\text {g }}$, Geerborragen.

\section{360.}

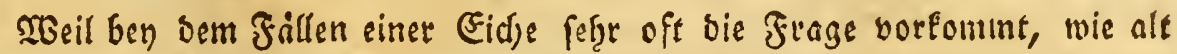

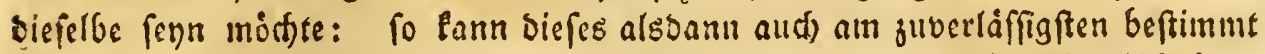
werden, renn man bas untere Ende bes Stamms alf ber nåmlicten fotrågen Flache in ber es abgef̧auen ift, stroas rein abarbeitet ober abjobelt und bie alsoann barauf beutlid)er erfdecincnoen Jabretinge voum mittelfren Mare bes

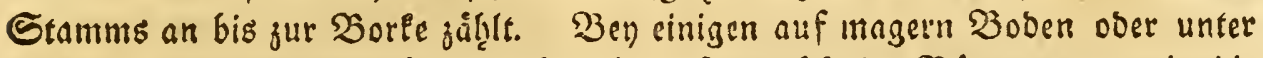
fonftigen-roibrigen $\mathfrak{H}$ mftanden fótwach aufgewadfferien Baimen, worin bie

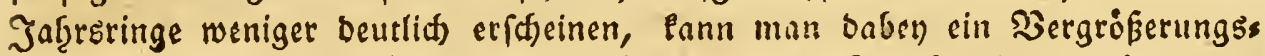

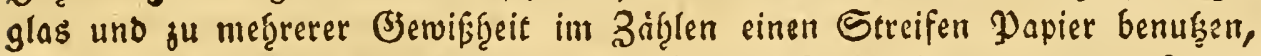
Den man an ben Mittelpunct bes $\mathfrak{B a u m s}$ bis fut $\mathfrak{B}$ orfe legt uno woranf man

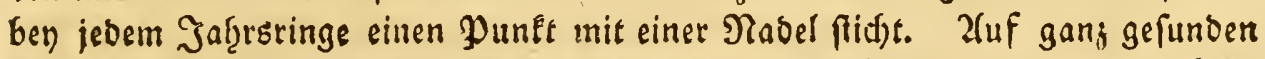

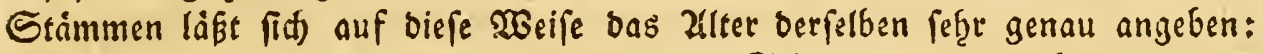
finb fie aber kernfaul, fo ift es mit meţreen Sdjwierigkeiten verbunden, bas Zåblen ber Jaltrstinge muf alsbann an ben vielleid)t gefunden obern Ende

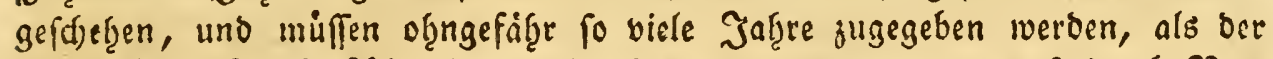

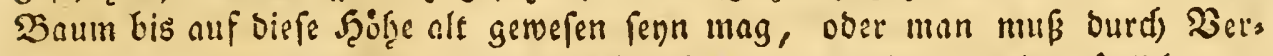

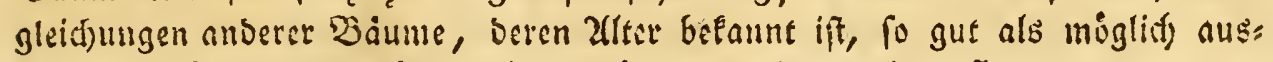

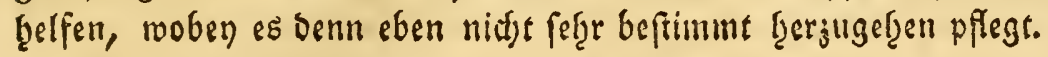

\section{§. $36 \mathrm{r}$.}

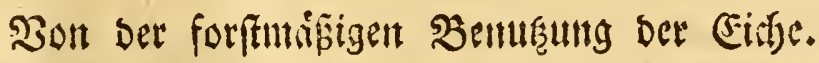

Die (Eid)en benutgen wir fowoh̨l wägreno if̧res vegetirenoen Sebens, als nad) Dempelben. Smerfern Salle burd) bie פiaft uno benu Betriebe auf

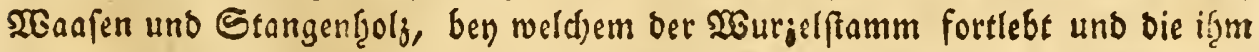

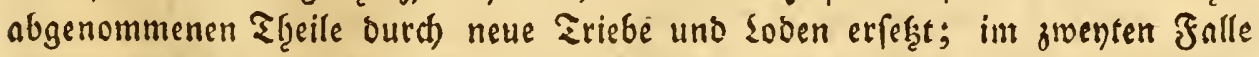
burd) ben Stamm felbft, wie es bey ber fällung ber grojern uno geringern

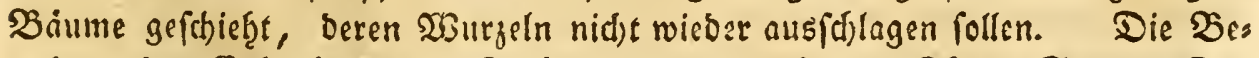
nuF̧ung ber Eichenborke jur Berberey findet in beyben Fållen Statt. Der Bebraud) ber (Eidfenblatter, Der (Jallapfel gur Färberey und oergleidhen, ift ju unbeosuteno, als boß bavon bier waitläuftis gef̧andelt werben follte.

§. 362. 


\section{§. 362. \\ Bon Der Mlaft.}

Unter ber Maft wirb in cigentlicten Sinne bie Benuf̧ung ber Eidfeln

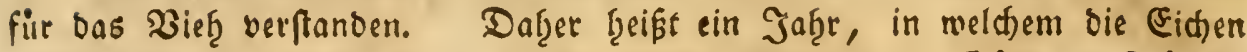

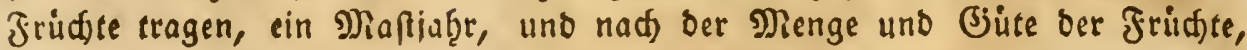

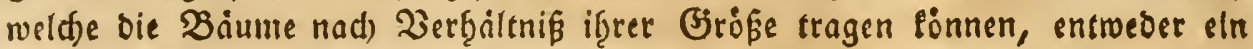
volles, ein Ģalbes, ein 3 iertel. SMaftiafte 1 . f. w.

Zfuch ein $\mathfrak{B}$ aum in bem Serftande ein voller, ftarler, ober alld nur ein geringer Maftbaum.

Die Miaft von ben Sommereiden wirb ber von ben 2 sintereiffen vorges gogen; es pflegt foldte, weil fie frifiger fällt, aud nidft fo lcid)t von ben frühen Şerbftrofiten julleiocn, als bie ben ben Waintereidjen, weldje in Den Bebirgen oft fdjon auf ben Biumen verfrict.

\section{§. $36_{3}$.}

Die Menge ber in einem Maftjaḩre gemad) fenen und jur geţorigen Reife und Bollfommenf̧eit gefommenen frudte beftimmt bie benufiungeart ber Dlaft felbft, nach reldher biefelbe entweder als befnamung für bie Ferft, als

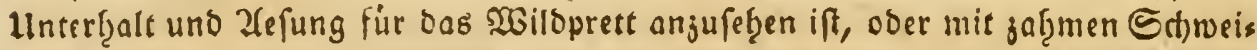
nen betrieben roird; in weldsen leften Falle es benn wieder barauf anfómmt, ob bic Maft nur zur Fütterung Der bas Jahre nid)t zum Ed)lad)ten beftimmten fogenannten Jafalfd)weine binreidft, und Daf̧er Jafelmaft ţeifft, ober ob to

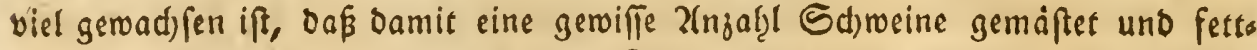
gemad)t werden lann; woḩer fie oann fettmaft genannt wirb.

\section{§. $\hat{3} 64$.}

Das Mittel, woourd) man gll beftimmen fudt, ob, und mieviel Maft

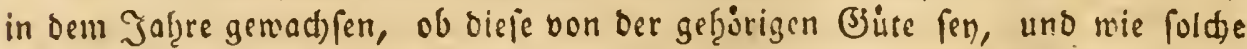

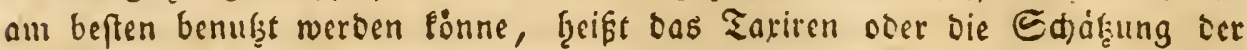
פiaft.

Weil die Maft von ifrem erften Şoffnungsjeidfen an, ben fitjon bas

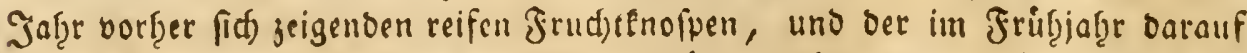
erfdeinenben männlid)en uno weiblid)en Shlitţen, his zu if̧rer baloigen Pieife

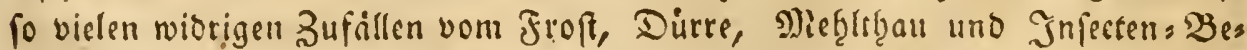

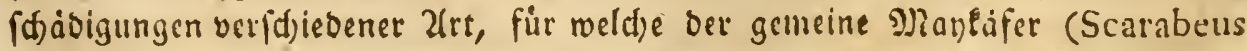
Melolonta) als einer ber gefäbrlid)fen feinde angejefgen werben fann, unters 
worfen ift, woourch fie fo oft verborben roird, bas man in einigen Gegenden - fingefälar nur alle fects und in andern befonders in ben gebirgigten (jegenden Faum alle jwölf Gobge batauf rectinen barf: To if man aud) nur furz vor ber Reife uno Falljeit ber Fidjeln iut Stande, die Maft mit Zuverlaffige it ju

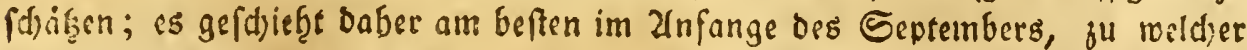

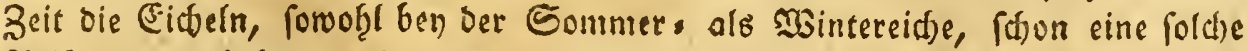
Rafe crlangt fraben, uno gegen alle brobende 2 efthabigungen in fo reit gefis

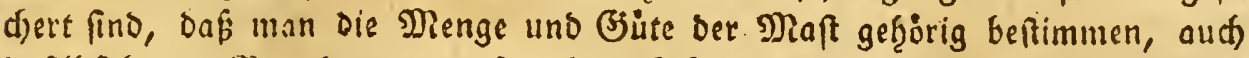
in 3bfid)t oer $\mathfrak{B}$ enutzungsart, fowob̨l auf Befaumung als auf bas Betreiben mit Sd)weinen, die nothigen $\mathfrak{B} 0$ trşrungen theffen Eann.

\section{§. 365 .}

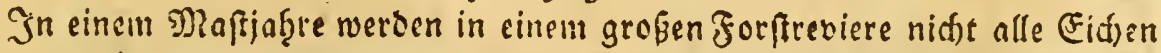

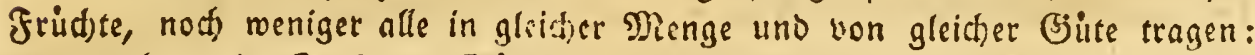
Denn nadjoem ber. Froft, bie Dirre, Infecten uno bergleidhen wiorige Sufálle meţr ober weniger, frif̧er oder fvater auf oic Eommers ober mintercichell, auf bie in ben Siefen ober auf ben Sjogen und auf ben Eonnen = ober Edats

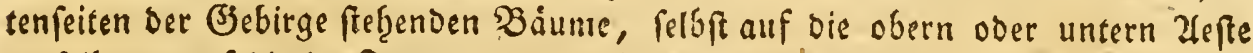
berfelben, auf bie im freven oder in Diffigten ftétgenden Fidjen, uno to wei: ser, gervirtt baben, fo werben aud) entweber auf jenen ober auf biefen bie Frudite gelitten f̧aben, verborben oder unbefaabigt geblieben und zur Reife gefommen reyn. Es miffen baher afle biefe Ulmftinde beym Sdjäfzen ber

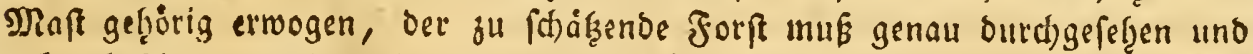

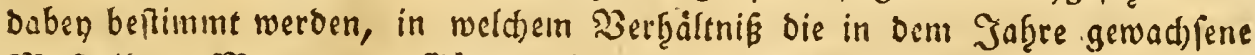

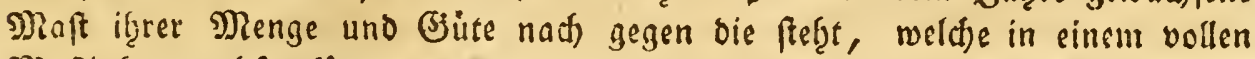
Diafijaf̧re wad)fen funnte, menn alle Mafteid)en volle ober wenigftens fo viele Frud)te bringen wurben, als man in cinem vollen Maftiafire ju baben pflegt, um Danach ju beftumen, ob, wie, uno mit wie vielen Sd)weinen bie Dlaft ju oetreiben fey. Da nun zu bem beffern Bedeifen uno fettwerben ber Sdweine mefrere Nebendinge bentragen lonner, jum Benfpiel, bie in vermifaten Drten mitwad)fenve Bud)maft, aud) bie (Erbmaft, weldhe aus verfdiebenen $\mathfrak{W}$ urgeln unb aus ben Minien einiger Siferaten, befonders Des groken Mayläfets bes ftef̧t; aud felbft ber oft mefer oder weniger brudigte Boben in einer (Jiegeno

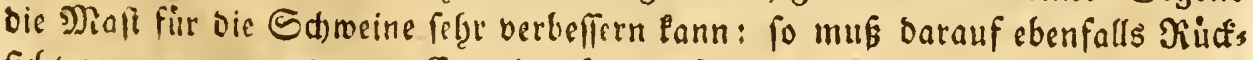
fictit genommen werden. Es tritt oft Der Fall ein, Dak in einer Jegend bie

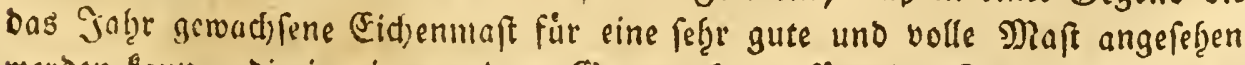
merben linn, bie in einer andern bjegend laum für sine Jafelmaft gefialten weroen wuros. 


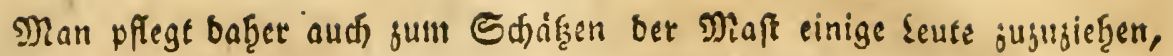
weld)e fid) barin burd) Erfaģrung eine guberliffige Fienntnif́ erworben ḩaben, wie man fie gerwį̨nlid) unter ben Şoljatbeitern, alten Şirten uno bergleid)en

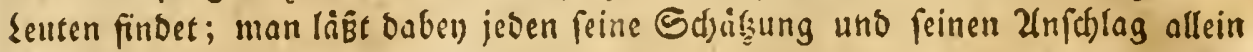

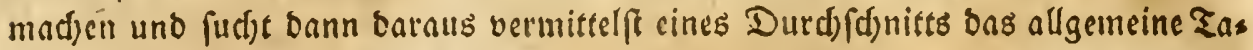

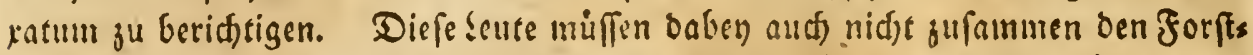

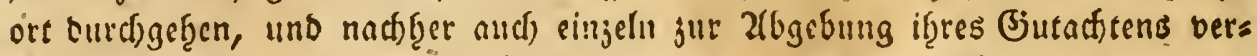
nummen werben, weil fonft gewớgnliá) ciner bem anoern nadjufprechen, unb

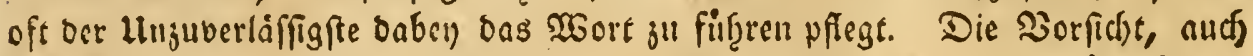

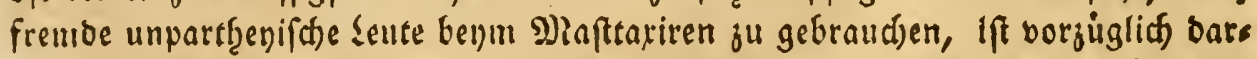

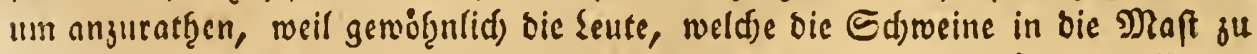
geben bercd)tigt fino, über ju geringe Maft fu flagen und ju befürchten pflegen, Daf folde nidjt ginteidjen mödjte, bie sinjutreibenden Edjweine fett ju machen.

\section{§. 366 .}

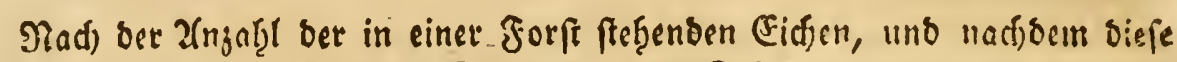
vermoge ifgres engent ober weiten Stanbes, ifgrer Stärle uno ifgess afters, methe

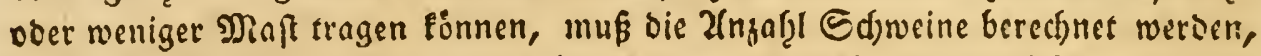
weld)e man bey voller Maft eintreiben Eann, uno biefe ift bemunidfif and) bent Maftanfd)lage für jebes Maftjaf̧r auEjumitteln. Da man nun im Durthfd)nitt zwifd)en gropen und Mitteleiden fünf und zwanjig Etricf fitr bie volle MRajtung auf ein Sd)wein redjnet: fo mürben junt beyfpiel in ber Bofjer forft im Sol:

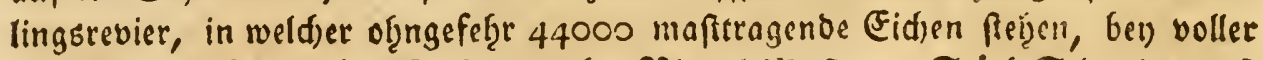

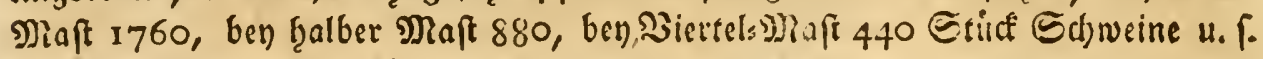
w. eingerrieben werben fonnen.

Wenn baben auf bie in bem Safere etwa gewadjfene Buffunaft mit gered)=

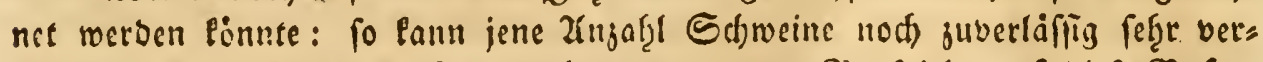

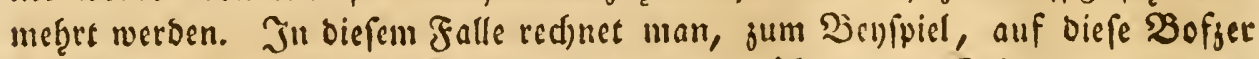
Forft bey voller $\mathfrak{B} u d$ und Eidjelmaft jufammen iber 2000 Sdjweine.

\section{§. 357.}

Die Reditsregel, baf bem Seern ber Forft und bes Baums auth bie

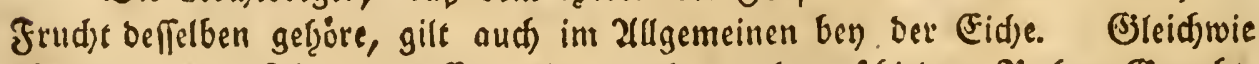

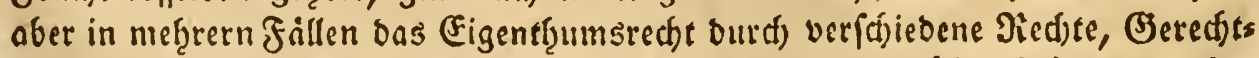
fame, unb Servitute begranjt mirb, bie cin Dritter auszuiben befugt ift, ober

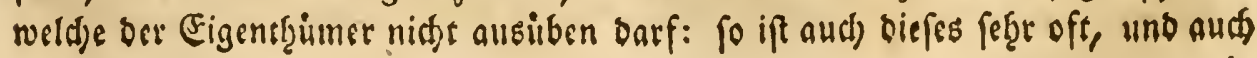




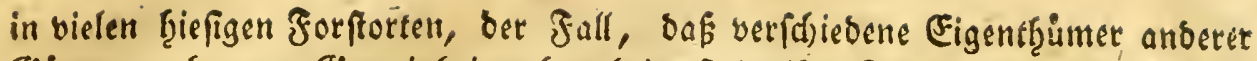
Bjuter, altf) ganje Bemeinfeiten bered)tigt fino, ifire Sd)weine entweder unents gettlic), ober gegen 2lbgabe eines beftimuten preifes, in bie andern gef̧irigen Forften zur Maft einzutreiben. Zluf biffe SBeife fino bie mebriften Dörfer ber benden 2 seferdiftricte bered)tigt, gewiffe Derter ber Furpticten Forften am Sols linge uno am Sille fur $\mathfrak{R a f t}$ mit Schmeinen ju betreiben, wofür fie, nebft eis

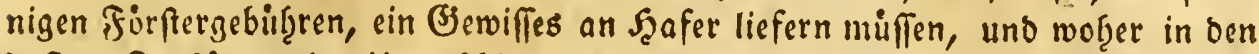
bafigen Forftörsern ber llnterf(b)e von Yropermaft, worin nämlid) Pein Z(nberer Bish ju treiben bered)tigt ift, uno von Şafermaft, oa einige Bemeinf̧eiten mit ber Maft berectitigt fino, entftanden ift.

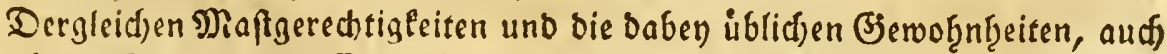
wie es benm Taxiren uno (sintreiben ber Sd)weine geந̧alten wirb, pflegen nun

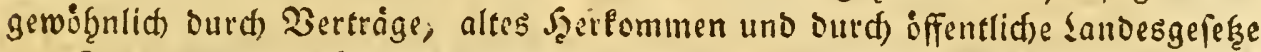
uno forftoronungen befrimmt 3 "l fenn; wie es aud) in ben biefigen Firftliden

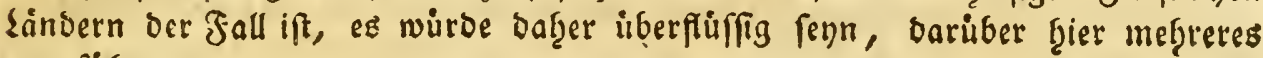
anjufitigren.

\section{\$. 368.}

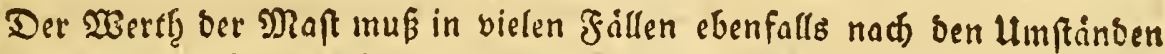

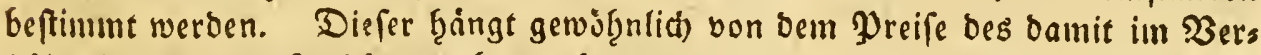
bältnís febenden Miafterns ab, aud) von ben vielen ober wenigen Sdyweinen,

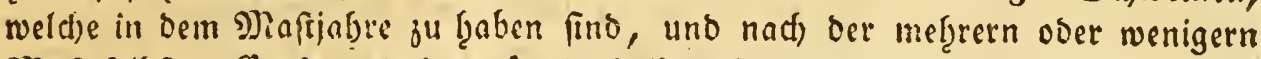
Maft ferbft. Es Eann saher oft ein halbes Miafijahre vortheilţafter fenn, als

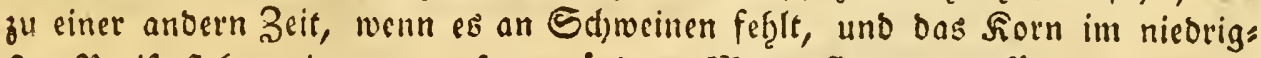
ften Preife fetet, ein ganjes fenn witrbe. Sian pflegt bie bafur ju zabilenden Wreife entweder $\mathfrak{W o c h e n w e i f e , ~ o d e r ~ f u ̈ r ~ b i e ~ g a n z e ~ M a f t j e i t ~ j u ~ r e d i n e n , ~ w o b e n ~}$

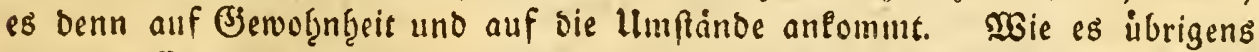
mit bell Einfeţmen ber Miaffd)weine, bem Zusfeg̨men, mit bem Eontrolliren Der Şirten, und fo weiter, geţalten wirt, bas ift genugfam betannt uno geţơt nidjs ḩierţer.

\section{\$. 369.}

Ben bem Betreiben mit Maptajweinen hat ber Forftbebiente befonbers barauf gu adjten, baßz bie Şirten $D a$, wo fie ben $\mathfrak{P}$ flanjungen, ben jungen

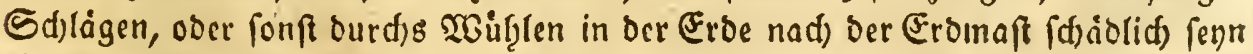
fönten, wie es oft ber Fall zu fenn pflegt, bes Miorgens ţintreiben müfen, weil bie Edjmeine alsbann ḩungrig find, unb nur bie Eidjeln auffudjen; bie übrige (Erftet Tyerl) 


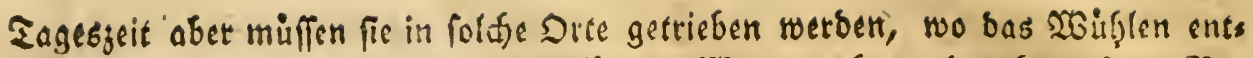
weber unfdjäblich ift, ober wohl gar für bie seundmadfung bes begrafeten $B_{0}=$

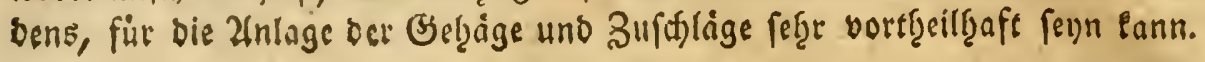

\section{§. 370.}

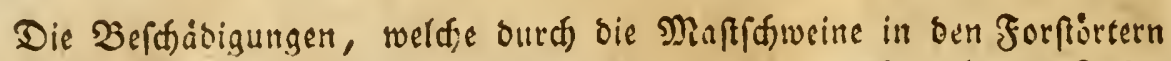
fowoht, wie auf oen Şutangern angerid)tet werbent, fino aud) nid)t alle Jaf̨re uno auf allen Prten gleid, weil foldtes von ber mefrerern oder wenigern Eromaft, bie bie Sd)weine auffuchen, abfiangt. Der adjtfame Forftumann wirb biefen Ilmftano gleid) in ben nád)fen Tagen nad) bem Eintreiben ber Solycine beiners

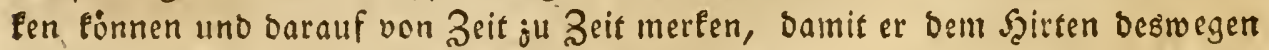
bie nothige 2lnweijung geben fönne. So miffen aud) bie burdh bie Sdimeine son Den Yflanjungen oder auf den jungen forftorten verurfacteten, oft nidjt unbebeutenden Befdabigungen nach beendigter $\mathfrak{M a f t}$ fo gut, als es fich ben $\mathcal{H}$ m: ftảnben nadj thun láét, ausgebeffert werden. Uebrigens hiat man mand)en fdo: nen jungen (Eid)enort ben Maftitjweinen ju banfen, indem fie burd) bas $\mathfrak{H}$ ms wib̨len ors Booens bie (Fid)eln einrobell uno cinpflanjen, weldte in bem folgens

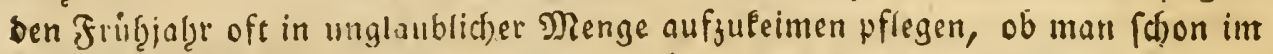

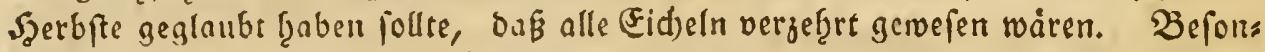
Ders fdáclid aber wirbe es firr bie Forftorte renn, in weld)en man biefen juns

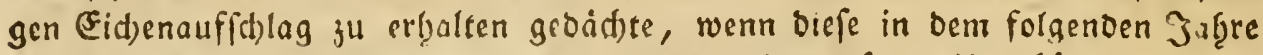
mit Sd)weinen burd)getrieben werden follten, wie es oft zur ulngebüler geidhief̨t, weil Die Sd)weine alsoann ben an ben jungen Seimen nod) befindlidjen Eidgens

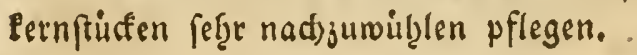

\section{§. 371.}

Do nun íbrigens bie Maft als sine Nebenbenufgung ber Forft angufeţen ift, uno folde alsoann nur bentzet werden barf, wenn bie ibrigen Bedurfniffe. Der Forft es geftatten: fo folgt baraus, bas in bem Jutgre, worin nur fo viel

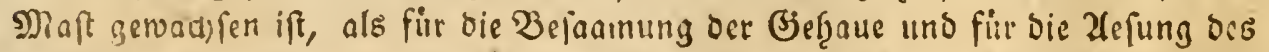
23010 prets erforoerlid) ift, meldhe man Sprengmaft tu nemen pflegt, Peine Mafts fd)weine eingetrieben werden burfen, wovon aud) foldhe Derter frey ful loffen

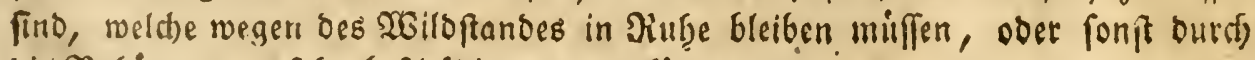

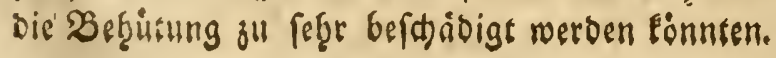


§. 372.

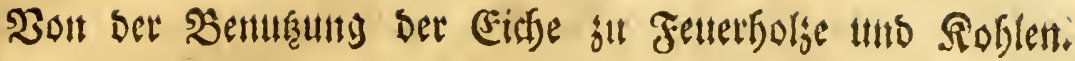

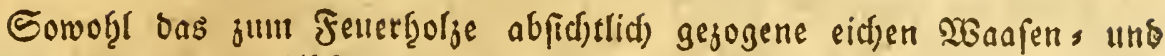
Stangenfiol ${ }_{j}$, als ber ?lbfall von ben zul veridfiedenen Beburfniffen vernufss

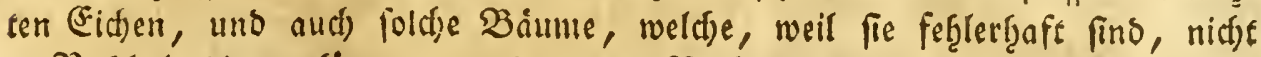
ju פlufigrolj bienen fornen, werben jum \$erbrennen uns jum Berfog̨len vers braudbt.

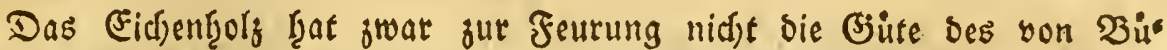
d)en, Saaynbichen, uno einigen andern ţarten Şoljarten; bod iff es baju beffer als man aus einem einmal bagegen angenommenen \$orurtfeile in

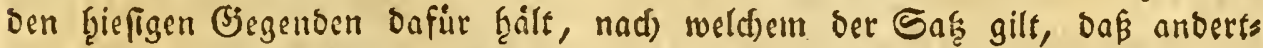
ḩalb bis jwen פialter (Eid)en für ein Malter Büásen geredjet werben.

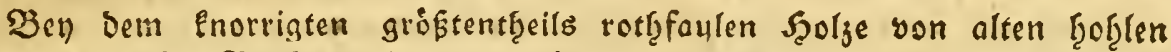
Eidfan mit bicter Borle, ober aud) bey bem abfalle von grofen (Eid)en,

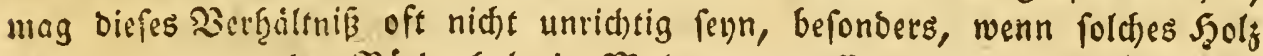

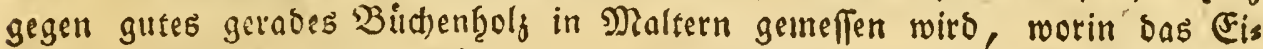

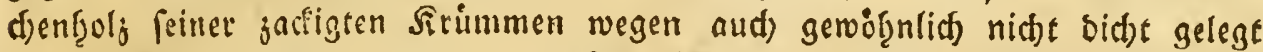
werben faun, und worin bie trodfene Borke, bie fef̧r wenig Brennbares

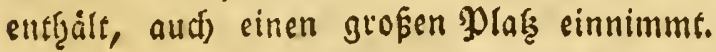

\section{\$. 373 .}

Das bidute uno fefte eiden Stuffen= uno Stammbolf aber, fo roie

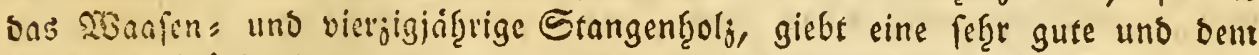

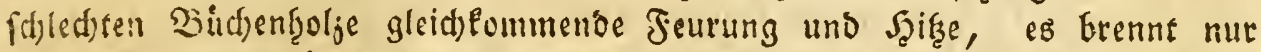

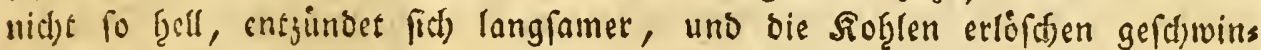
Der; es erfordert baf̧er einen etwas ftairfern suftzug, als andere fdyeller becnnende Sholjarten. Das fefte, gute, befonders bas junge Eidfentzolj bृat Dafer ben folden Jeuerungen, bey weldjen es auf eine langlame antaltenoe Şifge antommt, als beym SBrannteweinbrennen, uno bey bergleifjen, merts lide $3 o r j i g e$.

Benm Blasmadjen, fum Porcellainfruer; in ben Bopfereyen uno beym Biegelbrennen aber, to wie in foldfen Feuerarbeiten, rooju eine fanellbrens nende leidfe Slamme erforbert wirb, ift bas Eidjenigoly faft unter allen bas ifgled)tefte. 


\section{\$. 374 .}

Die Eidfenajde ftehet ber Buddenajde weit nad, inbem fie wenigere und (d)ledtere Yottafde giebt; aud) bie baraus gejogene Sauge in ben Fäs bereven uno Bleiffen madtt bas Zellg nidft fo weíf, wie bie aus Bidjens

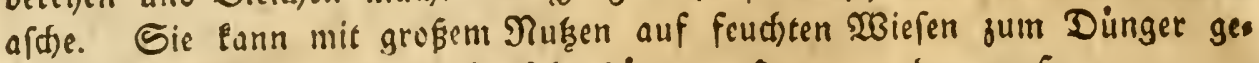
braudje werben, auf weldje fie fef̧r binne geftreut werben mus.

\section{§. 375 .}

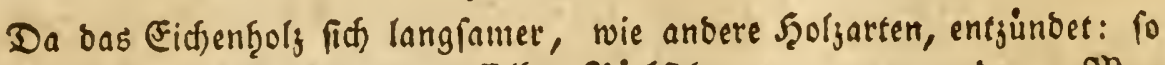
muß bierauf ben ber 3 erloḩlung beffelben Piuffidt genommen merben. Shan

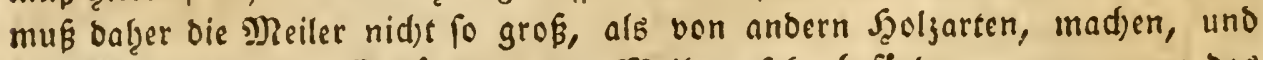
man eann bie gleidie Entjünoung bes Meilers fef̧r beförbern, wenn man bas Fidentiols erft, wenn es fiarl abgetroffnet ift, verfoblet, uno es baben mit eis nem geringen Egeile bon andern Szoljarten verferst, weldes lefigtere of̧nebies ben

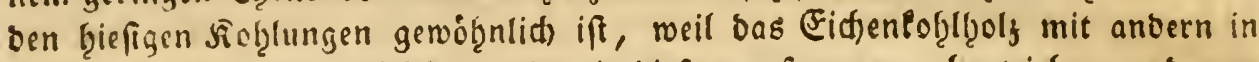
Den Forften gemijidst raddft, und init biefen jufammen abgetrieben unb vers pob̨lt wirb.

\section{§. 376.}

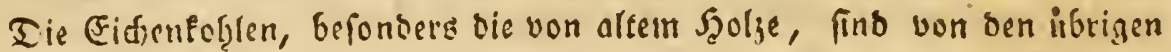

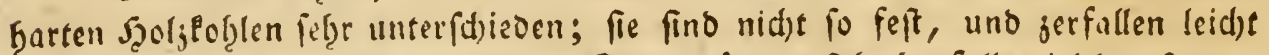
benm Berfageren uno Berarbeiten: Sie entjinden fich ebenfalls viel langfainer, uno geben fein fo belles feuer; felbft ben ftarfem Bjeblife wiro man barin bie

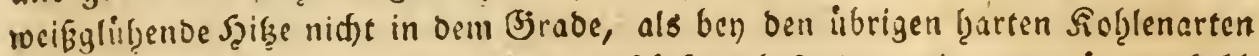
waḩrneb̨men; fie fpringen uno eniftern frärfer, befonders die von grün verfolgls

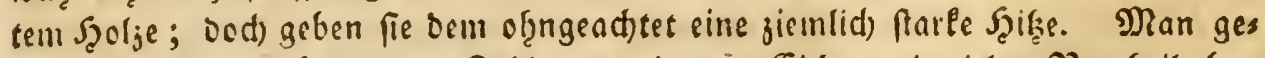

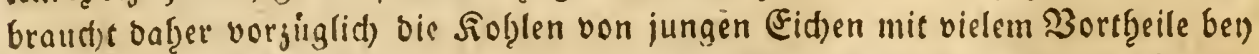
bem Sd)meljen ber Eifenerge in ben befenen Defen, in weldten fie eine eben to

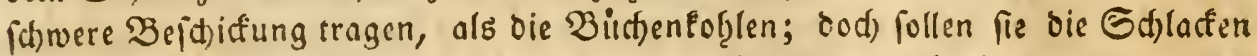
nidf fo rein, wie biefe, ausfdimelzen, wenn fie allsin verblafen werben, wess

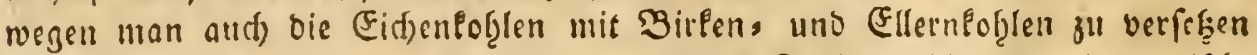
pflegt, roenn fie nid)t, wie bie aus bin biefigen forfen, fd)on bamit gemifdt fino. Zum Jrifthfener taugen bie Eidfenfoblen aum wenigften, woju man ims mer bie leid)teften, fid gefdrwind entzundenden nebmen mus. 2(ud) bie Sdsutes

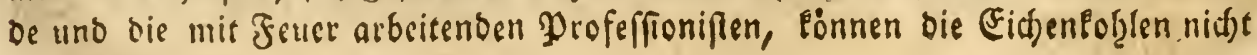
gut gebraud)en. 
§. 377.

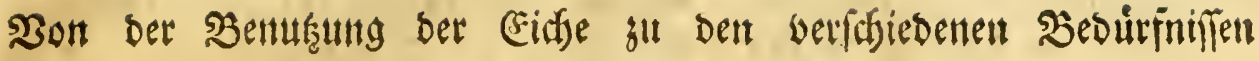

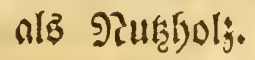

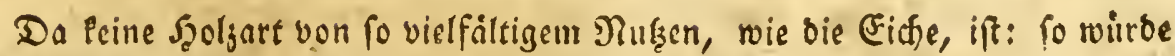
biefer abfdnitt gu weitlauftig werden miffen, menn barin alle Bebirfniffe, mels de burch bie (Eid)en am beften befriesigt werben esonnen, aud) nur regiftermisig aufgefiifire merben follten.

Der Sefer wirb fich baber begnigen, Gier nur die Saupteluffen berfelken, unb bariber nur foldee Bemerlungen ju finben, bie im allgemeinen aud) auf bie abrigen, nidje benannten, Etucfe anwenobar fimb.

\section{\$. 378.}

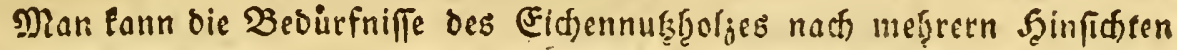

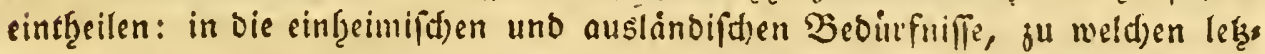

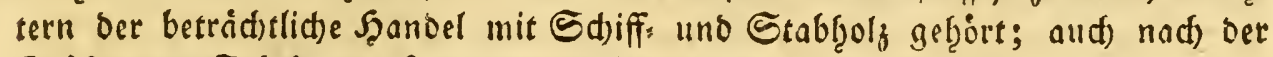

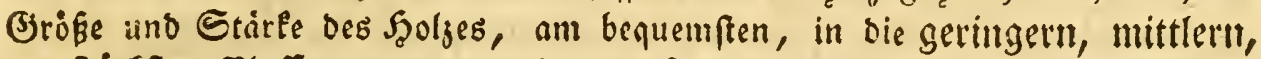
uno ftíreffen Claffen, uno zur erften bie Şoljforten rectinen, weiche, zuแ Bey.

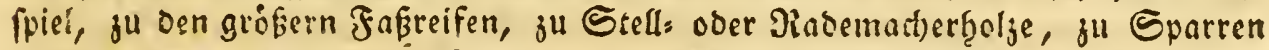

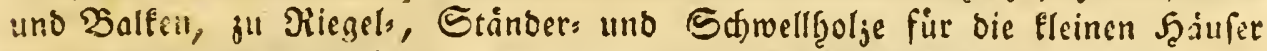

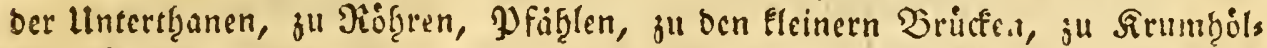

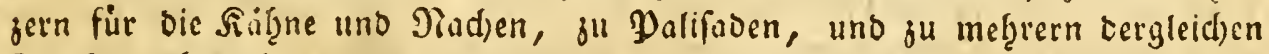
Brocfert gebraud)t verben, ju weld)en bie Baiume entweber in Eleinere Stidfe gefpaiten werden muffen, ober als einftrimmiges $\mathcal{H}_{2} \mathfrak{l}_{3}$, wo bie Diffe bes Stamms

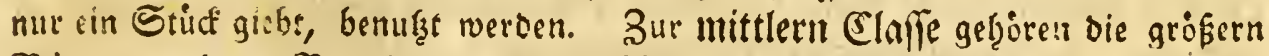
Bàume, ju beren Benußzung entweber fidon eine mef̧rere Stärle, obcr Stumı= lange, ober eime fouftige befondere Eigenfthaft erforbert wirb, ober aus beren

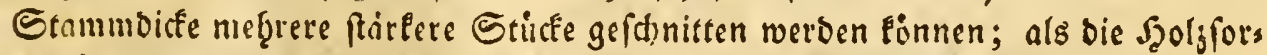

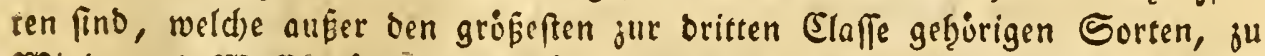

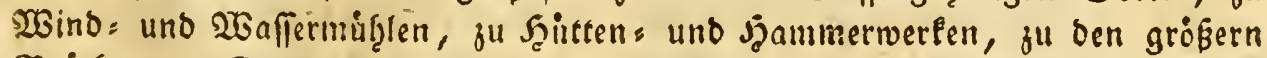
Bricfen und Edjiffen, ju Stänbern, Edywellen, uno andern Bimunerţolje für

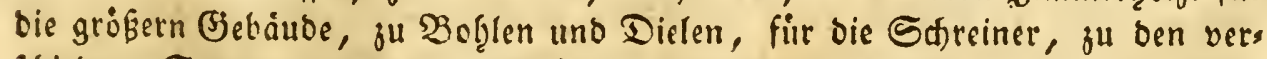

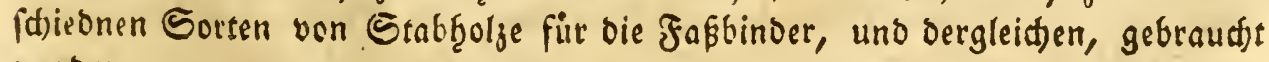
werben.

Sur britten unt fróreften Claffe eann man aber foldse Stucte zaiflen, wels de wegen ig̨rer vorjüglidjen Stätte, länge, Beftalt uno meţrern Bollemmens 
freit nut aus folden Baiunten jü erf̧alten finto, bie fid regen biefer feltenen Eis genfd)afen befonders auszeidjnen, und oft felbft in ben mitt ģaubaren Eiden gut beftandenen Forften nur in geringer ? (njongt gefunden und als Seltenţeiten angefetcen werben Ëonnen, als bie Silels und fomftigen frárlern Stucfe ju ben

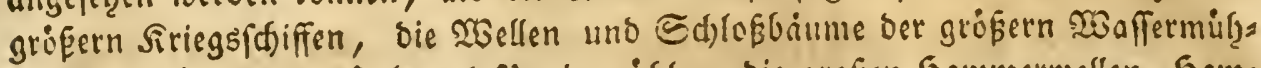

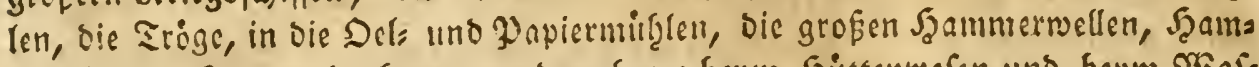

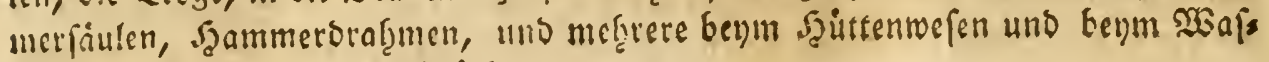
ferbaul erforderlidje farte Eticte.

\section{§. 379 .}

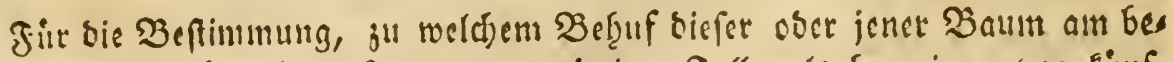
fien, fowobl in Jildficht nuf ecn gegenwartigen Jall, als bey einet etwa Eunfs

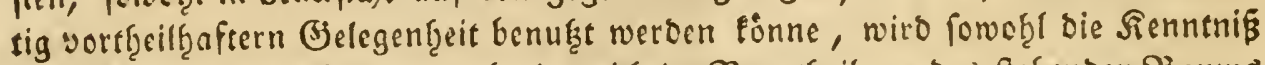

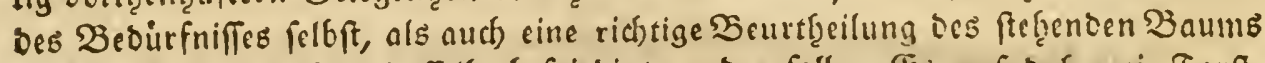
erforbert, mit weidsem baffelbe befriebigt werben foll. Es múp baf̧er ein forfts mann von beyben gef̧örig unterrichtet feun, wenn er feincm Dienfte mit bem ers

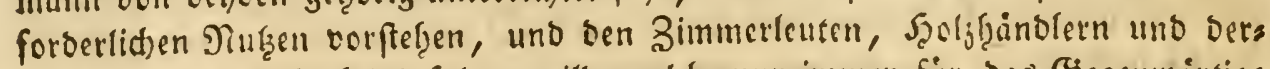
gleițen Eeuten nidjt blino folgen will, weld)e nur immer fitr bas Begenmairtige

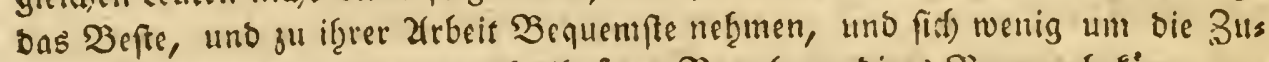

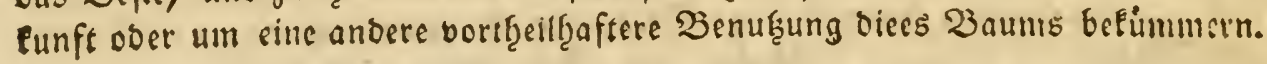

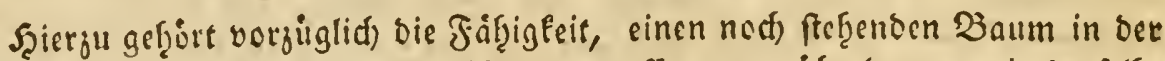

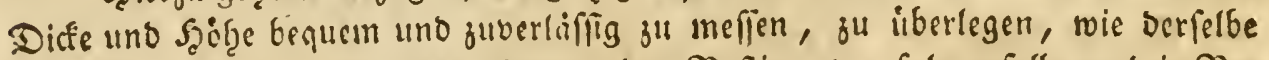

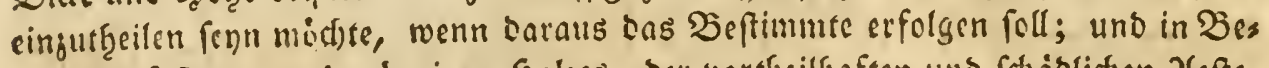

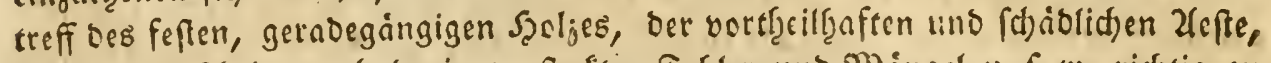

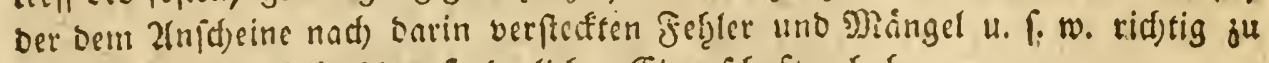
urtfeilen, ob berfelbe bie erforberfictsen Eigenfdjaften Fabe.

\section{\$. 380.}

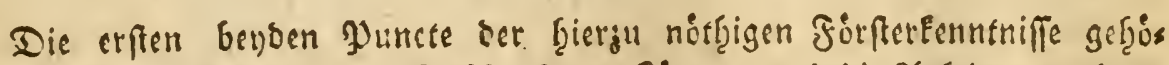

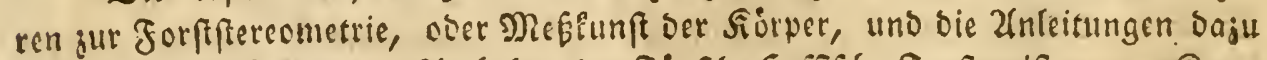

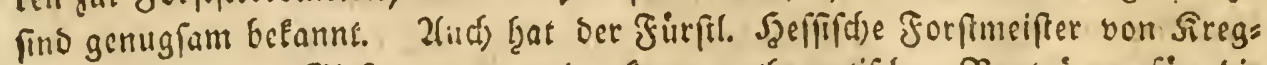
ting in feinen ju Biefen 1788 georudeten maţematifhen Bentrigen fïr. bie פiffing oer Baiume ein fefgr bequemes uno woblfeiles Inftrument angegeben,

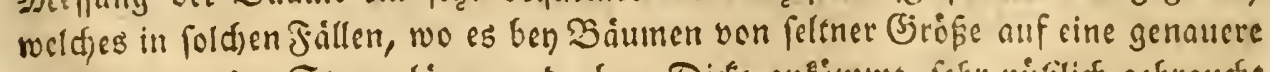

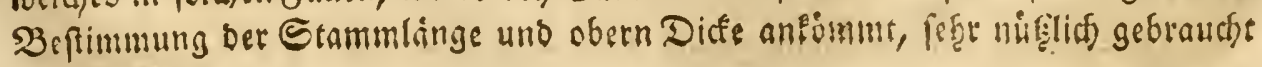
werben lann. 


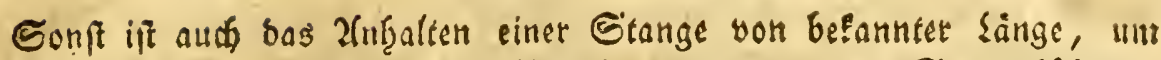

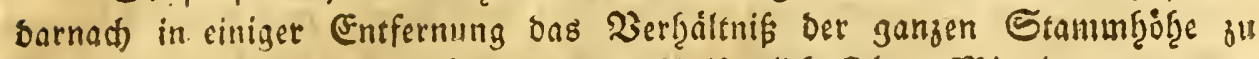
iberjidlagen, baju bas gemón̨ulidje uno f̧inlängliff fidere Mittel.

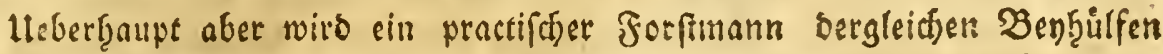

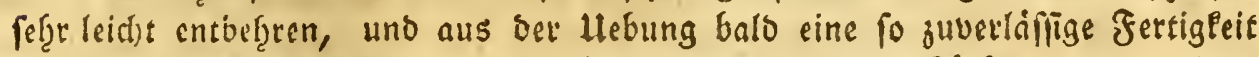

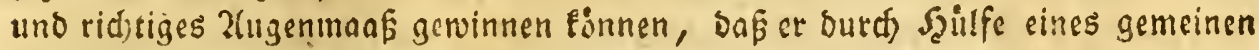

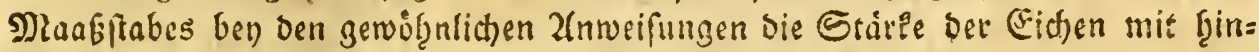

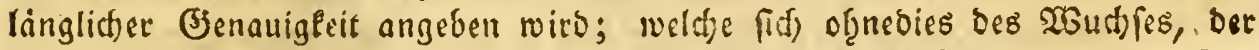

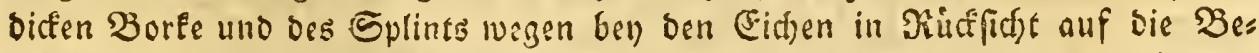

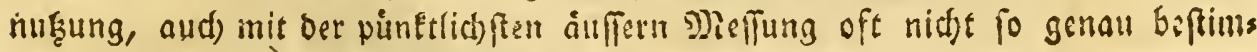

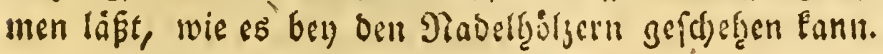

\section{\$. $38 \mathrm{r}$.}

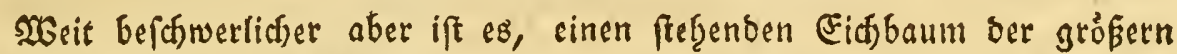

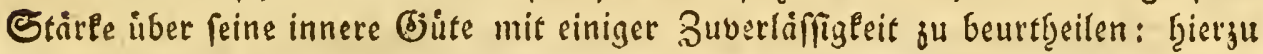

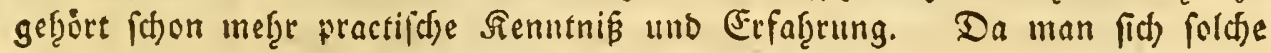

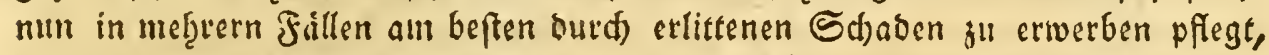

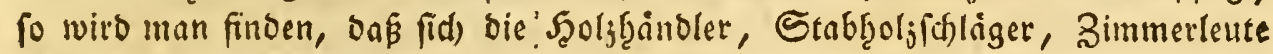
uno, Dergleiden Yrofeffioniften gewifgnlid) beffer barauf verfeţen, als bie Jorfts

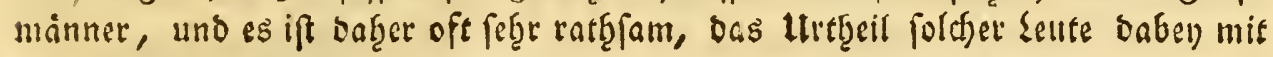
ju banugen.

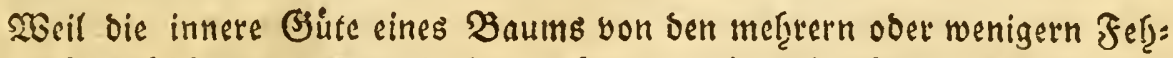
lern beffelben abfiangt: To eann foldje ain beften nads bisfen beurtheilet werben, nur fino bie fef̧ler nicht immer an bem Xeufern bes Baums fict)tbar, und

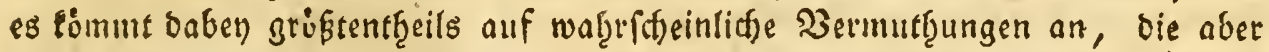
nur fu oft nad) ber Faillung und $\mathfrak{B}$ earbeitung eines $\mathfrak{B} a u m s$ gants inders ausfallen, fo, Dás mand)er aufferlich feţlerţafte Saum gegen alle Errwartung

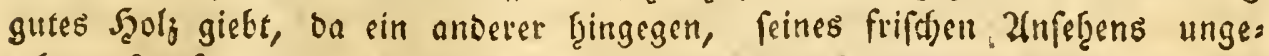
adtet, lernfaul ift, uno nur zu Bitennģolz Dienen lann.

\section{§. 382.}

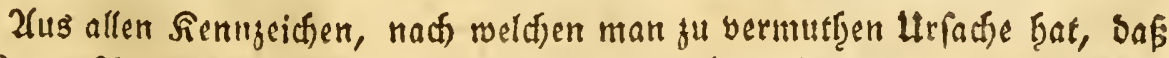

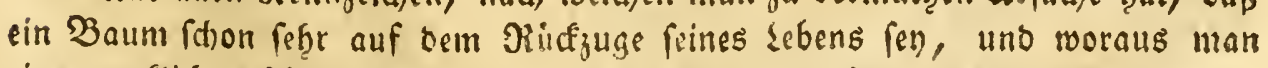

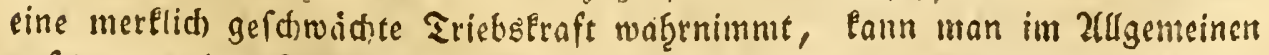

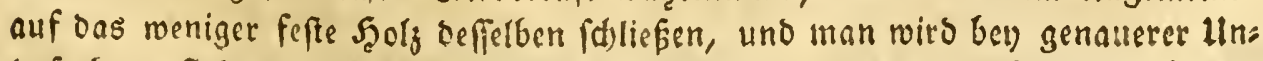
serfudung finoen, bafie die unendlid vielen Stoffungen in ben feinern Rosgerens. 
gefägen bie Ulrfacte von ber geringern fefrigleit bes alten Faolzes fint. Diefe feinern Stocfungen werben von Beit zu Zeit vergroßsert, und fo entferbt aus bem juerft ftoffenden mittelften 刃arle bie Sernfäulnis, aus ben fleinern bie

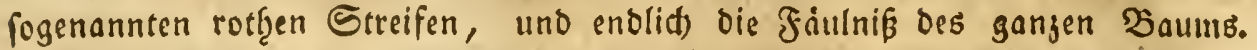
2llte uno lange Zeit iun Etillftande ifres Zumad) fes geftanone Bàume haben

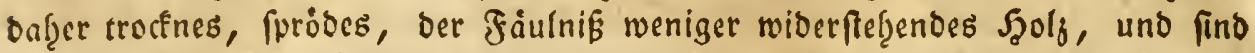

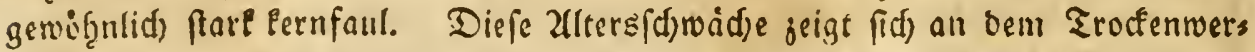
Den ber obern Zefte, aus bein man alfo, nadjoem es meţr ober meniger ift, cuif bie geringere ober grókere Feftigleit bes Szoljeg, auf rothe Streifen, auf

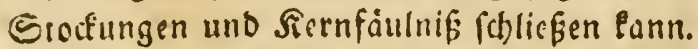

Einige Bảume, bie mit nach) und nad) vertrocfneten Dberaifen an ben untern nod) frärfern neue ₹riebe jeigen, fint beswegen beppelt verdad)tig, uns gewớg̨nlich ferge Pernfaul.

\section{§. 383.}

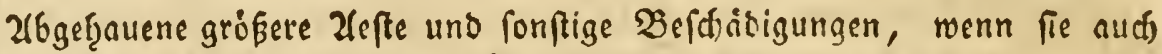
nadjoem init ber Borke wieber ganj ibergewad)fen fino, geben oft bie nidjpe.

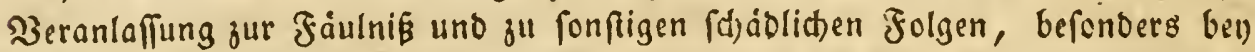
alten Bảumen, weldse jeder 2(rt Stociung melgr unterworfen find, und ben

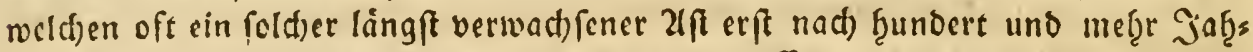
ren in ocm Snnern bes Baums un fid) fault. (Fine jebe 3 ermad)fungsnarbe,

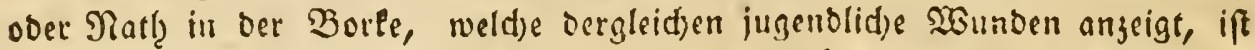

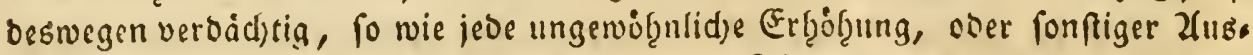
mudbs auf berfelben, weil faft immer barunter siaulnis verfectit zu feun phegt.

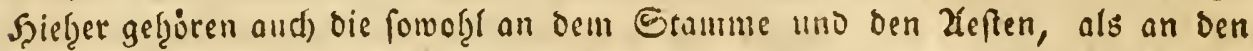

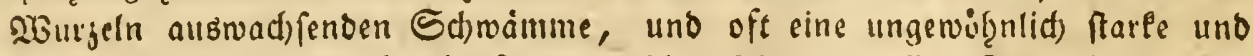
bid)te $\mathfrak{D}$ smoojung, weldje ebenfalls eine fdon fef̧r eingeriffene Fäulniß anjeigen.

Die burd) ben $\mathfrak{W}$ ind oder vom $\mathfrak{B}$ lif̧ abgefdlagenen 2 (efte, weld)e ocr Baum eift bann gang abwerfen tann, wein fie dicht ain Staumm abgefault

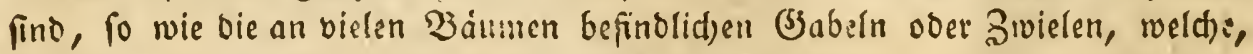

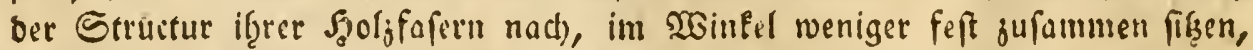
unb zwifd)en weldyen, fo; wie in jenen, ons Piegenwaffer oft ftefgen bleibt uno einjieg̨t, milfen verjigglid) unterfud)t werben, wenn man fid übergengen will,

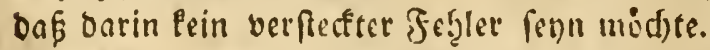

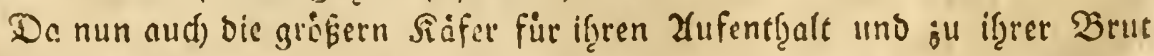

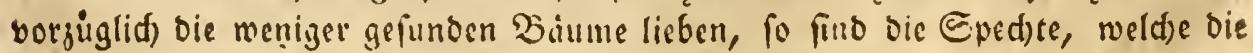
Maben und larven berfelben auffud)en, cin ebenfalls verdád)tiges వeidsen, 
miewoble es benn bod babey auf bie ubrigen Itmftande mit anlommt, inbeint

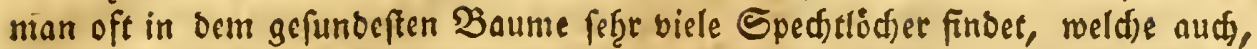
weil fie nur bie Borfe und bie jüngern Jab̧ršringe im Splint ber (Eid)e treffen,

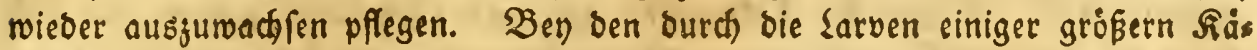
ferarten, befonders bes groben Şirfheäfers (Lucanus cervus) eingefreffenen

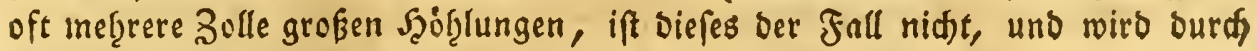

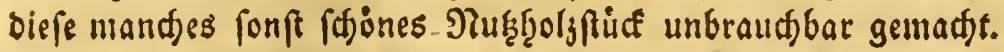

$$
\text { §. } 384 \text {. }
$$

Die boffefter zeiden finb bie ber länge bes Daaums nad) geţenden Streis

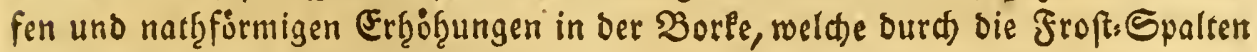
uno Borften entftanoen find.

Dergleici)en $\mathfrak{B a u m e}$ find faft zu allen $\mathfrak{B e d u r f n i f f e n , ~ z u ~ w e l d a n ~ b i d s e s ~}$ feftes $S_{2}$ olf erfordert wird, untauglids, indem fie auffer ber fidftbaren frofts

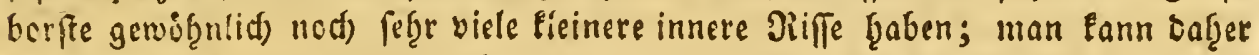
Das Şolj Davon, wenn es nidft ju alt und nod) hinlänglid feft ift, nut zu gefpaltenen Sticfen gebraudsen, als ju Speidjen, Wellern und Dergleidjen, feltener zu Fafftăben ber ftärlern Sorten.

\section{§. 385 .}

Fine ungerwóg̨nliche ftarle Dicfe bes $\mathfrak{B a u m s}$ am untern Stammenbe mit

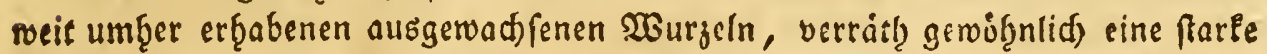

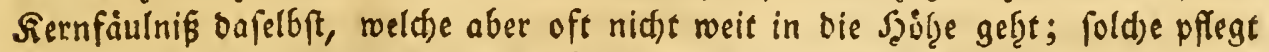

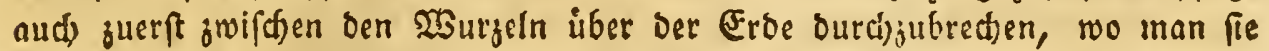

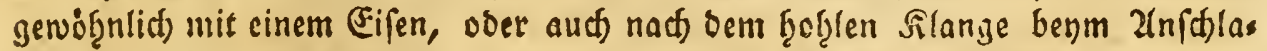

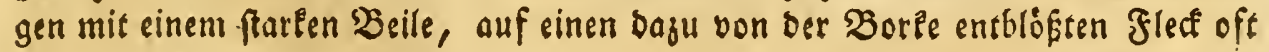
entoecten kann.

\section{§. 386.}

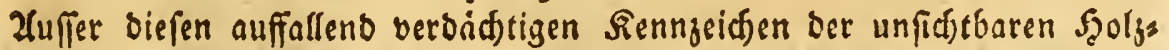
fef̧let in einem fettenden Baume, giebt es auld einige, auf bie man aus ben

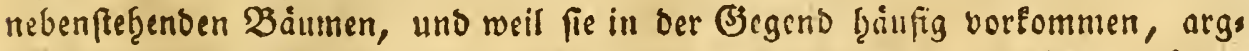

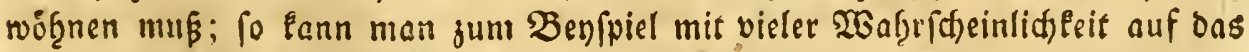
weniger fefte und oft fdion rotgftreifige $\mathcal{F}_{2}$ ol ciner alten Eiche, weld)e im Camps

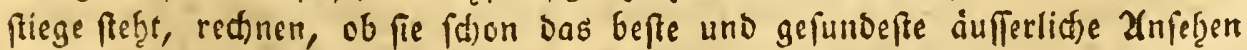

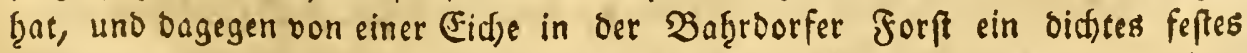

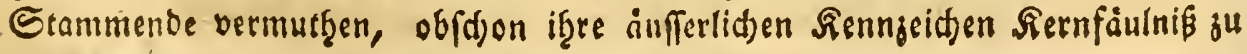


berrathen fdjeinen. Leberhaupt aber wübe man in biefer uno sergleidjen (jes genden, wo bic (Eid)en gefdrwint road) en, Eein fo feftes ftarles Syolj erivarten, als von folden $\mathfrak{Z}$ áumen, bie in magerm Boben uno in oen Bebirgen aufges wadjen finb. Bey jenen find bafeer aud alle Beidjen, aus benen man

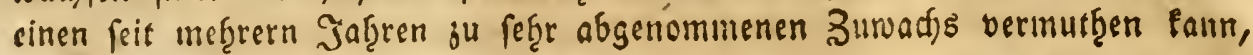
weit verdácfiger, als bey biefen.

\section{387.}

Eine bunlelgrune und reidje Belanbung, ftarle Stolgtriebe an ben obarn 2leften, eine nid)t abgerunbete, nidft verbuttete Frone, eine nidjt ung!eid) aufs geriffene Borke und bergleidjen gute Dinge meţr, zesigen bie volle Befundf̧eit eines $\mathfrak{B a u m s}$ an, uno nadb biefen lann man auf gutes, bidjtes und fejglerreines Jably redinen. Da es aber in vielen Fällen auffer biefen guten Eigenfdaften auf ben $23 u d j s$, auf bie gerabe geţenden Szoljtóf̧ren beffelben, obcr auf ges wiffe natủrlid) geroadjene Frummen anfommt: fo muE bev ber Zuswaf̨r eines Baums aud) barauf-ßickfid)t genommen 'werben, weil ribrigenfalls aud bas

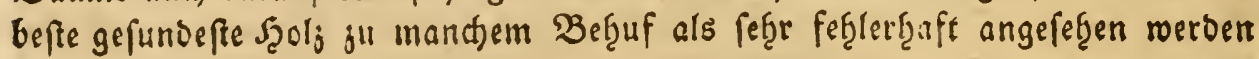
Pann.

So giebt es aud) Bàme, beren einziger Fef̧ler nur tarin beftef̧t, boß

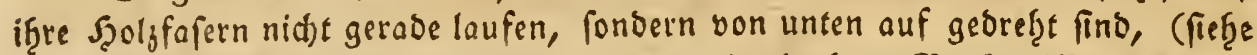
\$. 233.) uno welche man ebenfalls an ben unitgeorelgten Borkenriffen erkennt; Das Stolj bavon iff faft gull allen Bebirfniffen untauglid; , weil ein jeber gerabe

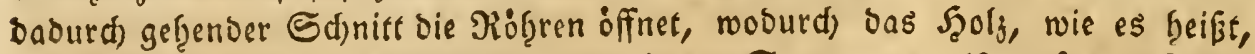
wiberpainig wirb; es zief̧e fid beswegen in ber Sonni, es reist aulf uno fault;

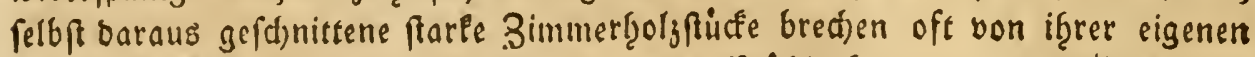

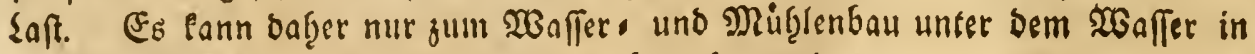
großen Studeten, uno ju Brenntgols gebraudtet werben.

\section{\$. 388.}

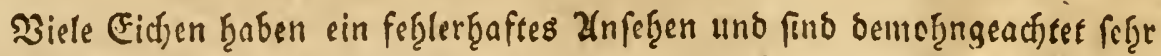

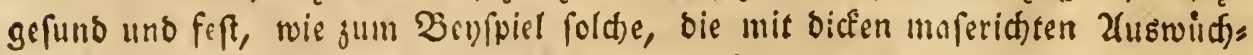

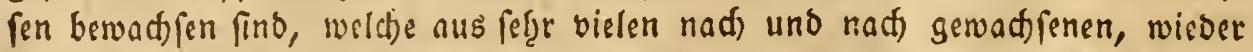
verfroffneten uno wieber ausgefthfagenen fleinen, felten jur Dieife lommenten

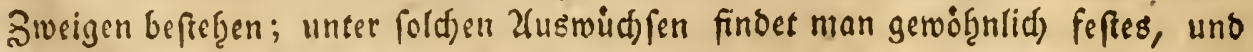
wenn fie bis alf bie Gaf̧reringe in benen fie entftanden find, abgearbeitet wers

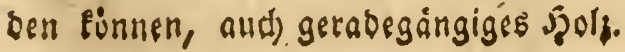


5. 389.

Die von einigen forfmännern angegebenen Mittel, bie innere Ssute

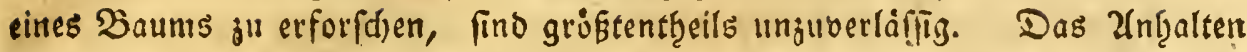

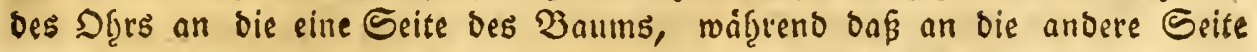

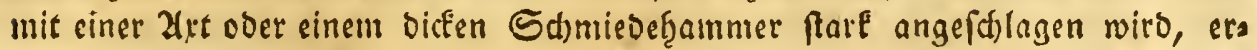
forbet fdjon cine gewiffe llebung, um burch ben meb̧r ober weniger harten

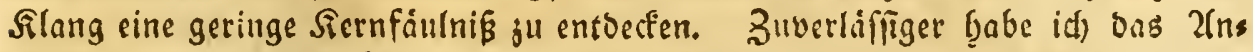
Elopfen mit einem Shliffel oder bergleidhen auf einen von ber Borke entblóbten Flect befunden, wobey das geubte Dhe cines andern auf oer (Jiegenfrite bes

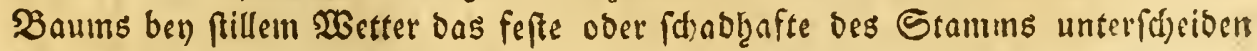

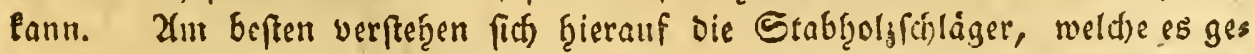

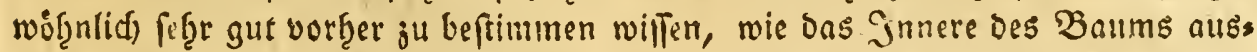

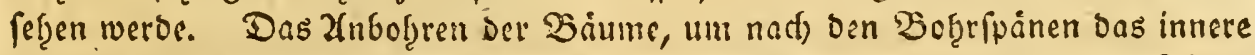

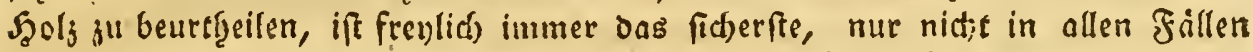
Das ratbfamfte Mittel, weld)es beswegen auch nur bey gefällten Stánmen ers laubt fann follte. Daber tönnen bie Scoljhänoler, bie mit Dem Forflbedienten gum 2(usfuden ber Boitune in ben 2 balo geren, nid)t genug beobad)tet werben,

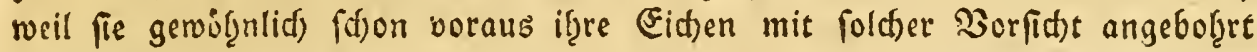
baben, Daßs man eb nid)t fef̧en fant, uns fie tann f(bon wiffen, wie hod) fie einen Baum bejab̨len fơnen, wenn man iğnen bie Băune auf bem Stamme vetrauft.

\section{§. 390.}

Bey ben Sgoljforten won ber erften, geringen Elaffe, zu welder of̧ngefähtr 50, 100 bie I 50 jąhrige Eidien genommen werben, lommt es borguglid auf bie Unterfud)m: an, ob foldbe bereits in ben Jafren, in weliden fie eigentlid

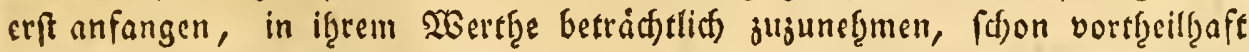

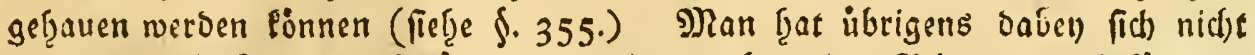
fef̧r um foldie Fef̧ler ju befiumern, die man bey alten $\mathfrak{B} a$ ämen ju befurd,ten

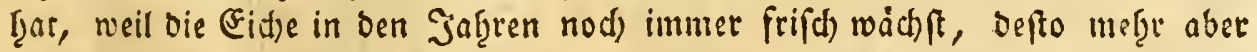
mus babey auf ben Splint gerednet werben, welder bey jungen baumen einen anfef̧nlid)en ₹heil ber Starke wegnimmt, tno foft in gar Peineın Falle,

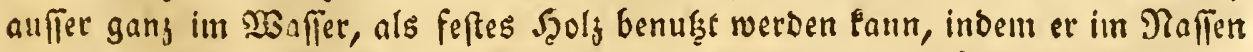
leid)t in friulung ibergebt, und im Trodnen bon ben Şolgwirmern angefreffen soiro. STur bon ben auf magerm $\mathfrak{B}$ oben gewad) fenen Wintereid)en ift ber Splint fo feft, baf er bey Speitfen und if̨nliden Studén nid)t ganj abgears beitet ju werben braudt. $D_{a}$ ber Splint an oen Zeften nod weniger ई? 2

feft, 
feft, als am Stamme ift, fo fallen biefe bey jungen Eiden grótentheils ins Feuerţolj.

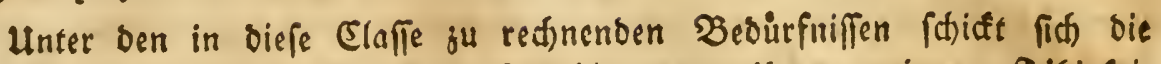
Eidje am roenigften zu Balten, fowoḩl wegen iţrer geringen Jäḩigleit groke saften ju tragen, als wegen ifgres wenig baju vaffenden wadsfes, Indem bie Eidjen, wenn fie nidjt in Fef̧r ftarlen Diafigten aufgerwadjen

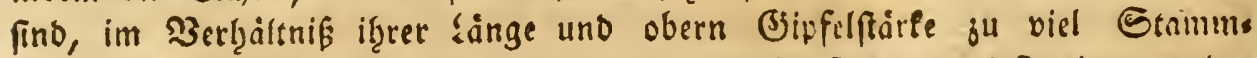
biffe graben, und felten to gerabe und aftrein find, um' fie in getaber

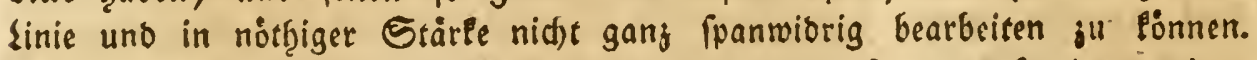
Dergleiden gefdjwädte Ballen pflegen fid) Daf̧er fogar auf eine geringe länge von if̧rer eigenen Edimere ju biegen, ober, wie bér Simmermann fagt, fich ourd)gufegenen, uno oft gar zu brecten, wie man es befonders an Den Baleen in ben alten Bauerf̧aufern fieţt, ben relthen es auf einen bुalben Juß $E_{p}$ lint Denn oft auch nidbt angefommen ift.

Man follte oafeer nur in folden Fällen bas Eidhenţols bem Nadels bolge borjiefgen, renn Davon in 2lbfidt) ber Jäulung und Stofung ein wefentfidjer 3 ortheil ju erwarten ift, als zu Balten iuber feuthte $\mathfrak{F e l l e r , ~ u ̈ b e r ~}$ Dumpfigte Stalle, und für oergleid)en (Sebaude, in weldben man benfelbin eine fefte uno naţe unterftüzung geben fann; alld) follte man barauf bes Dadjt fenn, dak in oen Bsegenden, wo es an Nadelf̧olje feḩlt, und zum grósten Nactstgeil für bie Forft und gur Laft für bie Hunterţanen alle Pleine Şutten ganj bon Eidjenļolje gejimmert merben milfen, inef̧reres

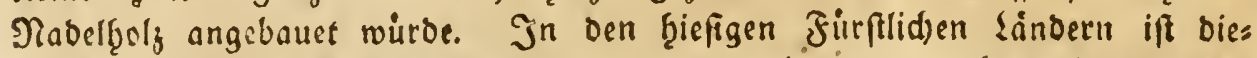

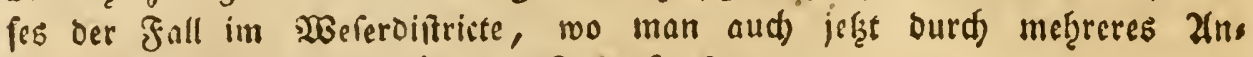
bauen bes Nadelf̧oljes für bie zulunft forgt.

\section{§. 391 .}

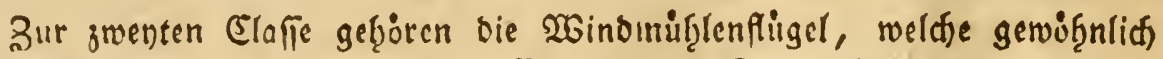

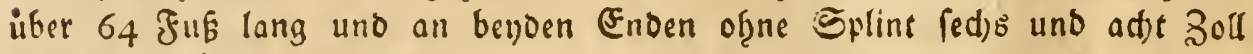
bick fenn milfen; fie werben alls einer gefunden, aftreinen und geraben (Eid)e gefdunitten, uno in einer jum Zluffangen Des Windes nothigen Sdjris ge bearbeitet. Dergleiden Baume fino wegen if̧rer sange uno erforberlis

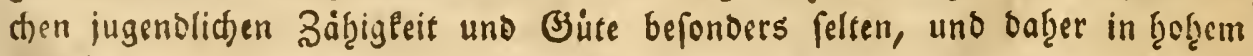
Dorile.

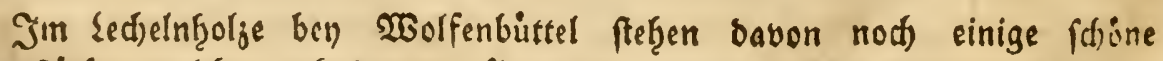

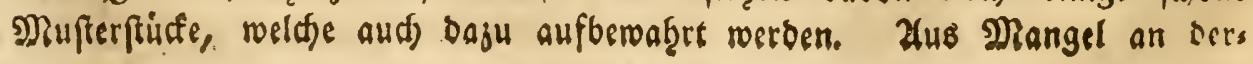
gleis 


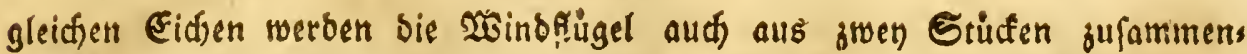
gefeşt; fie fino alsbann weniger felten, aber nidft to bauerţaft.

Die übrigen zu biefer Elnfle gef̧örigen Şoljorten fino zum Theil ges

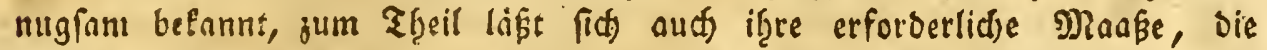
nad) ben llinftanben oft ftarleer oft geringer genommen wirb, nid)t ganz senau beftimmen, um fie b̧ier eingeín anjufübren, reldjes aud of̧nebies

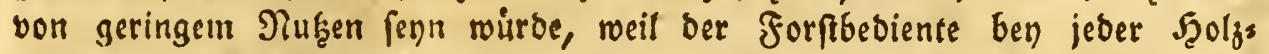
anweifung bie genaue Beftimmung der notbigen Sthcfe-forbern, uno Das nad) feine Berect)nung und Zuswab̨ ber Bàume einricten mus.

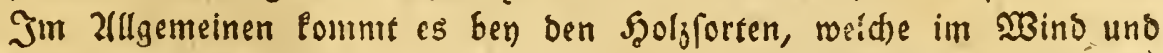

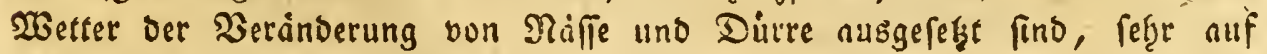

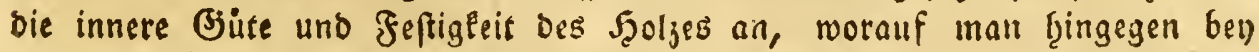
foldfen Studen, bie ins Troffne ju liegen Pommen, wie zum Benfpiel bas

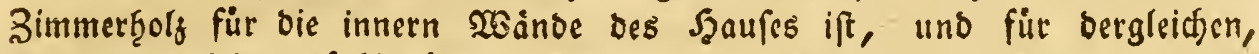
seniger oul fer̨en nòtḩig ţat.

\section{§. 392.}

Die Sthreiner pflegen bas alte fprodo Eiffenţols, was fie purjpipanig

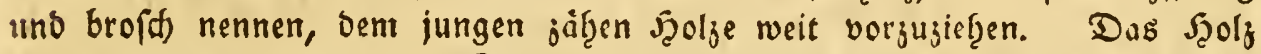
bon ber raff) gewad) fenen Sommereidye, befonders wenn es etwas ins Siotfis getblid)e fpielt, ift fur bie Sdyreinerarbeit bas befte; es vergieg̨t fid aud)

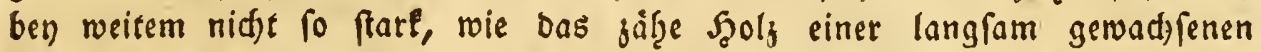
Eiche, und befonders wie bas meţre ins Graue fallende- Szold von ber wintereidse.

Die alten gefunden Eidjen in Sampitiege, auf bem $\mathbb{E} l j e$, in ber Baf̧roorfer, uno in Dergleidsen flathen Lanoesforfen nit gutem frudt)tbaren Boben, aud bie aus ben frudt)tbaren F̧ălern Der Borgebirge, geben vors

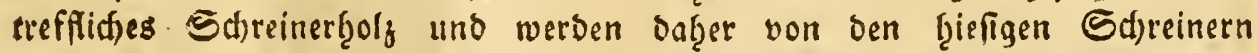

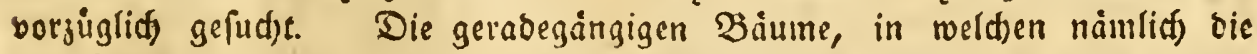

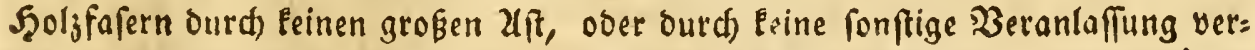
brefget worden, fino vorjuglid gut für bie Sdreinerarbeiten, und múffen

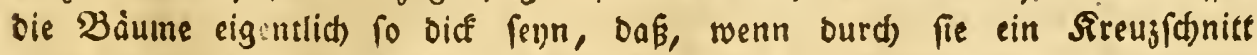

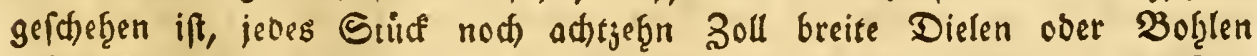
geben eann; woben ber Sern bes Baunts an bie suffern Sianten ber Dits telbielen fälle, uno alfo bequem abgearbeitet reerben eann. Die Sdjreiner laften bas Şols ein bis anberthalb Zoll biaf ju Dielen, ober aud ju zwey,

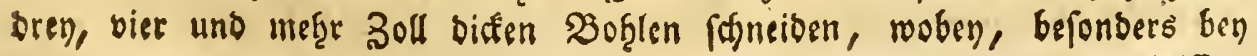

beifiem 


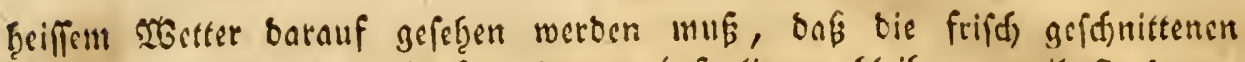
Dielen ober Bob̨len nidft frey in ber suft liegen bleiben, weil fie bayon

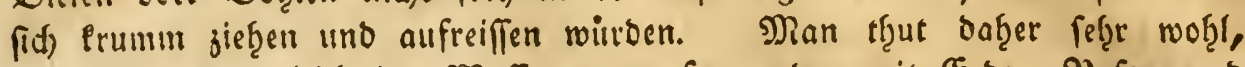
folde entweber gleid) ins $\mathfrak{x a f f e r}$ zu merfen, ober mit Erbe, Rajen uno \{aub ju bebecfen; erfteres ift vorzlizisf̧en, weil im 2 affer bie ban Eidjens Golje eigente Sauge mef̧e verbinnet und ausgejogen, uno baburd bas ges

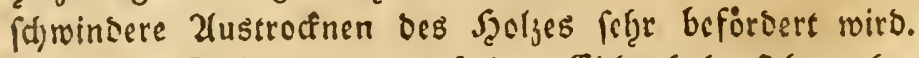

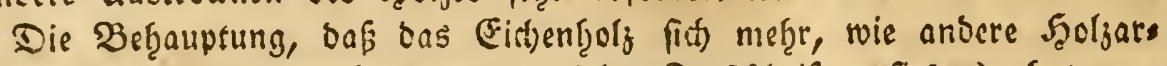
sen, verjieften folle, (woldé) man in vielen Jorftátriften finoet) hat vors

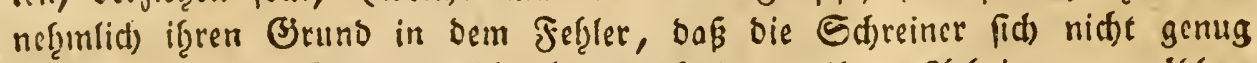

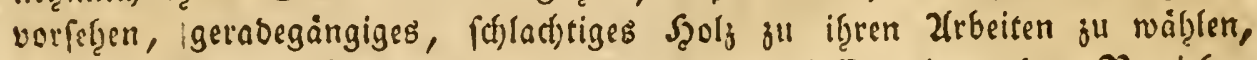

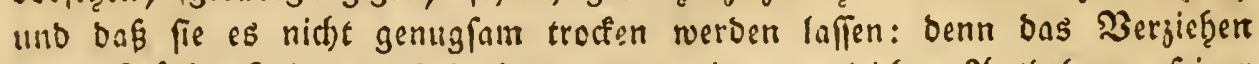

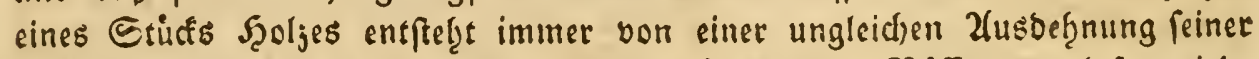

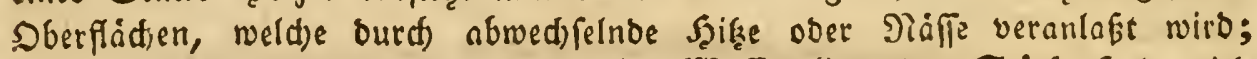

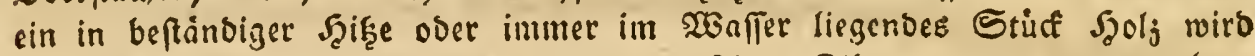
bie einmal barin, nad) ber Sparmung feiner Jibern angenommene sage ober biegung nidht verónbern, welches aber gewís gefitief̧en wurbe, wenn

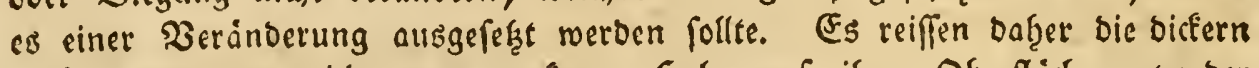
Etidfe von bem nid)t ganz trockenen Sholje auf ifree Dberfindje entweber in reniger grópern ober in meigreen Eleinern Diffen auf, weil bie Zuffens feiten gegen bas Jinnere beffelben ju gefdiwind trodénen und fidf jufaus

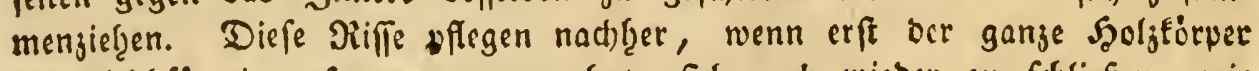
fid) gleidformig jufammengejogen hat, fith auch wieber ju fdfliegen, wie man es in bem frifd) verarbsiteten Bimmerţelze beutlid) waf̧rnef̧men eann.

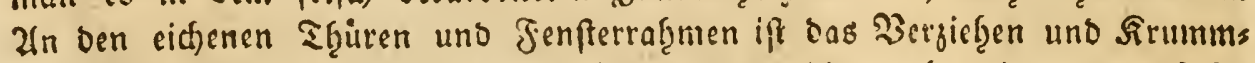

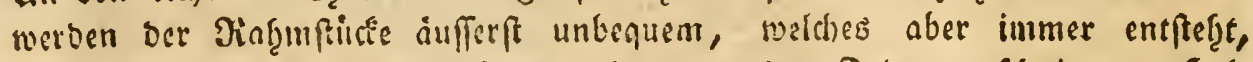
wenn bajll ungerade gervadjenes und gegen ben Jaben gefdnittenes Seolg genommen soirb, wie es befonders in Braunforweig wegen ber Seltenfeit bes guten Edjreinerholjes leiber. gu gefdetgen pifegt. Das befte Syolg fierjil ift Sas, weld)es aus ben Stammenden ocr Eid)en befolnders baju gefpalsen wirb, ooer aud) bas, was von bemt gefunden ofgngefifgr anderts

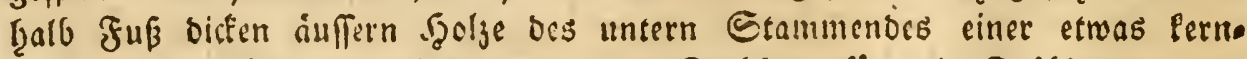
fauten Eidse fält, weld)cs, wie das Stabtgoly für bie Fafbinder, ber Epiegelfeite nad) geipalten, unto zu fedfs bis ad)t Boll bidén Studefen aus bem Broben gearbeitet wiro, uno dann von den St)reinern meiter init Sagen geffnnitfen werten Eann. Es ift baher für bicjenigen, weldje juun elinftigen

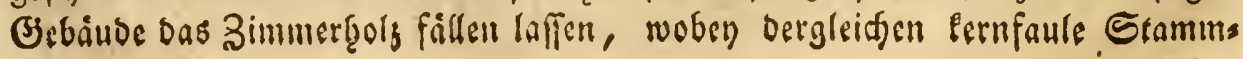


enben abgefduitten uno nid)t gead)tet werben, fef̧r ratbfam, foldje nidft, wie

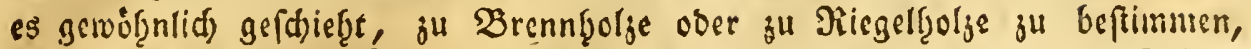

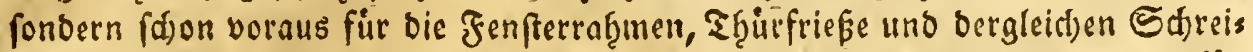

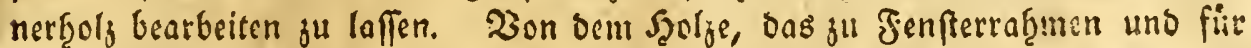

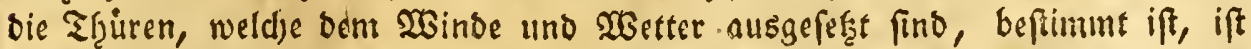

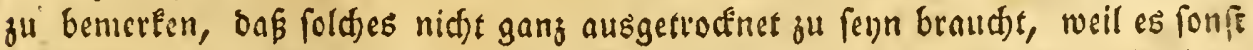

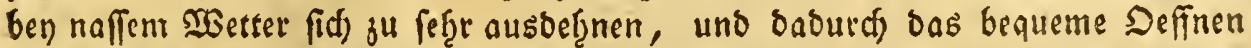

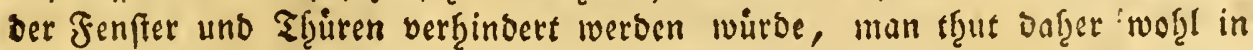
bem Jalle, wenn baju ganj trocfnes Şolj genommen werben foll, foldes bor bem 2lusarbeiten an cinem feudjen Drte, oser in feudfer suft fí ctros auss betgnen ju laffen.

\section{§. 393.}

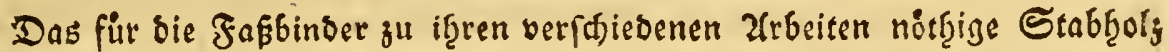
geţort auch in biefe zweyte Elaffe, weldes aber, weil bavon mef̧reres ju fagen

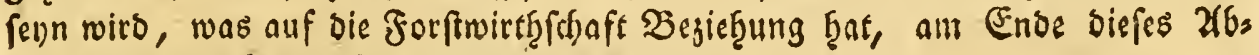
fanitts rocitlauftiger abgefandelt werben foll.

\section{§. 394.}

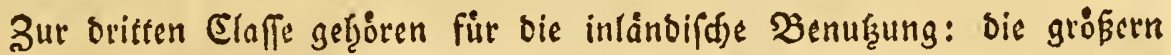
Tellen fite bie verfd)iedenen Zrten bon Müf̨len. Unter biefen find bie Şams merwellen auf ben Eifenbititten bie ftäreften, gewób̨nlid müfen fie vier uno gwangig bis adt und jwanjig Juß lang feyn. Doळ pflegt man bey nellen

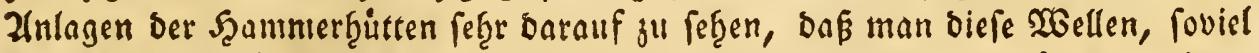

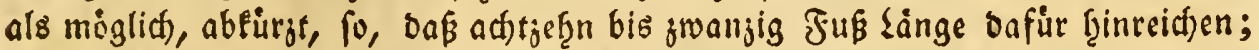
bie Stärle berfelben muß fid) nad) Dem (Serwidfte bes Şammers rid)ten, und ba man jefst biefe Scammet fef̨r fdjwer ju madjell pflegt: fo miffen bie mellen Daju aud farfer genommen verben; oren bis vier fup am untern Enbe unb

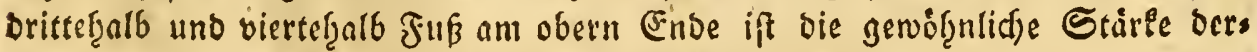
felben fowoḥl in ben, in fiurftentf̧um 2 lanlenburg, als in Şarg: und Wefer:

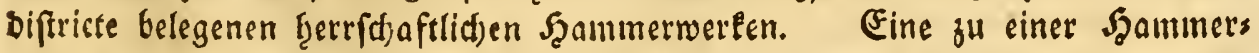

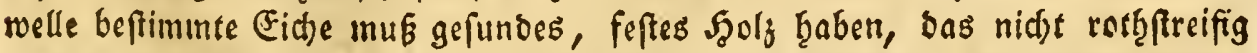
und nid)t ftodffecfig ift, weil es fonft nid)t lange Seit ber Faulniß wiberfetgen fonnte; aud mus eine fold)e Welle im Sern finlänglid feft fenn, bamit ber Japfen bolleommen barin befeftigt werben fann. Der Fern bes Scoljes mú, fo viel als moglid), in ber Mitte uno ber Stamm überţaupt vorguglid in ber

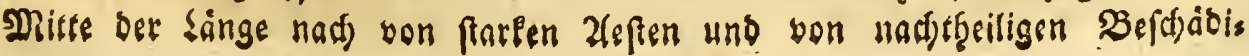


gungen rein fenn, meil bie wellen wiorigenfalls fid trumm ju jieģem, aufo jureifien uno zu bald gu faulen plegen.

Heberf̨aupt ift eine gefunde, holjfefte, gerabegängige welle, aud,

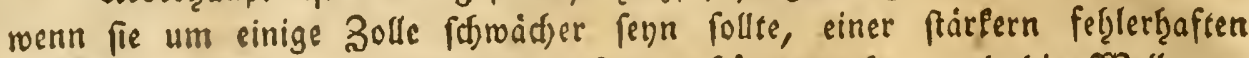

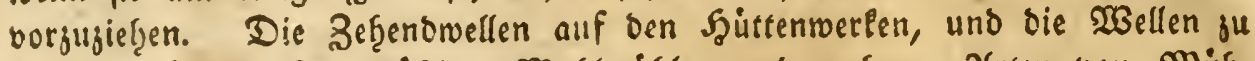

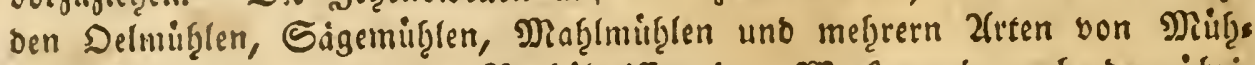
fenmerlen, werben nach ben Zerţâlteniffen ber Werle uno nach ben ibria

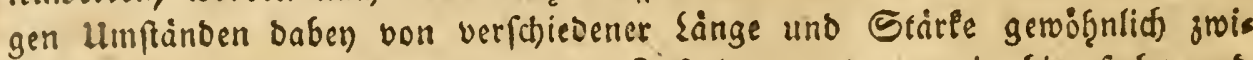
fchen jwanjig uno adjt und jwanjig furs lang uno gwarigig bis fects uno orenfig Zoll fare genommen, robey denn bie obigen Bemerlungen ebens falls anwenobar find. Bul langern wsellen, als ju foldien von orensig bis vierjig Juß lang, ift bas Nabelf̧ols vorjujiefgen, weil es fïh befonders,

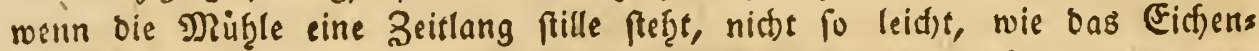
boly, Prumm gieght. Unter bie übrigen bey ben Sammerwerfen vorfommens

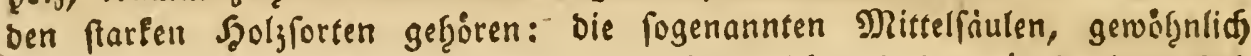

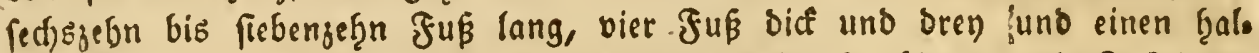

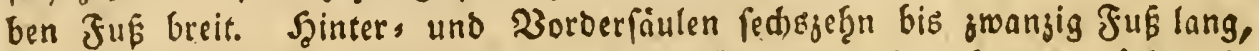

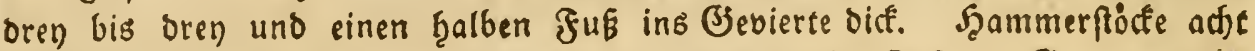

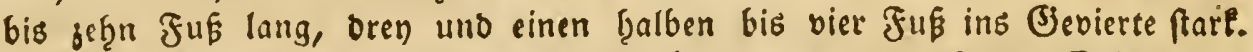
3u ben Trógen itl ben Papiermutglen werden gefunde Eidfen bon

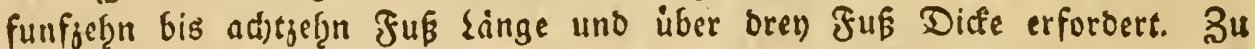
ben Sdjlobbriumen an ben Flutgrwarfen werben nad) ben Uniftanden aud oft ferter lange und farke Eidjen von brensig bis vierzig fup lang und zwey Fus ourd)aus biaf genommen.

26eil nun dergleiden (Fid)en, Der erforberliden Stärle und Bjüte bes Syoljes wegen, falt allgentein felten fint: fo miffen foldse aud bey einer

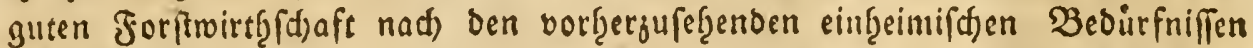

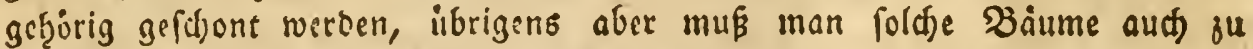
rect)eer Beit jul benufgen wifien, wenn fie, wie es oft ber Jall ift, aus ubertriebenem forftgeige nid)t endidf) gar verberben follen.

\section{§. 395}

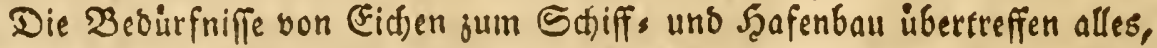
was man in biefem Jad)e fid) grofes gebenlen eann, und erregen bey jedem, oer nur mit einigem Nad)oeneen bie Eecţafen geferten bat, in welden Sdjiffe

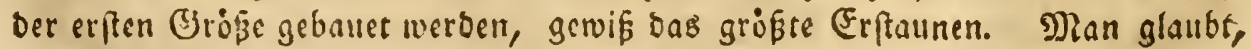
es müsten in allen 20 äldern ber Erof auf einmal alle beften Bàme abgeţauen 


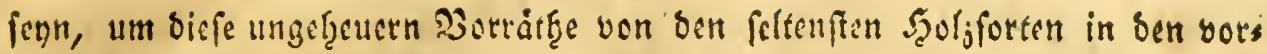
trefflithften Eigenjijaften jul liefern. Erft da lernt man bie Eididen in if̧ren 3ollfommentzeiten fennen, und fief̧t, was bie menfdlid)e Setriebfamfeit bers mag, und wie alle Stinberniffe ben ter 2(nifdaffung aller Dinge iberwunben werben, wenn es nur Bienvinn und Belohnung giebt. Die unermefliden Wals bungen in 2(meriêa, in welthen nod) feine 2 (rt getraud)t ift, liefern ţierju einen

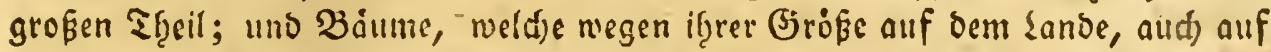
eine geringe Entfermung, faum fortgufdiffen fino, werben auf taufeno und mef̧rere Meilen weit mit entfegelitgen Soften von borther gebradt.

2(ud) aus Deutfd)land wiro jäbrelid) eine fef̧r grope Menge (Eid)enţol's zum

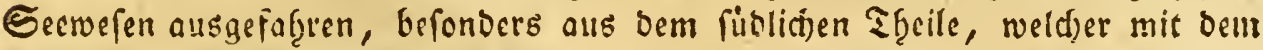

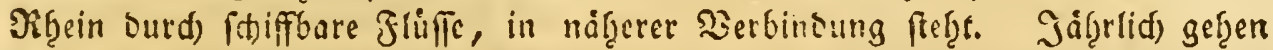

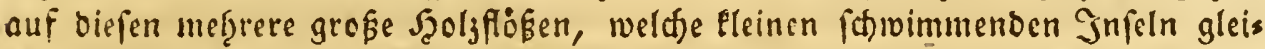

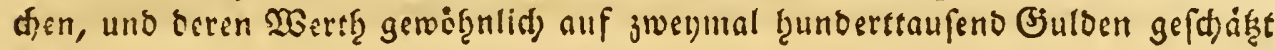
wirb, nach Sgollano.

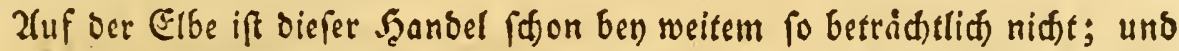

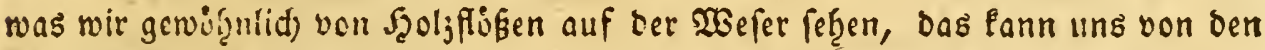

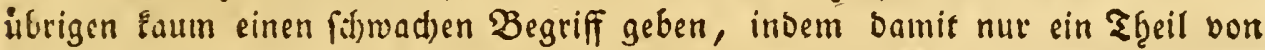

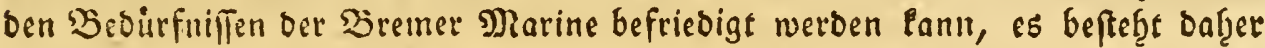

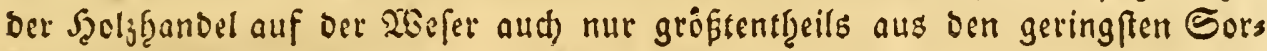
ten Sdiffigoly.

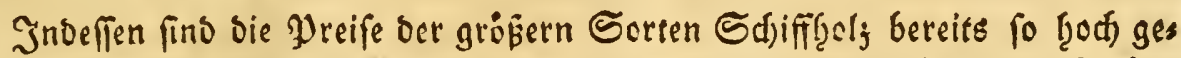

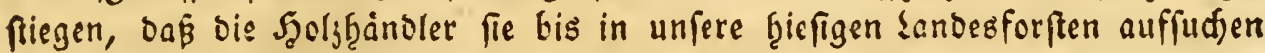
und fitr bie feltenen Sorten feine Tranfportfopten bis an bie $\mathfrak{B e f e r , ~ o b e r ~ a u c h ~}$

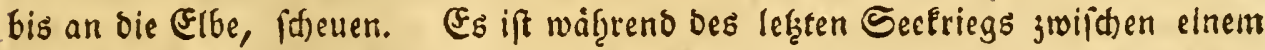
Theil von 2(merifa, Englano uno. Frantreid), aud) cine fef̧r große Nienge

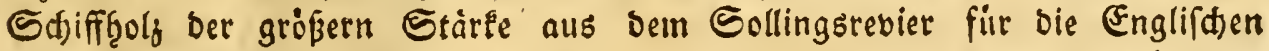
(Sd)iffe, uno gleid) nad) bempelben eben fo viel ju bem neuen franjofifden Secţafenbau zu Egerbourg verarbeitet und abgeflóft worben. Daher ift es aud) in biefen Jürftlid)en ländern, uno befonders im SEeferbiftrict für ben

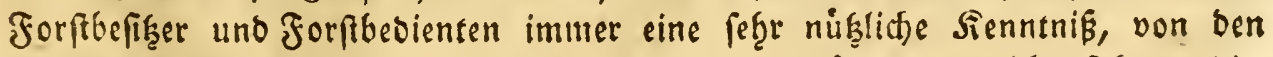

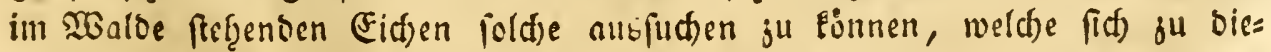

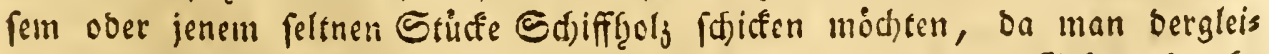

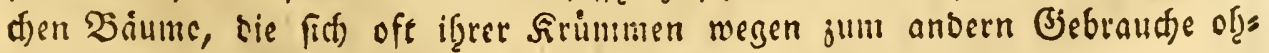
nebies weniget fdicfen, baju fefgr vortheillfaft verfaufsn tann. 


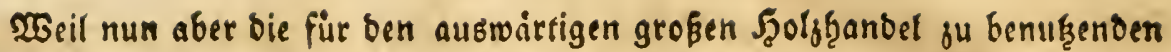
Sticfe nad) ben $\mathfrak{H}$ mftanden urio nach ben von ben Syoljganolern ubernommenen Sieferúngen, fowohgl in ifren Formen uno Daaken, als in ber Zart uno Weife fie

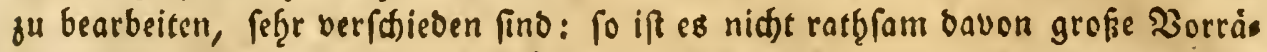
the, ober aud) eingelne feltene Stude of̧ne fidbere Zusfidften gang fertig ausars beiten zu laffen. Beffer iftes, foldje nur aus bem Broben fo viel befdjlagen ju laffen, bak fie etwa leidter zu tranfportiren, uno bemnàd)ft, wenn cs bortf̧eils ţafter fenn follte, bequemer ganz ausgearbeitet werden lönnen.

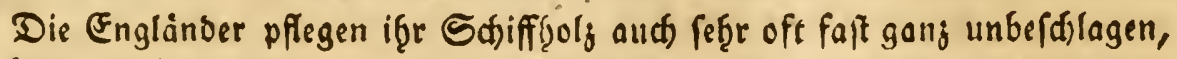
und iberf̧aupt bey meitem nidft to volléantig bearbeitet fu verlangen, als $e s$ in ben Spaniften uno Jranjofifiten Seeträen geforbert wirb.

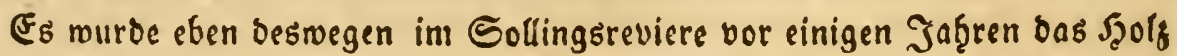
für ben Şafen in Sḩerbourg nod) einmal Eantiger nad)gearbeitet, was borbem

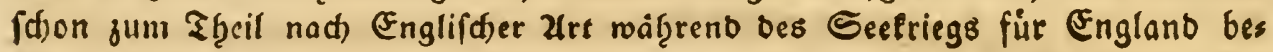
ftimut und nidtt fo pefgr ins Pieine befdlagen war.

\section{§. 396.}

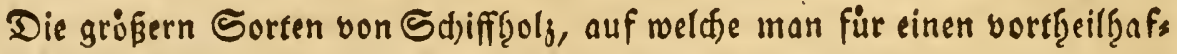

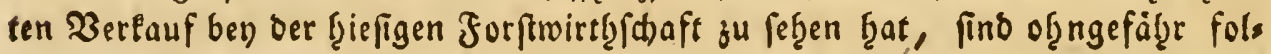
genoe:

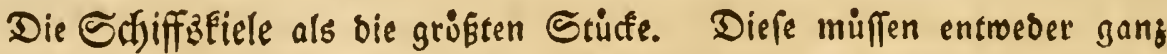
gerabe ooer nur äuferft wenig nach einer Seite bin gebogen, uno ofgne Fåulnif, aud) fo viel, als möglid), bon grofen 2leften rein feun; fie wers ben fo lang und to fare genommen, wie man fie nur immer faben pann,

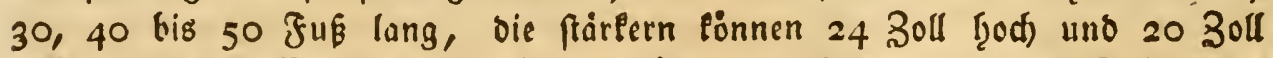
biof am fpigen Ende fenn. Die gewöbnlid)en find 30 bis 35 Fuf lang, 17 und 16, 16 und 15, 15 und 14 3oll am fpiken Ende vid, nadbem man fie aus oen vorfallenden Etainmen am beften erf̧alten fann. Iक etinnere mid) einen febre idionen Sielftamm am Sollinge gepę̧en fu ţaben, Der nach) Englijdem Mlanße benrbeitet, ain obern Ende ins Bjevierte ganj volleantig, 24 Boll biff uno iber 50 fuf lang war, uno mis meţr als 30 $\mathfrak{P}$ ferden an bie Wefer traniportirt werben mußte.

Unter bie actoif̨nlid)en uno am mef̧rften gefud)ten Sorten Frummb̨olz geţoren Die Siniee, woraus tie to genannten Ditpen ber Ediffe gemad)t werden; man theilt fie in große, mittel = unb lleine Siniee, Der längere

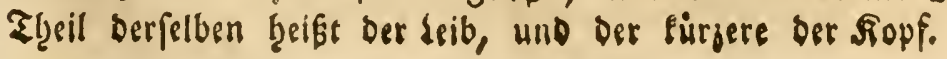


Unter bie gropen Sinice werben bie geredjnet, wethe is bis 20 Fu位 lang in scibe, und 7 bis 9 Juf lang ant Sopfe, uno an benden Enden gleid) 20 bis" 36 3oll bidf uno ţod) fint.

Ilnter bie Mitteleniee, bie bon I 2 bis 18 Fuß länge im leibe unb 5 bis 6 am Ropfe, und 14 bis 18 ?oll ins Bebierte auf beyben Enden gleidf fare find.

Unter ti. fleinen Snice geţoren bie von 6 bis ro Jus lang im seibe und 3 bis 4 Juk lang am Fiopfe, und 10 bis 12 Boll ins Bevierte gleid biff.

Diefe Sniee miffen eigettlid, auf jwen Seiten gerabe, und nach biefen

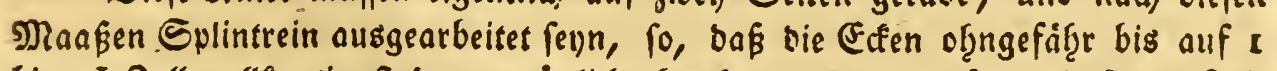
bis $1 \frac{\pi}{2}$ Boll volleantig finb, borguglich aber fomint es barauf an, baß bas Syols

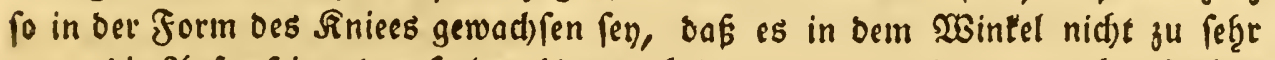

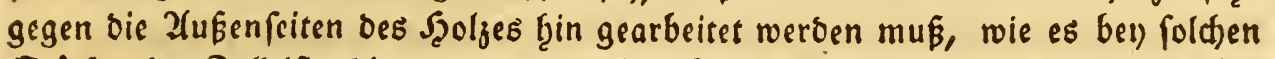
Etücfen ber Fall ift, bie aus einem bicfen Stamme mit einem ju geringen affe geţauen fino, uno ben weldten man, um ingnen mę̧rere Sirumme ju geben, bie Breite bes Stamms zu feg̨r benuk̨t Gat.

Die beften Frummen ber $\mathfrak{K}$ niee find bie, wobon ber אopf unit bem Leibe

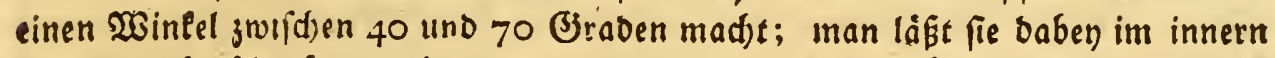
Winfel nicft idjarf ausarbeiten, fo, baß fie mit einer Rünung mę̧r Stärle beţalten.

Heberbaupt aber múb bey allen Srummb̧oljforten bie Regel beobadtet wers ben, baß bie gebogene Seite bie ftärffte fenn, uno benm 2(usarbeiten borguglid gefdont werben muk.

Die unter bem Namen von Budften befannten Sirummftucfe, merben if̨s rer form nach in $S$ und $C$ Budften: und aud ber Grópe nad in grof̧e, Mittel= uno Eleine SBudften getţeilt, von benen bie großen 24 bis 40 Jukl lang, und 24 bis 36 3oll pare.

Die Mittel6uditen

15 bis 20 fus lang und

It bis 20 Soll fark, bie

lleinen aber ro bis 14 Jup lang unb 10 bis 14 3oll ftart fenn inulfen. Sie muffen auf zmen Seiten gerabe, unb an beyben Enben gleift bif uno ins Gies vierte bolleantig ausgearbeitet fenn. Der Preis ift zwifden ben $S$ und $C$

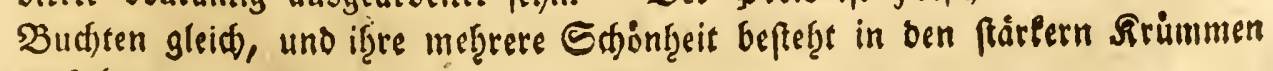
berjelben. 
Die unter bem Namen von Seşarn belannten Sdjiffgoljfilcie fino jum

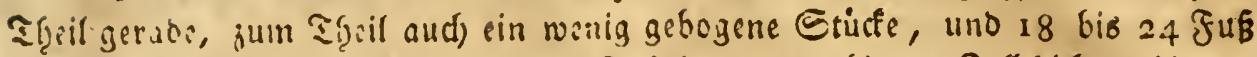
lang, 24 bis 36 3oll bick, 12 bis 18 Juk lang, 14 bis 18 3oll biff, 6 bis 10 Jup lang, 10 bis 14 Zoll biat.

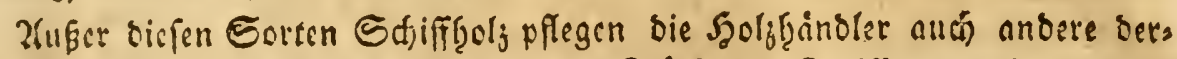
gleidjen jul neflinen, aus melchen bie gernoen Stude bes Edjiffs gemadit nerten,

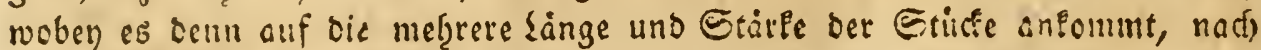

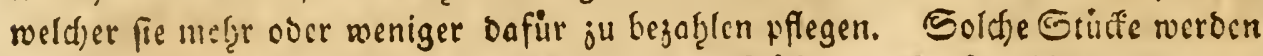

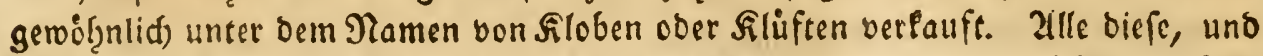

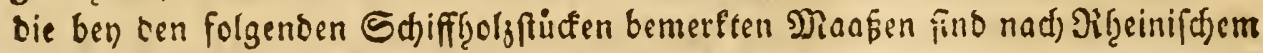
Raafie bercdinet, weldes babey burdigeţends angenommen wito.

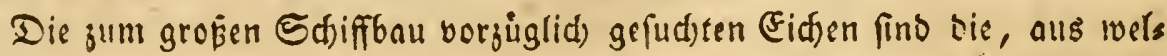
d)en bie fogenannten Solanlen oder Crabclen gefdnitten werben Ënnen, weil biefe von allen Feb̧lern, als von grö́sern Zleften, rothen und weiffen Etreifen, und fonftigen Etedffecfen, ftarlen Diiffen rein uno feler gerabegängig fenn muifs fen. Dod) einnen fie aud von cinem auf einer Eeite gebogenen $\mathfrak{B}$ aume ber Srimme nad) gefdnitten werben, infoweit fid) lef̧tere in bie Biegung bes Sd)iffs fdicft, nls nad) relder die geraben Planén burdss feuer gebogen merden milfen.

Eie werben nach forgensen Manfen gefdinitten:

Son 24 Fub lang, $2 \frac{x}{2}$ Zoll bicf und 16 3oll breit am Sops ober fleinen Ende.

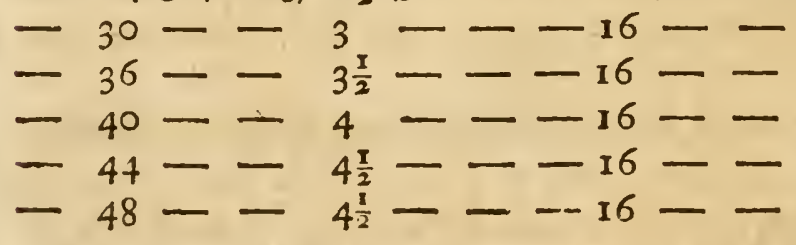

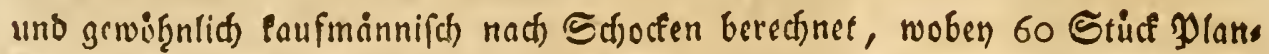
fen von 24 Juk lang und $2 \frac{7}{2}$ Joll biff jum Brunde angenommen fino, po, bak I Planfe von 24 Fuf für 1 Eravele oder glanle,

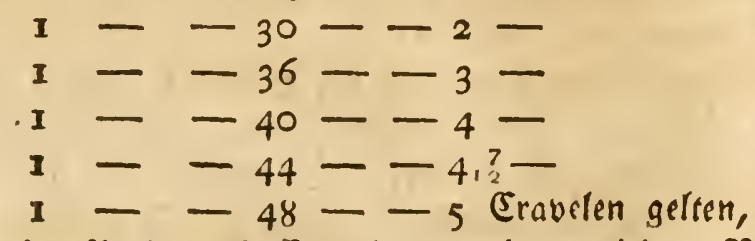

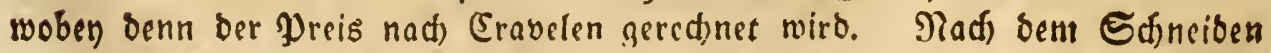
biefer Planten múfen fie gegen die Sonne uno ftarfen \&uftjug gebefit, und, bas 
mit fie fich nid)t jief̧en, gerobe alfgelegt werben; aud fönnen fie, wie oben

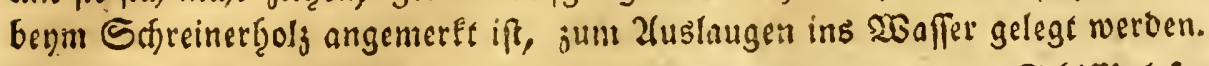

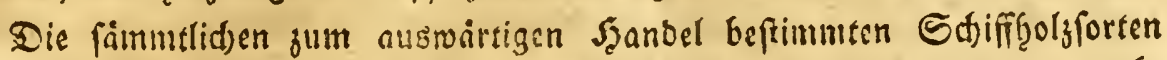

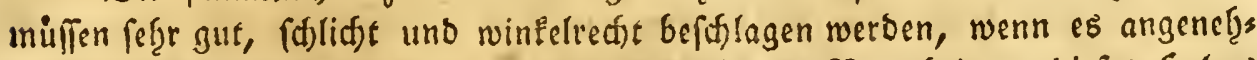

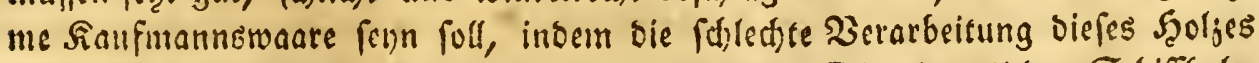

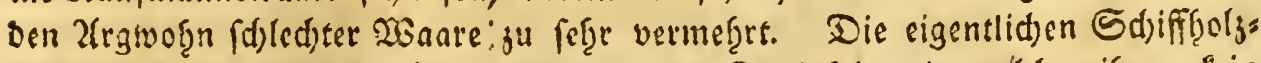
Gauer haben ben biefer arbeit eine befonbre Fertigfeit, in weld)er ifnen fein

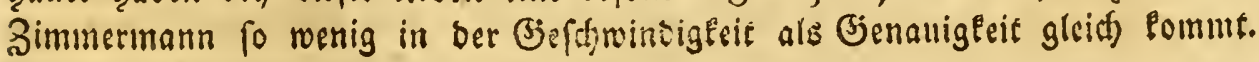

\section{§. 397.}

Sn bem Sollings, Dberforftreviere werben jum Sdiffball all ber 20 es

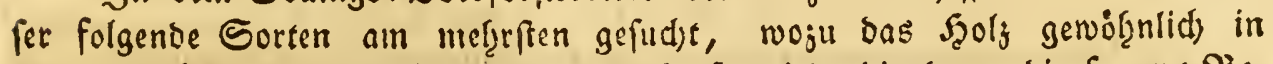
ganjen Stücfen an bie J̧oljfinoler verlauft mirb, die bann bie fernere Bes arbeitung beforgen laffen, weldes ibrigens gutes, feptes und fehterreines

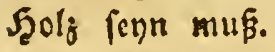

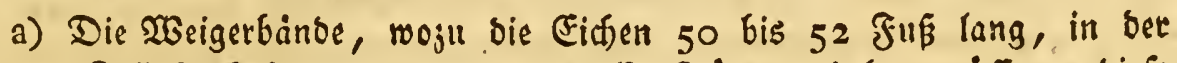
Mitte 14 Zoll ftark jeın, und cine gewiffe Rrumme haben miffen; biefe retben baf̧er als feltene Stucte angefefren.

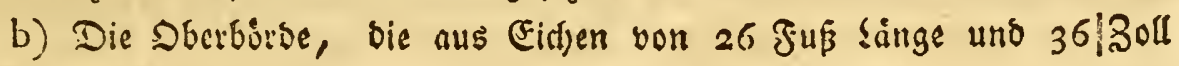
Starte, uno

c) bic Unterborbe, bie aus foldfen yon 26 fup linge und 30 Zoll Stärle geiduitten werbert. sicf.

d) Das Stumpfgolj, von 30 bis 40 fup lang, und 16 bis 18 Soll

e) Bieringe Saniee voln 7 Sus an jebem Ende lang, uno 6 bis 8 Boll bick.

Diefe Syoljforten werben in Sem Sollings, Dberforftreviere nad) Eubis

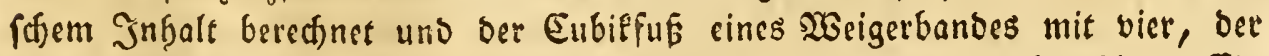
übrigen Sorten aber mit brittehalb Butengrofdhen Forfigins bejaf̨lt. Eitt Jaar geringe Sinie Poften gerwög̨nlith jeţn Gutégrofden.

\section{§. 398.}

Die Wreife für bie jum auswärtigen Şandel geţorigen Şoljforten find nidft genau zu beftimmen, weil folde von ber Menge uno von ber Seltens

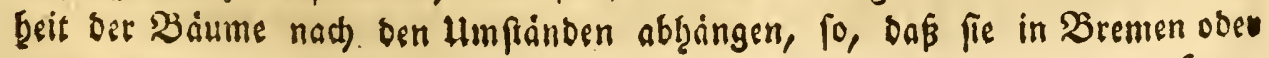
Şams 
Şamburg ju Reiten bas Doppelte bes gewöh̨nliden Preifes Eoften; wonach man fidf alfo bey einem vorf̧abenben Şanbel fu exfunbigen uno fu rid)ten ḩat. Nod) weniger lïßt fid) im allgemeinen ber Werth fold)er Soljforten in ben Forften beftimmen, da folder, auper ben fo fef̧r verfdjiebenen nad)= theiligen ober bortb̨eilf̧aften Beitumftänoen, ourd gróbere ober geringere Entfernung ber forfren von ben flöbaren Flüben, burch Ģöbere ober niebris gere Berge, gute uno böfe rage uno bergleidjen, erf̧öbet ober verminbert wiro, fo baj man nur ju oft gejrungen ift, ben fitonften Baum weit unter feinem 2 serth zu Stabf̧or fdlagen zu laffen, ber an einem andern Drte ben beften Sdjiffstiel gegeben ḩaben rürbe.

\section{§. 399.}

Ulebrigens maden bie vielen nid)t ju beftimmenoen Mebenunloften von ber Zearbeitung, bem ₹ranfport an bas $\mathfrak{W a f f e r}$, ben Floffeften, bem $\mathfrak{W a f s}$

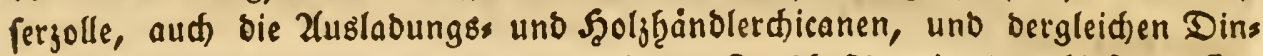

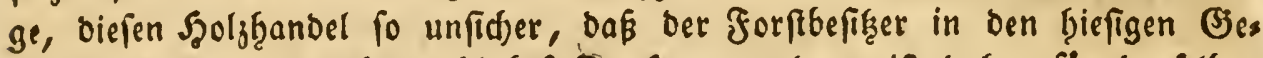
genoen fid bomit nidgt molgl befaften eann, uns es if bafer für benfelben

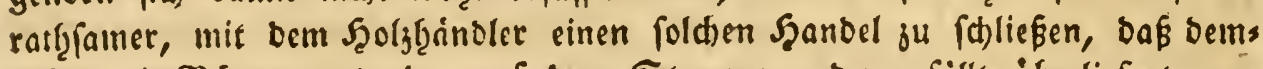
felben bie $\mathfrak{B a}$ aume entrober nuf bem Stamme, ober gefält uberliefert wers

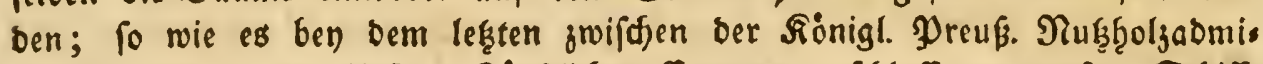
niftration und ber Giefigen Furftictien Eammer gefdloffenen großsen $S_{d i f f s}$ holjhandel an Sollinge aud gefdetzen ift; woben erftere alle Bearbeitungss uno Tranfportfoften ubernommen batte. Heberb̧aupt aber lann fid ein Forfteigentbiumer ben einem foldsen Scanbel nid)t genug borffren, uno mujs

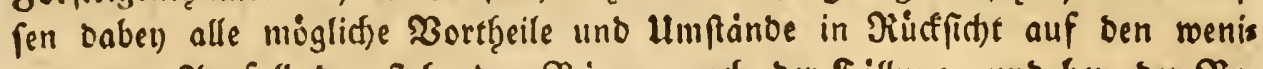
ger guten Zusfall oer febenden $\mathfrak{B}$ iume nad) ber fallung, uno bey ber $\mathfrak{B e s}$

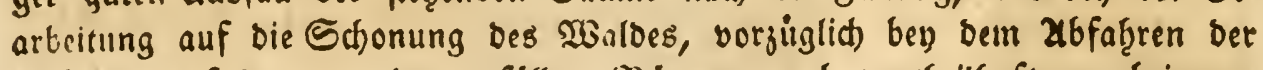
Sticfe, auf bas bon ben gefälten saaumen aud vortbeilfgaft anjubringens be abfallţol\}, und bergleidhen boraus uberlegt uno baruber bas Nöthige mit bein Fiufer bes Szolzes genau berabrebet werben; to wie aud eine genauere Controlle für bie Forftbedienten baben notţig jul fenn pflegt.

Tirgenos babe id) bie Sdjifftboljeid)en in ben biefigen Begenoen Deutfdlanos theurer, als im Münfterfhen, bezaf̧len gefef̨n, vorgiglich in

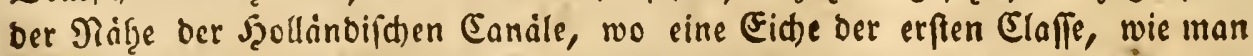
fie bafelbft um die einjelnen Bauerb̨ofe antriff, mit mef̧r als zroenhüundert Rithltr. bejal̨lt miro, mofür man in ben fiefigen Giegenden, wegen bet

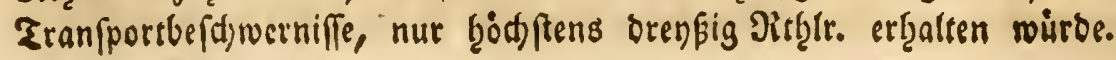

§. 400 . 


\section{§. 400.}

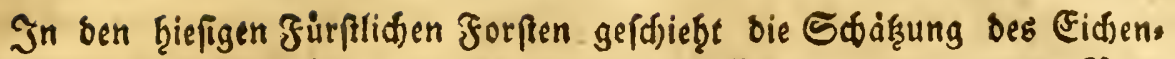

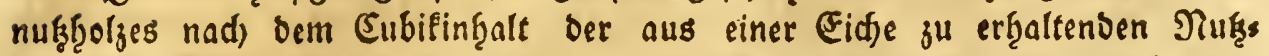
holifticfe. Die Tare berfelben ift in ben Dberforftrebieren Fef̧e verifieten, wobey benn bie beftimmten 1 reife für bie Lanbesuntertiganen niebriger ju

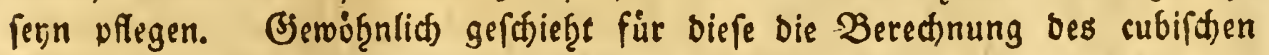
Jnţalts, remn bie (Eid)e burch bie barauf beeibigten Bimmerleute befdlagen ift, weil foldse alsoann mit meţrerer Suberläffigletit Statt finden tann; wor bey benn ber Pevierforftebiente barauf ju fefgen f̧at, baß bas bon einer

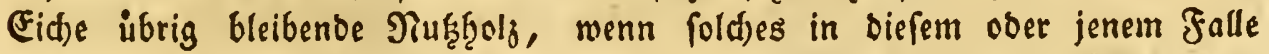
nid)t gang abgegeben werben fann, geţorig bis zu einer andern Belegenfecit gefpart und baf aud bas bavon abfallende Jeuerf̧ol gef̧örig benuk̨t merbe.

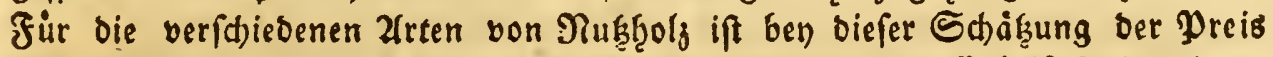
ebenfalls ref̧r verfdieben; to wiro zum Benfipiel ein Eubiffús in einem Stücf, bas zu einer Mhif̧lenwelle beftimmt ift, viel giof̧er berednet, als in einem Baume, von bem Zimmerf̧oly gefdnitten werben foll. Eine Eidje;

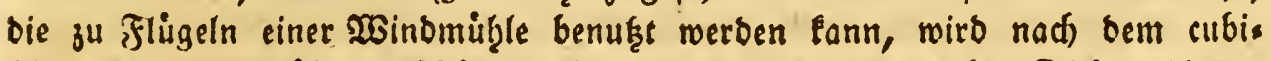

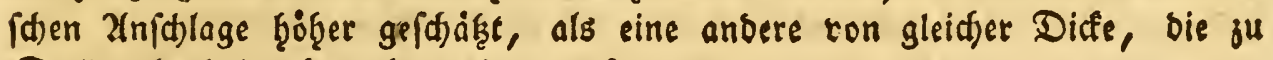
Etellmadjerḩols abgegeben roiro, u. f. w.

\section{§. $40 \mathrm{r}$.}

Bon ber faillung ber Eidfen in ben serfdjebenen Jabrşjeitent.

Die eigentliche forftmápige Fällungsjeit ber (Eid)en fowobl, wic aller ubrigen Şolzarten, bauert yom 2lbfallen bes Laubes im Şerbfte an, bis ins

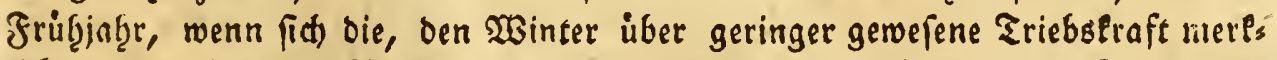
lid) ju verftirlen anfängt. Mef̧rere umftande, weldse mit ber forftwirtly: fd)aft in enger $\mathfrak{3 e r b i n b u n g ~ f t e f e n , ~ u n o ~ f o w o f e l ~ a u f ~ b i e ~ E r f ̧ a l t u n g ~ b e r ~ f o r s ~}$

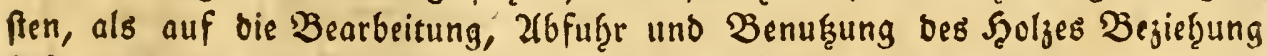
hraben, machen biefes allgemein ju einem natürlid)en Forifgrunbfak̨e, meldber offnebies an ben mef̧rften Dertern aud nod als ein gejọriebenes Biefęs, in ben Forforonungen eingeführert ift.

\section{\$. 402 .}

In einigen befonbern fällen aber wirb biefe Sgaunngsteriobe, um ges

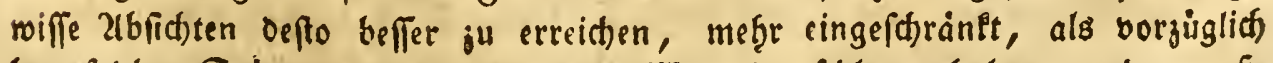
bey foldjen Stàmmen, von Denen ber 2 Surjelausfdlag erf̧alten werben mus, 
wie ben beut vierjigjäfrigen Stangentgolje uns funfjeb̨ns bis jwangigiągris

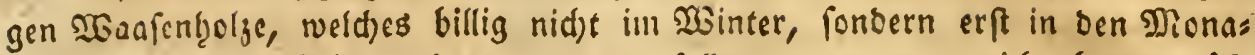
ten februar und Diarg gef̧auen werben folle, wenn man nid) benm grof: fern Forfthaushalte, um oer 2rocit vorjulominen, fdoon friţer, uno of benm Zlbfallen ber Blaitter bainit anfangen nubite, weld)es aber bod) ibers baupt ben ber (Fid)e von wenigerer Ertheblidfleit, als bey ber Sinde ift, weil bie Fide fehr gut aus bem Stamme wieber nusfolảgt und der Stamm: fäulniśs weniger unterworfen ift. Fin glcides fintet mit ber feauung bel) foldjen Eid)en Statt, welche oer babon ju eríaltenoen bierberborle wegen ppater, uno nur in ber farfern Enftjeit getgauen merben miffen, bie nut jäbrtlid) renige $\mathfrak{T O d j e n ~ D a u e r t . ~}$

\section{§. 403 .}

Finige widftige Bebentlidleiten entfeben bey ber Frage: of es fix

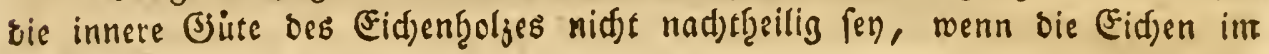
saube getrauen wirben?

Die Forftgeleferten uno borfuglid) bie bornef̧mern $\mathfrak{B}$ aumeifter vout Blenftift uno Dinfel fino bieruber fo, wie uber mef̧rete bargleiden Dinge, nid)t einig, wovon bie Scaupturfad)e in fold)en alten trobitionsartigan Jors

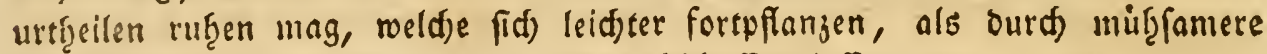
Beobadstungen uno ourd) Beleb̨rung abfdaffen laffen.

(Es freipt saben gewoinnlid), ber in bem alsoann unrcifen Sgoije ben Sommer iber befindlide viele Saft, veranlaffe Jjährung, Stofung uno

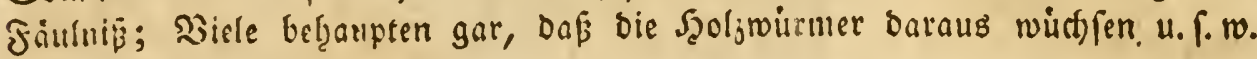

2lber bie Baitme fino ja aud im SBinter nid)t fo faftleer, als fie es bey einer weniger genauen 2 eobachtung zu fenn fdeinen; ifgr Saft ift alsbann wegen ber Sölte nur mef̧r verbidft uno nidjt fo flüffig, als er es wátcreno bes wärmern Wetters ber ftärfern Begetationsjeit ift, wovon bie 2áume, reldye in ben Wintermonaten gefället und bis an bas Ende bes Man's unbearbeitet liegen geblicben find, uberfübrende Beroeife geben, in:

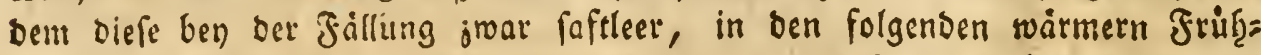
lingstagen aber oft fo voller Saft erfdeinen, baf fogar bey viclen bie Borfe fid) bequem ablofen list, roobey aud bic Sinofpen jul fdwellen, und oft fid ful entfalten anfangen. Zlud bie im frithling ber Berberborle wes gen gefälten Däume laffen fidh, wenn fie einige Tage gelegen f̧aben, beum

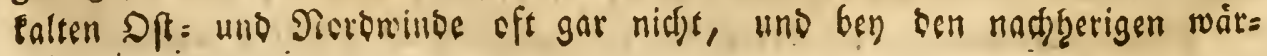




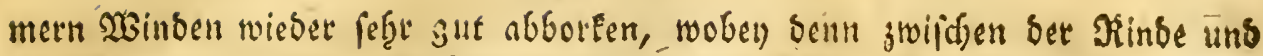
bem Solje wieber ber volle Saft exfdjeint, Der in ben falten Tagen juvor gang auggeborret gu fern fdietr.

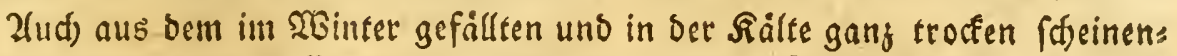
ben Şolje mito man aut Enbe nod) b̧äufigen Saft laufen feben, wenn sin Stud Davon ans Feuer gelegt wirt, weld)es ebenfalls bie Wirkung ber Saife auf bie 2fusoef̧nung bes Safts bewcipet. Es ift wägreno der ftarkern Begetationsjeit

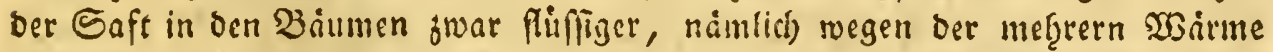

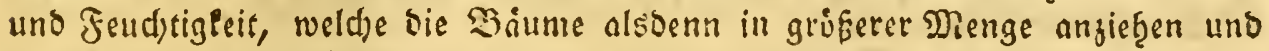

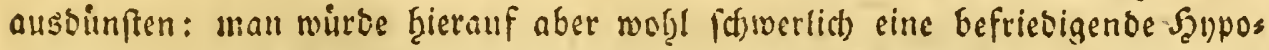

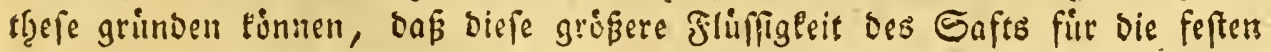

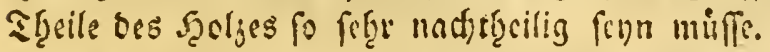

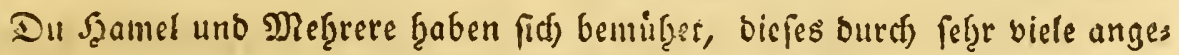

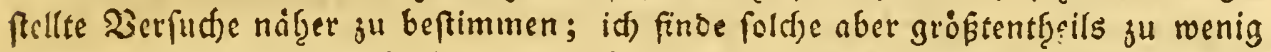

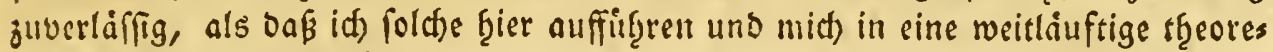

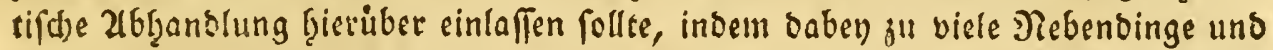

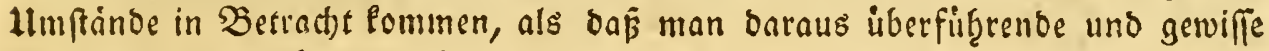
Diefultate zictenen Einnte. Denn felbft ift in ben Sadumen, welche auf einem (j)runde oft neben einander gewad) fen find, in Betreff if̧res meţr ober weniget

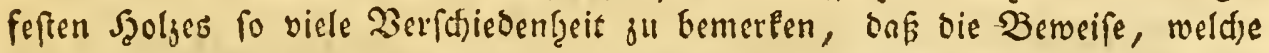

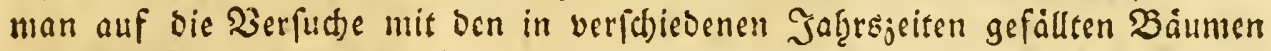

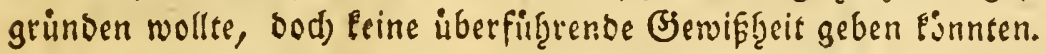

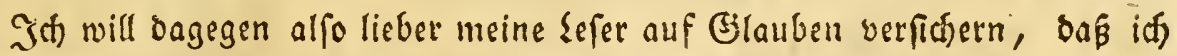
feit mef̧ern Jab̨ren auf biefen Bunit feg̨e aufmerefaum gerwefen bin, uno fie aufmuntern, ju ifgrer eigenen und 2(norer Belef̨rung ebenfalls barauf ad) faum

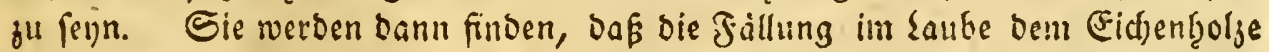

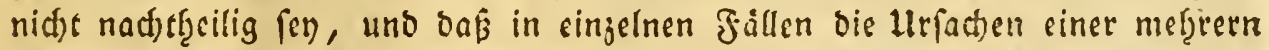

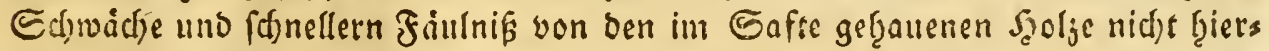

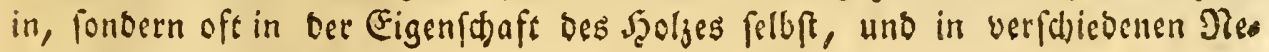
benbingen fu fuchen jey.

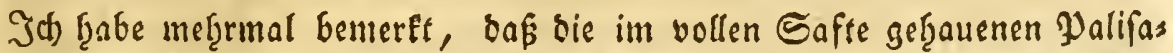
Den uno Zaunpfäbzle um sie Bauerţofe eine weit metrere Dauter uno Fefrigzeif

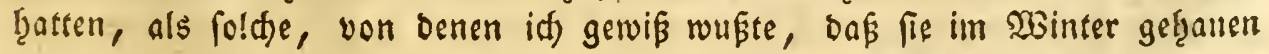
waren.

S(d) ţabe fowof̧l bas im Minter, als bas im Commer, geţauene Eid)en

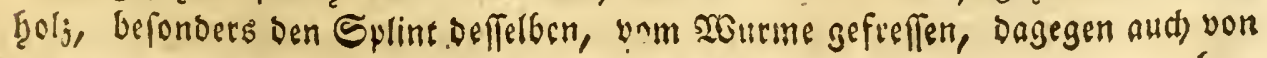
(Erfter Theil) $\mathfrak{I}$ beys 


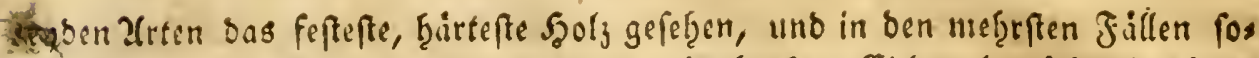
gar ons Eptintfgoly, bejonbers von ben abgeborlten Eidten beträd)tlid) ţarter befunden, als von foldsen, welde im SBinter gefält, uno in ber Borte getrod"s net roaren.

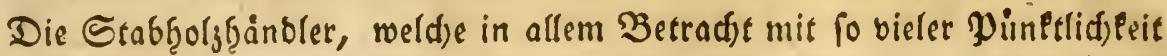

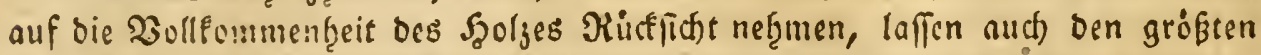

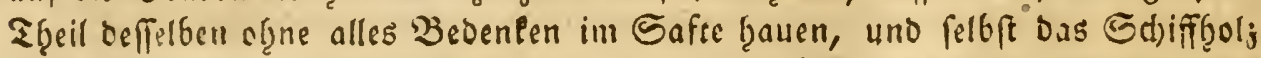
wiro im కaube gef̧auen, weil man fíd) b̧inlänglid) úbergeugt ḩat, baß es bavon nid)ts an feiner Bjite verliert.

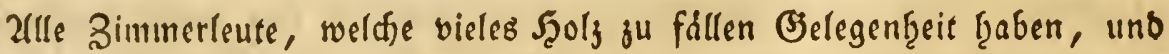
von benen man mit einiger Zuverlaffigleit sin grindlid)es Butacten erwarten Pann, werben ein Bleithes verfidfern.

Da uns nun bey biefen und äbnliden Dingen bie praftifde Erfafrung

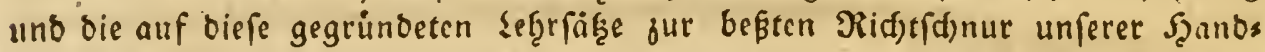

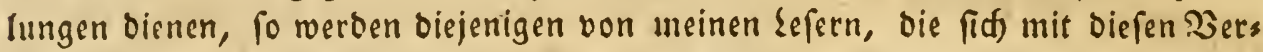
fid)erungen nid)t begniigen, if̧re etwa nod) gehegten Zweifet ourd) eigente 'Zes merlungen gull heben felbft Belegenţeiten genug finden.

\section{§. 404 .}

Nur wirte es nidft rathfam fenn, einen Baum, ber in ber ftärften Safts

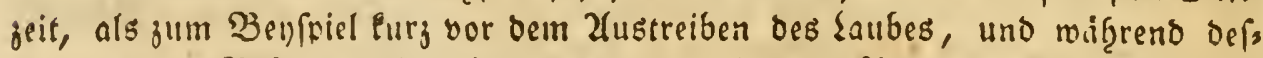

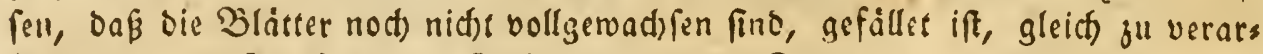
beiten, als zu Baulzolj, z" Bof̧len, ober zu Dielelt ju figneiden, rueil bas

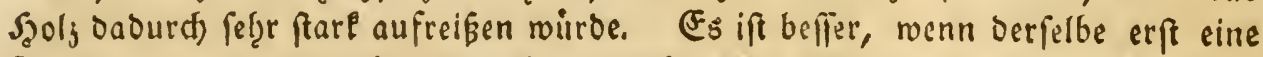
Deitlang liegen uno nach uno nad) austrodfnen faun, meldhes febre gefdiwind oas burd) berwirft wiro, wenn man einem fold)en Baume bie fámuntlid)en 2fefte uno Sweige nid)t gleid) nad) Der Fällung, fondern erft vierjefon Fage bis brey $\mathfrak{W}_{0}$ den nact)her abnimmt, Dantit biefe ben im Stamm befindidjen Saft erft augjies Gen uno veroinften.

Zluf fold)e 2art habe id Bäume, bie in ocr ftärffen Safrzeit gefálet was

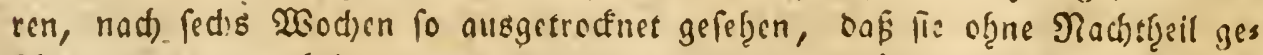
fd)nitten uno verarbeitet wersen ponnten. WBie oenn uberţaupt Das im laube gebauene $S_{2}$ olj oer mehreren 2 errinnung ocs Saftes wegen, gefdiwinter auss trodfnet, als bas in $\mathfrak{x i n t e r}$ geflauene $\mathfrak{S}_{2} \mathfrak{l}_{3}$, weld)es man vorjuglid) an fold)en (Eid)en bemerlen fann, bie in Den heifen Tagen ben einer längere Zeit angefrals tenen Dirre gefällt fino, in meld)en wegen oer ftirtern 2fusbunftung uno Des 


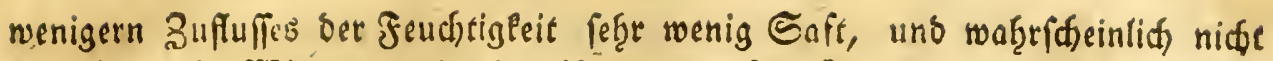
fo viel, als im Winter, vorbianden ift; aus biefem Brunde pflegt man aud) im Nad) fommer, nach Beendigung bes jmenten Sriebes, mit wenigerm Bebenlen bie Eidjen zu fällen.

\section{§. 405.}

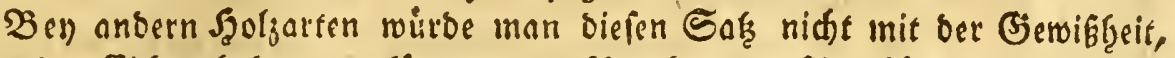
wie bey ber Eiche, bef̧aupten fönnen; es fällt ben ben Bothbuhchen und Ellern

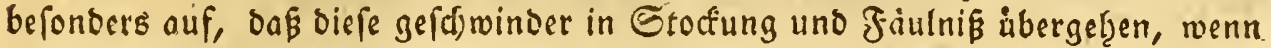
fie in ber ftarkern Saftzeit gef̧allen weroen, wovon bie, burch bie Şärme in

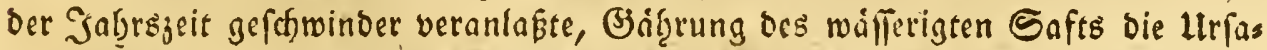

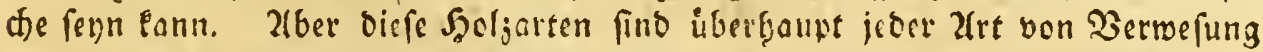

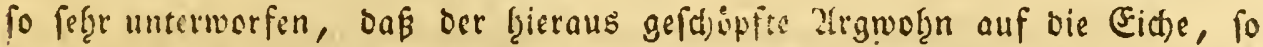

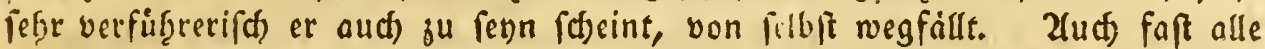

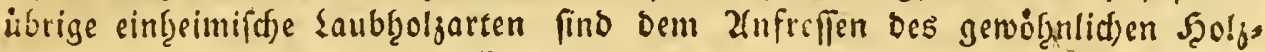

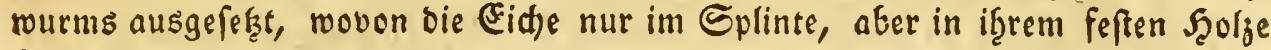
auserff felten, angegriffen wirb, es mag folde in 2 Sinter ober im Sommer gefállet fèn.

\section{§. $40 \%$.}

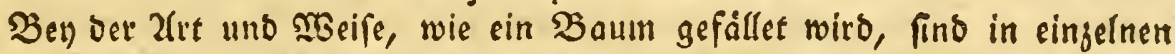

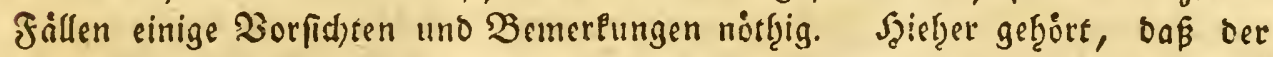
Stamm einer jungen (Fid)e, wenn er wieber ausfdjlagen foll, nicht ţod) iber ber Erbe, uno fdyrảg von einer Scite her abgetzauen werben mußs, bamit bas

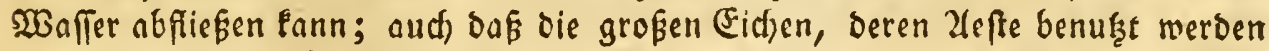
follen, mit einiger 30 orficht gefället werben miffen, weil bie Zefte wibrigenfalls fef̧re oft ju fpalten und jerfd)lagen zu werben pflegen, man lákt fie beswegen ges

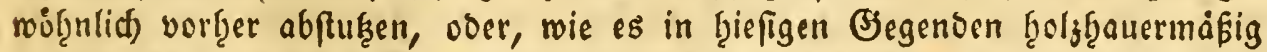
hei

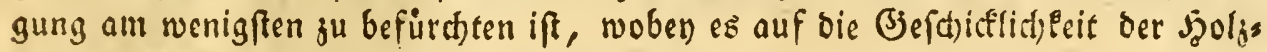
bauer anfoimnt. 2lls cine 3 emerlung, bie nur felten beobachtet wirb, veroient

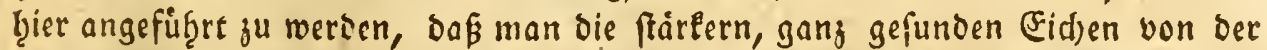

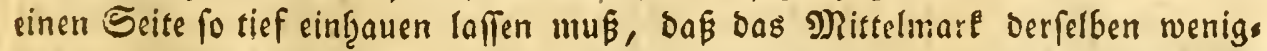
fens um einige Zolle getroffen und abgergauen wiro, weil fonft bie um baffelbe

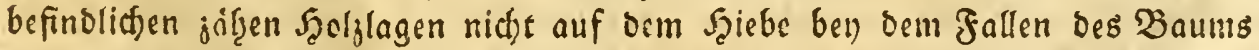

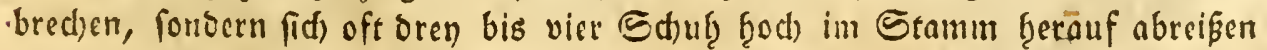

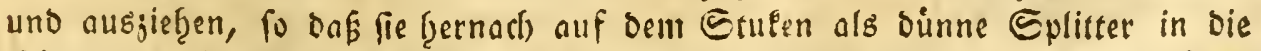

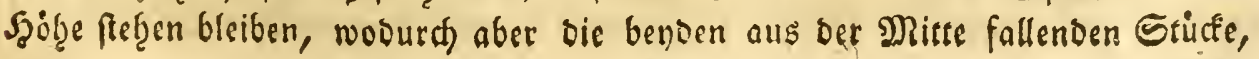


wann ber Baum gu Dielen obet betgleidgen gefafnitten werben follte, fef̧r bes fifjabigt werben.

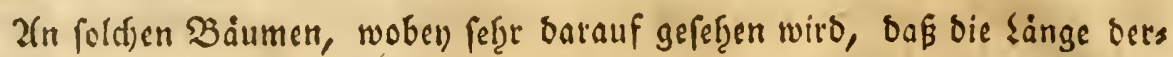

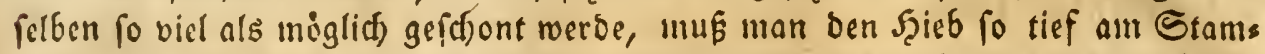

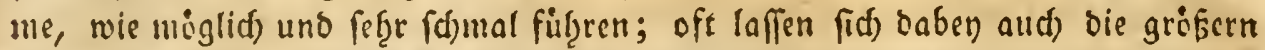

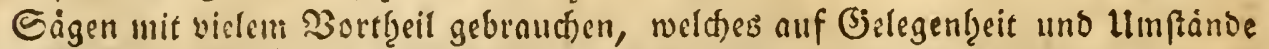

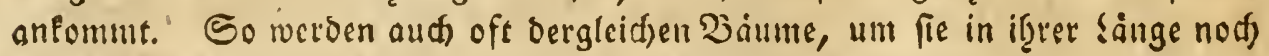
mef̧r zu fdjonen, ausgerobet uno fo mit į̧rer 23 urgel gefállet.

\section{§. 407. \\ Bom Stabrolje.}

Ilnter bem Stabgolze wirb basjenige Nukgholz verftanden, weldfes für bie Fafbinder zu Fallerftäben beftimmt iff, uno oaju aus bim Groben vorgearbeis tef wirb, woraus bann nadjeger bie Faßjtabe burd) ferneres Spalten ober alld) wobl mit oer Sage in jwen bis bren Sthefen ber 2 reite nach gefpalten ober ges idjnitten werben. Es wirb ju Jäflern von einigem Wurthe von Eictjenţolje ges madbt, und beifift benn im engern 3 erftante Stabfidj. Su Fäfern von ges

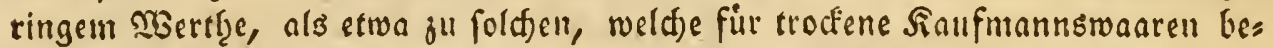
ftinmt find, werben aud) andere Szoljarten und in ben Begenden von Stemen und Şamburg wirb aud) bidientgols genommen, und biefes benn Paufmännifd Flapptiolz ober aud) Büden Stabrgolz genannt; von biefem lefitern wiro metzs

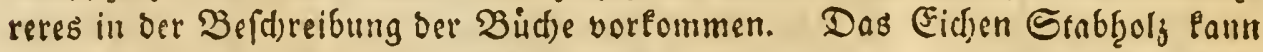
man, nachoen es für bie inlänbifden Beburfniffe ober jum Şanbel ins 2luss lano beftimmt ift, in einfecimifdes uno frembes Stabrolj, uno nach ber lange

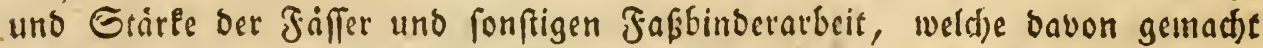
merben foll, vom groken sagerfaffe an bis zum Eleinfen Eimer, in megrere Élaffent theilen; To giebt es Lagerfäffer, Sticffäffer, Dphajote, Eimer, Stabe u. T. 10.

\section{§. 408.}

Die Stabe fur bie inländifd)en Besirfniffe und etwa bie fïr sen gerins gen Şandel, ben baunit einjelue Jabbinder treiben, werben von biefen leuten gewöhnlid) felbet, ober ourd) if̧re oaju beftellten alrbeiter, berfertigt, moju if̧nen

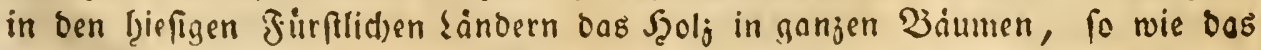

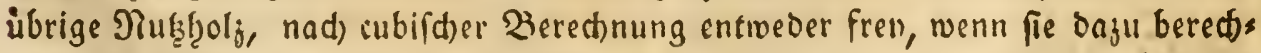
tigt find, oder gegen Den übliden feftgefergen forftzins angerwiefen und überlafs 


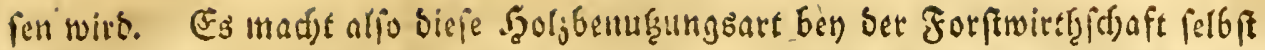

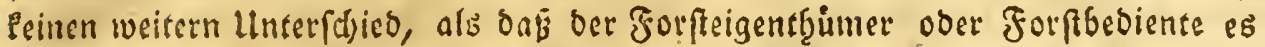

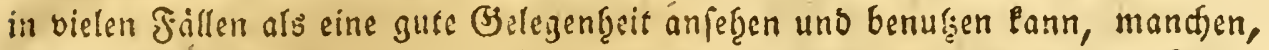

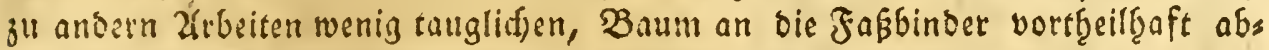

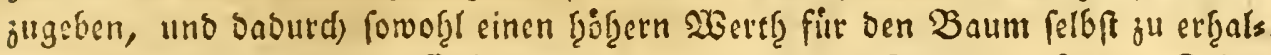

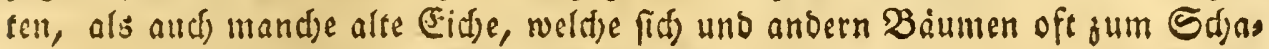
ben feetet, anjubringen uno losizwerden.

\section{§. 409.}

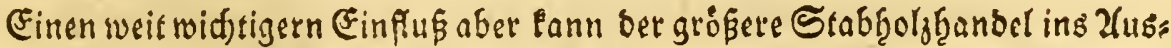

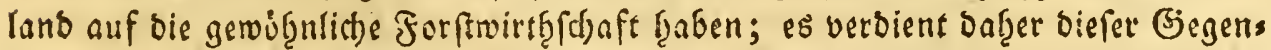
ftand unt fo mef̧r weitlauftig abgetgandelt zu werben, weil fold)es Stabfioljs

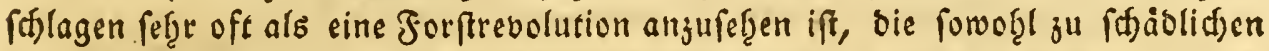
Folgen 2(nlaß geben, als aud jur 2 erbefferung ber forft felbft, uno zum unges

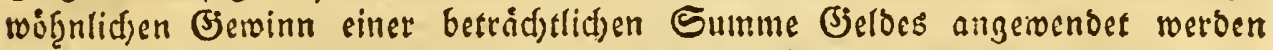
eann, uns weil baben fo vicle Dinge vorlommen, weldye man gemótgnlict) erft aus ber Erfaţrung ju erlernen pflegt, went es ju fpat und man erft burd Sdjas Den Elug geworben ift.

\section{§. $4 \mathrm{ro.}$}

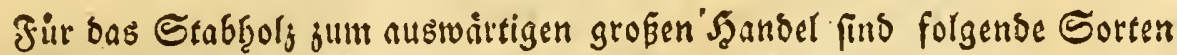
als gewón̨lid)e gängige Salfmanngwante befannt, und angenommen:

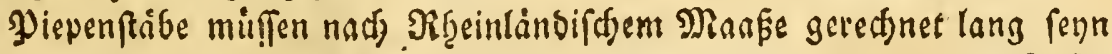

Drf̧oftftibe

Zonnenftibe

Bobentitibe

fie miffen alle finf bis fieben Soll breit fenn, und ber Diffe nath werben fie in brey Sorten getbeilet, von benen

bie Ifte Sorte 2 Zoll uno Daruber.

Die 2 te - I $\frac{3}{4}$ - und

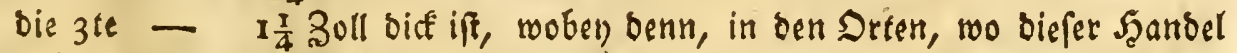
getrieben wirb, aud) ore Regel gilt, baf́ ein Stab ber erften Sorte jur zwenten Doer jur britten geworfen und gered)net wirb, wenn er nidt an allen Seiten volle Stärle f̧at, ober wegen einiger Miffe ober Mängel nidje als sin voller Stab ber erfen oder der gwenten Sorte benufgt werden eann. 
2uffer obigen Sorten bon Stabfgoly toerben aud nod geringere, uno

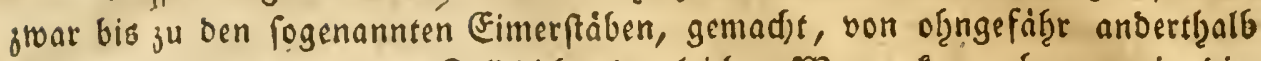

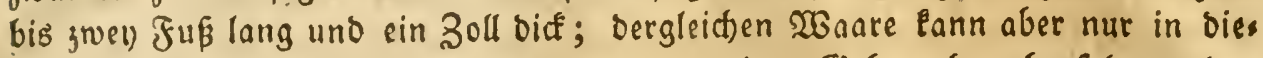
fen Bjegenden, und in Bremen mur jum cortigen (jebraud), abgefefte werben

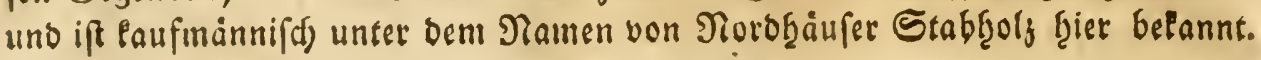

\section{§. 411.}

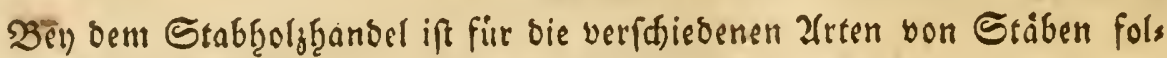
genoe Pied)nung Paufminnifd) angenommen worben, uno gelten

100 Stud Diepenftäbe für

100 - Difioft, 3 - 2 Piepenftabe

100 - Tonnen, 2 -

$100-$ Booen, 4 -

Diefe 400 Stuck madien alfo nad) Piepenftäben beredjnet

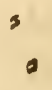

3

3
100 Stif. $66 \frac{2}{3}-$

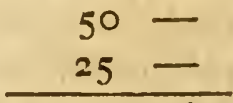

$241 \frac{\overline{3} \text { Cricf. }}{3}$

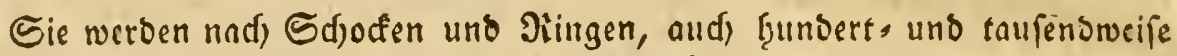

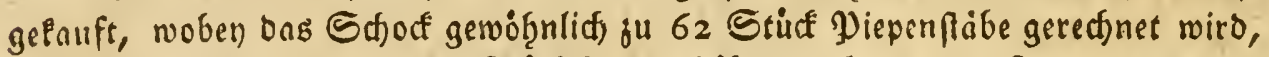
vier fold)e Shodfe ober 248 Stúcf Piepenftábe madjen eimen Ring, uno alfo

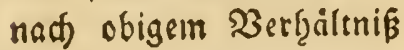

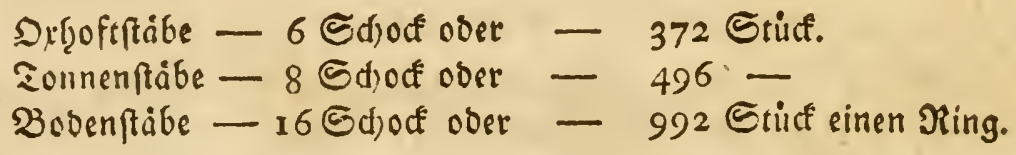

YGenn f̧undert, ober faufenoweife geredfnct wird, fo wird barunter ges wóf̨nlid faufuannifh bas grofe Şundert oder grofe ₹aufeno verftanden, uno für jenes 120 Stucf fur biefes 1200 Stude angenommen, mobev benn abermals

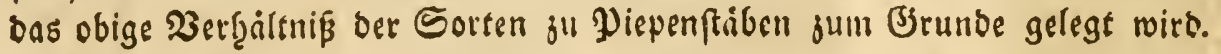

\section{§. 412.}

Bu gutem untabeligaftem: Etablgolge werben folgenbe Eigenifaften er. forbert:

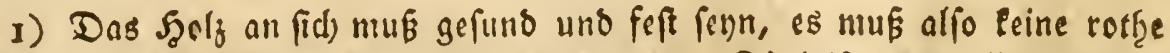

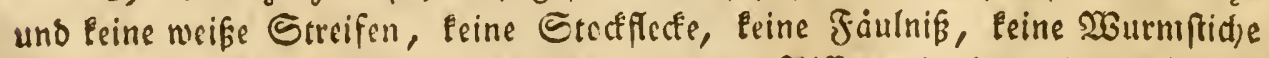
haben; es mub ofne Splint, obne 30 orften uno Jiffe, uno ofgne alle bergleiden Feftler feun. Eolde gluue Errifen aber, welde fid) befonoers in oen פintereiden finoen uno leine spanen von irgeno ciner wenigern Feftigleit

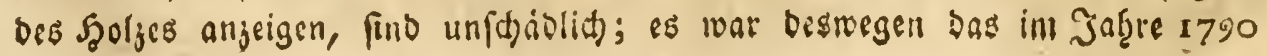




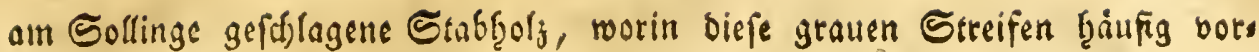
laumen, untabelfaft.

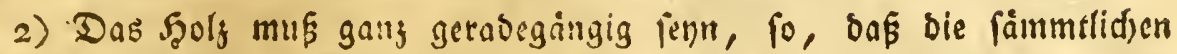

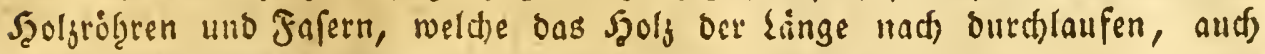
in. bem Etabe allf allen vier Seiten gerabegangig durch geţen.

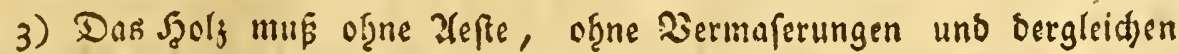
3erwadfungen fern.

4) Ein Stab mus auf allen Stellen bie volle Maake ḩaben.

5) Er muF ganj gerabe, nidft roindig ober uber bas Erf geffroben gearbeitet fenn, fo, baf er, wsun man mit beon 2fuge barauf berunter fiebte, ganj gerabe wie ein vollfommnes Warallefepipedum erfdeint, bed) ift ingm sime Pleine regulaire Frimme ben breiten (Seiten nach unfdáblict).

6) Das f̧ols muß nad) ber Epiegelfeite, das ift, bon ber Borle bes Stamms nad bem Mittefmarl fin gefpalten fenn.

Dak biefe Stäbe fo feģr felglerrein fenn muffert, Davon liegt die llts fact)e in if̧rer SBeftimmung, uno nid)t in ber ubertriebenen Eigenţeit ber Sauffeute, wie es llnwifiente vorgeben, benn, wenn man bedenlt, Daf bas von fajfier für bie theuerften fliffiggeiten gemad)t werben follen, bie burd)

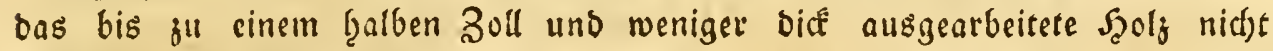
ourdjoringen birrfen, fo wiro man wohl begreifen, wie gegrinnoet bie jooes rung ifrer 30 olleommentzeit fey.

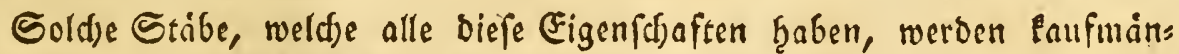
nifh, feine, gute, untadelfgafte $\mathfrak{x}_{\mathfrak{S} a a r e}$ genennet, bie aber, weldte nid)t ganj

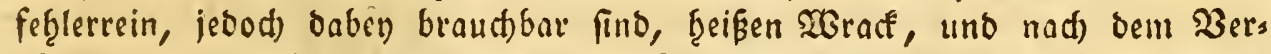

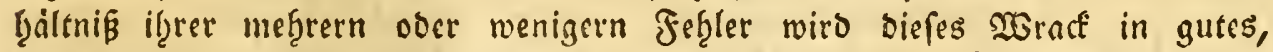

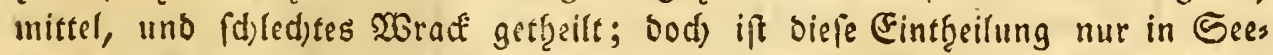
banolungsorten im Bjange, und in Den biefigen Bjegenden wollen die Gabs ţoljbainoler biefen unterfdjes nidjt gern onnergmen; fie ţeilen es nur in

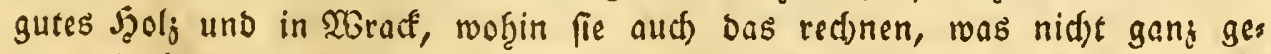
nau bie beftinumte Stírke b̧at, und nur für bie Şälfte angenommen wirb,

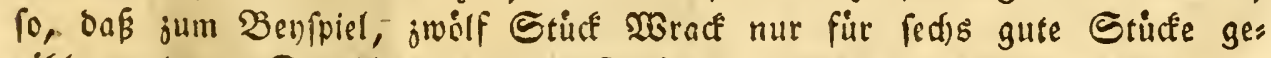

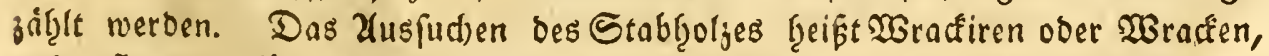

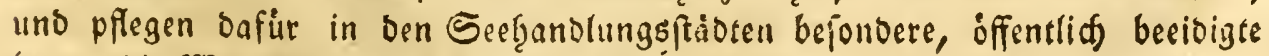

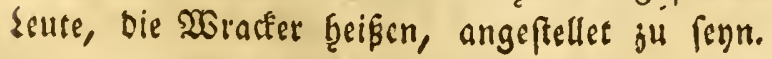




\section{413.}

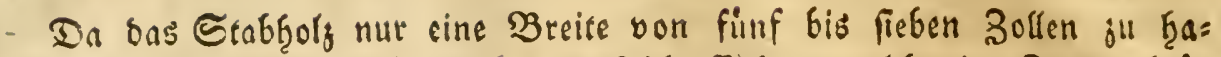

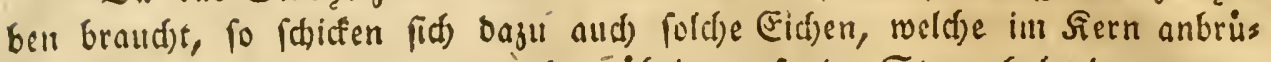
(f)ig und rothfaul find, went bas ibrige gefunde Etammigoly bavon nur nic)t angegriffen uno fonft untabelfiaft ift, uno cs nat) 2 (bgang bes Splints nod) fünf bis fieben Zoll Starle frat; foldjes Şolj pflegt aud) vidl aftreiner zul fenn, uno fids weit beffer paiten zil laffen, als bas näfer um ben Rern ges

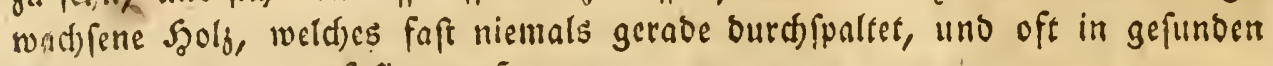
(Eid)en beswegen regfallen mus.

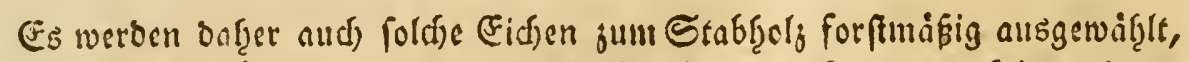

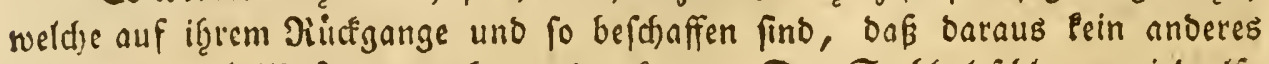

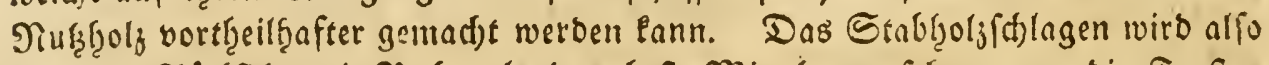

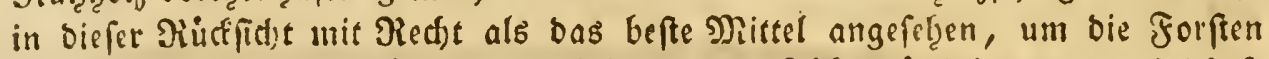

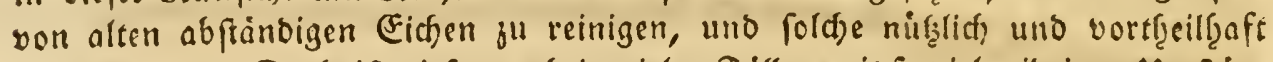
anjubringen. Dody ift biefes audh in vielen fiallen mit fo viel mibrigen limfsins

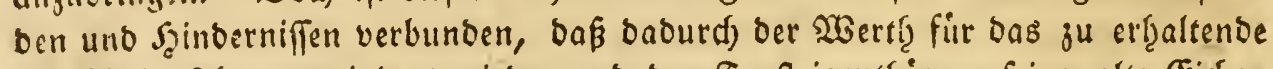
Stabf̧olj felge vermindert wiro, uno ber Forfteigentfiimer feine alte Eidjen vortheillyafter ă Brennhgols verbammen wirbe.

\section{§. 414 .}

Die Stabe miffen alls ben Flokgen, weld)e in ben oben bemerlten Sangen abgefdynitten fino, ber Spiegelfeite oes Jjoljes nad) gefwalten merben, weil fíth

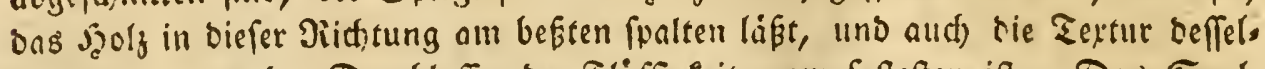
ben barin gegen bas Durdslaffen ber fliffigleiten aum fefteften ift. Das Spals

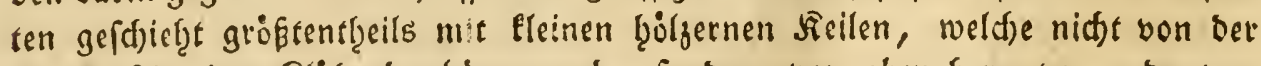

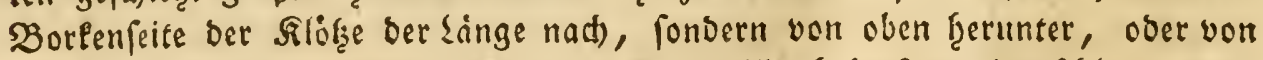

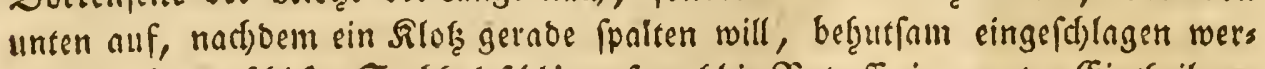

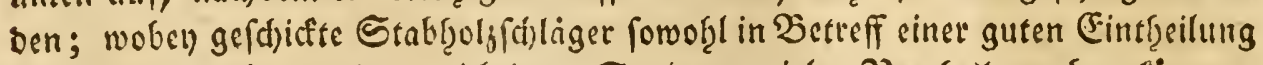

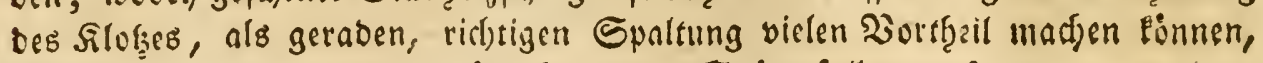
inbem babey fo wenig, wie inoglidy, in bie Spane fallen muई.

\section{§. 415.}

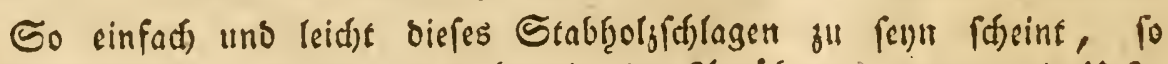
biele Sdmwierigleiten zeigen fid) onbey in oer ?lusitbung, wovon sie $\mathfrak{u t r a s}$

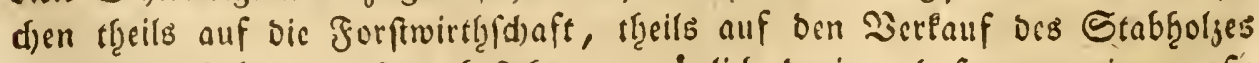

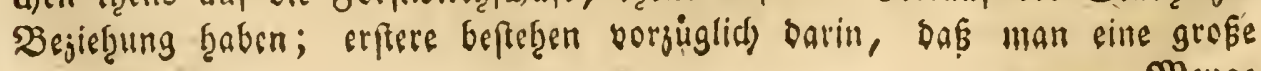




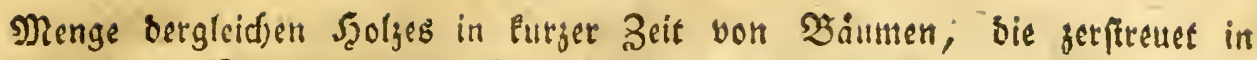

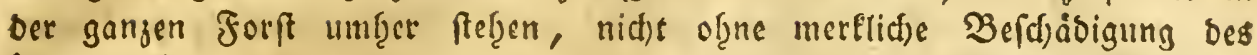
iibrigen. Szoljes fdjlagen laffen Pann; lejtere aber in ben vielen Nebentos ften, welche in ben biefigen Biegenden burd) ben weitläuftigen, entfernten

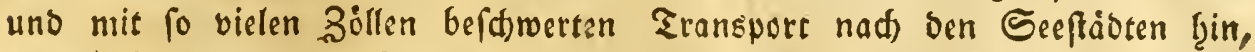
verurfadit werben. Sindeffen hat biefer Şandel aud mandie Bortheile,

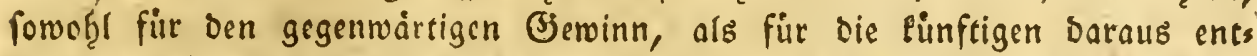
fteţenden Forftuerbefferungen, wenn er mit ber geţorigen Siennenis ber Sacte betrieben wirb.

\section{\$. 416.}

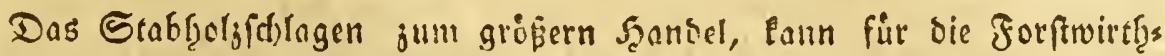
(d)aft befonders unter folgenden Beoingungen becrutende Bortheile bringen:

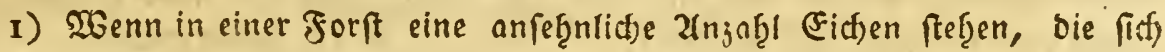

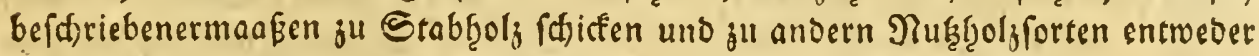
untauglich ober baju nich) fo vortheilfgaft ju benutzen fenn würben.

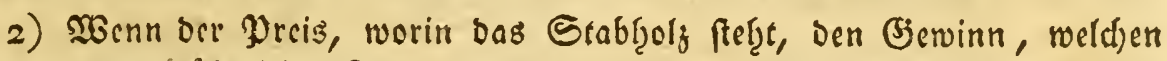
inan von ben gewöb̨nlichen $\mathfrak{B}$ enuşungen za haben pflegt, wenigftens in fo weit

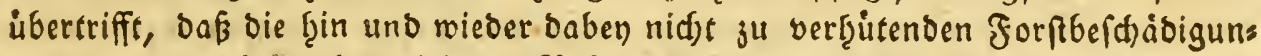

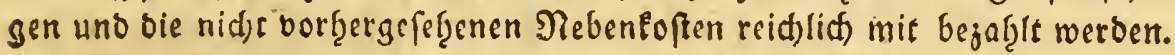

3) Wenn befonders, wie es in mandjen (jegenden der Jall ift, bie alfen abgängigen (Eict)en faft gar nidft ju benukgen finto, uno aud) nod) woh̆l ủberbies

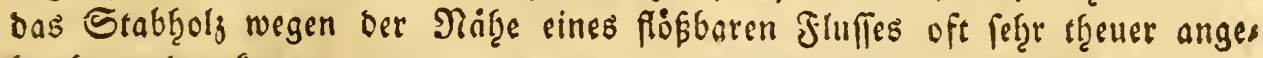
bracbt werbin tann.

4) 2Benn alte Eidjen, welde in foldfen beftandenen Forftorten feefen, woraus fie fith in grofenen Studen nidgt gut tranfportiren laffen, zu Stiben gearbeitet, fammt ben in Malter gefdlagenen $2(6$ fallfzolze leid)t auf bie nód ften Wege berausgetragen und alio benukget werben fonnen, da fie fonft bis jur Şauung bes umfteh̨enden Şolzes viclleidy ganj unbraudjbar geworben fenn wurben.

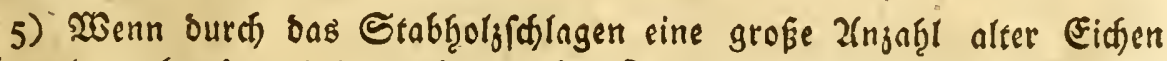
ouf cimmal angebrad)t uno baburd) mandher Forfmutzen als bie Pieinigung oer jungen Sd)läge uno bergleidjen erreid)t.

6) 2(ud) bas 2(bid)lagholz uno bie Borle, weld)e bon ben zu Stabţslz gef̣lagenen Baiumen aófállt, gut benugęt werben Paun, uno

(Erfet Thacil) 


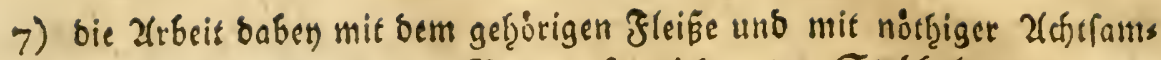

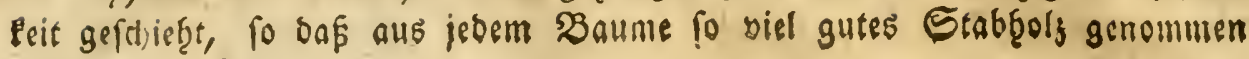
wirto, als mightion.

\section{§. 417.}

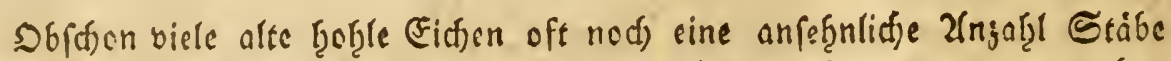
geten: fo wilite es bod in mandhen faillen nachtheifig fern, wenn man ben

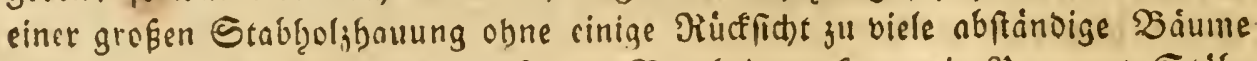
fällen wollte, aus weldsen ben erfolgter bearbeitung faum ein Yaar gute Stäbe

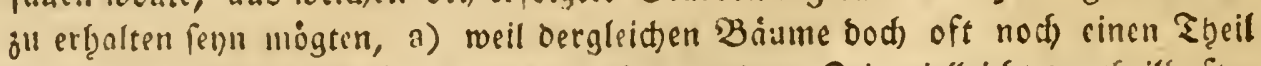

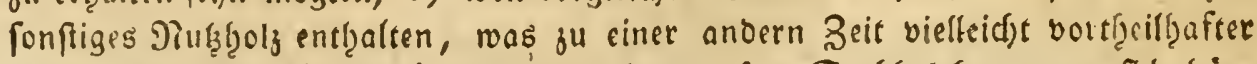

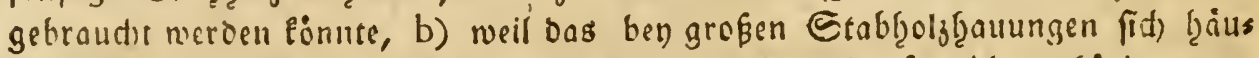

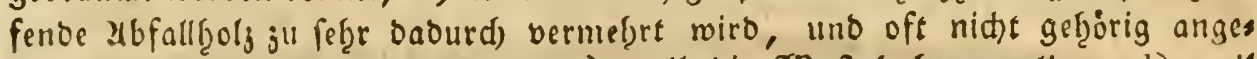
bradte ober verfauft werben eann, c) weil bie 'Maft baben verliert, d) weil

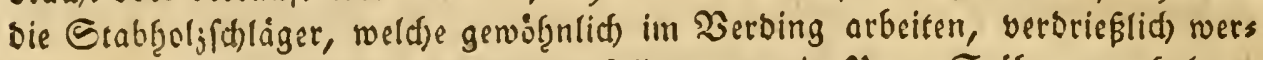
ben, wenn fie vieles Şolj verarbeiten follen, um ein Waar Stábe zu erf̧alten, uno beswegen weniger vortheilf̨aft arbeiten, uno e) weil es iberf̧aupt gewoif̨n= lid) zll viel E(t)reien madts, wenn auf einmal eine fo grofe গieberlage in ber Forft vorgenommen wiro; meswegen aud) ber gróste Şaufen ber Unters

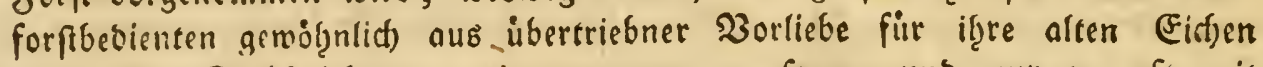
gegen bie Stabfoljbauung eingenommen jul fenn, und nur zu oft mit

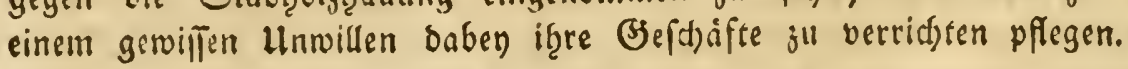

In folden Gorften, worin andre mit ber Maft, ober audf mit freyem

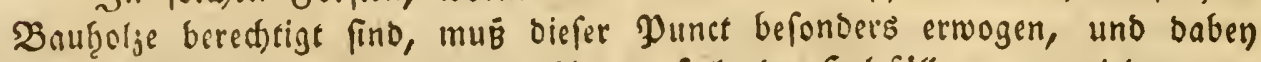
alle in ben Forften feģr in bie Zlugen fallende Sgoljfällung vermieben wer: ben, weldje ofgneties bey dem Fillen ber Eidjen in laube fo febre verwis ficrio ausjufitgen pflegt." Es follte alfo billig Pein Baum ju Stabbiolz ges fället werben, aus weidfem nid)t wenigfens jwen braudbare Silége jul lans

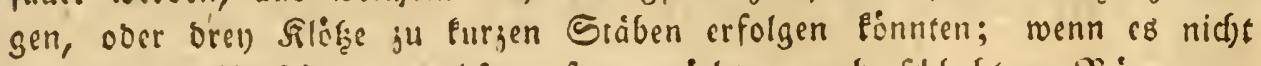
alls antern llmptinoen ratbfan fenn mod)te, aud) fdefedtere Biume jus gleid) mit wegjunthymen; wie es auf fold)en Drten ber fall fernn fann,

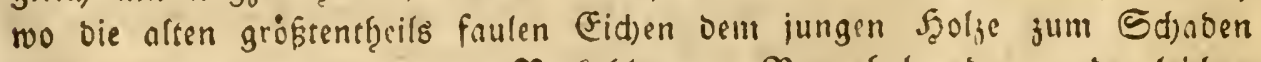
ftef̧en, oder wo fie nur jum Berlob̧len, ju Brennf̧ols ober ju berglcidjen Bebiirfniffen benuşt merden fönnen, uno man alsbann die barin entigaltes nen wenigen Stribe, als eine beffere Nebennukgung anfieţt. 
§. 418.

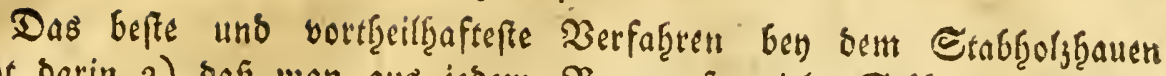

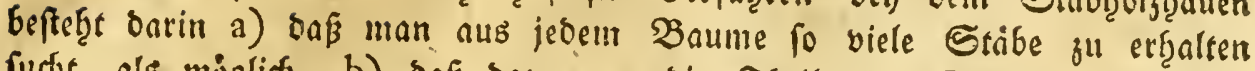
fudte, als múglid, b) bás onju nur bie Theile bes Saums genommen

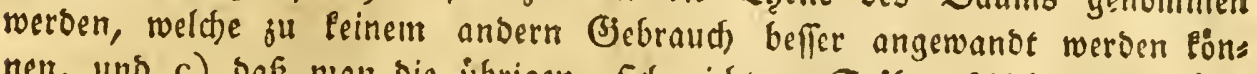

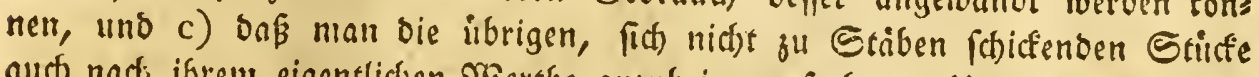

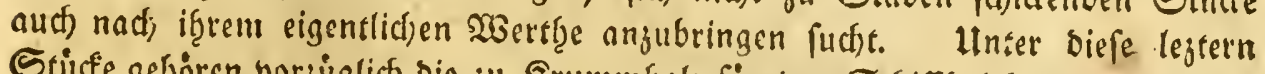

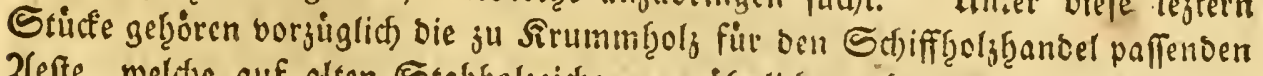
Zefte, welde auf alten Etabbalzeiden gewifgntich vorformmen; es muś alfo

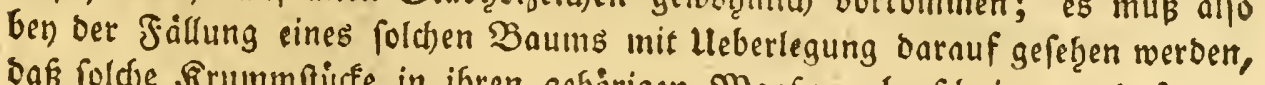

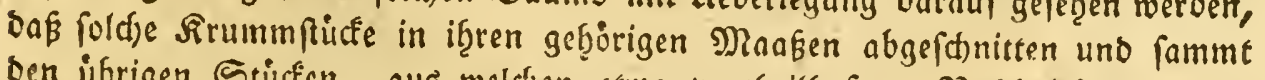

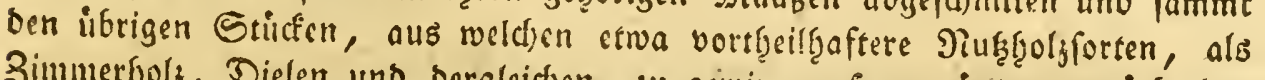

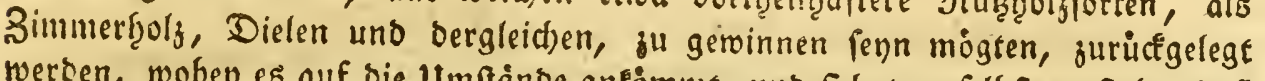
werben, wobey es auf bie $\mathfrak{H m}$ månoe antimmit, unb fid) von felbft verftebct, baf bev) ber fällung sines fold)en Baums aud für bie Erf̧altung feiner brauthbas ren 2(efte burd) bas abespfen berfelben voraus geforgt werbe, weil foldfe in Nieberfallen ferge oft gu" zerfplittern pflegen.

Itm ben grö́ten $23 e r t h$ an Etabgels alts einem Baume, ober aus bemt Dafür beftimunten Theile Defielben zu erţalten, imuß ben ber Eintheilung ber abjufdneidenden Silife anf bie längern uno theuretn Sorten von Stäben juerft, uno bann nad) biefem auf bie lirizern Sorten gefitgen werocn, fo, bak ein oder ber andere Flof, weldher wegen eines aftes ober einer nachtheiligen

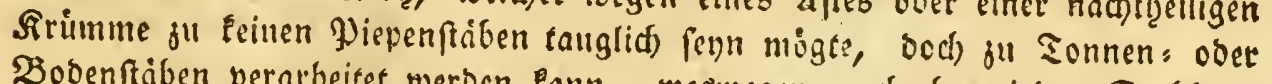
Bobenftiben verarbeitet werben eann, westregen aud) ber jeber Srabgholjs Jauung alle Sorten von Stäben zugleid) gemadjt werosn muffen.

\section{§. 419.}

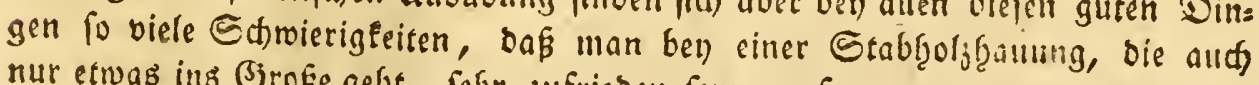
nur etwas ins Brope gefet, fefre jufrieden fenn mus, wenn man nut die wes (entlich)ften bavon überwinoen Pann.

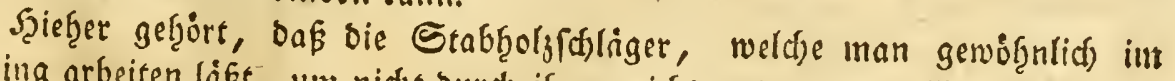

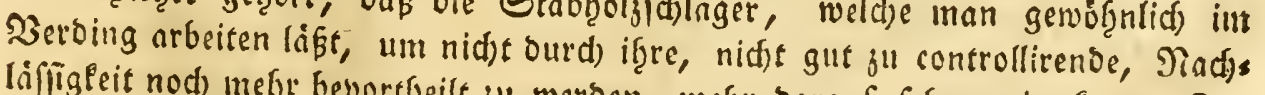

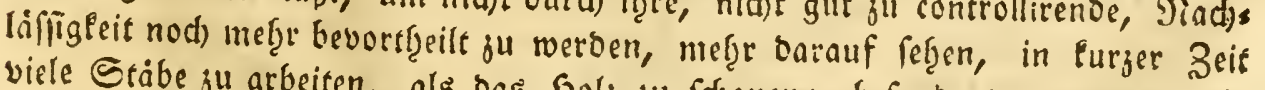
viele Stäbe ju arbeiten, als bas Saly ju fdjonen; befonbers wenn es, wie gemoigntidy, frembe ?eute fine, bie man nur zu biefer ?llbeit angenommen hat,

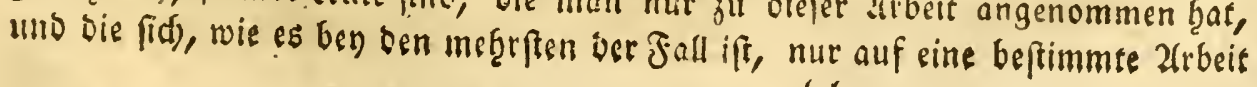




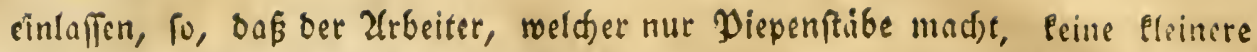
Sorten berfertigt und beswegen oft fum grösten Sdjaben grope Stidi: aus

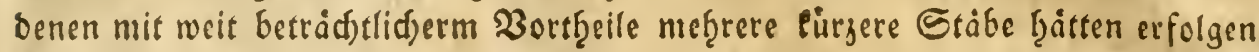

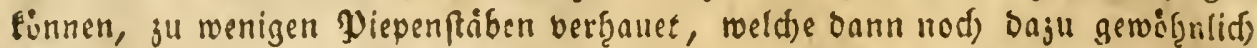
weil fie gegen oen nitt) gerabe getzenden Jaben gearbeitet fino, nur als wract gelten Ënnen. Denn aud) aus einem gu piepenftiben abgelängten Floke fonnen cft nur auf oer einen Seite bergleiden Stábe erfolgen, ba bie antere Seite wegen cines aftes ober bergleid)en beffer ju mebrern furjern Sráben zu benuken ift; wobey es fdon beym ablangen ber Slokge folbft auf eine gute Eintbecilung anfömmt.

\section{§. 420 .}

Es ift beswegen bey ber Bearbeitung oes Stabfioljes eine ber wefentlid;s ften ßorficten, fur 2eftimmung ber aus einem Baume ou erf̧alteriben Şolj: forten fowohl, mie jur Eintbeilung und Spaltung bes Stabfzolges felbft, fithere

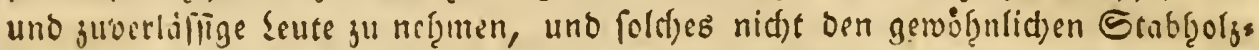
hauern willeubrrlid gu uberlaffen, welden nur bie abgejt)nittenen Flög̨e, ober not) beffer, bie gefpaltenen Stucfe ubergeben uno jugezibglt werben minfen; fo,

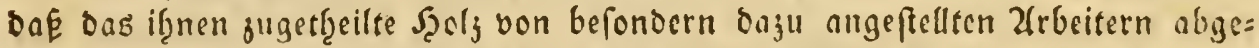
theilt uno jugefdnitten wirb. 2(ud) muß man óen biefer arbeit barauf lif̧en, Dak man foldse alrbeiter finbet, weld)e genaue 2(róeit mad)en, bie bie vorges

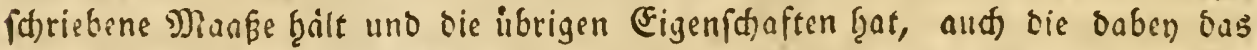
Sodj fparen; man giebt beswegen ben guten 2trbeitern lieber cine Fleinigleit meţr, weil fie es boppelt einbringen, uno fudfe bie ubrigen meniger guten 2(rs beiter, bie man ben Dergleid)en (J)legenţeit im 24nfange nid)t genug gefannt bat lino oft aus Mlangel befferer b̧at nef̧men miffen, nad) uno nac) losjumer: oen, ober ifgnen andere arbeit ju geben.

\section{§. $42 \mathrm{I}$.}

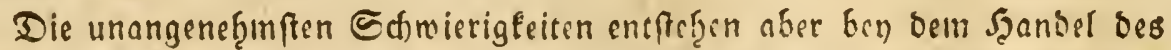
Stabb̨oljes felbjt, coer vielmeb̨r bey oen babey singugeţenden Zedingungen uno ben baraus entipringenten Jolgen.

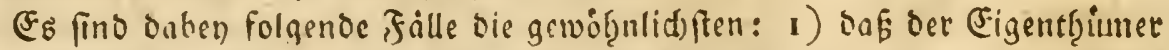
ber Forft bas Stabboly auf feine Pied)nung maden libt und es bann bem Stabs boljbanoler, mit sem er entweoer vorteer, ober bey verfertigter Waate, ben

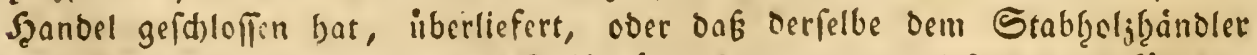
Das J̨auen uno Derfertigen ber Stäbe überläpt uno von biefem bann fitr Das 


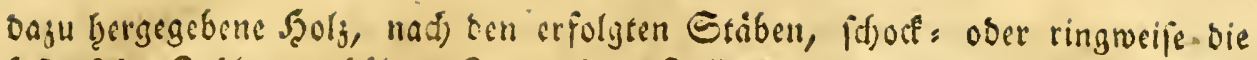

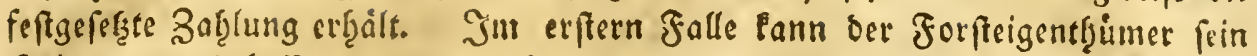
$\mathfrak{J g}_{\mathrm{g}} \mathrm{l}_{\mathrm{g}}$ jwar weit beffer ausnutzen, befonders wenn er bamit nid)t ju ferge eilt, und

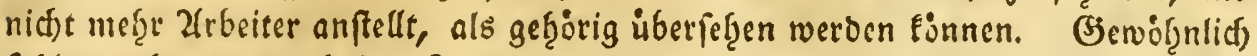

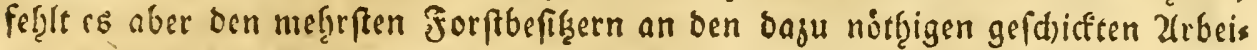
tern uno an oer genauern Senntnié ber Waare, weldse, weil baju weniger geibte Ctobtgo!jfdliger genommen werben, auth faft niemals oie gef̧irige Net. tigkeit uno bas erforberlidbe eaufmannifde anfeben erbält, moourct Denn ben

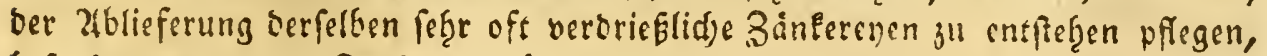
befonders wenn oer jorfteigenthimer und bie Jorfterdienten bas Zusuracten

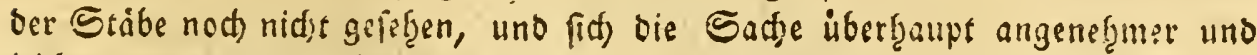
leid)ser vorgefiellt babeit.

\section{§. 422.}

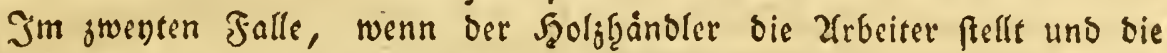

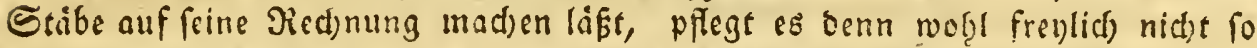

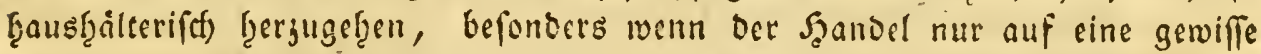

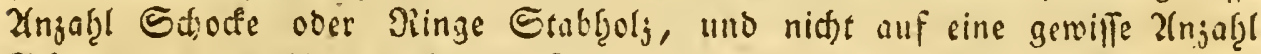

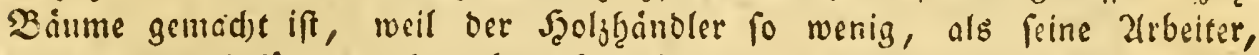

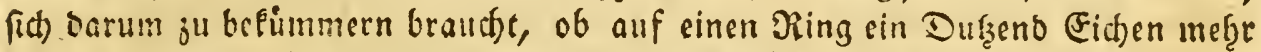
ober meniger berwhifite und unt aus fold)en Stidten Etibe gefpalten werben,

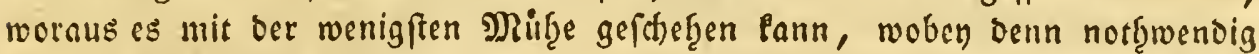

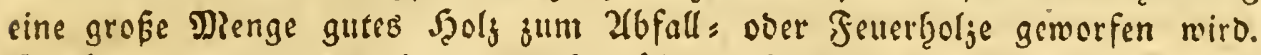

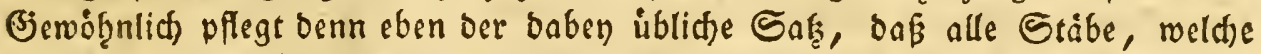

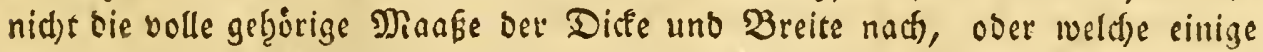

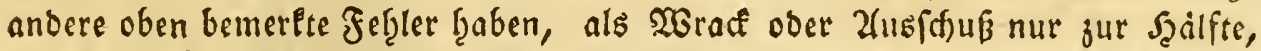

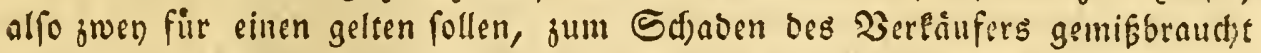
uno bie Zarbeiter beinlid) angewiren ju werben, bie Stibe in etras geringerer Maafe ber Dicfe nach ausjuarbeiten, weil Dei Sgoljbandler fie alesann für bie

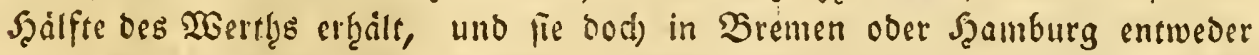
segen volle Zablung ooer wenigftens gegen einen unbebeutenoen Pabbat als Stabe der zwevten Sorte von ein uno breybiertel Doll Didfe angubringen im

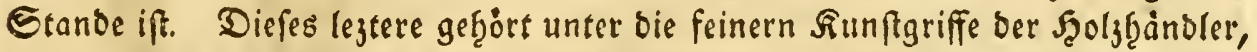

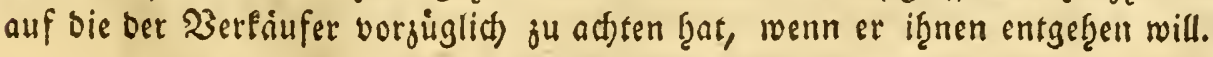

\section{§. 423.}

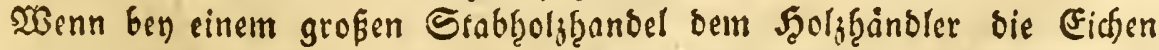
ftuctweife auf bem Stamme angerviefen und verkauft werben: fo fann 6 b bem 


\section{8}

Forfteigenthimer grwar einerlen fenth, of bataus viel ober wenig Stabf̧olf ex: folgen mód)te; es pflegen aber babey, reil biefe Beoingung gemötchlid) vor ber

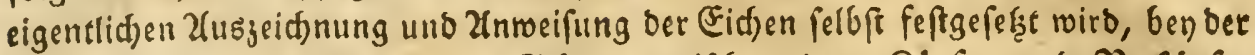

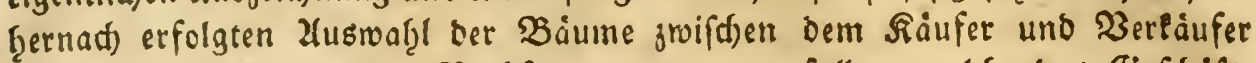

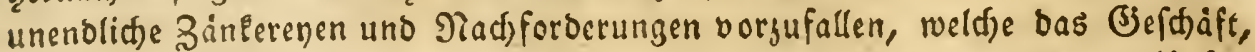

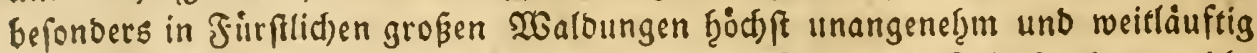

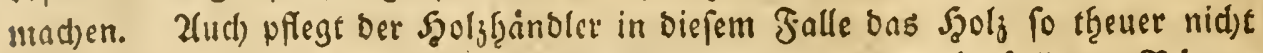

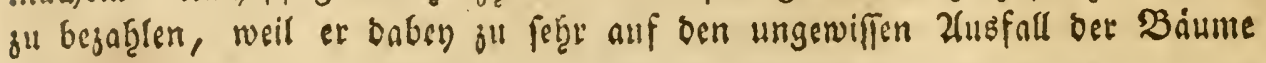
redfret.

\section{§. 424.}

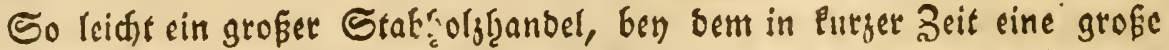

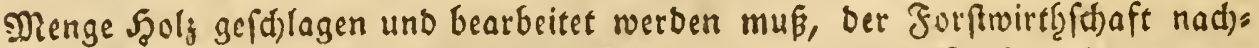

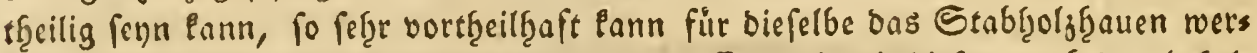

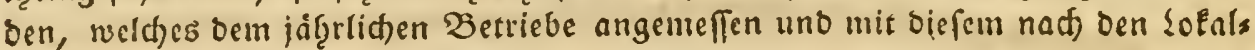

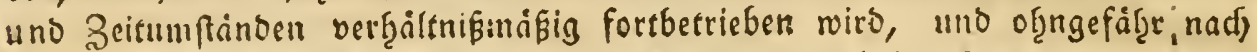
Der biefigen Forftrirthidhaftsart folgendermaaken gefdefgear :ann.

In ben hiefigen furrftliden forften, befonders in ben benden Dberforfts

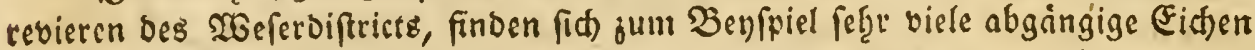

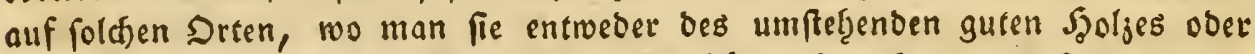

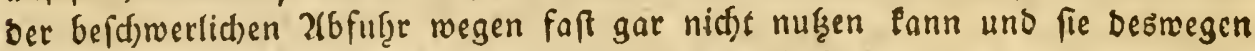

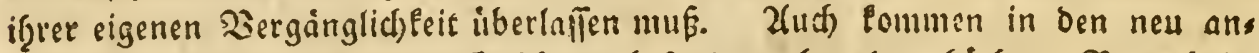

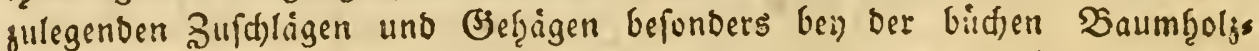

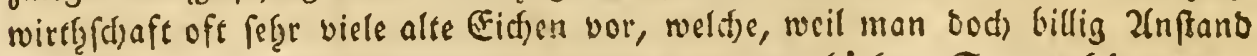
genommen feat, fold)e mit ben weggenommenen bidfen Saamenbaumen gu

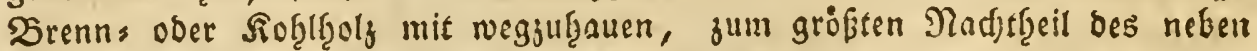

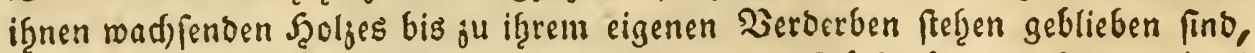
wie iman foldje In ben Gegenden faft in allen alten Bidjenortern oft of̧ne saub

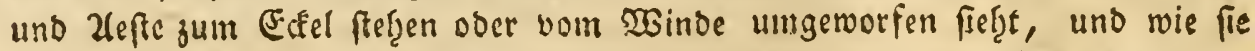
unfere Nad)fommen einft in Den jef̧igen Zufdhlägen leiber antreffen werben.

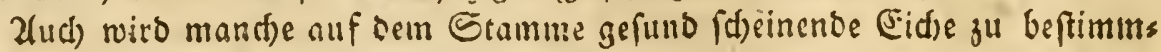

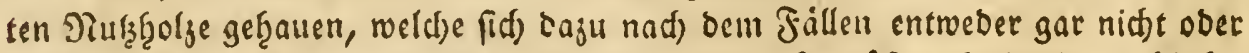

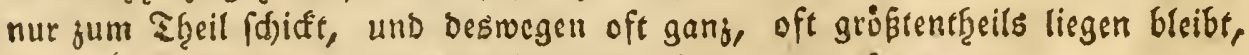

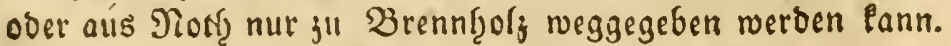

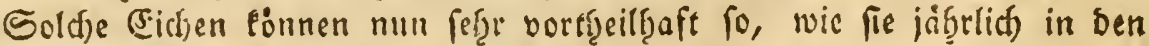

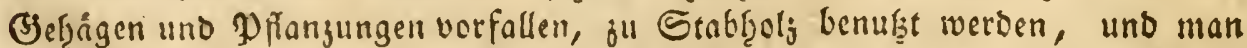

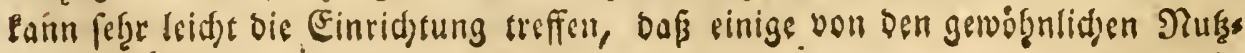
hุolio 


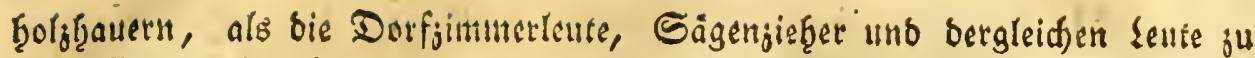

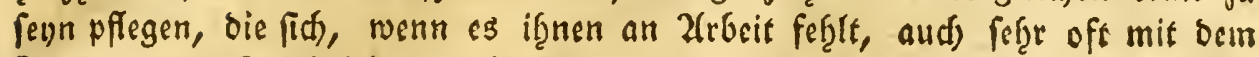

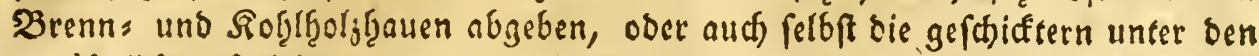

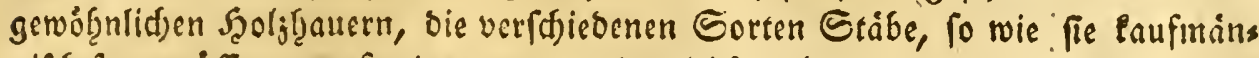
nifch fenn müfien, berfertigen, woju bergleiffen leute, wie wir es bey bein

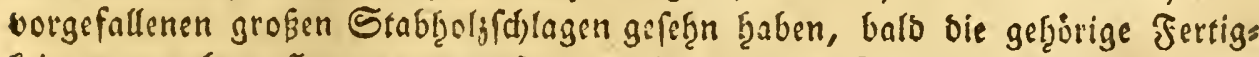
keit gu erroerben plegen, wenn fie bon einem guten Stabtgolzģauer angewiefen werben.

Diefen Seuten wurben von ben Forftebienten biejenigen Eidjen anges wiejen, welde forwof̧l if̧rar idjeinbaren 2loftánbigéeit, als bes unter bens

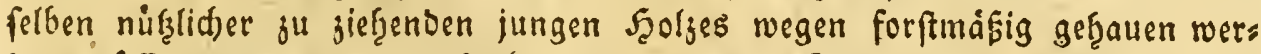
ben muffen, alts benen, biefe Éute bann alle Sorten von Stabgholz vers fertigten, weldse baraus aim vorttgeilfrafteften fallen fönnten, und ben $2 b_{5}$

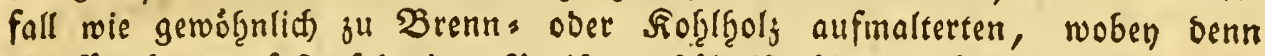

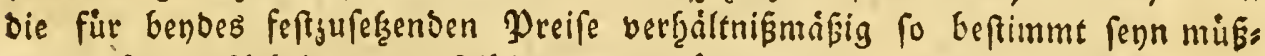

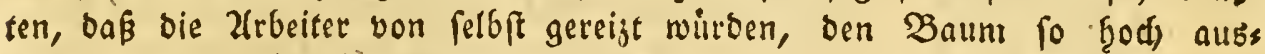

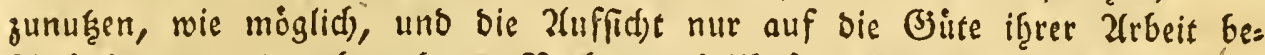

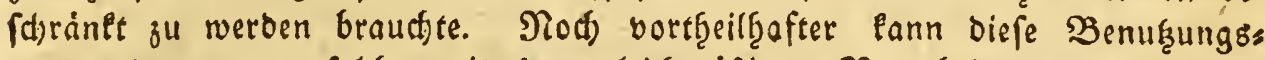
art werben, wenn folthe mit ber gleidmáfigen Berarbeitung aller 2arten von Schiffrolj verbunden wirb.

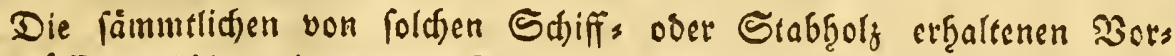
ròthe milfen nadjoem in einem Magazine, woju fid befonders Şoljminden pegre gut idjicfen wirbe, aufbewahret werben, bis fie auf eine vortheilf̧afte Zart verfauft werden fonnen, woju bey den jef̧igen immet b̧öber fteigenden

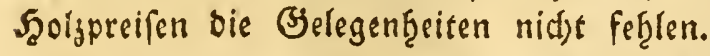

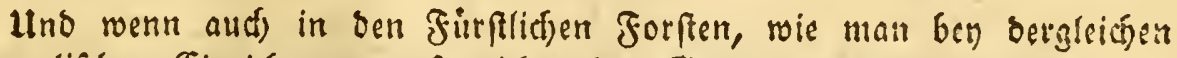
Pammeralifhen Einrichtungen oft nidgt of̧ne Grumb Dagegen einnendet, in

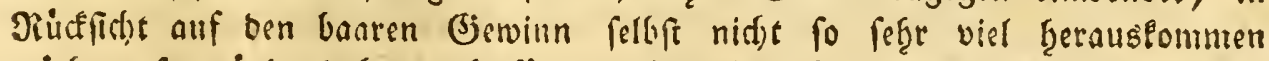
midjte: fo wurbe baben bod für ben Forftbetrieb felbit und für ben Jgands verdienft des gemeinen Mlannes, woran es in ben Syoljgegenden fo off fę̧lt, rȩ̣r vieles gewonnen werben.

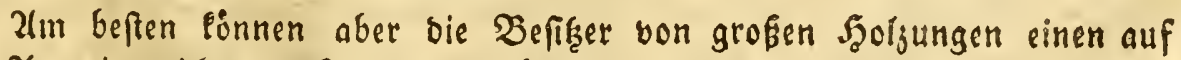

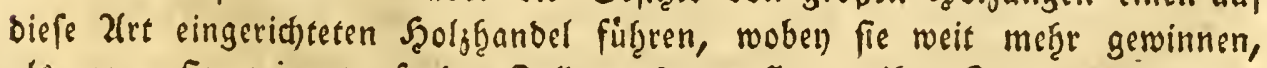
als wenn fie, wie es oft ber Jall ju fenn pflegt, ifere Forften burds bie

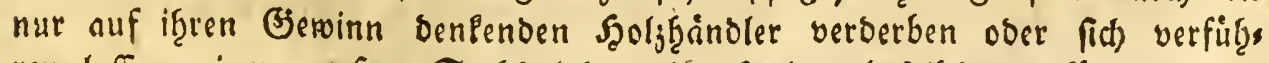

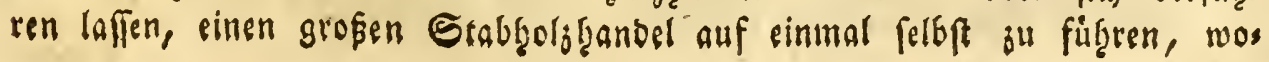




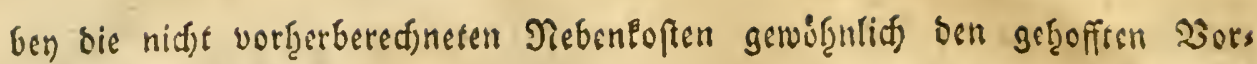
theil bu verífillingen ptegenen.

\section{\$. 425.}

Der seerth und Preis des Etabtroljes ridjet fid in ben Giefigen Sanden nad) ben Sioften, welde fir ben Transport bis Bremen eber Szamburg, und alfo bis an bie flópbaren Strỏme anjuwenden find; es läpt fich Deswegen nidfts gerviffes beftimmen, auds hängen bie Preife in

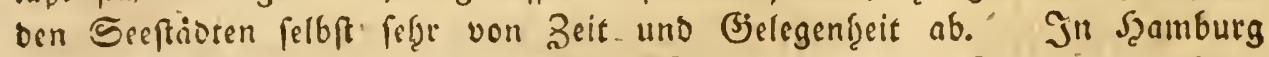
pflegt der Wreis gemól̨nlid) 10 Drocent thenrer, als in Bremen, fu renn, überb̧aupt aber fino fie oort in 3 ergleid)ung mit oen beiefigen $\mathfrak{D}$ reifen aufs falleno theuer, bemolengead)tet aber wirbe fdwerlid) für einen, ber nidje Raufmann ift, etwas daben zu gerwinnen fenn, wenn er fid) bamit befaften wollte, fein Stabţolj aus ben tiefigen (begenden nadt) Bremen oder Szams burg transportiren uno ba verfaufen jul lafen, meil bas Jliken, die vielen

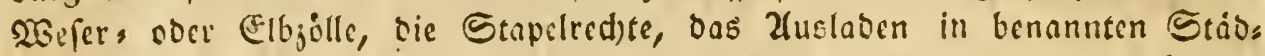
ten, uno alle bie bey biefen Dingen vorfommenden nifjt verber ju beredss nenien Siffen uno bie jeocm, oer nidjt Saufmann ift, Daben leidft ges

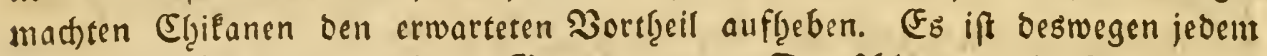
Forfteigentb̧umer ber Giefigen Begenden von Deutfhlano viefmę̧r anjuras

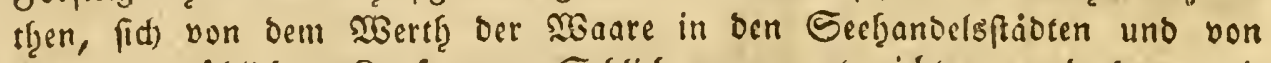
ben Daben ibliden Soufmanns: Sd)liden ful unterridten, uno bann mit

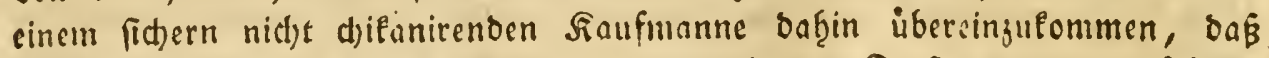
biefer von if̧m bie fertige Waare entweder in ber Forft, ober all nadjften flöbaren Fluffe ibernelgme.

\section{§. 426.}

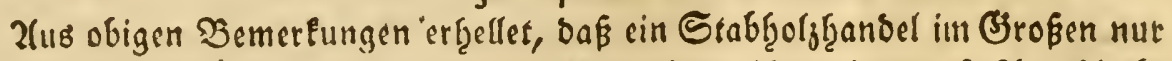

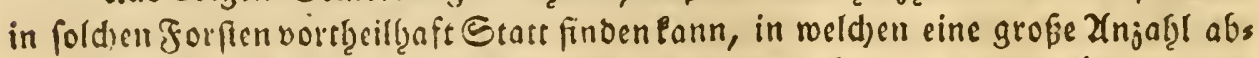

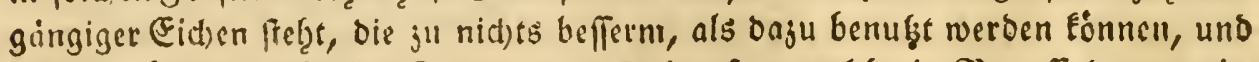
alfo vorjiglid) in foldsen jorften anjuratgen fen, melde in Betreff ber ju vies len alten (Fichen nidjet ganj regelmágig beg̨anoelt fino. Es wiro bestregen

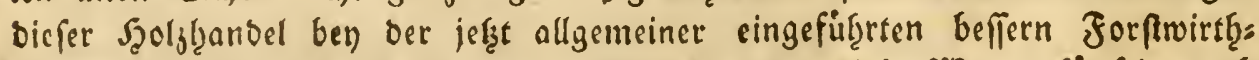
fd)aft immer melgr uno meţr eingefdrảnlt, uno biefe Waare elunftig nody

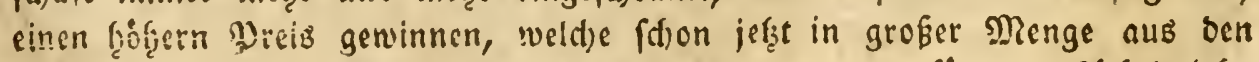

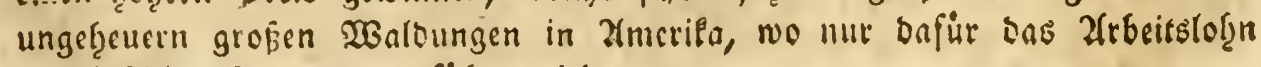

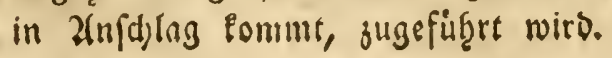




\section{8. $42 \%$.}

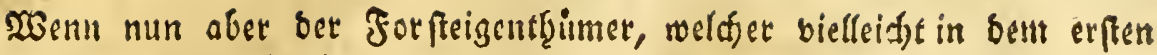

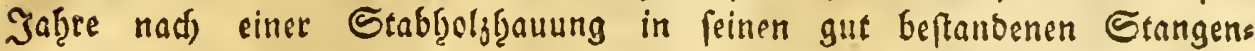

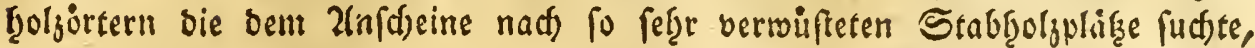
befonders wenn bie barauf ibereinanderliegenden Zlefe uno Zapfen bere Eidjen und mandje fdjone mit niebergefdlagene Shübe nod) nidfe aufges rätmit ift, woben benn wogl bुin und wieber ganje unbraudjbare Eifjen

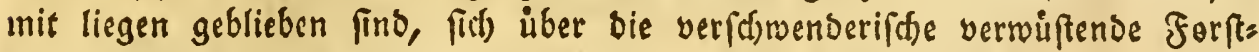

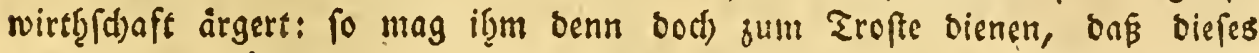
alles nidst to ubel ift, als es im erften Jabere su feyn ideint, inbeut Das unter uno neben ben alten Eiden unteroriuft geftandene Saor pef̧e

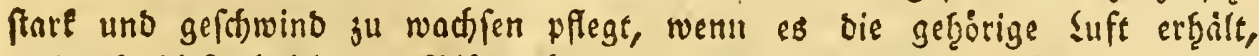

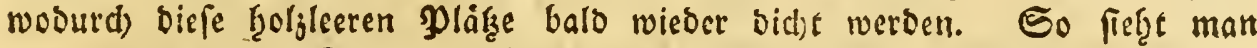

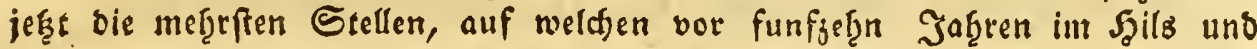
ill cineut Theile bes Şargreviers bas Stabhols gefrauen ift, uno weldje Damals fo fef̧r verwuftet ausfahen, wieber bidfe mit jungem Şolje beftans ben, to bas man fie faum bafür erkennen würbe, wenn nid)e bie barauf

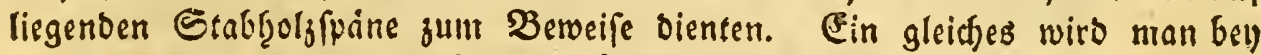
bent 2tbranuen ber alten Saamenbuchen finden, weldhe jur Ungebuf̧r in

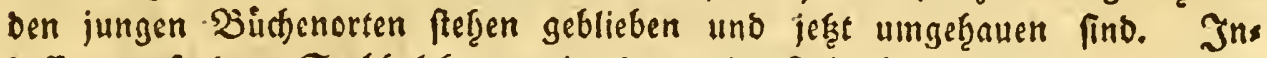
beffen mus das Stabjolffrauen in ben mit Saolz beftandenen Drten mit

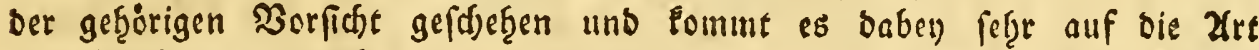
Des Sholzbeftandes felbft an, in wie weit von siefem fid bas Heberwadjen folder blosen gläkęe erwarten laffe ober nidjt.

\section{§. 428 . \\ Bon ber Senthung Der Eidfentrorke zur S̈erberey.}

Die Eidfenborle ift faft allgemein und wenigftens in Deutfáfland als bas befte Bribemittel für bie gróbern Leberarten angenommen; aud) frat

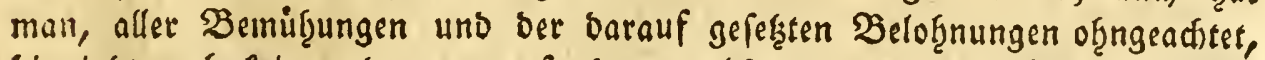
bis jefet noch Pein anores ausgefunden, weld)es an innerer (Jite ber Eichens borfe gleid ware, unb in erforberlidfer Menge vorţ̧eilf̧after angefdafft werben fonnte. Z(ud) bie Borlen ber ibrigen Şoljarten Pommen barin ber von ber (Eidje ben weitem nid)t bey, und bie zum Jierben nodf yor anbern braudbaren Nabclfoljborlen werben nur wie idfectere Eidfenborle jum Borgerben ber ftäreften Sgaute gebraudt, um bie beffere Eidjenborke ju (Erffire Fosil) $\mathfrak{M} \mathfrak{m}$

erfpas 
eriparen.: Die Birlen's und Ellernorerle aber, welde zwar auth bon ben

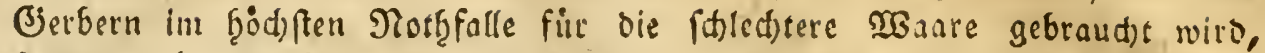

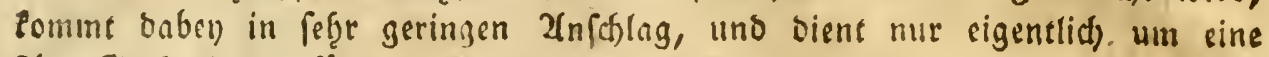
2lrt Berberlauge für bie fleinern Şăute llar zu madten.

\section{§. 429.}

Die Berbetraft ber Eidjenborle beftef̧t in ber jufuumengicḩenden laugenartigen Saiure, weld)e barin befindlid) ift, und von ben (jierbern

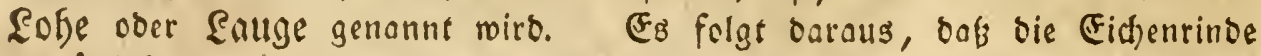
vorjuglith ongu gebraudst merben Pann, weld)e obige Siure in grojserer Menge entb̧alt, nemlid) bie binne $\mathfrak{B}$ orle oor jüngern und nur bie innern faftrollern Dindenlagen ber alten (Eid)en, und daß bie vertrocénete aufges forungene autfere Borle vor alten Bäumen daju eben fo renig tauglifa fen, als ausgelaugte ftarlberegnete uno angefaulte Borle.

\section{§. 430.}

Die Solggerber exţalten bie Eidfenborle entweder fo, roie fie von ben Baumen abgefdailt ift, als gang rofe Waare in Bunben fdjocfweife, in Maltern oder Juber, uno Sarrenweife, uno miffen foldge bann von ben

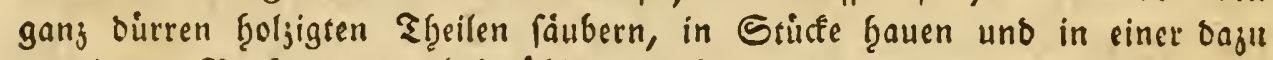

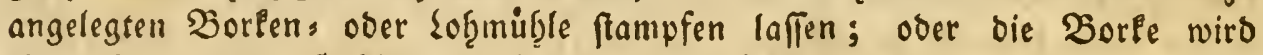

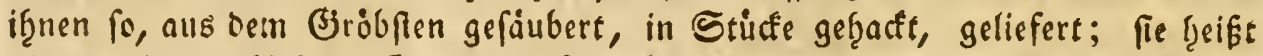
alebann in ben biefigen Biegenden feine Borle, weil bazu bie Piinde von ben jungen Etaimmen uno Zeften genommen wiro, ober audh wofel Sactborle, weil fie in Saden angefą̧ren uno verlauft wiro.

Ein großser Theil der f̧iefigen Berberborle aber mirb in ben Szarzgegenden fdjon ganj als fertige Waare in Den Borlenmüf̧len geftampft uno fo von ben Sof̧müllern an bie Sof̧gerber berlauft.

\section{§. 431 .}

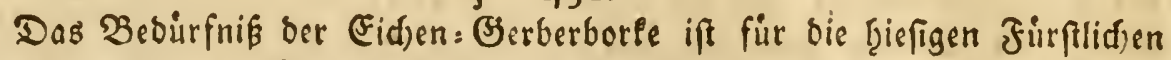
Sander ein ridstigerer (Begenftand, als es ber) einer weniger genauen lleberfid) ber Sacte zu fernn (d)eint. Fir bie Stabt. Braunfdyeig allein eann man, wie midh einige ber vorjúglidffen (Berber verfid)ert b̧aben, bie Borlen. Eons fumtion jäl̨rlid) wob̨l auf 5000 bis 6000 Mithilr. anfdilagen, uno nad) berfels ben bie für bie übrigen Drte, nach) Der barin vorḩandenen 2(njah̨! Jierber,

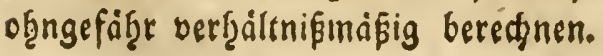




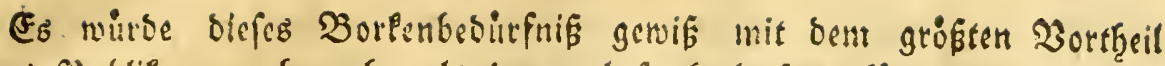
fur bas gublitum nod) metgr als bremmal fo feod) fenn fönnen, wenn bie Borle nur in gröjerer Mienge uno für geringere \$reife angefd)afft weroen

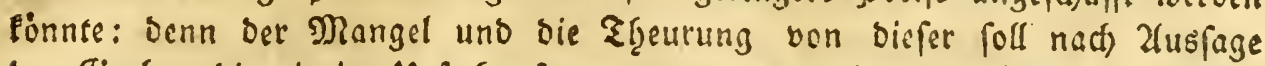
ber Berber bie einzige Urfacte fenn, warmm bie fiefigen Jerber nidft mit Den jur Meffe Eommenden fremben Berbern gleid)e goreife balten Eonnen, wenn fie ber fiefigen Waare die erforberlid)e bshite geben mollen, befonders, ba auf bell bicfigen Miefien ber frembe seberţanbel einen ber widtigfen Irtilel ausmad)t.

\section{§. 432.}

Die Seitengeit ber Eid)engerberborle entfeftet bauptfädlidf aus ber 2ret uno 20 sife, fie ju geroinnen; inoem fid) sie (Fid)en mur in ber Safts

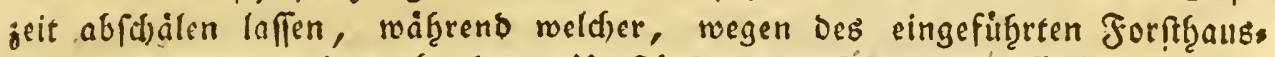

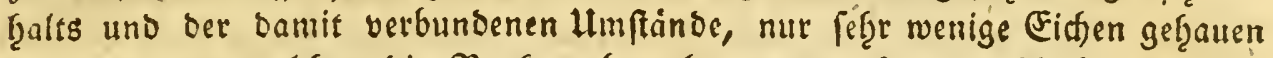
werben, von welden bie Borke gebraudse merben eann. 2fud) past bas Borfenreigen cigentlid) iberb̧aupt nur fü Den Eleinern Forftbetrieb, und

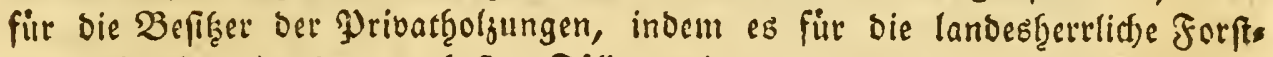
abminiftration in ben mebreften fällen mit gar fu vielem Fleinigleitswefen verbunden ift.

Ein grober Stgeil ber Bierberborle toummt beswegen in Den biefigen

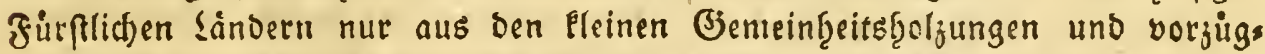
lid) aus bem benad)barten Şildestzeimifdyen hee, wo fie ber Bauer bon ben

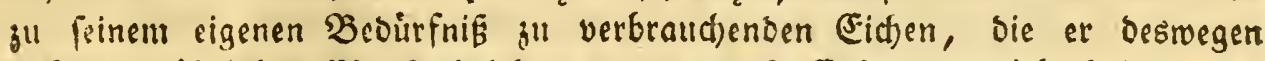

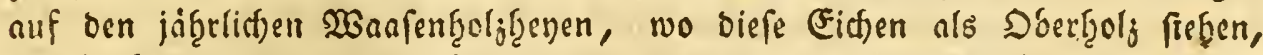
im Saube trauet, abgeftailt, uno getrodinet fu Markte bringt. Diefe

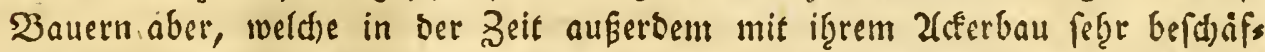
tiat fins, fetren biefen Nebenverbienft als gang unbedeutens an; fie fennen

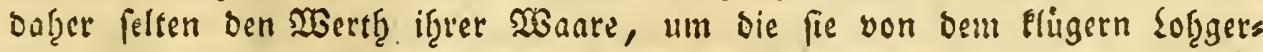
ber benn auch oft to fef̧r djicanirt werben, bas ber Bauer, weld)er fü

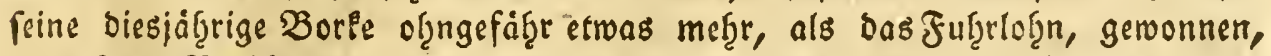

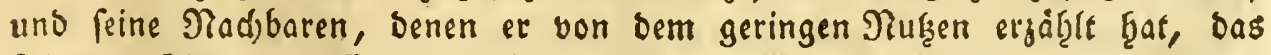
folgende Jabzr if̧re (Eid)en nid)e wieber abborlen, befonders wenn fie von

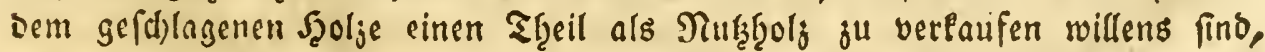

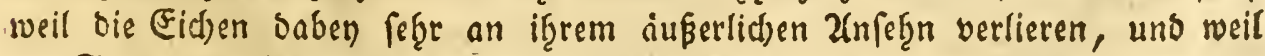

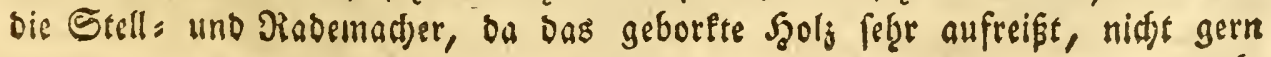




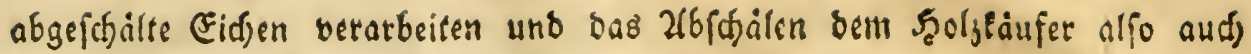
oft jum ungegrundeten ₹abel 2 (nlak giebt.

Sủr bie Stäbte Braunfdjweig uno 2 Solfenbittel wirb bie mer̨rfte Borle

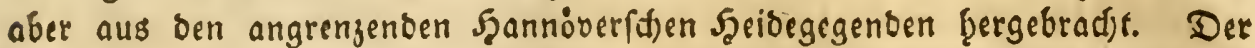
Bauer, weldher fid bafelbft mit weniger Feldarbeit befajt, uno alfo in bee

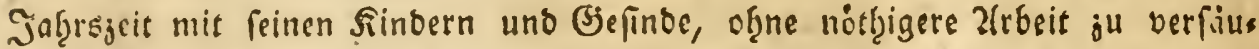
men, ben fleinen Biewinn ber ßorfe mit benufen fann, treib: diefen

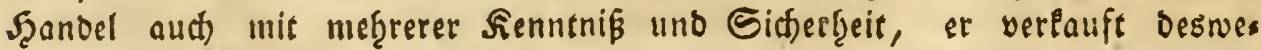
gen bie Borle nidft fo, wie er fie bon bem Baume abfdält, fonbern fifjon von ben gröbern trodenen holgigten Theilen gereinigt, uno bie beffere Borle bis zum Stampfen fertig in Studen getracft in Siden, woburch er berfels ben einen mef̧r beftimmten Werth geben Pann, und nidjt fo, wie bie ibris

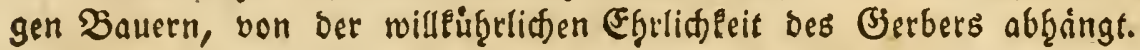

2uth bie Forftrirthidhaft in ben bortigen Szeibegegenten begunftigt dies fen Borlenţandel vorguglid, weil bie meţrften Eid)en in ber Stärle gef̧auen werben, bey welder fie bie befte Borle jur Berberey bृaben, und biefes auth

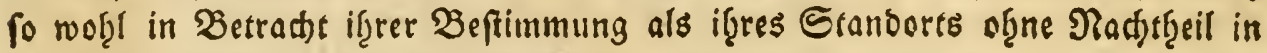
ber Laub, und Saftzeit gefdecten Cann.

\section{§. 433.}

Weil bie Eidfen fich nute in ber Saftzeit und vorzüglid lutg yor und wåhereno bem 2usbrechen bes lanbes uno wenige Tage benm jwenten Soms mertriebe bequem abborken laffen: to if bas einmal allgentein angerams

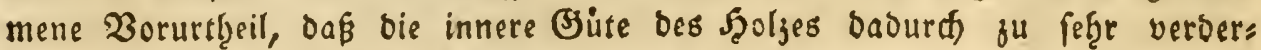
ben wirbe, wenn man bie Eicten in ber Saftgeit hallen ließe, eine ber grósten Sd)wierigleiten gegen das borlenreißen, uno b̧ierauf grünen fíf aud) Die in einigen Forffoeroronungen bagegen enthaltene $\mathfrak{D e r b o t e}$

Db nun gleid) biefer Sefrefage, weldeer aud) in ber praftifchen forfts roirtbidaft noch an ben mef̧rften Deten befolgt mirb, nidft fo gegrinbet fevn mag, als er bafür angenommen ift, (man ferge $\$$. 403.) fo mod)te cs

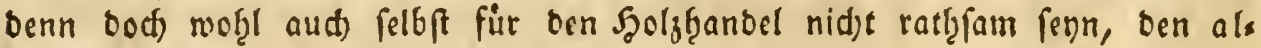
ten Sdjenorian bierin unbefdringt zu andern, fo feţr es alld für bie Zufnahme ber inlandijden Berberen zu minfden waire, baj bavon in metrs rern fällen abgegangen mürbe. Bemólfnlidf werben in foldfen forften, worin auf ben (berwinn ber Borle cinige Rudfid)t genommen rirb, nur fold)e (Eichen in ber Saftjeit geţauen, welde ju ßabemadjerţols uno ju Den Eleinern 


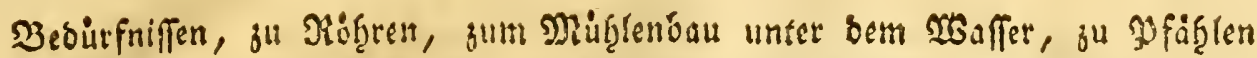
in bie Eroe und ju bergleidjen beftimint fino, weldje fid if̧rer geringen Starte wegen aud) am beften jur Sierberborle fohiden.

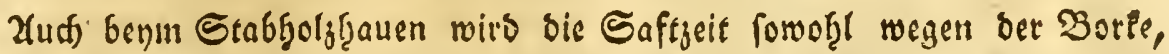
als wegen ber bequemern Zlrbeit und bes beffern Spaltens bes Sadjes, vors gezogen, obidton bie Borke von ben alten Stabg̨oljecitgen am wertigfen braudbar ift, und nidjt haod) begahlt rirb.

\section{§. 434 .}

Bey bemt grósern Fouftétriebe fallen bey ber Şautung im Safte uno

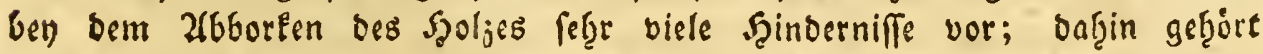
a) Daß́ man off bie Jaauungen nidjt beenbigen Ẻonnte, wenn man nid)t ben ganzen winter úber arbeiten ließe; b) bas es alsbann an Jufrteuten jum

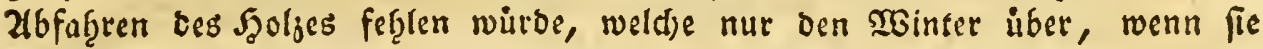

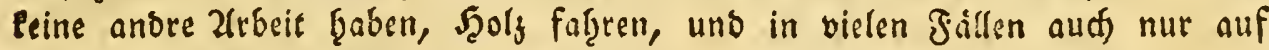

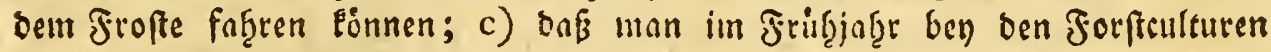

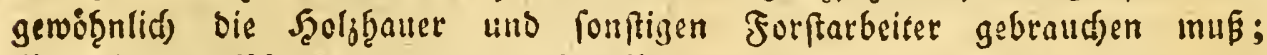
d) Daß Das 2lbborfen ber in biefer 2(Giid)t gefäleten Eid)en oft, uno vors

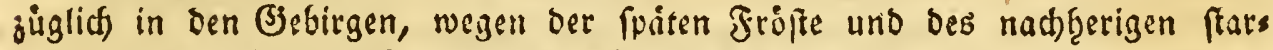

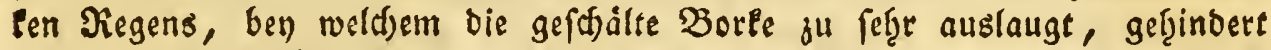
mirb; e) Dak es für bie jungen Şene idjäblid) fenn eann, wenn fie wegen bes

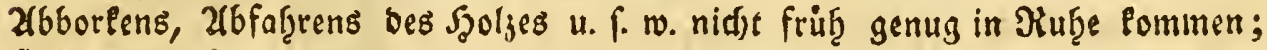
f) Dak es in ben fällen, in weld)en auf bas Woieberausfdjlagen bes Stamms

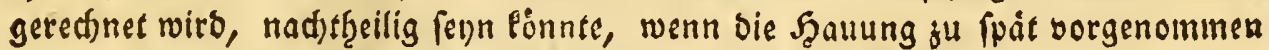
werben follte; g) Dás aud in vielen frallen nur ein ferfer geringer uno oft gang unbebeutender Gervinn babey gemtad) werden Pann; fo roirbe man jum bens fpiel von bem in Malter gefdlugenen alten (Fid)enţolje auf jwen Malter faft sin

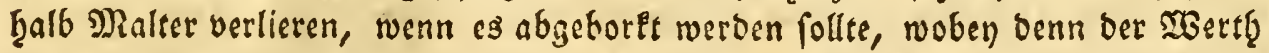

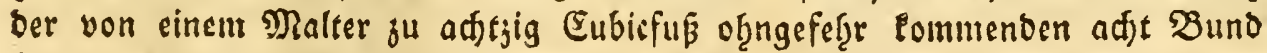
Borle der (d)lecttern Sorte gegen ben obigen abgang abgered)net werben

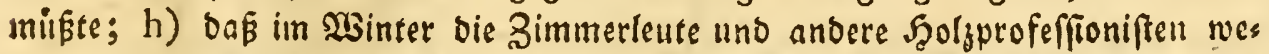

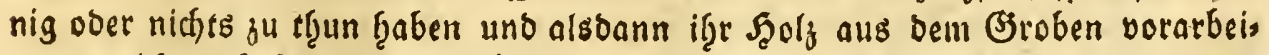

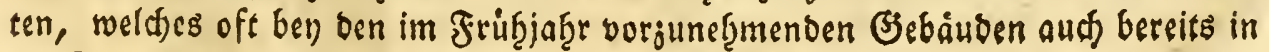
Der Beit abgefaf̧ren uno bearbeitet feyn mus u. f. w.

§. 435 . 


\section{\$. 435 .}

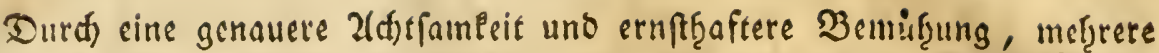
(Eid)enborle ju gewinnen, laffen fich benn boch, bell allen obigen Forfibejdiwer.

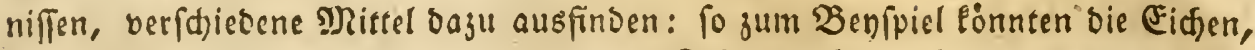
weldse in sen Stangenfgolzorten, bie jur Fiof̧lung abgetrieben werben, mit ans Dern Jెgljarten vermifd)t ftetgen, etp nad) biefen im 2(nfange ber Saftzeit, nact)s getfanen werben, - weldes ebenfalle mit folden Eidjen, bie in bergleiden Drten als Dberfiols gefället werben follen, entweber im erften ober jwelsten

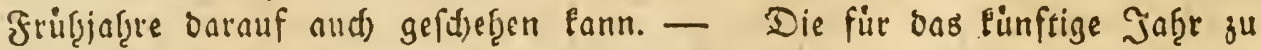

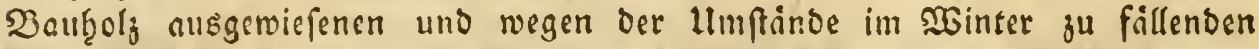
Eidjen fonnten in ber Saftjeit vorţer auf bem Etamme abgeborlet werben, wie es in ben Sänoem, wo bie Berberel) Pef̧e fark getrieben wirb, wie im

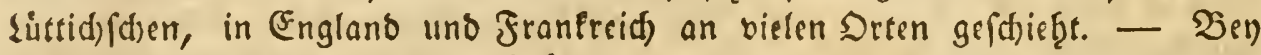
vielen (Eid)en, weld)e fpat in Jrubjab̧r aud) vor ber Saftjeit geţauen fino, láft fid) bie Borle bey ben erfien warmen Fagen ebenfalls feḩr gut abs fodilen, nur muk man bafür bie erftern warmen Tage benulisen, fo wie bey bem barauf folgenben Piltern Wetter fich bie Eidjen uberlaaupt nidft

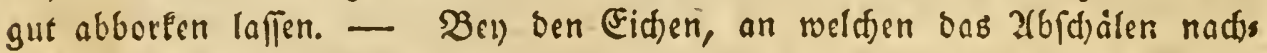
theilig fenn Eann, weil fie banat), befonbers wenn fie in offenen Drten in ber Sonne liegen, febre aufjureifen pflegen, pann fold)es ourd) zwedimábis ges 3erarbeiten aus beim Broben, jum Benfpiel Durds Edinciben zu Bau: hol; ober ourd)s Spalten in Pleinere Sticfe, to roie aud) bas 3ufreifien ber gefdinittenen Sticfe ourd)s Zuflegen in Sacufen, uno auf bergleid)en mefrete arten verf̧indert werben.

Lleberbnupt aber laffen fid obige Sd,wierigheiten burd) eine ben llms

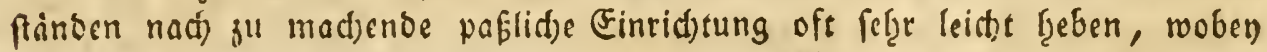
es auf ben guten Willen ber forftedienten anformmt, uno es taf̧er aud)

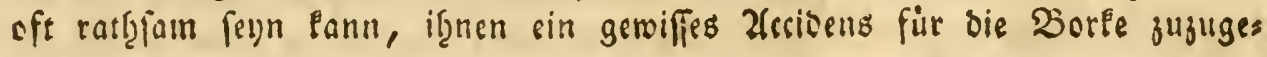
ftef̧en.

\section{§. 436.}

Die befte unb meţrfte Eidjenborle ift von ben viergiajêtrigen Eidjens

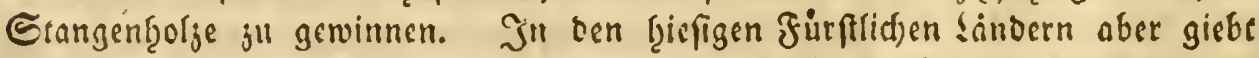

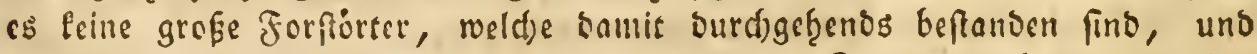

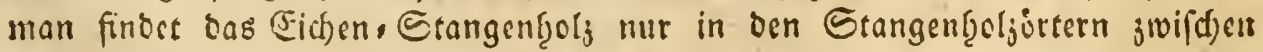

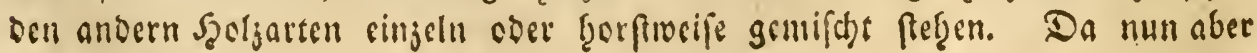




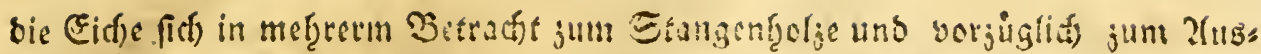
beffern fold)er Saeve fdjicft, mie gebirigen Drts bemeret werben wirb: fo ift

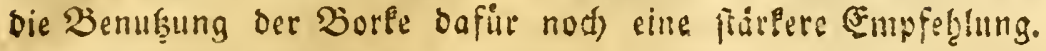

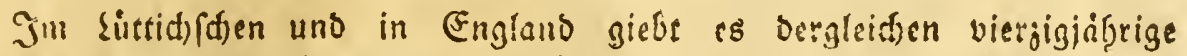

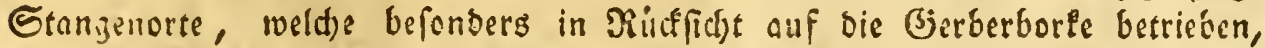

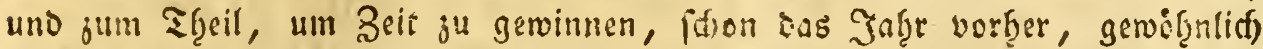
beym jwenten Sriebe auf bem Stamme geidaalt werben, fo, baj man ganje Drte von gefdålten und jum Tf̧eil bod) grünenden Bäumen feţen Eann,

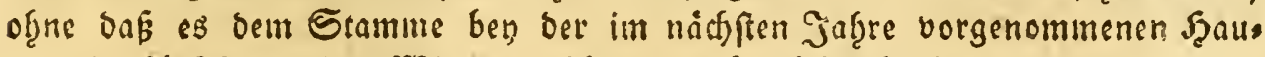

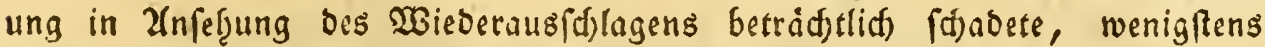

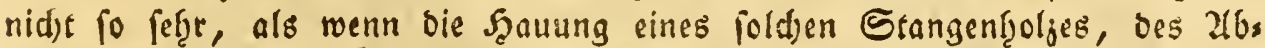

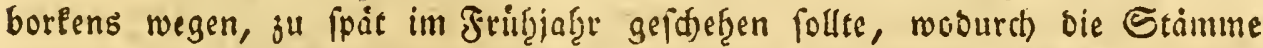
bie ftäreere Triebstraft bereits verloren fraben, uno nut elende Sommerlos

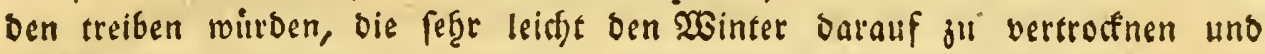
zu erfrieren pflegen.

\section{§. 437.}

Iri ben Giefigen Fürftlitfen Forften, fält aud in ben Forftrevieren bie

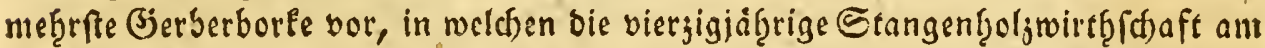

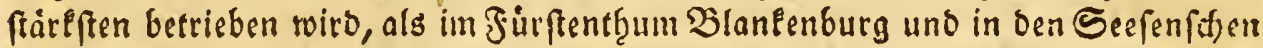
uno Szarjburger Sargrebieren, wo bie Borle in Bunben idjodtweife vertanft

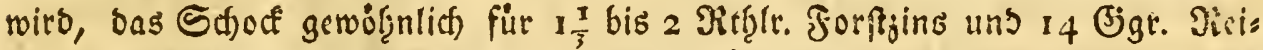

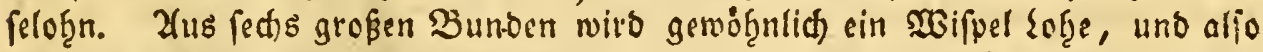

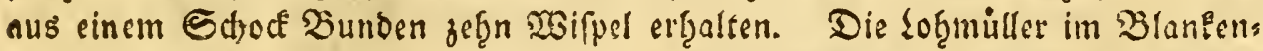
burgfajen follen ben 2 sifpel für I $_{4}$ bis 18 Gjgr. verfaufen, und würber alfo bas Sdjocf of̧ngefäbre für $6 \frac{2}{3}$ Rtthir. ausbringen.

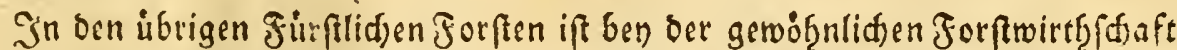

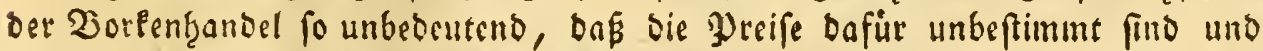
von ben llmftảnoen abţăngen.

Nur ben cinigen befonders ginftigen 3orfällen, als bey ben vorgenommes

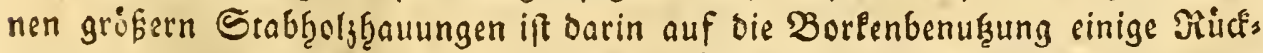

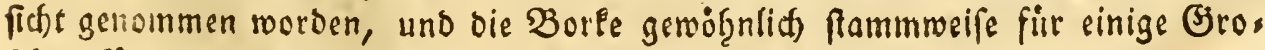
fdjen fur jeben Baun verkauft uns bered met worben.

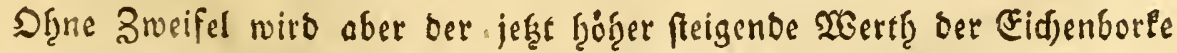

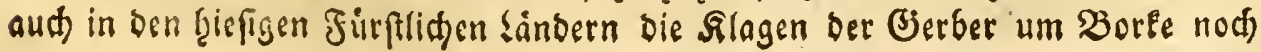




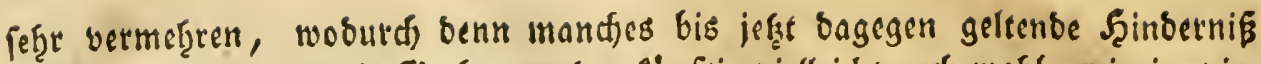
aufgoren wirb; und bie Berber merben finftig vielleid)t aud) wob̧l, mie in vies len Begenden von Deutfdiland ge(d)iefze, nidft allein bie Borle, fonbern aud.

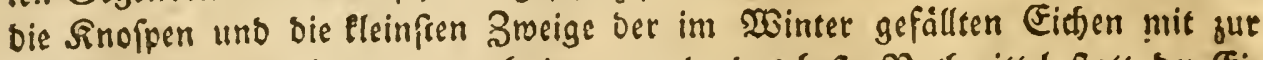
forge benuf̧en, meld)es man nod) immer als bas befte Notf̧mittel fratt ber Fis

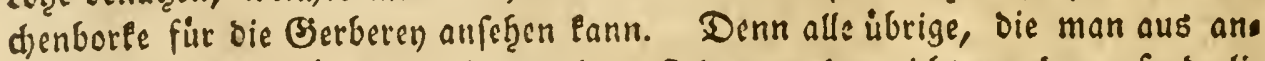
Dern Berwadjen bafür vorgefdlagen jat, find entweber nid)t von ber erforberlis

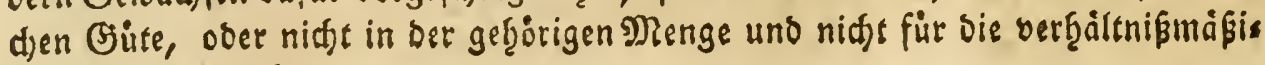
gen Preife zu ḩaben.

\section{§. 438.}

Die leģte Benufgung ber Eidjenborle, nadjoent fie zur B̈erberen ausges

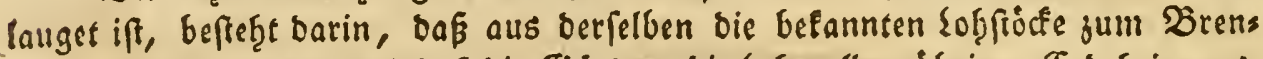

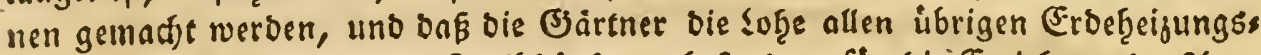

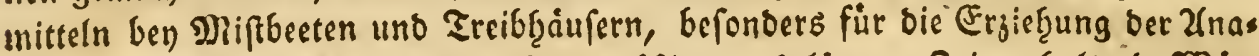

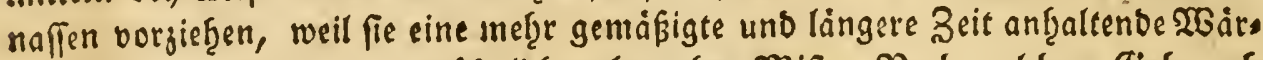
me geben, als bet baju getwoingnlid gebraud)e Mift. Nath meld)em (jebrauds biefelbe nod als eine gute Dingung in ben Bairten benutgt werben fann. 2(ud)

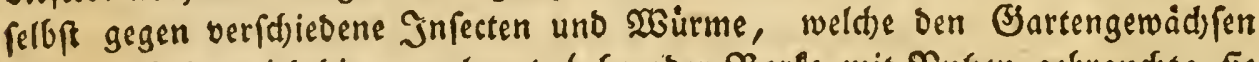

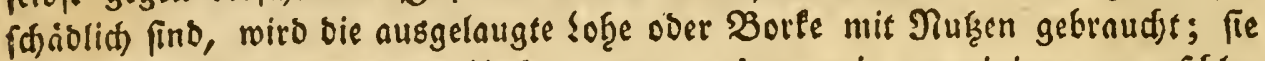
aber als ein Mittel gegen bas UnFraut anjuwenden, wie von einigen vorgeffilas gen wirb, mübe mobl von wenigen গukgen fenn, ba fie bafïr nur fo lange Zeit bienen wirbe, als bie barin noht enthaltene ju ftarle Stjorfe sas Siraut viels

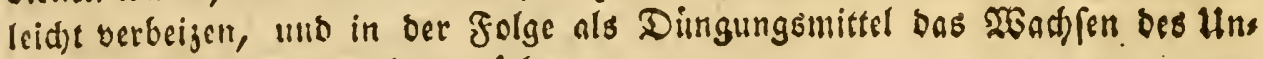
trauts noch mef̧r vermefiren módjte.

Ente des erfen sgeilb. 


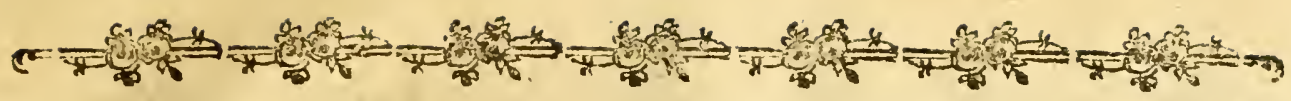

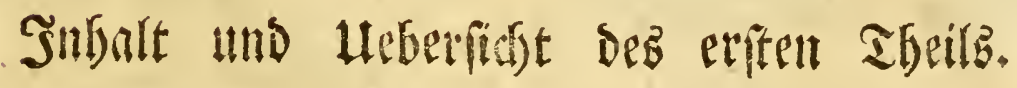

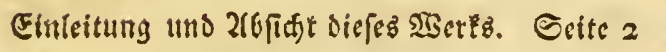

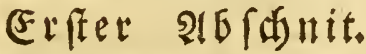

Ueber bie Forftitteratur

Eintheilung Der Forfifdriftent

Berzeichnif eintiger der beftelt forfts fderiftelt

\section{Sweyter 2 b/dut.}

\section{von ser forltbotanit.}

Don Sor Eyftemtunde

Eintfyeilura der B̈cwádfe in Şolzatten uno Sriututer

Eintbellung oer Şolgarten in verfdieonen Şinfiditen

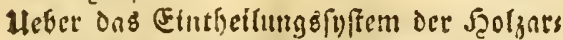
ten in \{antholz uno Nadeelholz

Sin Soumfolz, Etraudjolz uno rantende Etrállde

23on ber Benentung oer Solzarten

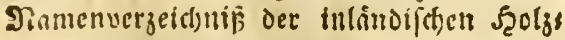
artein

Lerfte Claffe, elfte Oronung, Baum: hol ber etfteit Ssrúfe

Sountholz oer zuenten sroffe

Salumfiz Der ortuten Brodre

Zwevte Dronung, Strauds bols det et:

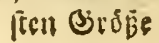

Etranchiols ocr ziweyten (5)

Dritte Oronung, Erofolz

Sinuturnde Grrándse

5. 19

20

2 I

Jovete Claffe, erfte abtyeilung, গa: Deloaumbolz

Sadetfernudbotz

II

Eintbellung th nut fm Sommer und in all zeit grune Selgarter

Int weidhe uno harte Şolzarten

Eoldie Einthetlung findet beym Nadel: Golge nidte Etitt

§. I

2

3

Taturbefareibung ber 3åume

4 Benenumb ber cinjetnen Theile oerfelsen Bom Etamm.

6 3on oen 2teftet uno 3ૈuctget

Solthe entfethen allo ben verfchiedenen situofpert

7

Diefe fitto entweder Jeolgs oder Frudjt: Enofpen

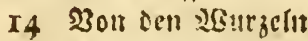

2oir Det D fabls uno Scrarwurgefir

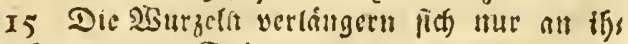

16 rell Epiben

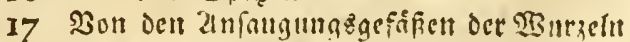

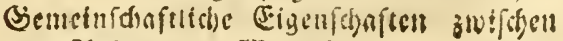
Zeften und 20 urzefn

กn 


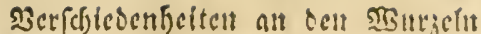

Bom BertrocEncn oev ćltern nuro tem Entfichan nener sisurzclt

Son ber Sinde und Borf: Det Dianme

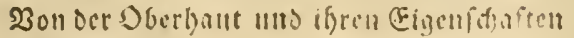

23on ben unter biefer liegenoen 3ellinger. ivebe.

Ileber oie untern Sindenlanen

Bon Delt befondern Enfigcrápen tn der Siritic.

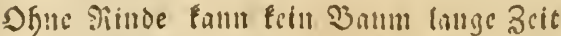
Brínch

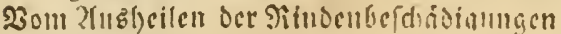

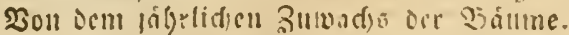
ziviferen oc

Bont Dett Blittern:

Hefer die Berfecheduhetten oerfelber

Ueber Die verfd)iconen (3)fáfe Der DZfitter.

Zum Zufallen oer $\mathfrak{Z}$ látter.

Bolt Der Beftimmung oer Blatter

Bon oct wohltfácigen 1 mo madjtbetligen Eigenforafteit ocriclocit

theber die ectdere beblítterung ber Frud)tก́\{te

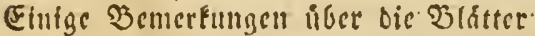

2ont Den Nebendingen an cinigen $\mathcal{F}_{\text {golzs }}$ arten

$23011 \mathrm{Cm}$ S $2013 \mathrm{c}$

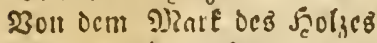

23on oent barin befinolid)en Epiegeli uns Etrnftwanocrt

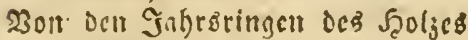

23om Eplint und iefen ŞOlz

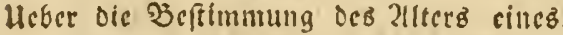
23aumg แath belt Jagreringen

Heber die Eigentdiaften oes Eplints

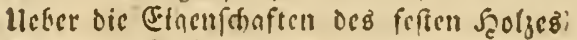

Son ocm Sisfrengeivebe oeb Solzes

3on ocm Soft in Dert. Bámmen

lleber dic Eaftzit

Einige Der aufallenoftet Eigendafiaftem des Saftz.

Zon bett Enftblízcticut

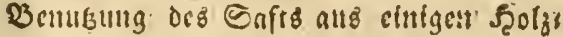
arten.

theber ons 2ruffecigen und Fallen oes Safts

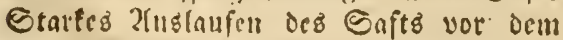

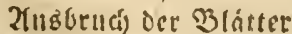

Einige befondere aufallende Ertforinungen Dabey?

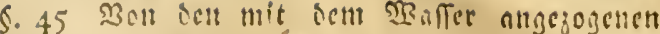

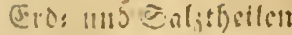

4723011 sim llmlum ocs Snftz tit ocn

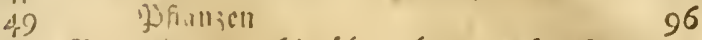

50 Beme Emacn bieritor fer) sepfreften

23.

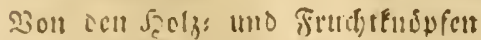

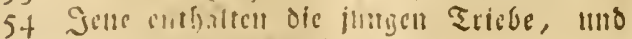
Diele ole bilitiselt 100

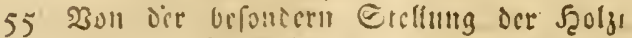
mino jirllitindpfi

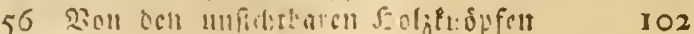

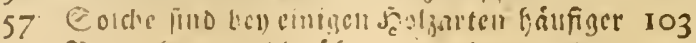

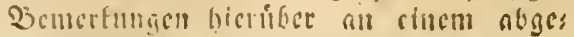
idnittencu 21 ite

58

60

$6 \mathrm{I}$

$\sigma_{4}$

65

66

67

2011 ben จilnthen Der Sisume

105

Soldbe fino entursier volfeummene ooer munnlleommine Blisthen

Dencunung oce cinzeliten Sgeile oer Blis thect:

3ont Delt Vlumenftelert

106

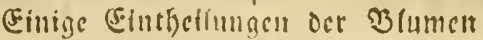

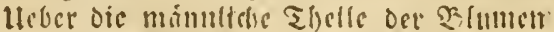

Lleber die weiblithe Sfeile oer \$ilamen

107

68

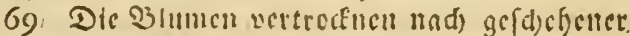
Sुcfrud tumb

108

109

110

I I I

112

II 3

72 Einige $\mathfrak{B a}$ ăme baben volltomntene $\mathfrak{B}$ lus

73. mett, andere mur tulvolleommetie,

74. chinge mánnliche uns weibliclle ab: scronoert zHfaummen

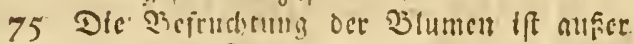

$70^{\circ}$ nllen 3̂ueticl

77 Bon.den silndten

Ir5

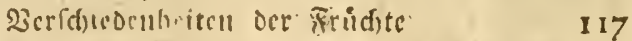

$7820 n$ bem Eanmen uno iefien Scimung 118

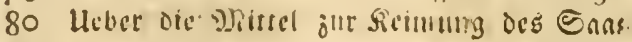

$8 x$

82

83

84

mens

IT9

Son ocu Ganmenblátretm

120

Eintge Eamminarich vefinten dic Sici: mungétrait langere Boit

Son dem aus ich Eanuch sutfeffenden $2 B$ urifleim

86

87

Sowoht oiclir, als oer Blatterfeim nef).

123 men alcidh beil ibrer Entwicfelung: ote ifuetr cigene Sone

89

90

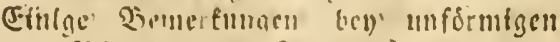
Q2/umen uno Eanmen:

124

Don sen Zlisnfliten ser 33 \&ume, 125

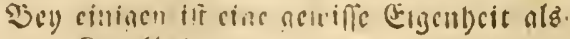

Sirnilycit angulebch

$\mathrm{r} 26$ 
\$olt ben 3ermundungen bet 3 ámme $\$ .127$

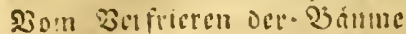
128

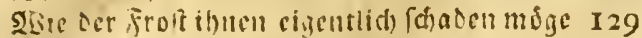

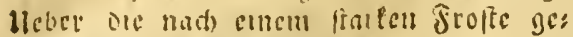
fáblidie Bommenblitfe

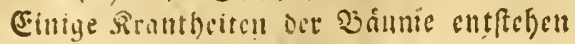
ourif) Die Julectert

Bemertutinen tiber ons fefen, und die if braen Eigenfaften ser barume

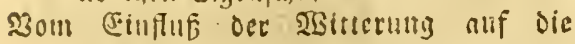
ถุ่a์แแแ

Hefer oie \$erocefungen an ben Etám: men unio 2le|ïen

Heber onz fratke Snamentragen einiger Şoliartent

Einige Dfanjel jeigen bet verfditedenen Briclentheiten einen gevilien Sieis

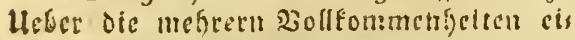
viger Dflanzersaten, uno oen finfs fenmósizen llebergang vom Plan: zen: วแm ₹glerteid)

\section{Bierter 2 (b) dit.}

\section{Don Sev Finfticten Zebandlung} Der 23 ăume

2on ber Fortpfangung oerfelean Durd) ab́leiser uno Etetflinge

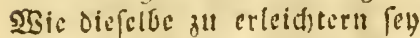

Zom Vefdnetoen oer bianme

Soldtes findet j" melyern 2rufichten Staft

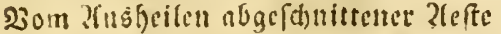

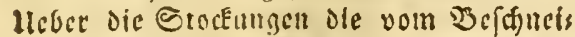
oen ensfiben "̈onnen

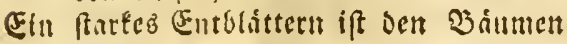

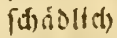

2on beun Befchncioen oce frud)tbåltme

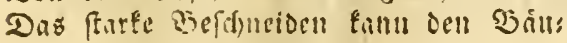
men nichts):ilig f(t)

2on oem IJfropfen ber bormm

2304 oen verfatiedenen ?reen oeffeloen

Heber dos Bufnmunchuact) uno Der sicrier

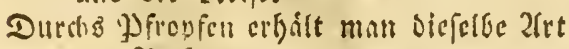
Des Sicifes

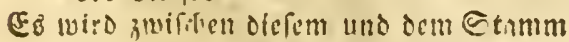
cine nenifie Zlefulichét erfordert 160

Der Urfamm elnes alten gepfropften Bantm ift unverd́ndert

I 30

I3 I

I 33

134 vom

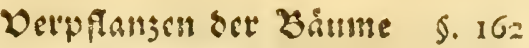
Fullfter शbffut.

Volt oct Lage citter Grgend und

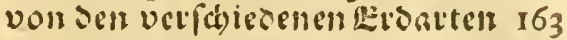

Der Forfmantt urnucht dic Eronten unr sfonomifol fll Fenten

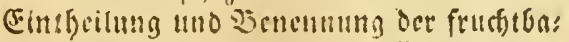
ren uno IInfrudt) barch Eronten 165

Don elner flachen Esezend . 166

$230 n$ ciner 11 fifl uno moraftigen (3egens 167

Darin fat ier sorftbetrieb viel Eigenes 168

lleber dic oarin am besten wadferroe Şolzarten

3on oen Darin yorzunefmenoen Forfetht: turelt

170

Neber die in bergleiden Begendent befind: licticn Eorflugen

IYI

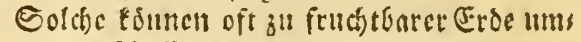
neldyaffen luerdeat

2fuf bon mit Eifletu befrandenen Brndien

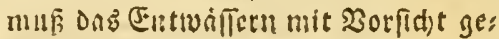
fobehelt

Int eigentlicjen Sridsen ift oer Forftoes trico (ebl: cinfach

Die Bestlląug oce Brude tịt oft fefre vorthcilbaft

3ont Fondigten Bienentent

¿on fitigrnden Canc und deffen Bim oung

\$on freliendem Sande

23on fandigt: moorigtem Birunbe I8

Heber die Jjeidegegenden 182

Zerféficoentseit oerfelben 183

Don oer Cuttur oer fladjen Jectoen úbers baupt

2301 Den Dafiel) vortommenten politiffien, 185 und uatúrlidien ŞtnderntTen

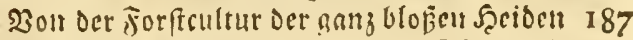

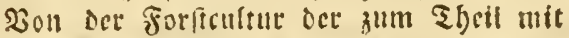
Feoly befandenen feetoent

Ueber Die behandinng des Jecidefrauts 189

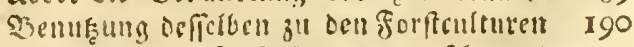

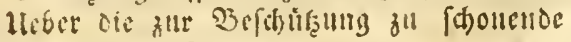
Sreideftrandier

Derfelbet fino ole fleinen Striduogel (d)áolita) 
2ont Bepflanzert ber Seitent

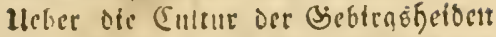

6. 194

195

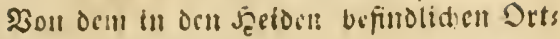
ftrill

פebanding ocfielben bel) oent forftculs rurcit

Bon elner gebtrgigten Ejegeno

Die Trudtourkett oer Sicrge ftehet aud mit ber Jeshe oerfelbell tin Ser: bíttuin

Meber dic Ero: InIO Gtematten Der Bies birge

Derfdictene Ragell oer Berge

Ueber oie arefe jrudjibarteit oce vulcant faren Eroen

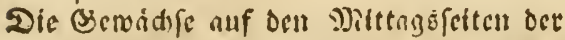
(b)ebirne find Dem Berfrieren fefre aนรู่อ

\section{Sechifer abidnit.}

\section{Zefhreibung oct Lide}

23011 Oen verfdjicocnen lirten ber Eifdent 207

Dencnnnng ocr cinfeimi (d)en Eichenarten 209

Ucber elnige Evielarien derfelfen

20ic foldic culfechen

Cirfificirum oer Eident nad) oem flimels (d)

Defdretbung oer Eictienturtfe

Wefthreifung oer Frucht

Heber Die 3elt oce Siluthe und Srudftretfe

Die Eicheln behalten nur eine Eutze Zelt Das నermogen ;

Ueber Daż Seimen Der (Fid)

Vefditetuma des jungen Triebs in oen erften Solyect

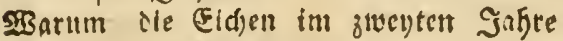
nitut ftart wad) (et

Heber ons $23 a d$ ) fen ocr Eidden in if aitern Juthren

Dou sen cinzelnen Theilen scr teis d)en

20on oer Borfe oier Sitnoe oer Eiclisen

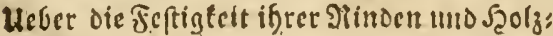
faferit

Ueber bie binufizen mentehtenten sirofpen in oer Sinte oer Eitten

Bott Dem Eplint uno forten Şolze

Heber bie mittlere Marktobre
196

197

199

200

201

202

203

204

210

211

212

213

214

216

218

219

220

222

224

2206

227

229

230

231

233

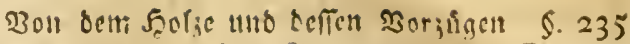

Ueber das langfame Zustrotencu des El:

$$
\text { chenlibolzez }
$$

236

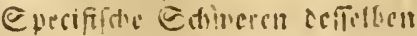

Uleber oic genuile Berleanil\}. Oer OBeftanos ibeile Ees (Eid)enbotico

237

238

Urber oar 25urzelyebanoe oer Eiden 239

Solducs lft nad) ocm Erancorte ret: fdicielt

$24 \mathrm{~T}$

2(uct) all bemfelfen Ratume mad) Den Ceros lagen abuedifeltio

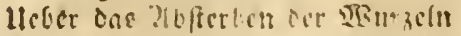

Beringe Trielfiaft ierfellen in fartem und ftcininatem Noien

243

244

245

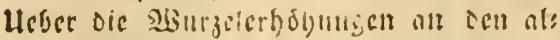
ten Eitiell

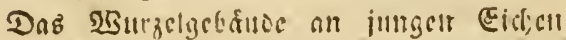
fanil ocrueflett weroch

246

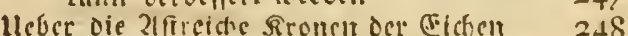

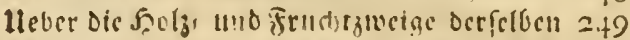

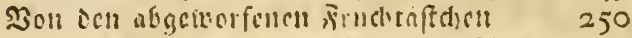

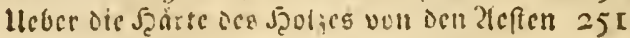

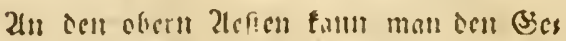
funobetrsinfano oer Fituch mabr: ucbmen

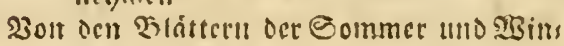
tercichen

Bom Lufullen uno Ruba Jer Tlótter

Ueber ocu Vamulate Ber Eiche

252

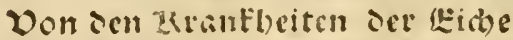

253

254

255

Sehr usuige Derlilben laiten fiat beilen 258

Ueber cintge Sacilung:mitel 259

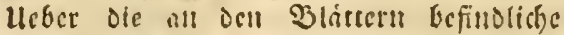
Balláufel

260

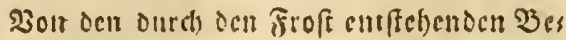
(d)a àinnungen

262

Don sem जrunse uns 3osen wors auf sic kichen gut madifu 263

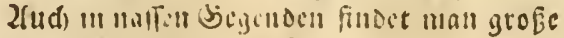
Eitien

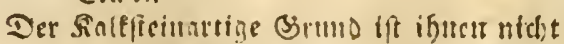
vorthettbart

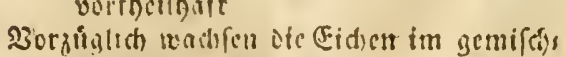
talt Ealn:becen

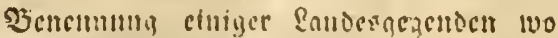
dic Eicfich gut watifin

Heber ste Tiefe des Bazll criorderlidien guten จุoocแt

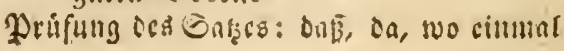


ftarfe Cicicti geftandert, Ocrglcidact wieder gejogen weroill fómen

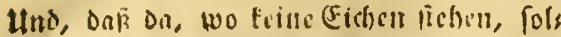
d) nid)t aeivanen wirden mulfen

Bon etnigetr vorjüglid) grofien (Etchen

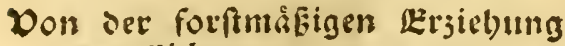
Ser Lithe

Die Eichen veroienen sine múbfame Ers zichung vorjinglid)

Eintheilumg oce Eratehumn oer Eichen tn Dte natirlidte und Eimflidie

In gropen 2 Balommen lapt mant dic (Eis chen, ohwe lid) onrum zu betínmern, allivadi[s]

Hebei die verfdjicocue Erzieflungonten oer Eidfen

Tुb

In Ferinfict)t auf Den Sirumo unto Boven

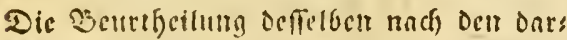
ali ftebenden (Etd)en ift oft nid)t zuls veclófing

Dic Eiticncultur if an viclen Ortedr ciner

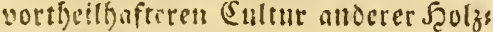
arten votaltitefitn

281

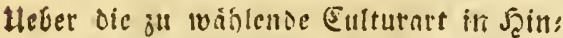
fidt alf oic jull cricholloe (5id)en 282

Sin Scimlitht alli mebrete Dabey sorfom: mende grebendinge

201: Ber แarúrltêcn Erjichuna ocr Eichen

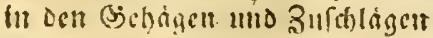

Bon der kimftictict Erzichung Derfeloen Dardh Dic 2 erpflanzumg

Ueber die dabel) vorfommende Effluierig: ecitert

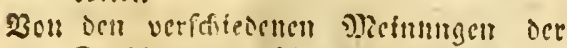
Forfibevientent liver oas Eichenpflams jeit

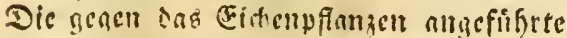
Bjenfpiele bewetert oft ons Segen: theil

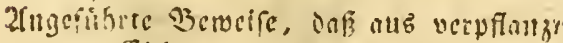
ten Eidien oic ftárfffert Ỏatume wad)s foir fomels

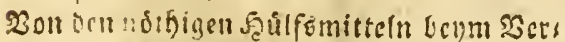
pifinicit

In Bencif oes Bruno und Sodetts

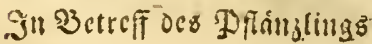

270

271

272

273

274

275

$=77$

278

279

280

284

285

286

287

288

289

290

29 I

292
276

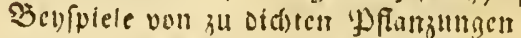

Hever dic, fúr die megrffen 2 fanjungen palferio, Entrfernung

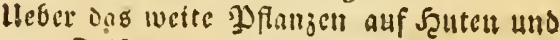
Triften

3ortheilc ocs \$lf anzens in Sintert

Das gute Geserntben ciner PD fanzung baingt

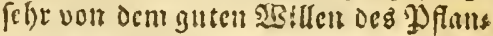
zers ab

Heber Die erforderlidien Eigenidaften eî "

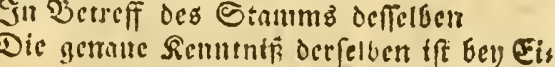
chenpflangungen befonders wichtio nicht zu alt fenn (d) (coenen 2luf(d)teit ocy) einer Pflan: zung zu beftimmen

Dite (id)ctrpflanzung mit cinjätrigen $\mathfrak{R}_{0}$ : Oen ift als cine Epiclerey anjufehen 298

3ె weldher İngrezjeit am beften gepflanzt wiro

Don feranogriffen mo 2orfichten gene madigefehen uno madjebolfen werden

Don ser Eersicbung auter Dflans:

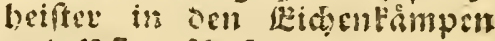
nato pronjlo ulen

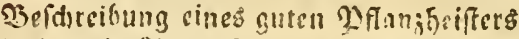

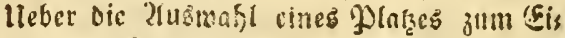
dicn formpe

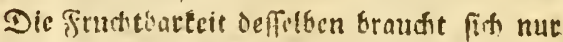
anf cine mâfige Ticfe 3 erfereffen

$230 n$ oen oarauf minwirfencen Dingen in i) achirgiaten (bignenden

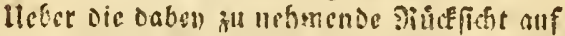
rie darang zu beffanzente Foriforter

Die Eidgenémpe find in 2tufange nidjt zit arof sul nefimen uno erfe madibet oll veratefiern

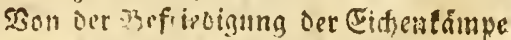

Son oer Behamuna derfelbert

Eolde şeldiebt alu befen gleidj nact oet Sicifi oer Eid)efn 
Son ser 2fusbefferung ber barin fofhlge: ritlazericir Erillen 9.318

2on den (e:) Dim Fidentampe anjulegin: oen Jifanzidulen

Bey Oer Ëziel)ung oer Zllaniheifer muß vorjúglith atf die Bzilcung guter Şsurseft geferen wetden

Ueber cas Ergielsen Der IIflankeifter ans abogefonnittcnen tounmen Siámmen

3on oen feilfsmitteln bin befdjoigten हैi, ())

Die Ergichungentten aus STurielerut uno burdh Siecfrcifer findet beil ben Ens (d)en nid)t Etatt

Doll bem zciduncioen uns 2luf: ichnetteln an Don leichen

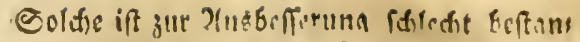

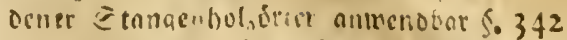

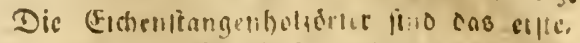

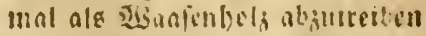

343

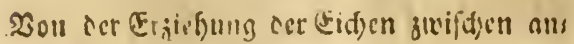
teren 5̧oljarien

320 In empon nut eingeridteten forfterwice

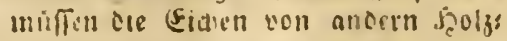

324 Soldte fdickt fich vorzuglidi fúr bie Eviden

Diefez ift in ben bia jecet befannten Forfis fdriften zul wenig erláutert

325

23on Dem Velitheiden oer llfanjfeifter 326

In oen Pflanif(t)uten muE es mit bejondes rer Dorlitdt gefdichen

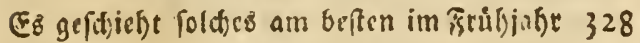

In weldien fisllen es Gey verpflangten f̧eis ftern nothig fey

2ln áltetn Bánmen foll man nur geringe 2lefte abnefinen

Som fitcioliden Sotinettiln on vesplanzs ten alten (Fid)en

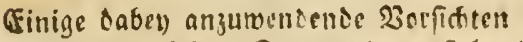

Son oen nadt oum Sdjuetteln entffelgenden Wafferrcifern

Son Der forfimábigen Erjiefung oer Eichen

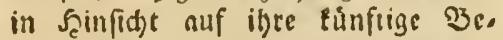
nuksung

Solde if nad ben werffiedenen Elaffen oer zll benufsenden Eidten einjuriditen

Son oer Eeziefhung Der Eid)en oie cine vors

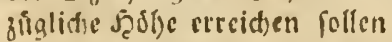

UeEer oie Billoung oer jungen (Eid)en nad) siner getviffen frrummung

2on der Erzichung Det Eidjen zu Brenn. uno Sotilisoly

Solde finost in biengen Begenten. nut

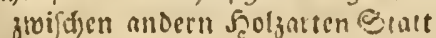

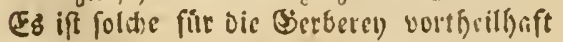

Bom 3erpflanzen oer ciden jur Stangens bolzivittbidjaft artell abgerondert bejogen werdocn

Sinftig reine Fichendrter tsmen im 2fns fange mit andern Selzurten genijd)t cultivit weroen

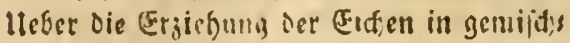
tim sibarenbol:örtern

In vierginjóbrigen Stangentioljơrtern $\quad 3+8$ won geringer Státke Bildenbanmi)oliorter

Bom Pflangen oer Sidsen zrifoten Sopf. bevilin

Von ber forfmåfigen brubatteit ock Litide

Dic nur mit Eidien beftaniene Forftorte werden nidit anf cimmal boutiar

SEeld) (Eid)en oarin jueth buabar firto 354

Bil) vielen (Fid)en hängt die Şanbatfit von sinigen Srebenaufititen aủ

Solde miro bel oen Eidjen vorjinglid ủber Dic Zcit binausgets

গ্Beldes in mancbem salle lifertricten wirs 357

ए5 ift oft nidt vertbeilfaft alte Eidsen oer gioft wegen ju lajonen

lleber die alten (Eidtin, weld)e man abfidjt.

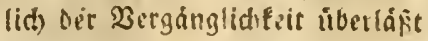

lleter daz zäblen oer Sahjéringe ben der Beftiminung das altets ciner gehaues uen Elibe

Vou ser forfinafigen 23 custgung Scr (leid)e

Von ser migft

lliber tie Bemurąungeaten Derfelben

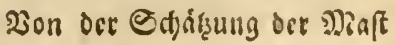

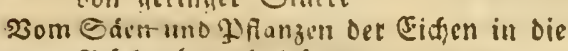


Srotauf Dobey Sitiffidt genommen werden mus mo ourd) weidse Qente folde

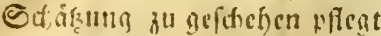

ङ. 365

Heber bie nad) oer $2\left(n_{j}\right.$ al)t Der Eidfen zu

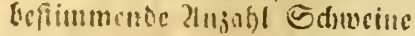

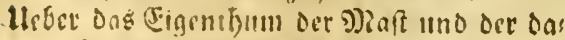
vil) bergebraditen Semenhbeiten

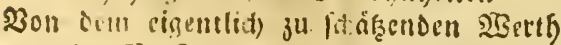
Der Jiaft

Şornuf dir Torffrediente beym জ̧etrciben

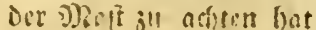

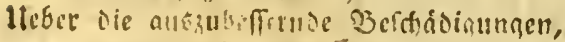

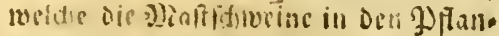
3ungen vetwfuchen

Heber oli Edomung der Jlaft fúr bie bes faamuแn uno fürè 23 ilo

Ueber rie 3enngung. 3 fenerbols; "Ino Zioblen

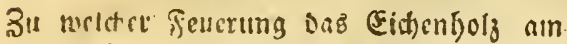
befren zu benusen (ey)

Hefer oie Bemu(jung oer Eid)enaide

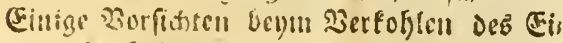
(b)enholzes

Ueber tie sinte set Eidfenfoblen

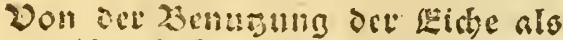
Rugboly

Eintreilung ous Eidjenboljez in mebrete elofien

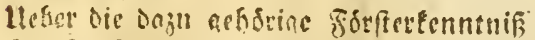

In Şinfidt auf tir Bomtheilung ocr Läns ge uno Etórée cines fechrnoen 23 anung

2ruf die inuse Brite und Feffigfeit deffelben.

Iteber bie Sentmestiten eines gefunden uno eimes f frabhaften ftebenoen 3 aum

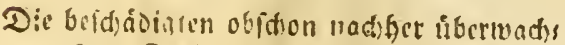
fen: Stellen an cinem $\mathfrak{b} a u n e$ fino. vertichtio

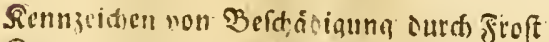

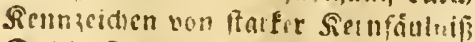

Eolde fino fry iturellaufgrmadjenen Bán: men liche betchintin

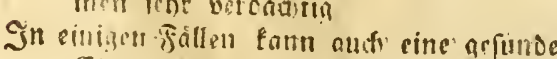

(Fite ale fellethoft anaifeben werden

Diele foblerbuft fidrinente (Eid)en find ocms ofnecachert aciund

TSic man dic Birie uno die Jehler cincs ¿aume ctforfd) ton tann. 337 368
Dev) Eidien won getinger Stiote hat man bie innerlicten febler weniger zu be: firteten.

23on Den Eicfien der zreyten Clafte: doer 6. 390 366.

3nn Dencu, die fid) vorjúglid zur Sdjecis nerarbeit fdticfen.

Sigoratts Stabbolz getrauen werden tann

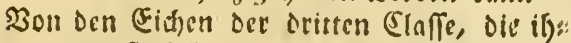
ter Stáre roegen fefre felten fino

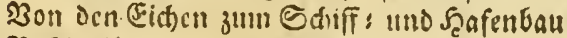

Befdreibung einiger $\Theta_{d i f f j o l}$ forten

velibreisung derfelben jum Sdiffoau auf Der sizefer

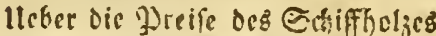

Siomertungen úter oen Sd)iffgalzhander

U⿺尢丶 oijden. BerEauf

Von bev fslluna oev leidben in ver fhiedenen Tablezeiten

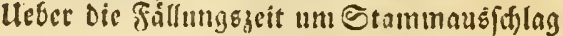
und (J)tEcrbot le zu crbalten

(Finige daber) anjumendende Borfidsten 404

2frocre feolzarten mulfen nidft in $\mathfrak{Q}_{\text {aube: }}$ gelianell verden

Einize Borfiditen beum Sáflen Jer Eicten! 406

\section{Vom Etabbolse}

Uefer oen inländiden Stabholifandel 409

Hefer oen Etabholybanocl ins zfueland 409

Befurcibunn ber gewónnitaen Eorten Stabbols

llebet bie nabey angenommene Eaufinåmi refic Sirdnum

Bon ben Eigenfanften bez guten Etab; bolizes

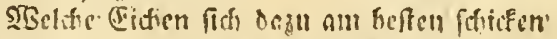

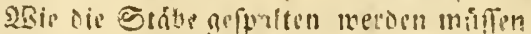

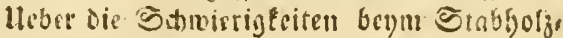
idilagen:

Unte: melthen trinfänden fold)es befoner vortforthait for)

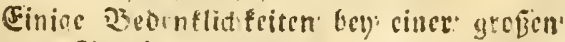
Statholahaming

Heber die vortheithofte Bemurisuna eines zu

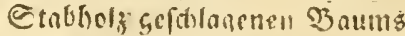
lung oeffeloen:

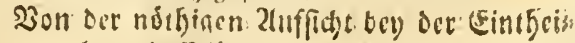




\section{6}

5̧icrzu minfon befonbere 21rbeiter genom. imen imerien

Heber die Sduvicrigtciten, menn ber Forfts eincutbintuer bas Stabbolz auf leine Sict)mung madjen líit

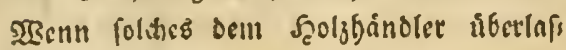
ren ift

Fsen! biefem baju bie Eiden auf bem Stamme vertauft merden

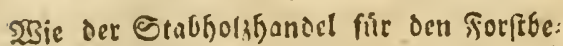
trieb vortheilbaft cinzutiditen fiv

23on Dem Wertfe Dez Stabholzes

Soldher wird bell einer befferen forft: wirthidjaft fteigen

Serubigung firr den Forfteigenthimer, welther zunt erfenmal die Stabgolzs pldafce fief)

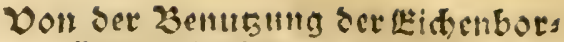
fe zut Jerbeley

§. $4=8$

Itefer Dic Birbefraft Ber Eidenterfo

2Sie rie Eidsentorle velfauft wird

421 lleber bie Bectitfute oerfolben für bie bie, Tige Bieneno

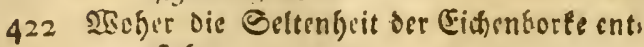
ftebct

423 Heber Ben Siad)theil Ber Durds Ŗotenreif. fen für ons Şoiz entftefien taun

424 Heber die Seilldernilfe des Bortenteifiens in grofsen sorften

434

425 NBie foldes datin betrieben merden fann 435

2011 Dem (5emintt der Borke vom vierzigs jábrigen (Eidhenftangentolize

In welchen hiefigen Ennorbforften die mefors fie Eorle serronnen roiro

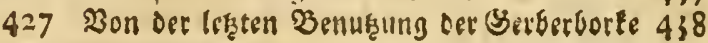

436 437 
INSERT FOLDOUT HERE 

INSERT FOLDOUT HERE 

INSERT FOLDOUT HERE 

INSERT FOLDOUT HERE 



\section{INSERT FOLDOUT HERE}





\section{INSERT FOLDOUT HERE}



INSERT FOLDOUT HERE 

INSERT FOLDOUT HERE 


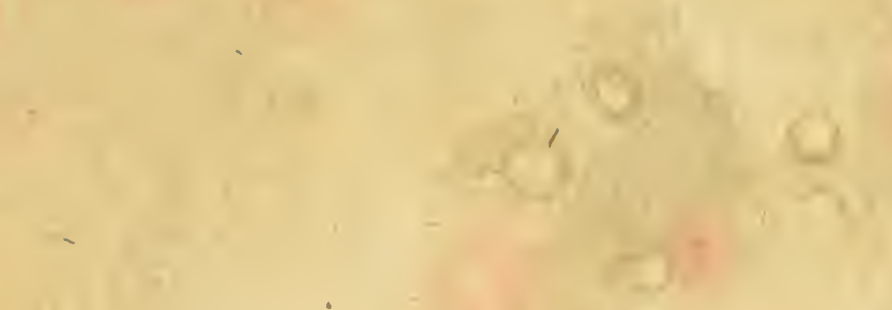


$\therefore+3$

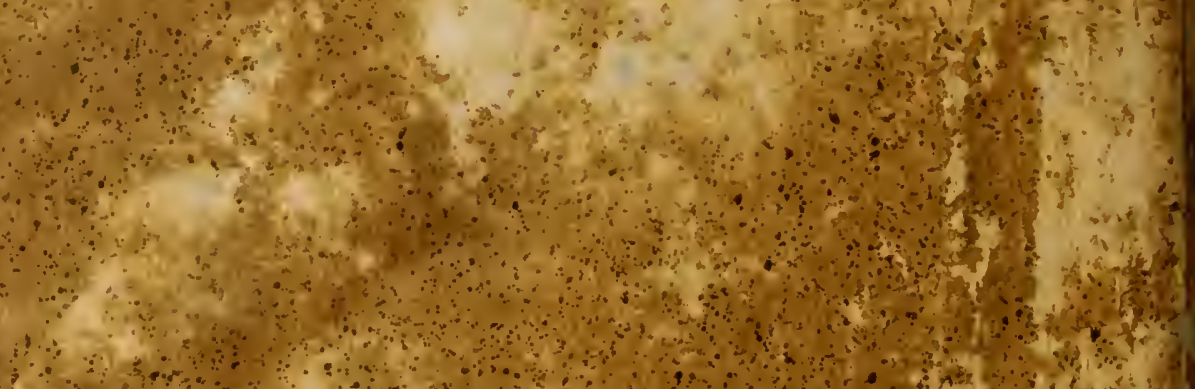

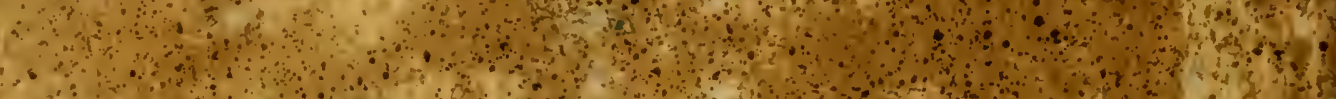
4 a $\rightarrow+\cdots, x^{2}$

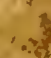
4 $\operatorname{los}_{2}+2$ $\because 0$

1.

a

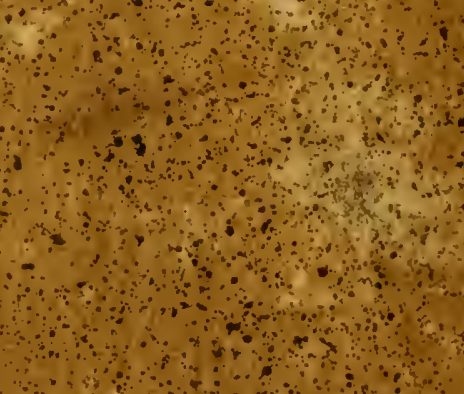

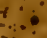

